\title{
Análisis de las relaciones tróficas entre peces y vertebrados ictiófagos de las Islas Orcadas del Sur, Antártida: Hacia el conocimiento integral del ecosistema y el manejo racional de los recursos
}

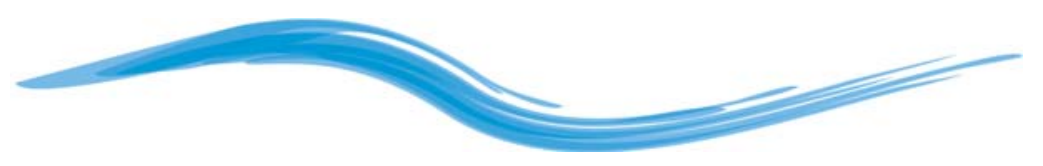

Autora: Lic. Maria Lila Bertolin

Director: Dr. Ricardo J. Casaux

Co-director: Dr. Carlos Darrieu

Facultad de Ciencias Naturales y Museo

Universidad de La Plata 
Dedico este trabajo a mis padres

Agradezco a la gente de postgrado de la Facultad de Ciencias Naturales y Museo de La Plata por la enorme paciencia y buena atención que me han dedicado estos 5 años, a la gente de becas de CONICET por el buen trato y la buena resolución frente a las dificultades y consultas, al Dr. Esteban Barrera-Oro por sus aportes y buena predisposición hacia todas mis dudas y al Dr. Fernando Momo por su rapidez y brillante ayuda. 


\section{RESUMEN}

Antártida presenta características climáticas que la convierten en el continente más inhóspito y riguroso del planeta. Los organismos que la habitan poseen mecanismos fisiológicos adaptados a las condiciones propias de la región y su biodiversidad es única. Su alto grado de especialización sumado a la rigurosidad del ambiente, hacen presuponer una marcada fragilidad en el ecosistema antártico. Es por ello que el manejo de los recursos vivos ha generado discusiones internacionales relacionadas con la importancia de proteger la integridad de estos ecosistemas. En general, la actividad antrópica más desarrollada en este continente ha sido la actividad pesquera (incluida la industria foquera y ballenera). El daño causado por estas intervenciones en el ecosistema aún tiene consecuencias y hoy día muchas actividades han sido cerradas o se hallan restringidas a ciertas zonas de control. En este contexto, el archipiélago de las Islas Orcadas del Sur (IOS) ha sido seriamente afectado. Actualmente la pesca en áreas antárticas y subantárticas está regulada por la Comisión para la Conservación de los Recursos Vivos Marinos Antárticos (CCRVMA), un organismo internacional conformado por 25 países miembro y 9 Estados adheridos. Sin embargo las políticas que emanan de esta comisión son insuficientes para preservar la fauna antártica. El comportamiento alimentario y la dinámica poblacional de los predadores tope marinos son altamente susceptibles a los cambios en la disponibilidad de sus presas. Por ello, el estudio concurrente de los aspectos alimentarios y poblacionales de los predadores tope marinos sensibles a la competencia con la actividad pesquera, es imprescindible para profundizar el conocimiento de la estructura trófica del ecosistema y para aumentar el poder de predicción de los efectos que las diferentes actividades ocasionan en el ambiente. Por ello, el objetivo de este trabajo es profundizar el conocimiento de los aspectos cuali-cuantitativos de las relaciones tróficas entre peces y vertebrados ictiófagos en las IOS y a través de ello avanzar en el conocimiento integral del ecosistema y generar información de utilidad para el manejo racional de los recursos vivos en Antártida.

La composición de la dieta de 16 vertebrados ictiófagos de las IOS fue analizada a partir de datos publicados y no publicados obtenidos durante períodos de entre 3 y 10 años según la especie. La información considerada fue obtenida mediante la aplicación de metodologías similares y fue analizada en función de los cambios anuales y estacionales. A partir de las bases de datos sin publicar se calcularon la frecuencia de ocurrencia porcentual (F\%), la importancia porcentual en número (N\%) y en masa (M\%) de las diferentes presas representadas en las muestras de acuerdo a las metodologías descriptas en Casaux et al. (2009).

A partir de la información analizada, los predadores fueron clasificados en 7 grupos tróficos según la proporción de las diversas presas en la dieta: 1) Krilleros 1; 2) Krilleros 2; 3) Ictiófagos 1; 4) Ictiófagos 2; 5) Carroñeros/cazadores; 6) Malacófagos; 7) Generalistas.

Considerando que la información sobre la composición de la dieta de los predadores tope puede reflejar las condiciones locales dentro de la comunidad de presas presentes en el área de forrajeo, y teniendo en cuenta que la sobreexplotación de la actividad pesquera desarrollada en la década del '70 generó una importante disminución en las poblaciones de Notothenia rossii y Gobionotothen gibberifrons, los resultados sobre la composición de la dieta evidenciaron la recuperación de la población de G. gibberifrons alrededor de las IOS. 
La información sobre la fauna ictícola de las IOS obtenida a partir de dos cruceros de investigación fue analizada en función de la composición de la dieta de los predadores tope. Los datos sobre biomasa y distribución de tallas fueron contrastados con la información sobre la composición de la dieta de los predadores tope con el objetivo de analizar el grado de selectividad de los predadores con respecto a las especies y las tallas consumidas. A su vez, los resultados sobre la composición de la ictiofauna de ambos cruceros de investigación fueron comparados mediante la estimación de parámetros ecológicos. El grado de selectividad de presas fue estimado para cada predador a partir del cálculo del Índice de Ivlev (1961). El grado de solapamiento entre las distribuciones de tallas de los peces representados en la dieta de los predadores y de los representados en los muestreos de ambos cruceros de investigación se analizó de acuerdo al cálculo del índice de similitud de Linton et al. (1981). La diversidad de la ictiofauna fue estimada a partir de la biomasa de los peces capturados en los cruceros mediante la aplicación del índice de diversidad (D) de Simpson (1949) y la Equitatividad (E) se estimó según Pielou (1966). La diversidad en el consumo de peces fue analizada en 4 predadores mediante la aplicación del Índice de Shannon y Weaver (1949).

Los valores de biomasa más altos de las capturas de peces reportadas por los cruceros de investigación correspondieron a la familia Nototheniidae, seguida por Myctophidae y Channichthyidae. No se observaron diferencias significativas en la distribución de los individuos con respecto a la profundidad tanto cuando estos fueron agrupados por especie como por familia $(W \lambda=0,976, p=0,55 ; W \lambda=0,975, p=0,54)$. La especie dominante en términos de biomasa fue $G$. gibberifrons, seguida de Lepidonotothen squamifrons. La comparación de la biomasa, abundancia y tasa de captura estimada en ambos cruceros de investigación sugiere que los stocks de $G$. gibberifrons, L. squamifrons, $N$. rossii y Pseudochaenichthys georgianus aumentaron luego del cierre de la pesca comercial, en tanto que la abundancia el de Pleuragramma antarcticum disminuyó marcadamente. La diversidad disminuyó entre los años 1987 y 1999 de 0,81 a 0,76, hecho que también ocurrió con la equitatividad (de 0,55 a 0,46). Esto sugiere que la recuperación de los stocks de peces no fue similar en todas las especies.

Los pingüinos de Adelia y de Barbijo mostraron tendencias hacia la selección de peces de la familia Myctophidae y del notothénido $T$. newnesi. Los predadores de hábitos mixtos (cuya dieta estuvo compuesta por krill y por peces en proporciones similares; grupos tróficos 2 y 4 ) tales como la Foca de Weddell (F. de Weddell), el lobo Fino Antártico (LFA) y el Pingüino Papúa (P. Papúa) seleccionaron especies de peces pelágicos y bento-demersales. Sin embargo, las especies seleccionadas por estos predadores fueron diferentes, lo que sugiere que explotan los diferentes ambientes con distinta intensidad. Tanto el Petrel Damero como el de las Nieves seleccionaron mycthóphidos, lo que refleja un hábito alimentario pelágico. El Cormorán de Georgias (C. de Georgias) seleccionó una gran variedad de especies bento-demersales pertenecientes a las familias Nototheniidae y Batylagidae.

El estudio del solapamiento de las distribuciones de tallas mostró que las aves generalmente se alimentan de peces menores a los representados en las capturas, lo que se debe al tamaño de la malla de las redes utilizadas en los cruceros. Sin embargo, las tallas de $L$. nudifrons consumidas por el C. de Georgias fueron similares a las representadas en las capturas de los cruceros. El rango de 
tallas de los peces consumidos por los mamíferos fue mayor que el de las aves. El solapamiento en las distribuciones de tallas observado en el LFA fue alto $(S>50)$ en $G$. gibberifrons y en $L$. larseni, lo que también ocurrió con G. gibberifrons en la F. de Weddell.

El análisis de diversidad de la dieta mostró que aquellos predadores que se alimentan exclusiva o preferentemente de peces bento-demersales presentaron los valores más altos de diversidad. Este hecho se debería a que la comunidad de peces bento-demersales es más diversa que la pelágica.

La competencia por el alimento fue estimada de acuerdo al índice de similitud de Linton et al. (1981). La re-ocurrencia de presas dentro de la comunidad fue estimada mediante el índice de Tyler (1972). De acuerdo a la composición general de la dieta, el solapamiento de las presas fue alto durante las temporadas reproductivas 1997/98, 1998/99 y 2001/02. Esto estuvo principalmente determinado por los predadores consumidores de krill, lo cual reflejó una importante competencia por dicho crustáceo durante el período 1997-2000. Se observó que cuando la disponibilidad de krill disminuye, los predadores de hábitos alimentarios más flexibles incrementan el consumo de peces. Los pingüinos de Adelia y de Barbijo fueron el par de especies que presentó los valores de solapamiento de la dieta más altos $(S=98,69 \%)$, El valor medio de $S$ para LFA - P. Papúa fue $57,61 \%$, observándose picos en las temporadas reproductivas $1995 / 96$ ( $\mathrm{S}=75,5 \%)$ y $1197 / 98$ ( $\mathrm{S}=$ $73,05 \%)$. Estos resultados sugieren que estos dos pares de especies, todas ellas consumidoras de krill, fueron los predadores con mayor competencia por el alimento. Aunque varios de los predadores aquí considerados presentan estrategias de alimentación generalistas/oportunistas, la re-ocurrencia de presas para la comunidad a lo largo de las temporadas reproductivas resultó ser de moderada (< $50 \%)$ a baja (<25\%), lo que refleja la existencia de mecanismo tendientes a disminuir la competencia interespecífica.

A través del conocimiento de la composición de la dieta de los predadores, de datos de censos poblacionales y de información sobre los requerimientos energéticos diarios de cada especie, se estimaron los requerimientos energéticos anuales de las poblaciones más importantes que conforman la comunidad de predadores ictiófagos de las IOS. Los requerimientos energéticos diarios de cada predador fueron extraídos de publicaciones o calculados a partir de las ecuaciones de Kendeigh (1970), Kleiberg (1975) y Nagy (1994) según corresponda. La estimación del tamaño de las poblaciones de los predadores en las IOS se obtuvo a partir de datos de censos de diversas fuentes bibliográficas. Los datos sobre las especies de interés comercial, tales cómo límites de captura y tallas permitidas fueron obtenidos de los informes elaborados por la CCRVMA.

En términos energéticos, la comunidad de predadores de las IOS presenta una demanda anual de 1,61 x $10^{9} \mathrm{MJ}$. Las mayor demanda energética corresponde al P. de Barbijo $\left(1,07 \times 10^{9} \mathrm{MJ}\right.$ año $\left.{ }^{-1}\right)$, seguida por la del P. de Adelia $\left(4,7 \times 10^{8} \mathrm{MJ}_{\text {año }}{ }^{-1}\right)$ y la del LFA $\left(1,98 \times 10^{7} \mathrm{MJ}\right.$ año $\left.{ }^{-1}\right)$, en tanto que la de menor demanda correspondió a la G. Cocinera $\left(7,11 \times 10^{4} \mathrm{MJ}\right.$ año-1 $)$. El consumo anual de alimento en términos de biomasa estimado para los predadores de todo el archipiélago fue $367.929,21 \mathrm{Tn}$., de los cuales el 98\% corresponde a la comunidad de aves marinas. Este valor de biomasa total estuvo compuesto, entre otros, por 359.546,07 Tn. de crustáceos, 4.997,32 Tn. de peces, $2.424,80 \mathrm{Tn}$. de pingüinos y sólo $875,38 \mathrm{Tn}$. de cefalópodos. Con respecto a los peces, los myctóphidos fueron consumidos mayormente por el Petrel de Damero (461,27 Tn), en tanto que los 
notothénidos (1.848,72 Tn.) y los channíchthyidos (312,85 Tn.) fueron principalmente consumidos por el P. Papúa y el LFA respectivamente. Gobionotothen gibberifrons y $E$. antarctica fueron especies consumidas por la mayoría de los predadores tope. Los predadores que mayor cantidad de peces consumieron fueron el P. Papúa (1933,70 Tn. anuales) y el LFA (921,51 Tn. año ${ }^{-1}$ ). Dado que la pesca comercial en las IOS está actualmente abierta para el krill, y que en un futuro cercano también puede estarlo para los peces, es necesario que, en términos de una explotación ecológicamente sustentable, en las estimaciones de los cupos a extraer se tengan en cuenta los requerimientos y comportamientos alimentarios de los predadores en la medida que la conservación de sus poblaciones siga siendo prioritario.

A modo exploratorio, se realizó un modelo matemático de predación y competencia entre tres predadores tope de las IOS (el LFA, el P. Papúa y el C. de Georgias). Es de esperar que el desarrollo de este modelo aporte a la comprensión de la dinámica entre predadores y presas y entre predadores entre si, y pueda ser utilizado como punto de partida para el desarrollo de modelos más abarcativos que contemplen las variaciones en la disponibilidad de presas. Se generó un modelo matemático continuo basado en las ecuaciones del modelo de Lotka (1925) y Volterra (1926), en función de la abundancia de krill (alta y baja), dependiente a su vez de la extensión de la cobertura de hielo marino y de la temperatura media del agua. Cuando la abundancia de krill es alta, la competencia interespecífica, fundamentalmente para el C. de Georgias, es baja. Por el contrario, cuando la disponibilidad de krill es baja, no sólo se incrementa la competencia por el escaso krill y fundamentalmente por los peces demersales, si no que el LFA preda con mayor intensidad sobre los pingüinos.

La abundancia del LFA en las IOS durante la temporada de verano es sumamente variable Según el modelo propuesto, el LFA influye fuertemente sobre el cambio en las relaciones interespecíficas de competencia, por lo que es importante conocer los factores que regulan su tendencia poblacional. Por ello, de comprenderse esto se podría conocer cuales son las implicancias a nivel ecosistémico del grado de competencia entre predadores. 


\section{ABSTRACT}

Antarctica presents hard weather conditions that makes it the most inhospitable and rigorous continent in the planet. Consequently, the organisms living there have physiological adaptations to those conditions. The high specialization of the organisms and the reduced biodiversity results in a haigh vulnerability of the Antarctic ecosystem. Therefore, the management of the resources generated international discussions related to the importance of protecting the ecosystem integrity.

In Antarctica, the commercial fishery, witch includes the exploitation of crustaceans, fish, seals and whales, has been the most important human activity. The impact on the ecosystem caused by such activity is important and consequently this activity was closed or restricted at several areas. The archipelago of South Orkney Islands (SOI) is one of the areas most seriously affected by the fisheries. Currently, Antarctic and Subantarctic fisheries are regulated by the Commission for the Conservation of Antarctic Marine Living Resources (CCAMLR), which is an international organism that involves 34 countries. Despite of the regulations derived from CCAMLR, appropriated strategies for the Antarctic ecosystem conservation are still required

The feeding behavior and the population dynamics of marine top predators are highly susceptible to changes in prey availability. Thus, the study of their trophic and population aspects, which are susceptive to be affected by the commercial fishery, is essential to predict the impact of that human activity on the ecosystem structure. Consequently, the aim of this study is to increase the knowledge of qualitative and quantities aspects of trophic relationships between fish and ichthyophagous vertebrates of the SOI to generate information useful for a rational management of living Antarctic resources.

Published and unpublished Information on diet composition of 16 top predators of the SOI obtained during periods of 3-10 years was analyzed. The methodology used in those reports was similar. The frequency of occurrence (F\%) and the contribution by number (N\%) and mass (M\%) of preys represented in the diet of the predators under study was estimated. Top predators were classified in seven "trophic groups" according to the prey predominating in their diets: 1) Krill feeders 1; 2) Krill feeders 2; 3) Ichthiyophagous 1; 4) Ichthyiyophagous 2; 5) Hunters/Scavengers; 6) Malacophagous; 7) Generalistics.

Given that top predator diet composition may reflect the prey availability at the foraging areas and taking into account the declining trend of Notothenia rossii y Gobionotothen gibberifrons populations caused by the fisheries carried out during the ' 70 , the results on diet composition of several predators suggest the recovery of $G$. gibberifrons population at the SOI.

Information on the fish fauna at the SOI was obtained from two Antarctic survey cruises. That information was analyzed in relation to diet of top predators. Information on biomass and length frequency of fish represented in the surveys was compared to those of fish represented in the diet of predators in order to determine their degree of prey selectivity. Prey selectivity was calculated for each predator according to the Ivlev (1961) index. The overlap between length of the fish represented in the diet of predators and those represented in the cruise catches was estimated according to the Linton et al. (1981) similarity index. The diversity of the fish fauna was estimated using the Simpson (1949) diversity index and the Equitability (E) was calculated according to Pielou (1966). The diversity 
of fish represented in the diet of four predators was estimated according to the Shannon-Weaver (1949) index.

Nototheniids, followed by myctophids and channichthyids, were the most abundant fish in terms of biomass in the cruise samples. There were no significant differences in the distribution of fish species and families according to depth $(W \lambda=0.976, p=0.55 ; W \lambda=0.975, p=0.54)$. Gobionotothen gibberifrons was dominant fish in the captures terms of biomass, followed by Lepidonotothen squamifrons. Information from both fish surveys suggested the recovery of $G$. gibberifrons, $L$. squamifrons, N. rossii, and Pseudochaenichthys georgianus populations. On the contrary, such information suggested an important declining trend in the Pleuragramma antarcticum population. Fish diversity (from 0.81 to 0.76 ) and equitativity (from 0.55 to 0.46 ) decreased between 1987 and 1999y, suggesting that the recovery of the fish stocks was not similar for all of the species.

Adélie (AP) and Chinstrap (CP) penguins tended to select fish from Myctophidae family and the Trematomus newnesi species. Predators belonging to the trophic groups 2 and 4 (see above) such as the Weddell (WS) and the Antarctic fur (AFS) seals and the Gentoo penguin (GP) selected different pelagic and demersal fish species, which suggest differences in the foraging areas and strategies. Due to the high consumption of G. gibberifrons, the competition between the WS and the GP was high. Snow (SP) and Cape (CP) petrels selected myctophids species, reflecting its pelagic foraging habits. The South Georgia shag (SGS) strongly selected the fish Harpagifer antarcticus as well as several demersal fishs belonging to the Nototheniidae and Batylagidae families.

Seabirds preyed on fish smaller than those represented in the cruise survey catches which was mainly related to the mesh size of the nets used. However, the length of the L. nudifrons individuals represented in the diet of the SGS were similar to those of specimens represented in the catches. Compared to seabirds, mammals preyed on a wider fish length range. The length distributions of G. gibberifrons and L. larseni specimens represented in the diet of the AFS were similar to the observed in the cruise catches. As observed in the AFS, the length distribution of $G$. gibberifrons was similar in the cruise catches and in the food samples from the WS. The diversity of the diet was higher in predators that foraged exclusively on benthic-demersal fish. This is explained by the fact that the benthic-demersal fish community is more diverse than the pelagic one.

Food competition was estimated according to the Linton et al. (1981) index and prey reoccurrence within the predator community was calculated according to the Tyler (1972) index. Prey overlap between predators was higher in the 1997/98, 1998/99 and 2001/02 seasons, mainly due to the intensive krill consumption reflecting an important competition for that crustacean during those seasons. It was observed that as krill abundance decreased generalist feeders increased the fish consumption... The highest values of prey overlap were observed between the AP and the CP (S = 98.69\%) and between the AFS and the Gentoo penguin (GP) ( $S=57.61 \%$ overall). Those results suggested an important competition for food between those two pairs of predators. Given that several predators considered in this study presented generalist/opportunist foraging strategies, which usually results in the reduction of the competition for food between species, the prey re-occurrence among species was moderated ( $<50 \%$ ) to low $(<25 \%)$. Annual energy requirements and food consumption at population and community levels were estimated considering information on diet composition, daily energy requirements, and population size of each predator at the SOI. The daily energy requirement 
of each predator was obtained from the literature or was calculated following the Kendeigh (1970), Kleiber (1975) and Nagy (1994) equations. Information on predators population size was also obtained from the literature. Commercial fish species, total allowable catch, and commercial fish lengths was obtained from CCAMLR reports. Annual energy requirement for the SOI predators' community was $1.61 \times 10^{9} \mathrm{MJ}$. At the population level, the CP presented the highest annual energy requirements $\left(1.07 \times 10^{9} \mathrm{MJ}\right.$ year $\left.{ }^{-1}\right)$, followed by the AP $\left(4.7 \times 10^{8} \mathrm{MJ}\right.$ year $\left.^{-1}\right)$ and the AFS $\left(1.98 \times 10^{7}\right.$ $M J$ year $\left.^{-1}\right)$, whereas the Brown skua (BS) presented the lowest requirements $\left(1.42 \times 10^{5} \mathrm{MJ}\right.$ year $\left.{ }^{-1}\right)$. The annual food consumption, in terms of biomass, estimated for the predators' community was $367,929.21$ tons, which can be separated $359,546.07$ tons of crustaceans, $4,997.32$ tons of fish, $2,424.80$ tons of penguins, and 875.38 tons of squids. Seabirds consumed around the $98 \%$ of the requirements of the predators' community. Regarding fish, myctophids were mainly consumed by the CP (461.27 Tn), whereas notothenids were mainly consumed by the GP (1,848.72 Tn) and channichthyids by the AFS (312.85 Tn). Gobionotothen gibberifrons and E. antarctica were the fish that most contributed to the diet of predators. The GP and the AFS presented the highest values of fish consumption (1,933.70 $\mathrm{Tn}_{\text {year }}{ }^{-1}$ and $921.51 \mathrm{Tn}$ year $^{-1}$ respectively). The highets values of length overlap between the fish represented in the diet and in cruise catches were observed in mammals. The results obtained suggest that, in terms of sustainable fish exploitation, the energy requirements of predators must be considered when the fisheries are planned.

A mathematical model was developed to analyze the food competition among three top predators from the SOI (the GP, the SGS and the AFS). The mathematical continuous model was build considering the Lotka (1925) and Volterra (1926) competition equations. Two alternative scenarios were proposed: (i) high availability of krill and (ii) low availability of krill. Krill availability strongly depended on the percentage of pack ice coverage and on seawater temperature. When the abundance of krill is high, interspecific competition is low, mainly for the SGS. Alternatively, when the abundance of krill is low, the competition for food between thoses three predators increase and the AFS prey more intensively on penguins. The abundance of the AFS at the SOI during summer is extremely variable. According to the proposed model, the AFS strongly influence interspecific relationships between these three predators. Thus, in order to increase the knowledgement on interspecific relationships and on the degree of food competition between species studies aimed to understand on the environmental factors regulating the AFS population trends are required. 


\section{Índice de contenidos}

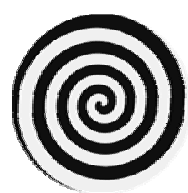

Resumen (español)

Resumen (inglés)

\section{Capítulo I}

El continente antártico 1

Características físicas y biológicas $\quad 1$

Aspecto geopolítico $\quad 9$

La actividad pesquera en Antártida 9

La regulación del manejo de los recursos naturales y el medio-ambiente en Antártida 11

La importancia del desarrollo de políticas de manejo 13

$\begin{array}{ll}\text { Objetivos generales } & 14\end{array}$

Referencias bibliográficas $\quad 16$

\section{Capítulo II}

Composición general de la dieta

Introducción

Materiales y métodos

Área de estudio

Recopilación de información bibliográfica $\quad 25$

Análisis de datos $\quad 25$

Resultados $\quad 29$

Composición general de la dieta, Islas Orcadas del Sur 29

$\begin{array}{ll}\text { Aves } & 29\end{array}$

Mamíferos $\quad 50$

Composición general de la dieta, Islas Shetland del Sur 56

Aves $\quad 56$

Discusión $\quad 58$

$\begin{array}{ll}\text { Composición general de la dieta } & 58\end{array}$ 
Aspectos metodológicos $\quad 71$

Conclusiones generales $\quad 72$

$\begin{array}{ll}\text { Referencias bibliográficas } & 74\end{array}$

Capítulo III

Selección del alimento

84

Introducción

Materiales y métodos $\quad 85$

Recopilación de datos de la fauna ictícola de las Islas Orcadas del Sur 85

$\begin{array}{ll}\text { Análisis de datos } & 87\end{array}$

Resultados 90

Estructura poblacional de la ictiofauna de las Islas Orcadas del Sur: Abundancia y distribución de la biomasa

Selección de presas

95

Distribución de la abundancia de tallas 108

Diversidad en el consumo de peces 114

Discusión 115

Composición y distribución de los peces en las Islas Orcadas del Sur 115

Análisis de selección de presas de los predadores tope en las Islas Orcadas del Sur 117

Diversidad en el consumo de 4 predadores tope de las Islas Orcadas del Sur $\quad 120$

$\begin{array}{ll}\text { Conclusiones generales } & 121\end{array}$

Referencias bibliográficas 122

\section{Capítulo IV}

Estrategias de alimentación

$\begin{array}{ll}\text { Introducción } & 125\end{array}$

Materiales y métodos 126

$\begin{array}{ll}\text { Descripción y categorización de los hábitos de forrajeo } & 126\end{array}$

Análisis del solapamiento de la dieta entre predadores tope y dentro de la comunidad de las IOS

Resultados 131

Hábitos de forrajeo de los predadores tope de las Islas Orcadas del Sur 131

$\begin{array}{ll}\text { Aves } & 131\end{array}$

Mamíferos 140

Solapamiento de dieta en la comunidad de predadores tope de las Islas Orcadas del Sur 148

Discusión 151

Estrategias de forrajeo $\quad 151$

Solapamiento y Re-ocurrencia de presas en la dieta de los predadores tope 154 
Conclusiones generales

Referencias bibliográficas

158

Anexo de tablas

\section{Capítulo V}

Introducción 177

Materiales y métodos $\quad 179$

$\begin{array}{ll}\text { Recopilación de datos } & 179\end{array}$

$\begin{array}{ll}\text { Análisis de datos } & 180\end{array}$

Resultados 186

Consumo de las poblaciones de predadores de las Islas Orcadas del Sur 186

$\begin{array}{ll}\text { Consideraciones generales } & 186\end{array}$

Consumo anual de presas para la comunidad de predadores tope de la Isla Laurie $\quad 189$

Consumo anual de presas para la comunidad de predadores tope de Islas Orcadas del Sur

Regulación de la pesca en el área de estudio $\quad 202$

Discusión 218

Conclusiones generales $\quad 212$

Referencias bibliográficas $\quad 214$

\section{Capítulo VI}

Modelización ecotrófica

219

Introducción

219

Materiales y métodos

220

Resultados

222

Discusión

224

Referencias bibliográficas

\section{Capítulo VII}





\section{Índice de tablas y figuras}

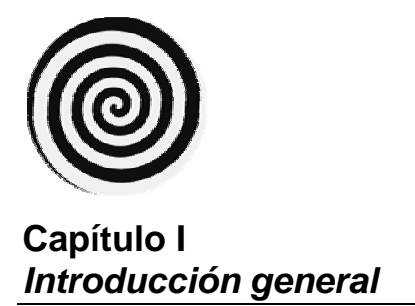

Figura I.1: Mapa de la Península Antártica y archipiélagos adyacentes 2

Figura I.2: Diagrama de la trama trófica antártica 4

Tabla I.1: Relaciones entre tipo de alimentación y zona de distribución de los peces 8

Figura I.3: Áreas estadísticas de pesca 13

\section{Capítulo II}

\section{Composición general de la dieta}

Figura II.1: Islas Orcadas del Sur (IOS)

Tabla II.1: Resumen de la información sobre la composición de la dieta de los predadores de las IOS

Tabla II.2: Resumen de la información sobre la composición de la dieta de los predadores de las Islas Shetlands del Sur

Tabla II.3: Detalle de la nomenclatura y abreviaciones utilizadas 27

Tabla II.4: Composición general de la dieta de los predadores de IOS (\%M media) 30

Tabla II.5: Composición general de la dieta del P. de Adelia (Isla Laurie) 30

Tabla II.6: Composición general de la dieta del P. de Adelia (Isla Signy) 31

Tabla II.7: Composición general de la dieta del P. de Barbijo 31

Tabla II.8: Composición general de la dieta del P. Papúa (Isla Laurie) 32

Figura II.2: Contribución en biomasa (\%) de las presas representadas en contenidos
estomacales del P. Papúa

Tabla II.9: Contribución de los peces a la dieta del P. Papúa 35

Tabla II.10: Tallas de los peces representados en los contenidos estomacales del P. Papúa 36

Figura II.3: Correlación entre las tallas medias de $T$. newnesi y L. nudifrons representadas en la dieta del P. Papúa

Tabla II.11: Composición de la dieta del P. Damero 38

Tabla II.12: Contribución de los peces a la dieta del P. Damero 39

Tabla II.13: Contribución de los peces a la dieta de adultos y pichones del P. Damero 39

Tabla II.14: Tallas (medias en cm., desvío estándar DE y rango) de los peces representados en la dieta del P. Damero

Tabla II.15: Composición de la dieta del P. Gigante 42

Tabla II.16: Composición general de la dieta del P. de las Nieves 42

Tabla II.17: Peces representados en la dieta del P. de las Nieves 43

Tabla II.18: Composición general de la dieta del C. de Georgias 45

Tabla II.19: Composición general de la dieta del C. de Georgias durante la temporada reproductiva 1994/95 
Tabla II.20: Peces representados en la dieta del C. de Georgias

Tabla II.21: Peces representados en la dieta del C. de Georgias durante la temporada reproductiva 1994/95

Tabla II.22: Tallas medias y rangos de los peces representados en la dieta del C. de Georgias

Tabla II.23: Cambios en las tallas medias y rangos de los peces representados en la dieta del C. de Georgias a lo largo de la temporada reproductiva 1994/95

Tabla II.24: Composición general de la dieta del E. Marrón

Tabla II.25: Peces representados en la dieta del E. Marrón

Tabla II.26: Composición general de la dieta de la F. de Weddell

Tabla II.27: Peces representados en la dieta de la F. de Weddell

Tabla II.28: Composición general de la dieta de la F. Cangrejera

Figura II.4: Contribución en términos de biomasa de las presas representadas en la dieta del LFA

Figura II.5: Contribución en términos de biomasa de los peces representados en la dieta del LFA

Figura II.6: Correlación entre el porcentaje en masa de krill y la biomasa relativa de myctóphidos obtenidas del análisis de la dieta del LFA

Tabla II.29: Contribución en peso y talla de los peces representados en la dieta del $P$. de las Tormentas

Tabla II.30: Composición general de la dieta del P. de las Tormentas 56

Tabla II.31: Composición general de la dieta del G. Antártico 57

Tabla II.32: Tallas de las presas_representadas en la dieta del G. Antártico 58

Tabla II.33: Especies de predadores tope de las IOS agrupados según los "Grupos tróficos" definidos previamente

Tabla II.34: Composición general de la dieta del LFA

Tabla II.35: Contribución de los peces a la dieta del LFA

Tabla II.36: Tallas de los peces representados en las feces del LFA

\section{Capítulo III}

\section{Selección del alimento}

Figura III.1: Estaciones de captura de los cruceros de investigación 86

Tabla III.1: Grupos Tróficos y predadores elegidas para el análisis de selección del alimento en las IOS

Tabla III.2: Temporadas de muestreos de la dieta y referencias utilizadas para el cálculo de I

Figura III.2: Composición específica de las capturas realizadas durante la campaña "Antártida 8611"

Figura III.3: Detalle por estrato de la composición específica de las capturas ("Antártida 8611") 91

Figura III.4: Composición específica de las capturas realizadas durante la campaña "US AMLR 99"

Figura III.5: Detalle por estrato de la composición específica de las capturas ("US AMLR 99")

Tabla III.3: Talla media, rango, moda, porcentaje de abundancia por estrato de profundidad y abundancia de 16 especies de peces de los cruceros "Antártida 8611" y "US AMLR 99"

Tabla III.4: Biomasa de las especies capturadas durante la campaña "Antártida 8611"

Tabla III.5: Detalle de las capturas $(\mathrm{N})$ de 11 especies de peces durante la campaña "Antártida 8611"

Tabla III.6: Análisis de la selectividad de presas para el P. de Adelia en I. Laurie a partir de los 
Tabla III.7: Análisis de la selectividad de presas para el P. de Adelia y el P. de Barbijo en I. Laurie a partir de los resultados de las capturas del crucero "US AMLR 99"

Tabla III.8: Análisis de la selectividad de presas para el P. Papúa en I. Laurie a partir de los resultados de las capturas del crucero "Antártida 8611"

Tabla III.9: Análisis de la selectividad de presas para el P. Papúa en I. Laurie a partir de los resultados de las capturas del crucero "US AMLR 99"

Tabla III.10: Análisis de la selectividad de presas para la F. de Weddell en I. Laurie a partir de los resultados de las capturas del crucero "Antártida 8611"

Tabla III.11: Análisis de la selectividad de presas para la F. de Weddell en I. Laurie a partir de los resultados de las capturas del crucero "US AMLR 99"

Tabla III.12: Análisis de la selectividad de presas para el LFA en I. Laurie a partir de los resultados de las capturas del crucero "Antártida 8611"

Tabla III.13: Análisis de la selectividad de presas para el LFA en I. Laurie a partir de los resultados de las capturas del crucero "US AMLR 99"

Tabla III.14: Análisis de la selectividad de presas para el C. de Georgias en I. Laurie a partir de los resultados de las capturas del crucero "Antártida 8611"

Tabla III.15: Análisis de la selectividad de presas para el C. de Georgias en I. Laurie a partir de los resultados de las capturas del crucero "US AMLR 99"

Tabla III.16: Análisis de la selectividad de presas para el P. Damero en I. Laurie a partir de los resultados de las capturas del crucero "Antártida 8611"

Tabla III.17: Análisis de la selectividad de presas para el P. Damero y P. de las Nieves en I. Laurie a partir de los resultados de las capturas del crucero "US AMLR 99"

Figura III.6: Superposición de la talla de los peces consumidos por el P. de Adelia y los representados en arrastres realizados por Kock et al. (2000)

Figura III.7: Superposición de la talla de los peces consumidos por el P. de Barbijo los representados en los arrastres realizados por Kock et al. (2000)

Figura III.8: Superposición de la talla de los peces consumidos por el P. Papúa y los representados en los arrastres realizados por Balguerías (1989) y por Kock et al. (2000)

Figura III.9: Superposición de las tallas de los peces consumidos por la foca de Weddell y los representados en los arrastres realizados por Balguerías (1989) y por Kock et al. (2000)

Figura III.10: Superposición de las tallas de los peces consumidos por el lobo Fino Antártico y los representados en los arrastres realizados por Balguerías (1989)

Figura III.11: Superposición de las tallas de los peces consumidos por el lobo Fino Antártico y los representados en los arrastres realizados por Kock et al. (2000)

Tabla III.18: Índice de solapamiento para las distribuciones de tallas de los peces consumidos por el LFA y los representados en los arrastres realizados por Balguerías (1989) y por Kock et al. (2000)

Figura III.12: Superposición de las tallas de los peces consumidos por el C. de Georgias y los representados en los arrastres realizados por Balguerías (1989)

Figura III.13: Superposición de las tallas de los peces consumidos por el C. de Georgias y los representados en los arrastres realizados por Kock et al. (2000)

Tabla III.19: Índice de solapamiento para las distribuciones de tallas de los peces consumidos por el C. de Georgias y los representados en los arrastres realizados por Balguerías (1989) y por Kock et al. (2000)

Figura III.14: Superposición de la talla de los peces consumidos por el P. Damero y los representados en los arrastres realizados por Kock et al. (2000)

Tabla III.20: Valores de Diversidad (H), Equitatividad y Riqueza observados en los predadores ictiófagos de las IOS durante la temporada reproductiva 1999

Tabla III.21: Valores de Diversidad $(H)$, Equitatividad y Riqueza observados en los predadores ictiófagos de las IOS durante la temporada reproductiva 1999 (los peces demersales fueron considerados como un único grupo funcional)

Tabla III.22: Peces seleccionados $(\mathrm{I}>0)$ por los predadores tope de las IOS 


\section{Capítulo IV \\ Estrategias de alimentación}

$\begin{array}{lr}\text { Figura IV.1: Profundidades de buceo de los predadores tope } & 128\end{array}$

Tabla IV.1: Áreas de forrajeo, estrategia utilizada por los predadores tope 129 y detalle de la bibliografía utilizada

Tabla IV.2: Índice de solapamiento de Linton para la composición general de la dieta 149

Tabla IV.3: Índice de solapamiento de Linton para la contribución en masa de peces en la dieta 150

Tabla IV.4: Predadores ordenados según el grupo trófico de solapamiento 150

Tabla IV.5: Re-ocurrencia de presas de acuerdo a la composición general de la dieta; Total 168

Tabla IV.6: Re-ocurrencia de presas de acuerdo a la composición general de la dieta; 1997/98 169

Tabla IV.7: Re-ocurrencia de presas de acuerdo a la composición general de la dieta; 1998/99 170

Tabla IV.8: Re-ocurrencia de presas de acuerdo a la composición general de la dieta; 1999/00 171

Tabla IV.9: Re-ocurrencia de los peces representados en la dieta; 1995/96 172

Tabla IV.10: Re-ocurrencia de los peces representados en la dieta; 1996/97 173

Tabla IV.11: Re-ocurrencia de los peces representados la dieta; 1997/98 174

Tabla IV.12: Re-ocurrencia de los peces representados la dieta; 1998/99 175

Tabla IV.13: Re-ocurrencia de los peces representados la dieta; 1999/00 176

\section{Capítulo V \\ Requerimientos energéticos}

Tabla V.1: Detalle de la bibliografía utilizada para obtener los valores de requerimientos Energéticos de los predadores tope de las IOS

Tabla V.2: Valores energéticos $(\mathrm{KJ} / \mathrm{g}$ ) de las principales presas de los predadores tope de las IOS 181

Tabla V.3: Requerimientos energéticos diarios (RED) de aves y mamíferos distribuidos en las IOS 186

Tabla V.4: Porcentaje energético (\%E) de las diferentes presas representadas en la dieta de los predadores tope de las IOS

Tabla V.5: Predadores agrupados según las presas que más aportan a la cobertura de los requerimientos energéticos

Tabla V.6: Demanda energética poblacional anual (DEP), consumo en términos de biomasa (Tn/año) y energía (MJ/año) de cada ítem alimentario y tamaño poblacional de los predadores tope de I. Laurie

Tabla V.7: Consumo anual de peces agrupados por familias (Tn y MJ anuales) por los predadores de la I. Laurie

Tabla V.8: Consumo anual de peces (Tn/año) por los predadores de la I. Laurie

Tabla V.9: Consumo anual de peces (MJ/año) por los predadores de la I. Laurie

Tabla V.10: Demanda energética poblacional anual (DEP), consumo en términos de biomasa (Tn/año) y energía (MJ/año) de cada ítem alimentario y tamaño poblacional de los predadores tope de las IOS

Tabla V.11: Consumo anual de peces (Tn/año) por los predadores de las IOS 199

Tabla V.12: Consumo anual de peces (MJ/año) por los predadores de las IOS 200

Tabla V.13: Requerimientos energéticos anuales (MJ/año) de los predadores tope de las IOS sobre las especies de peces

Tabla V.14: Toneladas de peces capturados por la pesca comercial entre los años 1970 y 1990

Figura V.1: Divisiones de las subáreas estadísticas de pesca designadas por la CCRVMA 204

Figura V.2: Límites del área marina protegida en la plataforma sur en las IOS

Tabla V.15: Estimación del consumo anual de especies de peces explotadas comercialmente por los predadores tope de la IOS 
Tabla V.16: Consumo de presas (máximo y mínimo en Tn.) por parte de los predadores de las IOS

\section{Capítulo VI}

\section{Modelización ecotrófica}

Figura VI.1: Modelo conceptual sobre las relaciones trófica con alta disponibilidad de krill

Figura VI.2: Modelo conceptual sobre las relaciones trófica con baja disponibilidad de krill 


\section{Introducción General}

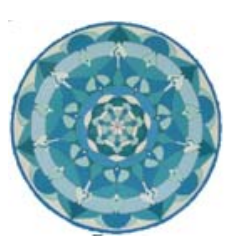

\section{I.1. El continente antártico}

\section{I.1.1. Características físicas y biológicas}

Antártida es el continente más extremo y riguroso del planeta, características que están fundamentalmente determinadas por sus condiciones climáticas adversas. La marcada estacionalidad del clima se refleja en los registros de su amplio rango término, observándose temperaturas extremas que varían entre $11{ }^{\circ} \mathrm{C}$ en verano y $-89{ }^{\circ} \mathrm{C}$ en invierno. Las precipitaciones son escasas y se manifiestan principalmente en forma de nieve, alcanzando un promedio anual que varía entre 150 y 2000 mm. año-1 para la sector Atlántico (Bromwich et al. 1995 y Bromwich y Ryan 2004) (Figura I.1). Debido a su ubicación geográfica, durante los meses de verano los rayos solares no pierden el contacto con los mares y el continente, en tanto que durante los meses de otoño e invierno la radiación solar es escasa o nula dependiendo de la latitud. Así entonces, debido a las bajas temperaturas, los fuertes vientos ${ }^{1}$ y la presencia de hielo que cubre casi la totalidad de su superficie, Antártida es un lugar inhóspito para el establecimiento y desarrollo de los organismos vivos.

La superficie continental, incluidas las barreras de hielo que limitan con el mar, cubre aproximadamente $14.107 .000 \mathrm{~km}^{2}$ y está rodeada por el Océano Antártico (OA) cuya superficie es de $20.327 .000 \mathrm{~km} .{ }^{2}$, cifra que comprende a los mares periféricos tales como el Mar de Amundsen, el Mar de Bellingshausen, parte del Pasaje de Drake, el Mar de Ross y el Mar de Weddell (Figura. I.1). Antártida contiene el 90\% del agua en estado sólido del planeta, lo que representa el $70 \%$ del agua dulce disponible. Con respecto a otros continentes, la plataforma continental antártica es estrecha y relativamente profunda. Las profundidades de la plataforma varían entre 400 y $800 \mathrm{~m}$. (Anderson 1999), en tanto que la media mundial es de 133 metros (Anderson 1999). La mayor parte del fondo oceánico está cubierta por depósitos de origen glacial, los que han sido excavados sobre el terreno

1

Ejemplo de ello son Los vientos catabáticos generados por el enfriamiento de las masas de aire en contacto con el hielo. Estos vientos al ras del suelo alcanzan velocidades de $150 \mathrm{~km}$. por hora y duran varios días. 
helado y posteriormente trasladados al mar. A su vez, el OA está dividido en tres sectores según la cercanía al océano adyacente con el cual limita concéntricamente: los sectores Atlántico, índico y Pacífico. Al noroeste del sector Atlántico nace la península Antártica (PA) (Figura I. 1), la cual integra junto con los Andes Patagónicos y los Andes Fueguinos, un mismo cinturón orogénico desarrollado entre el Mesozoico y el Cenozoico (Anderson 1999). La PA se extiende aproximadamente desde los $63^{\circ} \mathrm{S}$ hasta los $74^{\circ} \mathrm{S}$ (Skvarca 1994). Frente a la costa oriental de la PA se ubican las Islas Shetland del Sur (ISS) y desde allí hacia el noreste, emerge un complejo de islas denominadas islas Orcadas del Sur (IOS). En particular, la región noroeste de la PA conforma una zona de plataforma continental rodeada de islas, tales como las ISS, las IOS, la Isla Georgia del Sur y las Islas Sandwich del Sur. A su vez, esas islas están ubicadas en una zona de frentes oceánicos muy importantes donde la Corriente Antártica Circumpolar (CAC) y el "giro del Weddell", o corriente marina principal del Mar de Weddell, entran en contacto (Deacon 1937, 1979). Así, las IOS reciben un flujo regular de masas de agua provenientes del Mar de Weddell, las que a su vez están reguladas por la CAC (Gordon 1998, Atkinson y Peck 1990).

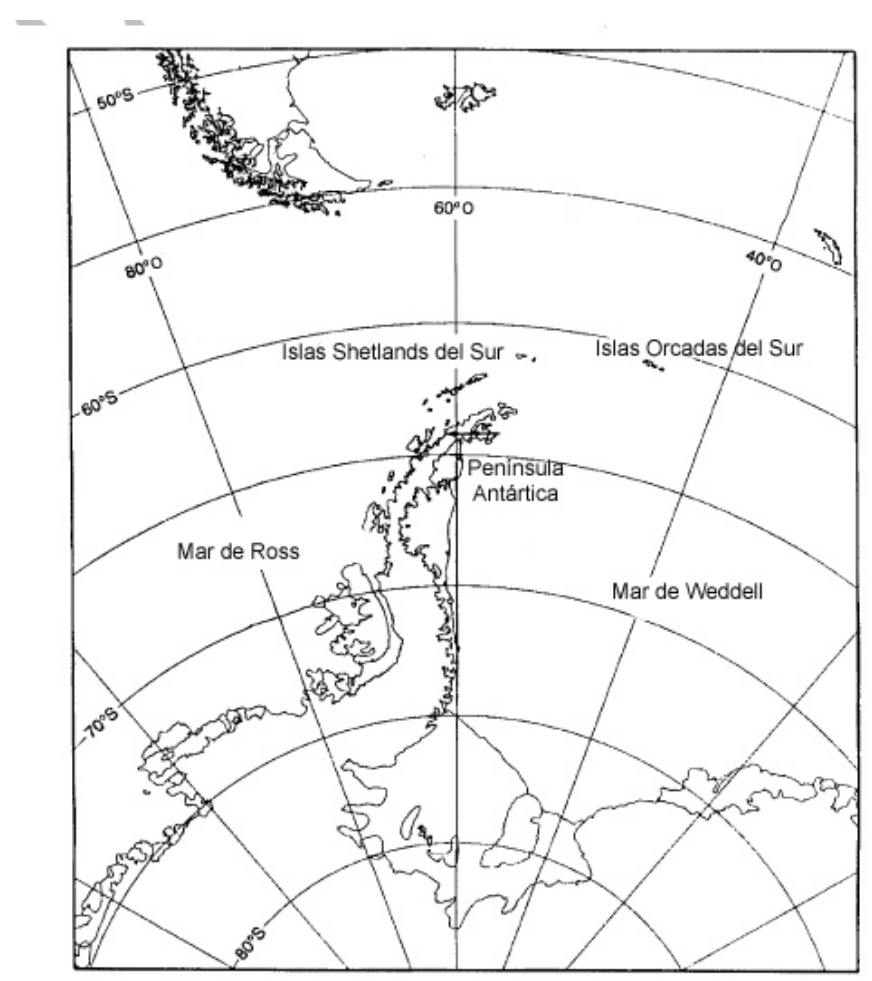

Figura I.1: Mapa de la Península Antártica y archipiélagos adyacentes (Islas Shetlands del Sur e Islas Orcadas del Sur).

Debido a las características ambientales descriptas previamente, los organismos que habitan la Antártida poseen mecanismos fisiológicos muy adaptados a las condiciones propias de la región. El alto grado de especialización observado en estos organismos, sumado a la rigurosidad del ambiente, hacen presuponer una marcada fragilidad en el ecosistema antártico. En la base de la trama trófica antártica (Figura I.2) se hallan los productores primarios constituidos principalmente por diatomeas silíceas, lo que se relaciona con los grandes depósitos de silicatos que se encuentran en 
los fondos marinos (Tréguer et al. 1995, Pondaven et al. 2000). En ciertas zonas marinas antárticas, las diatomeas silíceas conforman sistemas de producción primaria muy importantes. En general, estos sistemas altamente productivos están asociados a zonas de hielo marginal y presentan una elevada diversidad de especies (Semeneh et al. 1998, Lizotte 2001). En las últimas dos décadas estos sitios han sido reconocidos como los de mayor producción primaria del OA (Lizotte 2001). Los eventos de floración fitoplanctónica que dan sustento a esta afirmación, se deben principalmente a los procesos de surgencia de agua profunda rica en nutrientes (nitratos, fosfatos y silicatos), al largo fotoperíodo del verano austral y a la estabilidad de la columna de agua debida a los procesos de derretimiento de hielo que ocurren durante la primavera austral (Nelson et al. 1987, Hoppema 2004).

En un nivel inmediatamente superior al de los productores primarios se encuentran los organismos zooplanctónicos, dentro de los cuales el 50\% está representado casi exclusivamente por el krill antártico (Euphausia superba) (Holdgate 1967). Su abundancia, su alto contenido calórico y su amplia distribución (Márquez et al. 1978, Marschoff y Tomo 1984, Ross y Quentin 1986, El-Sayed 1981, Mashall 1988, Priddle et al. 1988, Quentin et al. 1994, Siegel y Loeb 1995, Croxall et al. 1999) hacen que el krill pueda sostener una abundante comunidad de consumidores secundarios dentro de los cuales los peces juegan un rol importante, no sólo como consumidores, sino también como nexo entre el krill y los predadores superiores. Los enjambres de krill pueden extenderse por kilómetros y estar constituidos por varios billones de individuos (Nicol 2006). A su vez, en zonas de aguas abiertas influenciadas por los sistemas de circulación oceánicos estos enjambres constituyen un recurso alimentario importantísimo. En este sentido, numerosos estudios desarrollados en la zona Atlántica del OA reportan la presencia de enjambres de krill asociados a giros oceánicos, tal como el "giro del Weddell" (Nicol et al. 2000, Pakhomov 2002, Klinck et al. 2004) o los del Arco de Scotia y de las Islas Orcadas del Sur (Barrera-Oro 2002), entre otros.

Inmediatamente en un nivel superior se encuentran los peces, con una gran abundancia dentro una pequeña variedad de familias (ver más adelante). Seguido de ellos, aparecen casi la mayoría de los predadores que se consideran tope, dentro de los cuales encontramos numerosas especies de aves y mamíferos marinos, todos ellos carnívoros. Dentro de las aves, dada la abundancia de especies se destacan las familias Pygoscelidae, Procellariidae, Laridae, Stercorariidae y Phalacrocoraxidae, siendo la primera familia exclusiva del hemisferio sur. Dentro de los mamíferos se destacan los cetáceos, los otáridos y las focas. Sus dietas varían desde el consumo casi exclusivo de krill, como las ballenas, hasta la predación sobre otros mamíferos y aves, como en el caso de las orcas o la foca leopardo. Las familias más destacadas dentro del grupo de mamíferos son Ottaridae y Phocidae, las cuales incluyen a los lobos y elefantes marinos y focas.

Las comunidades de peces antárticos presentan propiedades únicas con respecto a las del resto del mundo y están caracterizadas por un alto grado de endemismo y una baja diversidad. Muchas de las especies de peces presentes hoy en Antártida son el resultado de una importante radiación evolutiva que tuvo lugar a partir del Cretácico inferior o Cenozoico temprano (hace 40-65 millones de años) como consecuencia del aislamiento geográfico del continente (Targett 1981). La fragmentación de Gondwana y el posterior desarrollo de los patrones oceanográficos que actualmente presenta Antártida influenciaron en gran medida la distribución de la fauna ictícola (Eastman 1995). De las 480 familias de peces descriptas mundialmente, sólo el 1,3\% se encuentran 
distribuidas en Antártida (Eschemeyer 1998). Esto significa que, teniendo en cuenta que el OA representa el $10 \%$ de la superficie oceánica global, en términos de diversidad taxonómica, la ictiofauna antártica es muy poco diversa. Además, alrededor del $70 \%$ de los órdenes y el $85 \%$ de las especies presentes en Antártida son altamente endémicas (Kulesz 1998).

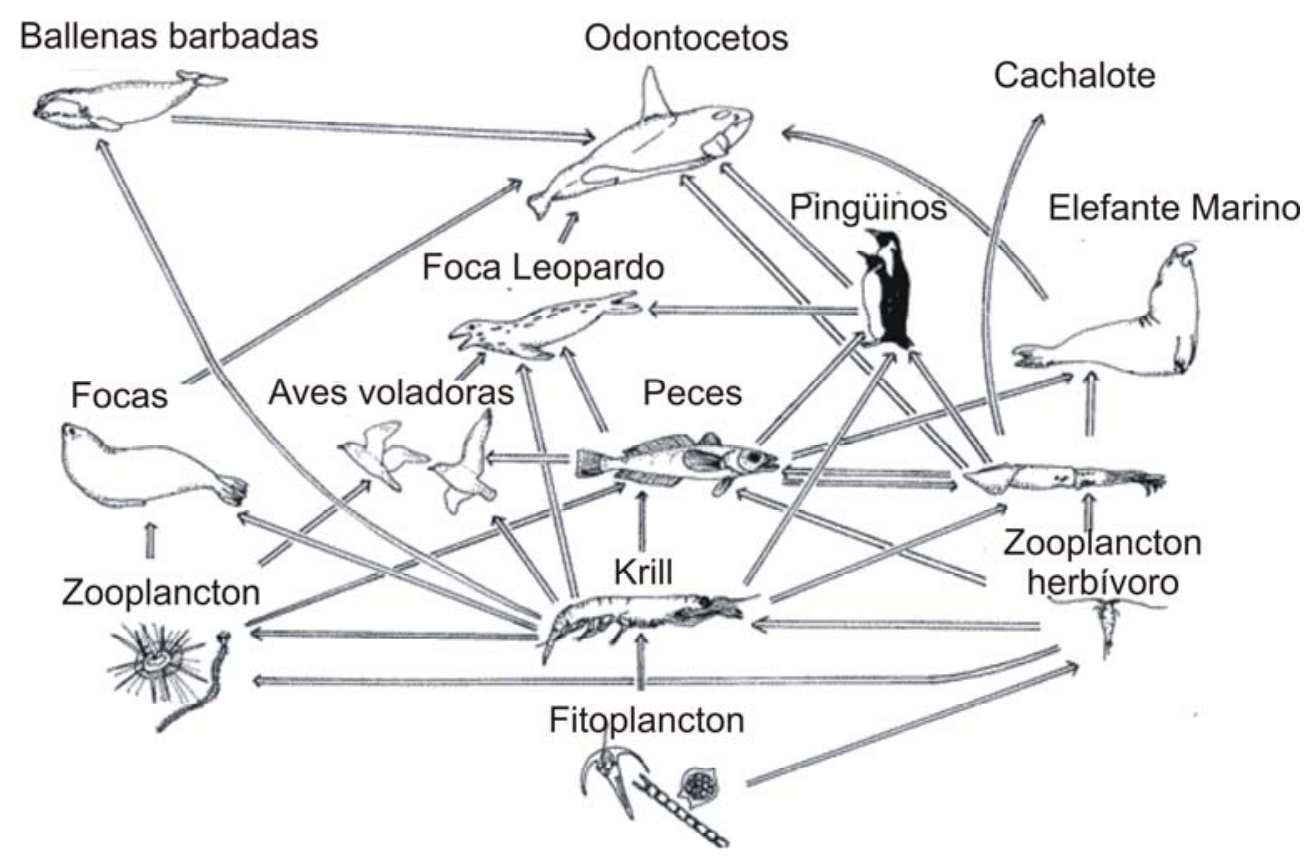

Figura I.2: Diagrama de la trama trófica antártica. (Tomado y adaptado de https://sites.google.com/a/pgcps.org/rmanningscience/home/msa-questions-answers/life-science-standard-3-0)

La Convergencia Antártica, las amplias áreas de plataforma y la existencia del Arco de Scotia, han marcado su efecto en la evolución y composición de las ictiofaunas costera y pelágica antárticas.

Las familias de peces actualmente representadas en aguas antárticas son catorce y sólo 4 de ellas (Nototheniidae o bacalaos antárticos, Bathydraconidae o peces dragón, Channichthyidae o peces de hielo, y Harpagiferidae o pilladores espinudos) pertenecientes al sub-orden Notothenioidei conforman el $70 \%$ de las especies de peces antárticos. Estas cuatro familias tienen una amplia distribución (desde el litoral hasta $1500 \mathrm{~m}$. de profundidad) formando parte de las poblaciones dominantes y más diversificadas en las zonas de plataforma antártica (Barrera-Oro 2002).

DeWitt (1971) describió la composición de la ictiofauna antártica en base a la distribución en relación a la profundidad y a la topografía del fondo. Desde un punto de vista zoogeográfico, basado en la distribución, origen y dispersión de especies, el OA fue dividido en dos subregiones: (I) la Glacial (que incluye el continente antártico en sí mismo), y (II) la Subregión Kerguelen (Andriashev 1965, DeWitt 1971, Hureau 1973, Kock 1985, Duhamel 1987). Desde un punto de vista ecológico esta división no es del todo satisfactoria ya que no incluye la dispersión de los peces pelágicos ni la presencia/ausencia de la cubierta de hielo y también ignora la distribución de los organismos planctónicos como así tampoco a la zona del Arco de Scotia. Kock (1992) y Hureau (1994) caracterizaron a las comunidades de peces según los hábitos de vida de cada especie y según sus 
hábitos alimentarios respectivamente, dando un panorama más amplio sobre su distribución en relación con su ecología. Kock (1992) reconoce tres regiones ecológicas en el OA: 1) la Zona Alta Antártica (ZAA) que incluye la plataforma continental, incluidos el Mar de Weddell y el Mar de Ross , 2) la Zona de Hielo marino Estacional (ZHE) y 3) la Zona Libre de Hielo (ZLH). En este sentido, los complejos de islas ubicadas al noroeste de la PA quedan incluidas en la ZHE, considerada como la zona de mayor productividad biológica de Antártida y con una fauna ictícola mayormente representada por especies de myctóphidos y notothéniidos de estadios post-larvales (Kock 1992, Kock 2005).

En términos generales, un primer acercamiento hacia la clasificación de la ictiofauna antártica diferencia dos comunidades bien marcadas en cuanto a los hábitos de vida y el hábitat que ocupan. Estos dos grandes grupos se corresponden con especies de hábitos pelágicos y especies de hábitos bentónicos o bento-demersales respectivamente. Kock (1992) hace una interpretación de las comunidades de peces de acuerdo a los hábitos alimentarios. Por medio de esta categorización se infiere fácilmente el hábito de vida (pelágico o bentónico) de cada especie. Así entonces, incorporando la información provista por Kock (1992), podemos diferenciar dos comunidades bien marcadas dentro de los ecosistemas costeros antárticos:

> Ictiofauna pelágica:

Dentro de este grupo Kock (1992) incluye a las especies de peces consumidoras de plancton (I) y de peces y plancton (II). Dentro del primer grupo se destacan especies altamente dependientes del krill, copépodos, pterópodos e hipéridos. Las especies de peces mejor representadas en esta categoría en la ZHE son Champsocephalus gunnari y Lepidonotothen larseni, mientras que en la ZAA están mejor representados Chaenodraco wilsoni y Pleuragramma antarcticum. Dentro del grupo II encontramos especies consumidoras principalmente de eufáusidos, copépodos, pterópodos y peces. Las especies mayormente representadas en la ZHE son Notothenia rossii y Pseudochaenichthys georgianus, en tanto que en la ZAA lo hacen especies del género Chionodraco.

Asimismo, la presencia de especies correspondientes a los géneros Electrona, Gymnoscopelus, Protomyctophum y Krefftichthys (todos incluidos en la familia Myctophidae) se destacan dentro del grupo. Se incluyen también dentro de este grupo a $P$. antarcticum correspondiente a la familia Nototheniidae como también ciertas especies de las familias Channichthyidae y Bathydraconidae.

$>$ Ictiofauna bentónica:

Este grupo se puede dividir en dos subgrupos grupos principales según su distribución batimétrica y sus relaciones filogenéticas: la ictiofauna de aguas profundas que habita la zona del talud continental y la de aguas costeras que habita la plataforma.

Las especies que habitan zonas de aguas profundas han sido muy poco estudiadas. Por el contrario, las especies de aguas costeras han sido estudiadas con más 
profundidad, y esto se debe fundamentalmente a la relativa menor dificultad logística que implica trabajar en esta zona.

Dentro de este grupo Kock (1992) incluye a los consumidores de bentos (I) y de peces y bentos (II). El primer grupo consume preferentemente organismos infaunales y epifaunales tales como poliquetos, moluscos y anfípodos. Estas especies de peces son muy comunes dentro de las comunidades costeras y, en la ZHE las especies Gobionotothen acuta y Lepidonotothen nudifrons están ampliamente representadas. El segundo grupo se caracteriza por consumir peces, cefalópodos y organismos epibentónicos como por ejemplo mýsidos. En la ZHE las especies mejor representadas son Dissostichus eleginoides y Chaenocephalus aceratus.

Existe un último grupo, los consumidores de plancton y bentos. Lepidonotothen squamifrons es una de las especies mayormente representadas en la ZHE. Este grupo se alimenta principalmente de eufáusidos, salpas, hipéridos y organismos epibentónicos.

Ahora bien, a escala local el ambiente marino puede dividirse en dos sistemas tróficos bien diferenciadas: el sistema litoral ó inshore (costa cercana) y el sistema de aguas profundas ú offshore (de costa lejana). Kock (1992) definió estas zonas de la siguiente manera:

$>$ Inshore:

Sublitoral: profundidad menor a 30 metros; fondo blando compuesto principalmente por arena y fango con abundancia de macroalgas. La fauna está compuesta principalmente por anfípodos gamarídeos, isópodos, decápodos, moluscos y peces. Aguas profundas: profundidades mayores a 30 metros en zonas de islas con pendientes de playa muy pronunciadas. La fauna está compuesta principalmente por nudibranquios, gasterópodos, ofiuroideos y anfípodos gamarídeos de mayor tamaño que en la zona sublitoral y peces.

En particular, para la zona del Arco de Scotia y oeste de la PA, los peces más frecuentes pertenecen al suborden Notothenioidei, los cuales pasan casi la totalidad de su ciclo de vida en estas aguas. Harpagifer antarcticus, Notothenia coriiceps y $\mathrm{N}$. rossii son las especies más neríticas, en tanto que Gobionotothen gibberifrons, $L$ nudifrons y Trematomus newnesi aparecen más frecuentemente a profundidades entre 30 y $45 \mathrm{~m}$. Las especies que suelen registrarse en las mayores profundidades de esta zona (entre 70 y $90 \mathrm{~m}$.) son Trematomus bernachii, Parachaenichthys charcoti y $C$. aceratus. En general, en lo que se refiere a esta zona, de la totalidad de especies mencionadas, $N$. coriiceps es la especie dominante tanto en número como biomasa (Everson 1970, Barrera-Oro et al. 2000, Casaux et al. 2000).

La ocurrencia de peces pelágicos tales como especies de myctóphidos o $P$. antarcticum, ha sido escasamente reportada para la zona inshore (Daniels 1982, Linkowski et al. 1983) y se ha indicado que la presencia de estas especies en esta zona estaría asociada a ingresos de masas de agua desde la zona de Offshore. Sin embargo, Casaux et al. (2008) observaron que la presencia de peces pelágicos en 
aguas inshore es marcadamente superior a la reportada previamente y consideran que una de las razones que explicarían esta diferencia se debe a fallas en los protocolos de muestreo seguidos en trabajos previos.

$>$ Offshore:

Esta zona corresponde al sector de la plataforma continental que va de los 110 a los 450 metros de profundidad, entre el límite inshore y el talud. La fauna de esta zona está compuesta principalmente por isópodos, eufáusidos, poliquetos, moluscos y peces pelágicos.

La ictiofauna de la zona offshore de las IOS e ISS y del oeste de la PA presenta marcadas similitudes (Targett 1981, Daniels 1982, Takahashi 1983, Kock 1986, Balguerías 1989) y exhibe una alta diversidad en relación a las zonas Inshore (Barrera-Oro 2002). Entre los peces que habitan la zona offshore, hay especies cuya distribución está restringida a esta zona (C. gunnari, L. squamifrons, Chionodraco rastrospinosus y $P$. antarcticum) en tanto que otras también se encuentran distribuidas en aguas inshore. Entre éste último grupo de especies hay algunas que, comparado con aguas litorales, son más abundantes a profundidades cercanas a los $450 \mathrm{~m}$, tales como G. gibberifrons, C. aceratus, L. larseni, N. rossii y T. eulepidotus (Barrera-Oro 2002). En general se considera que los myctóphidos (e.g. Electrona antarctica, Gymnoscopelus nicholsi, etc.) se distribuyen exclusivamente fuera de la zona de plataforma. Sin embargo, Kock (1992) reporta que estas especies suelen encontrarse regularmente sobre la plataforma o incluso en fiordos y bahías. Casaux et al. (2008), a partir de un estudio sobre la dieta del Gaviotín Antártico (Sterna vittata gaini) sugieren que la presencia de especies como $E$. antarctica en aguas costeras durante el día parece ser más importante de lo que previamente se pensaba.

Las relaciones tróficas observadas en las zonas inshore y offshore (Tabla I.1) son marcadamente diferentes (DeWitt 1971). Barrera-Oro (2002) analizó las distribuciones de los peces de la zona del Arco de Scotia en relación a los tipos de alimentación y a los sectores de distribución. Según este trabajo, el rol ecológico de los peces demersales en la zona inshore es mucho más importante que el del krill. El bentos y el zooplancton son consumidos por estos peces, los cuales pasan a formar parte del pool de presas principales de aves y mamíferos. En Antártida las únicas aves voladoras que se alimentan casi con exclusividad de peces demersales costeros son el cormorán de Georgias (Phalacrocorax georgianus) en las IOS y el cormorán Antártico ( $P$. bransfieldensis) en las ISS y en la PA (Shaw 1984, Casaux y Barrera-Oro 1993, Coria et al. 1995, Casaux et al. 1997a y 1998, Favero et al. 1998, Casaux y Ramón 2002, Casaux 2003). Por lo tanto, no es sorprendente observar que la profundidad máxima de buceo de estos cormoranes coincida con el límite de distribución de sus presas (N. coriiceps, N. rossii, T. newnesi, L. nudifrons, G. gibberifrons, H. antarcticus, etc.) (Casaux y Barrera-Oro 1998), lo que hace que se los considere un grupo potencialmente indicador de la distribución y abundancia del recurso que explotan. 
Tabla I.1: Relaciones entre tipo de alimentación y zona de distribución local de los peces registrados en el Arco de Scotia y Oeste de la Península Antártica. Tomado de Barrera-Oro (2002).

\begin{tabular}{|c|c|c|c|}
\hline \multirow[t]{2}{*}{ Familia/Especie } & \multicolumn{2}{|c|}{ Zona local distribución } & \multirow[t]{2}{*}{ Tipo de alimentación } \\
\hline & Inshore & Offshore & \\
\hline \multicolumn{4}{|l|}{ Bathydraconidae } \\
\hline Parachaenichthys charcoti & ocasional & raro & Consumidor de plancton y bentos \\
\hline \multicolumn{4}{|l|}{ Channichthyidae } \\
\hline Chaenocephalus aceratus & ocasional & común & Consumidor de plancton y bentos \\
\hline Champsocephalus gunnari & raro & abundante & Consumidor de plancton y bentos \\
\hline Chionodraco rastrospinosus & raro & común & Consumidor de plancton y bentos \\
\hline \multicolumn{4}{|l|}{ Harpagiferidae } \\
\hline Harpagifer antarcticus & abundante & raro & Consumidor de bentos ${ }^{*} 1$ \\
\hline \multicolumn{4}{|l|}{ Nototheniidae } \\
\hline Gobionotothen gibberifrons & común & abundante & Consumidor de bentos \\
\hline Lepidonotothen larseni & ocasional & común & Consumidor de plancton \\
\hline Lepidonotothen nudifrons & abundante & ocasional & Consumidor de plancton \\
\hline Lepidonotothen squamifrons & raro & abundante & Consumidor de plancton y bentos \\
\hline Notothenia coriiceps & abundante & común & Consumidor de bentos \\
\hline Notothenia rossii & ocasional & ocasional & Consumidor de plancton y bentos \\
\hline Pleuragramma antarcticum & ocasional & abundante & Consumidor de plancton \\
\hline Trematomus bernachii & común & ocasional & Consumidor de plancton y bentos \\
\hline Trematomus eulepidotus & raro & común & Consumidor de plancton \\
\hline Trematomus newnesi & abundante & raro & Consumidor de plancton y bentos \\
\hline \multicolumn{4}{|l|}{ Myctophidae } \\
\hline Electrona antarctica & Ocasional *2 & común & Consumidor de plancton \\
\hline Gymnoscopelus nicholsi & ocasional & común & Consumidor de plancton \\
\hline
\end{tabular}

*1 En la mayoría de los trabajos sobre dieta, esta especie es considerada como un consumidor de bentos. Sin embargo, a partir de datos de dieta del Cormorán Antártico (P. bransfieldensis) Casaux (1998) halló restos de krill en los estómagos de estos peces luego de haber sido ingeridos por los cormoranes. Estos resultados sugieren que el krill parece ser una presa más importante en relación a lo informado en trabajos previos.

*2 Según Kock (1992) y Casaux et al. (2007) la presencia de esta especie en aguas costeras parece ser más importante de lo que anteriormente se informaba.

Otras aves que, aunque con menor intensidad que los cormoranes, también predan frecuentemente sobre peces demersales o pelágicos en aguas inshore son el pingüino Papúa Pygoscelis papua (Brown et al. 1990, Bost et al. 1994, Casaux 1998b, Coria et al. 2000, Berón et al. 2004) y el petrel damero Daption capense (Casaux et al. 1998). A diferencia de estas aves, los mamíferos marinos en general predan parcialmente sobre este tipo de presas, prefiriendo los peces de aguas más abiertas o pelágicos (Everson 1970, Green y Williams 1986, Plötz et al. 1991, Casaux et al. 1997b y 1998b, Burns et al. 1998, Daneri y Carlini 2002).

En la zona offshore los peces demersales dependen menos del bentos y pastorean más frecuentemente sobre el zooplancton (krill) y el necton. Asimismo, los peces pelágicos constituyen un recurso alimentario importante tanto para aves como para mamíferos (Barrera-Oro 2002). En esta zona $E$. antarctica y $P$. antarcticum han sido registrados como dos ítems importantes dentro de la dieta de aves voladoras como el petrel damero (D. capense), el petrel de Wilson (Fregetta tropica), el petrel de las nieves (Pagodroma nivea) y el Escúa polar (Catharacta maccormicki) (Beck 1969, Montalti et al. 1996, Soave et al. 1996a y b, Coria et al. 1997, Hahn 1998, Ferretti et al. 2001).

Hacia la zona establecida desde el final de la plataforma hacia océano abierto o aguas abiertas, el krill es la presa más importante para todos los vertebrados (Barrera-Oro 2002). 


\section{I.1.2. Aspecto Geopolítico}

El manejo de los recursos vivos marinos antárticos recientemente ha generado discusiones internacionales relacionadas con la importancia de proteger la integridad de los ecosistemas. Sumado a ello, la necesidad de establecer un acuerdo político que contemplara el tema de la soberanía se hizo cada vez mayor conforme los intereses económicos y políticos aumentaban su peso dentro de un marco de discusión internacional sobre el destino de los distintos sectores del continente. Para introducirnos en el tema es necesario hacer una breve reseña histórica de los acontecimientos a nivel político y económico ocurridos desde la primera presencia del hombre en Antártida y así entender con mayor profundidad la problemática que se cierne sobre el destino de este continente.

A principios del siglo $X X$ la presencia humana en Antártida estaba limitada a algunos buques foqueros y balleneros y a algunas expediciones científicas, lo que dio lugar a los primeros asentamientos temporarios. Argentina fue el primer país con asentamiento permanente en el sector, evento que data del año 1904. En ese entonces no existía legislación internacional ni organismos reguladores que rigieran sobre el continente y menos aún sobre el uso de sus espacios marinos y costeros ni sobre la administración de los recursos. Los intereses encontrados en relación al aprovechamiento de recursos y a la ocupación del territorio dieron lugar a los primeros conflictos internacionales relacionados con el continente antártico. Para el año '40 los reclamos de soberanía argentina ya se solapaban con los de Chile y el Reino Unido y, al mismo tiempo, otros países reclamaban territorio y el aprovechamiento exclusivo de los recursos de otros sectores del continente. Si bien el interés geopolítico por Antártida ya era importante durante la segunda guerra mundial, las pujas por su dominio fueron aún mas evidentes durante el inicio de la guerra fría. Debido a ello comenzó a cobrar fuerza la idea de que sólo a partir de un sistema coadministrado del territorio se evitarían enfrentamientos armados entre países derivados de las actividades comerciales y de las políticas de asentamiento. El primer paso que se da en ese sentido es entre los años 1957 y 1958 cuando 12 países declaran el Año Geofísico Internacional con el fin de promover la investigación científica, entre otros objetivos no menos relevantes. En 1959 estos mismos países, a los que se suma EEUU, redactan lo que sería luego el Tratado Antártico (TA), un tratado internacional que establece que Antártida será utilizada exclusivamente para fines pacíficos. Entre otros objetivos, el TA intenta establecer mecanismos de control sobre las actividades que se desarrollen en Antártida y promueve el intercambio científico y la cooperación internacional, especificando claramente que al sur de los $60^{\circ}$ sur queda exclusivamente prohibida toda clase de actividad militar. El TA reconoce a todos los países reclamantes de soberanía territorial como tales, pero no resuelve en absoluto ninguno de estos conflictos. Considerando que la cuestión de la soberanía en Antártida es de suma importancia para Argentina, nuestro país debería tener una fuerte presencia dentro de este ámbito de discusión y decisión.

\section{I.1.3. La actividad pesquera en Antártida}

El inicio de la explotación de los recursos vivos en Antártida tuvo su origen al menos a partir del año 1818 con la explotación foquera (Moltalban y Capdevilla 2005). A medida que esta industria comienza a perder rentabilidad debido a la sobreexplotación de los recursos comienza a tomar 
impulso la industria ballenera. Hacia 1849, y luego de que los niveles de capturas de ballenas en el hemisferio norte bajaran marcadamente, empresas inglesas intentaron establecer la industria ballenera en los mares australes. Sin embargo, las condiciones logísticas de aquella época hicieron de esta empresa un fracaso. La capacidad de cazar ballenas de aleta se incrementó a partir del desarrollo del cañón lanza-arpones inventado en 1865 por Svend Foyn. El factor que faltaba para que dicha industria tuviera un desarrollo altamente rentable era el conocimiento de la geografía marítima de la Antártida sudamericana, y esto se logró en el corto lapso de una década, principalmente a partir de los informes generados por las expediciones de los balleneros de Dundee (1892 y 1893), Larsen (1892 a 1894), Gerlache (1897 a 1899), Nordenskjold (1901 a 1903) y Charcot (1903 a 1905 y 1908 a 1910). A principios del siglo XX la actividad ballenera ya se encontraba bien desarrollada y en esa época era habitual que los reportes de las navegaciones también incluyeran información sobre distribución y abundancia de peces, en particular de $N$. rossii (Tønnesen y Johnsen 1982).

La actividad pesquera en Antártida, comenzó hacia el año 1904. Debido a informes alentadores, en el año 1905 la Compañía Argentina de Pesca inicia las actividades pesqueras en Antártida, siendo el objetivo casi excluyente la explotación de N. rossii (Walton 1982). Sin embargo, debido a la interferencia operativa y comercial entre las industrias pesquera y ballenera, la pesca comercial de peces quedaría suspendida para volver con más fuerzas unas décadas después (Dickinson 1985).

La explotación ballenera prácticamente hizo desaparecer a los cetáceos de aguas antárticas y este hecho, entre otros correlatos, se tradujo en un aumento importantísimo en la abundancia de krill (Fraser et al. 1992, Ainley et al. 2006). Es por esto que en la década del 60 la Unión Soviética crea el Atlantic Scientific Institute of Marine Fisheries and Oceanography cuyo principal objetivo era generar información sobre el krill en vistas a la potencial explotación de dicho recurso. Inmediatamente, la explotación del krill pasa a ser una de las pesquerías más importantes de aquella década. El auge de la industria del krill fue el sustento que permitió generar gran cantidad de información sobre la batimetría, la geografía y la oceanografía antártica, como así también sobre la biología de la fauna ictícola (distribución, abundancia, reproducción, crecimiento y alimentación). Este nuevo y alentador cúmulo de información, sumado a la reconversión de la flota ballenera ociosa, dio lugar al inicio de la explotación de la ictiofauna antártica.

El gran ciclo de explotación pesquera comercial en el sector atlántico del OA comenzó en las Islas Georgias del Sur (IGS) durante el período estival entre los años 1969/70 y durante la temporada $1977 / 78$ se extendió a las IOS en donde se pescaron 138.895 toneladas de peces (Kock 1992). Un año mas tarde la actividad pesquera se extendió a las ISS donde, debido a la sobre-explotación, en muy pocos años se observó una marcada disminución en los stocks de peces.

Con el objetivo de resumir la información sobre el desarrollo de las pesquerías en la zona correspondiente al sector Atlántico de la Antártida, dividiremos los sucesos en dos etapas diferentes: la primera correspondiente a finales de la década del ' 60 y comienzos del '70; la segunda ubicada hacia fines de los años '70 y comienzos de los '80. Durante la primera etapa, el acercamiento hacia el conocimiento sobre la ictiofauna antártica se abría paso de la mano de la Unión Soviética junto con la explotación comercial de N. rossii en el área de las IGS (1969/70 y 1970/71) (Kock 1992). En la 
segunda etapa, las compañías de pesca se dedican casi exclusivamente a la explotación de $C$. gunnari en los alrededores de las IGS, IOS y las ISS. Asimismo, durante el verano austral siguiente (1979/80), la actividad pesquera vuelve a focalizarse en la explotación de N. rossii pero esta vez en inmediaciones de las ISS. A pesar de que la industria pesquera se concentró en estas dos especies, debido al sistema de capturas otras especies tales como $G$. gibberifrons, $P$. antarcticum y muchos channíchthyidos juveniles también se vieron seriamente afectadas (Rembiszewski 1978, Williams 1985). El país con mayor participación en la captura y comercialización de los recursos pesqueros antárticos fue la Unión Soviética, la que capturó el $88,4 \%$ del total de la pesca reportada para el sector Atlántico del OA (aproximadamente 1.951.684 toneladas) y entre el 65,8 y el 91,9\% de la pesca registrada para otros sectores antárticos (Anon. 1990a y b, Kock 1992).

Las tres especies de peces sobreexplotadas durante estas dos fases de explotación fueron: C. gunnari, G. gibberifrons y N. rossii. Es notable ver cómo las capturas disminuyen a lo largo del período de explotación. A modo de ejemplo, la captura de C. gunnari disminuyó desde las $285 \mathrm{kt}$ capturadas en 1977/78 hasta 14-29 kt durante el periodo 1979 -1984. Finalmente, entre mediados y fines de la década del ' 80 las capturas en términos de biomasa decaen hasta valores menores al 5\% de los registrados durante el período 1977/78 (Kock y Köster 1989). Sintetizando, la actividad pesquera afectó seriamente al ecosistema antártico, al punto que algunas especies de peces prácticamente han desaparecido de las capturas en aguas abiertas y costeras (ver Barrera-Oro y Marschoff 1991, Kock 1992, Barrera-Oro et al. 2000) y que las poblaciones de algunos de sus predadores han disminuido marcadamente (ver Barrera-Oro y Casaux 1996, Casaux y Barrera-Oro 2006).

El archipiélago de las IOS fue quizás uno de los sectores mas afectados. La actividad pesquera en este sector fue tan intensa que la pesca comercial dejó de ser rentable en tan solo 3 años de explotación (Kock 1992). La abrupta declinación en los stocks de peces llamó la atención hacia la toma de medidas de conservación por lo que, a partir de una iniciativa de Argentina, la Comisión para la Conservación de los Recursos Vivos Marinos Antárticos (CCRVMA) cierra la actividad pesquera para las IOS y las ISS a partir del verano 1990/91. Si bien la pesca comercial en el área de las IOS se encuentra cerrada desde 1991, hasta el momento no se han desarrollado estudios abarcativos tendientes al conocimiento integral del ecosistema que puedan ser de utilidad para generar políticas de manejo del ecosistema y de administración de los recursos ante una eventual reapertura de la actividad pesquera.

\section{I.1.4. La regulación del manejo de los recursos naturales y el medio-ambiente} en Antártida

A finales de los años '70, una convención internacional de la que participan 24 países $^{2}$ comienza a trabajar para salvaguardar el medioambiente antártico, para lo que considera indispensable el aumento del conocimiento de dichos ecosistemas. Este acuerdo dio lugar a la creación de la Comisión para la Conservación de los Recursos Vivos Marinos Antárticos (CCRVMA, o por sus siglas

\footnotetext{
${ }^{2}$ Argentina, Australia, Bélgica, Brasil, Chile, Francia, Alemania, India, Italia, Japón, Korea del Sur, Namibia, Nueva Zelanda, Noruega, Polonia, Rusia, Sudáfrica, España, Suecia, Ucrania, el Reino Unido, EEUU, Uruguay, Bulgaria, Canadá, Finlandia, Grecia, los Países Bajos, Perú y Vanuatu
} 
en inglés: CCAMLR, Commission for the Conservation of Antarctic Marine Living Resources), la que actualmente está integrada por miembros diplomáticos y científicos de los países que adhirieron a dicha comisión. La CCRVMA fue la primera convención a nivel internacional que formalizó la incorporación de políticas de manejo de los recursos naturales marinos y la primera en implementarlas. Dos de los principales preceptos fundacionales de esta convención son: evitar que cualquier explotación haga disminuir el tamaño poblacional de la especie explotada a niveles inferiores a aquéllos que aseguren su restablecimiento a niveles estables, y que cualquier explotación no debe afectar de modo permanente a las especies explotadas ni a las especies dependientes o relacionadas con dicho recurso. Para que todos estos conceptos tengan sentido se requiere de la implementación de programas de investigación y monitoreo a largo plazo.

Así entonces, la pesca en aguas antárticas y sub-antárticas actualmente está regulada por la CCRVMA. Teniendo en cuenta informes de cruceros de investigación y reportes de captura de empresas pesqueras, CCRVMA determina qué especies pueden ser capturadas, las áreas habilitadas para la actividad pesquera (Figura I.3), las artes permitidas y los cupos a extraer. Sin embargo, dado el costo de las operaciones, los cruceros de investigación son escasos y por lo general están restringidos a las zonas de las IGS y alrededores de la Isla Elefante (ISS). Además, los reportes de captura suelen estar manipulados por los países/empresas pesqueras en su propio favor (reportan menor número de barcos en el área de pesca, menor cantidad de pescado extraído, etc.) y en Antártida no está instrumentado el "poder de policía" para controlar la pesca. Por ello, en relación al manejo racional de los recursos y de la conservación del medioambiente, el panorama no es tan alentador como a priori parecía. Asimismo, teniendo en cuenta que nuestro país reclama la soberanía de un sector de la Antártida, Argentina debería tener una fuerte presencia dentro de este ámbito de discusión y decisión. Sin embargo, dado que nuestro país no tiene posibilidad de realizar cruceros de investigación dentro de aguas antárticas, la participación en la toma de decisiones no está a la altura de lo esperado. Ante la falta de recursos para desarrollar estudios convencionales, Argentina debería desarrollar estrategias alternativas que le permitan trabajar en defensa de los intereses reclamados $\mathrm{y}$, consecuentemente, en pos del manejo racional de los recursos y de la conservación del medioambiente antártico 


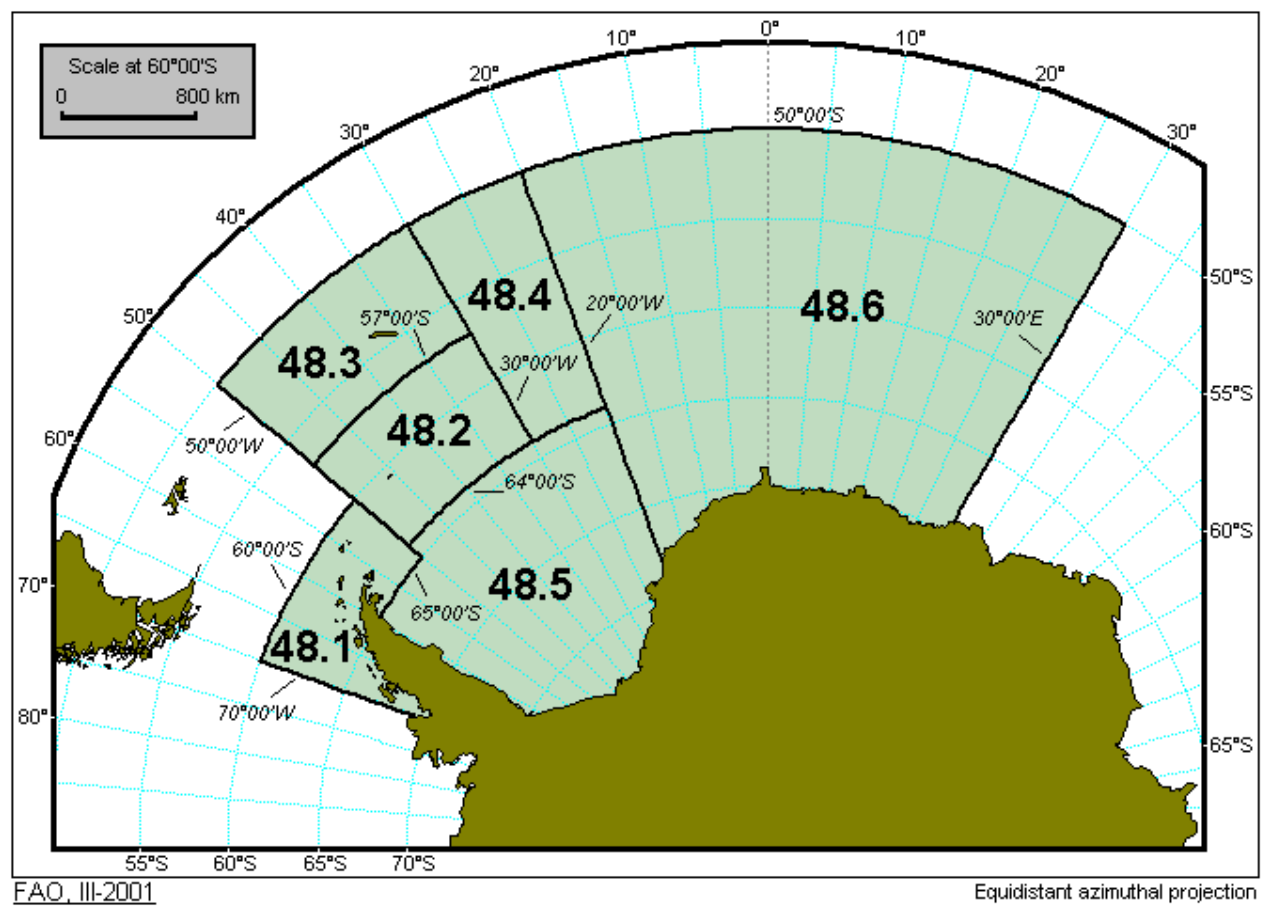

Figura I.3: Áreas estadísticas de pesca establecidas por la CCRVMA para el sector Atlántico. Nótese que la zona 48.2 incluye a las IOS.

\section{I.1.5. La importancia del desarrollo de políticas de manejo}

Parte de las investigaciones sobre recursos pesqueros orientadas a abordar la problemática del manejo de los mismos, también han servido para focalizar la atención en la interacción de la totalidad de los componentes naturales del ecosistema. La biología de las especies ictiófagas y sobre todo sus tasas de consumo y estrategias de forrajeo se vuelven puntos vitales al momento de adoptar políticas referidas al manejo de los recursos marinos, sobretodo por la competencia potencial entre los predadores tope y las pesquerías comerciales.

El comportamiento alimentario y la dinámica poblacional de los predadores tope marinos son altamente sensibles a los cambios en la disponibilidad de sus presas (ver Cairns 1987, Burger y Piatt 1990, Montevecchi 1993, Casaux 1998, entre otros). Como ejemplo de ello se puede mencionar que durante la última década el número de parejas reproductoras de cormorán Antártico ha disminuido marcadamente en numerosas colonias de las ISS (Casaux y Barrera-Oro 1996) en correspondencia con los cambios observados en la estructura de las comunidades de peces litorales (Barrera-Oro y Marschoff 1991, Barrera-Oro et al. 2000). Esto abre la posibilidad de utilizar diferentes parámetros reproductivos, alimentarios y poblacionales de predadores tope como indicadores de procesos de cambio en las comunidades de peces, lo que podría suplir, en cierta medida, la falta de información derivada de cruceros de investigación. La ventaja de este tipo de estudios en comparación con los que se desarrollan desde buques de investigación es que son poco costosos, de fácil implementación y de impacto nulo para los organismos a estudiar. Una vez calibradas las metodologías de trabajo, a través del estudio de diferentes parámetros de predadores ictiófagos se puede monitorear cambios en la abundancia, estructura y distribución de las diferentes poblaciones de peces, detectar cambios 
en las estructuras de las comunidades de peces, etc. Debido a la falta de recursos para implementar programas a gran escala relacionados con la conservación del medioambiente y el manejo de recursos y/o por la imposibilidad de aplicar metodologías alternativas, actualmente en América del Norte y Europa se desarrollan y/o impulsan programas basados en metodologías de trabajo similares a las descriptas previamente (ver entre otros Barrett 1991, los trabajos recopilados en Furness y Greenwood 1993, Rail y Chapdelaine 1998). Dentro de este contexto, a través de programas de investigación coordinados por el Instituto Antártico Argentino, a partir de 1990 Argentina inició estudios relacionados con la interacción predador-presa entre aves y mamíferos marinos ictiófagos y los peces antárticos. Los principales objetivos de esta línea de trabajo son ampliar el conocimiento de la biología de las especies bajo estudio e identificar parámetros confiables que permitan detectar tempranamente cambios en el ecosistema (naturales o de origen antrópico tales como los originados por la pesca mal administrada) y/o que ayuden a administrar racionalmente la pesca o la actividad humana en Antártida. Uno de los avances mas significativos en este sentido ha sido desarrollar una metodología que permite estimar la tasa de consumo diaria del cormorán Antártico (y por que especies y tallas de peces es cubierta) mediante el análisis de pellets regurgitados (ver Casaux et al. 1995a y b, Casaux 2003). Dado que el cormorán Antártico es un predador oportunista, esta metodología permite monitorear el estado de las poblaciones de peces costeros y además posibilita estimar localmente los requerimientos alimentarios de estas aves para que sean tenidos en cuenta al momento de fijar cupos de pesca. Esta metodología fue presentada ante CCRVMA (Casaux y Barrera-Oro 1998), siendo aceptada como un "Standard Method" de dicha comisión (ver SC-CAMLR, 1998, párrafo 9.30) comenzando su aplicación a nivel internacional a partir del año 1998. Asimismo, varios trabajos indican que diferentes aspectos alimentarios del pingüino Papua (Coria et al. 2000, Berón et al. 2002), del cormorán de Georgia (Casaux y Ramón 2002), del lobo Fino Antártico (Casaux et al. 2003a y b), de la foca de Weddell (Casaux et al. 2006), y del gaviotín Antártico (Casaux et al. 2007) podrían reflejar condiciones locales de las comunidades de peces y ser de utilidad para monitorear tendencias en las poblaciones de peces, lo que alienta la profundización del estudio de estos aspectos. Sin embargo, los patrones de forrajeo de las diferentes especies no solo estarían determinados por la disponibilidad (en tiempo y espacio) de alimento sino también por procesos denso-dependientes y por la intensidad de la competencia inter-específica por el mismo, entre otros factores. Por ello, el estudio concurrente de los aspectos alimentarios de los diferentes predadores ictiófagos, como así también de los aspectos relacionados con la competencia por el alimento, son imprescindibles para profundizar el conocimiento de la estructura trófica del ecosistema y para aumentar el poder de predicción de los efectos que los diferentes procesos de cambio ambiental (naturales o antrópicos) podrían producir en el mismo. Salvo el trabajo realizado por Green et al. (1998) y Green y Woehler (1992) en Isla Heard (zona Índica del OA), no existen antecedentes sobre este tipo de estudio integral del ecosistema para regiones antárticas o sub-antárticas.

\section{I.2. Objetivos generales}

La información relacionada con los hábitos alimentarios de los predadores tope en las IOS es abundante (Burton 1968, Beck 1969, Beck y Brown 1972, Conroy y Twelves 1972, Laws 1981, Malcolm y McLeod 1982, Hemmings 1984, Daneri y Coria 1993, Soave et al. 1996a y b, Coria et al. 
1997 y 2000, Casaux et al. 1998 y 2009, Ferretti et al. 2001, Casaux y Ramón 2002, Libertelli et al. 2003, Carlini et al. 2006). Sin embargo, aún no se han realizado estudios que determinen los requerimientos energéticos de las diferentes poblaciones, que analicen las interrelaciones tróficas entre los diferentes predadores, y menos aún las variaciones intra- e inter-anuales en los niveles de competencia inter-específica. Para avanzar en el conocimiento de esta temática es necesario analizar conjuntamente toda la información disponible relacionada con la composición de la dieta de los diferentes vertebrados ictiófagos en las IOS y con las variaciones estacionales en la misma, determinar el grado de superposición de la dieta y de competencia por el alimento y estimar sus requerimientos alimentarios (y por que presas son cubiertos). Este nivel de análisis de los aspectos alimentarios de los predadores tope es fundamental para avanzar en el conocimiento del funcionamiento integral del ecosistema. Tal como se comentó previamente, la actividad pesquera desarrollada en las IOS afectó seriamente los stocks de varias especies de peces, incluidas $N$. rossii y G. gibberifrons cuya población juvenil habita aguas costeras y su estatus actual es desconocido. En este sentido, los métodos alternativos planteados en la CCVRMA (Casaux 1998) tendientes a analizar el estatus de las poblaciones de peces y a detectar procesos de cambio en las mismas, requieren la profundización del conocimiento del comportamiento alimentario y de los requerimientos energéticos de los predadores estimados a escala poblacional y de comunidad. Además, y en vistas a una probable reapertura de la pesca comercial en las IOS, tal tipo de información sería de suma utilidad al momento de fijar cupos de pesca y de determinar las especies de peces a pescar. La consideración de dicha información permitiría disminuir la competencia por los recursos entre las pesquerías y los predadores, lo que podría contribuir a la estabilidad de las poblaciones de los mismos y avanzar en la implementación de una estrategia de manejo pesquero que sea racional y sustentable en términos ecológicos.

Teniendo en cuenta lo comentado previamente, el objetivo de este trabajo es profundizar el conocimiento de los aspectos cuali-cuantitativos de las relaciones tróficas entre peces y vertebrados ictiófagos en las IOS y a través de ello avanzar en el conocimiento integral del ecosistema y generar información de utilidad para el manejo racional de los recursos vivos en Antártida. 


\section{I.3. Referencias bibliográficas}

Ainley DG, Ballard G y Dugger K (2006) Competition among penguins and cetaceans reveals trophic cascades in the western Ross Sea, Antarctica. Ecology 87: 2080-2093.

Anderson JB (1999) Antarctic marine geology. Cambridge University Press, Cambridge, 292 pp.

Andriashev AP (1965) A general review of the Antarctic fish fauna. En: Biogeography and ecology of Antarctic, 491-550 pp. Van Oye, P y Van Mieghem J (Eds). The Hague: Junk.

Anon (1990a) CCAMLR Statistical Bulletin Volume I (1970-1979). CCAMLR, Hobart

Anon (1990b) CCAMLR Statistical Bulletin Volume 2 (1980-1989). CCAMLR, Hobart

Atckinson A. y Peck JM (1990) The distribution of zooplankton in relation of the South Georgia shelf in summer and winter. En Antarctic ecosystems: ecological change and conservation, 159-165 pp. Kerry KR y Hempel G (Eds.). Berlín: Springer,

Balguerías E (1989) Informe de resultados Antártida 8611. Biología Pesquera. Publ. Inst. Esp. Oceanogr.

Barrera-Oro E (2002) Review: The role of fish in the Antarctic marine food web: differences between inshore and offshore waters in the southern Scotia Arc and west Antarctic Peninsula. Antarctic Science 14(4): 293-309.

Barrera-Oro E, Marschoff E y Casaux R (2000) Trends in relative abundance of fjord Notothenia rossii, Gobionotothen gibberifrons and Notothenia coriiceps observed in Potter Cove, South Shetland Islands, after the commercial fishing in the area. CCAMLR Science 7: 43-52.

Barrera-Oro E, Marschoff E, Casaux R (2000) Trends in relative abundance of fjord Notothenia rossii, Gobionotothen gibberifrons and Notothenia coriiceps at South Shetland Islands, after commercial fishing in the area. CCAMLR Science 7: 43-52.

Barrera-Oro ER, Casaux RJ (1998) Ecology of demersal fish species from Potter Cove. En: The Potter Cove coastal ecosystem, Antarctica. Wiencke C, Ferreyra G, Arntz W, Rinaldi C (Eds.). Ber Polarforsch 299: 156-167.

Barrera-Oro E y Casaux R (1996) Fish as diet of the Blue-eyed Shag Phalacrocorax atriceps bransfieldensis at Halfmoon Island, South Shetland Islands. Cybium 20: 37-45.

Barrera-Oro y Marschoff E (1991) a declining trend in the abundance of Notothenia rossii mamorata and Notothenia gibberifrons observed in fjords in teo sotes of the South Shetland Islands. Selected Scientific Papers, (SC-CAMLR-SSP/7) CCAMLR. Hobart.

Barlow KE, Boyd IL, Croxall JP, Reid K, Staniland IJ y Brierley AS (2002) Are penguins and seals in competition for Antarctic krill at South Georgia? Marine Biology 140: 205-213.

Barret RT (1991) Shags (Phalacrocorax aristotelis L.) as potential samplers of juvenile saithe (Pollachius virens (L.)) stocks in North Norway. Sarsia 76: 153-156.

Bax NJ (1998) The significance and prediction of predation in marine fisheries. ICES Journal of Marine Science, 55: 997-1030.

Beck J (1969) Food, moult and age of first breeding in the cape pigeon, Daption capensis Linnaeus. Br Antarct Surv Bull 21: 33-44.

Beck JR y Brown DW (1972) The biology of Wilson's storm-petrel Oceanites oceanicus (Kuhl), at Signy Island, South Orkney Islands. BAS Sci Rep 69: 1-54.

Berón MP, Coria NR y Favero M (2002) Monitorio de la dieta post-reproductiva del Pingüino Papúa (Pygoscelis papua) en Isla Laurie (Orcadas del Sur, Antártida): Período 1997-1999. Ornitología Neotropical 13: 413-422.

Berruti A y Colclough J (1987) Comparison of the abundance of pilchard in cape gannet diet and commercial catches off the Western Cape South Africa. South African Journal of Marine Science 51: 863-869.

Bost CA, Koubbi P, Genvois F, Ruchon L, Ridoux V (1994) Gentoo penguin, Pygoscelis papua, diet as an indicator of planktonic availability in the Kerguelen Islands. Polar Biology 14:147-153.

Bromwich DH y Ryan LF (2004) Strong Trends in the Skill of the ERA-40 and NCEP-NCAR Reanalyses in the High and Midlatitudes of the Southern Hemisphere, 1958-2001. American Meteorological Society 17: 4603: 4619.

Bromwich DH, Robasky FM, Cullather RI y Van Woert ML (1995) The atmospheric hydrologic cycle over the Southern Ocean and Antarctica from operational numerical analyses. Mon Wea Rev 123: 3518-3538.

Brown C, Klages N y Adams N (1990) Short and medium term variation in the diet of penguins at Marion Islands. South African Journal of Antarctic Research 20: 13-20

Burger AE y Piatt JE (1990) Flexible time budgets in breeding Common Murres: buffers against variable prey abundance. Studies of Avian Biology 14: 7183. 
Burns JM, Cheer JF y Castellini MA (1997) Physiological effects on dive patterns and foraging strategies in yerarling Weddell seals (Leptonychotes weddellii). Canadian Journal of Zoology 75: 1796-1810.

Burns JM, Trumble SJ, Castellini MA y Testa JW (1997)The diet of Weddell seals in McMurdo Sound, Antarctica determined from scat collections and stable isotope analysis. Polar Biology 19: 272-282.

Burton RW (1968) Breeding biology of the brown skua. Catharacta lonnbergii, at Signy Island, South Orkney Islands. Br Antarct Surv Bull 15: 9-28.

Cairos DK (1987) Seabrids as indicators of marine food suplies. Biology Oceanography 5: 261-271.

Carlini A, Daneri GA, Casaux R y Márquez MEl (2006) Haul-out pattern of itinerant male Antarctic fue seals (Arctocephalus gazella) at Laurie Island, South Orkney Islands. Polar Research 25 (2): 139-144.

Casaux R (2003) On the accuracy of the pellet analysis to estimate the food intake in the antarctic shag, Phalacrocorax georgianus. Folia Zoology 52 (2): 167-176.

Casaux R (1998) Biología reproductiva y ecología alimentaria del cormorán antártico Phalacrocorax bransfieldensis (Aves, Phalacrocoracidae) en las Islas Shetland del Sur, Antártida. Tesis doctoral, Universidad del La Plata, La Plata, Buenos Aires, 262 p. (No publicado).

Casaux R. y Barrera-Oro E (2006) Shags in Antarctica: their feeding behaviour and ecological role in the marine food web. Antarctic Science 18: 3-14.

Casaux R y Ramón A (2002) The diet of the South Georgia shag Phalacrocorax georgianus at South Orkney Island in five consecutive years. Polar Biology 25: 557-561.

Casaux R y Barrera-Oro E (1998) Monitoring changes in coastal fish population by the analysis of pellets of the Antarctic Shag: a new proposed standard method. CCAMLR WG-EMM-98/11. Item 9.

Casaux R y Barrera-Oro (1993) The diet of the blue-eyed shag, Phalacrocorx atriceps bransfieldensis feeding in the Bransfield Strait. Antarctic Science 5: 335-338.

Casaux R, Carlini A, Corbalán, A, Bertolin ML y DiPrinzio C (2009) The diet of the Weddell Seal Leptonychotes weddellii at Laurie Island, South Orkney Islands. Polar Biology 32: 833-838.

Casaux R, Baroni A. Ramón, Favero y Silva MP (2007) Aspects of the foraging behaviour of the Antarctic TernSterna vittata gaini at Harmony Point, South Shetland Islands. Polar Biology 31: 327-331. doi: 10.1007/s00300-007-0362-3

Casaux R, Baroni A, y Ramón A (2006) The diet of the Weddell Seal Leptonychotes weddellii at the Danco Coast, Antarctic Peninsula. Polar Biology 29: 257-262.

Casaux R, Baroni A, Arrighetti F, Ramón A y Carlini A (2003a) Geographical variation in the diet of the Antarctic fur seal Arctocephalus gazella. Polar Biology 26: 753-758.

Casaux R, Baroni A y Ramón A (2003b) The diet of antarctic fur seals Arctocephalus gazella at the Danco coast, Antarctic Peninsula. Polar Biology 26: 49-54.

Casaux R. Baroni A y Carlini A (1998a) The diet of Antarctic fur seal Arctochepalus gazella at Harmony Point, Nelson Island, South Shetland Islands. Polar Biology 20: 424-428.

Casaux R, Soave G y Coria N (1998b) Laternfish (Myctophidae) in the diet of Cape Petrel Daption Capense at the South Orkney Islands, Antarctica. Polar Biology 20: 364-366.

Casaux R, Baroni A y Carlini A (1997a) The diet of the Weddell seal Leptonychotes weddelli at Harmony Point, South Shetland Is-lands. Polar Biology I 18:371-375.

Casaux R, Coria N y Barrera-Oro E (1997b) Fish in the diet of the Antarctic shag Phalacrocorax bransfieldensis at Laurie Island, South Orkney Islands Polar Biology 18(3): 219-222. doi: 10.1007/s003000050179.

Casaux R, Barrera-Oro E, Favero M y Silva MP (1995a) New correction factors for the quantification of fish represented in pellets of the Blueeyed Shag Phalacrocorax atriceps. Comm. Conserv. Antarctic Mar. Living Resour. Ecosys. Monitoring Manage. Working Group, Documento 95/83:1-18, Siena, Italy.

Casaux R, Favero M, Barrera-Oro E y Silva MP (1995b) Feeding trial on an Imperial Cormorant Phalacrocorax atriceps: preliminary results on fish intake and otolith digestion. Marine Ornithology 23: 7 y 82.

Clarke MR y MacLeod N (1982) Cephalopods in the diet of elephant seals at Signy Island, South Orkney Islands. Br Antarct Surv Bull 57: 27-31.

Conroy JWH y Twelves EL (1972) Diving depths of the gentoo penguin (Pygoscelis papua) and blue-eyed shag (Phalacrocorax atriceps) from the South Orkney islands. Br Antarct Surv Bull 30: 106-108.

Coria N, Libertelli M, Casaux R y Darrieu C (2000) Inter-annual variation in the autumm diet of the gentoo penguin at Laurie Island, Antartctica. Waterbirds 23: 511-517. 
Coria NR, Soave GE y Montalti D (1997) Diet of Cape Petrel Daption capense during the post-hatching period at Laurie Island, South Okney Islands, Antarctica. Polar Biology 18: 236-239.

Coria NR, Spairani H, Vivequin S y Fontana R (1995) Diet of Adelie penguins Pygoscelis adeliae during the post-hatching period at Esperanza Bay, Antarctica, 1987/88. Polar Biology 15: 415-418.

Creet S, van Franeker JA, van Spanje TM y Wolff WJ (1994) Diet of the pintado petrel Daption capense at King George Island, Antarctica, 1990/91. Marine Ornithology 22: 221-229.

Croll DA y Tershy BR (1998) Penguins, fur seal and fishing: prey requirements and potential in the South Shetland Islands, Antarctica. Polar Biology 19: 365-374.

Croxall JP, Reid K y Prince PA (1999) Diet, provisioning and productivity responses of marine predators to differences in availability of Antarctic krill. MEPS 177: 115-131.

Croxall JP, Prince PA, Rothery P y Wood AG (1998) Population changes in albatrosses at South Georgia. En: Albatross biology and conservation. Robertson G y Gales R (Eds). Chipping Norton, UK: Surrey Beatty \& Sons, pp. 69-83.

Daneri GA y Carlini A (2002) Fish prey of the southern elephant seal, Mirounga leonina at King George Island, South Shetland Islands, as reflected by stomach lavage. Polar Biology 25: 739-743.

Daneri GA (1996) Fish diet of the Antarctic fur seal, Arctocephalus gazella, in summer, at Stranger Point, King George Island, South Shetland Islands. Polar Biology 16: 353-355.

Daneri GA y Coria N (1993) Fish prey of the Antarctic fur seals, Arctocephalus gazella, during the summer-autumm period at Laurie Island, South Orkney Islands. Polar Biology 13: 287-289.

Daneri GA y Coria NR (1992) The diet of Antarctic fur seals, Arctocephalus gazella, during the summer-autumn period at Mossman Peninsula, Laurie Island (South Orkneys). Polar Biology 11: 565-566.

Daneri GA, Negri A, Carlini AR y Corbalán A (2007) Estudio interanual del componente íctico de la dieta de Leptonychotes weddellii en Caleta choza, Península antártica. VI Simposio Argentino y III Latinoamericano sobre Investigaciones Antárticas CD-ROM. Contribución tipo Poster, Código CVCO307.

Deacon GE (1937) The hydrology of the Southern ocean. Discovery Reports 15: 1-124.

Deacon GE (1979) The Weddell Gyre. Deep-Sea Research 26: 981-998.

De la Mare WK (1994) Estimating confidence intervals for fish stock abundance estimates from trawl surveys. CCAMLR Science 1: 203-207.

DeWitt HH (1971) Coastal and deep-water benthic fishes of the Antarctic. En:.Antartic Map Folio Series. Folio 15. Bushnell VC (Ed). New York: American Goegrphical Society, pp 1-10.

Dickinson WR (1985) Interpreting provenance relations from detrital modes of sandstones. En: Provenance of Arenites. 333361 pp. Zuffa GG (Ed.). Dordrecht: Reidel Publishing Co.

Duhamel G (1987) Ichtyofaune des secteurs indien occidental et atlantique oriental de l'oce' ean austral: biogeography, cycles biologiques et dynamique des populations. Tesis doctoral. Universidad Pierre y Marie Curie, Paris, 687 pp.

Eastman JT (1995) The evolution of Antarctic fishes: questions for consideration and avenues for research. Cybium 19: $371-$ 389

El-Sayed SZ, Taguchi S (1981) Primary production and standing crop of phytoplankton along the ice-edge in the Weddell Sea. Deep Sea Res 28:1017-1032. doi: 10.1016/0198-0149(81)90015-7.

Eschemeyer WN (1998) Catalgog of fishes. Special publication No 1 of the Center for Biodiversity Research and information. Vols 1-3. San Francisco, California Academy of Science, $2905 \mathrm{pp}$

Everson I (1997) Preliminary report of UK fish survey in subarea 48.3. WG-FSA-97/39, 6pp. CCAMLR, Hobart, Australia.

Everson I (1970) The population dynamics and energy budget of Notothenia neglecta Nybelin at Signy Island, South Orkney Islands. Br. Antarct. Surv. Bull. 23: 25-50.

Everson I, Marlow T, Belchier M, Forster R, Morley S, North AW, Szlakowski J y Wilhelms S (2002) fish stock assessment survey in subarea 48.3. WG-FSA 02/34, 6pp. CCAMLR, Hobart, Australia.

Everson I, Kock KH y Ellison J (2000) Inter-annual variation in the gonad cycle of the mackerel icefish. Journal of fish biology 57(A): 103-111.

Everson I, Parkes G, Kock KH, Goss C, Cielniaszek Z, Szlakowski J, Daly H, Allcock L y Phillip G (1994) Result of the UK demersal fish in subarea 48.3. WG-FSA-94/18, 34pp. CCAMLR, Hobart, Australia. 
Everson I, Kock KH, Campbell S, Parkes G, Cielniaszek D y Szlakowski J (1991) Reproduction in the mackerel icefish, Champsocephalus gunnari, at South Georgia Document WG-FSA 91/7. CCAMLR, Hobart, Australia.

Everson I, Parkes G, Campbell S, Kock KH, Szlakowski J, Cielniaszek D, Gos K y Wilhelms S (1992) Fish stock assessment survey in Subarea 48.3. Document WG-FSL4-9211 7. CCAMLR, Hobart, Australia.

Everson I, Watkins JL, Bone DG y Foote KG (1990) Implications of a new acoustic strength for abundance estimate of Antarctic krill. Nature 345: 338-340.

Favero M, Casaux R, Silva MP, Barrera-Oro E y Coria N (1998) The diet of the Antarctic Shag during summer at Nelson Island Antarctica. Condor 100: 112-18.

Ferretti V, Soave G, Casaux R y Coria N (2001) Diet of the Snow petrel Pagodroma nivea at Laurie Island, Antarctica, during the 1997-98 breeding season. Marine Ornithology 29: 71-73.

Fraser WR, Trivelpiece WZ, Ainley DG y Trivelpiece SG (1992) Increases in antarctic penguin populations: reduced competition with whales or a loss of sea ice due to environmental warming? Polar Biology 11: 525-531.

Furness RW y Greenwood JJD (1993) Can birds be used to monitor the environment? En: Birds as monitors of environmenta change. Furness RW y Greenwood JJD (Eds). Chapman \& Hall, London, pp. 2-41.

Gordon AL (1998) Western Weddell Sea Termohaline stratification. Ocean, Ice and Atmosphere: Interactions at the Antarctic Continental margin. Antarctic Research Series 75: 215-240.

Green K y Burton HR (1987) Seasonal and geographical variation in the food of Weddell seals, Leptonychotes weddellii, in Antarctica. Australian Wildlife Researches 14: 475-489.

Green K y Williams R (1986) Observation of food remains in faeces of elephant, Leopard and crebeater Seals. Polar Biology 6: 43-45.

Green K, Slip DJ y Moore GJ (1998) The take of fish species by seabirds and marine mammals in the Australian Fisheries Zone around Heard Island: the potential for competition with commercial fishery. Polar Biology 20: $273-280$.

Green K, Burton H y Watts D (1995) Studies of the Weddell seals in the Vestfold Hills, East Antarctica. ANARE Research Notes 93: 1-64.

Greig-Smith P (1983) Quantative plant ecology, $3^{\text {rd }}$ edn. Blackwell Scientific Publications, Oxford.

Hahn S (1998) The food and chick feeding of black bellied storm petrel at King George Island. Polar Biology 19: $365-374$.

Hemmings AD (1984) Aspects of the breeding biology of McCormick's skua Catharacta maccormicki at Signy Island, SOI. Br Antarct Surv Bull 65: 65-79.

Hill MO (1973) Diversity and evenness: a unifying notation and its consequence. Ecology 54: 427-432.

Holgate MW (1970) Antarctic ecology, vol 1. London, Academic Press, 604 pp.

Hoppema M (2004) Weddell Sea turned from source to sink for atmospheric CO2 between pre-industrial time and present. Global Planet Change 40:219-231. DOI:10.1016/j.gloplacha.2003.08.001.

Hureau JC (1994) The significance of fish in the marine Antarctic ecosystem. Polar Biology 14: 307-313.

Hureau JC (1973) La distribution geographic des pissons de IÁntarctique. CR Séanc Soc Biogeogr Paris 50(434): 4-16.

Ichii T, Takao T, Bengstson JL, Boveng P, Jansen JK, Hiruki LM, Meyer WR, Cameron MF, Naganobu M, Kawaguchi S y Ogishima T (1997) Importance of myctophid fish distribution for formation of foraging areas of chinstrap penguins and antarctic fur seals at seal Island. WG-EMM 97/28, 96/49 y 95/87 Agenda Item $N^{\circ} 6$ y Nº. CCAMLR.

Ichii T, Naganobu M y Ogishima T (1996) Competition between the krill fishery and penguins in the South Shetland Islands. Polar Biology 16: 63-70.

Ichii T, Takao T, Bengtson J, Boveng P, Hansen J, Hiruki L, Meyer W, Cameron M, Naganobu M, Kawaguchi S y Ogishima T (1995) Importance of myctophids fish distributions for formation of foraging areas of chinstrap penguins and Antarctic fur seals at Seal Island. CCAMLR. Ecosystem Monitoring and Management Working group, document 97/28, 24 pp.

Ivlev VS (1961) Experimental ecology of the feed-ing of fishes. Yale University Press, New Haven, Connecticut, USA.

Jones CD, Kock KH y Balguerías E (2000) Changes in biomass of eight species of finfish around the South Orkney Islands (Subarea 48.2) from three bottom trawl surveys. CCAMLR Science 7: 53-74.

Kasatkina SM y Ivanova VF (2003) Fishing intensity of the Soviet fleet in krill fisheries in the southern Atlantic (Subareas 48.2 and 48.3). CCAMLR Science 10: 15-35. 
Kellermann A (1996) Midwater fish ecology. En: Foundation for Antarctic Research west of the Antarctic Peninsula. Ross RM, Hofmann E, Quetin LB (Eds). Antarctic Research Series 70: 231-256.

Kerfoot WC, y Sih A (1987) Predation: direct and indirect impacts on aquatic communities. University Press of New England, Hanover.

Klinck JM, Hofmann EE, Robert C, Salihoglua BB y Howard S (2004) Water-mass properties and circulation on the west Antarctic Peninsula Continental Shelf in Austral Fall and Winter 2001. Deep Sea Research Part II: Topical Studies in Oceanography51(17-19): 1925-1946.

Kock KH (2005) Antarctic icefishes (Channichthyidae): a unique family of fishes. A review, Part I .Polar Biology 28: 862-895. doi 10.1007/s00300-005-0019-z.

Kock KH (1992) Antarctic fish and fisheries. Cambridge University Press, Cambridge.

Kock KH (1986) The state of exploited Antarctic fish stocks in the Scotia Arc region during SIBEX (1983-1985). Arch FischWiss 37 (Beih. 1): 129-186

Kock KH (1985) Antarctic fish. En: Key environments: Antarctica. Bonner Wn y Walton DWH (Eds.). Oxford: Pergamon Press, pp.173-192.

Kock KH y Köster FW (1989) The status of exploited fish stocks in the Atlantic sector of the Southern Ocean. Mitteilungen aus dem Institut für Seefischerei der Bundesforschunsanstalt für Fischerei. Institut für Seefischerei, Hamburg 46: 1-73.

Kock KH, Jones CD y Wilhelms S (2000) Biological characteristics of Antarctic fish stocks in the Southern Scotia Arc region. CCAMLR Science 7: 1-41.

Kock KH, Duhamel G y Hureau JC (1985) Biology and status of exploited Antarctic fish stocks: a review. BIOMASS Scient Ser 6: $1-143$.

Kulesz J (1998) Fishes of the West Antartic. A review. Pol. Arch. Hydrobiol. 45: 103-129.

La Mesa M, Ashford J, Larson E y Vacchi M (2004) Age and growth of Scotia Sea icefish, Chaenocephalus aceratus, from the South Shetland Islands. Antarct Sci 16(3): 253-262.

Laws RM (1981) Seal surveys, South Orkney Islands, 1971 and 1974. Br. Antarct. Surv. Bull. 54: $136-139$.

Libertelli M, Coria N y Marateo G (2003) Diet of Adelia penguin during three consecutive chick rearing at Laurie island. Polish Polar Research 24(2): 133-142.

Lizzote MP (2001) The contribution of sea ice algae to Antarctic marine primary production. Am Zool 41:57-73. doi: 10.1668/0003-1569(2001)041.

Lubimova TG, Shust KV, Troyanovski FM y Semenov AB (1983) To the ecology of mass species of myctophids from the Antarctic Atlantic. In: Soviet Committee of Antarctic Research. The Antarctic. The Committee Report 22: 99-106.

Lubimova TG, Shust KV y Popov VV (1987) Some features of the ecology of mesopelagic fish of family Myctophidae in the Southern Ocean. En: Biological Resources of the Arctic and Antarctic. Nauka, Moscow: 320-337.

Magurran AE (1988) Ecological diversity and its measurement. 179 pp Croom Helm Limited. London. University press. Cambridge

Márquez ME, Quadraccia A, Portela M Sambucetti M y Sanahuja J (1978) Antarctic krill (Euphausia superba Dana): composition and nutritive value. Abstracts Free Communication. XI International Congreso of Nutrition, August 27September 1, 1978. Rio de Janeiro, Brasil, Abstract No 603, 366.

Marschoff E y Tomo A (1984) Vertical distribution of calyptopes larvae of Euphausia superba in the Scotia Sea. Journal of Crustacean Biology 4: 247-251.

Maschall H-P (1988) The overwintering strategy of Antarctic krill unde the pack ice of the Weddell Sea. Polar Biology 9: 129135.

Moline MA, Karnovsky NJ, Brown Z, Divoky GJ, Frazer TK, Jacoby CA, Torres JJ y Fraser WR (2008) High Latitude Changes in Ice Dynamics and Their Impact on Polar Marine Ecosystems. Ann NY Acad Sci 1134: 267.

Montalti D, Casaux R, Coria N, Soave G (1996) The importance of fish in the diet of the south polar skua Catharacta maccormicki at the South Shetland Islands, Antarctica. Documento WG-EMM-96/32.CCAMLR, Hobart, 7 pp.

Montalbán C y Capdevila R (2005) Los puertos del Plata en la ruta Antártica durante la "etapa heroica". Derroteros de la Mar del Sur 13: 79-94.

Montevecchi WA (1993) Birds as indicators of change in marine prey stocks. En: Birds as Monitors of Environmental Change. Furness RW y Greenwood JJD (Eds.) Chapman y Hall, Londres, 633 pp. 
Nelson DM, Smith WO Jr, Gordon LI, Huber BA (1987) Spring distributions of density, nutrients and phytoplankton biomass in the ice edge zone of the Weddell-Scotia Sea. J Geophys Res 92C: 7181-7190. doi: 10.1029/JC092iC07p07181

Nicol S (2006) Frill, Currents, and Sea Ice: Euphasia superba and its changing environment. BioScience 56(2): 111-120.

Nicol S, Pauly T, Bindoff NL, Wright S, Thiele D, Hoise GW, Strutton PG y Woehler E (2000) Ocean circulation off Antarctica affects ecosystem structure and sea-ice extent. Nature V: 406, 504-507.

Pakhomov EA, Froneman PW y Perissinotto R (2002) Salp/Krill interactions in the southern Ocean: especial segregation and implications for the carbon flux. Deep Sea Research 49: 1881-1907.

Pauly D, Christensen V, Guénette S, Pitcher T, Sumaila UR, Walters C, Watson R y Zeller D (2002) Toward sustainability in world fisheries. Nature 418: 689-695.

Pennington M (1983) Efficient estimators of abundance, for fish and plankton surveys. Biometrics 39281-39286.

Pielou EC (1966) The measurement of diversity in different types of biological collections. Journal of Theoretical Biology 13 : 131-144.

Plötz J (1986) Summer diet of Weddell seals (Leptonychotes weddelli) in the Eastern and Southern Weddell Sea, Antarctica. Polar Biology 6: 97-102.

Plötz J, Bornemann H, Knust R, Schröder A y Bester M (1991) Foraging behaviour of Weddell seals, and its ecological implications. Polar Biology 24: 901-909.

Pondaven P, Ruizpino D, Fravalo C, Treguer P y Jeandel C (2000) Interannual variability of Si and N cycles at the time-series station KERFIX between 1990 and 1995 a 1-D modelling study. Deep Sea Research Part I: Oceanographic Research Papers 47(2): 223-257. doi: 10.1016/S0967-0637(99)00053-9.

Priddle J, Croxall JP, Everson IE, Heywood RB, Murphy EJ, Prince PA y Sear CB (1988) Large-scale fluctuations in distribution and abundance of krill-a discussion of possible causes. En: Antarctic Ocean and resources variability. Sahrhage D (Ed). Springer-Verlag. Berlin, pp. 169-182.

Quentin LB, Ross RM y Clarcke A (1994) Krill energetics: seasonal and environmental aspects of the physiology of Eupahusia superba. En: Southern Ocean ecology The BIOMASS Perspective. El-Sayed SZ (Ed). Cambridge University Press, Cambridge, pp. 165-184.

Rail JF y Chapdelaine G (1998) Food of Double-crested Cormorants, Phalacrocorax auritus, in the Gulf and Estuary of the St. Lawrence River, Quebec, Canada. Canadian Journal of Zoology 76(4): 635-643. doi: 10.1139/z97-237.

Reid K (1995) The diet of Antarctic fur seals Arctocephalus gazella Peters 1875 during winter at South Georgia. Antarctic Science 7: 241-249.

Reid K, Sims M, White RW y Gillon KW (2004) Spatial distribution of predator/prey interactions in the Scotia Sea: implications for measuring predator/fisheries overlap. Deep-Sea Research II 51: 1383-1396.

Rembiszewski JM, Krzeptowski M y Linkowski TB (1978) Fishes (Pisces) as a by-catch in fisheries of krill Euphausia superba Dana (Euphausiacea, Crustacea). Pol Arch Hydrobiol 25: 677-695.

Robasky FM, Cullather RI y Van Woert ML (1995) The atmospheric hydrologic cycle over the Southern Ocean and Antarctica from operational numerical analyses. Mon Wea Rev 123: 3518-3538.

Ross RM y Quetin LB (1986) How Productive Are Antarctic Krill? BioScience 36(4): 264-269.

Semeneh M, Dehairs F, Elskens M, Baumann MEM, Kopczynska EE, Lancelot C y Goeyens L (1998) Nitrogen uptake regime and phytoplankton community structure in the Atlantic and Indian sectors of the Southern Ocean. J Mar Syst 17: $159-177$. doi: 10.1016/S0924-7963(98)00036-0.

Shannon CE y Weaverw (1949) The mathematical theory of communiation. The Univ. of Illinois Press, Urbana, IL.

Shaw P (1984) Factors affectin the breeding performance of the Antarctic Blue-eyed shag (Phalacrocorax atrices bransfieldensis). Tesis doctoral, Universidad de Durham (No publicado).

Siegel V (1988) A concept of seasonal variation of krill (Euphausia superba) distribution and abundance west of the Antarctic Peninsula. En: Antarctic Ocean and resources variability. Sahrhage D (Ed). Berlin. Springer, pp. 119-230.

Siegel V y Loeb V (1995) Recruitment of Antarctic krill Euphausia superba and possible causes for its variability. Mar Ecol Pro Ser 123:45-56. doi:10.3354/meps123045.

Simpson EH (1949) Measurement of Diversity. Nature 163: 688-688. doi:10.1038/163688a0.

Sinclair M, Valdimarsson G, Garcia S y de Leiva Moreno I (2003) Global overview of marine fisheries. En: Responsible Fisheries in the Marine Ecosystem, Sinclair M y Valdimarsson G (Eds). Wallingford, UK: FAO Rome, and CABI Publishing, pp. 1-24. 
Skvarca P (1994) Changes and surface features of the Larsen Ice Shelf, Antarctica, derived from Landsat and Kosmos mosaics. Ann Glaciol 20: 6-12.

Soave GE, Coria N, Silva P, Montalti D, FaveroM (1996a) The diet of cape pigeon Daption capense during the chick-rearing period at Fildes Peninsula and Harmony Point, South Shetland Islands, Antarctica. WG-EMM-96/17, CCAMLR, Hobart, Australia, 14 pp (mimeogr).

Soave G., Coria N y Montalti D (1996b) Diet of the Pintado Petrel, Daption capense during the late incubation and chick-rearing periods at Laurie Island, South Orkney Islands, Antarctica, January-February 1995. Mar Ornith 24: 35-37.

Targett TE (1981) Trophic ecology and structure of coastal Antarctic fish communities. Mar Ecol Prog Ser 4: $243-263$.

Tønnessen JN y Johnsen AO (1982) The History of Modern Whaling. C. Hurst \& Co., London. 798 pp.

Trivelpiece WZ y Trivelpiece SG (1995) Changes in Adelia penguin recruitment: correlations to krill biomass estimates and implications for the fisheries managment in the southern ocean. Wg-Emm 95/63, Methods Agenda item $\mathrm{N}^{\circ} 7$.

Tréguer P, Nelson DM, Van Bennekom AJ, Demaster DJ, Leynaert A y Quéguiner B(1995) The silica balance in the world Ocean: a reestimated. Science 268: $375-379$

Vacchi M, La mesa M, Dalu M y McDonald J (2004) Early life stages in the life cycle of Antarctic silverfish, Pleuragramma antarcticum in Terra Nova Bay, Ross Sea. Antarctic Science 16 (3): 299-305. doi: 10.1017/S0954102004002135.

Walton DWH (1982) The Signy Island terrestrial reference sites: XV. Microclimate monitoring. 1972-74. Br Antarct Surv Bull 55: 111-126.

Williams R (1985) Trophic relationship between pelagic fish and euphausiids in Antarctic waters. En: Antarctic nutrient cycles and food webs. Siegfred WR, Condy y Lwas RM (Eds). Berlín, Springer, pp. 452-459.

Zhao CS, DabuX y Li Y (2004) Relationship between Climatic factors and dust storm frequency in Inner Mongolia of China, Geophys. Res. Lett., 31, L01103. doi:10.1029/2003GL018351. 


\section{Composición General de la Dieta}

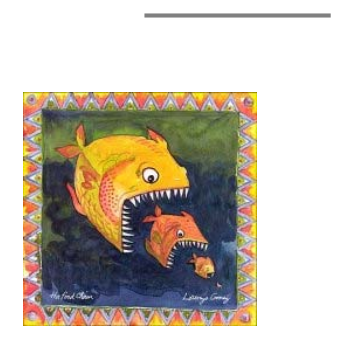

\section{II.1. Introducción}

La composición general de la dieta, junto con el conocimiento de los patrones de forrajeo y la localización de las áreas de alimentación, conforman los principales interrogantes de la ecología trófica de los predadores tope (Croxall 1995). En el caso de las aves y los mamíferos marinos, su estudio provee información sobre la disponibilidad y distribución de sus recursos alimentarios, y en muchos casos aporta datos sobre especies de presas que no son sistemáticamente estudiadas. Debido a las condiciones adversas de Antártida (presencia de hielo, fuertes tormentas, áreas de navegabilidad restringida, etc.), a los altos costos de las expediciones y a las restricciones de tipo logístico, las investigaciones sobre las comunidades de peces son escasas. Es por ello que el estudio de la dieta de los predadores ictiófagos es de suma importancia para la comprensión de las estructuras de las tramas tróficas y, además, para un manejo sustentable de sus recursos vivos.

Las metodologías de muestreo para la obtención de información sobre la composición de la dieta son variadas. En el caso de las aves marinas la obtención de regurgitados espontáneos, de contenidos estomacales y de pellets (Shaw 1984, Espitalier-Noel et al. 1988, Green et al. 1990, Wanless y Harris 1993, entre otros) son las técnicas más comúnmente utilizadas. En el primer caso, a partir del regurgitado, se obtiene todo el material que el animal elimina espontáneamente cuando uno se acerca al nido o lo manipula durante la obtención de otro tipo de información. Los contenidos estomacales son obtenidos mediante dos métodos, el lavado estomacal (Epistalier-Noel et al. 1988) y la regurgitación provocada (Coria et al. 1995). A diferencia de estos dos tipos de muestras, los pellets están compuestos por restos de presas no digeribles y en general se los encuentra en las proximidades de los nidos. En el caso de los mamíferos marinos, los estudios de dieta son principalmente llevados a cabo por recolección de feces o por medio de lavados estomacales. Si bien estas metodologías siguen vigentes, en términos cuantitativos son seriamente cuestionadas (ver sección II.4).

La información disponible acerca de la composición de la dieta de aves y mamíferos antárticos es abundante. Sin embargo, son pocos los trabajos que intentan ofrecer una perspectiva más íntegra de la estructura y el funcionamiento de los ecosistemas y que profundicen en el análisis 
de los flujos de energía. En la zona insular de la Península Antártica (PA) las actividades pesqueras llevadas a cabo durante la década del ' 70 y principios del ' 80 generaron un importante impacto en las comunidades de peces, siendo Chamsocephalus gunnari, Notothenia rossii y Gobionotothen gibberifrons las especies más afectadas (Kock 1992). Si bien la información sobre la abundancia y estructura de las comunidades de peces de las Islas Orcadas del Sur (IOS) es escasa y/o está fraccionada en el tiempo, los trabajos existentes indican que la actividad pesquera desarrollada en el pasado también afectó seriamente a las comunidades de peces de este archipiélago (Kock 1992, Hureau 1994, Jones et al. 2000, Kock et al. 2000, Casaux y Barrera-Oro 2002). En relación a ello, la información obtenida a partir de los estudios de dieta de predadores tope proporciona una fuente alternativa de datos que permite comprender el estado de las comunidades de peces para tomar decisiones sobre su manejo. A modo de ejemplo, dado que el Cormorán Antártico Phalacrocorax bransfieldensis es considerado un predador oportunista (Casaux y Barrera-Oro 1993), la CCRVMA (Comisión para la Conservación de los Recursos Vivos Marinos Antárticos). ha tomado en consideración el estudio de la dieta de esta especie como un parámetro indicador del estado de las comunidades de peces, en especial de las poblaciones de peces de interés económico tales como $\mathrm{N}$. rossii y G. gibberifrons (SC-CCAMLR 1998). En relación a ello, el estudio de la dieta de predadores tope representa un núcleo de investigación fundamental para la planificación del uso sustentable de los recursos de las IOS.

En el marco de lo mencionado anteriormente, el objetivo principal de este capítulo será analizar la composición general de la dieta de los principales predadores tope distribuidos en las IOS, como así también determinar la magnitud y los factores de los cambios estacionales en la misma, conforme a la información con que se disponga en cada caso, en función del sexo y status reproductivo de los ejemplares. Este análisis también permitirá elaborar información necesaria para el desarrollo de los capítulos siguientes.

\section{II.2. Materiales y métodos}

\section{I.2 Área de estudio}

Las IOS fueron descubiertas por buques foqueros norteamericanos y británicos a principios del siglo XIX. Tanto Isla Laurie como Isla Signy fueron desde ese momento sitios en donde se emplazaron bases comerciales y científicas de diversos países, tales como Inglaterra (presente en Isla Signy desde 1947) y Argentina (presente en Isla Laurie desde 1904). El archipiélago de las IOS se encuentra ubicado a una distancia de $1400 \mathrm{Km}$. de Tierra del Fuego, a $800 \mathrm{Km}$. de la Convergencia Antártica y $600 \mathrm{Km}$. al noreste de la PA. Todo el complejo de islas se distribuye desde los $60^{\circ} 30^{\prime} \mathrm{S}$ hasta los $61^{\circ} 22^{\prime} \mathrm{S}$ y desde los $44^{\circ} 24^{\prime} \mathrm{O}$ hasta los $46^{\circ} 24^{\prime} \mathrm{O}$ y está formado por las islas Coronación, Laurie, Powell, Signy, Robertson, Fredriksen e Inaccesibles, de las cuales las dos primeras son las más importantes en cuanto a su extensión (Fig. II.1). 


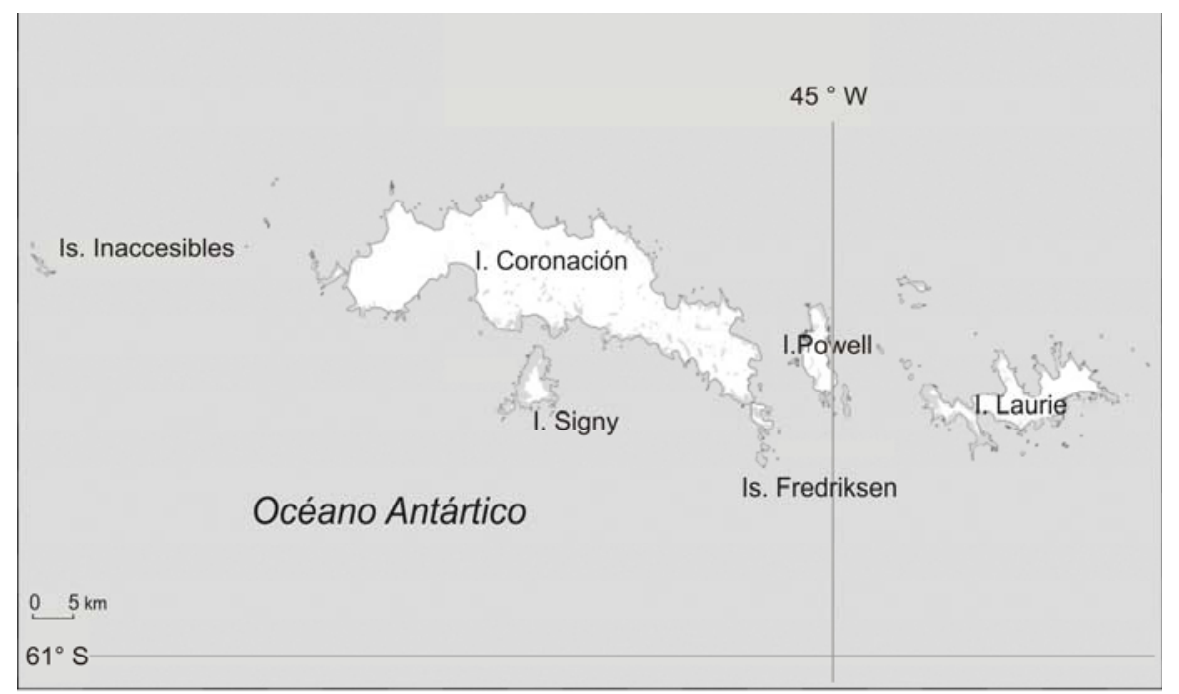

Figura II.1: Islas Orcadas del Sur

\section{II.2.1. Recopilación de información bibliográfica}

La información sobre la composición general de la dieta de los predadores de las IOS se obtuvo tanto a partir de trabajos publicados como de datos no publicados. El detalle de las fuentes de información se presenta en la tabla II.1. Dada la similitud biológica y cercanía que mantienen las Islas Shetland del Sur (ISS) con las IOS, la falta de información sobre la dieta de alguno de los predadores tope en la zona de estudio fue obtenida de las ISS (Tabla II.2). Aunque se consideró la cercanía a otros sitios como las Islas Georgias del Sur, los estudios sobre dieta que se necesitaron para completar este análisis sólo fueron realizados en las ISS. Sumado a ello también se consideró que esos estudios eran similares en cuanto a las metodologías. Para ciertas especies de predadores la información extraída de los distintos trabajos pudo ser analizada en función de variaciones anuales y estacionales, como así también en relación al sexo.

\section{II.2.2. Análisis de datos}

A partir de las bases de datos sin publicar consideradas en este trabajo se calculó la frecuencia de ocurrencia porcentual (F\%) como la proporción de veces que una presa aparece en una muestra de dieta sobre el total de las muestras, la importancia porcentual en número (N\%) como la proporción sobre el total de muestras de dieta del numero de veces que una presa aparece cada muestra y la importancia en masa (M\%) como la proporción en peso de la masa en gramos que compone a cada presa en el total de las muestras. Las bases de datos fueron el resultado de la aplicación de las técnicas de cuantificación de la dieta descriptas en Casaux et al. 2009.

En relación a los resultados, y tomando en cuenta las presas principales y secundarias, se clasificó a los predadores en diferentes grupos tróficos. De acuerdo a la información aquí presentada (analizada en términos de biomasa) se identificaron 7 Grupos Tróficos. En cada uno de estos grupos se consideraron "presa principal" a aquellos ítems alimentarios que superaron el $50 \%$ de la biomasa en la mayoría de las temporadas consideradas. 
En la tabla 11.3 se resumen los nombres con que se tratarán a los predadores, presas y localidades en esta tesis.

Tabla Il.1: Resumen de la información sobre la composición de la dieta de los predadores en las IOS, indicando localidad, presas principales y metodología empleada (número de muestras en paréntesis).

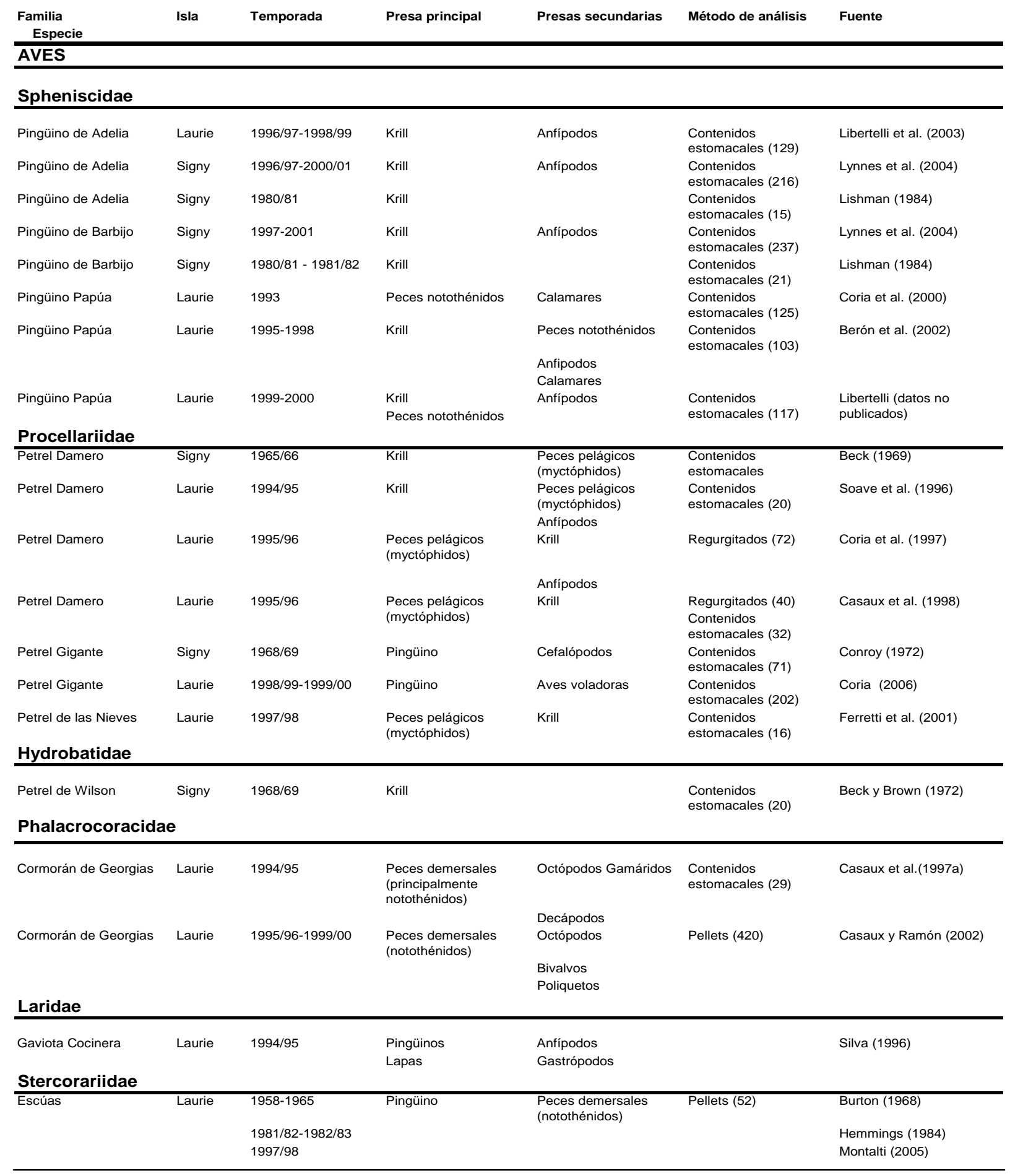


Tabla Il.1: Continuación.

MAMIFEROS

\begin{tabular}{|c|c|c|c|c|c|c|}
\hline \multicolumn{7}{|l|}{ Phocidae } \\
\hline Foca de Weddell & Laurie & $1998 / 99$ y $2000 / 01$ & $\begin{array}{l}\text { Krill } \\
\text { Octópodos }\end{array}$ & $\begin{array}{l}\text { Peces } \\
\text { Pinqüinos }\end{array}$ & Fecas $(71)$ & Casaux et al. (2009) \\
\hline Foca Cangrejera & Laurie & $2001 / 02$ & Krill & & Fecas (5) & $\begin{array}{l}\text { Casaux y Carlini (datos sin } \\
\text { publicar). }\end{array}$ \\
\hline \multicolumn{7}{|l|}{ Otariidae } \\
\hline \multirow[t]{2}{*}{ Lobo Fino Antártico } & Laurie & $1994-2003$ & Krill & Peces pelágicos & & $\begin{array}{l}\text { Casaux et al. (datos no } \\
\text { publicados) }\end{array}$ \\
\hline & & & Peces pelágicos & Krill & & \\
\hline
\end{tabular}

Tabla II.2: Resumen de la información sobre la composición de la dieta de los predadores en las ISS, indicando localidad, presas principales y metodología empleada (número de muestras en paréntesis).

AVES

Hydrobatidae

\begin{tabular}{|c|c|c|c|c|c|c|}
\hline \multirow[t]{2}{*}{ Petrel de las Tormentas } & \multirow[t]{2}{*}{25 de Mayo } & $1996 / 97$ & Peces & \multirow[t]{2}{*}{ Cefalópodos } & $\begin{array}{l}\text { Contenidos estomacales } \\
\text { (109) Regurgitados (182) }\end{array}$ & Hahn (1998) \\
\hline & & 1999/00 & Krill & & Contenidos estomacales (10) & Casaux (datos un publicados) \\
\hline \multicolumn{7}{|l|}{ Laridae } \\
\hline Gavtiotín Antártico & Nelson & 2002/03-2003/04 & Peces & Krill & 'observación ad libitum' (291) & Casaux et al. (2007) \\
\hline
\end{tabular}

Tabla II.3: Detalle de los nombres vulgares de los predadores y acrónimos de las zonas/áreas/islas incluidos en este trabajo de tesis. (...): Refiere al nombre de cada sitio en particular.

\begin{tabular}{|ll|}
\hline Predadores & \\
\hline Spheniscidae & \\
\hline $\begin{array}{l}\text { Pygscelis adeliae } \\
\text { Pygoscelis antarctica } \\
\text { Pygoscelis papua } \\
\text { Procellariidae }\end{array}$ & Pingüino de Adelia \\
\hline $\begin{array}{l}\text { Daption capense } \\
\text { Macronectes giganteus } \\
\text { Pagodroma nivea } \\
\text { Hydrobatidae }\end{array}$ & Pingüino Papúa \\
\hline $\begin{array}{l}\text { Oceanites oceanicus } \\
\text { Fregetta tropica } \\
\text { Phalacrocoracidae }\end{array}$ & Petrel Damero Gigante \\
\hline $\begin{array}{l}\text { Phalacrocorax georgianus } \\
\text { Laridae }\end{array}$ & Petrel de las Nieves \\
\hline $\begin{array}{l}\text { Larus dominicanus } \\
\text { Sternidae }\end{array}$ & Petrel de Wilson \\
\hline $\begin{array}{l}\text { Sterna vitatta } \\
\text { Stercorariidae }\end{array}$ & Gaviota Cocinera \\
\hline $\begin{array}{l}\text { Catharacta lonnbergi } \\
\text { Catharacta antarctica }\end{array}$ & Escún de Georgias \\
& Escúa Marrón \\
\hline Phocidae & Leopardón Antártico \\
\hline $\begin{array}{l}\text { Hydrurga leptonyx } \\
\text { Leptonychotes weddellii } \\
\text { Mirounga leonina }\end{array}$ & Elefante Marino \\
\hline
\end{tabular}


Tabla II.3: Continuación.

\begin{tabular}{|ll|}
\hline Otariidae & \\
\hline Arctocephalus gazella & Lobo Fino Antártico \\
& \\
Zonas/Áreas/lslas & \\
\hline Islas Orcas del Sur & IOS \\
Islas Shetlands del Sur & ISS \\
Islas Georgias del Sur & IGS \\
Península Antártica & PA \\
Convergencia Antártica & CA \\
Océano Antártico & OA \\
Isla (..) & I. (...) \\
Punta (...) & P. (...) \\
\hline
\end{tabular}




\section{II.3. Resultados}

\section{II.3.1. Composición general de la dieta, Islas Orcadas del Sur}

La tabla II.1 resume los datos de \%M (\%M media) obtenida a partir de la información presentada en este capítulo para las especies de predadores de las IOS.

\section{II.3.1.1. Aves}

\section{Spheniscidae}

\section{Pingüino de Adelia Pygoscelis adeliae}

En Antártida el pingüino de Adelia presenta una distribución circumpolar (Martínez 1992, Williams 1995) y sólo el $8 \%$ de su población habita las IOS durante la temporada reproductiva (Croxall 1984, Woehler 1993). Los primeros arribos a las colonias ocurren entre mediados de Septiembre y principio de Octubre. Por lo general este pingüino anida en costas rocosas libres de hielo. La información reunida sobre la composición de la dieta del pingüino de Adelia en las IOS está basada en el análisis de contenidos estomacales y se presenta en la tabla II.5.

Los estudios más antiguos sobre la dieta del pingüino de Adelia fueron realizados en la Isla Signy, IOS (Sladen 1958 y White y Conroy 1975), e indican que el krill fue la única presa representada en los contenidos estomacales analizados. De un modo diferente, Lishman (1985) observó en la misma localidad que durante las temporadas 1980/81 y 1981/82 la dieta fue más diversa, aunque de todos modos el krill fue la presa más importante en términos de abundancia $(>99 \mathrm{~N} \%$ ) y biomasa (>98M\%) (Tabla II.5). Los restos de peces encontrados por Lishman (1985) correspondieron a Trematomus eulepidotus y contribuyeron a la dieta con menos del $1 \%$ en biomasa. De un modo similar, Lynnes et al. (2004) indicaron que entre las temporadas 1997/98 y 2001/02 la dieta del pingüino de Adelia estuvo mayormente constituida por krill (>99M\%), en tanto que los peces y los calamares, aunque representados en todas las temporadas, contribuyeron con menos del $1 \%$ en biomasa. Los restos de peces identificados por Lynnes et al. (2004) correspondieron a las especies Electrona antarctica, Champsocephalus gunnari, Chaenocephalus aceratus, Pseudochaenichthys georgianus, G. gibberifrons, Gobionotothen marionensis, Nototheniops nybelini y Notothenia coriiceps. Entre estas especies sólo C. gunnari y N. nybelini fueron registradas en más de una ocasión. En relación a los cefalópodos, Lynnes et al. (2004) informaron que su contribución a la dieta fue muy baja $(<0,01 \mathrm{M} \%)$ y que la única especie identificada fue el calamar Psychroteuthis glacialis.

Libertelli et al. (2003) reportaron que entre las temporadas reproductivas 1996/97 y 1998/99 el krill fue la presa más frecuente (100\%) y abundante ( $>99 \mathrm{~N} \%$ ) en la dieta del pingüino de Adelia en Isla Laurie y que los peces solo contribuyeron con el 0,1\% en biomasa (Tabla II.6). Con respecto a los peces, Libertelli et al. (2003) identificaron sólo 10 ejemplares y estos correspondieron a las especies Trematomus newnesi, Protomyctophum normani y Protomyctophum choriodon (temporada 1997/98) y E. antarctica (1998/99). Asimismo, durante la temporada 1998/99 estos autores identificaron 35 larvas de notothéniidos, las que probablemente correspondían a especies del género Trematomus sp. 
Tabla II.4: Composición general de la dieta de los predadores de las IOS. Los resultados están presentados como M\% media de todas las temporadas de muestreo para cada uno.

\begin{tabular}{|c|c|c|c|c|c|c|c|c|c|c|}
\hline & P. de Adelia & P. de Barbijo & P. Papúa & P. Damero & P. Gigante & P. de las Nieves & P. de Wilson & C. de Georgias & LFA & F. de Weddell \\
\hline $\begin{array}{l}\text { Crustáceos } \\
\text { Krill } \\
\text { Anfípodos gamarídeos } \\
\text { Isópodos } \\
\text { Glyptonotus antarcticus } \\
\text { Moluscos } \\
\text { Cefalópodos } \\
\text { Octópodos } \\
\text { Pareledone sp. } \\
\text { Teutónidos } \\
\text { Psychroteutis glacialis } \\
\text { Gastrópodos } \\
\text { Nacella concinna } \\
\text { Otros } \\
\text { Bivalvos } \\
\text { Peces } \\
\text { Pingüinos } \\
\text { Aves voladoras } \\
\text { Mamíferos marinos }\end{array}$ & $\begin{array}{l}0,14 \\
0,03\end{array}$ & $\begin{array}{c}99,59 \\
0,03\end{array}$ & $\begin{array}{c}54,28 \\
0,11 \\
\\
1,06 \\
\end{array}$ & $\begin{array}{c}65,66 \\
0,55 \\
26,8\end{array}$ & $\begin{array}{l}0,78 \\
0,05 \\
2,16\end{array}$ & 1 & 100 & $\begin{array}{c}7,59 \\
\\
\\
0,15 \\
\\
0,73 \\
0,07 \\
91,46\end{array}$ & $\begin{array}{l}3,8 \\
0,4\end{array}$ & $\begin{array}{c}27,7 \\
3,4 \\
0,1 \\
0,1 \\
17,2 \\
19,65\end{array}$ \\
\hline
\end{tabular}

Tabla II.5: Composición general de la dieta del pingüino de Adelia tal como lo refleja el análisis de contenidos estomacales en la I. Signy (IOS). N: número de muestras analizadas, F\%: frecuencia de ocurrencia porcentual, N\%: importancia en número porcentual, M\%: importancia en masa porcentual.

\begin{tabular}{|c|c|c|c|c|c|c|c|c|c|c|c|}
\hline $\begin{array}{l}\text { Temporada } \\
\mathrm{N}\end{array}$ & M\% & M\% & $\begin{array}{c}1980 / 81 \\
15 \\
M \% \\
\end{array}$ & M\% & $\begin{array}{c}1981 / 82 \\
13 \\
\mathrm{~N} \% \\
\end{array}$ & M\% & $\begin{array}{c}1996 / 97 \\
30 \\
M \%\end{array}$ & $\begin{array}{c}1997 / 98 \\
50 \\
\text { М\% } \\
\end{array}$ & $\begin{array}{c}1998 / 99 \\
49 \\
\text { М\% } \\
\end{array}$ & $\begin{array}{c}1999 / 00 \\
48 \\
\text { М\% }\end{array}$ & $\begin{array}{c}2000 / 01 \\
39 \\
\text { M\% }\end{array}$ \\
\hline $\begin{array}{l}\text { Crustáceos } \\
\text { Krill } \\
\text { Anfípodos } \\
\text { Peces } \\
\text { Otros }\end{array}$ & 100,00 & 100,00 & $\begin{array}{c}99,30 \\
0,60 \\
0,10\end{array}$ & $\begin{array}{c}98,30 \\
0,30 \\
1,40\end{array}$ & $\begin{array}{c}99,70 \\
0,30 \\
0,01\end{array}$ & $\begin{array}{c}99,10 \\
0,50 \\
0,40\end{array}$ & $\begin{array}{c}99,96 \\
0,02 \\
0,01\end{array}$ & $\begin{array}{c}99,60 \\
0,17 \\
0,01\end{array}$ & $\begin{array}{c}99,56 \\
0,21 \\
0,01\end{array}$ & $\begin{array}{c}98,93 \\
0,45 \\
0,01\end{array}$ & $\begin{array}{c}99,74 \\
0,07 \\
0,01\end{array}$ \\
\hline Referencia & 1 & 2 & 3 & & 4 & & & & & & \\
\hline
\end{tabular}

1 Sladen (1958)

White y Conroy (1975)

4 Lynnes et al. (2004) 
Tabla II.6: Composición general de la dieta del pingüino de Adelia tal como lo refleja el análisis de contenidos estomacales en la I. Laurie (IOS). N: número de muestras analizadas, F\%: frecuencia de ocurrencia porcentual, N\%: importancia en número porcentual, M\%: importancia en masa porcentual. Tomado de Libertelli et al. (2003).

\begin{tabular}{|c|c|c|c|c|c|c|c|c|c|}
\hline \multirow[t]{2}{*}{$\begin{array}{l}\text { Temporada } \\
\mathrm{N}\end{array}$} & \multicolumn{3}{|c|}{$\begin{array}{c}1996 / 97 \\
48\end{array}$} & \multicolumn{3}{|c|}{$\begin{array}{c}1997 / 98 \\
42\end{array}$} & \multicolumn{3}{|c|}{$\begin{array}{c}1998 / 99 \\
35\end{array}$} \\
\hline & F\% & $\mathrm{N} \%$ & M\% & F\% & $\mathrm{N} \%$ & M\% & F\% & $\mathrm{N} \%$ & M\% \\
\hline \multicolumn{10}{|l|}{ Crustáceos } \\
\hline Krill & 100,00 & 99,93 & 99,91 & 100,00 & 97,92 & 99,35 & 100,00 & 99,50 & 99,81 \\
\hline Anfípodos & 31,91 & 0,06 & 0,02 & 64,29 & 2,01 & 0,41 & 34,29 & 0,16 & 0,00 \\
\hline Peces & 2,13 & 0,00 & 0,00 & 21,43 & 0,06 & 0,21 & 54,29 & 0,31 & 0,19 \\
\hline Otros & 17,02 & 0,01 & 0,06 & 4,76 & 0,01 & 0,03 & 8,57 & 0,04 & 0,00 \\
\hline
\end{tabular}

Tabla II.7: Composición general de la dieta del pingüino de Barbijo en las IOS tal como lo refleja el análisis de contenidos estomacales. N: número de muestras analizadas, N\%: importancia en número porcentual, M\%: importancia en masa porcentual

\begin{tabular}{|c|c|c|c|c|c|c|c|c|c|c|c|}
\hline $\begin{array}{l}\text { Temporada } \\
\mathbf{N}\end{array}$ & M\% & M\% & $\begin{array}{c}1980 / 81 \\
21 \\
\text { N\% } \\
\end{array}$ & M\% & $\begin{array}{c}1981 / 82 \\
14 \\
\mathrm{~N} \% \\
\end{array}$ & M\% & $\begin{array}{c}1997 \\
43 \\
\text { M\% } \\
\end{array}$ & $\begin{array}{c}1998 \\
55 \\
\text { M\% } \\
\end{array}$ & $\begin{array}{c}1999 \\
50 \\
\mathrm{M} \% \\
\end{array}$ & $\begin{array}{c}2000 \\
49 \\
\mathrm{M} \% \\
\end{array}$ & $\begin{array}{c}2001 \\
40 \\
\mathrm{M} \% \\
\end{array}$ \\
\hline $\begin{array}{l}\text { Crustáceos } \\
\text { Krill } \\
\text { Anfípodos } \\
\text { Cefalópodos } \\
\text { Calamares } \\
\text { Peces } \\
\text { Otros } \\
\end{array}$ & 100,00 & 100,00 & $\begin{array}{c}99,80 \\
0,10\end{array}$ & $\begin{array}{c}97,00 \\
0,10\end{array}$ & $\begin{array}{l}99,91 \\
<0,01 \\
<0,01\end{array}$ & $\begin{array}{c}99,82 \\
0,10\end{array}$ & $\begin{array}{l}99,83 \\
<0,01 \\
<0,01 \\
<0,01 \\
<0,01\end{array}$ & $\begin{array}{l}100,00 \\
<0,01 \\
<0,01 \\
<0,01 \\
<0,01\end{array}$ & $\begin{array}{l}99,92 \\
<0,01 \\
<0,01 \\
<0,01 \\
<0,01\end{array}$ & $\begin{array}{l}99,83 \\
<0,01 \\
<0,01 \\
<0,01 \\
<0,01\end{array}$ & $\begin{array}{l}99,86 \\
<0,01 \\
<0,01 \\
<0,01 \\
<0,01\end{array}$ \\
\hline Referencia & 1 & 2 & 3 & & & & 4 & & & & \\
\hline
\end{tabular}




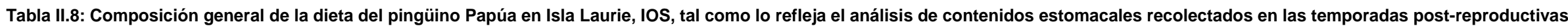
1993 y 1995 a 2000. N: número de muestras analizadas, F\%: frecuencia de ocurrencia porcentual, N\%: importancia en número porcentual.

\begin{tabular}{|c|c|c|c|c|c|c|c|c|c|c|c|c|c|c|}
\hline $\begin{array}{l}\text { Temporada } \\
\mathbf{N}\end{array}$ & $\begin{array}{c}1993 \\
37 \\
\text { F\% } \\
\end{array}$ & N\% & $\begin{array}{c}1995 \\
46 \\
F \% \\
\end{array}$ & N\% & $\begin{array}{c}1996 \\
42 \\
\text { F\% } \\
\end{array}$ & N\% & $\begin{array}{c}1997 \\
37 \\
\text { F\% } \\
\end{array}$ & N\% & $\begin{array}{c}1998 \\
15 \\
\text { F\% } \\
\end{array}$ & N\% & $\begin{array}{c}1999 \\
31 \\
\text { F\% } \\
\end{array}$ & N\% & $\begin{array}{c}2000 \\
67 \\
\text { F\% } \\
\end{array}$ & N\% \\
\hline Crustáceos & & & & & & & & & & & & & & \\
\hline Krill & 89,19 & 85,01 & 84,78 & 37,38 & 50,00 & 76,44 & 70,30 & 94,20 & 100,00 & 98,10 & 100,00 & 93,67 & 97,01 & 72,01 \\
\hline $\begin{array}{l}\text { Anfípodos } \\
\text { Cefalópodos }\end{array}$ & 40,54 & 0,42 & 65,22 & 2,32 & 54,76 & 0,33 & 56,80 & 0,30 & 40,00 & 0,30 & 35,48 & 2,51 & 61,19 & 1,88 \\
\hline Calamares & 35,14 & 2,49 & 82,61 & 13,71 & 28,57 & 3,12 & 10,80 & 0,00 & 6,70 & 0,00 & 12,90 & 0,32 & 16,42 & 0,08 \\
\hline $\begin{array}{l}\text { Peces } \\
\text { Piedras }\end{array}$ & 59,46 & 11,96 & 97,83 & 46,13 & 92,86 & 16,45 & 86,50 & 5,40 & 66,70 & 1,60 & $\begin{array}{l}77,42 \\
83,87\end{array}$ & 1,57 & $\begin{array}{l}95,52 \\
83,58\end{array}$ & 25,43 \\
\hline Otros & 18,92 & 0,13 & 23,91 & 0,46 & 54,76 & 3,66 & & & & & 41,94 & 1,93 & 44,78 & 0,60 \\
\hline Referencia & 1 & & 2 & & & & & & & & 3 & & & \\
\hline
\end{tabular}

1 Coria et al. (2000)

2 Berón et al. (2001)

3 Libertelli (datos no publicados) 


\section{Pingüino de Barbijo Pygoscelis antarctica}

El pingüino de Barbijo se distribuye de manera circumantártica y ocupa principalmente el sector Atlántico de este continente (Martínez 1992). Las zonas reproductivas se encuentran al sur de la Convergencia Antártica (CA) y comprenden localidades insulares tanto antárticas como subantárticas, llegando en la Península Antártica (PA) hasta los $64^{\circ} \mathrm{S}$ (Williams 1995). Durante la temporada reproductiva el $10 \%$ de la población de este pingüino se encuentra distribuida en las IOS (Croxall et al. 1984, Woehler 1993) y el arribo a las colonias comienza entre los meses de Octubre y Noviembre. Por lo general este pingüino anida en zonas rocosas y costas con poca cubierta de hielo marino (10 a $30 \%$ de cobertura de hielo) (Martínez 1992), a diferencia del pingüino de Adelia, el cual nidifica preferentemente en zonas con mayor porcentaje de mar cubierto por hielo (más del $70 \%$ de cobertura de hielo marino) (Cline et al. 1969, Ainley et al. 1994). La información sobre la composición de la dieta del pingüino de Barbijo en las IOS se basa en el análisis de contenidos estomacales y está resumida en la tabla II.7.

En general, todos los trabajos desarrollados en las IOS indican que el krill es la presa dominante en la dieta del pingüino de Barbijo (>97M\%) y sólo en las muestras analizadas por Lynnes et al (2004) se observó la presencia de calamares. Los peces estuvieron muy poco representados en las muestras analizadas y su contribución en biomasa a la dieta varió entre $0,01 \%$ y 2,9\%. Entre los peces, Lynnes et al. (2004) reportaron la presencia en la dieta de E. antarctica, C. gunnari, C. aceratus, P. georgianus, G. gibberifrons, G. marionensis, N. nybelini y N. coriiceps, de las cuales sólo $C$ gunnari y $N$. nybelini fueron encontradas en más de una ocasión.

\section{Pingüino Papúa Pygoscelis papua}

El pingüino Papúa es un importante integrante de la avifauna antártica y subantártica. Esta especie tiene una distribución circumpolar y su área de reproducción se extiende hacia el norte hasta los $60^{\circ}$ de latitud Sur (Martínez 1992). El 2,8\% de la población se encuentra distribuido en las IOS durante las temporadas reproductiva y post-reproductiva (Octubre a Marzo) y el arribo a las colonias ocurre entre los meses de Junio y Noviembre (Croxall et al. 1984, Davis 1989, Martínez 1992, Woehler 1993, Coria et al. 1995). El pingüino Papua anida en costas rocosas y en ocasiones lo hace junto con otras especies de aves. La dieta del pingüino Papúa ha sido estudiada, principalmente durante el período reproductivo, en numerosas localidades antárticas y subantárticas, tales como Islas Georgias del Sur (IGS), Isla Heard, ISS, Isla Macquarie, (Croxall y Prince 1980, Volkman et al. 1980, LaCock et al. 1984, Jablonski 1985, Ridoux 1988, Adams y Klages1989, Bost y Jouventin 1990, Robinson y Hindell 1996). De todas las especies del género Pygoscelis, el pingüino Papúa es la que forrajea con mayor frecuencia e intensidad sobre peces, principalmente sobre especies de notothéniidos y myctóphidos.

La información relacionada con la composición de la dieta del pingüino Papúa en Isla Laurie proviene del análisis de contenidos estomacales recolectados durante las temporadas postreproductivas (otoño austral) de los años 1993 y 1995 a 2000 (Tabla II.8, figura II.2) 


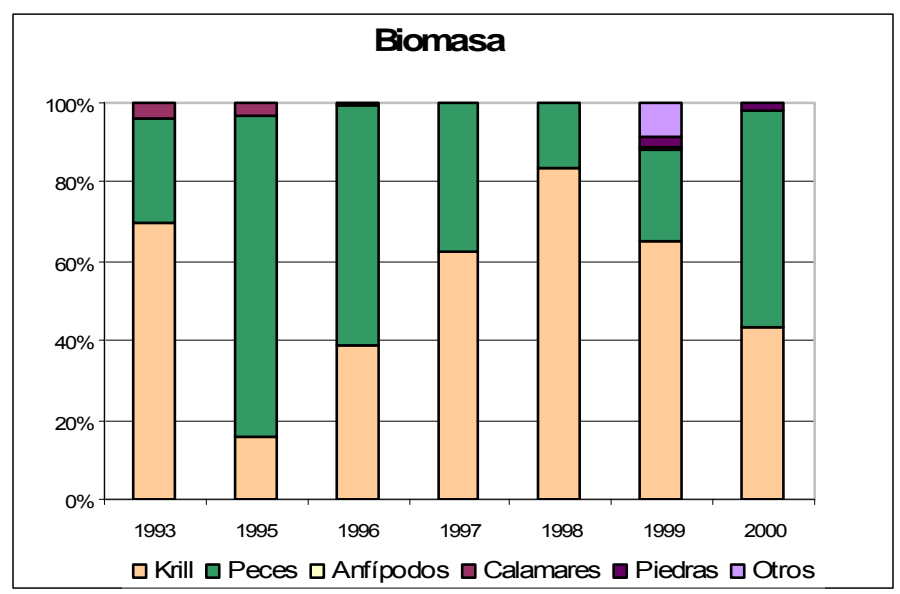

Figura II.2: Contribución en biomasa (\%) de las presas representadas en contenidos estomacales del pingüino Papúa obtenidos durante las temporadas post-reproductivas 1993 y 1995-2000 en I. Laurie, IOS.

El krill o los peces fueron las presas más frecuentes e importantes en número y biomasa en todas las temporadas consideradas. Durante los otoños australes de 1995, 1996 y 1997 los peces fueron la presa más frecuente (>85\%), en tanto que en 1995, 1996 y 2000 también fueron los que más contribuyeron a la dieta en términos de biomasa $(80 \%, 60 \%$ y $54 \%$ respectivamente). En la figura II.2 se observa que la contribución del krill a la dieta de este pingüino fluctuó ampliamente a lo largo del período de estudio observándose valores máximos durante 1993 y 1998 y un mínimo muy pronunciado en 1995. Con respecto a las demás presas, el calamar $P$. glacialis estuvo representado en las muestras obtenidas en el año 1995 ( $F \%$ 82,5) y su aporte en términos de biomasa fue bajo $(<4 \%)$. Si bien los anfípodos fueron una presa frecuente ( $>35 \%$ en todas las temporadas), su aporte en masa fue casi insignificante $(<1 \%)$.

Los peces identificados en las muestras provenientes de I. Laurie pertenecieron a las familias Nototheniidae, Harpagiferidae, Myctophidae y Channichthyidae. Entre ellas, Nototheniidae fue la familia mejor representada y $G$. gibberifrons fue la especie que más contribuyó en términos de biomasa en todas las temporadas, excepto 1996 cuando predominó N. nybelini. La contribución de los myctóphidos a la dieta fue baja (Tabla II.9). 
Tabla II.9: Contribución de los peces a la dieta del pingüino Papúa tal como lo reflejara el análisis de contenidos estomacales recolectados en I. Laurie, IOS, durante las temporadas post-reproductivas 1993, 1995, 1996, 1999 y 2000. N: número de muestras analizadas, F\%: frecuencia de ocurrencia porcentual, N\%: importancia en número porcentual, M\%:

\begin{tabular}{|c|c|c|c|c|c|c|c|c|c|c|c|c|c|c|c|}
\hline \multirow[t]{2}{*}{$\begin{array}{l}\text { Temporada } \\
\mathrm{N}\end{array}$} & \multicolumn{3}{|c|}{$\begin{array}{c}1993 \\
37 \\
\end{array}$} & \multicolumn{3}{|c|}{$\begin{array}{c}1995 \\
46 \\
\end{array}$} & \multicolumn{3}{|c|}{$\begin{array}{c}1996 \\
42\end{array}$} & \multicolumn{3}{|c|}{$\begin{array}{c}1999 \\
67\end{array}$} & \multicolumn{3}{|c|}{$\begin{array}{c}2000 \\
31 \\
\end{array}$} \\
\hline & F\% & N\% & M\% & F\% & N\% & M\% & $\mathrm{F} \%$ & N\% & M\% & F\% & N\% & M\% & F\% & N\% & M\% \\
\hline \multicolumn{16}{|l|}{ Nototheniidae } \\
\hline G. gibberifrons & 33,00 & 15,20 & 44,60 & 50,00 & 30,20 & 73,50 & 36,00 & 2,50 & 39,30 & 29,03 & 63,08 & 84,93 & 49,25 & 12,74 & 87,54 \\
\hline L. nudifrons & 22,00 & 9,10 & & 33,00 & 11,30 & & 24,00 & 0,40 & & 3,23 & 0,77 & 0,04 & 22,39 & 2,98 & 1,40 \\
\hline N. coriiceps & & & & & & & & & & & & & 1,49 & 0,09 & 0,10 \\
\hline N. nybelini & 22,00 & 33,30 & 36,60 & & & & 72,00 & 4,10 & 44,60 & & & & & & \\
\hline N. rossii & & & & & & & & & & & & & 1,49 & 0,09 & 1,64 \\
\hline T. bernacchii & & & & 8,00 & 1,90 & 1,10 & 4,00 & 0,00 & 0,10 & & & & 4,48 & 0,37 & 0,37 \\
\hline T. newnesi & 44,00 & 12,10 & 6,10 & 25,00 & 7,50 & 7,60 & 68,00 & 2,70 & 10,80 & 9,68 & 4,62 & 0,63 & 23,88 & 2,88 & 1,99 \\
\hline No identificados & & & & 17,00 & 26,40 & & 71,00 & 88,00 & & & & & & & \\
\hline \multicolumn{16}{|l|}{ Harpagiferidae } \\
\hline H. antarcticus & & & & & & & 28,00 & 1,00 & 0,60 & & & & 11,94 & 2,05 & 0,49 \\
\hline \multicolumn{16}{|l|}{ Channichthyidae } \\
\hline C. rhinoceratus & 11,00 & 3,00 & & & & & & & & & & & & & \\
\hline C. gunnari & & & & & & & 4,00 & 0,00 & 1,80 & & & & 1,49 & 0,09 & 0,09 \\
\hline No identificados & & & 8,00 & 8,00 & 1,90 & & & & & & & & & & \\
\hline \multicolumn{16}{|l|}{ Myctophidae } \\
\hline E. antarctica & 11,00 & 3,00 & 0,10 & & & & & & & & & & 1,49 & 0,09 & 0,01 \\
\hline \multicolumn{16}{|l|}{ E. carlsbergi } \\
\hline G. nicholsi & 11,00 & 3,00 & 3,50 & & & & 4,00 & 0,00 & 0,60 & & & & 2,99 & 4,28 & 1,65 \\
\hline G. fraseri & & & & & & & 4,00 & 0,10 & 0,00 & & & & & & \\
\hline \multicolumn{16}{|l|}{ P. choriodon } \\
\hline P. normani & & & & 8,00 & 1,90 & & & & & & & & & & \\
\hline No identificados & 33,00 & 21,20 & & 33,00 & 18,90 & & 20,00 & 1,20 & & & & & & & \\
\hline Referencia & 1 & & & & & & & & & 2 & & & & & \\
\hline
\end{tabular}

1 Coria et al. (2000)

2 Libertelli (datos no publicados) 
Tabla II.10: Tallas (medias, desvío estándar DE y rango) de los peces representados en los contenidos estomacales del pingüino Papúa recolectados en I. Laurie, IOS, durante las temporadas post-reproductivas 1993, 1995, 1996, 1999 y 2000.

\begin{tabular}{|c|c|c|c|c|c|c|c|c|c|c|c|c|c|c|c|}
\hline \multirow[t]{2}{*}{ Temporada } & \multicolumn{3}{|c|}{1993} & \multicolumn{3}{|c|}{1995} & \multicolumn{3}{|c|}{1996} & \multicolumn{3}{|c|}{1999} & \multicolumn{3}{|c|}{2000} \\
\hline & Media & $\mathrm{DE}$ & Rango & Media & $\mathrm{DE}$ & Rango & Media & $\mathrm{DE}$ & Rango & Media & DE & Rango & Media & $\mathrm{DE}$ & Rango \\
\hline \multicolumn{16}{|l|}{ Nototheniidae } \\
\hline G. gibberifrons & 18,60 & 8,00 & $8,8-29,0$ & 17,00 & 3,60 & $8,9-24,0$ & 12,00 & 6,70 & $6,5-35,2$ & 14,76 & 8,17 & $5,96-37,89$ & 26,65 & 10,38 & $4,28-38,79$ \\
\hline L. nudifrons & 10,80 & 2,30 & $9,2-13,5$ & 12,70 & 1,20 & $11,4-14,9$ & 9,10 & 2,60 & $5,9-12,9$ & 5,84 & & 5,84 & 9,26 & 2,55 & $5,63-13,82$ \\
\hline N. rossii & & & & & & & & & & & & & 29,74 & & 29,74 \\
\hline N. coriiceps & & & & & & & & & & & & & 3,67 & & 3,67 \\
\hline N. nybelini & 11,30 & 1,80 & $8,9-14,2$ & --- & & & 8,60 & 2,70 & $5,6-17,2$ & 10,57 & 2,02 & $7,14-13,44$ & 8,27 & 2,02 & $5,31-15,34$ \\
\hline T. bernacchii & --- & & & 11,30 & & & 8,70 & & & & & & 13,79 & 1,07 & $12,25-14,72$ \\
\hline T. newnesi & 8,30 & 2,20 & $6,0-11,4$ & 9,70 & 1,80 & $7,1-10,9$ & 6,70 & 1,10 & $5,4-11,2$ & 4,21 & 4,26 & $1,56-11,3$ & 8,66 & 2,50 & $5,32-13,24$ \\
\hline \multicolumn{16}{|l|}{ Harpagiferidae } \\
\hline H. antarcticus & --- & & & & & & 6,20 & 0,30 & $5,4-6,9$ & & & & 6,44 & 0,37 & $5,5-6,97$ \\
\hline Myctophidae & & & & & & & & & & & & & & & \\
\hline E. antarctica & 4,60 & & & & & & & & & & & & 5,88 & & 5,88 \\
\hline G. nicholsi & 17,40 & & & & & & 16,70 & & & & & & 20,32 & 7,87 & $9,99-27,59$ \\
\hline G. fraseri & --- & & & & & & 3,30 & & & & & & & & \\
\hline P. normani & --- & & & 6,10 & & & & & & & & & & & \\
\hline Channichthyidae & & & & & & & & & & & & & & & \\
\hline C. rhinoceratus & 17,20 & & & & & & 22,90 & & & & & & & & \\
\hline C. antarcticus & & & & & & & & & & 31,61 & 5,22 & $\begin{array}{l}25,76- \\
35,81\end{array}$ & 14,59 & 2,83 & $12,59-16,59$ \\
\hline C. gunnari & ---- & & & & & & & & & & & & 15,86 & & 15,86 \\
\hline TOTALES & 12,60 & 5,29 & $6,0-29$ & 11,36 & 4,00 & $7,1-24$ & 10,47 & 6,00 & $5,4-35,2$ & 14,11 & 12,56 & $1,56-37,89$ & 14,08 & 8,56 & $3,67-38,79$ \\
\hline Referencias & 1 & & & & & & & & & 2 & & & & & \\
\hline
\end{tabular}

1 Coria et al. (2000)

2 Libertelli (datos no publicados) 
Teniendo en cuenta el total de las especies de peces representadas en las muestras, la talla media más baja $(10,5 \mathrm{~cm}$.) se observó en 1996, en tanto que el valor máximo fue registrado durante la temporada de 2000 (13,6 cm.) (Tabla II.8). Se observaron diferencias significativas en las tallas y en las especies de peces consumidas en las temporadas 1993, 1995 y 1996 (ANOVA W $\lambda=0,85$; g.l. = 4; $p<0,05$ ). Asimismo, los análisis post-hoc (Newman Keuls) reflejaron diferencias en la contribución de las distintas especies de peces a la dieta entre los años 93-95 ( $p<0,001)$ y 93-96 $(p<0,001)$ y en las tallas de peces consumidos entre los años 93-95 y 95-96. Al analizar las variaciones interanuales en las tallas de las especies mejor representadas en la dieta se observa que $L$. nudifrons y $T$. newnesi presentaron un patrón similar $\left(R^{2}=0,87\right.$, figura II.3), aunque $L$. nudifrons estuvo representada por tallas mayores en todos los años $(W \lambda=0,64 ; g . l=4 ; p<0,05)$. Nototheniops nybelini y G. gibberifrons presentaron un aumento en las tallas medias entre 1996 y 1999, y en el año 2000 las tallas de N. nybelini disminuyen y las de G. gibberifrons aumentan, alcanzando en esa temporada el valor máximo.

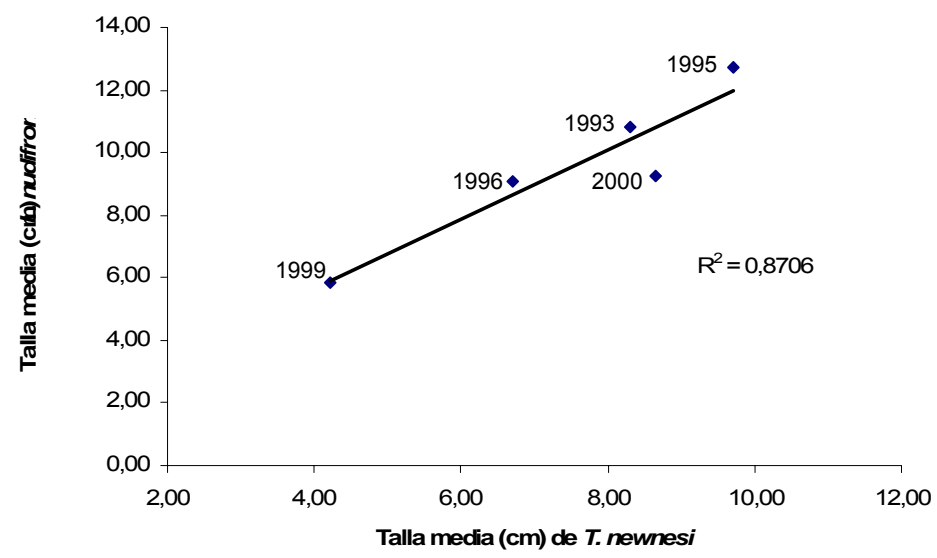

Figura II.3: Correlación entre las tallas medias de T. newnesi y L. nudifrons representadas en la dieta del pingüino Papúa en la I. Laurie, IOS, durante las temporadas post-reproductivas 1993, 1995, 1996, 1999 y 2000.

\section{Procellaridae}

\section{Petrel Damero Daption capense}

El petrel Damero o Pintado presenta una amplia distribución en zonas antárticas y subantárticas y su arribo a las colonias ocurre frecuentemente en Noviembre (Carboneras 1992). De acuerdo a información generada en el sector Indico del OA, el petrel Damero se alimenta principalmente de krill, aunque frecuentemente también consume peces, predominando entre ellos el notothéniido Pleuragramma antarcticum (Carboneras 1992). Los estudios orientados al conocimiento de los hábitos alimentarios del petrel Damero en las IOS son escasos (Tabla II.10). En las temporadas reproductivas 1965/66 (Beck 1969) y 1994/95 (Soave et al. 1996) el krill, seguido por los peces, fue la presa más frecuente y también predominó en número y biomasa. A diferencia de lo observado en esas temporadas, si bien el krill fue la presa más recuente y abundante en 1995/96, los peces predominaron en la dieta en términos de biomasa (Tabla II.11). En general, tanto los anfípodos 
(hyperídeos y gamarídeos) como los octópodos fueron presas escasamente representadas en la dieta. Las muestras analizadas por Coria et al. (1997) provinieron de ejemplares adultos (contenidos estomacales) y de pichones (regurgitados). En ambos grupos el krill y los peces fueron las presas más frecuentes, en tanto que el krill predominó en número y los peces en biomasa. La biomasa estimada para los contenidos estomacales de los adultos y los regurgitados de los pichones no presentaron diferencias significativas $(t=1,749$, g.I. $=70, \mathrm{NS})$.

Tabla II.11: Composición de la dieta del petrel Damero de acuerdo al análisis de las muestras recolectadas en las temporadas 1965/66 (contenidos estomacales), 1994/95 (contenidos estomacales) y 1995/96 (contenidos estomacales y regurgitados) en las IOS. N: número de muestras analizadas, F\%: frecuencia de ocurrencia porcentual, N\%: importancia en número porcentual, M\%: importancia en masa porcentual.

\begin{tabular}{|c|c|c|c|c|c|c|c|}
\hline \multirow[t]{2}{*}{$\begin{array}{l}\text { Temporada } \\
\mathrm{N} \\
\text { Localidad }\end{array}$} & \multirow{2}{*}{$\begin{array}{c}1965 / 66 \\
94 \\
\text { I. Signy } \\
\text { M\% } \\
\end{array}$} & \multicolumn{3}{|c|}{$\begin{array}{c}\text { 1994/95 } \\
20 \\
\text { I. Laurie }\end{array}$} & \multicolumn{3}{|c|}{$\begin{array}{c}\text { 1995/96 } \\
72 \\
\text { I. Laurie }\end{array}$} \\
\hline & & F\% & $\mathrm{N} \%$ & M\% & F\% & $\mathrm{N} \%$ & M\% \\
\hline \multicolumn{8}{|l|}{ Crustáceos } \\
\hline Krill & 64,00 & 95,00 & 94,80 & 97,20 & 100,00 & 92,20 & 35,80 \\
\hline Anfípodos & & 5,00 & 3,40 & $<0,5$ & 34,70 & 0,90 & 0,60 \\
\hline \multicolumn{8}{|l|}{ Cefalópodos } \\
\hline Octópodos & & & & & 1,40 & $<0,1$ & \\
\hline Peces & 15,00 & 20,00 & 1,20 & 1,80 & 100,00 & 6,90 & 63,60 \\
\hline Otros & 21,00 & 10,00 & 0,60 & 0,90 & & & $<0,1$ \\
\hline Referencias & 1 & 2 & & & 3 & & \\
\hline
\end{tabular}

1 Beck (1969, (9 de adultos +85 de pichones)

2 Soave et al. (1996)

3 Coria et al. (1997)

Los peces representados en las muestras provenientes del petrel Damero en las IOS pertenecieron principalmente a la familia Myctophidae y entre ellos predominaron E. antarctica, $G$. opisthopterus, G. nicholsi, G. braueri, K. anderssoni y P. normani (Tabla II.12). Electrona antarctica fue la especie más importante en todas las temporadas, excepto en 1999/00 cuando G. opisthopterus predominó en términos de biomasa. Cabe destacar que en la temporada 2000/01 se obtuvo un escaso número de muestras $(\mathrm{N}=5)$, lo que podría explicar que $E$. antarctica haya sido la única especie identificada.

Casaux et al. (1998) analizaron separadamente la contribución de los peces a la dieta de pichones y adultos de petrel Damero durante la temporada 1995/96. Estos autores observaron que si bien en ambos grupos $E$. antarctica fue el pez dominante, en los adultos las especies que le siguieron en importancia fueron $G$. braueri y $K$. anderssoni en tanto que en pichones lo hizo $G$. nicholsi (Tabla II.11). A diferencia de lo reportado por Coria et al (1997) para la composición general de la dieta, la información provista por Casaux et al. (1998) refleja diferencias significativas en el aporte de la biomasa las diferentes especies de peces a la dieta de adultos y pichones. La talla media de los peces consumidos por el petrel Damero en las temporadas 1995/96, 1996/97, 1998/99, $1999 / 00$ y $2000 / 01$ fue $10,14 \pm 3,94 \mathrm{~cm}$. y varío entre 3,60 y $17,04 \mathrm{~cm}$. (Tabla II.12). No se observaron diferencias significativas en las tallas (ANOVA NS; g.l.: 4, $\mathscr{F}=1,820190 ; p>0,01$ ) y especies de peces (ANOVA NS; g.l.: 4, $\mathscr{F}=0,881168 ; p>0,01$ ) representadas en las muestras de las diferentes temporadas. 
Tabla Il.12: Contribución de los peces a la dieta del Petrel Damero de acuerdo al análisis de contenidos estomacales y regurgitados recolectados durante las temporadas 1995/96, 1996/97, 1998/99, 1999/00 y 2000/01 en I. Laurie, IOS. F\%: frecuencia de ocurrencia porcentual, N\%: importancia en número porcentual, M\%: importancia en masa porcentual.

\begin{tabular}{|c|c|c|c|c|c|c|c|c|c|c|c|c|c|c|c|}
\hline \multirow{2}{*}{$\begin{array}{l}\text { Temporada } \\
\mathrm{N}\end{array}$} & \multicolumn{3}{|c|}{$1995 / 96$} & \multicolumn{3}{|c|}{ 1996/97 } & \multicolumn{3}{|c|}{ 1998/99 } & \multicolumn{3}{|c|}{$1999 / 00$} & \multicolumn{3}{|c|}{$2000 / 01$} \\
\hline & F\% & N\% & M\% & F\% & N\% & M\% & F\% & N\% & M\% & F\% & N\% & M\% & F\% & N\% & M\% \\
\hline Myctophidae & & & & & & & & & & & & & & & \\
\hline Electrona antarctica & 92,30 & 74,40 & & 96,30 & 85,70 & 75,80 & 88,80 & 78,46 & 59,86 & 75,00 & 68,75 & 22,44 & 100,00 & 100,00 & 100,00 \\
\hline Gymnoscopelus braueri & 14,30 & 5,50 & & 3,70 & 1,40 & 5,90 & & & & & & & & & \\
\hline Gymnoscopelus nicholsi & 2,40 & 1,20 & & 3,70 & 1,40 & 12,00 & 5,55 & 1,53 & 10,68 & & & & & & \\
\hline Gymnoscopelus ophistopterus & 9,50 & 4,90 & & & & & 11,11 & 3,08 & 24,48 & 25,00 & 12,50 & 77,51 & & & \\
\hline Protomyctophum normani & & & & & & & 5,55 & 3,07 & 4,99 & & & & & & \\
\hline Krefftichthys anderssoni & & & & 3,70 & 1,40 & 6,30 & & & & & & & & & \\
\hline No identificados & 2,40 & 1,20 & & & & & & & & & & & & & \\
\hline Channiychtiidae & & & & 3,70 & 1,40 & & & & & & & & & & \\
\hline No identificados & 21,40 & 12,80 & & 14,80 & 8,60 & & 33,33 & 13,84 & & 37,50 & 18,75 & & & & \\
\hline Referencias & 1 & & & 2 & & & & & & & & & & & \\
\hline
\end{tabular}

Tabla II.13: Contribución de los peces a la dieta de de adultos y pichones del Petrel Damero en las IOS durante la temporada reproductiva 1995/96. F\%: frecuencia de ocurrencia porcentual, N\%: importancia en número porcentual, M\%: importancia en masa porcentual, número de muestras en paréntesis. Tomado de Casaux et al. (1998).

\begin{tabular}{|l|ccc|ccc|}
\hline Temporada 1995/96 & \multicolumn{3}{|c|}{ Adultos } & \multicolumn{3}{c|}{ Pichones } \\
N & \multicolumn{3}{|c|}{$\mathbf{3 2}$} & & $\mathbf{4 0}$ & \\
& F\% & N\% & M\% & F\% & N\% & M\% \\
\hline Myctophidae & & & & & & \\
Electrona antarctica & 100,00 & 71,90 & 52,60 & 85,70 & 77,80 & 73,60 \\
Gymnoscopelus braueri & 23,80 & 9,40 & 23,30 & 4,80 & 2,20 & 5,10 \\
Gymnoscopelus nicholsi & & & & 4,80 & 2,20 & 21,40 \\
Gymnoscopelus opisthopterus & 4,80 & 1,60 & 9,50 & & & \\
Protomyctophum normani & & & & & & \\
Krefftichthys anderssoni & 19,10 & 7,80 & 14,60 & & & \\
No identificados & 19,10 & 9,40 & & 23,80 & 17,80 & \\
\hline
\end{tabular}


Tabla II.14: Tallas (medias en cm, desvío estándar DE y rango) de los peces representados en la dieta del Petrel Damero durante las temporadas reproductivas 1995/96 y 1996/97, $1998 / 99,1999 / 00$ y 2000/01 en la I. Laurie, IOS.

\begin{tabular}{|c|c|c|c|c|c|c|c|c|c|c|c|c|}
\hline \multirow[t]{2}{*}{$\begin{array}{l}\text { Temporada } \\
\mathrm{N} \\
\end{array}$} & \multicolumn{3}{|c|}{$\begin{array}{c}1995 / 96 \\
32 \\
\end{array}$} & \multicolumn{3}{|c|}{$\begin{array}{c}1996 / 97 \\
27 \\
\end{array}$} & \multicolumn{3}{|c|}{$\begin{array}{c}1998 / 99 \\
18 \\
\end{array}$} & \multicolumn{3}{|c|}{$\begin{array}{c}1999 / 00 \\
8 \\
\end{array}$} \\
\hline & Talla & $\mathrm{DE}$ & Rango & Talla & DE & Rango & Talla & DE & Rango & Talla & $\mathrm{DE}$ & Rango \\
\hline \multicolumn{13}{|l|}{ Myctophidae } \\
\hline Electrona antarctica & 6,20 & 0,81 & $3,6-7,7$ & 5,90 & 2,47 & $3,67-6,72$ & 5,86 & 0,84 & $4,09-7,80$ & 5,24 & 0,77 & $4,02-6,74$ \\
\hline Gymnoscopelus braueri & 9,99 & 1,52 & $7.84-12,69$ & 10,89 & & & & & & & & \\
\hline Gymnoscopelus nicholsi & & & & 16,15 & & & 15,96 & & & & & \\
\hline Gymnoscopelus opisthopterus & 13,72 & & & & & & 13,49 & 4,29 & $\begin{array}{c}10,45- \\
16,53\end{array}$ & 15,15 & 2,68 & $\begin{array}{c}13,25- \\
17,04\end{array}$ \\
\hline Protomyctophum normani & & & & & & & 7,14 & 0,06 & $7,09-7,19$ & & & \\
\hline Krefftichthys anderssoni & 11,03 & 1,13 & $9,74-12,77$ & 8,17 & & & & & & & & \\
\hline
\end{tabular}

Tabla Il.14: Continuación

\begin{tabular}{|l|ccc|}
\hline Temporada & \multicolumn{3}{|c|}{$\mathbf{2 0 0 0 / 0 1}$} \\
$\mathbf{N}$ & \multicolumn{2}{|c|}{ DE } & Rango \\
\hline & Talla & & \\
\hline Myctophidae & & 0,41 & \\
Electrona antarctica & 7,22 & & \\
Gymnoscopelus braueri & & & \\
$\begin{array}{l}\text { Gymnoscopelus nicholsi } \\
\text { Gymnoscopelus opisthopterus } \\
\text { Protomyctophum normani } \\
\text { Krefftichthys anderssoni }\end{array}$ & & & \\
\hline
\end{tabular}




\section{Petrel Gigante Común Macronectes giganteus}

El petrel Gigante Común es, junto al petrel Gigante Oscuro Macronectes halli, el ave de mayor tamaño dentro de la familia Procellaridae (Hunter 1983). El petrel Gigante Común tiene una distribución circumpolar y presenta hábitos carroñeros y depredadores (Hunter y Brooke 1992), aunque usualmente también consume peces, cefalópodos y krill (Carboneras 1992). El área reproductiva en Antártida abarca los archipiélagos cercanos a la CA y algunas zonas de la PA y los arribos a la colonia ocurren usualmente en Octubre (Carboneras 1992).

La información disponible sobre la dieta de esta especie en Antártida es escasa y en relación a las IOS sólo se desarrolló un estudio en I. Signy (Conroy 1972) y otro en I. Laurie (Coria 2006) (Tabla II.14). Mediante el procesamiento de regurgitados y de contenidos estomacales de ejemplares sacrificados Conroy (1972) observó que los pingüinos, seguidos de los cefalópodos, fueron la presa más frecuente en la dieta del P. Gigante durante la temporada 1968/69. De un modo similar, los pingüinos fueron la presa más frecuente y la que más contribuyó en términos de biomasa a la dieta durante las temporadas 1998/99 y 1999/00 (Coria 2006). En relación al krill, el aporte de esta presa a la dieta fue mayor en las muestras analizadas por Conroy (1972) que en las de Coria (2006) (Tabla II.14). En relación a los cambios ontogenéticos en la dieta, Conroy (1972) reportó que el krill fue más frecuente en los regurgitados de pichones (no indica \%) que en los de adultos $(27 \%)$, resultando una presa importante en los primeros 14 días de vida.

$\mathrm{Si}$ bien los peces estuvieron poco representados en los trabajos desarrollados en las IOS, Coria (2006) observó que durante la temporada 1999/00 en Península Potter, Isla 25 de Mayo (ISS), los peces representaron el $30 \%$ de la dieta en biomasa. Lamentablemente, los trabajos de Conroy (1972) y Coria (2006) no brindan detalle de las especies de peces representadas en la dieta del P. Gigante en las IOS.

\section{Petrel de las Nieves Pagodroma nivea}

El petrel de las nieves es endémico de Antártida y de los archipiélagos de las islas circundantes (Harrison 1983) y presenta una distribución circumpolar (Carboneras 1992). La población reproductora estimada es de 2.000 .000 de individuos (Carboneras 1992), reproduce en zonas aledañas a la cubierta de hielo marino y la temporada reproductiva comienza aproximadamente a principios de Noviembre. Si bien Carboneras (1992) afirma que existe una tendencia hacia el aumento de la población, BirdLife International (2003) incluyó a $P$. nivea dentro de la Lista Roja de Especies Amenazadas de la IUCN. (Ekstrom J. y Butchart S., BirdLife International Red List Authority). Existen muy pocos estudios sobre la dieta del petrel de las Nieves, lo que se debe principalmente al difícil acceso a las colonias y a la alta sensibilidad de los individuos al disturbio. El único trabajo sobre la composición de la dieta de esta especie en las IOS se basó en el análisis de contenidos estomacales y regurgitados de adultos recolectados durante el período de cría (enerofebrero) de la temporada reproductiva 1997/98 (Ferretti et al. 2001). En dicho trabajo se observó que los peces, seguidos del krill antártico, fueron las presas que más contribuyeron a la composición de la dieta (Tabla II.16). Los peces que predominaron en las muestras correspondieron a la familia Myctophidae (principalmente E. antarctica) y la talla de los ejemplares varió entre 5,7 y 10,7 cm. (Tabla II.17). 
Tabla II.15: Composición de la dieta del P. Gigante de acuerdo al análisis de contenidos estomacales recolectados en las temporadas 1968/69 (n=71), 1998/99 ( $n=135)$ y 1999/00 (n=82) en las IOS. F\%: frecuencia de ocurrencia porcentual, N\%: importancia en número porcentual, M\%: importancia en masa porcentual.

\begin{tabular}{|c|c|c|c|c|c|c|c|c|c|c|c|}
\hline \multirow[t]{2}{*}{$\begin{array}{l}\text { Temporada } \\
\mathrm{N}\end{array}$} & \multirow{2}{*}{$\begin{array}{c}1968 / 69 \\
71 \\
\text { F\% }\end{array}$} & \multirow{2}{*}{$\begin{array}{c}1998 / 99 a \\
48 \\
\text { F\% } \\
\end{array}$} & \multirow[b]{2}{*}{ M\% } & \multicolumn{2}{|c|}{$\begin{array}{c}1998 / 99 b \\
87\end{array}$} & \multicolumn{3}{|c|}{$\begin{array}{c}1999 / 00 a \\
42\end{array}$} & \multicolumn{3}{|c|}{$\begin{array}{c}1999 / 00 b \\
40\end{array}$} \\
\hline & & & & F\% & M\% & F\% & N\% & M\% & F\% & N\% & M\% \\
\hline \multicolumn{12}{|l|}{ Crustáceos } \\
\hline Krill & 28,00 & 4,79 & 1,40 & 1,14 & 0,12 & 2,40 & 75,70 & 1,60 & 2,50 & 5,60 & 0,01 \\
\hline Anfipodos & & 4,19 & 0,13 & 2,27 & 0,06 & 0,00 & 0,00 & 0,00 & 2,50 & 1,40 & 0,01 \\
\hline No identificados & 6,00 & 0,00 & 0,00 & 0,00 & 0,00 & 0,00 & 0,00 & 0,00 & 0,00 & 0,00 & 0,00 \\
\hline Cefalópodos & 72,00 & 25,01 & 1,29 & 13,78 & 1,06 & 21,40 & 4,00 & 2,00 & 22,50 & 18,30 & 4,30 \\
\hline Peces & 4,00 & 6,25 & 1,06 & 0,00 & 0,00 & 4,80 & 1,20 & 0,20 & 10,00 & 5,60 & 0,60 \\
\hline Pingüinos & 85,00 & 93,78 & 85,19 & 96,68 & 95,60 & 90,50 & 17,10 & 87,70 & 95,00 & 59,20 & 88,90 \\
\hline Aves voladoras & 13,00 & 33,34 & 10,94 & 6,38 & 3,16 & 11,90 & 2,00 & 8,50 & 12,50 & 8,50 & 5,90 \\
\hline Mamíferos marinos & 21,00 & 0,00 & 0,00 & 0,00 & 0,00 & 0,00 & 0,00 & 0,00 & 2,50 & 1,40 & 0,20 \\
\hline Otros & 21,00 & 2,10 & 0,01 & 0,00 & 0,00 & 0,00 & 0,00 & 0,00 & 2,50 & 1,40 & 0,01 \\
\hline Referencia & 1 & 2 & & & & & & & & & \\
\hline
\end{tabular}

Tabla Il.16: Composición general de la dieta del Petrel de las Nieves de acuerdo al análisis de contenidos estomacales ( $\mathrm{N}=16)$ recolectados en las IOS durante la temporada reproductiva 1997/98. F\%: frecuencia de ocurrencia porcentual, N: importancia en número porcentual, M\%: Importancia en masa porcentual. Tomado de Ferretti et al. (2001).

\begin{tabular}{|l|ccc|}
\hline \begin{tabular}{l|ccc|} 
Temporada 1997/98 \\
$\mathbf{N}$
\end{tabular} & \multicolumn{3}{|c|}{$\mathbf{1 6}$} \\
& $\mathbf{F \%}$ & $\mathbf{N} \%$ & $\mathbf{M} \%$ \\
\hline Crustáceos & & & \\
Krill & 81,30 & 36,10 & 8,30 \\
Otros & 56,30 & 10,10 & 1,40 \\
Cefalópodos & & & \\
Calamar & 6,30 & 0,60 & 1,00 \\
Peces & 93,80 & 53,20 & 90,30 \\
\hline
\end{tabular}


Tabla II.17: Peces representados en la dieta del Petrel de las Nieves durante la temporada reproductiva 1997/98 en las IOS. \%F: frecuencia de ocurrencia porcentual, \%N: importancia en número porcentual, \%M: importancia en masa porcentual y Talla (Largo total de los ejemplares en $\mathrm{cm}$. \pm desvío estándar y rango entre paréntesis). Tomado de Ferretti et al. (2001).

\begin{tabular}{|l|ccc|cc|}
\hline Temporada 1997/98 & F\% & N\% & M\% & $\begin{array}{c}\text { Talla media } \\
\pm \text { DE }\end{array}$ & Rango \\
\hline Myctophidae & & & & & \\
Electrona antarctica & 100,00 & 95,80 & 86,60 & $5,7 \pm 0,9$ & $3,5-7,3$ \\
Gymnoscopelus opisthopterus & 6,30 & 2,10 & 9,10 & 10,7 & \\
Bathylagidae & & & & & \\
Bathylagus glacialis & 6,30 & 2,10 & 4,30 & 9,0 & \\
\hline
\end{tabular}

\section{Hydrobatidae}

\section{Petrel de Wilson Oceanites oceanicus}

El petrel de Wilson habita las costas antárticas y las islas subantártcas. Esta especie presenta hábitos pelágicos marinos y su temporada reproductiva comienza a mediados de Noviembre. Las colonias se ubican principalmente en zonas rocosas.

El único trabajo sobre la composición de la dieta del petrel de Wilson en las IOS fue realizado en I. Signy durante la temporada reproductiva 1967/68 y consiste en el análisis de 20 contenidos estomacales y regurgitados obtenidos de ejemplares reproductores al retornar al nido luego de un viaje de forrajeo (Beck y Brown 1972). Según este trabajo, el krill antártico fue la única presa y estuvo representado en todas las muestras. Sumado a ello, Beck y Brown (1972) informaron que el consumo de animales muertos disponibles en las costas o en el mar a través de un proceso de facilitación por parte de otros predadores podría ser una frecuente estrategia de alimentación, principalmente en períodos de escasez de krill (ver también Murphy 1936, Falla 1937 y Roberts 1940).

\section{Phalacrocoracidae}

\section{Cormorán de Georgias Phalacrocorax georgianus}

El cormorán de Georgias se reproduce en las Islas Georgias del Sur, IOS e Islas Sandwich del Sur (Costa 1992). El status taxonómico de esta especie es aún tema de discusión (Marchant y Higgins 1990, Orta 1992, Casaux et al. 1997b). Si bien algunos autores consideran al cormorán que habita las IOS como una subespecie de Phalacrocorax atriceps, otros lo clasifican como la especie $P$. georgianus (Orta 1992). A pesar de las discrepancias en cuanto a la consideración de la población de las IOS, en este trabajo se adoptará la postura de Orta (1992).

Al igual que otros cormoranes, el cormorán de Georgias nidifica formando colonias cuyos tamaños varían entre unas pocas parejas hasta varios cientos. El período reproductivo se extiende desde los primeros días de Octubre hasta los últimos días de Febrero, momento en el cual los pichones comienzan a emanciparse.

Numerosos estudios sobre la biología alimentaria y reproductiva de especies de la familia Phalacrocoracidae han sido desarrollados en Antártida y sub-Antártida (ver revisión en Casaux y Barrera-Oro 2006). Aunque esta información es abundante, sólo unos pocos autores informan sobre 
la composición de la dieta del cormorán de Georgias en las IOS (Conroy y Twelves 1973, Shaw 1984, Casaux et al. 1997b, Casaux y Ramón 2002). En el trabajo más reciente desarrollado en las IOS (Casaux y Ramón 2002) se observó que los peces fueron la presa que más contribuyó a la dieta en todas las temporadas consideradas y que el resto de las presas representadas en las muestras aportaron muy poco a la dieta en términos de biomasa (Tabla II.18). Además, y tal como indicara Casaux et al. (1997b), la mayoría de estas presas podrían ser producto de ingesta secundaria (i.e. provendrían de los estómagos de los peces ingeridos), lo que también se ve sustentado por su escasa representación en los contenidos estomacales (donde los peces son recuperados enteros) recolectados en 1994/95 (Tabla II.19).

Al analizar la composición de la dieta a lo largo de la temporada reproductiva Casaux et al. (1997a) observaron que los peces fueron siempre la presa principal y que su contribución a la dieta se incrementó a medida que los requerimientos alimentarios de los pichones aumentaban (Tabla II.19).

Las familias de peces mejor representadas en la dieta del Cormorán de Georgias en la I. Laurie fueron Notothenidae y Harpafigeridae (Tabla II.20). Notothenia coriiceps, Harpagifer antarcticus y G. gibberifrons fueron los peces que más contribuyeron en masa a la dieta en las diferentes temporadas analizadas.

En relación a los cambios en la contribución a la dieta de las diferentes especies de peces a lo largo de la temporada reproductiva, la información obtenida por Casaux et al. (1997a) en I. Laurie indica que $N$. coriiceps fue la presa más importante durante la etapa de cría de los pichones (Tabla II.21), en tanto que durante la etapa de emancipación de los mismos la dieta se diversifica, aumentando marcadamente el consumo de $L$. nudifrons y $T$. newnesi.

De acuerdo a los datos provistos por Casaux y Ramón (2002), las tallas medias de los peces representados en la dieta del cormorán de Georgias variaron significativamente (ANOVA, $\left.\mathscr{F}_{4.12082}=185,2, \quad p<0,00001\right)$ a lo largo de las temporadas consideradas, aunque sin presentar un patrón evidente (Tabla II.22).

Casaux et al. (1997a) indicaron que, durante el período de cría tardía la masa de los contenidos estomacales fue mayor que durante el período de cría temprana/media, en tanto que el número de peces representados en los mismos disminuyó. Durante el período de emancipación el peso de los contenidos estomacales disminuyó y, debido a la diversificación en la dieta y al aumento del consumo de especies de menor tamaño, el número de peces representados por muestra aumentó (Tabla II.23). Consecuentemente con estos cambios en la estrategia de forrajeo se observaron diferencias significativas en las tallas de peces consumidas en las diferentes etapas de ciclo reproductivo (ANOVA, $\mathscr{F}_{162}=8,17 ; p<0,001$ ), siendo los peces consumidos durante la etapa de cría tardía significativamente más grandes que los ingeridos en las etapas de cría temprana/media y emancipación (Newman- Keuls $p<0,05$ y $p<0,001$ respectivamente). 


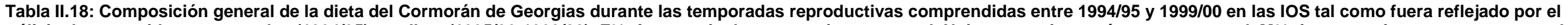

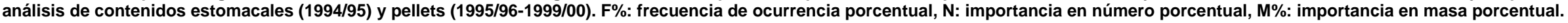

\begin{tabular}{|c|c|c|c|c|c|c|c|c|c|c|c|c|c|c|c|c|c|c|}
\hline \multirow[t]{2}{*}{$\begin{array}{l}\text { Temporada } \\
\mathrm{N}\end{array}$} & \multicolumn{3}{|c|}{$\begin{array}{c}1994 / 95 \\
29 \\
\end{array}$} & \multicolumn{3}{|c|}{$\begin{array}{c}1995 / 96 \\
24 \\
\end{array}$} & \multicolumn{3}{|c|}{$\begin{array}{c}1996 / 97 \\
226\end{array}$} & \multicolumn{3}{|c|}{$\begin{array}{c}1997 / 98 \\
54 \\
\end{array}$} & \multicolumn{3}{|c|}{$\begin{array}{c}1998 / 99 \\
77 \\
\end{array}$} & \multicolumn{3}{|c|}{$\begin{array}{c}1999 / 00 \\
39 \\
\end{array}$} \\
\hline & F\% & $\mathrm{N} \%$ & M\% & F\% & N\% & M\% & F\% & N\% & M\% & $\mathrm{F} \%$ & N\% & M\% & F\% & N\% & M\% & $\mathrm{F} \%$ & N\% & M\% \\
\hline Peces & 100,00 & 90,45 & 97,45 & 100,00 & 96,80 & 95,35 & 100,00 & 93,20 & 94,16 & 100,00 & 92,50 & 83,62 & 100,00 & 93,20 & 88,16 & 100,00 & 91,30 & 92,05 \\
\hline Octópodos & 17,00 & 2,86 & 1,90 & 62,50 & 1,60 & 3,6 & 67,30 & 3,00 & 4,75 & 53,70 & 5,60 & 16,17 & 54,60 & 5,00 & 11,24 & 48,70 & 6,80 & 7,86 \\
\hline $\begin{array}{l}\text { Decápodos } \\
\text { Anfípodos } \\
\text { gamarídeos }\end{array}$ & $\begin{array}{l}17,00 \\
7,00\end{array}$ & $\begin{array}{l}3,55 \\
3,45\end{array}$ & $\begin{array}{l}0,66 \\
0,00\end{array}$ & & & & & & & & & & & & & & & \\
\hline Bivalvos & & & & 70,80 & 0,60 & 0,06 & 44,30 & 2,40 & 0,54 & 13,00 & 0,80 & 0,09 & 13,00 & 0,50 & 0,06 & 5,10 & 0,40 & 0,02 \\
\hline Lapas & & & & 8,30 & 0,10 & 0,17 & 2,10 & 0,00 & 0,03 & & & & & & & & & 0,02 \\
\hline Caracoles & & & & 70,80 & 0,10 & 0,47 & 29,70 & 0,50 & 0,18 & 1,90 & 0,10 & 0,00 & 6,50 & 0,20 & 0,03 & 15,40 & 1,10 & 0,00 \\
\hline Calamares & & & & & & & 0,40 & 0,00 & 0,14 & & & & 1,30 & 0,00 & 0,36 & & & \\
\hline Poliquetos & & & & 25,00 & 0,20 & 0,17 & 18,60 & 0,30 & 0,08 & 18,50 & 0,80 & 0,07 & 5,20 & 0,20 & 0,02 & & & \\
\hline Braquiópodos & & & & & & & 4,00 & 0,50 & 0,10 & 3,70 & 0,30 & 0,04 & 7,80 & 0,90 & 0,11 & 5,10 & 0,40 & 0,02 \\
\hline Crustáceos & & & & & & & 2,20 & 0,00 & & & & & 2,60 & 0,10 & & 2,60 & 0,10 & \\
\hline Algas & & & & 100,00 & & & 70,80 & & & 29,60 & & & 33,80 & & & 61,50 & & \\
\hline Referencias & 1 & & & 2 & & & & & & & & & & & & & & \\
\hline
\end{tabular}

1 Casaux et al. (1997a)

2 Casaux y Ramón (2002)

Tabla II.19: Composición general de la dieta del Cormorán de Georgias durante la temporada reproductiva 1994/95 en las IOS. F\%: frecuencia de ocurrencia porcentual, N: importancia en número porcentual, M\%: importancia en masa porcentual. Tomado de Casaux et al. (1997a).

\begin{tabular}{|c|c|c|c|c|c|c|c|c|c|}
\hline \multirow[t]{2}{*}{$\begin{array}{l}1994 / 95 \\
N\end{array}$} & \multicolumn{3}{|c|}{$\begin{array}{c}1^{\circ} \text { período } \\
9\end{array}$} & \multicolumn{3}{|c|}{$\begin{array}{c}2^{\circ} \text { período } \\
10\end{array}$} & \multicolumn{3}{|c|}{$\begin{array}{c}3^{\circ} \text { período } \\
10\end{array}$} \\
\hline & F\% & N\% & M\% & F\% & N\% & M\% & F\% & $\mathrm{N} \%$ & M\% \\
\hline $\begin{array}{l}\text { Peces } \\
\text { Moluscos }\end{array}$ & 100,00 & 87,00 & 94,00 & 100,00 & 87,00 & 98,00 & 100,00 & 97,00 & 100,00 \\
\hline $\begin{array}{l}\text { Octópodos } \\
\text { Crustáceos }\end{array}$ & 44,00 & 7,00 & 5,00 & 10,00 & 2,00 & 1,00 & & & \\
\hline Decápodos & 44,00 & 7,00 & 1,00 & 10,00 & 4,00 & 1,00 & & & \\
\hline Gamáridos & & & & 10,00 & 7,00 & 0,00 & 10,00 & 3,00 & 0,00 \\
\hline
\end{tabular}




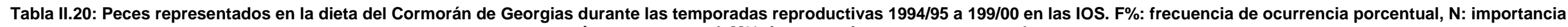
en número porcentual, M\%: importancia en masa porcentual.

\begin{tabular}{|c|c|c|c|c|c|c|c|c|c|c|c|c|c|c|c|c|c|c|}
\hline \multirow[t]{2}{*}{$\begin{array}{l}\text { Temporada } \\
\text { N }\end{array}$} & \multicolumn{3}{|c|}{$\begin{array}{c}1994 / 95 \\
29\end{array}$} & \multicolumn{3}{|c|}{$\begin{array}{c}1995 / 96 \\
24\end{array}$} & \multicolumn{3}{|c|}{$\begin{array}{c}1996 / 97 \\
226\end{array}$} & \multicolumn{3}{|c|}{$\begin{array}{c}1997 / 98 \\
54\end{array}$} & \multicolumn{3}{|c|}{$\begin{array}{c}1998 / 99 \\
77\end{array}$} & \multicolumn{3}{|c|}{$\begin{array}{c}1999 / 00 \\
39\end{array}$} \\
\hline & $\mathbf{F} \%$ & N\% & $\mathrm{M} \%$ & F\% & N\% & $\mathbf{M} \%$ & $\mathrm{~F} \%$ & N\% & M\% & F\% & N\% & M\% & $\mathrm{F} \%$ & N\% & M\% & $\mathrm{F} \%$ & N\% & M\% \\
\hline \multicolumn{19}{|l|}{ Nototheniidae } \\
\hline Gobionotothen gibberifrons & 3 & 2 & 1 & 70,8 & 1,8 & 7,9 & 61,5 & 3,8 & 7,9 & 66,7 & 10,6 & 33,9 & 67,5 & 11,8 & 13,6 & 61,5 & 14,1 & 38,3 \\
\hline Lepidonotothen nybelini & & & & 29,2 & 0,9 & 3,7 & 25,7 & 1,4 & 1,7 & 26 & 3,1 & 3,2 & 32,5 & 2,5 & 3,2 & 12,8 & 1 & 0,1 \\
\hline Lepidonotothen nudifrons & 28 & 34 & 11 & 75 & 4,2 & 16 & 85,4 & 9,4 & 13,8 & 70,4 & 15,6 & 15 & 75,3 & 16,1 & 15,1 & 59 & 17,4 & 6,9 \\
\hline Lepidonotothen squamifrons & & & & & & & 0,4 & 0 & 0,2 & & & & & & & & & \\
\hline Notothenia coriiceps & 41 & 10 & 66 & 37,5 & 0,9 & 19,1 & 49,1 & 1,8 & 28 & 48,1 & 2,6 & 20,1 & 50,7 & 2,5 & 32,4 & 59 & 7,9 & 38 \\
\hline Notothenia rossii & & & & & & & 2,2 & 0 & 0,6 & 5,6 & 0,2 & 2,4 & & & & 5,1 & 0,3 & 3 \\
\hline Trematomus bernacchii & & & & 4,2 & 0 & 0,1 & 3,1 & 0,1 & 0,3 & 9,3 & 0,4 & 0,7 & 20,8 & 0,8 & 2,2 & 25,6 & 2,2 & 2,4 \\
\hline Trematomus eulepidotus & & & & 4,2 & 0 & 0,4 & & & & & & & & & & & & \\
\hline Trematomus newnesi & 41 & 37 & 17 & 79,2 & 4,6 & 15,7 & 70,8 & 4,7 & 10,1 & 46,3 & 4,4 & 8,2 & 44,2 & 2,8 & 5,8 & 23,1 & 2,5 & 1,5 \\
\hline Trematomus scotti & & & & & & & & & & 1,9 & 0,1 & 0,6 & & & & & & \\
\hline Pleuragramma antarcticum & 3 & 0 & 0 & & & & & & & & & & & & & & & \\
\hline \multicolumn{19}{|l|}{ Harpagiferidae } \\
\hline Harpafiger antarcticus & 17 & 13 & 4 & 87,5 & 16,8 & 36,8 & 79,2 & 24,7 & 36,8 & 63 & 18 & 14,7 & 83,1 & 31,9 & 26,7 & 69,2 & 30,2 & 9,2 \\
\hline \multicolumn{19}{|l|}{ Channichthyidae } \\
\hline Chaenodraco wilsoni & & & & & & & & & & 1,9 & 0,1 & 0,3 & & & & & & \\
\hline Chaenodraco rastrospinosus & & & & & & & 0,4 & 0 & 0 & & & & & & & & & \\
\hline Champsocephalus gunnari & & & & 4,2 & 0 & 0,3 & & & & & & & & & & & & \\
\hline \multicolumn{19}{|l|}{ Bathydraconidae } \\
\hline Parachaenichthys charcoti & 3 & 2 & 1 & & & & 1,3 & 0 & 0,3 & 1,9 & 0,1 & 0,6 & 6,1 & 0,2 & 2,2 & & & \\
\hline \multicolumn{19}{|l|}{ Artedidraconidae } \\
\hline Pogonophryne scotti & & & & & & & & & & 1,9 & 0,1 & 0,1 & & & & & & \\
\hline \multicolumn{19}{|l|}{ Myctophidae } \\
\hline Protomyctophum normani & & & & & & & 0,4 & 0 & 0 & & & & & & & & & \\
\hline No identificados & & & & 100 & 70,9 & & 93,4 & 54 & & 90,7 & 44,8 & & 87,8 & 37,7 & & 71,8 & 24,4 & \\
\hline Referencias & 1 & & & 2 & & & & & & & & & & & & & & \\
\hline
\end{tabular}

1 Casaux et al. (1997a)

2 Casaux y Ramón (2002) 
Tabla II.21: Peces representados en la dieta del Cormorán de Georgias durante la temporada reproductiva 1994/95 en las IOS. F\%: frecuencia de ocurrencia porcentual, N: importancia en número porcentual, M\%: importancia en masa porcentual, tomado de Casaux et al. (1997a).

\begin{tabular}{|c|c|c|c|c|c|c|c|c|c|}
\hline \multirow[t]{2}{*}{$\begin{array}{l}1994 / 95 \\
N \\
\end{array}$} & \multicolumn{3}{|c|}{$\begin{array}{l}1^{\circ} \\
\text { período } \\
\quad 9 \\
\end{array}$} & \multicolumn{3}{|c|}{$\begin{array}{l}2^{\circ} \\
\text { período } \\
10 \\
\end{array}$} & \multicolumn{3}{|c|}{$\begin{array}{l}3^{\circ} \\
\text { período } \\
10 \\
\end{array}$} \\
\hline & $\mathrm{F} \%$ & N\% & $\mathrm{M} \%$ & $\mathrm{~F} \%$ & N\% & M\% & $\mathrm{F} \%$ & N\% & M\% \\
\hline \multicolumn{10}{|l|}{ Nototheniidae } \\
\hline Gobionotothen gibberifrons & & & & & & & 10 & 6 & 7 \\
\hline Lepidonotothen nudifrons & 11 & 2 & 1 & 30 & 54 & 9 & 40 & 47 & 34 \\
\hline Notothenia coriiceps & 44 & 11 & 62 & 70 & 23 & 85 & 10 & 1 & 22 \\
\hline Trematomus newnesi & 67 & 54 & 29 & 10 & 21 & 5 & 50 & 33 & 28 \\
\hline \multicolumn{10}{|l|}{ Trematomus scotti } \\
\hline \multicolumn{10}{|l|}{ Harpagiferidae } \\
\hline Harpafiger antarcticus & 33 & 22 & 6 & 10 & 3 & 0 & 10 & 13 & 9 \\
\hline \multicolumn{10}{|l|}{ Bathydraconidae } \\
\hline Parachaenichthys charcoti & 11 & 11 & 3 & & & & & & \\
\hline
\end{tabular}

Tabla II.22: Tallas medias, desvío estándar (DE) y rangos (Largo total de los ejemplares en cm. \pm desvío estándar) de los peces representados en la dieta del Cormorán de Georgias durante las temporadas reproductivas $1995 / 96$ a $1999 / 00$ en las IOS. Tomado de Casaux y Ramón (2002).

\begin{tabular}{|c|c|c|c|c|c|c|c|c|c|c|c|c|}
\hline Temporada & $\begin{array}{c}1996 / 97 \\
\text { Media } \\
\end{array}$ & $\mathrm{DE}$ & Rango & $\begin{array}{c}\text { 1997/98 } \\
\text { Media }\end{array}$ & DE & Rango & $\begin{array}{c}\text { 1998/99 } \\
\text { Media }\end{array}$ & DE & Rango & $\begin{array}{c}\text { 1999/00 } \\
\text { Media }\end{array}$ & DE & Rango \\
\hline \multicolumn{13}{|l|}{ Nototheniidae } \\
\hline G. gibberifrons & 8,7 & 3,7 & $0,3-30,8$ & 11,5 & 5,5 & $4,8-30,2$ & 10,4 & 2,7 & $4,7-18,3$ & 14,4 & 8,1 & $3,3-35,8$ \\
\hline L. larseni & 7,7 & 1,8 & $4-19,2$ & 8,9 & 1,6 & $6,9-17,5$ & 10,1 & 0,9 & $7,5-11,3$ & 9,9 & 1,2 & $7,4-10,8$ \\
\hline L. nudifrons & 7,8 & 2 & $3,9-14,5$ & 8,2 & 1,7 & $5,1-12,9$ & 8,4 & 1,5 & $4,4-13,2$ & 8,6 & 1,5 & $5,5-12,5$ \\
\hline L. squamifrons & 22,1 & & & & & & & & & & & \\
\hline N. coriiceps & 13,8 & 5,8 & $0,2-26,5$ & 13,2 & 4,2 & $5,4-22,1$ & 15,8 & 5 & $5,7-25,9$ & 16,6 & 5,6 & $2,4-29,9$ \\
\hline N. rossi & 18,7 & 2,4 & $16,1-21$ & 19 & 5,1 & $13,3-23,1$ & & & & 23,7 & 6,1 & $19,4-28,0$ \\
\hline $\begin{array}{l}\text { T. bernacchii } \\
\text { T. eulepidotus }\end{array}$ & 10,5 & 3,2 & $7,8-21,9$ & 11,4 & 2,5 & $8,7-15,9$ & 13,8 & 1 & $12,1-15,8$ & 13,1 & 3 & $8,2-18,6$ \\
\hline T. newnesi & 7,1 & 1 & $4,8-12$ & 8,5 & 0,9 & $6,7-11,9$ & 8,7 & 1,2 & $6,2-10,6$ & 8 & 1,3 & $6,1-10,6$ \\
\hline T. scotti & & & & 13,1 & 0 & $13,1-13,1$ & & & & & & \\
\hline
\end{tabular}


Tabla Il.22: Continuación.

\begin{tabular}{|c|c|c|c|c|c|c|c|c|c|c|c|c|}
\hline $\begin{array}{l}\text { Harpagiferidae } \\
\text { H. antarticus }\end{array}$ & 6,5 & 0,6 & $4,2-10,1$ & 6,9 & 0,6 & $5,3-8,6$ & 6,9 & 0,5 & $5,8-8,8$ & 6,9 & 0,5 & $5,7-8,1$ \\
\hline Channichthyidae & & & & & & & & & & & & \\
\hline C. wilsoni & & & & 16,3 & & & & & & & & \\
\hline C. gunnari & & & & & & & & & & & & \\
\hline C. rastrispinosus & 12,7 & & & & & & & & & & & \\
\hline Batrydraconidae & & & & & & & & & & & & \\
\hline P. charcoti & 18,3 & 3,2 & $14,9-23,1$ & 18,8 & & & 25,7 & 2,7 & $23,8-27,6$ & & & \\
\hline Artedidraconidae & & & & & & & & & & & & \\
\hline P. scotti & & & & 11,6 & & & & & & & & \\
\hline Myctophidae & & & & & & & & & & & & \\
\hline P. normani & 5,4 & 0,1 & $5,3-5,5$ & & & & & & & & & \\
\hline
\end{tabular}

Tabla II.23: Cambios en las tallas medias y rangos (Largo total de los ejemplares en cm. \pm desvío estándar) de los peces representados en la dieta del Cormorán de Georgias a lo largo de la temporada reproductiva 1994/95 en las IOS. Tomado de Casaux et al. (1997a).

\begin{tabular}{|c|c|c|c|c|c|c|c|c|c|}
\hline \multirow{2}{*}{$1994 / 95$} & \multicolumn{3}{|c|}{ Cría temprana media } & \multicolumn{3}{|l|}{ Cría tardía } & \multicolumn{3}{|l|}{ Emancipación } \\
\hline & Talla media & DE & Rango & Talla media & DE & Rango & Talla media & DE & Rango \\
\hline \multicolumn{10}{|l|}{ Nototheniidae } \\
\hline Gobionotothen gibberifrons & & & & & & & 10,5 & 1,0 & $9,8-12,0$ \\
\hline Lepidonotothen nudifrons & 9,7 & & 9,7 & 9,0 & 0,6 & $8,7-11,5$ & 8,5 & 0,8 & $6,5-10,2$ \\
\hline Notothenia coriiceps & 20,7 & 4,0 & $15,0-25,0$ & 24,4 & 3,5 & $15,0-29,0$ & 22,0 & & 22,0 \\
\hline Trematomus newnesi & 9,6 & 2,7 & $4,0-14,0$ & 9,2 & & & 8,8 & 2,3 & $7,0-15,0$ \\
\hline Harpagiferidae & & & & & & & & & \\
\hline Harpafiger antarcticus & 8,0 & 0,8 & $6,0-9,0$ & 7,5 & & 7,5 & 8,0 & 0,4 & $7,2-8,7$ \\
\hline Bathydraconidae & & & & & & & & & \\
\hline Parachaenichthys charcoti & 9,6 & 4,2 & $6,0-20,6$ & & & & & & \\
\hline
\end{tabular}




\section{Laridae}

\section{Gaviota Cocinera Larus dominicanus}

La gaviota Cocinera está ampliamente distribuida en Sudamérica, Sudáfrica, Nueva Zelanda, Subantártida y Antártida (Burger y Gochfeld 1996). Usualmente las colonias reproductivas se encuentran asociadas a colonias de otras aves marinas (tales como pingüinos) y pinnípedos (Boswall y Prytherch 1972, Boswall 1973, Burger 1981, del Hoyo et al. 1996).

De acuerdo a Silva (1996), la dieta de la gaviota Cocinera en las IOS se compone principalmente de pingüinos y lapas, seguidos por anfípodos gamarídeos y gastrópodos (tróquidos). En cuanto a los peces, Silva (2006) reporta que estos estuvieron poco representados en la dieta, lo que contrasta con lo reportado por Maxson y Bernstein (1984) y Fraser (1989) para la PA. Si bien los otolitos no fueron determinados a nivel específico, Silva (1996) indicó que los peces representados en las muestras de las IOS pertenecerían a las familias Nototheniidae y Myctophidae.

\section{Stercorariidae}

\section{Escúa marrón Catharacta antarctica y escúa Polar Catharacta maccormicki}

Tanto el escúa Polar como el escúa Marrón tienen una amplia distribución en Antártida y presentan una marcada diversidad en la composición de la dieta (Furness y Monaghan 1987). Los únicos estudios sobre la composición de la dieta de estas especies en las IOS fueron desarrollados por Burton (1968) y Hemmings (1984) en Isla Signy y por Montalti (2005) en Isla Laurie.

\section{Escúa Marrón}

Según Burton (1968), la dieta del escúa Marrón varió ampliamente a lo largo de las temporadas consideradas (entre 1958 y 1965), lo que estuvo asociado a la diversidad de estrategias alimentarias desplegadas por los individuos tales como kleptoparasitismo a la gaviota Cocinera, el petrel Gigante y el cormorán de Georgias, carroñeo, la predación directa sobre huevos, pichones y adultos de pingüinos y aves voladoras, y a la predación de presas pelágicas tales como crustáceos y peces. En términos generales, las presas más frecuentes fueron huevos y pichones de pingüinos, en tanto que los peces y crustáceos pelágicos fueron más abundantes principalmente durante los períodos reproductivos. Con respecto a los peces, Burton (1968) indicó que no observó la captura directa de esta presa. Hemmings (1984) indicó que durante las temporadas reproductivas de 1981/82 y 1982/83 el escúa Marrón se alimentó principalmente de pingüinos y ocasionalmente de pequeños petreles. En un estudio más reciente Montalti (2005) observó que la composición de la dieta del escúa Marrón en I. Laurie estuvo dominada por pingüinos y peces en menor medida (Tabla II.24). Sólo 2 especies de peces fueron identificadas y entre ellas $L$. nudifrons fue la más importante en términos de biomasa (Tabla II.25). La talla de los peces identificados fluctuó entre 6,3 y $11,5 \mathrm{~cm}$. 
Tabla II.24: Composición general de la dieta del escúa Marrón durante la temporada reproductiva 1997/98 en las IOS. F\%: frecuencia de ocurrencia porcentual. Tomado de Montalti (2005)

\begin{tabular}{|c|c|}
\hline $\begin{array}{l}\text { Temporada } \\
\mathbf{N}\end{array}$ & $\begin{array}{c}1997 / 98 \\
52 \\
F \%\end{array}$ \\
\hline $\begin{array}{l}\text { Mamíferos marinos } \\
\text { Aves }\end{array}$ & 1,90 \\
\hline Pingüino & 100 \\
\hline Petrel de Wilson & 1,90 \\
\hline Peces & 15,40 \\
\hline Moluscos & \\
\hline Cefalópodos & 3,80 \\
\hline Piedras & 5,80 \\
\hline
\end{tabular}

Tabla II.25: Peces representados en la dieta del escúa Marrón durante la temporada reproductiva $1997 / 98$ en las IOS. F\%: frecuencia de ocurrencia porcentual, $\mathrm{N}$ : importancia en número porcentual, $\mathrm{M} \%$ : importancia en masa porcentual y Talla (Largo total de los ejemplares en cm. \pm desvío estándar y rango entre paréntesis). Tomado de Montalti (2005).

\begin{tabular}{|c|c|c|c|c|c|}
\hline $1997 / 98$ & F\% & N\% & M\% & Talla media & Rango \\
\hline \multicolumn{6}{|l|}{ Nototheniidae } \\
\hline Lepidonotothen nudifrons & 50 & 83,40 & 93,80 & $8,3 \pm 2$ & $6,3-11,5$ \\
\hline Gobionotothen gibberifrons & 25 & 8,30 & 6,20 & 8,81 & 8,81 \\
\hline No identificados & 25 & 8,30 & & & \\
\hline
\end{tabular}

\section{Escúa Polar}

En contraste con lo informado sobre la dieta del escúa Marrón, los peces fueron la presa más importante en la dieta del escúa Polar en I. Signy, seguidos por el krill y restos de aves voladoras (principalmente petrel de Wilson, Oceanites oceanicus), en tanto que los restos de pingüinos ocurrieron sólo ocasionalmente (Hemmings 1984). En relación a la presencia de krill en las muestras, Hemmings (1984) sugiere que estos restos podrían provenir de los estómagos de los peces ingeridos. La única especie de pez identificada en las muestras fue $P$. antarcticum, la que ocurrió en 25 de las 18 muestras analizadas.

\section{II.3.1.2. Mamíferos}

\section{Phocidae}

\section{Elefante Marino del Sur Mirounga leonina}

En Antártida el elefante Marino del Sur se distribuye de manera circumpolar y las áreas reproductivas más importantes se ubican en las islas Georgias del Sur, Kerguelen, Heard y Macquarie (McCann 1985, Green y Burton 1993, Laws 1994).

Sólo se desarrolló un estudio sobre la composición de la dieta del elefante Marino en las IOS. El análisis de los contenidos estomacales de once ejemplares sacrificados en I. Signy entre Noviembre de 1962 y Mayo de 1963 indicó que las únicas presas fueron cefalópodos (principalmente Gonatus antarcticus) (Clarke y McLeod 1982b). 


\section{Foca de Weddell Leptonychotes weddellii}

La foca de Weddell presenta una distribución circumpolar y en general se la encuentra asociada a las costas y a bandejones de hielo cercanos a las mismas. La temporada reproductiva de esta foca se extiende desde Septiembre hasta mediados de Noviembre y el área de reproducción abarca la banquisa de hielo continental y las costas de la PA, las ISS y las IOS, en donde centenares de individuos pueden llegar a conformar los asentamientos reproductivos (Fischer y Hureau 1988). La única información acerca de la dieta de la foca de Weddell en las IOS proviene de un estudio realizado por Casaux et al. (2009) en I. Laurie durante las temporadas 1999/00 y 2001/02. Estos autores reportaron una amplia variación en la composición de la dieta entre las dos temporadas consideradas. Los octópodos, seguidos de peces y pingüinos, fueron la presa más importante en 1999/00, en tanto que en 2001/02 el krill, seguido por pingüinos y cefalópodos, fue la presa que más contribuyó a la composición de la dieta (Tabla II.26).

Tabla Il.26: Composición general de la dieta de la Foca de Weddell durante las temporadas reproductivas 1999/00 y 2001/02 en las IOS. F\%: frecuencia de ocurrencia porcentual, N\%: importancia en número porcentual, M\%: importancia en masa porcentual. Tomado de Casaux et al. (2009).

\begin{tabular}{|c|c|c|c|c|c|c|}
\hline \multirow[t]{2}{*}{$\begin{array}{l}\text { Temporada } \\
\mathrm{N}\end{array}$} & \multicolumn{3}{|c|}{$\begin{array}{c}1999 / 00 \\
44\end{array}$} & \multicolumn{3}{|c|}{$\begin{array}{c}2001 / 02 \\
26\end{array}$} \\
\hline & $\mathrm{F} \%$ & N\% & M\% & $\mathrm{F} \%$ & N\% & M\% \\
\hline \multicolumn{7}{|l|}{ Crustáceos } \\
\hline Krill & 9,10 & 5,90 & 0,20 & 61,90 & 99,00 & 63,80 \\
\hline $\begin{array}{l}\text { Anfípodos gamarídeos } \\
\text { Isópodos }\end{array}$ & - & - & - & 4,80 & 0,00 & 0,00 \\
\hline $\begin{array}{l}\text { Glyptonotus antarcticus } \\
\text { Moluscos } \\
\text { Cefalópodos } \\
\text { Octópodos }\end{array}$ & 3,00 & 0,30 & 0,10 & - & - & - \\
\hline $\begin{array}{l}\text { Pareledone sp. } \\
\text { Teutónidos }\end{array}$ & 66,70 & 15,30 & 46,60 & 61,90 & 0,10 & 8,80 \\
\hline $\begin{array}{l}\text { Psychroteutis glacialis } \\
\text { Gastrópodos }\end{array}$ & 0,00 & 0,00 & 0,00 & 9,50 & 0,00 & 6,80 \\
\hline Nacella concinna & 3,00 & 0,60 & 0,10 & - & - & - \\
\hline Otros & 3,00 & 2,40 & 0,10 & - & - & - \\
\hline Bivalvos & - & - & - & 38,10 & 0,10 & 0,10 \\
\hline Peces & 90,90 & 75,20 & 30,20 & 85,70 & 0,90 & 4,20 \\
\hline Pingüinos & 3,00 & 0,30 & 22,90 & 9,50 & 0,00 & 16,40 \\
\hline
\end{tabular}

Las especies de peces representadas en las muestras pertenecieron a las familias

Nototheniidae y Channichthyidae (Casaux et al. 2009). Gobionotothen gibberifrons fue el pez que más contribuyó a la composición de la dieta en ambas temporadas (Tabla II.25). Esta especie fue seguida en importancia por los Channíchthyidos C. aceratus y Chionodraco rastrospinosus en $1999 / 00$ y por los Notothéniidos N. nybelini y L. nudifrons en 2001/02. En general, el rango de tallas de los peces consumidos en ambas temporadas varió entre 6,4 y 48,5 cm., y las diferencias entre ambas temporadas fueron significativas tanto entre las tallas de los peces en su conjunto (MannWithney U-test $p<0,05)$ como entre los ejemplares de G. gibberifrons $(p<0,05)$ (Casaux et al. 2009). 


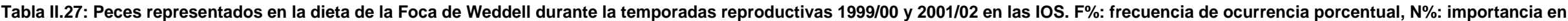
número porcentual, M\%: importancia en masa porcentual y tallas (Largo total de los ejemplares en cm. \pm desvío estándar y rango entre paréntesis). Tomado de Casaux et al. (2009).

\begin{tabular}{|c|c|c|c|c|c|c|c|c|c|c|}
\hline Temporada & $\begin{array}{c}1999 / 00 \\
\text { F\% } \\
\end{array}$ & $\mathrm{N} \%$ & M\% & Talla & Rango & $\begin{array}{c}2001 / 02 \\
\text { F\% }\end{array}$ & $\mathrm{N} \%$ & M\% & Talla & Rango \\
\hline \multicolumn{11}{|l|}{ Channichthyidae } \\
\hline Chaenocephalus aceratus & 3,03 & 3,57 & 29,12 & 48,50 & & & & & & \\
\hline Chionodraco rastrospinosus & 3,03 & 3,57 & 5,82 & 23,40 & & & & & & \\
\hline \multicolumn{11}{|l|}{ Nototheniidae } \\
\hline Gobionotothen gibberifrons & 21,21 & 71,43 & 61,86 & $16,62 \pm 6,65$ & $(7,42-35,04)$ & 19,04 & 51,06 & 90,34 & $14,88 \pm 4,97$ & $(6,42-27,16)$ \\
\hline Nototheniops nybelini & 3,03 & 3,57 & 0,96 & 13,95 & & 4,76 & 6,38 & 6,93 & $12,96 \pm 2,25$ & $(11,54-15,56)$ \\
\hline Lepidonotothen nudifrons & 6,06 & 7,14 & 1,19 & $11,09 \pm 1,15$ & $(10,28-11,91)$ & 14,28 & 6,38 & 3,26 & $9,74 \pm 0,85$ & $(8,78-10,44)$ \\
\hline Trematomus newnesi & 3,03 & 3,57 & 1,06 & 11,69 & & & & & & \\
\hline No identificados & 3,03 & 7,14 & & & & 19,04 & 36,17 & & & \\
\hline
\end{tabular}




\section{Foca Cangrejera Lobodon carcinophagus}

La distribución de la foca Cangrejera en Antártida está fuertemente ligada a las fluctuaciones estacionales de la cubierta de hielo marino dado que reproduce sobre los bandejones o sobre el pack de hielo marino. La temporada reproductiva se extiende desde fines de Septiembre a Marzo. La única información disponible relacionada con la composición de la dieta de esta especie en las IOS proviene del análisis de 5 feces recolectadas en las costas de I. Laurie en Diciembre de 2001 (Casaux y Carlini, datos sin publicar). El análisis de estas muestras indica que el krill fue la presa principal y que el aporte en biomasa del resto de las presas fue muy bajo (Tabla II.27).

Tabla Il.28: Composición general de la dieta de la Foca Cangrejera durante Diciembre de 2001 en las IOS. F\%: frecuencia de ocurrencia porcentual, N\%: importancia en número porcentual, M\%: importancia en masa porcentual.

\begin{tabular}{|l|ccc|}
\hline $\begin{array}{l}\text { Temporada } \\
\mathbf{N}\end{array}$ & \multicolumn{3}{|c|}{$\mathbf{2 0 0 1 / 0 2}$} \\
$\mathbf{5}$ & $\mathbf{M} \%$ \\
\hline $\begin{array}{l}\text { Crustáceos } \\
\text { Krill }\end{array}$ & $\mathbf{F} \%$ & $\mathbf{M}$ \\
Moluscos & 100,00 & 100,00 & 100,00 \\
Bivalvos & & & \\
Peces & 40,00 & 0,00 & 0,00 \\
Algas & 20,00 & 0,00 & 0,00 \\
\hline
\end{tabular}

\section{Othariidae}

\section{Lobo Fino Antártico Arctocephalus gazella}

El Lobo Fino Antártico presenta una distribución circumpolar (Fischer y Hureau 1988, Whitehouse y Veit 1994) y las áreas de reproducción se encuentran al norte de los $65^{\circ} \mathrm{S}$ (Fischer y Hureau 1988). Si bien las IOS están ubicadas dentro de estos límites, no es un área de reproducción frecuente y los individuos que la habitan durante el verano austral son casi exclusivamente machos juveniles y adultos no reproductores (Laws 1981, Carlini et al. 2006). Durante fines del siglo XVIII esta especie fue intensamente explotada (Payne 1977) hasta el punto de casi desaparecer. Luego de prohibirse la caza en el año 1930, la población comenzó a recuperarse, encontrándose actualmente en vías de crecimiento (Laws 1973, Bonner 1981, Carlini et al. 2006). Son pocos los trabajos publicados sobre la dieta del Lobo Fino Antártico en las IOS (Daneri y Coria 1992,1994; Daneri et al. 1999; Casaux et al. 2003b, Libertelli et al. 2004). En este estudio se presentan datos provenientes de muestras de feces $(\mathrm{N}=1104)$ recolectadas durante los veranos australes 1994 a 2003 en la I. Laurie (IOS) (Casaux et al. 2007). El análisis de estas muestras indicó que la composición de la dieta fue variada y que cambió a lo largo del período de estudio (tabla II.34, figura II.4). Dependiendo de la temporada, el krill, los pingüinos y los peces fueron las presas que más contribuyeron a la composición de la dieta. 


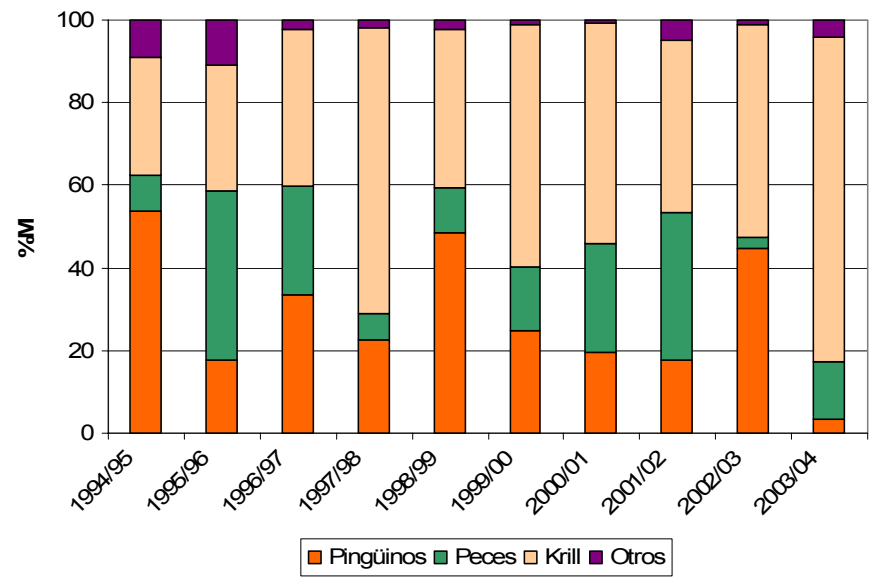

Figura II.4: Contribución en términos de biomasa (importancia en masa porcentual) de las presas representadas en la dieta del Lobo Fino Antártico durante las temporadas reproductivas 1994/95 - 2003-04 en la I. Laurie, IOS.

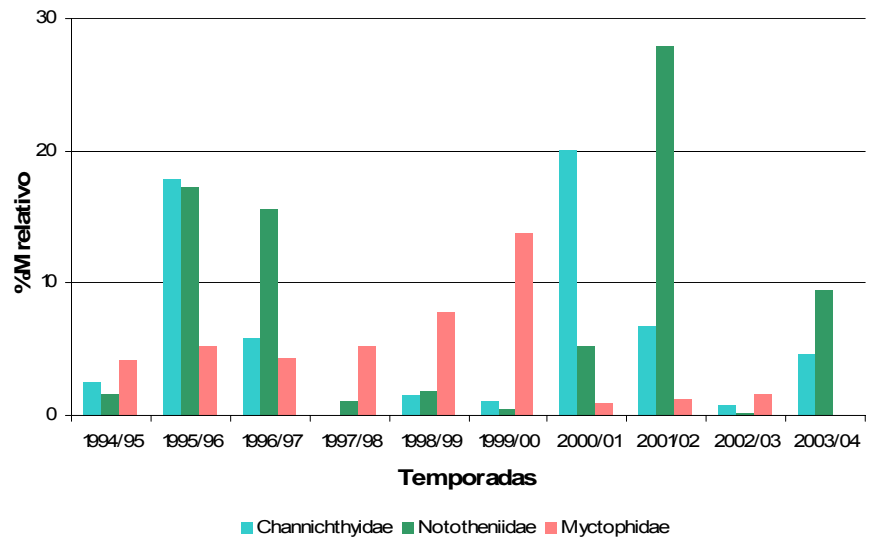

Figura II.5: Contribución en términos de biomasa (importancia en masa porcentual) de los peces representados en la dieta del Lobo Fino Antártico durante las temporadas reproductivas 1994/95 a 2003/04 en la I. Laurie, IOS. 
Los peces identificados en la dieta pertenecieron a las familias Channichthyidae, Myctophidae, Nototheniidae, Paralepididae, Bathydraconidae y Harpagiferidae (Tabla II.35) y dentro de ellas, las tres primeras fueron las más importantes en términos de biomasa (Figura II.5). El myctóphido G. nicholsi fue el pez que más aportó a la dieta en la mayoría de las temporadas, en tanto que en 1995/96 y 2001/02 lo hizo el notothéniido G. gibberifrons y en 2000/01 el channíchthyido $C$. aceratus. En términos generales, en los años en que el krill fue un componente importante de la dieta (e.g. las temporadas 1997/98 y 1999/00), los Myctóphidos fueron los peces más consumidos (Figuras II.6 y II.7). Por el contrario, en los años en que dicho crustáceo contribuyó poco a la composición de la dieta (e.g. las temporadas 1995/96 y 2001/02) los channíchthyidos y notothéniidos fueron los peces mejor representados. En relación a ello, la figura II.6 muestra una correlación positiva entre el M\% de krill y la cantidad relativa de peces myctóphidos.

Las tallas medias estimadas para los peces representados en las muestras variaron entre 1,4 y 45,4 cm. (Tabla II.36), siendo la media de 12,8 \pm 8,9 cm. Llamativamente, las temporadas en que se registró el mayor número de especies en las muestras (1994/95 y 1995/96) los rangos de tallas fueron mayores.

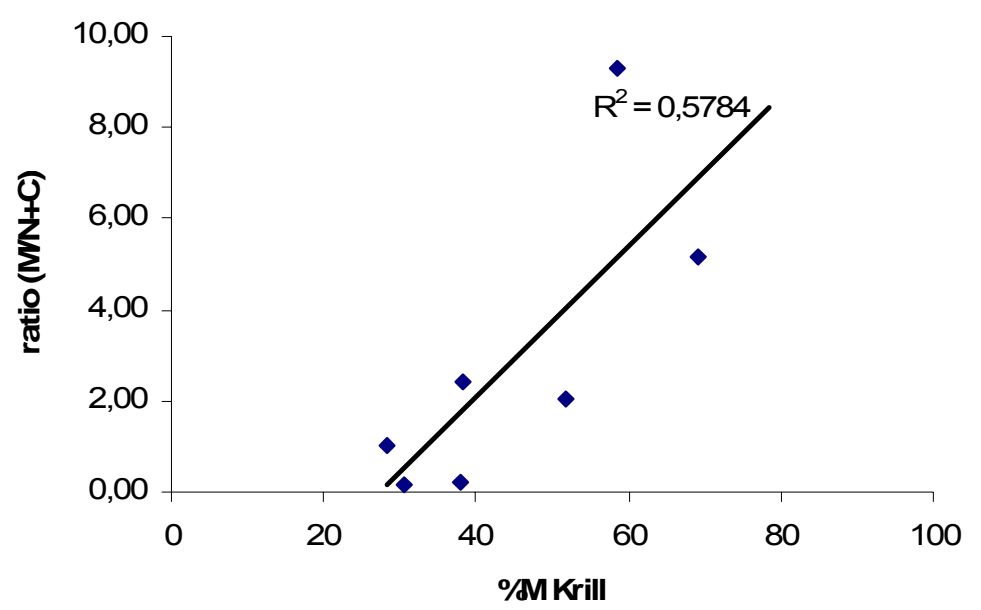

Figura II.6: Correlación entre el porcentaje en masa de krill y la biomasa relativa de myctóphidos obtenidas del análisis de la dieta del Lobo Fino Antártico. Ratio (M/N+C): \%M de myctóphidos/(\%M notothéniidos+\%M channíchthyidos). 


\section{II.3.2. Composición general de la dieta, Islas Shetland del Sur}

\section{II.3.2.1. Aves}

\section{Hydrobatidae}

\section{Petrel de las Tormentas de Vientre Negro Fregetta tropica}

El petrel de las Tormentas de Vientre Negro es una de las aves antárticas menos estudiadas. Se distribuye de manera circumpolar y mantiene hábitos pelágicos durante todo su ciclo de vida. La estación reproductiva comienza a principios de noviembre y termina a finales de febrero. Nidifica en sitios rocosos en las ISS, IGS, IOS, Antípodas y Bouvet como así también en algunas islas subantárticas al sur de Nueva Zelanda (Carboneras 1992). Sólo unos pocos trabajos sobre la biología reproductiva y alimentaria de esta especie han sido publicados (Ainley et al. 1984, Jouventin et al 1985, Obst 1986, Croxall y North 1988, Ridoux 1994, Hahn 1998) y ninguno de ellos fue desarrollado en las IOS. Sin embargo, hay información que podría considerarse como anecdótica relacionada con la identificación de los otolitos presentes en diez muestras recolectadas durante la temporada 1999/00 en I. Laurie (Casaux datos no publicados) (Tabla II.29). Es por ello que en este trabajo también se considerará información sobre la composición de la dieta de esta especie en las ISS.

De acuerdo a Hahn (1998), las presas más frecuentes en regurgitados y contenidos estomacales del petrel de las Tormentas de Vientre Negro recolectados en las ISS fueron peces y diferentes tipos de crustáceos (principalmente krill) (Tabla II.30). Este autor también indica que la composición de la dieta no varió a lo largo del ciclo reproductivo. Con respecto a los peces, Hahn (1998) reporta que la única especie identificada en las muestras fue el myctóphido $E$. antarctica, lo que coincide con el resultado de la identificación de los otolitos representados en las muestras de las IOS (ver arriba).

Tabla Il.29: Contribución en peso (M\%: importancia en masa porcentual) y talla (media y rango) de los peces representados en la dieta del Petrel de las Tormentas durante la temporada reproductiva 1999/00 en las IOS. Tomado de Casaux (datos no publicados).

\begin{tabular}{|l|ccc|}
\hline Temporada & $1999 / 00$ & & \\
Tipo de muestra & Contenido estomacal & & \\
$\mathbf{N}$ & $\mathbf{1 0}$ & & \\
& M\% & Talla media & Rango \\
\hline Myctophidae & & & \\
E. antarctica & 100,00 & $5,87 \pm 0,81$ & $4,45-7,53$ \\
\hline
\end{tabular}

Tabla Il.30: Composición general de la dieta del Petrel de las Tormentas durante la temporada reproductiva 1996/97 en las ISS. F\%: frecuencia de ocurrencia porcentual. Tomado de Hahn (1998).

\begin{tabular}{|l|cc|}
\hline Temporada & 1996 & \\
Tipo de muestra & Regurgitados & Cont. estomacal \\
N & 182 & 109 \\
& F\% & F\% \\
\hline Crustáceos & & \\
Eufáusidos & 21,70 & \\
\hline
\end{tabular}


Tabla Il.30: Continuación.

\begin{tabular}{|l|cc|}
\hline Anfípodos & 8,30 & \\
Otros & 20,00 & 31,80 \\
Moluscos & & \\
Cefalópodos & 1,70 & \\
Peces & 53,30 & 30,70 \\
No identificados & 8,30 & 46,60 \\
\hline
\end{tabular}

\section{Sternidae}

\section{Gaviotín Antártico Sterna vittata}

El Gaviotín Antártico se distribuye de manera circumpolar y se reproduce durante el verano austral (Carboneras 1992). A pesar de ser susceptible de ser afectada por diferentes tipos de disturbios ambientales (Howes y Montevecchi 1993, Gochfeld y Burger 1996, Silva et al. 1998, Milius 2000, Casaux et al. 2007), los estudios sobre la biología alimentaria de esta especie son escasos (Parmelee y Maxson 1975, Cordier et al. 1983, Peter et al. 1998, Jablonski 1995, Jardzewiski y Konopacka 1999, Casaux et al. 2007), y ninguno de ellos fue realizado en las IOS. Por tal razón, como referencia para el desarrollo de este trabajo se utilizará la información generada por Casaux et al. (2007) en I. Nelson, ISS, durante las temporadas 2002/03 y 2003/04.

Mediante observación de las presas llevadas al nido por reproductores Casaux et al. (2007) determinaron que los peces, seguidos por krill o anfípodos gamarídeos, fueron las presas que más contribuyeron a la dieta en términos de biomasa en ambas temporadas (Tabla II.31). Sólo dos especies de peces fueron identificadas y de ellas $N$. coriiceps fue la dominante en la dieta de ambas temporadas. Casaux et al. (2007) también informaron que el consumo de peces se incrementa a medida que los pichones crecen y que las tallas de los ejemplares consumidos promediaron 6,4 y 6,2 cm. para E. antarctica y N. coriiceps respectivamente (Tabla II.32).

Tabla II.31: Composición general de la dieta del Gaviotín Antártico durante las temporadas reproductivas 2002/03 y 2003/04 en las ISS. N\%: importancia en número porcentual, M\%: importancia en masa porcentual. Tomado de Casaux et al. (2007).

\begin{tabular}{|c|c|c|c|c|}
\hline $\begin{array}{l}\text { Temporada } \\
\mathbf{N}\end{array}$ & $\begin{array}{c}2002 / 03 \\
182 \\
N \%\end{array}$ & M\% & $\begin{array}{l}2003 / 04 \\
109 \\
\text { N\% }\end{array}$ & M\% \\
\hline Crustáceos & & & & \\
\hline Eufáusidos & 13,70 & 4,30 & 0,90 & 0,10 \\
\hline $\begin{array}{l}\text { Anfípodos gamarídeos } \\
\text { Peces }\end{array}$ & 41,80 & 3,10 & 10,10 & 2,30 \\
\hline Notothenia coriiceps & 26,40 & 67,50 & 78,90 & 93,70 \\
\hline Electrona antarctica & 5,50 & 25,10 & 1,80 & 3,90 \\
\hline No identificados & 5,00 & & 7,30 & \\
\hline
\end{tabular}


Tabla II.32: Tallas (largo total en cm. \pm desvío estándar y rango) de las presas_representadas en la dieta del Gaviotín Antártico durante las temporadas reproductivas 2002/03 y 2003/04 en las ISS. Tomado de Casaux et al. (2007).

\begin{tabular}{|l|cc|}
\hline & Talla & Rango \\
\hline $\begin{array}{l}\text { Peces } \\
\text { Myctophidae }\end{array}$ & & \\
$\quad$ Electrona antarctica & $6,40 \pm 0,20$ & $6,2-6,6$ \\
Nototheniidae & & \\
$\quad$ Notothenia coriiceps & $6,20 \pm 0,60$ & $5,7-7,2$ \\
$\begin{array}{l}\text { Anfípodos } \\
\text { Eurimera monticulosa }\end{array}$ & 1,90 & \\
\hline
\end{tabular}

\section{II.4. Discusión}

\section{II.4.1. Composición general de la dieta}

\section{II.4.1.1. Aves}

\section{Sphenicidae}

\section{Pingüino de Adelia Pygoscelis adeliae}

El pingüino de Adelia es considerado un predador especializado en el krill antártico Euphausia superba (Trivelpiece et al. 1983, Jablonski 1985, Lishman 1985, Green y Jhonstone 1988, van Heezik 1988, Ridoux y Offredo 1989, Coria et al. 1995, entre otros). En coincidencia con dichos trabajos, los estudios desarrollados en las IOS también indicaron que este pingüino consume casi exclusivamente krill, y las frecuencias de ocurrencia de este crustáceo en la dieta, como así también su contribución en número y biomasa, estuvieron cercanos al 100\% (Libertelli et al. 2003; Libertelli datos no publicados), Lynnes et al. 2004). El krill también fue la presa principal en diversos trabajos desarrollados en las ISS (Volkman et al. 1980, Jansen et al. 1998). Aún así en todos estos trabajos mencionados tanto los peces como los cefalópodos estuvieron representados en la dieta. De modo interesante, Lynnes (2004) observó que en la PA la contribución de peces a la dieta fue mayor que la observada en zonas insulares. Si bien este y otros trabajos realizados en las ISS (Jablonski 1985, Coria et al. 1995) reportaron que Pleuragramma antarcticum fue la especie más importante en la dieta del pingüino de Adelia (hasta el 74\% de la biomasa de los peces representados en la dieta), Cabe destacar que este pez no estuvo representado en ninguno de los estudios sobre dieta realizados en las IOS (Sladen 1958, White y Conroy 1975, Lishman 1984, Libertelli et al. 2003) y las especies que más aportaron a la dieta variaron según la localidad de muestreo y los períodos del año. Numerosos autores indican que el pingüino de Adelia tiende a consumir mayor cantidad de peces cuando la cubierta de hielo marino en el área de forrajeo se vuelve más fina (Watanuki et al. 1993, Ainley et al. 1998, Wienecke et al. 2000, Endo et al. 2002, Rombolá et al. 2003). Esta variable parece ser un factor ambiental que determina fuertemente las estrategias de alimentación a emplear por este pingüino e incluso determina también el grado de competencia interespecífica por el alimento con el pingüino de Barbijo (Fraser y Trivelpiece 1996, Rodary et al. 2000, Wilson et al. 2001). Este tema será desarrollado en profundidad en el Capítulo IV. 
Mediante el desarrollo de estudios paleontológicos Emslie et al. (2002) analizaron la evolución de la composición de la dieta del pingüino de Adelia. Según este trabajo, entre unos 100 y 38000 años atrás estos pingüinos se alimentaban principalmente de peces. Si esta hipótesis fuera correcta, el actual e intensivo consumo de krill estaría reflejando un cambio en la selección o en la disponibilidad de las presas. Según Ledford (2007) el cambio en la composición de la dieta podría ser consecuencia de la actividad pesquera desarrollada durante el siglo XIX. Tanto la industria foquera como la ballenera ${ }^{1}$, deprimieron de manera importante las poblaciones de focas y ballenas antárticas, las cuales se alimentaban casi exclusivamente de krill. Sumado a ello, la intensa captura de peces durante la década del ' 70 agotó los stocks de algunas poblaciones de peces consumidores de krill tales como Notothenia rossii (Barrera-Oro 2002). Así entonces, la alta acumulación de krill y el agotamiento de las poblaciones de peces fueron, posiblemente, el eje conductor de este cambio en la composición de la dieta de este pingüino. Esta flexibilidad trófica demostraría la habilidad de los pingüinos para ajustarse a los cambios ecológicos (Ledford 2007).

\section{Pingüino de Barbijo Pygoscelis antarctica}

Numerosos trabajos indican que la presa principal del pingüino de Barbijo es el krill antártico (Lishman 1985, Trivelpiece et al. 1990, Lynnes et al. 2002, Takahashi et al. 2003). Tal como fuera reportado para el pingüino de Adelia, Lynnes et al. (2004) observaron que el krill (>99M\% para todas las temporadas) constituyó la presa principal del pingüino de Barbijo en la I. Signy, IOS, entre los meses de enero y marzo de 1997 y 2001. Sumado a ello, estudios realizados en las ISS (Volkman et al. 1980, Jansen et al. 1998) y en la PA (Favero y Coria 2007), también reflejaron que el krill fue la presa principal de esta especie, y su aporte a la composición de la dieta en términos de biomasa fue superior al $99 \%$.

Con respecto a las presas secundarias, los trabajos previamente citados indicaron que, aunque con aportes de biomasa inferiores al $1 \%$, los peces y los cefalópodos fueron presas que ocurrieron con frecuencia variable en la dieta. El único trabajo que informa sobre los peces representados en la dieta del pingüino de Barbijo en las IOS es el de Lynnes et al (2004). Sin embargo, dicha información fue procesada conjuntamente con la del pingüino de Adelia por lo que las especies de peces reportadas no fueron relacionadas con el consumo diferencial de ambos pingüinos. Por otro lado, a partir de la comparación de las distintas estrategias alimentarias de los pingüinos de Adelia y de Barbijo, numerosos autores (Watanuki et al. 1993, Ainley et al. 1998, 2003, Jansen et al. 1998, Endo et al. 2002, Lynnes et al. 2004) sugieren que cuando comparten territorios reproductivos el pingüino de Barbijo tiende a consumir mas peces que el pingüino de Adelia, en tanto que cuando este pingüino aumenta la extensión de sus áreas de forrajeo tiende a diversificar la composición de su dieta (Lynnes et al. 2004). La discusión sobre la competencia interespecífica de ambos pingüinos será desarrollada en el Capítulo IV,

\footnotetext{
${ }^{1}$ Se estima que entre 1793 hasta 1807 se capturaron 32 millones de focas y que las poblaciones de ballenas se redujeron en un 90\% (Ledford 2007).
} 


\section{Pingüino Papúa Pygoscelis papua}

A diferencia de los pingüinos previamente tratados, en términos generales el Papúa es un importante consumidor de peces litorales. Los trabajos previos realizados en las IOS (Croxall y Prince 1987) y la información recopilada en este trabajo (Tablas II.8, II.9, II.10; Figuras II.2, II.3) sustentan dichos conceptos e indican que el krill y los peces constituyen las presas dominantes en la dieta de esta especie. Con respecto al krill, la figura II.2 refleja que el aporte del krill a la dieta del pingüino Papua varía gradualmente a lo largo de un ciclo de 7 años. Si bien este tema será discutido más adelante en conjunto con los resultados de los demás predadores, es importante destacar que dicho ciclo es similar al observado en $A$. gazella (ver más adelante).

Con respecto a las presas secundarias, trabajos desarrollados en diferentes localidades indican que los calamares ocurren regularmente en la dieta de esta especie tanto en las temporadas reproductivas como post-reproductivas, aunque en bajas proporciones (Croxall y Prince 1980, Adams y Klages 1989, Hindell 1989, Klages et al. 1990, Ridoux 1994). En relación a esto, la información obtenida en las IOS durante los otoños de 1993 a 2000 sugieren que el calamar fue una presa frecuente ( $F \% 12$ a 82) en la dieta del pingüino Papúa, aunque su aporte en biomasa fue escaso.

Las especies de peces que más contribuyeron a la dieta del pingüino Papúa pertenecieron a la familia Nototheniidae y entre ellas, G. gibberifrons, L. nudifrons, $N$. nybelini y $T$. newnesi fueron las mejor representadas. Ejemplares de las familias Channichthyidae y Myctophidae presentaron una frecuencia de ocurrencia baja, lo que coincide con lo informado para otros sitios de Antártida tales como las Islas Georgias del Sur ( $F \%<11)$ (Williams 1991).

$\mathrm{Si}$ bien en las IOS no se han desarrollado estudios tendientes a analizar las diferencias sexuales en la composición de la dieta, Trivelpiece et al. (1983) observaron en las ISS diferencias en términos de biomasa entre machos y hembras en el consumo de peces (23-32\% en machos y $2-15 \%$ en hembras y sugieren que si bien el tamaño del pico es diferente, las diferencias sexuales en la dieta se ven relacionadas con comportamientos tendientes a disminuir la competencia intraespecífica.

\section{Procellariidae}

\section{Petrel Damero Daption capense}

El área reproductiva del petrel Damero es extensa y comprende diferentes sectores de Antártida tales como las Islas Georgias del Sur, ISS, I. Bouvet, I. Crozet, Islas Kerguelen, I. Heard, I. Macquarie, I. Baleeny, diversas localidades de la PA (Watson 1975), entre otros. A pesar de su amplio rango de distribución los trabajos orientados a comprender su comportamiento alimentario son escasos. Además, en la mayoría de trabajos desarrollados no se han tomado datos del status de los ejemplares y las muestras se limitaron al análisis de ejemplares recolectados ocasionalmente en el mar (Falla 1937, Bierman y Voous 1950, Mougin 1975, Ainley et al. 1984). Los estudios desarrollados en otras localidades, si bien han evidenciado una amplia diversidad en la composición de la dieta (Falla 1937, Paulian 1953, Mougin 1968, Griffiths 1983, Creet et al. 1994, Abrams 1985, van Franeker y Williams 1992, Soave et al. 1996, Coria et al. 1997, Casaux et al. 1998b). Sumado a ello, Casaux et al. (1998) hallaron que los peces son un importante componente de la dieta tanto de adultos como de pichones. En coincidencia con lo indicado, la información obtenida en las IOS indica 
que la dieta del petrel Damero estuvo mayormente constituida por krill y peces pelágicos (principalmente Myctóphidos).

Con respecto a las presas secundarias, Soave et al. (1996) sugirieron que cuando los petreles se alimentan en aguas abiertas cercanas a las IOS los calamares se constituyen en una presa frecuente. Sin embargo, datos recolectados en colonias de otras localidades (Beck 1969, Green 1986, Ridoux y Offredo 1989, Arnould y Whitehead 1991, Creet et al. 1994, Ridoux 1994), reportaron muy bajas cantidades de calamares.

En relación a los peces, los primeros estudios sobre esta especie desarrollados en las ISS y en la isla Windmill reportaban la ocurrencia de P. antarcticum en la dieta (Arnould y Whitehead 1991, van Franeker y Williams 1992, Creet et al. 1994). Según Beck (1969), los restos de peces (vértebras y cristalinos) hallados en muestras de regurgitados de las IOS también se corresponderían con $P$. antarcticum. Llamativamente, estudios recientes revelaron que este notothéniido estuvo ausente de la dieta del petrel Damero y de otros predadores de las IOS. Si se asume que Beck (1969) y Creet et al. (1994) determinaron correctamente la presencia de $P$. antarcticum en la dieta del petrel Damero en las IOS e ISS, respectivamente, la ausencia de este pez en la dieta de predadores de dichos archipiélagos observada recientemente (ver en Casaux et al. 1998b, Casaux et al. 2003a, Casaux et al. 2009) podría deberse una fuerte fluctuación interanual en su abundancia y/o un desplazamiento de sus poblaciones fuera de las áreas de forrajeo de los predadores siendo si nicho ocupado por myctóphidos, los que también los reemplazaron en su rol de presas (ver también Casaux et al. 2003a).

\section{Petrel Gigante Común Macronectes giganteus}

La información acerca de aspectos alimentarios del P. Gigante en las IOS coincide con la reportada para otras áreas subantárticas (Hunter 1983, Hunter y Brooke 1992, Ridoux 1994) y antárticas (Mougin 1968, Green 1986, Bastos et al. 1998), e indica que la composición de su dieta y sus estrategias de alimentación son diversas.

En términos generales, los pingüinos son la presa más importante del petrel Gigante, y estos son obtenidos ya sea por carroñeo de carcasas de individuos matados por mamíferos marinos (Voisin 1968, Warham y Bell 1979, Hunter y Brooke 1992) como por predación directa (Bonner y Hunter 1982, Warham 1990, Hunter y Brooke 1992, Le Bohec et al. 2003). Entre los pingüinos el de Adelia fue la especie consumida con más frecuencia en Cabo Geddes (I. Laurie, IOS) (Coria 2006). En cuanto al modo de acceso a la presa, el consumo de carcasas de pingüinos muertos por mamíferos marinos parece ser más frecuente en I. Signy que en I. Laurie (Conroy 1972, Coria 2006), lo que probablemente esté relacionado con las diferencias entre localidades en el número de ejemplares de Lobo Fino Antártico (rangos de valores máximos durante los meses de verano austral: $4.780-20.727$ para I. Signy y $2571-11.577$ para I. Laurie, Waluda et al. 2010, Carlini datos no publicados).

Con respecto a las presas secundarias representadas en muestras obtenidas en las IOS, los calamares son frecuentemente reportados como presas del petrel Gigante y es probable que sean consumidos de manera indirecta a través de cleptoparasitismo o carroñeo o que hayan sido capturados directamente durante la noche cuando estos ascienden a la superficie (Daneri et al. 
2000). Estudios desarrollados en otras localidades reportan la presencia de aves voladoras y de peces (Murphy 1936, Downes et al. 1959, Warham 1962, entre otros) en la dieta del P. Gigante; sin embargo, ambas presas ocurrieron en muy baja proporción en muestras obtenidas en las IOS y su contribución en términos de biomasa también fue baja (Tabla II.14). Por el contrario, información obtenida en las ISS durante la temporada 1999/00 indica que en ese archipiélago el aporte de los peces a la dieta del petrel Gigante es alto (Coria 2006). Tal como ocurre para varios de los predadores considerados en este trabajo (e.g. la foca de Weddell, el petrel Damero y el Lobo Fino Antártico), si bien $P$. antarcticum es una presa que aparece frecuentemente en los reportes de dieta tanto en las ISS (Lipinski y Woyciechowski 1981, Clarke y MacLeod 1982a, Casaux et al. 1997a) como en la PA (Casaux et al. 2006), este pez no estuvo representado en las muestras obtenidas en las IOS. Si bien en las IOS no se desarrollaron estudios tendientes a analizar diferencias sexuales en la composición de la dieta del petrel Gigante, Coria (2006) observó en P. Armonía, I. Nelson (ISS), que los contenidos estomacales obtenidos de machos fueron significativamente más pesados que los de las hembras (Mann-Whitney, $Z=3,49, \quad p<0,001$ ) y que las hembras consumieron más frecuentemente que los machos anfípodos, krill, calamares y peces. Coincidentemente Hunter (1983) observó en la I. Bird, IGS, que durante el período de cría las hembras del petrel Gigante del Norte $M$. halli consumieron principalmente presas capturadas en alta mar (krill, calamares y peces), en tanto que los machos ingirieron con mayor frecuencia carroña de mamíferos marinos (principalmente Lobo Fino Antártico) y de pingüinos.

\section{Petrel de las nieves Pagodroma nivea}

Durante la temporada reproductiva el petrel de las Nieves en las IOS se alimenta principalmente de peces, en tanto que el krill, otros crustáceos (fundamentalmente anfípodos hyperídeos), y calamares fueron presas secundarias (Ferretti et al. 2001). Estos resultados difieren de los reportados para otras localidades antárticas en las que el krill fue la presa principal de este predador (Falla 1937, Bierman y Voous 1950, Brown 1966, Griffiths 1983, Ridoux y Offredo 1989, Ainley et al. 1991, van Franeker y Williams 1992, van Franeker et al. 2001). Con respecto a los peces, según lo informado por Ferretti et al. (2001) los myctóphidos (principalmente E. antarctica) fueron la presa más importante. Ainley et al. (1991) observaron que en proximidades de la CA entre otoño y primavera los myctóphidos también son la presa principal de este petrel. De un modo diferente, Ridoux y Offredo (1989) indicaron que en I. Crozet los peces representaron el $95 \%$ de la biomasa de las presas del petrel de las Nieves, siendo $P$. antarcticum la especie más abundante.

\section{Petrel de Wilson Oceanites oceanicus y petrel de las Tormentas de Vientre Negro Fregetta tropica}

La información existente sobre la biología de ambos predadores, y en especial sobre su dieta, es escasa. De acuerdo a los trabajos presentados en este estudio, si bien el krill parece ser una presa importante dentro de la dieta, los peces estuvieron bien representados tanto en los estudios desarrollados en las ISS como en las IOS. Hahn (1998) sugirió que la baja ocurrencia de krill en las muestras de F. tropica durante la temporada reproductiva 1996/97 en las ISS, evidencia una clara separación en la composición de la dieta de ambas especies. 
$\mathrm{Si}$ bien la información sobre el petrel de Wilson es sumamente escasa, estudios desarrollados en las IGS indicaron que se alimenta de krill y myctóphidos (Croxall y North 1988, Croxall et al. 1988), de larvas de peces no identificados (Wasilewski 1986) y probablemente del notothéniido $P$. antarcticum (Ainley et al. 1984). Las proporciones son informadas por Croxall et al. 1988 y se corresponden con los siguientes valores de porcentajes en masa: $36,72 \%$ para el krill, $30,32 \%$ anfípodos y $28,3 \%$ para los peces de los cuales, todos myctóphidos, el $18,3 \%$ se correspondió con P. normani y el $9,9 \%$ con P. bolini. De manera similar, Croxall y North (1988) indicaron que el myctóphido $P$. normani estuvo representado en el $41 \%$ de las muestras analizadas también en las IGS y sugieren que $K$. anderssoni, G. braueri, E. antarctica, E. carslbergi y estadios tempranos de los notothéniidos N. nybelini, G. gibberifrons, $P$. hansoni y del channíchthyido $C$. gunnari también podrían ser presas frecuentes.

\section{Phalacrocoracidae}

\section{Cormorán de Georgias Phalacrocorax georgianus}

La composición general de la dieta del cormorán de Georgias en las IOS (Casaux et al. 1997b, Casaux y Ramón 2002) es similar a la reportada para otros cormoranes distribuidos en regiones antárticas y sub-antárticas (Shaw 1984, Brothers 1985, Espitalier-Noel et al. 1988, Green et al. 1990, Wanless y Harris 1993, Ridoux 1994, Coria et al. 1995, Kato et al. 1996, Favero et al. 1998, Casaux y Barrera-Oro 2006, entre otros). Estas similitudes entre las distintas localidades se deben en parte a que los cormoranes son considerados predadores generalizadores (principalmente ictiófagos) y por ende su dieta refleja la composición de la fauna bentónica litoral, la cual, evidentemente, parece guardar semejanzas entre localidades (Lumshen y Haddow 1946, West et al. 1975, Craven y Lev 1987, Keller 1995).

Los peces, principalmente notothéniidos bentónicos, son la presa principal del cormorán de Georgias en las IOS, en tanto que diferentes invertebrados (poliquetos, octópodos, anfípodos gamarídeos, gastrópodos, etc.) contribuyen de manera poco significativa a la dieta, sobretodo en términos de biomasa (Casaux et al. 1997b, Casaux y Ramón 2002). La mayoría de los invertebrados bentónicos y algas representadas en los pellets analizados podrían provenir de su ingesta secundaria; es decir, podrían provenir de los estómagos de los peces ingeridos por los cormoranes (ver también Green et al. 1990, Casaux et al. 1995a,b y Casaux y Barrera-Oro 2003). Esto podría indicar que el estudio de la dieta de este cormorán a través del análisis de pellets sobreestima el aporte de dichas presas a la dieta. A modo de ejemplo se puede indicar que los poliquetos aparecen como una presa frecuente cuando se analizan pellets, en tanto que suelen estar ausentes cuando se analizan contenidos estomacales donde los peces se recuperan casi sin digerir. Esto evidencia que los diferentes tipos de muestras pueden arrojar diferentes resultados, lo que debe ser tenido en cuenta al comparar información sobre la dieta de este cormorán (ver Casaux et al. 1997b). Con respecto a los peces, los resultados del análisis de regurgitados indicaron que $H$. antarcticus, seguido por G. gibberifrons, $T$. newnesi y $N$. coriiceps, fue la presa más frecuente, en tanto que $N$. coriiceps, seguido por $G$. gibberifrons y $H$. antarcticus, fue la presa que más aportó a la dieta del cormorán de Georgias en términos de biomasa. En un trabajo previo Conroy y Twelves (1973) observaron que $N$. coriiceps (previamente llamada $N$. neglecta) fue el único pez representado en contenidos 
estomacales recolectados en I. Signy (IOS) durante la temporada reproductiva 1970/71. Posteriormente, y en la misma localidad, a partir del análisis de 84 regurgitados recolectados durante las temporadas 1979/80 y 1980/81 Shaw (1984) observó que N. coriiceps, seguida de Trematomus spp. y Notothenia rossii, fue la presa principal del cormorán de Georgias. Es importante destacar que los muestreos de Shaw (1984) fueron realizados dos años después de una intensa explotación pesquera en el área, la cual en sólo tres años disminuyó marcadamente los stocks de peces (Kock 1992). Por ello no resulta extraño que, si bien los juveniles de $N$. rossii representaron el $13,4 \%$ de la dieta en términos de biomasa, el aporte de $G$. gibberifrons fue muy bajo (1\%). Estos resultados no coinciden con la información generada en la década del 90 (Casaux et al. 1997b, Casaux y Ramón 2002), en donde G. gibberifrons ocupó un lugar central en la dieta del cormorán de Georgias y N. rossii no estuvo representada en las muestras. La diferencia entre estos resultados y los de Shaw (1984) parece estar reflejando el deterioro que sufrieron las poblaciones de G. gibberifrons y N. rossii debido a la intensa actividad en ese archipiélago durante la década del 70 , proceso que también fue reportado para las IGS (North et al. 1983), I. Kerguelen (Duhamel 1990) y a las ISS (Barrera-Oro y Marschoff 1990). Al analizar los cambios en la composición de la dieta del cormorán de Georgias a lo largo de la temporada de cría 1994/95, Casaux et al. (1997a) observaron que durante los períodos de cría temprana/media y cría tardía la dieta fue más variada y que el pez más importante en términos de biomasa fue $N$. coriiceps. Estos autores también observaron que durante el período de cría tardía los contenidos estomacales eran más pesados y contenían menos peces lo que indica que los cormoranes se alimentaron de ejemplares de mayor talla. Según Casaux et al. (1997a), durante dicho período los requerimientos energéticos de los pichones son muy altos por lo que los individuos reproductores deben optimizar las salidas de alimentación y ello explicaría el consumo de peces de mayor talla, fundamentalmente $N$. coriiceps (ver también Wanless et al. 1993). Durante la etapa de emancipación, los pichones empiezan a alimentarse por sí mismos y su incapacidad para capturar presas de gran tamaño, sumado a que las exigencias de los adultos disminuyen, explicaría que los peces representados en los pellets recuperados en esta etapa sean de menor talla (Tablas II.17 y II.21). Este patrón de alimentación también fue observado en el cormorán Antártico Phalacrocorax bransfieldensis en I. Media Luna, ISS (Casaux y Barrera-Oro 1995), lo que indicaría que esta sería una estrategia generalizada en los cormoranes del OA. Este comportamiento está vinculado con el aporte energético de las presas, tema que será tratado en el Capítulo VI.

Aunque los estudios realizados en las IOS no analizaron las diferencias sexuales en la composición de la dieta, trabajos desarrollados en las ISS evidenciaron diferencias en la estrategia de alimentación entre machos y hembras (Favero et al. 1998, Casaux et al. 2001, Casaux y BarreraOro 2006). Por medio del análisis de contenidos estomacales de aves retornando al nido luego de un viaje de forrajeo, estos autores observaron que si bien los peces fueron la presa principal en ambos sexos, las hembras predaron más frecuentemente que los machos sobre ejemplares y especies de menor talla y sobre invertebrados. Con respecto a ello Casaux y Barrera-Oro (2006) plantearon dos hipótesis que pueden explicar dichas diferencias: 1) Las diferencias sexuales en la dieta se deben a diferencias temporales en disponibilidad de las presas durante los períodos de actividad de cada uno de los sexos y 2) Las diferencias sexuales en la dieta son debidas a diferencias morfológicas (dimorfismo sexual). Otra alternativa sugerida por Casaux et al. (1998) y Favero et al. (1998) indica 
que las diferencias sexuales en la selección del alimento se deben a estrategias que disminuirían la competencia intraespecífica, favoreciendo entonces la eficiencia en la explotación de los recursos para toda la población.

Dado que el cormorán es un predador oportunista (Craven y Lev 1987, Keller 1995) y que el análisis de regurgitados o contenidos estomacales tiende a reflejar la abundancia de las especies de peces presa dentro de las áreas de forrajeo (Casaux y Barrera-Oro 1993), Argentina propuso que estas aves podrían ser utilizadas como bioindicadores en programas de monitoreo de ecosistemas costeros marinos (Casaux y Barrera-Oro 1998). Esta propuesta fue aceptada por la Comisión para la Conservación de los Recursos Vivos Marinos Antárticos (CCRVMA) (SC-CAMLR 1998) y actualmente el cormorán Antártico y el cormorán de Georgias son consideradas especies indicadoras para dicha comisión y son utilizadas para identificar procesos de cambio en poblaciones de peces litorales antárticos en general y para el monitoreo de stocks de peces de interés comercial (G. gibberifrons y $N$. rossii, entre otras) en particular.

\section{Laridae}

\section{Gaviota Cocinera Larus dominicanus}

La composición de la dieta de $L$. dominicanus en diferentes localidades antárticas muestra una gran variabilidad estacional y latitudinal y presenta gran diversidad de presas tales como invertebrados marinos (principalmente moluscos y crustáceos), peces, restos de aves (principalmente pingüinos), carroña proveniente de pingüineras y de asentamientos de mamíferos marinos, y restos de basura generada en bases (Silva 1996). La información recopilada en este trabajo indicó que la dieta de la gaviota Cocinera en las IOS esta principalmente constituida por restos de pingüinos y lapas (Silva 1996). La frecuente presencia de restos de pingüinos en la dieta explica la usual simpatría durante la temporada reproductiva entre esta gaviota y especies del género Pygoscelis. A diferencia de reportado para las IOS, resultados obtenidos en la PA (Silva et al. 2001, Silva 1996) y en las ISS (Favero et al. 1997) indicaron que si bien el krill fue la presa principal, los peces estuvieron bien representados en la dieta y alcanzaron aportes en biomasa de entre el $8,1 \%$ y $14,3 \%$ en regurgitados de pichones. De acuerdo a Silva et al. (2001), la composición de la dieta fue marcadamente diferente en los tres sitios considerados durante la temporada 1997/98 (Punta Cierva en PA, Punta Armonía en ISS y I. Laurie en IOS), lo que se debió principalmente al mayor aporte de las lapas a la dieta en las localidades de las ISS e IOS. En relación a los peces, las especies y tallas representadas en la dieta de la gaviota Cocinera nidificando en P. Armonía, I. Nelson (ISS), frecuentemente coincidieron con las identificadas en la dieta de cormoranes de esa localidad (ver Casaux et al. 1998a, Favero y Silva 1998), lo que es consecuente con los habituales intentos de cleptoparasitismo observados en gaviotas (Silva 1996). Sumado a ello, gaviota Cocinera fue vista frecuentemente consumiendo feces y vómitos de la foca de Weddell tanto en P. Armonía (Casaux et al. 1997a) como en P. Cierva (Silva et al. 2001) y esto ocurre con mayor frecuencia hasta el comienzo del período reproductivo de pingüinos (Silva 1996). Según Silva (2006), los altos contenidos lipídicos observados en las muestras de dieta podrían provenir de feces de foca, las que consumen peces myctóphidos con elevados contenidos grasos en sus tejidos (Reinhardt y Van Vleet 1986). Además, los vómitos de focas también están compuestos por restos no digeridos de cefalópodos y peces. Esta información sugiere 
que los peces y pulpos representados en la dieta de las gaviotas, al menos en parte, podrían provenir de presas capturadas por otros predadores. De todos modos, y tal como ocurrió con otros predadores, $P$. antarcticum estuvo ausente de las muestras de gaviota Cocinera obtenidas en las IOS.

Silva et al. (2001) observaron que cuando la gaviota cocinera consume presas pelágicas con alto retorno energético (peces myctóphidos ó krill) los éxitos reproductivos son mayores que cuando se alimentan de otras presas. Esta observación se sustenta por lo reportado por Pierotti (1982) quien documentó que en años de malas condiciones climáticas los éxitos reproductivos fueron bajos, lo que se debería a que los recursos pelágicos son más difíciles de obtener para las gaviotas.

\section{Stercorariidae}

\section{Escúa Marrón Catharacta antarctica y escúa Polar C. maccormicki}

La información referida a las IOS indica que las presas principales del escúa Marrón son los pingüinos y otras aves voladoras (principalmente petrel de las Tormentas), en tanto que las del escúa Polar son los peces y el krill. Con respecto a los pingüinos, Pietz (1987) y Reinhard et al. (2000) sugieren que el alto aporte de estas aves a la dieta del escúa Marrón se debe a que los pichones de pingüinos son una presa abundante y de fácil acceso. Sumado a ello, Norman et al. (1994) y Votier et al. (2003) indicaron que cuando estos escúas predan sobre pingüinos el retorno energético es mayor que cuando consumen peces. Además, Young y Millar (1999) indicaron que en localidades donde la disponibilidad de pingüinos es alta, el escúa marrón tiende a no forrajear sobre recursos marinos.

Al parecer, ambos escúas desarrollan mecanismos tendientes a disminuir la competencia interespecífica por el alimento. En este sentido, se ha reportado que cuando reproducen en simpatría el escúa Marrón consume principalmente huevos y pichones de pingüinos, en tanto que el escúa Polar se alimenta casi exclusivamente de recursos marinos (Parmelee et al. 1978, Trivelpiece et al. 1980, Hemmings 1984, Pietz 1987, Peter et al 1990). Además, Hemmings (1984) observó que cuando nidifica conjuntamente con el escúa Marrón, el escúa Polar no se aproxima a las colonias de Pygoscélidos. Todo esto parece indicar que el escúa Marrón despliega una fuerte territorialidad alrededor de las colonias de pingüinos y desplaza al escúa Polar a predar sobre otros recursos, lo cual coincide con lo observado por Malzof y Quintana para la PA (Malzof y Quintana 2008).

Según los resultados compilados en este trabajo en relación a la contribución de peces a la dieta sólo los notothéniidos estuvieron representados en la dieta de ambos escúas en las IOS. Aún así, durante las temporadas 1981/82 y 1982/83 en un estudio realizado en la I. Signy, Hemmings (1984) informó que los restos de peces hallados en las muestras de dieta del escúa marrón pertenecían a la especie $P$. antarcticum. Es por ello que este autor sugiere que la presencia del escúa Polar en las IOS estaría fuertemente ligada a la disponibilidad y distribución de $P$. antarcticum. Por el contrario, los myctóphidos fueron las presas que más contribuyeron a la dieta (hasta el $98 \%$ en biomasa) del escúa Polar en Isla Media Luna, ISS, a lo largo de toda la temporada reproductiva 1995/96 (Montalti et al. 1996). Para otra localidad de las ISS (Isla 25 de Mayo) Hahn et al. (2008) observaron que durante la temporada 1994/95 E. antarctica fue la presa más importante del escúa Polar y que $P$. antarcticum le siguió en importancia. Lo resultados presentados por Hahn et al. (2008) coinciden con lo observado por Malzof y Quintana (2008) en la PA. 


\section{Sternidae}

\section{Gaviotín Antártico Sterna vitatta}

Diversos estudios han indicado que los peces, el krill y los anfípodos gamarídeos son las presas más importantes del Gaviotín Antártico (Jablonski 1995, Goschfeld y Burger 1996, Casaux et al. 2007). A pesar de estas coincidencias, las presas principales de este gaviotín parecen cambiar según las localidades. Mientras que Casaux et al. (2007) observaron en Punta Armonía, I. Nelson, ISS, que las presas principales fueron los peces, Jablonski (1995) reportó que en Bahía del Almirantazgo, también ISS, el krill fue la presa que más contribuyó a la dieta del Gaviotín Antártico durante las temporadas 1978/79 a 1980/81. Casaux et al. (2007) proponen 4 hipótesis alternativas que intentan explicar estas diferencias en la composición de la dieta: (1) la disponibilidad de presas es diferentes en ambos sitios de muestreo, (2) existen diferencias temporales en los ciclos reproductivos de los gaviotines y eso se reflejada en la composición de la dieta, (3) la presión de predación de los escúas (C. antarctica) hacia los pichones de gaviotín es diferente en cada localidad lo que determina diferencias en las estrategias de forrajeo, y (4) las disponibilidad de presas cambia a lo largo del día y los muestreos de cada localidad fueron realizados en diferentes períodos del mismo.

En relación a los peces, Jablonski (1995) reportó que $P$. antarcticum, seguido por otros notothéniidos juveniles, fue la presas más consumida y que los myctóphidos estuvieron ausentes de la dieta. A diferencia de ello, Casaux et al. (2007) observaron que $N$. coriiceps, seguido del myctóphido $E$. antarctica, fue la presa más importante, en tanto que $P$. antarcticum no estuvo representado en las muestras. Estas diferencias en el consumo de myctóphidos y $P$. antarcticum podrían deberse a 1) diferencias espaciales o temporales en la disponibilidad de estos peces, o 2) a que los gaviotines tienden a seleccionar presas de menor tamaño para así transferir más fácilmente el alimento a los pichones por lo que, cuando la disponibilidad es adecuada, estas aves consumirían preferentemente myctóphidos independientemente de la presencia de $P$. antarcticum (Casaux et al. 2007). Con respecto a $E$. antarctica, Hulley (1990) indica que se distribuye en profundidades cercanas a $250 \mathrm{~m}$. y que durante la noche desarrolla migraciones hacia los 50-100 m., en tanto que Kock (1992) la describe como un pez de hábitos mesopelágicos. Teniendo en cuenta que durante la etapa reproductiva el Gaviotín Antártico se alimenta en aguas muy poco profundas y muy próximas a las colonias, la presencia de este myctóphido en su dieta llama la atención. Para explicar esta aparente contradicción Casaux et al (2007) plantean la posibilidad de que E. antarctica presente una distribución espacial diferencial según los distintos estadíos de crecimiento, siendo entonces los juveniles los que se acercan a la zonas de aguas poco profundas (lo que estaría sustentado por las tallas de los peces representados en la dieta), o que la presencia de esta especie en aguas costeras poco profundas sea un hecho habitual que no fue documentado previamente debido a las limitaciones para operar buques de investigación en estas aguas. 


\section{II.4.1.2. Mamíferos}

\section{Phocidae}

\section{Elefante Marino del Sur Mirounga leonina}

La única información proveniente de las IOS indica que durante la temporada 1962/63 la dieta del elefante Marino del Sur estuvo compuesta exclusivamente por cefalópodos (Clarke y McLeod 1982b), lo que coincide con lo reportado para otras regiones de Antártida (Rodhouse et al. 1992, Green y Burton 1993, Slip 1995, Daneri et al. 2000).

En relación a los peces, Green y Burton (1993) han reportado que éstos fueron presas frecuentes en la dieta del elefante Marino del Sur en las islas Heard y Macquarie. Según este estudio los peces pelágicos (Electrona sp. y Gymnoscopelus sp.) dominaron en las muestras de Macquarie, en tanto que en Isla Heard los elefantes marinos predaron sobre especies pelágicas (principalmente E. carlsbergi y G. nicholsi), bento-pelágicas (C. gunnari) y bentónicas (principalmente Nototheniops acuta y $N$. squamifrons). De un modo similar a lo reportado para Isla Heard, los peces que dominaron en contenidos estomacales obtenidos en las ISS durante las temporadas reproductivas de 1993/94 a 1999/00 pertenecieron a especies pelágicas (principalmente G. nicholsi y P. antarcticum) (Daneri y Carlini 2002).

\section{Foca de Weddell Leptonychotes weddellii}

Estudios realizados en los mares de Weddell y de Ross indicaron que los peces fueron la presa principal de la foca de Weddell (Dearborn 1965, Øritsland 1977, Weiner et al. 1981, Plötz 1986, Green y Burton 1987, Plötz et al. 1991, Green et al. 1995, entre otros) o que contribuyeron a la dieta de un modo similar que los octópodos (Bertram 1940). En cuanto a las ISS, Casaux et al. (1997) indicaron que los peces fueron la presa más abundante en la dieta de esta foca, en tanto que los octópodos dominaron en términos de biomasa (ver también Lipinski y Woyciechowski 1981, Clarke y MacLeod 1982a). Con respecto a estos resultados, numerosos autores (Dearborn 1965, Øritsland 1977, Weiner et al. 1981, Plötz 1986, Green y Burton 1987, Plötz et al. 1991, Casaux et al. 1997a) sugieren que la contribución de peces a la dieta suele ser subestimada (ver sección II.4.2) La composición de la dieta de la foca de Weddell en las IOS es diversa y de acuerdo a las temporadas consideradas, los octópodos seguidos por peces (1999/00) o el krill (2001/02) dominaron en la dieta en términos de biomasa (Casaux et al. 2009). Si bien los resultados obtenidos por Casaux et al. (2009) durante 1999/00 coinciden con lo reportado para las ISS (Casaux et al. 1997a), la información obtenida durante 2001/02 es la primera que muestra al krill como la presa más importante de la foca de Weddell. Dado que la foca de Weddell es considerada un predador con una alta tendencia a la ictiofagia, se puede especular que el krill es una presa secundaria (provendría de los estómagos de los peces ingeridos) o que es capturado oportunísticamente mientras las focas se alimentan de los peces pelágicos asociados a los enjambres de krill. Llamativamente, los peces pelágicos no estuvieron representados en las muestras obtenidas durante 2001/02 y el aporte general de los peces a la dieta en esa temporada fue bajo, lo que plantea un escenario alternativo: quizás en esa temporada el krill fue particularmente abundante y, ya sea sólo a través de dicha abundancia o porque eso disminuyó la competencia interespecífica por ese recurso, la foca predó prioritariamente sobre este crustáceo. Esta hipótesis está sustentada por: 1) Lake et al. (2003) observaron que en 
ocasiones la foca de Weddell preda sobre enjambres de misidáceos, 2) la contribución de peces pelágicos (especialmente myctóphidos) a la dieta en las IOS durante la temporada 2001/02 fue muy escasa y 3 ) ante condiciones particulares de la cubierta de hielo marino el krill presenta incrementos poblacionales importantes (Fraser y Hoffman 2003, Nicol 2006), los que a su vez suelen estar asociados a cambios en las estrategias de forrajeo de los predadores.

En relación a los peces, estudios realizados en los mares de Weddell (Plötz et al. 1991) y de Ross (Plötz 1986, Green y Burton 1987, Green et al. 1995, Burns et al. 1998, Lake et al. 2003, entre otros) indican que la foca de Weddell forrajea sobre recursos pelágicos o bento-demersales de acuerdo a la disponibilidad de los mismos, siendo $P$. antarcticum una de las presas principales. Sin embargo, en años en que este notothéniido es poco abundante en el Mar de Weddell es reemplazado por channíchthyidos y otros notothéniidos (Plötz et al. 1991). Pleuragramma antarcticum, junto con el channíchthyido C. rastrospinosus, fueron las especies con mayor contribución a la dieta de la foca de Weddell en la PA durante las temporadas 1998/99 y 2000/01 (Casaux et al. 2006). En relación a las ISS, Casaux et al. (1997c) indicaron que durante la temporada 1996/97 los myctóphidos (principalmente G. nicholsi) fueron la presa dominante, en tanto que $P$. antarcticum no estuvo representado en las muestras. La información disponible de las IOS difiere de la previamente presentada ya que las especies pelágicas tales como myctóphidos y $P$. antarcticum no estuvieron presentes en la dieta, siendo el notothéniido bento-demersal G. gibberifrons el pez que más contribuyó en términos de biomasa en las 2 temporadas consideradas (Tabla II.26).

La contribución de los pingüinos a la dieta de la foca de Weddell en las IOS en las 2 temporadas consideradas por Casaux et al. (2009) fue alta. La presencia de estas aves en la dieta fue reportada en sólo dos estudios previos (Pingüino de Barbijo: Todd 1988, Pingüino Papúa: Cobley y Bell 1998). Si bien Todd (1988) sugirió que el consumo de pingüinos es un evento poco usual, Cobley y Bell (1998) observaron a varias focas predando sobre pingüinos e indicaron que esa estrategia es utilizada para complementar la dieta. Por el contrario, los pingüinos estuvieron ausentes de la dieta de focas en la Isla Nelson, ISS (Casaux et al. 1997a), y en la Costa Danco, PA (Casaux et al. 2006). Sin embargo, R. Casaux (comunicación personal) observó que durante las temporadas 2000/01 a 2005/06 estas aves fueron una presa frecuente en muestras recolectadas en la Isla Nelson. En relación a lo observado en las ISS, y considerando lo indicado por Cobley y Bell (1988), la ocurrencia de pingüinos en la dieta de la foca de Weddell, podría estar reflejando cambios en la disponibilidad de presas principales. Alternativamente, y como indicaran Casaux et al. (2009), estos cambios en la dieta podrían estar reflejando estrategias de forrajeo tendientes a disminuir la competencia interespecífica con otros predadores

\section{Foca Cangrejera Lobodon carcinophagus}

Laws $(1977,1984)$ definió a la foca Cangrejera como un consumidor exclusivo de krill antártico (ver también Wilson 1907, Marr 1962, Øritsland 1977) e indicó que la biomasa de este crustáceo consumida por esta foca era mayor que el estimado para las ballenas en Antártida. La única información disponible sobre la dieta de esta foca en las IOS indicó que el krill fue la única presa representada en las muestras. De un modo similar, Green y Williams (1986) observaron que en la región Índica del OA la composición general de la dieta de la foca Cangrejera estuvo constituida 
mayormente por krill y en menor medida por el misidáceo Antarctomysis maxima, un crustáceo característico de las comunidades zooplantónicas antárticas. Estudios desarrollados en varias localidades antárticas informan sobre la presencia ocasional en la dieta de la foca Cangrejera de pulpos (Perkins 1945) y peces pelágicos (principalmente $P$. antarcticum) (Schultz 1945, Lowry et al. 1988). En esta sentido, Croxall y Prince (1979) indican que si bien la foca Cangrejera consume prioritariamente krill, ante la disminución de la abundancia de este crustáceo diversifica su dieta y preda sobre otros recursos.

\section{Othariidae}

\section{Lobo Fino Antártico Arctocephalus gazella}

La dieta del Lobo Fino Antártico es diversa y varía según las diferentes localidades. Sin embargo, la mayoría de los trabajos coinciden en indicar que el krill y los peces son las presas más frecuentes y numerosas en la dieta de este lobo durante los meses de verano (Bonner 1968, North et al. 1983, Doidge y Croxall 1985, Daneri y Coria 1992, Daneri 1996, Daneri y Carlini 1999, Casaux et al., 2002, 2003). En coincidencia con esto, la información generada en las IOS (Casaux et al. 2003a, Casaux datos no publicados; Tablas II.34, II.35, II.36 y figuras II.5 y II.6) indica que el krill fue la presa más importante en todos los años de muestreo, seguido por peces y pingüinos. De un modo similar a lo observado en el pingüino Papúa, en las temporadas 1995/96 y 1997/98 se registraron los niveles de consumo de más bajos y más altos respectivamente. Con respecto a los peces, Daneri y Coria (1994) observaron que durante la temporada 1988/89 los myctóphidos fueron la presa principal, en tanto que los resultados presentados en este estudio (Casaux datos no publicados) reflejaron que en los años de mayor consumo de krill el consumo relativo de estos peces se incrementó, probablemente debido a suelen estar asociados a los enjambres de dicho crustáceo (Figura II.8) (Loots et al. 2007). Así entonces, estos cambios en la dominancia en la dieta entre especies pelágicas (myctóphidos) y bento-demersales (notothéniidos y channíchthyidos) parecen responder a cambios estacionales en la disponibilidad de krill. A su vez, y tal como se viene observando en otros predadores, $P$. antarcticum estuvo muy poco representado en la dieta del Lobo Fino antártico en las IOS (Tabla II.32).

La presencia de pingüinos en la dieta ha sido reportada en trabajos previos desarrollados en las IOS e ISS y en la PA (Daneri y Coria 1992, Casaux et al. 1998a, 2002, 2004). Previamente se hipotetizaba que el lobo mataba pingüinos sólo como parte de un juego y que los ejemplares muertos no eran ingeridos (Bonner y Hunter 1982, Fischer y Hureau 1988). Sin embargo, Casaux et al. (2003) determinaron que los pingüinos eran matados intencionalmente para ser consumidos, que en algunas temporadas llegaban a constituirse en la presa principal, y que en cierta medida la abundancia de pingüinos determinaba la distribución de lobos. En relación a los cefalópodos, Bonner (1968) sugirió que estas presas no constituyen una fracción importante dentro de la dieta del Lobo Fino Antártico a lo largo del verano y que su contribución a la dieta aumenta en otoño (ver también (Daneri et al. 1999). 


\section{II.4.2. Aspectos metodológicos}

Las metodologías de muestreo y de análisis de las muestras suelen estar asociadas a errores que dificultan la interpretación de los resultados. Como ejemplo de ello se discutirán alguno de los casos más estudiados.

En el caso del cormorán (de Georgias o Antártico) (ver Casaux et al. 1997b) los contenidos estomacales reflejan mejor los alimentos que los cormoranes capturan directamente, en tanto que los pellets o regurgitados espontáneos contienen restos de alimento parcialmente digerido por lo pueden sub- o sobre-estimar la presencia, cantidad y masa de algunos de las presas comúnmente registrados en los contenidos estomacales. Además, los otolitos representados en pellets suelen estar fuertemente erosionados debido a procesos digestivos, e incluso algunos pueden llegar a disgregarse totalmente. La obtención de contenidos estomacales es una técnica altamente estresante para los individuos en tanto que la obtención de pellets no los afecta de un modo evidente por lo que el análisis de pellets, a pesar de los errores asociados, resulta una técnica apropiada para estudios a largo plazo. Debido a ello, recientemente Casaux et al. (1995) y Casaux (2003) han desarrollado una metodología que permite compensar la erosión de los otolitos representados en pellets o su pérdida a través del tracto gastrointestinal por lo que dichos errores pueden ser salvados y este tipo de muestras pueden ser utilizadas incluso en estudios de incorporación de energía. Finalmente, cuando se trabaja con técnicas que involucran recolección de pellets, es probable que presas representadas en las muestras tales como crustáceos, algas, y moluscos provengan de los estómagos de los peces ingeridos por los cormoranes, constituyéndose de este modo en ingesta secundaria y siendo sobreestimados por la metodología de muestreo.

Otro caso importante de mencionar es el del escúa Polar. Los resultados presentados en este estudio indicaron que en ciertas localidades los peces parecen ser más importantes de lo que previamente se estimaba, lo que puede estar relacionado con la técnica de muestreo considerando que los restos de krill o de peces pueden provenir de los estómagos de los pingüinos con que se hayan alimentado. Como fue mencionado anteriormente en el caso de los cormoranes, los estudios de dieta basados en el análisis de pellets es una técnica plausible de generar sub- o sobreestimaciones en la cuantificación de las presas consumidas, sumado a la erosión o pérdida de otolitos debido a los procesos digestivos. Además, dado que los restos blandos (vísceras y tejido muscular) ingeridos a través del carroñeo no dejan restos duros identificables en los pellets, esta técnica suele sub-estimar el consumo de aves (principalmente pingüinos) y mamíferos marinos (Votier et al. 2003).

Por otro lado, las técnicas que involucran la recolección y el procesamiento de feces también pueden enmascarar la composición real de la dieta. Por ejemplo, en un trabajo desarrollado en las I. 25 de Mayo (ISS) durante la temporada reproductiva 1995/96, Daneri et al. (2000) no registraron restos de peces en muestras de feces del elefante Marino. Estos autores sugirieron que la ausencia de peces en las muestras se debió a la baja disponibilidad de estas presas en el ambiente a lo largo del período de muestreo. Dadas las altas tasas de digestión que presentan estos animales, y la consecuente digestión de los otolitos, también es probable que la ausencia de peces en las muestras se haya debido a la técnica de muestreo. Las tasas de digestión de peces y calamares en mamíferos marinos (principalmente otarios) fueron estudiadas por Bigg y Fawcett (1985). Según este 
estudio, una gran parte de los restos quitinosos de picos de cefalópodos son resistentes a los procesos digestivos de los elefantes, en tanto que los restos de peces (huesos y otolitos) son fácilmente digeridos rápidamente. A su vez, a través de un estudio en el que se compararon las tasas de digestión de varios mamíferos, Krockenberger y Bryden (1994) indicaron que los elefantes marinos presentan una alta tasa de tránsito gastrointestinal. De manera similar, numerosos autores sostienen que dichos conceptos relacionados con la sub-estimación de la contribución de los peces a la dieta también serían aplicables al Lobo Fino Antártico y a la foca de Weddell (Jobling y Breiby 1986, Dellings y Trillmich 1988, Casaux et al. 2003a).

\section{II.5. Conclusiones Generales}

El análisis de la composición de la dieta de los predadores tope constituye una herramienta que permite avanzar en la identificación de los niveles tróficos en los que cada uno de ellos se encuentra dentro del sistema. Así entonces los grupos fueron definidos como:

- Krill (1): Consumidores exclusivos de krill con presencia eventual $(<1 \%$ en biomasa) de presas secundarias tales como otros crustáceos (mayormente anfípodos) cefalópodos y peces.

- Krill (2): Consumidores de krill con importante aporte de peces a su dieta ( $>30 \%$ en biomasa). Entre los peces las familias Nototheniidae, Myctophidae y Channichthyidae suelen ser las más representadas.

- Ictiófagos (1): Consumidores exclusivos de peces, con presencia eventual de presas secundarias tales como crustáceos y cefalópodos.

- Ictiófagos (2): Predadores cuya dieta estuvo constituida mayoritariamente por peces pelágicos (channíchthyidos y myctóphidos) y una fracción importante de krill ( $>30 \%$ en biomasa).

- Carroñeros/cazadores: Predadores cuya dieta estuvo mayormente constituida por pingüinos y otras presas secundarias tales como aves voladoras, peces, restos de mamíferos, moluscos y crustáceos.

- Malacófagos: Predadores cuya dieta se basa principalmente en moluscos

- Generalistas: Predadores cuya presa principal varía marcadamente de acuerdo a la disponibilidad temporal de alimento y que frecuentemente también consumen carroña (Tabla II.32).

Tabla II.32: Especies de predadores tope de las IOS agrupados según los "Grupos tróficos" definidos previamente

\begin{tabular}{|c|c|c|c|c|c|c|}
\hline Krill (1) & Krill (2) & Ictiófagos (1) & Ictiófagos (2) & $\begin{array}{l}\text { Carroñeros/ } \\
\text { cazadores }\end{array}$ & Malacófagos & Generalistas \\
\hline $\begin{array}{l}\text { P de Adelia } \\
\text { Pingüino de } \\
\text { Barbijo } \\
\text { Petrel de } \\
\text { Wilson }\end{array}$ & $\begin{array}{l}\text { Pingüino Papúa } \\
\text { Foca } \\
\text { Cangrejera } \\
\text { Foca de } \\
\text { Weddell } \\
\text { Lobo Fino } \\
\text { Antártico }\end{array}$ & $\begin{array}{l}\text { Cormorán de } \\
\text { Georgias }\end{array}$ & $\begin{array}{l}\text { Petrel Damero } \\
\text { Petrel de las Nieves } \\
\text { Petrel de las } \\
\text { Tormentas } \\
\text { Escúa Polar } \\
\text { Gaviotín Antártico }\end{array}$ & P. Gigante & $\begin{array}{l}\text { Elefante Marino } \\
\text { Gaviota Cocinera }\end{array}$ & Escúa Marrón \\
\hline
\end{tabular}


Tal como se discutiera previamente, es importante tener en cuenta que los resultados aquí presentados están fuertemente determinados por las limitaciones e imprecisiones asociadas a las diferentes metodologías. En relación a ello, y como fuera mencionado en la discusión, en el caso de las aves el análisis de los pellets tiende a sobreestimar la presencia de invertebrados dada la posibilidad de que provengan de restos de los estómagos de los peces ingeridos por parte del predador. Con respecto a los mamíferos, las muestras de feces presentaron dificultades (subestimación) en la identificación de presas (principalmente peces) principalmente debido a los procesos digestivos de los predadores. Aún así, ambas metodologías proveen información sobre la composición de la dieta con poco esfuerzo de muestreo, a bajo costo y minimizando la perturbación de las colonias o asentamientos reproductivos.

Para finalizar, y tal como ocurriera en I. Kerguelen (Duhamel 1990) y las ISS (Barrera-Oro y Marschoff 1990), la explotación pesquera alrededor de las IOS afectó seriamente a la comunidad de peces, siendo C. gunnari y G. gibberifrons dos de las especies más afectadas (ver Capitulo I) (Kock 1992). Considerando que la información sobre la composición de la dieta de los predadores tope podría reflejar las condiciones locales dentro de la comunidad de presas presentes en el área de forrajeo (Casaux et al. 1995a, Casaux y Barrera-Oro 1998 Coria et al. 2000, Berón et al. 2002 Casaux y Ramón 2002, Casaux et al. 2003a y b, Casaux et al. 2006, Casaux et al. 2007, entre otros), y teniendo en cuenta que la sobreexplotación de la actividad pesquera desarrollada en la década del '70 tanto en las IOS como en otras zonas insulares de Antártida (ISS e IGS principalmente) generó una importante declinación en las poblaciones de N. rossii y G. gibberifrons (Barrera-Oro y Marschoff 1990), la información aquí presentada parece evidenciar la recuperación de la población de $G$. gibberifrons alrededor de las IOS. Con respecto a $P$. antarcticum, llama la atención que este pez frecuentemente representado en la dieta de numerosos predadores (foca de Weddell, escúa Polar, petrel Damero, y Pygoscelis sp.) en otras localidades de la PA y las ISS estuviera ausente en las muestras obtenidas en las IOS. La comparación de la información obtenida en diferentes áreas parece estar reflejando el patrón de distribución de $P$. antarcticum e indica que los myctóphidos cumplen el rol de este pez en el ecosistema de las IOS (Slosarczyk y Cielniaszek 1985, Kellerman 1986, Casaux et al. 1998b). Este tipo de información alienta la utilización del estudio de la composición de la dieta de los predadores tope como herramienta alternativa para desarrollar programas de monitoreos de comunidades de peces y para estudiar sus patrones de distribución. 


\section{II.7. Referencias bibliográficas}

Abrams RW y Griffiths AM (1981) Ecological structure of the pelagic seabird community in the Benguela Current region. Mar Ecol Prog Ser 5: 269-277.

Adams NJ y Klages NT (1987) Seasonal variation in the diet of the king penguin (Aptenodytes patagonicus) at sub-Antarctic Marion Island. Journal of Zoology Lond 212: 303-324.

Ainley DG, Wilson PR, Barton KJ, Ballard G, Nur N y Karl B (1998) Diet and foraging effort of Adelie penguins in relation to pack-ice conditions in the southern Ross Sea. Polar Biology 20: 311-319.

Ainley DG, Sydeman WJ, Hatch SA y Wilson UW (1994) Seabird population trends along the west coast of North America: causes and the extent of regional concordance. Studies of Avian Biology 15: 119-133.

Ainley DG, Fraser WR, Smith Jr WO, Hopkins TL y Torres JJ (1991) The structure of upper level pelagic food webs in the Antarctic: effect of phytoplankton distribution. Journal of Marine Systems 2: 111-122.

Ainley DG, O'connor EF y Boekelheide RJ (1984) The marine ecology of birds in the Ross Sea, Antarctica. Ornithological Monographs 32: 1-97.

Arnould JPY Whitehead MD (1991) The diet of Antarctic petrels, cape petrels and southern fulmars rearing chicks in Prydz Bay. Antarctic Science 3: 19-27.

Barrera-Oro E y Marschoff E (1990) A declining trend in the abundance of Notothenia rossii and Notothenia gibberifrons observed in fjords in two sites in the South Shetland Islands. Commission for the Conservation of Antarctic Marine Living Resources, Fish Stock Assessment Working Group, Selected Scientific Papers: 263-273.

Beck JR y Brown DW (1972) The biology of Wilson's storm-petrel Oceanites oceanicus (Kuhl), at Signy Island, South Orkney Islands. Sci Rep. Br Antarct Surv Bull 69: 1-54.

Berón MP, Coria NR y Favero M (2002) Monitorio de la dieta post-reproductiva del Pingüino Papúa (Pygoscelis papua) en Isla Laurie (Orcadas del Sur, Antártida): Período 1997-1999.Ornitología Neotropical 13: 413-422.

Bierman WH y Voous KH (1950) Birds observed and collected during the whaling expeditions of the Willem Barendsz in the Antarctic, 1946-47 and 1947-48. Ardea 37, extra number, 1-132.

Bigg MA y Fawcett I (1985) Two biases in diet determination of northern fur seals. En: Marine Mammals and Fisheries, pp. Beddington JR, Beverton RJH, Lavigne DM (Eds). Boston: George Allen and Unwin, pp. 277-282.

Bird PG (1965) Bird report, Deception, 1965.

Bonner WN (1981) Southern fur seals Arctocephalus. En: Handbook of marine mammals, vol 1. The walrus, sea lions, fur seals, and sea otters. Ridgway SH, Harrison RJ (Eds) Academic Press, London, pp. 161-208.

Bonner WN (1968) The fur seal of South Georgia. Sci Rep. Br Antarct Surv Bull 56: 1-81.

Bost CA y Jouventin P (1990) Evolutionary ecology of the gentoo penguin Pygoscelis papua. En: Penguins biology. Davis L, Darby J (Eds). Academic, San Diego, pp. 85-112.

Boswall J (1973) Supplementary notes on the birds of Point Tombo, Argentina. Bulletin of the British Ornithologists' Club 93:3336.

Boswall J y Prytherch RJ (1972) Some notes on the birds of Point Tombo, Argentina. Bulletin of the British Ornithologists Club 92:118-129.

Brown DA (1966) Breeding biology of the Snow Petrel (Pagodroma nivea (Forster)). Anare Sci Rep Ser B 89(1): 1-63.

Burger J (1981) The effect of human activity on birds at a coastal bay. Biology Conservation 21: 231-241.

Burger J y Gochfeld M (1996) Fish advisories: Useful or difficult to interpret. Risk: Health, Environment, and Safety 7: 23-33.

Burton RW (1968) Breeding biology of the brown skua. Catharacta lonnbergi (Mathews) at Signy Island, South Orkney Islands. Br Antarct Surv Bull 15: 9-28.

Burns JM, Trumble SJ, Castellini MA y Testa JW (1998) The diet of Weddell seals in McMurdo Sound, Antarctica as determined from scat collections and stable isotope analysis. Polar Biology 19: 272-282.

Carboneras C (1992) Family Procellariidae (petrels and shearwaters). En: Handbook of the Birds of the World, vol 1. del Hoyo J, Elliott A y Sargatal J (Eds). Lynx Edicions, Barcelona, España, pp. 216-257. 
Carboneras C (1992) Order Hydrobatidae. En: Handbook of birds of the world, vol 1. J. del Hoyo, Elliot A y Sargatal (Eds). Lynx Edicions, Barcelona.

Carlini A, Daneri GA, Casaux R y Márquez MEI (2006) Haul-out pattern of itinerant male Antarctic fur seals (Arctocephalus gazella) at Laurie Island, South Orkney Islands. Polar Research 25 (2): 139-144.

Casaux R (2003) On the accuracy of the pellet analysis to estimate the food intake in the antarctic shag, Phalacrocorax georgianus. Folia Zoology 52 (2): 167-176.

Casaux R (1998) Biología reproductiva y ecología alimentaria del cormorán antártico Phalacrocorax bransfieldensis (Aves, Phalacrocoracidae) en las Islas Shetlands del Sur, Antártida. Tesis doctoral, Universidad del La Plata, La Plata, Buenos Aires, 262 pp.

Casaux R. y Barrera-Oro E (2006) Shags in Antarctica: their feeding behaviour and ecological role in the marine food web. Antarctic Science 18: 3-14.

Casaux R. y Barrera-Oro E (2002) Effects a shore-based sampling programme on Notothenia coriiceps populations. Antarctic Science 14(3): 221-224.

Casaux R y Ramón A (2002) The diet of the South Georgia Shag Phalacrocorax georgianus at South Orkney Island in five consecutive years. Polar Biology 25: 557-561.

Casaux R y Barrera-Oro E (1998) Monitoring changes in coastal fish population by the analysis of pellets of the Antarctic Shag: a new proposed standard method. CCAMLR WG-EMM-98/11, Item 9.

Casaux R y Barrera-Oro E (1995) Variation in the diet of the Blue-eyed Shag Phalacrocorax atriceps throughout the breeding season at Half-moon Island, South Shetland Islands. Commission for the Conservation of Antarctic Marine Living Resources, Ecosystem Monitoring and Management Working Group,Document WG-EMM-95/78, 12 pp.

Casaux R y Barrera-Oro (1993) The diet of the blue-eyed shag, Phalacrocorax atriceps bransfieldensis feeding in the Bransfield Strait. Antarctic Science 5: 335-338.

Casaux R, Baroni A, Ramon A, Bertolin ML y DiPrinzio C (2009a) The diet of post-breeding Antarctic shags, Phalacrocorax bransfieldensis, at the Danco Coast, Antarctic Peninsula. Antarctic Science 32(3): 221-227.

Casaux R., Baroni A, Ramon A, Carlini A, Bertolin ML y DiPrinzio C (2009b) Diet of leopard seal Hidrurga leptonyx, at the Danco Coast, Antarctic Peninsula. Polar Biology 32: 307-310.

Casaux R., Carlini A, Corbalán, A., Bertolin M.L. y DiPrinzio C. (2009c) The diet of the Weddell Seal Leptonychotes weddellii at Laurie Island, South Orkney Islands. Polar Biology 32: 833-838.

Casaux R, Baroni A. Ramón, Favero y Silva MP (2007) Aspects of the foraging behaviour of the Antarctic Tern Sterna vittata gaini at Harmony Point, South Shetland Islands. Polar Biology 31: 327-331. doi:10.1007/s00300-007-0362-3.

Casaux R, Baroni A, y Ramón A (2006) The diet of the Weddell Seal Leptonychotes weddellii at the Danco Coast, Antarctic Peninsula. Polar Biology 29: 257-262.

Casaux R, Baroni A, Arrighetti F, Ramón A y Carlini A (2003a) Geographical variation in the diet of the Antarctic fur seal Arctocephalus gazella. Polar Biology 26: 753-758.

Casaux R, Baroni A y Ramón A (2003b) The diet of antarctic fur seals Arctocephalus gazella at the Danco coast, Antarctic Peninsula. Polar Biology 26: 49-54.

Casaux R, Baroni A y Barrera-Oro E (2002) Fish in the diet of the Antarctic shag Phalacrocorax bransfieldensis breeding at four colonies in the Danco Coast, Antarctic Peninsula. Antarctic Science 14: 32-36.

Casaux R. Baroni A y Carlini A (1998a) The diet of Antarctic fur seal Arctochepalus gazella at Harmony Point, Nelson Island, South Shetland Islands. Polar Biology 20: 424-428.

Casaux R, Soave G y Coria N (1998b) Laternfish (Myctophidae) in the diet of Cape Petrel Daption Capense at the South Orkney Islands, Antarctica. Polar Biology 20: 364-366.

Casaux R, Baroni A y Carlini A (1997a) The diet of the Weddell seal Leptonychotes weddelli at Harmony Point, South Shetland Is-lands. Polar Biology 18:371-375.

Casaux R, Coria N y Barrera-Oro E (1997b) Fish in the diet of the Antarctic shag Phalacrocorax bransfieldensis at Laurie Island, South Orkney Islands Polar Biology 18(3): 219-222. doi: 10.1007/s003000050179.

Casaux R, Barrera-Oro E, Favero M y Silva MP (1995a) New correction factors for the quantification of fish represented in pellets of the Blue-eyed Shag Phalacrocorax atriceps. Comm. Conserv. Antarctic Mar. Living Resour. Ecosys. Monitoring Manage. Working Group, Documento 95/83:1-18, Siena, Italy.

Casaux R, Favero M, Barrera-Oro E y Silva MP (1995b) Feeding trial on an Imperial Cormorant Phalacrocorax atriceps: preliminary results on fish intake and otolith digestion. Marine Ornithology 23: 7 y 82.

Clarke MR y MacLeod N (1982a) Cephalopod remains in the stomachs of eight Weddell seals. Br Antarct Surv Bull 57: 33-40. 
Clarke MR, MacLeod N (1982b) Cephalopods in the diet of elephant seals at Signy Island, South Orkney Islands. Br Antarct Surv Bull 57:27-31.

Cline DR, Siniff DB y Erickson AW (1969) Summer birds of the pack ice in the Weddell Sea, Antarctica. Auk 86: 701-716.

Conroy JWH (1972) Ecological aspects of the biology of the Giant Petrel, Macronectes giganteus (Gmelin) in the maritime Antarctic. Br Antarct Surv Scientific Reports 75, 74 pp.

Conroy JWH y Twelves EL (1972) Diving depths of the gentoo penguin (Pygoscelis papua) and blue-eyed shag (Phalacrocorax atriceps) from the South Orkney Islands. Br Antarct Surv Bull 30: 106-108.

Cordier J, Mendez A, Mougin J y Visbeek G (1983) Les oiseaux de la baie d'Espe'rance, Pe'ninsule antarctique (63_240S, 56_590W). L'Oiseau et R.F.O. 53: 371-390.

Coria NR (2006) Biología reproductiva y ecología alimentaria del Petrel gigante del sur Macronectes giganteus (AVES, Procellariidae) en las Islas Shetland del Sur y Orcadas del Sur, Antártida. Tesis Doctoral. Facultad de Ciencias Naturales y Museo, Universidad Nacional de La Plata, La Plata, Buenos Aires, Argentina.

Coria N, Libertelli M, Casaux R y Darrieu C (2000) Inter-annual variation in the autumn diet of the Gentoo Penguin at Laurie Island, Antartctica. Waterbirds 23: 511-517.

Coria NR, Soave GE y Montalti D (1997) Diet of Cape Petrel Daption capense during the post-hatching period at Laurie Island, South Orkney Islands, Antarctica. Polar Biology 18: 236-239.

Coria NR, Spairani H, Vivequin S y Fontana R (1995) Diet of Adelie penguins Pygoscelis adeliae during the post-hatching period at Esperanza Bay, Antarctica, 1987/88. Polar Biology 15: 415-418.

Creet S, van Franeker JA, van Spanje TM y Wolff WJ (1994) Diet of the pintado petrel Daption capense at King George Island, Antarctica, 1990/91. Marine Ornithology 22: 221-229.

Croxall JP (1995) Sexual size dimorphism in seabirds. Oikos 73: 399-402.

Croxall JP (1984) Seabirds. En: Antarctic ecology, vol 2, 534-618 pp. Academic Press, London.

Croxall JP y North AW (1988) Fish prey of Wilson' storm petrel Oceanites oceanicus at South Georgia. Br Antarct Surv Bull 78: $37-42$.

Croxall JP y Prince PA (1987) Seabirds as predators on marine resources, especially krill, at South Georgia. En: Seabirds: Feeding Ecology and Role in Marine Ecosystems. Croxall JP (Ed) Cambridge University Press, Cambridge, pp. 347-368.

Croxall JP y Prince PA (1980) Food, feeding ecology and ecological segregation of seabirds at South Georgia. Biological Journal of the Linnean Society 14: 103-131.

Croxall JP, Hill HJ, Lidstone-Scott R, O'Connell MJ y Prince PA (1988) Food and feeding ecology of Wilson's storm petrel Oceanites oceanicus at South Georgia. Journal of Zoology Lond 216: 83-102.

Croxall JP, Prince PA, Hunter I, McInnes SJ y Copestake PG (1984) The seabirds of the Antarctic Peninsula, islands of the Scotia Sea, and Antarctic continent between $80^{\circ} \mathrm{W}$ and $20^{\circ} \mathrm{W}$ : their status and conservation. ICBP Tech Publication 2: $637-$ 666.

Daneri GA (1996) Fish diet of the Antarctic fur seal, Arctocephalus gazella, in summer, at Stranger Point, King George Island, South Shetland Islands. Polar Biology 16: 353-355.

Daneri GA y Carlini A (2002) Fish prey of the southern elephant seal, Mirounga leonine, at King George Island, South Shetland Islands, as reflected by stomach lavagEscúa Polar Biology 25: 739-743.

Daneri GA y Carlini AR (1999) Spring and summer predation on fish by the Antarctic fur seal, Arctocephalus gazella, at King George Island, South Shetland Islands. Canadian Journal of Zoology 77: 1157-1160.

Daneri GA y Coria NR (1994) Fish prey of Antarctic Fur Seals, Arctocephalus gazella, during the summer-autumn period at Laurie Island, South Orkney Islands. Polar Biology 13: 287-289.

Daneri GA y Coria NR (1992) The diet of Antarctic fur seals, Arctocephalus gazella, during the summer-autumn period at Mossman Peninsula, Laurie Island (South Orkneys). Polar Biology 11: 565-566.

Daneri GA, Carlini AR y Rodhouse PGK (2000) Cephalopod diet of the southern elephant seal, Mirounga leonina, at King George Island, South Shetland Islands. Antarctic Science 12:16-19.

Daneri GA, Piatkowski U, Coria R y Carlini AR (1999) Predation on cephalopods by Antarctic fur seals, Arctocephalus gazella, at two localities of the Scotia Arc, Antarctica. Polar Biology 21: 59-63.

Davis RW, Croxall JP y O'Connell MJ (1989) The reproductive energetic of Gentoo (Pygoscelis papua) and Macaroni (Eudyptes chrysolophus) Penguins at South Georgia. Journal of Animal Ecology 58: 59-74. 
Dearborn JH (1965) Food of Weddell seals at McMurdo Sound, Antarctica. Journal of Mammals 46: 37-43.

Dellinger T y Trillmich F (1988) Estimating diet composition from scat analysis of otariid seals (Otariidae): is it reliable? Canadian Journal of Fish Aquatic Science 42: 1865-1870.

Del Hoyo J, Elliott A y Sargatal J (1992) Handbook of the birds of the world, vol 1. Ostrich to ducks. Lynx Edicions, Barcelona.

Doidge DW y Croxall JP (1985) Diet and energy budget of the Antarctic fur seal, Arctocephalus gazella, at South Georgia. En: Antarctic nutrient cycles and food webs. Siegfried WR, Condy PR, Laws RM (Eds) Springer, Berlin Heidelberg New York, pp. 543-550.

Duhamel G (1990) Supplementary data on exploited stocks in Division 58.5.1 (Kerguelen). Selected Scientific Papers (SCCAMLR-SSP/6). CCAMLR, Hobart.

Endo Y, Asari H, Watanuki Y, Kato A, Kuroki M y Nishikawa J (2002) Biological characteristics of euphausiids preyed upon by Adelie penguins in relation to sea-ice conditions in Lutzow-Holm Bay, Antarctica. Polar Biology 25: 730-738.

Emslie SD y Patterson WP (2007) Abrupt recent shift in $\delta 13 \mathrm{C}$ and $\delta 15 \mathrm{~N}$ values in Adelie penguin eggshell in Antarctica. PNAS 104(28): 11666-11669.

Espitalier-Noel G, Adams NJ y Klages NT (1988) Diet of the Imperial Cormorant Phalacrocorax atriceps at subantarctic Marion Island. Emu 88: 43-46.

Everson I (1970) The population dynamics and energy budget of Notothenia neglecta nybelin at Signy Island, South Orkney Islands. Br Antarct Surv Bull 23: 25-50.

Falla RA (1937) Birds. Banzare Report Series B 2: 1-288.

Favero M y Coria NR (2007) Feeding aggregation and diets of seabirds at Gerlache Strait, Antarctica. Acta Zoológica Sinica 53(3): 425-430.

Favero M y Silva MP (1998) How important are pelagic preys for the kelp gull during chick rearing at the South Shetland Islands? Polar Biology 19: 32-36.

Favero M, Casaux R, Silva P, Barrera-Oro E y Coria N (1998) The diet of the Antarctic Shag during summer at Nelson Island, Antarctica. Condor 100: 112-118.

Ferretti V, Soave GE, Casaux R y Coria NR (2001) Diet of the snow petrel Pagodroma nivea at Laurie Island, Antarctica, during the 1997/98 breeding season. Marine Ornithology 29: 71-73.

Fischer W y Hureau J (1988) Fichas FAO de identificación de especies para los fines de pesca. Océano Austral (áreas de pesca 48, 58 y 88, área de la Convención CCAMLR). Roma, FAO 1(1): 232 pp.

Fraser WR (1989) Aspects of the ecology of kelp gull (Larus dominicanus) on Anvers Island, Antarctic Peninsula. Tesis doctoral. Universidad de Minneapolis.

Fraser WR y Hofmann EE (2003) A predator's perspective on causal links between climate change, physical forcing and ecosystem response. Marine ecology progress series 265: 1-15.

Furness RV y Monaghan P (1987) Seabird ecology. Chapman and Hall/Methuen, Inc, New York.

Gochfeld M y Burger J (1996) Family Sternidae (Terns). En: Handbook of the birds of the world, vol 3. del Hoyo J, Elliot A, Sargatal J (Eds). Lynx Editions, Barcelona, pp. 624-667.

Green K (1986) Observations on the food of the south polar skua Catharacta maccormicki near Davis, Antarctica. Polar Biology 6: $185-186$.

Green K y Burton HR (1993) Comparison of the stomach contents of southern elephant seals, Mirounga leonina, from two breeding populations. Marine Mammals Science 9: 10-22.

Green K y Burton HR (1987) Seasonal and geographical variation in the food of Weddell seals, Leptonychotes weddellii, in Antarctica. Australian Wildlife Researches 14: 475-489.

Green K y Williams R (1986) Observations on food remains in faeces of elephant, leopard and crabeater seals. Polar Biology 6 : 43-45.

Green K, Williams R y Slip D (1990) Diet of Macquarie Island Cormorant Phalacrocorax atriceps purpurascens. Corella 14(2): 53-55.

Green K, Burton H y Watts D (1995) Studies of the Weddell seals in the Vestfold Hills, East Antarctica. ANARE Research Notes 93: 1-64. 
Green K, Williams R y Burton HR (1991) The diet of Antarctic fur seals during the late autumn and early winter around Heard Island. Antarctic Science 3: 359-361.

Green K, Williams R, Woehler E, Burton H, Gales N y Jones R (1990) Diet of the Heard Island cormorant Phalacrocorax atriceps nivalis. Antarctic Science 2(2): 139-141.

Green K, Burton HR y Williams R (1989) The diet of Antarctic fur seals Arctocephalus gazella during the breeding season at Heard Island. Antarctic Science 1: 317-324.

Griffiths AM (1983) Factors affecting the distribution of the Snow Petrel (Pagodroma nivea) and Antarctic Petrel (Thalassoica antarctica). Ardea 71: 145-150.

Hahn S (1998) The food and chick feeding of blackbellied stormpetrel (Fregetta tropica) at King George Island, South Shetlands. Polar Biology 19: 354-357.

Harrison P (1983) Seabirds. An identification guide. Beckenham: Croom Helm.

Hemmings AD (1984) Aspects of the breeding biology of McCormick's skua Catharacta maccormicki at Signy Island, South Orkney Islands. Br Antarct Surv Bull 65: 65-79.

Hindell MA (1989) The diet of gentoo penguins Pygoscelis papua at Macquarie Island: winter and early breeding season. Emu 89: $71-78$.

Howes L y Montevecchi W (1993) Population trends and interactions among terns and gulls in Gros Morne National Park, Newfound-land. Canadian Journal of Zoology 71: 1516-1520.

Hulley PA (1990) Myctophidae. En: Fishes of the Southern Ocean. Gon O, Heemstra PC (Eds). J.L.B. Smith Institute of Ichthyology, Grahamstown, pp. 146-178.

Hunter S (1983) The food and feeding ecology of the giant petrels Macronectes halli and M. giganteus at South Georgia. Journal of Zoology 200(4): 521-538. doi: 10.1111/j.1469-7998.1983.tb02813.x

Hunter S y Brooke MDL (1992) The diet of giant petrels Macronectes spp. at Marion Island, Southern Indian Ocean. Colonial Waterbirds 15:56-65

Hureau JC (1994) The significance of fish in the marine Antarctic ecosystem. Polar Biology 14: 307-313.

Jablonski B (1995) Distribution, abundance and biology of the Antarctic Tern Sterna vittata on King George Island (South Shetland Islands). Acta Zoológica Cracoviensia 29: 117-186.

Jablonski B (1985) The diet of penguins on King George Island, South Shetland Islands. Acta Zoológica Cracoviensia 29: 117186.

Jansen JK, Boveng PL, Bengtson JL (1998) Foraging modes of chinstrap penguins: contrasts between day and night. Marine Ecology Progress Series 165: 161-172.

Jazdzewski K y Konopacka A (1999) Necrophagous Iysianassoid Amphipoda in the diet of Antarctic tern at King George Island, Antarctica. Antarctic Science 11: 316-321.

Jobling M y Breiby A (1986) The use and abuse of fish otoliths in studies of feeding habits of marine piscivores. Sarsia 71: 265274.

Jones CD, Kock KH y Balguerías E (2000) Changes in biomass of eight species of finfish around the South Orkney Islands (Subarea 48.2) from three bottom trawl surveys. CCAMLR Science 7: 53-74.

Jouventin P, Mougin JL, Stahl JC y Weimerskirch H (1985) Comparative biology of the burrowing petrels of the Crozet Islands. Notornis 32: 157-220.

Klages NTW, Pemberton D y Gales RP (1990) The diets of king and Gentoo penguins at Heard Island. Australian Wildlife Research 17: 53-60.

Kellermann A (1986) Geographical distribution and abundance of postlarval and juvenile Pleuragramma antarcticum (Pisces Notothenioidei) of the Antarctic Peninsula. Polar Biology 6: 111-119.

Kock KH (1992) Antarctic fish and fisheries. Cambridge University Press, Cambridge

Kock KH, Jones CD y Wilhelms S (2000) Biological characteristics of Antarctic fish stocks in the Southern Scotia Arc region. CCAMLR Science 7: 1-41.

Koslov AN (1995) A review of the trophic role of mesopelagic fish of the family Myctophidae in the southern Ocean ecosystem. CCAMLR Science 2: 71-77.

Krackenberger MB y Bryden MM (1994) Rate of passage of digesta through the alimentary tract of southern elephant seals (Mirounga leonina) (Carnivora: Phocidae). Journal of Zoology 234: 229-237.

La Cock GD, Hecht T y Klages N (1984) The winter diet of Gentoo penguins at Marion Island. Ostrich 55: $188-191$. 
Lake S, Burton $\mathrm{H}$ y van den Hoff J (2003) Regional, temporal and fine-scale spatial variation in Weddell seal diet at four coastal locations in east Antarctica. Marine Ecology Progress Series 254: 293-305.

Laws RM (1994) History and present status of southern elephant seal populations En: Elephant seals: population ecology, behaviour, and physiology. Le Boeuf BJ, Laws RM (Eds). University of California Press, Berkeley, pp. 49-65.

Laws RM (1984) Seals. En: Antarctic ecology. 81-96 pp. Laws RM (Ed). Academic Press, London.

Laws RM (1981) Seal surveys, South Orkney Islands, 1971 and 1974. Br Antarct Surv Bull 54: 136-139.

Laws RM (1973) Population increase of fur seals at South Georgia. Polar Rec 16: 856-858.

Ledford $\mathrm{H}$ (2007) Whaling made penguins switch to krill. Birds changed diet after humans killed shrimp eaters. Published online: 9 July 2007, doi: 10.1038/news070709-1.

Libertelli M, Daneri GA, Piatkowski U, Coria NR, Carlini AR (2004) Predation on cephalopods by Pygoscelis papua and Arctocephalus gazella at South Orkney Islands. Polish Polar Research 25(3-4): 267-274.

Libertelli M, Coria N y Marateo G (2003) Diet of Adelia penguin during three consecutive chick rearing at Laurie Island. Polish Polar Research 24(2): 133-142.

Lishman GS (1985) The food and feeding ecology of Adelie penguins (Pygoscelis adeliae) and chinstrap penguins (Pygoscelis antarctica) at Signy Island, South Orkney Islands. Journal of Zoology Lond 205: 245-263.

Loots C, Koubbi P y Duhamel G (2007) Habitat modelling of Electrona antarctica (Myctophidae, Pisces) in Kerguelen by generalized additive models and geographic information systems. Polar Biology 30(8): 951-959. doi: 10.1007/s00300-0070253-7.

Lowry LF, Testa JW y Calvert W (1988) Winter feeding of Crabeater and Leopard seals near the Antarctic Peninsula. Polar Biology 8: 475-478.

Lynnes AS, Reid K y Croxall JP (2004) Diet and reproductive success of Adelie and Chinstrap penguins: linking response of predators to prey population dynamics. Polar Biology 27: 544-554. doi: 10.1007/s00300-004-0617-1.

Lynnes AS, Reid K, Croxall JP y Trathan PN (2002) Conflict or coexistence? Foraging distribution and competition for prey between Adelie and Chinstrap penguins. Marine Biology 141: 1165-1174.

McCann TS (1985) Size, status, and demography of southern elephant seal (Mirounga leonina) populations. En: Sea Mammals in South Latitudes: Proceedings of Symposium of the 52d ANZAAS Congress in Sydney. Ling JK y Bryden MM (Eds). Northefield, South Australian Museum, pp. 1-17.

Martinez I (1992) Family Spheniscidae (Penguins). En: Handbook of the birds of the world, vol 1. del Hoyo J, Elliott AR y Sargatal J (Eds). Barcelona: Lynx Edicions ICBP, pp. 140-158.

Malzof SL y Quintana RD (2008) Diet of the South Polar Skua Catharacta maccormicki and the Brown Skua C. antarctica lonnbergi at Cierva Point, Antarctic Peninsula. Polar Biology 31: 827-835. doi: 10.1007/s00300-008-0421-4.

Maxson SJ y Bernstein NP (1984) Breeding season time budgets of the southern black-backed gull in Antarctica. Condor 86: 401-409.

Milius N (2000) The birds of Rothera, Adelaide Island, Antarctic Peninsula. Marine Ornithology 28: 63-67.

Montalti D (2005) Morfología y Biología reproductiva de las especies del género Catharacta (Aves, Stercorariidae) de la Antartida. Tesis Doctoral, Facultad de Ciencias Naturales y Museo, UNLP.

Montalti D, Casaux R, Coria N y Soave G (1996) The importance of fish in the diet of the South Polar Skua Catharacta maccormicki at the South Shetland Islands, Antarctica. Document WG-EMM-96/32. CCAMLR, Hobart, 7 pp.

Murphy RC (1936) Oceanic birds of South America. New York: American Museum of Natural History.

Nicol S (2006) Frill, Currents, and Sea Ice: Euphasia superba and its changing environment. BioScience 56 (2): 111-120.

North AW, Croxall JP y Doidge DW (1983) Fish prey of the Antarctic fur seal Arctocephalus gazella at South Georgia. Br Antarct Surv Bull 61: 27-37.

Obst BS y Nagy KA (1993) Stomach oil and the energy budget of Wilson's storm-petrel nestlings. Condor 95: 792-805.

Odum EP (1959) Fundaments of Ecology. 2da. Edición. Odum EP (Ed) Philadelphia, Saunders Co.

Øritsland T (1977) Food consumption of seals in the Antarctic pack-ice. En: Adaptations within Antarctic ecosystems. Llano GA (Ed). Smithsonian Institution, Washington DC, pp. 749-768.

Orta J (1992) Family Phalacrocoracidae (Cormorants). En: Handbook of the birds of the world, vol 1. del Hoyo J, Elliot A y Sargatal J (Eds). Lynx, Barcelona. 
Parmelee D y Maxson S (1975) The Antarctic Terns of Anvers Island. Living Bird 13: 233-250.

Parmelee DF, Bernstein NP y Neilson DR (1978) Impact of unfavourable ice conditions on bird productivity at Palmer Station during the 1977-78 field season. Antarctic Journal US 13: 146-147.

Patterson DL, Woehler EJ, Croxall JP, Cooper J, Poncet S, Peter HU, Hunter S y Fraser WR (2008) Breeding distribution and population status of the Northern Giant Petrel Macronectes halli and Southern Giant Petrel M. giganteus. Marine Ornithology 36: 115-124.

Paulian P (1953) Pinnipedes, cetaces, oiseaux des lles Kerguelen et Amsterdam. Mission Kerguelen 1951. Mem Inst Sci Madagascar $8(\mathrm{~A}): 111-234$

Payne MR (1977) Growth of a fur seal population. Polar Record 16: 856-858.

Peter HU, Kaiser M y Gebaner A (1990) Ecological and morphological investigations on South Polar Skua (Catharacta maccormicki) and Brown Skua (Catharacta antarctica lonnbergi) on Fildes Peninsula, King George Island, South Shetland Islands. Zool JB Syst 117: 201-218.

Peter H, Kaiser M y Gebauer A (1988) Untersunchungen an Vo"gel und Robben auf King George Island (South Shetland Islands, Antarktis). Geod Geoph Vero" ff 1: 1-127.

Pierotti R (1982) Habitat selection and its effets on reproductive output in the Herring Gull in Newfoundland. Ecology 63: 854868.

Pietz PJ (1987) Feeding and nesting ecology of sympatric South Polar and Brown skuas. Auk 104: 617-627.

Plötz J (1986) Summer diet of Weddell seals (Leptonychotes weddelli) in the Eastern and Southern Weddell Sea, Antarctica. Polar Biology 6: 97-102.

Plötz J, Ekau W y Reijnders PJH (1991) Diet of Weddell seals Leptonychotes weddellii at Vestkapp, Eastern Weddell Sea (Antarctica), in relation to local food supply. Marine Mammals Science 7: 136-144.

Reinhardt SB y Van Vleet ES (1986) Lipid composition of twenty-two species of Antarctic midwater zooplankton and fish. Marine Biology 91: 149-159.

Reinhardt K, Hahn S, Peter HU y Wemhoff H (2000) A review of the diet of southern hemisphere skua. Mar Ornith 28: 7-19.

Reinhardt K, Hahn S y Peter H-U (1998) The role of skuas in the food web of Potter Cove system —a review. Ber Polarforsch 299: $279-284$.

Ridoux V (1994) The diets and dietary segregation of seabirds at the subantarctic Crozét Islands. Marine Ornithology 22: 1192.

Ridoux V (1988) Subantarctic krill Euphausia vallentini preyed upon by penguins around Crozet Islands (Southern Indian Ocean): population structure and avian cycle. Journal of Plankton Reserach10: 675-690.

Ridoux V y Offredo C (1989) The diets of five summer breeding seabirds in Adélie Land, Antarctica. Polar Biology 9: 137-145.

Rodhouse PG, Arnbom TR, Fedak MA, Yeatman J y Murray AWA (1992) Cephalopod prey of the southern elephant seal, Mirounga leonina L. Canadian Journal of Zoology 70: 1007-1015.

Roberts B (1940) The life cycle of Wilson's petrel Oceanites oceanicus (Kuhl). Sci Rep British Graham Land Exped 1: 141-194.

Robinson SA y Hindell MA (1996) Foraging ecology of Gentoo penguins Pygoscelis papua at Macquarie Island during the period of chick care. Ibis 138: 722-731.

Rombola E, Marschoff E y Coria N (2003) Comparative study of the effects of the late pack-ice break-off on chinstrap and Adelie penguins' diet and reproductive success at Laurie Island, South Orkney Islands, Antarctica. Polar Biology 26: 41-48.

Schulz M y Gales R (2004) Winter diet of the Subantarctic Skua Catharacta antarctica at Macquarie Island. Mar Ornith 32: 179181.

Shaw P (1984) Factors affecting the breeding performance of the Antarctic blue-eyed shag (Phalacrocorax atriceps bransfieldensis). Tesis doctoral. Universidad de Durham.

Silva MP (2006) Ecología trófica de la Gaviota Cocinera Larus dominicanus en áreas con diferente grado de antropización. Tesis doctoral, Univ. Nacional de Mar del Plata, Mar del Plata, Argentina

Silva MP (1996) Alimentación de la Gaviota Cocinera Larus dominicanus en Islas Shetland del Sur, Antártida. Tesis de licenciatura, Univ. Nacional de Mar del Plata, Mar del Plata, Argentina

Silva P, Favero M, Casaux R y Baroni A (1998) The status of breeding birds at Harmony Point, Nelson Island, Antarctica in summer1995/96. Marine Ornithology 26: 75-78.

Sladen WJL (1958) The pygoscelid penguins, I. Methods of study, II. The Adelie penguin. Falkland IsI Depend Surv Sci Rep 17: $1-97$. 
Slip DJ (1995) The diet of juvenile and adult southern elephant seals (Mirounga leonina) from Heard Island. Canadian Journal of Zoology 73: 1519-1528.

Slosarczyk W y Cielniaszek Z (1985) Postlarval and juvenile fish (Pisces, Perciformes and Myctophiformes) in the Antarctic Peninsula during BIOMASS-SIBEX, 1983/1984. Polish Polar Research 6: 159-165.

Soave G, Coria N, Silva P, Montalti D y Favero M (1996) The diet of the Cape petrel Daption capense during the chick-rearing period at Fildes Peninsula and Harmony Point, South Shetland Islands, Antarctica. Commission for the conservation of Antarctic marine living resources, ecosystem monitoring and management working group, document 96/17, Bergen, Norway.

Takahashi A, Dunn MJ, Trathan PN, Sato K, Naito Y y Croxall JP (2003) Foraging strategies of Chinstrap penguins at Signy Island, Antarctica: importance of benthic feeding on Antarctic krill. Mar Ecol Prog Ser 250: 279-289.

Trivelpiece WZ, Trivelpiece SG, Volkman NJ y Ware SH (1983) Breeding and feeding ecologies of pygoscelid penguins. Antarctic Journal U.S.18: 209-210.

Trivelpiece W, Butler RG y Volkman NJ (1980) Feeding territories of Brown skuas (Catharacta lonnbergi). Auk 97: 669-676.

Van Franeker JA (2001) Mirrors in ice. Fulmarine petrels and Antarctic ecosystems. Tesis doctoral. Universidad de Groningen, $274 \mathrm{pp}$.

Van Franeker JA, Williams R, Imber MJ y Wolff WJ (2001) Diet and foraging ecology of southern fulmar (Fulmarus glacialoides), Antarctic petrel Thalassoica antarctica, cape petrel Daption capense and snow petrels Pagodroma nivea ssp on Ardery Island, Wilkes Land, Antarctica. Chapter 11 (p 58). En: Mirrors in ice. Chapter 11, 58 p. Tesis doctoral. Uniersidad de Groningen. Alterra, Texel.

Van Franeker JA y Williams R (1992) Diet of fulmarine petrels in the Windmill Islands, Wilkes Land, Antarctica. Preliminary results. Circumpolar Journal 7: 134-138.

Van Heezik Y (1988) Diet of Adelie penguins during the incubation period at Cape Bird, Ross Island, Antarctica. Notornis.

Volkman NJ, Presler P y Trivelpiece W (1980) Diets of pygoscelid penguins at King George Island, Antarctica. Condor 82: 373378.

Votier SC, Bearhop S, MacCormick A, Ratcliffe N y Furness RW (2003) Assessing the diet of great skuas, Catharacta skua, using five different techniques. Polar Biology 26: 20-26.

Waluda CM, Gregory S y Dunn MJ (2010) Long-term variability in the abundance of Antarctic fur seals Arctocephalus gazella at Signy Island, South Orkneys. Polar Biology 33(3): 305-312. doi: 10.1007/s00300-009-0706-2.

Wanless S y Harris M (1993) Use of mutually exclusive foraging areas by adjacent colonies of blue-eyed shags (Phalacrocorax atriceps) at South Georgia. Colon Waterbirds 16:176-182.

Watanuki Y, Kato A, Mori Y y Naito Y (1993) Diving performance of Adelie penguins in relation to food availability in fast sea-ice areas-comparison between years. Journal of Animal Ecology 62: 634-646.

Watson GE (1975) Birds of the Antarctic and Subantarctic. William Byrd Press, Richmond, Virginia.

White MG y Conroy JWH (1975) Aspects of competition between pygoscelid penguins at Signy Island, South Orkney Islands. Ibis 117: $371-373$

Whitehouse MJ y Veit RR (1994) Distribution and abundance of seabirds and fur seals near the Antarctic Peninsula during the austral winter, 1986. Polar Biology 14(5): 325-330. doi: 10.1007/BF00238448.

Wienecke BC, Lawless R, Rodary D, Bost CA, Thomson R, Pauly T, Robertson G, Kerry KR y Le Maho Y (2000) Adelie penguin foraging behaviour and krill abundance along the Wilkes and Adelie land coasts, Antarctica. Deep Sea Research Part II 47: 2573-2587.

Williams TD (1995) The penguins. Á Oxford University Press, Oxford.

Williams TD (1991) Foraging ecology and diet of gentoo penguins Pygoscelis papua at South Georgia during winter and an assessment of their winter prey consumption. Ibis 133: 3-13.

Woehler EJ (1993) The distribution and abundance of Antarctic and Subantarctic penguins. Sci Comm Antarc Res, Scott Polar Res Inst, Cambridge.

Young EC y Millar CD (1999) Skua (Catharacta sp.) foraging behaviour at the Cape Crozier Adelie penguin (Pygoscelis adeliae) colony, Ross Island, Antarctica, and implications for breeding. Notornis 46: 287-297. 


\section{II.6. Anexo Tablas}

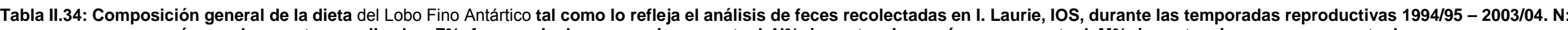
número de muestras analizadas, F\%: frecuencia de ocurrencia porcentual, N\%: importancia en número porcentual, M\%: importancia en masa porcentual.

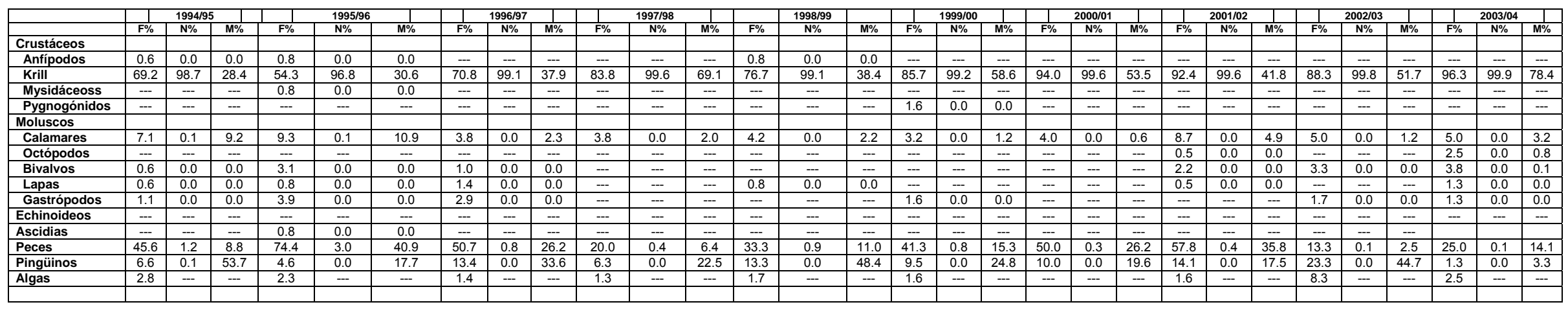

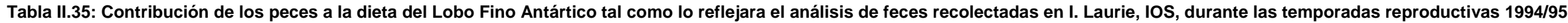
- 2003/04. F\%: frecuencia de ocurrencia porcentual, N\% importancia en número porcentual, M\%: importancia en masa porcentual.

\begin{tabular}{|c|c|c|c|c|c|c|c|c|c|c|c|c|c|c|c|c|c|c|c|c|c|c|c|c|c|c|c|c|c|c|}
\hline \multirow{2}{*}{ Bathydraconidae } & \multirow{2}{*}{\multicolumn{3}{|c|}{\begin{tabular}{l|l}
$1994 / 95$ & 1 \\
\end{tabular}}} & \multicolumn{3}{|c|}{$1995 / 96$} & \multirow{2}{*}{\multicolumn{3}{|c|}{\begin{tabular}{l|l}
$1996 / 97$ \\
\end{tabular}}} & \multicolumn{3}{|c|}{$1997 / 98$} & \multicolumn{3}{|c|}{$1998 / 99$} & \multicolumn{3}{|c|}{ 1999/100 } & \multicolumn{3}{|c|}{2000101} & \multicolumn{3}{|c|}{$2001 / 02$} & \multicolumn{3}{|c|}{2002103} & \multicolumn{3}{|c|}{2003104} \\
\hline & & & м\% & F\% & N\% & М\% & $\mathrm{F} \%$ & & & $F \%$ & $\mathrm{~N} \%$ & М\% & $\mathrm{F} \%$ & N\% & $\mathrm{M} \%$ & $\mathrm{~F} \%$ & $\mathrm{~N} \%$ & M\% & F\% & N\% & $\mathrm{M} \%$ & $\mathrm{~F} \%$ & $\mathrm{~N} \%$ & M\% & $\mathrm{F} \%$ & N\% & $\mathrm{M} \%$ & F\% & N\% & М\% \\
\hline Bathydraconidae & - & $\ldots$ & $\ldots$ & 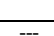 & 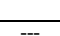 & -- & 05 & $\overline{01}$ & 03 & & & & & & & $-\ldots$ & & & & & & & & & 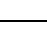 & & 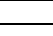 & - & - & \\
\hline G.a & --- & $-\ldots-$ & --- & --- & --- & -.-- & 0,5 & 0,1 & 0,1 & --- & --- & -- & -- & -- & $\ldots$ & --- & --- & -- & --- & -- & -- & -- & --- & --- & -- & --- & --- & -- & --- & 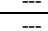 \\
\hline$P . c h$ & - & $-\ldots$ & --- & 1,6 & 0,3 & 0,3 & 0,5 & 0,1 & 1,1 & - & --- & --- & --- & --- & $\ldots$ & --- & --- & --- & --- & --- & $\ldots$ & -- & $-\ldots-$ & --- & - & -- & --- & --- & --- & --- \\
\hline Chann & & & & & & & & & & & & & & & & & & & & & & & & & & & & & & \\
\hline C. rh & --- & --- & --- & --- & --- & --- & 1,0 & 0,3 & 0,3 & -- & -- & -- & -- & --- & --- & --- & --- & -- & -- & --- & --- & --- & --- & -- & -- & -- & --- & -- & --- & -- \\
\hline C. aceratus & 1,1 & 0,9 & 12,6 & 3,9 & 0,8 & 19,6 & 1,0 & 0,5 & 4,3 & -- & - & -- & 0,8 & 0,3 & 3,0 & 1,6 & 0,3 & 3,9 & 20,2 & 21,4 & 61,2 & 14,1 & 9,0 & 13,4 & --- & -- & -- & --- & --- & --- \\
\hline C. wilso & -- & - & --- & --- & - & --- & 0,5 & 0,6 & 2,6 & --- & - & $\ldots$ & -- & --- & $\cdots$ & -- & -- & --- & -- & --- & -- & & 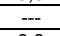 & & -- & --- & --- & --- & --- & --- \\
\hline C. gunnari & & & & --- & & --- & & & & --- & - & -- & --- & --- & & --- & --- & --- & - & -- & & 0,5 & 0,3 & 0,3 & -- & 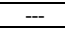 & 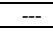 & & & \\
\hline C. rastrospinosu & 0,6 & 0,9 & 16,8 & 7,8 & 2,4 & 12,7 & 3,8 & 3.5 & 9,9 & --- & - & $-\cdots$ & 0,8 & 2,1 & 10,6 & $-\cdots$ & --- & --- & 6,0 & 8,6 & $\begin{array}{ll}14,5 \\
\end{array}$ & 6,5 & 4,6 & 5,0 & 5,0 & 6,4 & 28,2 & 3,8 & 40,0 & 24,4 \\
\hline C. $a$ & -- & - & -- & 4,7 & 0,7 & 6,7 & 3,4 & 1, & 3,8 & --- & - & - & -- & - & -- & 1,6 & 0,6 & 3,1 & & 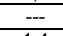 & --- & $\cdots$ & - & - & -- & -- & -- & 3,8 & 6,7 & 8,3 \\
\hline$P . g 6$ & & - & & 2,3 & 1,1 & & 1,9 & & 1,2 & $\ldots$ & - & $\ldots$ & --- & --- & & -- & $\ldots$ & -- & 2,0 & 1,4 & 1,0 & -- & --. & $\ldots$ & $-\ldots$ & & --- & $\ldots$ & & - \\
\hline Notot & - & $\cdots$ & 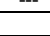 & 2,0 & 1,1 & 4,0 & 1,9 & 0,5 & 1,2 & 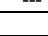 & 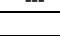 & - & 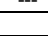 & 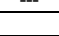 & -- & $\cdots$ & 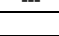 & 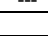 & 2,0 & 1,4 & 1,0 & -- & -- & $\ldots$ & - & - & - & 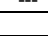 & - & \\
\hline G. $g i$ & 1,1 & 2,3 & 12,1 & & & 20 & 11,5 & 13, & 55,7 & 1,3 & 0, & 1, & 1,7 & 0,9 & 13,3 & - & $\ldots$ & - & 12,0 & 15,7 & 14,9 & 30,8 & 48,9 & 77,0 & 1,7 & 2, & 4,6 & 6,3 & 37,8 & 66,4 \\
\hline & 0,6 & 0,4 & 2,2 & & & & & & & & & & $\ldots$ & $\ldots$ & -- & $\ldots$ & & $\ldots$ & & & 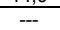 & -- & & & -- & $\ldots$ & -- & -- & -- & -- \\
\hline & 2,2 & 1 & 2 & 14 & $\frac{12}{12}$ & 14 & 9 & 5 & 3, & 1, & 4, & 9 & - & - & $\ldots$ & 4, & 1 & 2, & 8, & 10 & 3 & 6 , & & 0 & & & & & & \\
\hline & 0,6 & 0,4 & 0,4 & 3, & 5,1 & $\begin{array}{l}3,4,8 \\
\end{array}$ & 1,4 & 0,9 & 0, & 1 & 2 & 4,7 & 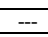 & $\ldots$ & $\ldots$ & $-\cdots$ & 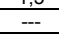 & 2, & $\begin{array}{l}0,0 \\
6,0 \\
\end{array}$ & 7 & 1. & 0 & 0, & 0, & & & - & 1,3 & 2,2 & 0,1 \\
\hline & --- & - & -- & $\ldots$ & -7 & - & --- & -- & - & - & 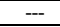 & - & 0,8 & 0,3 & 2,4 & - & - & - & - & --- & --- & -- & --- & $\ldots$ & -- & -- & -- & 1,3 & 2,2 & 0,4 \\
\hline & & & - & 0,8 & 0,1 & 0,1 & 0,5 & 0,1 & 0,1 & & --- & - & -- & - & 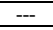 & 1,6 & 0,3 & 0,7 & $\ldots$ & --- & & & - & --- & - & $\cdots$ & -- & $\cdots$ & - & \\
\hline T. newnesi & 1,7 & 1,3 & 1,6 & 2,3 & 0,3 & 0,1 & --- & --- & --- & --- & --- & --- & --- & --- & $\ldots$ & $-\cdots$ & --- & --- & --- & $-\cdots$ & --- & 0,5 & 0,3 & 0,1 & --- & --- & -- & --- & --- & --- \\
\hline
\end{tabular}


Tabla II.35: Continuación

\begin{tabular}{|c|c|c|c|c|c|c|c|c|c|c|c|c|c|c|c|c|c|c|c|c|c|c|c|c|c|c|c|c|c|c|}
\hline \multirow{3}{*}{ Harpagiferidae } & \multicolumn{3}{|c|}{$1994 / 95$} & \multirow{2}{*}{\multicolumn{3}{|c|}{$\frac{1995 / 96}{}$ № }} & \multicolumn{3}{|c|}{\begin{tabular}{|c|}
$1996 / 197$ \\
N\%
\end{tabular}} & \multicolumn{3}{|c|}{$1997 / 98$} & \multicolumn{3}{|c|}{$1998 / 99$} & \multicolumn{3}{|c|}{ 1999/00 } & \multicolumn{3}{|c|}{$2000 / 01$} & \multicolumn{3}{|c|}{$2001 / 02$} & \multicolumn{3}{|c|}{2002103} & \multicolumn{3}{|c|}{2003104} \\
\hline & F\% & N\% & $\mathrm{M} \%$ & & N\% & М\% & F\% & N\% & $\mathrm{M} \%$ & F\% & $\mathrm{N} \%$ & M\% & F\% & $\mathrm{N} \%$ & $\mathrm{M} \%$ & $\mathrm{~F} \%$ & N\% & м\% & $\mathrm{F} \%$ & N\% & M\% & $\mathrm{F} \%$ & N\% & $\mathrm{M} \%$ & F\% & $\mathrm{N} \%$ & M\% & $\mathrm{F} \%$ & N\% & M\% \\
\hline & & & & & & & & & & & & & & & & & & & & & & & & & & & & & & \\
\hline H. antarcticus & --- & - & --- & 0,8 & 0,2 & $\overline{0,1}$ & -- & --- & --- & -- & -- & -- & --- & --- & --- & --- & --- & --- & --- & --- & --- & --- & - & --- & --- & --- & --- & --- & --- & --- \\
\hline$\frac{\mathrm{Myctoph}}{E}$ & & & & & & & & & & & & & & & & & & & & & & & & & & & & & & \\
\hline $\begin{array}{l}\text { E. carls } \\
\text { E. anta }\end{array}$ & --- & -- & -- & $\frac{--}{56}$ & $\frac{--}{438}$ & $\frac{--}{41}$ & 2,9 & 1,4 & 0,3 & --- & $-\ldots$ & ---1 & --- & --- & --- & -- & --- & --- & -- & $\cdots$ & --- & --- & --- & -- & $\overline{17}$ & --- & $--\overline{0}$ & --- & --- & $\overline{01}$ \\
\hline G.an & $(\mathrm{N}, \mathrm{L}$ & 20,8 & 3,9 & $\frac{25,6}{0,8}$ & $\begin{array}{c}4,0,0 \\
0,2\end{array}$ & $\begin{array}{l}, 1 \\
0,1\end{array}$ & $\frac{10,1}{1,0}$ & $\frac{24}{0,}$ & 0,0 & 8,8 & & & & & & 10,0 & & & & & & & & & & $0, v$ & e, & , & & 0,1 \\
\hline G. nic & 12,6 & 40,5 & 43,9 & 13,2 & 10,6 & 8,1 & 14,4 & 39,7 & 14,9 & 10,0 & 46,0 & 74,6 & 21,7 & 64,1 & 66,5 & 36,5 & 82,6 & 88,8 & 14,0 & 10,7 & 2,9 & 7,0 & 22,8 & 3,2 & 5,0 & 83,0 & 66,3 & 1,3 & 2,2 & 0,3 \\
\hline G. opi & & & & 1,6 & 0,4 & 0,4 & --- & --- & --- & --- & --- & --- & --- & --- & --- & --- & --- & -- & --- & --- & --- & -- & --- & --- & -- & --- & -- & -- & --- & -- \\
\hline K.an & 0,6 & 0,4 & 0,1 & 1,6 & 0,5 & 0,2 & --- & --- & --- & --- & --- & --- & --- & --- & --- & --- & --- & --- & --- & --- & --- & --- & --- & --- & --- & --- & --- & --- & --- & -- \\
\hline L. ach & 0,6 & 0,4 & 0,3 & & & & & 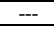 & & -- & --- & --- & -- & --- & --- & -- & -- & --- & --- & --- & --- & -- & --- & --- & --- & --- & -- & --- & --- & --- \\
\hline P. chc & --- & -- & --- & 0,8 & 0,1 & 0 & 0,5 & 0,1 & 0,0 & -- & $\ldots$ & --- & -- & --- & --- & -- & -- & -- & -- & -- & --- & -- & --- & --- & -- & -- & -- & --- & --- & -- \\
\hline P. nol & 0,6 & 0,4 & 0,2 & 3,1 & 1,2 & 0,1 & 3,4 & 1,5 & 0, & $\ldots$ & $\ldots$ & --- & 1,7 & 1,2 & 0,2 & -- & -- & -- & -- & -- & --- & -- & --- & -- & -- & -- & - & -- & --- & --- \\
\hline P.ten & -- & --- & --- & -- & -- & -- & 1,0 & 0,3 & 0,0 & - & 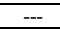 & $\ldots$ & $\ldots$ & --- & --- & $\ldots$ & --- & - & - & --- & --- & --- & - & - & --- & --- & -- & -- & --- & -- \\
\hline Parale & & & & & & & & & & & & & & & & & & & & & & & & & & & & & & \\
\hline N. co & 1,1 & 2,2 & 3,4 & 2,3 & 1,5 & 1,1 & 1,0 & 0,8 & 0,3 & 1,3 & 1, & 1,4 & - & - & -- & - & - & -- & - & --- & $-\ldots$ & - & -- & -- & --- & -- & - & --- & --- & -- \\
\hline No identificados & 10,4 & 21,3 & -- & 27,1 & 13,2 & -- & 7,2 & 4,5 & -- & 6,3 & 10,2 & -- & 5,0 & 6,4 & --- & 11,1 & 4,1 & --- & 6,0 & 7,9 & --- & 7,0 & 4,3 & $-\ldots$ & --- & --- & $-\ldots$ & 1,3 & 2,2 & \\
\hline
\end{tabular}

Tabla II.36: Tallas (medias, desvío estándar DE y rango) de los peces representados en las feces del Lobo Fino Antártico recolectadas en I. Laurie, IOS, durante las temporadas

\begin{tabular}{|c|c|c|c|c|c|c|c|c|c|c|c|c|c|c|c|c|c|c|c|c|c|c|c|c|c|c|c|c|c|c|}
\hline & & 994/95 & & & $1995 / 96$ & & & $1996 /$ & & $\square$ & $1997 / 98$ & & & $1998 / 99$ & & $t$ & $999 / 100$ & & & $2000 / 01$ & & & $\overline{2001 / 02}$ & & & $2002 / 03$ & & & 2003104 & \\
\hline & Media & & Rango & Media & $\mathrm{DE}$ & Rango & Media & DE & $\begin{array}{l}\text { Rango } \\
\text { Rang }\end{array}$ & Media & DE & Rango & Media & $\mathrm{DE}$ & $\frac{1}{\text { Rango }}$ & \begin{tabular}{|l} 
Media \\
\end{tabular} & DE & $\begin{array}{l}\frac{1}{\text { Rango }} \\
\text { Re }\end{array}$ & Media & $\mathrm{DE}$ & $\begin{array}{l}\text { Rango } \\
\text { Ren }\end{array}$ & \begin{tabular}{|l|l|} 
Media \\
\end{tabular} & DE & Rango & Media & DE & $\begin{array}{l}\text { Pango } \\
\text { Rano }\end{array}$ & Media & DE & $\begin{array}{l}\frac{1}{\text { Rango }} \\
\text { Re }\end{array}$ \\
\hline \begin{tabular}{|l|l|} 
Bathydraconidae \\
G.australis
\end{tabular} & --- & $\ldots$ & $\ldots$ & $\ldots$ & $\ldots$ & 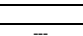 & 222 & $\cdots$ & & $\ldots$ & $\ldots$ & & & $-\ldots$ & & & $\ldots$ & & & & & $\ldots$ & $\cdots$ & & $\ldots$ & $\cdots$ & & & $\ldots$ & \\
\hline G. acuticeps & --- & --- & $\ldots$ & -- & \begin{tabular}{|c|}
--- \\
\end{tabular} & 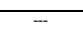 & 18,8 & $\cdots$ & $-\cdots$ & -- & $\cdots$ & $-\cdots$ & $-\cdots$ & $-\cdots$ & $-\cdots$ & $\cdots$ & $\cdots$ & $-\overline{-}$ & -- & $\cdots$ & $\overline{-}-$ & -- & $-\overline{-}$ & $\overline{--}$ & 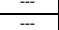 & -- & $\overline{-}-$ & $\cdots$ & $-\cdots$ & $\overline{--}$ \\
\hline P. charcot & $-\cdots$ & $-\cdots$ & $-\cdots$ & 16,3 & \begin{tabular}{|l|l|}
8,5 & \\
\end{tabular} & $10,0-26,0$ & 36,4 & -- & -- & -- & - & --- & -- & -- & -- & $-\cdots$ & -- & -- & -- & $-\cdots$ & -- & --- & -- & -- & $-\cdots$ & $\cdots$ & $-\cdots$ & --- & $-\cdots$ & 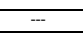 \\
\hline Channichthyidae & & & & & & & & & (2) & & & & & & & & & & & & & & & & & & & & & \\
\hline & & & & & & & 24,1 & 4,8 & $20,7-27,5$ & $\cdots$ & $\ldots$ & - & & $\ldots$ & - & & $\cdots$ & - & & & & & & & 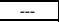 & $\cdots$ & $=$ & $\cdots$ & - & $\cdots$ \\
\hline C. aceratus & 32,0 & $\begin{array}{ll}13,0 \\
\end{array}$ & $22,7-41,2$ & \begin{tabular}{|l|l|}
45,4 \\
\end{tabular} & $\begin{array}{ll}7,6 \\
\end{array}$ & $\begin{array}{l}3,5-60,3 \\
\end{array}$ & $\begin{array}{lll}41,0 \\
\end{array}$ & $\begin{array}{ll}6,4 \\
\end{array}$ & $32,9-48,5$ & -- & -- & -- & \begin{tabular}{|l|}
33,7 \\
\end{tabular} & $\ldots$ & -- & \begin{tabular}{|l|}
36,4 \\
\end{tabular} & $\ldots$ & - & \begin{tabular}{|l|l|}
34,6 \\
\end{tabular} & 6,3 & 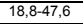 & \begin{tabular}{|l|}
34,3 \\
\end{tabular} & $\begin{array}{ll}4,9 \\
\end{array}$ & 19,3-41,4 & -- & -- & - & -- & -- & --- \\
\hline C. wilsoni & $-\cdots$ & $-\cdots$ & -- & -- & \begin{tabular}{|l|l|}
$-\cdots$ & \\
\end{tabular} & --- & 26,9 & 3,5 & $20,8-29,5$ & -- & -- & -- & -- & $-\cdots$ & -- & -- & -- & --- & -- & -- & -- & \begin{tabular}{|c|}
$-\cdots$ \\
-
\end{tabular} & $-\cdots$ & -- & -- & -- & -- & $\cdots$ & -- & --- \\
\hline C. gunnari & & -- & & -- & & & & & & -- & - & -- & & & & -- & -- & --- & & $\cdots$ & $\ldots$ & \begin{tabular}{|l|l|}
29,8 \\
\end{tabular} & 1,1 & $29,1-30,5$ & - & - & & 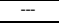 & - & \\
\hline C. rastrospinosus & 29,7 & 5,7 & $25,7-3,7$ & 23,0 & 3,3 & $17,2-30,9$ & 23,5 & 2,6 & $18,6-29,0$ & -- & $\ldots$ & -- & $\begin{array}{ll}20,8 \\
\end{array}$ & 1,3 & 19,4-22,4 & & -- & 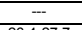 & \begin{tabular}{ll|}
23,6 \\
\end{tabular} & 2,4 & $19,8-29,0$ & 24,7 & 2,0 & $20,7-28,4$ & $\begin{array}{ll}23,0 \\
\end{array}$ & 2,3 & $21,4,-25,7$ & 21,1 & 2,0 & $16,0-24,0$ \\
\hline$\frac{\text { C. antarcticius }}{\text { P. georgianus }}$ & \begin{tabular}{|l|}
$-\cdots$ \\
\end{tabular} & $\cdots$ & $\cdots$ & $\frac{30,0}{27,8}$ & \begin{tabular}{|l|}
11,6 \\
2,8 \\
\end{tabular} & 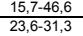 & \begin{tabular}{|l|}
27,3 \\
28,8 \\
\end{tabular} & $\frac{5,4}{1,5}$ & $\frac{18,5-34,2}{26,8-3,3}$ & $\cdots$ & 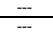 & $\cdots$ & - & $\cdots$ & -- & \begin{tabular}{|l|l}
27,0 \\
--
\end{tabular} & $\frac{1,0}{-n}$ & $26,4-27,7$ & \begin{tabular}{|l|l|}
24,7 \\
\end{tabular} & 0,8 & $24,1-25,2$ & 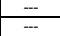 & $\cdots$ & - & $\cdots$ & $\approx$ & -- & 32,2 & 6,1 & $\frac{25,7-37,7}{--}$ \\
\hline Nototheniidae & & & & & & & & & & & & & & & & & & & & & & & & & & & & & & \\
\hline G. gibberifrons & \begin{tabular}{|l|l|}
18,7 \\
\end{tabular} & 8,6 & $10,0-32,3$ & 24,3 & 9,9 & $8,6,-43,0$ & 27,8 & 6,4 & $11,4-40,7$ & \begin{tabular}{|l|l|}
16,6 \\
\end{tabular} & $\cdots$ & -- & 27,2 & 16,1 & $8,7,-37,5$ & --- & -- & -- & \begin{tabular}{ll|}
18,8 \\
\end{tabular} & 7,0 & $10,5-40,1$ & \begin{tabular}{|l|}
29,0 \\
\end{tabular} & 6,1 & $11,2-45,3$ & 20,2 & -- & -- & 30,8 & 7,2 & $16,3-47,0$ \\
\hline N. coriiceps & 17,3 & $-\cdots$ & -- & 1,4 & $\cdots$ & $--\cdot$ & & & & -- & -- & -- & -- & --- & $\cdots$ & --- & -- & -- & -- & -- & -- & \begin{tabular}{|c|}
$-\cdots$ \\
\end{tabular} & -- & -- & $-\cdots$ & -- & -- & --- & -- & --- \\
\hline $\begin{array}{l}\text { N. larseni } \\
N \text { nudifirons }\end{array}$ & \begin{tabular}{|l|l|}
13,4 \\
111,1 \\
\end{tabular} & 2,2 & $\begin{array}{l}10,6-15,9 \\
--\end{array}$ & $\begin{array}{l}14,1 \\
11,7 \\
\end{array}$ & \begin{tabular}{|l|}
2,8 \\
2,7 \\
\end{tabular} & $\begin{array}{l}5,9-21,5 \\
6,5-211,6 \\
\end{array}$ & \begin{tabular}{|l|l|}
15,3 \\
12,3 \\
\end{tabular} & $\frac{2,9}{1,2}$ & $\begin{array}{l}\frac{6,2-2-2,8}{10,8-1,6} \\
10,1,6\end{array}$ & \begin{tabular}{|l|}
15,0 \\
13,3 \\
\end{tabular} & $\frac{1,5}{1,6}$ & $\begin{array}{l}\frac{12,6-6-1,3}{10,915,2} \\
10,5\end{array}$ & $-\cdots$ & $\cdots$ & $\cdots$ & \begin{tabular}{|l|l|}
14,6 \\
.- \\
\end{tabular} & 1,5 & $\begin{array}{ll}12,7-16,2 \\
--\cdot\end{array}$ & $\frac{15,0}{11,3}$ & $\begin{array}{l}1,6 \\
2,2 \\
\end{array}$ & $\frac{11,2-17,0}{7,8-14,3}$ & \begin{tabular}{|l|}
14,6 \\
12,3 \\
\end{tabular} & $\frac{1,9}{3,0}$ & $\begin{array}{l}\frac{10,8-18,7}{10.214 .5} \\
10.5\end{array}$ & $\cdots$ & $\because$ & $\ddot{-}$ & $\overline{9.3}$ & 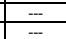 & $\ldots$ \\
\hline P. bernacchii & \begin{tabular}{|c|}
$-\cdots$ \\
\end{tabular} & --- & --- & $\cdots$ & $-\cdots$ & $\ldots$ & $\cdots$ & $\ldots$ & $\cdots$ & $\cdots$ & $\ldots$ & $\cdots$ & 24,9 & $\cdots$ & $\ldots$ & $\ldots$ & $\ldots$ & $-\cdots$ & -- & $2,--$ & $-\cdots$ & \begin{tabular}{|l|l|}
$-\cdots$ \\
--
\end{tabular} & $-\cdots$ & 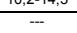 & $\cdots$ & $\cdots$ & $=$ & 15,6 & $-\overline{-}$ & $=$ \\
\hline P. antarcticum & & $-\cdots$ & & 14,5 & $\cdots$ & & 15,0 & -- & $\ldots$ & --- & -- & -- & & $\ldots$ & $\ldots$ & \begin{tabular}{|l|}
19,4 \\
\end{tabular} & -- & & -- & $-\cdots$ & & 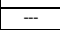 & -- & & -- & $\cdots$ & -- & -- & 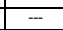 & \\
\hline $\begin{array}{l}\text { T. newnesi } \\
\end{array}$ & \begin{tabular}{|l|}
10,1 \\
\end{tabular} & 1,2 & $8,8-11,0$ & 7,8 & \begin{tabular}{|l|}
0,8 \\
\end{tabular} & $7,0-8,5$ & $-\cdots$ & $\cdots$ & $\ldots$ & -- & -- & $\ldots$ & $-\cdots$ & $\cdots$ & - & \begin{tabular}{|l|l|}
$-\cdots$ \\
$-\cdots$
\end{tabular} & $\cdots$ & $\cdots$ & $\cdots$ & $\cdots$ & - & \begin{tabular}{|l|}
10,9 \\
\end{tabular} & 0,2 & $10,7-11,0$ & $\cdots$ & $\cdots$ & - & $-\cdots$ & $\cdots$ & - \\
\hline $\begin{array}{l}\text { Harpagiferidae } \\
\text { H. antarcticus }\end{array}$ & $\ldots$ & $\ldots$ & $\ldots$ & $\begin{array}{ll}6.9 \\
\end{array}$ & 0.8 & $6,3-7,4$ & $\ldots$ & --- & $\ldots$ & $-\cdots$ & $\ldots$ & $\ldots$ & $\ldots$ & $=$ & $\ldots$ & $\ldots$ & $\ldots$ & $\cdots$ & $\ldots$ & -- & $\ldots$ & $\cdots$ & $\ldots$ & & $\ldots$ & $\cdots$ & $\overline{-z}$ & - & $\ldots$ & $\overline{--}$ \\
\hline Myctophidae & & & & & & & & & & & & & & & & & & & & & & & & & & & & & & \\
\hline E. antarctica & 5,6 & 1,0 & $2,4-7,2$ & 5,7 & 0,8 & $3,1-7,9$ & 5,9 & 0,9 & $3,2-7,5$ & 6,3 & 0,8 & $4,5-7,8$ & 6,3 & 0,7 & $4,6-7,5$ & 6,2 & 0,7 & $4,6-7,3$ & 5,9 & 0,6 & $5,1-7,3$ & 6,0 & 0,8 & $4,2-7,3$ & 6,4 & 0,6 & $5,9-7,2$ & 6,1 & 1,0 & $4,9-6,7$ \\
\hline E. carlsbergi & $\cdots$ & $-\cdots$ & --- & & & & 9,0 & 1,1 & $7,3-10,6$ & $\cdots$ & -- & $-\cdots$ & -- & $\cdots$ & $\ldots$ & -- & -- & -- & -- & -- & $\cdots$ & $-\cdots$ & --- & - & $-\cdots$ & -- & $\ldots$ & -- & - & \\
\hline $\begin{array}{l}\text { G. braueri } \\
\text { G.jicholsi }\end{array}$ & 138 & 24 & $84-183$ & $\begin{array}{l}9,1 \\
146\end{array}$ & $\begin{array}{l}1,0 \\
32\end{array}$ & $\begin{array}{l}8,4-9,7 \\
9399\end{array}$ & 5,8 & 2,0 & $\begin{array}{l}4,5-8,2 \\
69-27 \\
\end{array}$ & 154 & 719 & $101-188$ & 150 & 18 & 94187 & 151 & 17 & $82-191$ & 14.9 & 40 & 80.240 & 152 & 18 & $71-180$ & 160 & 14 & 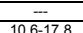 & 154 & 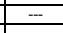 & 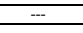 \\
\hline $\begin{array}{l}\text { G nichols } \\
\text { G. opisth }\end{array}$ & $1,0,0$ & & & 13,1 & \begin{tabular}{|l|}
2,2 \\
1,6 \\
\end{tabular} & 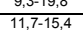 & & $\frac{2,2}{2-}$ & & 15,4 & - & $10,1-18,8$ & & 1,8 & & 15,1 & $1, r$ & & 14,9 & 4,0 & $8,0-24,0$ & \begin{tabular}{|l}
15,2 \\
\end{tabular} & 1,8 & $\pi, 1-18,0$ & 10,0 & 1,4 & $10,6-1,1 /, 8$ & 15,4 & $\ldots$ & -- \\
\hline $\begin{array}{l}K \text { K. anderssoni } \\
\end{array}$ & 7,7 & $\cdots$ & $\cdots$ & 9,3 & 0,6 & $8,4-10$, & $-\cdots$ & $=$ & $-\cdots$ & -- & -- & -- & $\cdots$ & 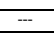 & $\cdots$ & $\ldots$ & 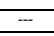 & 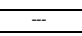 & -- & $-\cdots$ & $\cdots$ & $\cdots$ & 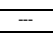 & $\cdots$ & $\cdots$ & -- & 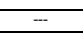 & $-\cdots$ & $\ldots$ & $\cdots$ \\
\hline L. achiru & \begin{tabular}{|l|}
14,3 \\
\end{tabular} & -- & --- & & $\cdots$ & $-\cdots$ & $\cdots$ & --- & -- & -- & $\cdots$ & --- & -- & --- & -- & --- & $\cdots$ & - & $\cdots$ & $-\cdots$ & - & -- & -- & - & $-\cdots$ & -- & -- & --- & --- & $-\cdots$ \\
\hline P. choriodon & 81 & $\ldots$ & $\ldots$ & $\begin{array}{l}6,1 \\
56 \\
\end{array}$ & - & 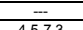 & 6,5 & 20 & $\ldots$ & $-\cdots$ & - & --- & & 04 & 62.71 & $\cdots$ & $\ldots$ & $\cdots$ & $\cdots$ & 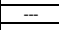 & - & - & 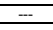 & - & $\ldots$ & - & - & --- & 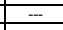 & -- \\
\hline$\frac{P \text { P. normani }}{\text { P. tenisoni }}$ & 8,1 & --- & --- & 0,0 & 0,9 & $4,-\cdots$, & $\frac{6,2}{55}$ & $\frac{2,0}{13}$ & $\frac{3,4-1,0,4}{4,6-6,3}$ & $\cdots$ & - & $\ldots$ & 0,8 & $0-4$ & $0,-2,1,1$ & $\cdots$ & $--\cdot$ & --- & $\cdots$ & $-\cdots$ & $-\overline{-}$ & $\cdots$ & $\cdots$ &.-- & 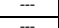 & - & - & - & - & $\overline{-}$ \\
\hline & & & & & & & & & & & & & & & & & & & & & & & & & & & & & & \\
\hline $\bar{N}$. coatsi & 23,7 & 3,4 & 18,5-27,6 & 24,3 & 4,6 & $88.5-32.8$ & 24,7 & 4.7 & $7,3-28,8$ & 24,2 & 5,0 & $\begin{array}{l}.7-27,8 \\
\end{array}$ & & & & -- & & & - & & &.- & & & 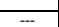 & & & - & & \\
\hline
\end{tabular}




\section{Selección del Alimento}

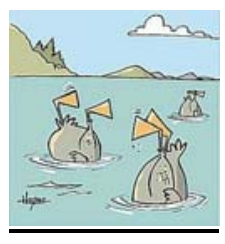

\section{III.1. Introducción}

Las relaciones tróficas de una comunidad biológica pueden ser estudiadas a partir de diversos acercamientos ecológicos. Las aproximaciones ecosistémicas centran su estudio sobre los diferentes patrones alimentarios y comportamentales con la intención de definir cuáles son las interacciones entre pares de especies y en qué medida éstas son influenciadas por la presencia y densidad de una especie respecto de la otra (Kerfoot y Sih 1987). Los diversos aspectos del comportamiento vinculados a la predación se combinan e influyen sobre la dinámica de las poblaciones de los predadores y de las presas. El comportamiento individual de cada predador dentro de una comunidad se halla vinculado a la disponibilidad de presas y a sus requerimientos energéticos (Begon et al. 1999). Estudiar la predación a partir de la estimación de la selectividad de presas, el grado de solapamiento de los recursos alimentarios y la utilización de los diferentes ambientes como áreas de alimentación, conforman información fundamental para comprender las relaciones densodependientes de los miembros de una comunidad. En este sentido, los estudios sobre la selección del alimento de los predadores tope permiten observar a la comunidad en un nivel multiespecífico y son el punto de partida hacia la construcción de modelos ecológicos que intenten explicar la complejidad del ecosistema. Si bien, la competencia interespecífica observada, en general, es difícil de ser medida (Barlow et al. 2002), los índices de selectividad y de diversidad, entre otros, permiten estimar en forma cuantitativa los efectos de los diversos tipos de alimentación entre pares de especies predadoras y la oferta de alimento disponible en la comunidad.

Las poblaciones de peces en la zona de las Islas Orcadas del Sur (IOS) se vieron afectadas por la pesca, principalmente durante la década del '70. La explotación pesquera en la zona del arco de Scotia se llevó a cabo desde 1997/78 a 1989/90, y tuvo su auge entre los años 1977/78 a 1981/82 (Kock et al. 2000). Con la excepción de estudios sobre los stocks de peces realizados en Isla Elefante, pocos son los estudios confinados a esta zona. Hasta el momento sólo se cuenta con la información suministrada por prospecciones científicas realizadas por Alemania (1985), España (1987 y 1991) y EEUU (1999). Sumado a ello, en las IOS no se han llevado a cabo estudios que involucren la abundancia/biomasa de las diversas especies de peces presentes en un área dada y el 
consumo por parte de sus predadores. En particular, en la zona insular del sector Atlántico del Océano Antártico (OA), este tipo de estudios se han centralizado en torno a las variaciones en la abundancia y distribución de krill en relación a las tasas de consumo y los hábitos de forrajeo de algunos de sus predadores más abundantes, por ejemplo el pingüino de Barbijo Pygoscelis antarctica y el lobo Fino Antártico Arctocephalus gazella (Ichii et al. 1995, 1996, 1997). Estas investigaciones tienen por objetivo evaluar los impactos potenciales de los predadores tope podrían ejercer sobre la actividad pesquera. Así entonces, en la mayoría de estos trabajos, las especies de presas evaluadas son aquellas que presentan algún tipo de interés comercial o especie "target" tales como Champsocephalus gunnari, Notothenia rossii y el krill antártico (Euphausia superba) (Trivelpiece y Trivelpiece 1995, Ichii et al. 1995, 1996, 1997, Bax 1998, Croxall 1998, Croll y Tershy 1998, Green et al. 1998, Kasatkina y Ivanova 2003, Reid et al. 2004, Zhao et al. 2004).

Teniendo en cuenta que en las IOS los relevamientos de la fauna ictícola son escasos (Balguerías 1989, Kock et al. 2000, Jones et al. 2000, Jones datos un publicados) es objetivo de este capítulo realizar un acercamiento exploratorio hacia la descripción de la composición de peces que habitan la zona, y su diversidad, como así también intentar comprender cómo la disponibilidad de presa afecta a los comportamientos tróficos de los predadores y cómo éstos interactúan entre sí en relación al cambio en la oferta alimentaria.

\section{III.2. Materiales y Métodos}

\section{III.2.1. Recopilación de datos de la fauna ictícola de las IOS}

La composición de especies de la comunidad ictícola de las IOS fue estudiada a partir de la información provista por los reportes de Balguerías (1989), Jones et al. (2000) y Kock et al. (2000) (estas dos últimas fuentes de información corresponden al mismo crucero de investigación) y se corresponden con los cruceros de investigación "Antártida 8611" y "US AMLR 99" respectivamente. En ambos cruceros las capturas fueron realizadas en tres intervalos o estratos de profundidad diferentes (1: 0-150 m; 2: 150-250 m; 3: 250-500 m) y se intentó cubrir el área circundante a las IOS, extendiéndose el área de muestreo entre los $43^{\circ}$ y $47^{\circ}$ de longitud $O$ y los $61,5^{\circ}$ y $62^{\circ}$ de latitud $S$. Las posiciones geográficas de las estaciones de muestreo de cada crucero se muestran en las figuras III.1a y III.1b.

El crucero reportado en Balguerías (1989) fue llevado a cabo en enero y febrero de 1987 y con una red de $60 \mathrm{~m}$. de largo con una boca horizontal de $26 \mathrm{~m}$. y una vertical de $8 \mathrm{~m}$. El tamaño de la celda de la malla fue de $68 \mathrm{~mm}$. Se realizaron 13 lances de arrastre en el estrato 1 (de 50 a 150 metros de profundidad), 30 en el estrato 2 (de 150 a 250 metros de profundidad) y 50 en el estrato 3 (de 250 a 500 metros de profundidad). El crucero reportado por Jones et al. (2000) y Kock et al. (2000) se llevó a cabo en marzo de 1999, y en él se desarrollaron 64 lances, 7 en el estrato 1, 24 en el 2 y 33 en el 3, con una red de $63 \mathrm{~m}$. de largo con una boca horizontal de $20 \mathrm{~m}$. y una vertical de 9 $\mathrm{m}$. con un tamaño de celda de $20 \mathrm{~mm}$. Ambos muestreos fueron realizados durante las horas diurnas (entre las 6:00 y las 19:00 hs. hora local), conservando la misma velocidad de arrastre y el tiempo de lance y captura. 
Los peces representados en las capturas fueron identificados hasta el nivel de especie y fueron medidos en su largo total. La abundancia de cada especies fue estandarizada a N/milla $n^{2}$ arrastrada por las redes. Con el objetivo de reducir los efectos de los valores excesivamente altos correspondientes a las poblaciones dominantes, tales como Gobionotothen gibberifrons y Lepidonotothen squamifrons, las estimaciones se normalizaron por medio de corrección logarítmica (Pennington 1983, de la Mare 1994). Asimismo, para determinar diferencias en la composición de especies y distribución de tallas dentro de la columna de agua, se aplicaron análisis de estadísticos de ANOVA.

Los datos de biomasa y abundancia de tallas de la ictiofauna presentados en Balguerías (1989), Jones et al. (2000) y Kock et al. (2000) fueron utilizados para ser contrastados con la información sobre la composición de la dieta de los predadores tope con el objetivo de analizar el grado de selectividad de los predadores con respecto a las especies y las tallas consumidas. A su vez, los resultados sobre la composición de la ictiofauna de ambos cruceros fueron comparados mediante la estimación de parámetros ecológicos con el objetivo de estudiar el cambio en la diversidad de especies.
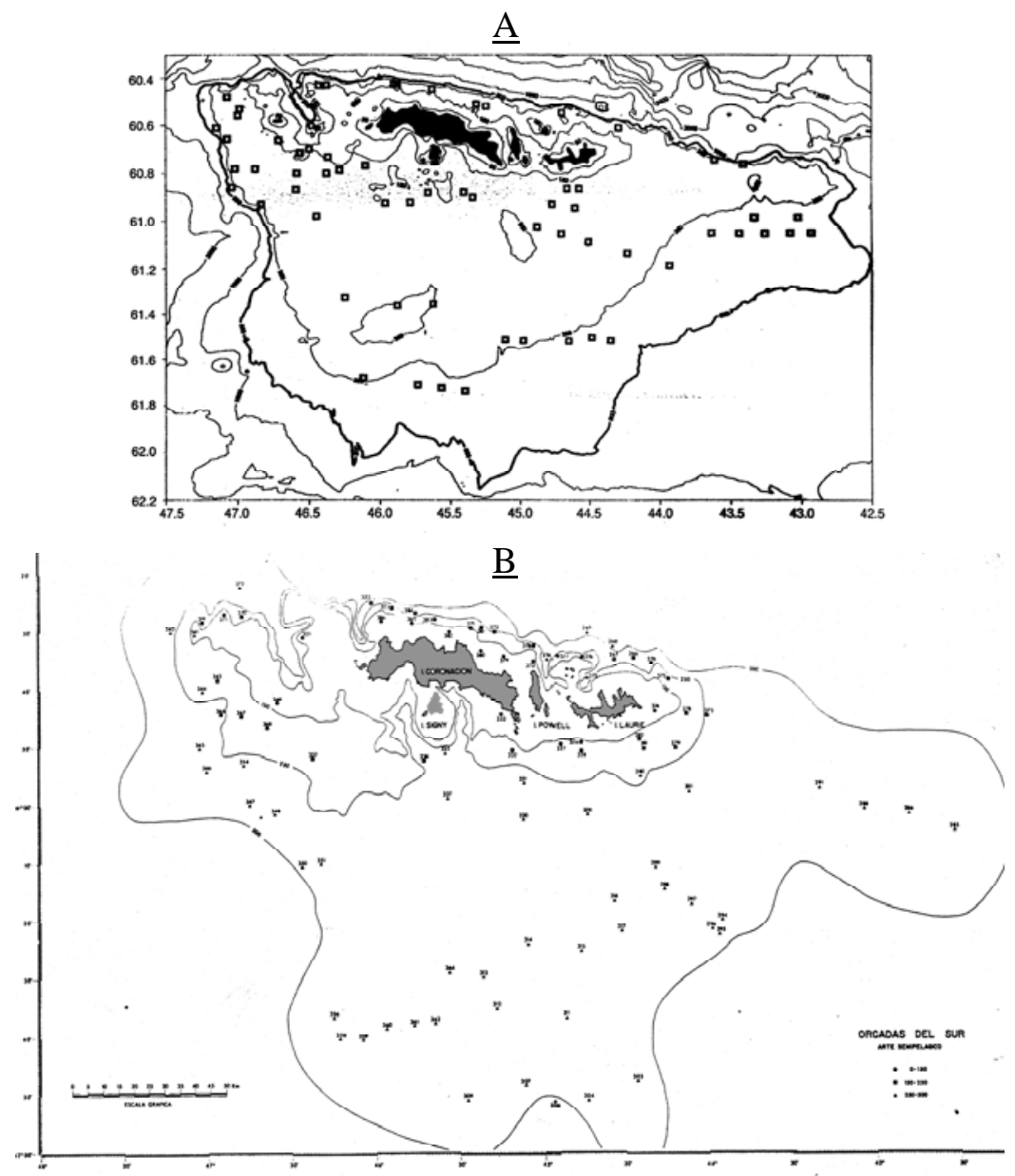

Figura III.1: Archipiélago de las Islas Orcadas del Sur; A) Los cuadrados representan las estaciones de captura de la campaña "Antártida 8611"; B) Los puntos representan las estaciones de capturas de la campaña "US AMLR 99". 
Los datos de tallas medias, rangos y número de individuos (en porcentaje) por estrato fueron comparados entre ambas campañas. Con el fin de encontrar diferencias significativas para la distribución de abundancia de peces en los diferentes estratos de profundidad correspondientes a los muestreos realizados durante 1987 se realizaron análisis de ANOVA.

\section{III.2.2. Análisis de datos}

\section{Selección del alimento}

El grado de selectividad de presas para cada predador fue estimado a partir del cálculo del Índice de Ivlev (1961) según la siguiente ecuación (1):

$$
I=\frac{D i-L i}{D i+L i}
$$

donde $D_{i}$ es el porcentaje en masa (M\%) de la especie $i$ en la dieta del predador 1 y $L_{i}$ es el M\% de la especie $i$ en el ambiente marino. Los valores positivos indican un comportamiento alimentario selectivo por parte del predador. En los casos en que se dispuso de los datos de abundancia de peces por cada intervalo de profundidad el Índice de Ivlev se calculó para cada uno de dichos intervalos y para el total de la columna de agua muestreada.

Los predadores seleccionados para este análisis (Tabla III.1) se agruparon según los Grupos Tróficos (GT) definidos en el Capítulo II. Aquellos predadores para los cuales no se tuvo información sobre la contribución de los peces a la dieta en las IOS, no fueron incluidos en este análisis.

Tabla III.1: Grupos Tróficos y especies elegidas para el análisis de selección del alimento en las IOS.

\begin{tabular}{|c|c|c|c|}
\hline Krilleros (1) & Krilleros (2) & Ictiófagos (1) & Ictiófagos (2) \\
\hline $\begin{array}{c}\text { Pingüino de } \\
\text { Adelia }\end{array}$ & Pingüino Papua & $\begin{array}{c}\text { Cormorán de } \\
\text { Georgias }\end{array}$ & Petrel Damero \\
$\begin{array}{c}\text { Pingüino de } \\
\text { Barbijo }\end{array}$ & Foca de Weddell & & $\begin{array}{c}\text { Petrel de las } \\
\text { Nieves }\end{array}$ \\
& $\begin{array}{c}\text { Lobo Fino } \\
\text { Antártico }\end{array}$ & & \\
\hline
\end{tabular}

Con el objetivo de determinar el grado de selectividad de las tallas de las diferentes especies de peces por parte de los predadores se compararon las distribuciones de tallas de los peces presentes en el archipiélago y los consumidos por los predadores. Los datos de frecuencia de tallas (F\%) presentes en el área fueron estimados a partir de los histogramas de distribuciones presentadas en los informes de Balguerías (1989) y Kock et al. (2000).

Es importante tener en cuenta que dada la falta de información disponible sobre la fauna ictícola del archipiélago de las IOS, las comparaciones entre capturas y composición de la dieta de los predadores, en términos generales, no son concurrentes, como así tampoco los sitios en donde se realizaron las capturas son representativas de las áreas de forrajeo de los predadores. Sumado a ello, las redes empleadas tienen baja capacidad de captura de peces de tallas entre los 5 y los 10 
$\mathrm{cm}$. aproximadamente, un rango importante para la dieta de alguno de los predadores presentados en este trabajo. Es por ello que este capitulo se llevó a cabo de modo únicamente exploratorio y los resultados deben ser tomados en cuenta como posibles tendencias en la selectividad de las presas.

Los datos de las temporadas de muestreo de cada predador se detalla en la tabla III.2.

Tabla III.2: Temporadas de muestreos de dieta de los predadores tope de las IOS para las cuales se estimaron el Índice de Ivlev con 1: datos de biomasa de peces durante enero y febrero de 1987 y 2: durante marzo de 1999.

\begin{tabular}{|l|ccl|}
\hline & $\mathbf{1}$ & $\mathbf{2}$ & Referencia \\
\hline P. de Adelia & $97 / 88$ & $98 / 99$ & Libertelli datos no publicados \\
P. de Barbijo & $98 / 99$ & $98 / 99$ & Casaux datos no publicados \\
P. Papúa & 1993 & 1999 & Berón et al. 2002, Libertelli datos no publicados \\
P. Damero & $95 / 96$ & $95 / 96$ & Casaux et al. 1998 \\
P. de las Nieves & $97 / 98$ & $97 / 98$ & Ferretti et al. 2001 \\
E. Marrón & $97 / 98$ & $97 / 98$ & Montalti 2005 \\
C. de Georgias & $94 / 95$ & $98 / 99$ & Casaux y Ramón 2002 \\
F. de Weddell & $99 / 00$ & $99 / 00$ & Casaux et al 2001 \\
LFA & $94 / 95$ & $98 / 99$ & Casaux datos no publicados \\
\hline
\end{tabular}

\section{Análisis del solapamiento entre las dietas y los ejemplares capturados}

A partir de las distribuciones de frecuencias de tallas se elegió un método para compararlas entre sí y poder determinar qué fracción de la población de peces consumen los diferentes predadores. Dado que no se tuvieron los datos crudos de las capturas (talla de cada pez capturado) y que las distribuciones de tallas de tales capturas fueron estimadas a partir de los gráficos de distribución, no fue posible aplicar ningún método estadístico como por ejemplo el análisis de la varianza o ANOVA. Es por ello que se procedíó a calcular el índice de soleamiento según lo indicado por Linton et al. (1981).

El grado de solapamiento entre las distribuciones de tallas de la dieta de los predadores y de las representadas según los muestreos de ambos cruceros (Balguerías 1989 y Kock et al. 2000) se calculó de acuerdo al índice de similitud "S" (Linton et al. 1981) según la ecuación (2):

$$
S=100\left(1-1 / 2 \sum\left|P_{x i}-P_{y i}\right|\right)
$$

donde $P_{x i}$ y $P_{y i}$ corresponden a las proporciones de tallas de la especie de pez $i$ correpondientes a la dieta del predador $x$ y del muestreo $y$. Los valores de $\mathbf{S}$ varían entre 0 , en donde las distribuciones de tallas no son compartidas por $x$ e $y$, y 100, en el caso de que las distribuciones sean idénticas. Para diferenciar el solapamiento de las distribuciones de tallas de los peces consumidos por los predadores y los capturados en los cruceros, se llamará $\mathrm{S}_{1}$ y $\mathrm{S}_{2}$ a los resultados obtenidos con los datos generados por Balguerías (1989) en los estratos de profundidad 1 y 2 y $S_{k}$ para lo reportado por Kock et al. (2000). Al momento de interpretar los resultados es importante tener en cuenta que, en varias ocasiones, el solapamiento entre las tallas ingeridas y aquellas capturadas que estuvieron por encima del valor de talla máxima ingerida registrada en la base de datos analizada para varios predadores, no debe ser interpretado como un resultado de evitamiento (selectividad negativa) ya 
que tallas muy grandes están sencillamente por encima de la capacidad física de ingesta de ciertas especies no existiendo proceso de selectividad alguno para ellas.

\section{Estudio de la Biodiversidad}

Diversidad de la ictiofauna

Los índices de Diversidad $(H)$ y Equitatividad $(E)$ fueron calculados a partir de los datos de biomasa de peces correspondientes a los cruceros de investigación de 1987 (Balguerías 1989) y de 1999 (Jones et al. 2000, Kock et al 2000) según las siguientes fórmulas:

Índice de diversidad de Simpson (S) (1949):

$S=\sum p_{i}^{2} ; \quad p_{i}=\frac{b_{i}}{B_{T}}$

(Ecuación 3)

donde $p_{i}$ es la proporción de la biomasa $\left(b_{i}\right)$ de la especie $i$ sobre el total de la biomasa pescada $\left(B_{T}\right)$. El índice $S$ representa la probabilidad de que dos individuos seleccionados al azar que habitan un mismo ambiente pertenezcan a especies diferentes. Este índice está fuertemente influido por las especies dominantes (Magurran 1988). Cuando $S=1$ la Diversidad es mínima por lo que la Diversidad $\left(H_{1}\right)$ máxima queda expresada según la siguiente ecuación desarrollada por Lande (1996):

$H_{1}=1-S$

(Ecuación 4)

La Equitatividad $(E)$ de la comunidad, o sea cómo están distribuidas las especies, se midió según la siguiente ecuación propuesta por Pielou (1966):

$E=\frac{H}{H_{\max }} ; H_{\max }=\log _{2} R$

(Ecuación 5)

donde $E$ queda expresada como una proporción del máximo que $H$ podría alcanzar para una misma Riqueza biológica $(R)$ o cantidad total de especies. Este índice mide la proporción del máximo valor que $\mathrm{H}$ podría asumir si las especies estuvieran distribuídas de modo totalmente uniforme. Para la estimación de E, $H$ se calcula a partir de la ecuación de diversidad de Shannon y Weaver (1949):

$H_{2}=-\sum p_{i} \log _{2}\left(p_{i}\right)$

(Ecuación 6)

donde $p_{i}$ indica la proporción en masa de cada especie de pez en las IOS.

\section{Diversidad del consumo de peces}

A partir de la composición de la dieta (biomasa consumida expresada como M\%) estimada para 4 predadores tope de las IOS (pingüino Papúa Pygoscelis papua, cormorán de Georgias Phalacrocorax georgianus, foca de Weddell Leptonychotes weddellii y lobo Fino Antártico Arctocephalus gazella) durante el verano 1999/00 se analizó la diversidad en el consumo de peces por medio de la 
aplicación del Índice de Shannon y Weaver (1949) (ecuación 4). Este índice mide la probabilidad de consumir las diferentes especies de peces en la proporción con que están disponibles en el ambiente, es decir, mide la probabilidad de que una muestra seleccionada al azar de una población infinitamente grande contenga exactamente $n_{1}$ individuos de la especie $1, n_{2}$ de la especie $2, \ldots$ y $n_{S}$ individuos de la especie S (Hill 1973, Greig-Smith 1983)

Dado que en las muestras de dieta no se ve representada la totalidad de las especies de peces presentes en el área de estudio, la Equitatividad (E) se calculó como la razón entre la diversidad de la dieta del predador $i(H)$ y la Riqueza biológica $(R$, cantidad de especies de peces totales disponibles en el área de estudio) según la ecuación 3 (ver arriba) o lo que es igual, la proporción entre la $\mathrm{H}$ obtenida y la máxima posible $(\mathrm{E}=1)$.

\section{III.3. Resultados}

III.3.2. Estructura poblacional de la ictiofauna de las IOS: Abundancia y distribución de la biomasa.

\section{Campaña "Antártida 8611"}

Las capturas de peces (en términos de biomasa) más elevadas fueron registradas en el segundo y el tercer estrato de profundidad (entre los 150 y $500 \mathrm{~m}$.). El total capturado fue $3672,02 \mathrm{Kg}$. La especie que predominó en las capturas fue G. gibberifrons, seguida por Notothenia kempi, Chaenocephalus aceratus y Lepidonotothen larseni (Figura III.2). Al analizar la distribución de las especies con respecto a la profundidad se observó que el primer estrato estuvo mayormente representado por ejemplares de G. gibberifrons y C. aceratus, el segundo por Pleuragramma antarcticum seguido de G. gibberifrons y en el tercer estrato predominó L. larseni, seguida por P. antarcticum (Figura III.2). Dado que los cruceros de investigación previos a los considerados en este trabajo estuvieron enfocados mayormente hacia el monitoreo de especies de interés pesquero, estos informes constituyen el primer reporte de abundancia y biomasa para las IOS de algunas de las especies aquí consideradas (por ejemplo: N. kempi y L. larseni).

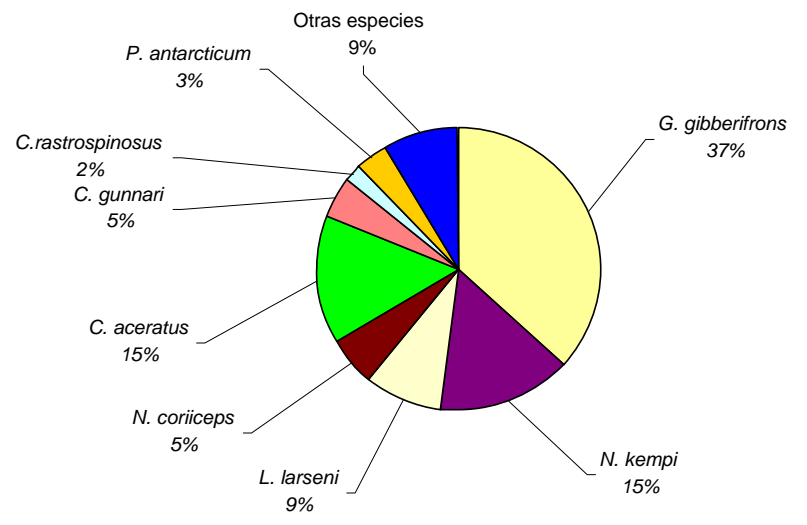

Figura III.2: Composición específica de las capturas (M\%) realizadas durante la campaña "Antártida 8611" (verano austral 1987) en las IOS. Tomado de Balguerías (1989). 


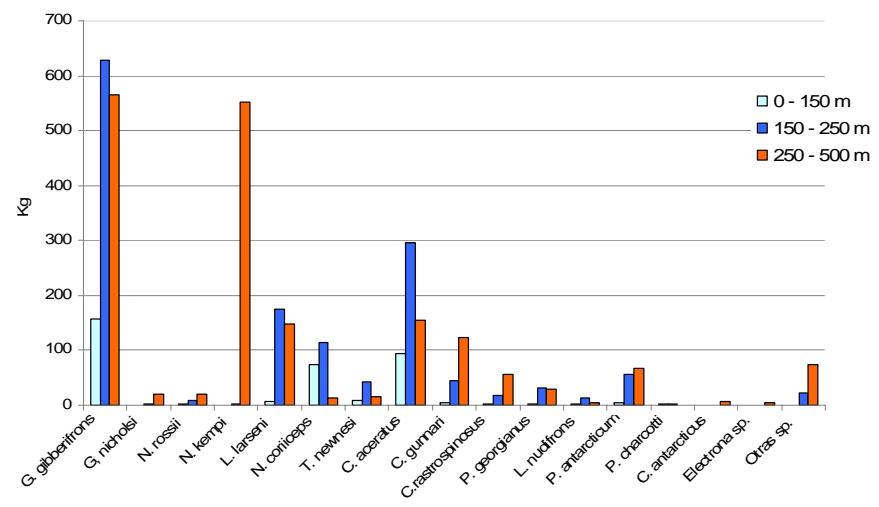

Figura III.3: Detalle por estrato de la composición específica de las capturas (kg) realizadas durante el verano austral 1987 en las IOS. Tomado de Balguerías (1989).

Los valores de biomasa más altos correspondieron a la familia Nototheniidae, seguida por Myctophidae y Channichthyidae. El 50,46\% de la biomasa global fue capturada a profundidades mayores a 250 m.; en este estrato se obtuvo el $51,6 \%$ de la biomasa de notothéniidos y $72,5 \%$ de la de channíchthyidos. Los ejemplares de la familia Myctophidae estuvieron mejor representados en el segundo estrato (52,1\%). Aún así, los análisis estadísticos de ANOVA indicaron que no se encontraron diferencias significativas entre las distribuciones de biomasa de las diversas especies de peces con respecto a la profundidad, como así tampoco entre las diversas familias $(W \lambda=0,976, p=$ $0,55 ; W \lambda=0,975, p=0,54)$.

\section{Campaña "US AMLR 99"}

Jones et al. (2000) y Kock et al. (2000) reportaron para Marzo de 1999 una captura total de $16.167,53 \mathrm{Kg}$ de peces (38 356 individuos) correspondientes a 42 especies identificadas. Asimismo, el $98 \%$ del total de las capturas estuvo compuesto por ejemplares de sólo 8 especies de peces (Figura III.4). La especie dominante en términos de biomasa fue G. gibberifrons seguida de Lepidonotothen squamifrons. La distribución vertical mostró que la especie dominante en el primer y segundo estrato fue $G$. gibberifrons seguida por $C$. aceratus en el primero y $L$. squamifrons en el segundo. El tercer estrato estuvo dominado por L. squamifrons, seguida por G. gibberifrons (Figura III.5).

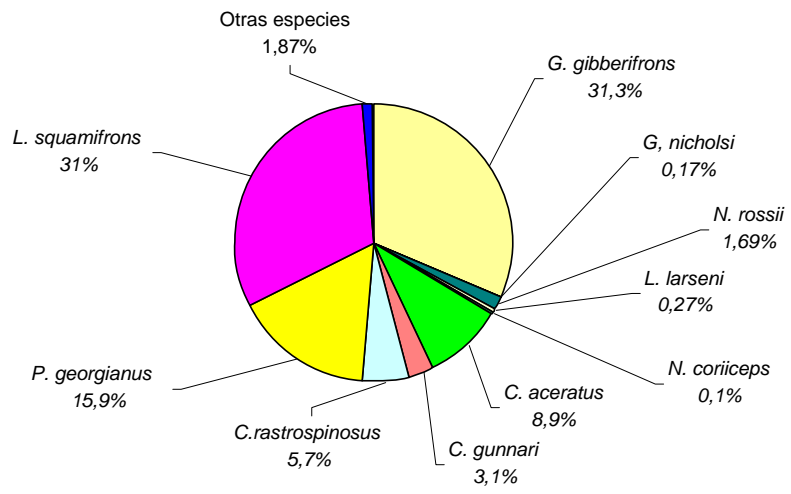

Figura III.4: Composición específica de las capturas (M\%) realizadas durante la campaña "US AMLR 99" (Marzo de 1999) en las IOS. Tomado de Jones et al. (2000). 


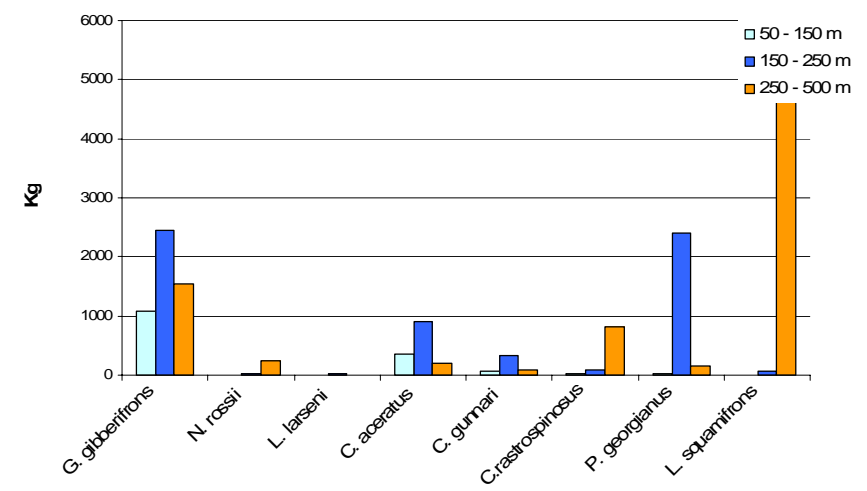

Figura III.5: Detalle por estrato de la composición específica $(\mathrm{Kg})$ de las capturas realizadas durante Marzo de 1999 en las IOS. Tomado de Jones et al. (2000).

Las abundancia y tallas de las especies capturadas por estrato de profundidad en cada crucero de investigación se muestran en la tabla III.3. En relación a la distribución de tallas, es importante aclarar que durante la campaña de muestreo de 1999 sólo se midieron algunas de las especies representadas en las capturas.

Asumiendo que los cruceros realizados en las IOS son comparables, el aumento de las capturas de cada especie en términos de biomasa (Tabla III.4) y abundancia (Tabla III.5) y de la tasa de captura (desde $13219 \mathrm{Kg} / \mathrm{mn}^{2}$ en 1991 hasta $18173 \mathrm{Kg} / \mathrm{mn}^{2}$ en 1999) sugieren una importante recuperación de la ictiofauna en este archipiélago. Con respecto a las tasas de captura, es importante considerar que durante 1985 y 1987 la actividad pesquera aún estaba en funcionamiento en el área y, como indicara Balguerías (1989), esta afectó principalmente a los stocks de los channíchthyidos $P$. georgianus y C. gunnari. Volviendo a la comparación entre las capturas de 1987 y 1999, se observó que el aumento de la biomasa estuvo concentrado especialmente en especies de channíchthyidos (particularmente $P$. georgianus que aumentó su biomasa en un 34\%) y de notothénidos (principalmente G. gibberifrons dado que registró un aumento del $275 \%$ ) que fueron fuertemente explotadas durante el período de actividad comercial. A diferencia de ello, notothénidos que no fueron fuertemente afectados por las pesquerías (e.g. N. coriiceps, $L$. larseni, T. newnesi y $L$. nudifrons) disminuyeron su biomasa a tasas cercanas al $100 \%$.

Tabla III.3: Talla media ( \pm desvío estándar), rango, moda (en $\mathrm{cm}$.), porcentaje de abundancia por estrato de profundidad ( $\mathrm{N} \%$ ), y cantidad de individuos capturados ( $\mathrm{N}$ total) para 16 especies de peces. Tomado de Balguerías (1989) y de Jones et al. (2000). Análisis de varianza para la distribución de abundancia de peces en los diferentes estratos de profundidad correspondientes a los muestreos realizados durante 1987. NS: no significativo. Las tallas medias calculadas para los arrastres de 1999 son aproximadas ya que se estimaron a partir de los datos de distribuciones de tallas, por tal razón no llevan desvío estándar. Los datos remarcados en negrita están calculados en base a una fracción del total (N).

\begin{tabular}{|c|c|c|c|c|c|c|c|c|c|c|}
\hline \multirow[t]{2}{*}{ Peces } & \multirow{2}{*}{\multicolumn{2}{|c|}{$\underline{\text { Media }(\mathrm{cm}) \pm \text { de }}$}} & \multirow[t]{2}{*}{ Rango $(\mathrm{cm})$} & \multicolumn{2}{|c|}{ Moda/s $(\mathrm{cm})$} & \multicolumn{3}{|c|}{ N\% por estrato } & \multirow[t]{2}{*}{$\underline{\mathrm{N} \text { total }}$} & \multirow{2}{*}{$\begin{array}{r}\text { ANOVA (1987) } \\
\text { (entre estratos) }\end{array}$} \\
\hline & & & & 1987 & 1999 & 1 & 2 & 3 & & \\
\hline \multirow{5}{*}{$\begin{array}{l}\text { Channichthyidae } \\
\text { C. aceratus }\end{array}$} & & & & & & & & & & \\
\hline & 1987 & $21,34 \pm 11,39$ & $11-64$ & 13 & 21 & 20,17 & 39,56 & 40,27 & 3832 & NS $(F=1,0948 ; g l: 2 ; P=0,33)$ \\
\hline & 1999 & 40,45 & $15-70$ & 22 & 35 & 25,53 & 56,19 & 18,29 & 2570 & \\
\hline & & & & 29 & 58 & & & & & \\
\hline & & & & 41 & & & & & & \\
\hline \multirow[t]{3}{*}{ C. gunnari } & 1987 & $26,49 \pm 7,49$ & $9--52$ & 12 & 23 & 5,54 & 33,06 & 61,40 & 1101 & $S(W \lambda=0,807 ; p<0,05)$ \\
\hline & 1999 & 42 & $13-58$ & 13 & 43 & 18,63 & 61,03 & 20,34 & 816 & \\
\hline & & & & 23 & & & & & & \\
\hline
\end{tabular}


Tabla III.3: Continuación.

\begin{tabular}{|c|c|c|c|c|c|c|c|c|c|c|}
\hline $\begin{array}{l}\text { C. } \\
\text { rastrospinosus }\end{array}$ & $\begin{array}{l}1987 \\
1999 \\
\end{array}$ & $\begin{array}{c}33,43 \pm 5,25 \\
31,16 \\
\end{array}$ & $\begin{array}{l}18--47 \\
16--48\end{array}$ & $\begin{array}{l}29 \\
37 \\
\end{array}$ & $\begin{array}{l}30 \\
41\end{array}$ & $\begin{array}{l}1,81 \\
1,14 \\
\end{array}$ & $\begin{array}{c}19,00 \\
\mathbf{5 , 4 3} \\
\end{array}$ & $\begin{array}{l}79,00 \\
\mathbf{9 9 , 4 2} \\
\end{array}$ & $\begin{array}{r}221 \\
2887 \\
\end{array}$ & $S(W \lambda=0,605 ; p<0,05)$ \\
\hline P. georgianus & $\begin{array}{l}1987 \\
1999\end{array}$ & $\begin{array}{c}19,01 \pm 8,94 \\
45,9\end{array}$ & $\begin{array}{l}12--53 \\
15--54\end{array}$ & $\begin{array}{l}14 \\
27 \\
39 \\
50\end{array}$ & $\begin{array}{l}29 \\
40 \\
48\end{array}$ & $\begin{array}{l}3,61 \\
2,35\end{array}$ & $\begin{array}{l}56,60 \\
\mathbf{8 1 , 8 6}\end{array}$ & $\begin{array}{l}39,73 \\
15,78\end{array}$ & $\begin{array}{c}526 \\
1020\end{array}$ & $S(W \lambda=0,827 ; p<0,05)$ \\
\hline C. antarcticus & 1999 & -- & $20--46$ & -- & 26 & -- & -- & -- & -- & -- \\
\hline Myctophidae & & & & & & & & & & \\
\hline G. nicholsi & 1999 & -- & $12--18$ & -- & 14 & -- & -- & -- & -- & -- \\
\hline E. antarctica & 1999 & -- & $6-16$ & -- & 9 & -- & -- & -- & -- & -- \\
\hline Nototheniidae & & & & & & & & & & \\
\hline G. gibberifrons & $\begin{array}{l}1986 \\
1999\end{array}$ & $\begin{array}{c}22,98 \pm 7,05 \\
27,33\end{array}$ & $\begin{array}{l}8--44 \\
8--47\end{array}$ & $\begin{array}{l}12 \\
20 \\
27 \\
33\end{array}$ & $\begin{array}{l}21 \\
26 \\
33\end{array}$ & $\begin{array}{l}16,00 \\
13,95\end{array}$ & $\begin{array}{l}51,00 \\
50,05\end{array}$ & $\begin{array}{l}33,00 \\
36,01\end{array}$ & $\begin{array}{l}10801 \\
10969\end{array}$ & $S(W \lambda=0,769 ; p<0,05)$ \\
\hline L. nudifrons & 1987 & $12,7 \pm 1,93$ & $6-20$ & 12 & -- & 14,80 & 64,00 & 21,20 & 990 & NS $(F=2,2001 ; g l: 2 ; P=0,13)$ \\
\hline L. squamifrons & 1999 & 32,86 & $9-50$ & -- & $\begin{array}{l}25 \\
28 \\
32 \\
\end{array}$ & -- & -- & -- & -- & -- \\
\hline N. coriiceps & 1987 & $41,02 \pm 3,71$ & $26--54$ & 40 & & 35,40 & 56,70 & 7,90 & 192 & $S(W \lambda=0,540 ; p<0,05)$ \\
\hline N. rossii & 1999 & 47,47 & $37--65$ & & $\begin{array}{l}42 \\
45 \\
48 \\
50\end{array}$ & 2,63 & 7,24 & 90,13 & 152 & \\
\hline L. Iarseni & $\begin{array}{l}1987 \\
1999 \\
\end{array}$ & $\begin{array}{c}16,24 \pm 2,47 \\
17,28 \\
\end{array}$ & $\begin{array}{c}6-23 \\
10--23 \\
\end{array}$ & 17 & 18 & $\begin{array}{r}2,50 \\
17,07 \\
\end{array}$ & $\begin{array}{l}55,00 \\
\mathbf{4 7 , 0 3} \\
\end{array}$ & $\begin{array}{l}42,50 \\
35,90 \\
\end{array}$ & $\begin{array}{c}9950 \\
791 \\
\end{array}$ & $S(W \lambda=0,704 ; p<0,05)$ \\
\hline P. antarcticum & 1987 & $10,52 \pm 3,14$ & $6--26$ & 8 & -- & 2,96 & 40,50 & 56,80 & 15290 & NS $(F=2,339 ; g l: 2 ; P=0,45)$ \\
\hline T. newnesi & 1987 & $16,5 \pm 2,08$ & $9--24$ & 16 & -- & 30,10 & 47,60 & 23,10 & 740 & $S(W \lambda=0,704 ; p<0,05)$ \\
\hline
\end{tabular}

Tabla III.4: Biomasa $(\mathrm{Kg})$ de las especies capturadas durante la campaña "Antártida 8611" (Tomado de Balguerías 1989) y la campaña US AMLR 99 (Tomado de Jones et al. 2000). Los valores en verde indican una disminución y los valores en rojo un aumento entre ambos muestreos.

\begin{tabular}{|lcc|}
\hline TAXON & Biomasa (Kg) & $\begin{array}{c}\text { Biomasa (Kg) } \\
1999\end{array}$ \\
\hline Aethotaxis mitopteryx & 5,28 & \\
Artedidraco skottsbergi & & 0,01 \\
Bathydraco marri & & 0,046 \\
Bathyraja eatonii & & 6,74 \\
Bathyraja maccaini & 7,96 & 64,795 \\
Bathyraja sp. & 1,45 & 7,917 \\
Chaenocephalus aceratus & 545,13 & 1454,16 \\
Chaenodraco wilsoni & & 0,575 \\
Champsocephalus gunnari & 172,4 & 502,42 \\
Chionodraco rastrospinosus & 77,39 & 923,92 \\
Cryodraco antarcticus & 6,22 & 27,89 \\
Electrona antarctica & & 12,49 \\
Electrona sp. & 4,18 & 0,01 \\
Gobionotothen gibberifrons & 1350,73 & 5061,57 \\
Gelarchea australis & 0,08 & \\
Genioliparis sp. & 0,1 & 1,231 \\
Gymnodraco acuticeps & 1,31 & 28,489 \\
Gymnoscopelus braueri & & \\
Gymnoscopelus nicholsi & 21,06 & \\
\hline
\end{tabular}


Tabla III.4: Continuación.

\begin{tabular}{|c|c|c|}
\hline Gymnoscopelus sp. & & 0,14 \\
\hline Krefftichthys anderssoni & & 0,01 \\
\hline Lepidonotothen larseni & 330,92 & 33,146 \\
\hline Lepidonotothen nudifrons & 22,4 & 0,695 \\
\hline Lepidonotothen squamifrons & & 5023,29 \\
\hline Lycodapus sp. & 0,61 & \\
\hline M. orangiensis & 3,08 & \\
\hline Magnisudis prionosa & & 0,46 \\
\hline Muraenolepis microps & & 3,28 \\
\hline Neopagetopsis ionah & 2,34 & 2,52 \\
\hline Notothenia coriiceps & 201,97 & 44,35 \\
\hline Notothenia kempi & 554,6 & \\
\hline Notothenia rossii & 32,35 & 273,3 \\
\hline Notothenia sp. & 0,09 & \\
\hline Pagothenia borchgrevinki & & 0,038 \\
\hline Parachaenichthys charcoti & 5,17 & 0,42 \\
\hline Paradiplospinus antarcticus & 1,15 & \\
\hline Paradiplospinus gracilis & & 0,683 \\
\hline Pleuragramma antarcticum & 126,53 & 1,19 \\
\hline Pogonophryne permitini & 2,83 & \\
\hline Pogonophryne sp. & 2,61 & 15,536 \\
\hline Pseudochaenichthys georgianus & 63,36 & 2583,4 \\
\hline Racovitzia glacialis & & 0,03 \\
\hline Scopelosaurus hamiltoni & & 0,05 \\
\hline Trematomus bernacchii & & 6,353 \\
\hline Trematomus eulepidotus & & 58,42 \\
\hline Trematomus hansoni & 7,19 & 21,85 \\
\hline Trematomus newnesi & 67,88 & 2,5 \\
\hline Trematomus nicolai & 1,03 & 0,05 \\
\hline Trematomus pennellii & 1 & 0,19 \\
\hline Trematomus tokarevi & & 0,411 \\
\hline Trematomus vicarius & 3,08 & \\
\hline Trematomus sp. & 48,54 & \\
\hline Totales & 3672,02 & 16165,611 \\
\hline
\end{tabular}

Tabla III.5: Detalle de las capturas (en número de individuos: N) para 11 especies durante la campaña "Antártida 8611" (Tomado de Balguerías 1989) y la campaña US AMLR 99 (Tomado de Jones et al. 2000). Los valores en verde indican una disminución y los valores en rojo un aumento entre ambos muestreos.

\begin{tabular}{|l|c|c|}
\hline Especie & N 1987 & N 1999 \\
\hline P. antarcticum & 15290 & 12 \\
\hline G. gibberifrons & 10801 & 18745 \\
\hline N. larseni & 9950 & 759 \\
\hline C. aceratus & 3838 & 2592 \\
\hline N. kempi & 1393 & -- \\
\hline C. gunnari & 1301 & 761 \\
\hline N. nudifrons & 990 & 18 \\
\hline T. newnesi & $\mathbf{7 4 0}$ & 24 \\
\hline P. georgianus & $\mathbf{5 2 6}$ & 1917 \\
\hline C. rastrospinosus & $\mathbf{2 2 1}$ & 3453 \\
\hline N. coriiceps & 192 & 32 \\
\hline
\end{tabular}


La Diversidad calculada a partir del Índice de Simpson decreció entre los años 1987 y 1999 de 0,81 a 0,76. Lo mismo ocurrió con la Equitatividad (de 0,55 a 0,46) lo que sugiere que la recuperación de los stocks no es similar en todas las especies.

\section{III.3.3. Selectividad de presas}

Las especies cuya dieta se basa en una alta proporción de krill tales como los pingüinos Adelia y de Barbijo seleccionaron positivamente especies de la familia Myctophidae y al notothénido $T$. newnesi (tablas III.6 y III.7). El grupo de los consumidores mixtos (krill-peces) seleccionó positivamente especies de notothénidos, myctóphidos y channíchthyidos. El pingüino Papúa, la foca de Weddell y el Iobo Fino Antártico seleccionaron positivamente los notothénidos L. larseni, L. nudifrons y $T$. newnesi (Tablas III.8, III.9, III.10, III.11, III.12 y III.13). Curiosamente, en el estrato 3 la foca de Weddell presentó una fuerte tendencia a la selección de especies de la familia Nototheniidae, en tanto que las especies seleccionadas a menor profundidad se correspondieron con los channíchthyidos $C$. aceratus y $C$. rastrospinosus. El lobo Fino Antártico en el primer estrato seleccionó fuertemente a $C$. aceratus, en tanto que en el tercero lo hizo con C. rastrospinosus (ver capítulo II).

El cormorán de Georgias, un predador exclusivamente ictiófago, seleccionó una gran variedad de especies bento-demersales pertenecientes a las familias Nototheniidae y Batylagidae (Tablas III.14 y III.15). Este cormorán predó fuertemente sobre el harpagiférido Harpagifer antarcticus, especie que no estuvo representada en las capturas debido a su distribución litoral (Casaux 1998), por lo que no se pudo estimar la intensidad con que fue seleccionado. A diferencia de lo observado en otros predadores, el pingüino Papúa y el cormorán de Georgias mostraron altos valores de selectividad de especies de notothénidos. 
Tabla III.6: Análisis de la selectividad de presas para el Pingüino de Adelia en I. Laurie (IOS). M\%_IOS: es el porcentaje en masa de las especies de peces que fueron capturadas durante la campaña "Antártida 8611" (Tomado de Balguerías 1989) expresadas para el total de la columna de agua y para cada estrato de profundidad (1, 2 y 3 ); M\% dieta: es el porcentaje en masa de cada especiepresa en la dieta del predador. Los valores de Ivlev $>0$ (enmarcados) indican selectividad positiva.

\begin{tabular}{|c|c|c|c|c|c|c|c|c|c|}
\hline \multirow[b]{2}{*}{ P. de Adelia } & \multicolumn{3}{|c|}{ Total columna de agua } & \multicolumn{6}{|c|}{ Por estrato de profundidad } \\
\hline & M\%_IOS & M\%_dieta & Ivlev & M\%_1 & Ivlev_1 & M\%_2 & Ivlev_2 & M\%_3 & Ivlev_3 \\
\hline \multicolumn{10}{|l|}{ Peces óseos } \\
\hline \multicolumn{10}{|l|}{ Artedidraconidae } \\
\hline Pogonophryne permitini & 0,08 & & $-1,00$ & 0,00 & & 0,00 & & 0,15 & $-1,00$ \\
\hline Pogonophryne sp. & 0,07 & & $-1,00$ & 0,00 & & 0,00 & $-1,00$ & 0,14 & $-1,00$ \\
\hline \multicolumn{10}{|l|}{ Bathydraconidae } \\
\hline Gelarchea australis & 0,00 & & $-1,00$ & 0,00 & & 0,00 & & 0,00 & $-1,00$ \\
\hline Gymnodraco acuticeps & 0,04 & & $-1,00$ & 0,04 & $-1,00$ & 0,01 & $-1,00$ & 0,05 & $-1,00$ \\
\hline Parachaenichthys charcotti & 0,14 & & $-1,00$ & 0,61 & $-1,00$ & 0,18 & $-1,00$ & 0,02 & $-1,00$ \\
\hline Prionodraco evansii & 0,02 & & $-1,00$ & 0,01 & $-1,00$ & 0,01 & $-1,00$ & 0,03 & $-1,00$ \\
\hline Psilodraco breviceps & 0,00 & & $-1,00$ & 0,00 & & 0,00 & $-1,00$ & 0,00 & $-1,00$ \\
\hline Channichthyidae & & & $-1,00$ & & & & & & \\
\hline Chaenocephalus aceratus & 14,82 & & $-1,00$ & 26,14 & $-1,00$ & 20,19 & $-1,00$ & 8,39 & $-1,00$ \\
\hline Chaenodraco rastrospinosus & 2,10 & & $-1,00$ & 0,61 & $-1,00$ & 1,25 & $-1,00$ & 3,07 & $-1,00$ \\
\hline Chamsocephalus gunnari & 4,69 & & $-1,00$ & 1,18 & $-1,00$ & 3,11 & $-1,00$ & 6,61 & $-1,00$ \\
\hline Cryodraco antarcticus & 0,17 & & $-1,00$ & 0,00 & & 0,01 & $-1,00$ & 0,33 & $-1,00$ \\
\hline Neopagetopsis ionah & 0,06 & & $-1,00$ & 0,00 & & 0,03 & $-1,00$ & 0,10 & $-1,00$ \\
\hline Pagetopsis macropterus & 0,01 & & $-1,00$ & 0,00 & & 0,00 & & 0,02 & $-1,00$ \\
\hline Pseudochaenichthys georgianus & 1,72 & & $-1,00$ & 0,38 & $-1,00$ & 2,17 & $-1,00$ & 1,63 & $-1,00$ \\
\hline \multicolumn{10}{|l|}{ Gempylidae } \\
\hline Paradiplospinus antarcticus & 0,03 & & $-1,00$ & 0,02 & $-1,00$ & 0,02 & $-1,00$ & 0,04 & $-1,00$ \\
\hline \multicolumn{10}{|l|}{ Liparididae } \\
\hline Genioliparis sp. & 0,00 & & $-1,00$ & 0,00 & & 0,00 & $-1,00$ & 0,00 & $-1,00$ \\
\hline Liparididae sp. & 0,00 & & $-1,00$ & 0,00 & & 0,00 & $-1,00$ & 0,00 & \\
\hline \multicolumn{10}{|l|}{ Moridae } \\
\hline Moroteuthis sp. & 0,03 & & $-1,00$ & 0,00 & & 0,04 & $-1,00$ & 0,03 & $-1,00$ \\
\hline \multicolumn{10}{|l|}{ Muraenolepididae } \\
\hline Muraenolepis orangiensis & 0,08 & & $-1,00$ & 0,00 & & 0,03 & $-1,00$ & 0,14 & $-1,00$ \\
\hline \multicolumn{10}{|l|}{ Melampahidae } \\
\hline Melanphaes microps & 0,06 & & $-1,00$ & 0,00 & & 0,10 & $-1,00$ & 0,04 & $-1,00$ \\
\hline Melanphaes sp. & 0,01 & & $-1,00$ & 0,00 & & 0,00 & $-1,00$ & 0,02 & $-1,00$ \\
\hline \multicolumn{10}{|l|}{ Myctophidae } \\
\hline Gimnoscopelus nicholsi & 0,57 & & $-1,00$ & 0,01 & $-1,00$ & 0,10 & $-1,00$ & 1,06 & $-1,00$ \\
\hline Etectrona sp. & 0,11 & & $-1,00$ & 0,05 & $-1,00$ & 0,03 & $-1,00$ & 0,19 & $-1,00$ \\
\hline Protomyctophum normani & & 41,50 & 1,00 & & 1,00 & & 1,00 & & 1,00 \\
\hline \multicolumn{10}{|l|}{ Notothenildae } \\
\hline Aethotaxis mitopteryx & 0,14 & & $-1,00$ & 0,01 & $-1,00$ & 0,06 & $-1,00$ & 0,23 & $-1,00$ \\
\hline Gobionotothen gibberifrons & 36,73 & & $-1,00$ & 43,69 & $-1,00$ & 42,97 & $-1,00$ & 30,45 & $-1,00$ \\
\hline Lepidonotothen nudifrons & 0,61 & & $-1,00$ & 0,74 & $-1,00$ & 0,99 & $-1,00$ & 0,28 & $-1,00$ \\
\hline Notothenia rossii & 0,88 & & $-1,00$ & 0,61 & $-1,00$ & 0,69 & $-1,00$ & 1,08 & $-1,00$ \\
\hline Notothenia kempi & 15,08 & & $-1,00$ & 0,00 & & 0,20 & $-1,00$ & 29,74 & $-1,00$ \\
\hline Notothenia coriiceps & 5,49 & & $-1,00$ & 20,49 & $-1,00$ & 7,89 & $-1,00$ & 0,68 & $-1,00$ \\
\hline Lepidonotothen macrophthalma & 0,00 & & & 0,00 & & 0,00 & $-1,00$ & 0,01 & $-1,00$ \\
\hline Lepidonotothen larseni & 9,00 & & $-1,00$ & 1,88 & $-1,00$ & 11,97 & $-1,00$ & 8,04 & $-1,00$ \\
\hline Tremtatomus mewnesi- & 1,85 & & $-1,00$ & $-2,45$ & $-1,00$ & 2,90 & $-1,00$ & 0,90 & $-1,00$ \\
\hline Trematomus hansoni & 0,20 & 58,50 & 0,94 & 0,00 & 0,92 & 0,00 & 0,91 & 0,39 & 0,97 \\
\hline 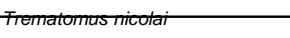 & -,os & & $-1,00$ & $0, \infty$ & & 0,02 & $-1,00$ & 0,04 & $-1,00$ \\
\hline Trematomus pennelli & 0,03 & & $-1,00$ & 0,00 & & 0,00 & & 0,05 & $-1,00$ \\
\hline Trematomus vicarius & 0,08 & & $-1,00$ & 0,00 & $-1,00$ & 0,13 & $-1,00$ & 0,07 & $-1,00$ \\
\hline Pleuragramma antarcticum & 3,44 & & $-1,00$ & 1,05 & $-1,00$ & 3,84 & $-1,00$ & 3,59 & $-1,00$ \\
\hline Notothenia sp. & 0,00 & & $-1,00$ & 0,00 & & 0,00 & & 0,00 & $-1,00$ \\
\hline Trematomus sp. & 1,32 & & $-1,00$ & 0,02 & $-1,00$ & 1,05 & $-1,00$ & 1,79 & $-1,00$ \\
\hline Paralepididae & & & & & & & & & \\
\hline Paralepididae sp. & 0,02 & & $-1,00$ & 0,00 & & 0,00 & & 0,03 & $-1,00$ \\
\hline Notolepis coatsi & & & & & & & & & \\
\hline Zorcidae & & & & & & & & & \\
\hline Lycodapus sp. & 0,02 & & $-1,00$ & 0,00 & & 0,00 & $-1,00$ & 0,03 & $-1,00$ \\
\hline Peces Cartilaginosos & & & & & & & & & \\
\hline Rajidae & & & & & & & & & \\
\hline Bathyraja maccaini & 0,22 & & $-1,00$ & 0,00 & & 0,00 & & 0,43 & $-1,00$ \\
\hline Bathyraja sp. & 0,04 & & $-1,00$ & 0,00 & & 0,00 & & 0,08 & $-1,00$ \\
\hline
\end{tabular}


Tabla III.7: Análisis de la selectividad de presas para los pingüinos de Barbijo y de Adelia en I. Laurie (IOS). M\%_IOS: es el porcentaje en masa de las especies de peces que fueron capturadas durante la campaña "US AMLR 9" (Tomado de Kock et al. 2000) expresadas para el total de la columna de agua y para cada estrato de profundidad $(1,2$ y 3 );

M\%_dieta: es el porcentaje en masa de cada especie presa en la dieta del predador. Los valores de Ivlev $>0$ (enmarcados) indican selectividad positiva.

\begin{tabular}{|c|c|c|c|c|c|c|c|c|c|c|c|c|c|}
\hline \multirow[b]{2}{*}{ P. de Barbijo } & \multicolumn{3}{|c|}{ Total columna de agua } & \multicolumn{4}{|c|}{ Total columna de agua } & \multicolumn{6}{|c|}{ Por estrato de profundidad } \\
\hline & M\%_IOS & M\%_dieta & Ivlev & P. de Adelia & M\%_IOS & M\%_dieta & Ivlev & M\%_1 & Ivlev_1 & M\%_2 & Ivlev_2 & M\%_3 & Ivlev_3 \\
\hline \multicolumn{14}{|l|}{ Peces Oseos } \\
\hline \multicolumn{14}{|l|}{ Artedidraconidae } \\
\hline Pogonophryne sp. & 0,10 & & $-1,00$ & & 0,10 & & $-1,00$ & & & & & & \\
\hline \multicolumn{14}{|l|}{ Bathydraconidae } \\
\hline Batydraco marri & 0,00 & & $-1,00$ & & 0,00 & & $-1,00$ & & & & & & \\
\hline Gymnodraco acuticeps & 0,01 & & $-1,00$ & & 0,01 & & $-1,00$ & & & & & & \\
\hline Parachaenichthys charcotti & 0,00 & & $-1,00$ & & 0,00 & & $-1,00$ & & & & & & \\
\hline Racovitzia glacialis & 0,00 & & $-1,00$ & & 0,00 & & $-1,00$ & & & & & & \\
\hline \multicolumn{14}{|l|}{ Channichthyidae } \\
\hline Chaenocephalus acceratus & 8,99 & & $-1,00$ & & 8,99 & & $-1,00$ & 22,40 & $-1,00$ & 14,35 & $-1,00$ & 2,54 & $-1,00$ \\
\hline Chaenodraco wilsoni & 0,00 & & $-1,00$ & & 0,00 & & $-1,00$ & & & & & & \\
\hline Champsocephalus gunnari & 3,11 & & $-1,00$ & & 3,11 & & $-1,00$ & 4,87 & $-1,00$ & 5,46 & $-1,00$ & 1,05 & $-1,00$ \\
\hline Chinodraco rastrospinosus & 5,71 & & $-1,00$ & & 5,71 & & $-1,00$ & 1,48 & $-1,00$ & 1,37 & $-1,00$ & 10,16 & $-1,00$ \\
\hline Cryodraco antarcticus & 0,17 & & $-1,00$ & & 0,17 & & $-1,00$ & & & 0,00 & & & \\
\hline Neopagetopsis ionah & 0,02 & & $-1,00$ & & 0,02 & & $-1,00$ & & & & & & \\
\hline Pseudochaenichthys georgianus & 13,78 & & $-1,00$ & & 13,78 & & $-1,00$ & 1,69 & $-1,00$ & 38,28 & $-1,00$ & 1,99 & $-1,00$ \\
\hline \multicolumn{14}{|l|}{ Gempylidae } \\
\hline Paradiplospinus gracilis & 0,00 & & $-1,00$ & & 0,00 & & $-1,00$ & & & & & & \\
\hline \multicolumn{14}{|l|}{ Muraenolepididae } \\
\hline Muraenolepis microps & 0,02 & & $-1,00$ & & 0,02 & & $-1,00$ & & & & & & \\
\hline \multicolumn{14}{|l|}{ Myctophidae } \\
\hline Electrona antarctica & 0,08 & 3,45 & 0,96 & & 0,08 & 100,00 & 1,00 & & & & & & \\
\hline Electrona sp. & 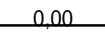 & & $-1,00$ & & معفم & & & & & & & & \\
\hline Gimnoscopelus braweri & 0,01 & & $-1,00$ & & 0,01 & & & & & & & & \\
\hline Gimnoscopelus nicholsi & 0,18 & 73,50 & 1,00 & & 0,18 & & $-1,00$ & & & & & & \\
\hline Sim sp. & - & & $-1,00$ & & 0 & & & & & & & & \\
\hline Krefftichthys andersoni & 0,00 & & $-1,00$ & & 0,00 & & & & & & & & \\
\hline \multicolumn{14}{|l|}{ Nototheniidae } \\
\hline Dissostichus mawsoni & 0,01 & & $-1,00$ & & 0,01 & & $-1,00$ & & & & & & \\
\hline Gobionotothen gibberifrons & 31,31 & 7,74 & $-0,60$ & & 31,31 & & $-1,00$ & 68,62 & $-1,00$ & 39,02 & $-1,00$ & 19,19 & $-1,00$ \\
\hline Lepidonotothen larseni & 0,21 & & $-1,00$ & & 0,21 & & $-1,00$ & 0,42 & $-1,00$ & 0,25 & $-1,00$ & 0,14 & $-1,00$ \\
\hline Lepidonotothen nudifrons & 0,00 & & $-1,00$ & & 0,00 & & $-1,00$ & & & & & & \\
\hline Lepidonotothen squamifrons & 31,07 & & & & 31,07 & & $-1,00$ & & & 1,05 & & 61,81 & \\
\hline Notothenia coriiceps & 0,27 & & $-1,00$ & & 0,27 & & $-1,00$ & & & & & & \\
\hline Notothenia rossii & 1,69 & & $-1,00$ & & 1,69 & & $-1,00$ & 0,52 & $-1,00$ & 0,22 & $-1,00$ & 3,13 & $-1,00$ \\
\hline Pagothenia borchgrevinki & 0,00 & & & & 0,00 & & & & & & & & \\
\hline Pleuragramma antarcticum & 0,01 & & $-1,00$ & & 0,01 & & $-1,00$ & & & & & & \\
\hline Trematomus bernachii & 0,04 & & $-1,00$ & & 0,04 & & $-1,00$ & & & & & & \\
\hline Trematomus eulepidotus & 0,36 & & $-1,00$ & & 0,36 & & $-1,00$ & & & & & & \\
\hline Irematomus hansoni & 0.14 & & -1.00 & & 0,14 & & $-1,00$ & & & & & & \\
\hline Trematomus newnesi & 0,02 & 3,95 & 0,99 & & 0,02 & & $-1,00$ & & & & & & \\
\hline Irematomus nicolai & مـمهم & & $-1,00$ & & 0,00 & & $-1,00$ & & & & & & \\
\hline Trematomus pennelli & 0,00 & & $-1,00$ & & 0,00 & & $-1,00$ & & & & & & \\
\hline Tramatomus tokarevi & 0,00 & & $-1,00$ & & 0,00 & & $-1,00$ & & & & & & \\
\hline \multicolumn{14}{|l|}{ Paralepididae } \\
\hline Magnisidus prionosa & 0,00 & & $-1,00$ & & 0,00 & & $-1,00$ & & & & & & \\
\hline \multicolumn{14}{|l|}{ Notosudidae } \\
\hline Scopelosaurus hamiltoni & 0,00 & & $-1,00$ & & 0,01 & & $-1,00$ & & & & & & \\
\hline \multicolumn{14}{|l|}{ Peces Cartilaginosos } \\
\hline Rajidae & & & & & & & & & & & & & \\
\hline Bathyraja eatonii & 0,04 & & $-1,00$ & & 0,04 & & $-1,00$ & & & & & & \\
\hline Bathyraja maccaini & 0,40 & & $-1,00$ & & 0,40 & & $-1,00$ & & & & & & \\
\hline Bathyraja sp. & 0,05 & & $-1,00$ & & 0,05 & & $-1,00$ & & & & & & \\
\hline
\end{tabular}


Tabla III.8: Análisis de la selectividad de presas para el Pingüino Papúa en I. Laurie (IOS). M\%_IOS: es el porcentaje en masa de las especies de peces que fueron capturadas durante la campaña "Antártida 8611" (Tomado de Balguerías 1989) expresadas para el total de la columna de agua y para cada estrato de profundidad $(1,2$ y 3 ; $M \%$ dieta: es el porcentaje en masa de cada especie presa en la dieta del predador. Los valores de Ivlev $>0$ (enmarcados) indican selectividad positiva.

\begin{tabular}{|c|c|c|c|c|c|c|c|c|c|}
\hline P. Papúa & M\%_IOS & $\% M$ & Ivlev & M\%_1 & Ivlev_1 & M\%_2 & Ivlev_2 & M\%_3 & Ivlev_3 \\
\hline \multicolumn{10}{|l|}{ Peces óseos } \\
\hline \multicolumn{10}{|l|}{ Artedidraconidae } \\
\hline Pogonophryne permitini & 0,08 & & $-1,00$ & 0,00 & & 0,00 & $-1,00$ & 0,15 & $-1,00$ \\
\hline Pogonophryne sp. & 0,07 & & $-1,00$ & 0,00 & $-1,00$ & 0,00 & $-1,00$ & 0,14 & $-1,00$ \\
\hline \multicolumn{10}{|l|}{ Bathydraconidae } \\
\hline Gelarchea australis & 0,00 & & $-1,00$ & 0,00 & & 0,00 & $-1,00$ & 0,00 & $-1,00$ \\
\hline Gymnodraco acuticeps & 0,04 & & $-1,00$ & 0,04 & $-1,00$ & 0,01 & $-1,00$ & 0,05 & $-1,00$ \\
\hline Parachaenichthys charcotti & 0,14 & & $-1,00$ & 0,61 & $-1,00$ & 0,18 & $-1,00$ & 0,02 & $-1,00$ \\
\hline Prionodraco evansii & 0,02 & & $-1,00$ & 0,01 & $-1,00$ & 0,01 & $-1,00$ & 0,03 & $-1,00$ \\
\hline Psilodraco breviceps & 0,00 & & $-1,00$ & 0,00 & & 0,00 & $-1,00$ & 0,00 & $-1,00$ \\
\hline Channichthyidae & & 8,00 & $-0,49$ & & $-0,54$ & & $-0,43$ & & $-0,49$ \\
\hline Chaenocephalus aceratus & 14,82 & & $-1,00$ & 26,14 & $-1,00$ & 20,19 & $-1,00$ & 8,39 & $-1,00$ \\
\hline Chaenodraco rastrospinosus & 2,10 & & $-1,00$ & 0,61 & $-1,00$ & 1,25 & $-1,00$ & 3,07 & $-1,00$ \\
\hline Chamsocephalus gunnari & 4,69 & & $-1,00$ & 1,18 & $-1,00$ & 3,11 & $-1,00$ & 6,61 & $-1,00$ \\
\hline Cryodraco antarcticus & 0,17 & & $-1,00$ & 0,00 & $-1,00$ & 0,01 & $-1,00$ & 0,33 & $-1,00$ \\
\hline Neopagetopsis ionah & 0,06 & & $-1,00$ & 0,00 & $-1,00$ & 0,03 & $-1,00$ & 0,10 & $-1,00$ \\
\hline Pagetopsis macropterus & 0,01 & & $-1,00$ & 0,00 & & 0,00 & $-1,00$ & 0,02 & $-1,00$ \\
\hline Pseudochaenichthys georgianus & 1,72 & & $-1,00$ & 0,38 & $-1,00$ & 2,17 & $-1,00$ & 1,63 & $-1,00$ \\
\hline \multicolumn{10}{|l|}{ Gempylidae } \\
\hline Paradiplospinus antarcticus & 0,03 & & $-1,00$ & 0,02 & $-1,00$ & 0,02 & $-1,00$ & 0,04 & $-1,00$ \\
\hline \multicolumn{10}{|l|}{ Liparididae } \\
\hline Genioliparis sp. & 0,00 & & $-1,00$ & 0,00 & $-1,00$ & 0,00 & $-1,00$ & 0,00 & $-1,00$ \\
\hline Liparididae sp. & 0,00 & & $-1,00$ & 0,00 & $-1,00$ & 0,00 & & 0,00 & $-1,00$ \\
\hline \multicolumn{10}{|l|}{ Moridae } \\
\hline Moroteuthis sp. & 0,03 & & $-1,00$ & 0,00 & $-1,00$ & 0,04 & $-1,00$ & 0,03 & $-1,00$ \\
\hline \multicolumn{10}{|l|}{ Muraenolepididae } \\
\hline Muraenolepis orangiensis & 0,08 & & $-1,00$ & 0,00 & $-1,00$ & 0,03 & $-1,00$ & 0,14 & $-1,00$ \\
\hline \multicolumn{10}{|l|}{ Melampahidae } \\
\hline Melanphaes microps & 0,06 & & $-1,00$ & 0,00 & & 0,10 & $-1,00$ & 0,04 & $-1,00$ \\
\hline Melanphaes sp. & 0,01 & & $-1,00$ & 0,00 & & 0,00 & $-1,00$ & 0,02 & $-1,00$ \\
\hline Myctophাdae & & & & & & & & & \\
\hline Gimnoscopelus nicholsi & 0,57 & 3,50 & 0,72 & 0,01 & 0,95 & 0,10 & 0,54 & 1,06 & 0,72 \\
\hline Etectroma sp. & 0,11 & 0,10 & $-0,06$ & 0,05 & 0,51 & 0,03 & $-0,31$ & 0,19 & $-0,06$ \\
\hline \multicolumn{10}{|l|}{ Krefftichthys andersoni } \\
\hline \multicolumn{10}{|l|}{ Lampanyctus achirus } \\
\hline \multicolumn{10}{|l|}{ Protomyctophum normani } \\
\hline \multicolumn{10}{|l|}{ Nototheniidae } \\
\hline Aethotaxis mitopteryx & 0,14 & & $-1,00$ & 0,01 & $-1,00$ & 0,06 & $-1,00$ & 0,23 & $-1,00$ \\
\hline Gobbionotothen gibberifrons & 36,73 & 44,60 & 0,10 & 43,69 & 0,02 & 42,97 & 0,19 & 30,45 & 0,10 \\
\hline Lepidortotottrentाudifforts & 0,01 & & $-1,00$ & 0,74 & $-1,00$ & 0,9 & $-1,00$ & 0,28 & $-1,00$ \\
\hline Notothenia rossii & 0,88 & & $-1,00$ & 0,61 & $-1,00$ & 0,69 & $-1,00$ & 1,08 & $-1,00$ \\
\hline Notothenia kempi & 15,08 & & $-1,00$ & 0,00 & $-1,00$ & 0,20 & $-1,00$ & 29,74 & $-1,00$ \\
\hline Notothenia coriiceps & 5,49 & & $-1,00$ & 20,49 & $-1,00$ & 7,89 & $-1,00$ & 0,68 & $-1,00$ \\
\hline 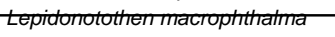 & 0,00 & & $-4,00$ & 0,0 & $-1,00$ & $0, \infty$ & $-4,00$ & 0,01 & $-4,00$ \\
\hline Lepidonotothen larseni & 9,00 & 36,60 & 0,61 & 1,88 & 0,51 & 11,97 & 0,64 & 8,04 & 0,61 \\
\hline Trematomus newnesi & 1,85 & 6,10 & 0,54 & 2,45 & 0,36 & 2,90 & 0,74 & 0,90 & 0,54 \\
\hline Trematomus hansoni & 0,20 & & $-4,00$ & 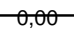 & & 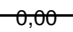 & $-1,00$ & - & $-4,00$ \\
\hline Trematomus nicolai & 0,03 & & $-1,00$ & 0,00 & $-1,00$ & 0,02 & $-1,00$ & 0,04 & $-1,00$ \\
\hline Trematomus pennelli & 0,03 & & $-1,00$ & 0,00 & & 0,00 & $-1,00$ & 0,05 & $-1,00$ \\
\hline Trematomus vicarius & 0,08 & & $-1,00$ & 0,00 & $-1,00$ & 0,13 & $-1,00$ & 0,07 & $-1,00$ \\
\hline Pleuragramma antarcticum & 3,44 & & $-1,00$ & 1,05 & $-1,00$ & 3,84 & $-1,00$ & 3,59 & $-1,00$ \\
\hline Notothenia sp. & 0,00 & & $-1,00$ & 0,00 & & 0,00 & $-1,00$ & 0,00 & $-1,00$ \\
\hline Trematomus sp. & 1,32 & & $-1,00$ & 0,02 & $-1,00$ & 1,05 & $-1,00$ & 1,79 & $-1,00$ \\
\hline \multicolumn{10}{|l|}{ Paralepididae } \\
\hline Paralepididae sp. & 0,02 & & $-1,00$ & 0,00 & & 0,00 & $-1,00$ & 0,03 & $-1,00$ \\
\hline Notolepis coatsi & & & & & & & & & \\
\hline Zorcidae & & & & & & & & & \\
\hline Lycodapus sp. & 0,02 & & $-1,00$ & 0,00 & $-1,00$ & 0,00 & $-1,00$ & 0,03 & $-1,00$ \\
\hline Peces Cartilaginosos & & & & & & & & & \\
\hline Rajidae & & & & & & & & & \\
\hline Bathyraja maccaini & 0,22 & & $-1,00$ & 0,00 & & 0,00 & $-1,00$ & 0,43 & $-1,00$ \\
\hline Bathyraja sp. & 0,04 & & $-1,00$ & 0,00 & & 0,00 & $-1,00$ & 0,08 & $-1,00$ \\
\hline
\end{tabular}


Tabla III.9: Análisis de la selectividad de presas para el Pingüino Papúa en I. Laurie (IOS). M\%_IOS: es el porcentaje en masa de las especies de peces que fueron capturadas durante la campaña "US AMLR 99" (Tomado de Kock et al. 2000) expresadas para el total de la columna de agua y para cada estrato de profundidad $(1,2$ y 3$)$; $M \%$ dieta: es el porcentaje en masa de cada especie presa en la dieta del predador. Los valores de Ivlev > 0 (enmarcados) indican selectividad positiva.

\section{Total columna de agua}

P. Papúa

M\% IOS M\% dieta Ivlev

$-1,00$

Artedidraconidae

Pogonophryne sp.

Bathydraconidae

Batydraco marri

Gymnodraco acuticeps

Parachaenichthys charcotti

Racovitzia glacialis

Channichthyidae

Chaenocephalus acceratus

Chaenodraco wilsoni

Champsocephalus gunnari

Chinodraco rastrospinosus

Cryodraco antarcticus

Neopagetopsis ionah

Pseudochaenichthys georgianus

Gempylidae

Paradiplospinus gracilis

Muraenolepididae

Muraenolepis microps

Myctophidae

Electrona antarctica

Electrona sp.

Gimnoscopelus braueri

Gimnoscopelus nicholsi

Gimnoscopelus sp.

Krefftichthys andersoni

Protomyctophum normani

Nototheniidae

Dissostichus mawsoni

Gobionotothen gibberifrons

Lepidonotothen larseni

Lepidonotothen nudifrons

Lepidonotothen squamifrons

Notothenia coriiceps

Notothenia rossii

Pagothenia borchgrevinki

Pleuragramma antarcticum

Trematomus bernachii

Trematomus eulepidotus

Trematomus hansoni

Trematomus newnesi

Trematomus nicolai

Trematomus pennelli

Tramatomus tokarevi

Paralepididae

Magnisidus prionosa

Notosudidae

Scopelosaurus hamiltoni

Peces Cartilaginosos

Rajidae

Bathyraja eatonii

Bathyraja maccaini

Bathyraja sp.
0,10

0,00

0,01

0,00

0,00

8,99

0,00

3,11

5,71

0,17

0,02

13,78

0,00

0,02

0,08

0,00

0,01

0,18

0,00

0,00
$-1,00$

$-1,00$

$-1,00$

$-1,00$

0,01

$-1,00$

$31,31 \quad 84,93 \quad 0,46$

$\begin{array}{lll}0,21 & 4,07 & 0,90 \\ 0,00 & 0,04 & 0,80\end{array}$

$31,07 \quad-1,00$

$0,27-1,00$

$1,69-1,00$

$0,00 \quad-1,00$

$0,01 \quad-1,00$

$\begin{array}{ll}0,01 & -1,00 \\ 0,04 & -1,00\end{array}$

$0,36 \quad-1,00$

$0,14 \quad-1,00$

$0,02 \quad 0,63 \quad 0,95$

$0,00 \quad-1,00$

$0,00 \quad-1,00$

$0,00 \quad-1,00$

$0,00 \quad-1,00$

$0,00 \quad-1,00$

$\begin{array}{ll}0,04 & -1,00 \\ 0,40 & -1,00 \\ 0,05 & -1,00\end{array}$

Por estrato de profundidad

M\% 1 Ivlev 1

Ivlev 2

M\%_3

Ivlev

\begin{tabular}{|c|c|c|c|c|c|c|}
\hline$-1,00$ & & & & & & \\
\hline$-1,00$ & & & & & & \\
\hline$-1,00$ & & & & & & \\
\hline$-1,00$ & & & & & & \\
\hline$-1,00$ & & & & & & \\
\hline$-1,00$ & 22,3 & $-1,00$ & 14,3 & $-1,00$ & 2,5 & $-1,00$ \\
\hline$-1,00$ & & & & & & \\
\hline$-1,00$ & 4,8 & $-1,00$ & 5,5 & $-1,00$ & 1,0 & $-1,00$ \\
\hline$-1,00$ & 1,5 & $-1,00$ & 1,4 & $-1,00$ & 10,1 & $-1,00$ \\
\hline$-1,00$ & & & & & & \\
\hline$-1,00$ & & & & & & \\
\hline$-1,00$ & 1,7 & $-1,00$ & 38,2 & $-1,00$ & 2,0 & $-1,00$ \\
\hline
\end{tabular}


Tabla III.10: Análisis de la selectividad de presas para la Foca de Weddell en I. Laurie (IOS). M\%_IOS: es el porcentaje en masa de las especies de peces que fueron capturadas durante la campaña "Antártida 8611" (Tomado de Balguerías 1989) expresadas para el total de la columna de agua y para cada estrato de profundidad $(1,2$ y 3$)$; M\%_dieta: es el porcentaje en masa de cada especie presa en la dieta del predador. Los valores de Ivlev $>0$ (enmarcados) indican selectividad positiva.

\begin{tabular}{|c|c|c|c|c|c|c|c|c|c|}
\hline F. de Weddell & M\%_IOS & $\% M$ & Ivlev & M\%_1 & Ivlev_1 & M\%_2 & Ivlev_2 & M\%_3 & Ivlev_3 \\
\hline \multicolumn{10}{|l|}{ Peces óseos } \\
\hline \multicolumn{10}{|l|}{ Artedidraconidae } \\
\hline Pogonophryne permitini & 0,08 & & $-1,00$ & 0,00 & & 0,00 & & 0,15 & $-1,00$ \\
\hline Pogonophryne sp. & 0,07 & & $-1,00$ & 0,00 & & 0,00 & $-1,00$ & 0,14 & $-1,00$ \\
\hline \multicolumn{10}{|l|}{ Bathydraconidae } \\
\hline Gelarchea australis & 0,00 & & $-1,00$ & 0,00 & & 0,00 & & 0,00 & $-1,00$ \\
\hline Gymnodraco acuticeps & 0,04 & & $-1,00$ & 0,04 & $-1,00$ & 0,01 & $-1,00$ & 0,05 & $-1,00$ \\
\hline Parachaenichthys charcotti & 0,14 & & $-1,00$ & 0,61 & $-1,00$ & 0,18 & $-1,00$ & 0,02 & $-1,00$ \\
\hline Prionodraco evansii & 0,02 & & $-1,00$ & 0,01 & $-1,00$ & 0,01 & $-1,00$ & 0,03 & $-1,00$ \\
\hline Psilodraco breviceps & 0,00 & & $-1,00$ & 0,00 & & 0,00 & & 0,00 & $-1,00$ \\
\hline \multicolumn{10}{|l|}{ Channichthyidae } \\
\hline Chaenocephalus aceratus & 14,82 & 29,12 & 0,33 & 26,14 & 0,05 & 20,19 & 0,18 & 8,39 & 0,55 \\
\hline Chaenodraco rastrospinosus & 2,10 & 5,82 & 0,47 & 0,61 & 0,81 & 1,25 & 0,65 & 3,07 & 0,31 \\
\hline chamsocephalus gunnari & 4,69 & & $-1,00$ & 1,18 & $-1,0$ & 3,11 & $-1,0$ & 661 & $-1,0$ \\
\hline Cryodraco antarcticus & 0,17 & & $-1,00$ & 0,00 & & 0,01 & $-1,00$ & 0,33 & $-1,00$ \\
\hline Neopagetopsis ionah & 0,06 & & $-1,00$ & 0,00 & & 0,03 & $-1,00$ & 0,10 & $-1,00$ \\
\hline Pagetopsis macropterus & 0,01 & & $-1,00$ & 0,00 & & 0,00 & & 0,02 & $-1,00$ \\
\hline Pseudochaenichthys georgianus & 1,72 & & $-1,00$ & 0,38 & $-1,00$ & 2,17 & $-1,00$ & 1,63 & $-1,00$ \\
\hline \multicolumn{10}{|l|}{ Gempylidae } \\
\hline Paradiplospinus antarcticus & 0,03 & & $-1,00$ & 0,02 & $-1,00$ & 0,02 & $-1,00$ & 0,04 & $-1,00$ \\
\hline \multicolumn{10}{|l|}{ Liparididae } \\
\hline Genioliparis sp. & 0,00 & & $-1,00$ & 0,00 & & 0,00 & $-1,00$ & 0,00 & $-1,00$ \\
\hline Liparididae sp. & 0,00 & & $-1,00$ & 0,00 & & 0,00 & $-1,00$ & 0,00 & \\
\hline \multicolumn{10}{|l|}{ Moridae } \\
\hline Moroteuthis sp. & 0,03 & & $-1,00$ & 0,00 & & 0,04 & $-1,00$ & 0,03 & $-1,00$ \\
\hline \multicolumn{10}{|l|}{ Muraenolepididae } \\
\hline Muraenolepis orangiensis & 0,08 & & $-1,00$ & 0,00 & & 0,03 & $-1,00$ & 0,14 & $-1,00$ \\
\hline \multicolumn{10}{|l|}{ Melampahidae } \\
\hline Melanphaes microps & 0,06 & & $-1,00$ & 0,00 & & 0,10 & $-1,00$ & 0,04 & $-1,00$ \\
\hline Melanphaes sp. & 0,01 & & $-1,00$ & 0,00 & & 0,00 & $-1,00$ & 0,02 & $-1,00$ \\
\hline \multicolumn{10}{|l|}{ Myctophidae } \\
\hline Gimnoscopelus nicholsi & 0,57 & & $-1,00$ & 0,01 & $-1,00$ & 0,10 & $-1,00$ & 1,06 & $-1,00$ \\
\hline Electrona sp. & 0,11 & & $-1,00$ & 0,05 & $-1,00$ & 0,03 & $-1,00$ & 0,19 & $-1,00$ \\
\hline \multicolumn{10}{|l|}{ Krefftichthys andersoni } \\
\hline \multicolumn{10}{|l|}{ Lampanyctus achirus } \\
\hline \multirow{2}{*}{\multicolumn{10}{|c|}{$\begin{array}{l}\text { Protomyctophum normani } \\
\text { Notothenidae }\end{array}$}} \\
\hline & & & & & & & & & \\
\hline Aethotaxis mitopteryx & 0,14 & & $-1,00$ & 0,01 & $-1,00$ & 0,06 & $-1,00$ & 0,23 & $-1,00$ \\
\hline Gobbionotothen gibberifrons & 36,73 & 91,86 & 0,43 & 43,69 & 0,36 & 42,97 & 0,36 & 30,45 & 0,50 \\
\hline Lepidonotothen nudifrons & 0,61 & 1,19 & 0,32 & 0,74 & 0,23 & 0,99 & 0,09 & 0,28 & 0,62 \\
\hline Notothenia rossii & 0,88 & & $-1,00$ & 0,61 & $-1,00$ & 0,69 & $-1,00$ & 1,08 & $-1,00$ \\
\hline Notothenia kempi & 15,08 & & $-1,00$ & 0,00 & & 0,20 & $-1,00$ & 29,74 & $-1,00$ \\
\hline Notothenia coriiceps & 5,49 & & $-1,00$ & 20,49 & $-1,00$ & 7,89 & $-1,00$ & 0,68 & $-1,00$ \\
\hline Lepidonotothen macrophthalma & 0,00 & & $-1,00$ & 0,00 & & 0,00 & $-1,00$ & 0,01 & $-1,00$ \\
\hline Lepidonotothen larseni & 9,00 & 0,96 & $-0,81$ & 1,88 & $-0,32$ & 11,97 & $-0,85$ & 8,04 & $-0,79$ \\
\hline Trematomus newnesi & 1,85 & 1,06 & $-0,27$ & 2,45 & $-0,40$ & 2,90 & $-0,46$ & 0,90 & 0,08 \\
\hline Trematomus hansoni & 0,20 & & $-1,00$ & 0,00 & & 0,00 & & 0,39 & $-1,00$ \\
\hline Trematomus nicolai & 0,03 & & $-1,00$ & 0,00 & & 0,02 & $-1,00$ & 0,04 & $-1,00$ \\
\hline Trematomus pennelli & 0,03 & & $-1,00$ & 0,00 & & 0,00 & & 0,05 & $-1,00$ \\
\hline Trematomus vicarius & 0,08 & & $-1,00$ & 0,00 & & 0,13 & $-1,00$ & 0,07 & $-1,00$ \\
\hline Pleuragramma antarcticum & 3,44 & & $-1,00$ & 1,05 & $-1,00$ & 3,84 & $-1,00$ & 3,59 & $-1,00$ \\
\hline Notothenia sp. & 0,00 & & $-1,00$ & 0,00 & & 0,00 & & 0,00 & $-1,00$ \\
\hline Trematomus sp. & 1,32 & & $-1,00$ & 0,02 & $-1,00$ & 1,05 & $-1,00$ & 1,79 & $-1,00$ \\
\hline Paralepididae & & & & & & & & & \\
\hline Paralepididae sp. & 0,02 & & $-1,00$ & 0,00 & & 0,00 & & 0,03 & $-1,00$ \\
\hline Notolepis coatsi & & & & & & & & & \\
\hline Zorcidae & & & & & & & & & \\
\hline Lycodapus sp. & 0,02 & & $-1,00$ & 0,00 & & 0,00 & $-1,00$ & 0,03 & $-1,00$ \\
\hline Peces Cartilaginosos & & & & & & & & & \\
\hline Rajidae & & & & & & & & & \\
\hline Bathyraja maccaini & 0,22 & & $-1,00$ & 0,00 & & 0,00 & & 0,43 & $-1,00$ \\
\hline Bathyraja sp. & 0,04 & & $-1,00$ & 0,00 & & 0,00 & & 0,08 & $-1,00$ \\
\hline
\end{tabular}


Tabla III.11: Análisis de la selectividad de presas para la Foca de Weddell en I. Laurie (IOS). M\%_IOS: es el porcentaje en masa de las especies de peces que fueron capturadas durante la campaña "US AMLR 99" (Tomado de Kock et al. 2000) expresadas para el total de la columna de agua y para cada estrato de profundidad $(1,2$ y 3 ); $M \%$ dieta: es el porcentaje en masa de cada especie presa en la dieta del predador. Los valores de Ivlev $>0$ (enmarcados) indican selectividad positiva.

\begin{tabular}{|c|c|c|c|c|c|c|c|c|c|}
\hline & \multicolumn{3}{|c|}{ Total columna de agua } & \multicolumn{3}{|c|}{ Por estrato de profundidad } & \multirow{3}{*}{ Ivlev_2 } & \multirow{3}{*}{ \%M_3 } & \multirow[b]{2}{*}{ Ivlev_3 } \\
\hline F. de Weddell & \%M_IOS & \%M_dieta & Ivlev & \%M_1 & Ivlev_1 & \%M_2 & & & \\
\hline \multicolumn{8}{|l|}{ Peces Oseos } & & \\
\hline \multicolumn{10}{|l|}{ Artedidraconidae } \\
\hline Pogonophryne sp. & 0,10 & & $-1,00$ & & & & & & \\
\hline \multicolumn{10}{|l|}{ Bathydraconidae } \\
\hline Batydraco marri & 0,00 & & $-1,00$ & & & & & & \\
\hline Gymnodraco acuticeps & 0,01 & & $-1,00$ & & & & & & \\
\hline Parachaenichthys charcotti & 0,00 & & $-1,00$ & & & & & & \\
\hline Racovitzia glacialis & 0,00 & & $-1,00$ & & & & & & \\
\hline \multicolumn{10}{|l|}{ Channichthyidae } \\
\hline $\begin{array}{l}\text { Chaenocephalus acceratus } \\
\text { Chaenodraco wilsoni }\end{array}$ & $\begin{array}{l}8,99 \\
0,00 \\
\end{array}$ & 29,12 & 0,53 & 22,3 & 0,13 & 14,3 & 0,34 & 2,5 & 0,84 \\
\hline Champsocephalus gunnari & 3,11 & & $-1,00$ & 4,8 & $-1,00$ & $-5,5$ & $-1,00$ & 1,0 & $-1,00$ \\
\hline Chinodraco rastrospinosus & 5,71 & 5,82 & 0,01 & 1,5 & 0,60 & 1,4 & 0,62 & 10,1 & $-0,27$ \\
\hline Cryodraco antareticus & 0,17 & & $-1,00$ & & & & & & \\
\hline Neopagetopsis ionah & 0,02 & & $-1,00$ & & & & & & \\
\hline Pseudochaenichthys georgianus & 13,78 & & & 1,7 & $-1,00$ & 38,2 & $-1,00$ & 2,0 & $-1,00$ \\
\hline \multicolumn{10}{|l|}{ Gempylidae } \\
\hline Paradiplospinus gracilis & 0,00 & & $-1,00$ & & & & & & \\
\hline \multicolumn{10}{|l|}{ Muraenolepididae } \\
\hline Muraenolepis microps & 0,02 & & $-1,00$ & & & & & & \\
\hline \multicolumn{10}{|l|}{ Myctophidae } \\
\hline Electrona antarctica & 0,08 & & $-1,00$ & & & & & & \\
\hline Electrona sp. & 0,00 & & $-1,00$ & & & & & & \\
\hline Gimnoscopelus braueri & 0,01 & & $-1,00$ & & & & & & \\
\hline Gimnoscopelus nicholsi & 0,18 & & $-1,00$ & & & & & & \\
\hline Gimnoscopelus spp. & 0,00 & & $-1,00$ & & & & & & \\
\hline Krefftichthys andersoni & 0,00 & & $-1,00$ & & & & & & \\
\hline \multicolumn{10}{|l|}{ Protomyctophum normani } \\
\hline \multicolumn{10}{|l|}{ Nototheniidae } \\
\hline Dissostichus mawsoni & 0,01 & & $-1,00$ & & & & & & \\
\hline Gobionotothen gibberifrons & 31,31 & 91,86 & 0,49 & 68,33 & 0,11 & 38,92 & 0,37 & 19,17 & 0,63 \\
\hline Lepidonotothen larseni & 0,21 & 0,96 & 0,65 & 0,42 & 0,81 & 0,25 & 0,88 & 0,14 & 0,94 \\
\hline Lepidonotothen nudifrons & 0,00 & 1,19 & 0,99 & & & & & & \\
\hline Lepidonotothen squamifrons & 31,07 & & & & & 1,04 & $-1,00$ & 61,72 & $-1,00$ \\
\hline Notothenia coriiceps & 0,27 & & $-1,00$ & & & & & & \\
\hline Notothenia rossii & 1,69 & & $-1,00$ & 0,51 & $-1,00$ & 0,22 & $-1,00$ & 3,13 & $-1,00$ \\
\hline Pagothenia borchgrevinki & 0,00 & & $-1,00$ & & & & & & \\
\hline Pleuragramma antarcticum & 0,01 & & $-1,00$ & & & & & & \\
\hline Trematomus bernachii & 0,04 & & $-1,00$ & & & & & & \\
\hline Trematomus eulepidotus & 0,36 & & $-1,00$ & & & & & & \\
\hline Trematomus hansoni & 0.14 & & -1.00 & & & & & & \\
\hline Trematomus newnesi & 0,02 & 1,06 & 0,97 & & & & & & \\
\hline Trematomus nicolai & ــمهـمـ & & $-1,00$ & & & & & & \\
\hline Trematomus pennelli & 0,00 & & $-1,00$ & & & & & & \\
\hline Tramatomus tokarevi & 0,00 & & $-1,00$ & & & & & & \\
\hline \multicolumn{10}{|l|}{ Paralepididae } \\
\hline Magnisidus prionosa & 0,00 & & $-1,00$ & & & & & & \\
\hline \multicolumn{10}{|l|}{ Notosudidae } \\
\hline Scopelosaurus hamiltoni & 0,00 & & $-1,00$ & & & & & & \\
\hline \multicolumn{10}{|l|}{ Peces Cartilaginosos } \\
\hline Rajidae & & & & & & & & & \\
\hline Bathyraja eatonii & 0,04 & & $-1,00$ & & & & & & \\
\hline Bathyraja maccaini & 0,40 & & $-1,00$ & & & & & & \\
\hline Bathyraja sp. & 0,05 & & $-1,00$ & & & & & & \\
\hline
\end{tabular}


Tabla III.12: Análisis de la selectividad de presas para el lobo Fino Antártico en I. Laurie (IOS). M\%_IOS: es el porcentaje en masa de las especies de peces que fueron capturadas durante la campaña "Antártida 8611" (Tomado de Balguerías 1989) expresadas para el total de la columna de agua y para cada estrato de profundidad (1, 2 y 3);

M\%_dieta: es el porcentaje en masa de cada especie presa en la dieta del predador. Los valores de Ivlev $>0$ (enmarcados) indican selectividad positiva.

\begin{tabular}{|c|c|c|c|c|c|c|c|c|c|}
\hline \multirow[b]{2}{*}{ LFA } & \multicolumn{3}{|c|}{ Total columna de agua } & \multicolumn{6}{|c|}{ Por estrato de profundidad } \\
\hline & M\%_IOS & $\% \mathrm{M}$ & Ivlev & $M \% \_1$ & Ivlev_1 & M\%_2 & Ivlev_2 & M\%_3 & Ivlev_3 \\
\hline \multicolumn{10}{|l|}{ Peces óseos } \\
\hline \multicolumn{10}{|l|}{ Artedidraconidae } \\
\hline Pogonophryne permitini & 0,08 & & $-1,00$ & 0,00 & & 0,00 & & 0,15 & $-1,00$ \\
\hline Pogonophryne sp. & 0,07 & & $-1,00$ & 0,00 & & 0,00 & $-1,00$ & 0,14 & $-1,00$ \\
\hline \multicolumn{10}{|l|}{ Bathydraconidae } \\
\hline Gelarchea australis & 0,00 & & $-1,00$ & 0,00 & & 0,00 & & 0,00 & $-1,00$ \\
\hline Gymnodraco acuticeps & 0,04 & & $-1,00$ & 0,04 & $-1,00$ & 0,01 & $-1,00$ & 0,05 & $-1,00$ \\
\hline Parachaenichthys charcotti & 0,14 & & $-1,00$ & 0,61 & $-1,00$ & 0,18 & $-1,00$ & 0,02 & $-1,00$ \\
\hline Prionodraco evansii & 0,02 & & $-1,00$ & 0,01 & $-1,00$ & 0,01 & $-1,00$ & 0,03 & $-1,00$ \\
\hline Psilodraco breviceps & 0,00 & & $-1,00$ & 0,00 & & 0,00 & & 0,00 & $-1,00$ \\
\hline \multicolumn{10}{|l|}{ Channichthyidae } \\
\hline Chaenocephalus aceratus & 14,82 & 12,00 & $-0,11$ & 26,14 & $-0,37$ & 20,19 & $-0,25$ & 8,39 & 0,18 \\
\hline Chaenodraco rastrospinosus & 2,10 & 16,84 & 0,78 & 0,61 & 0,93 & 1,25 & 0,86 & 3,07 & 0,69 \\
\hline Chamsocephalus gunnari & 4,69 & & $-1,00$ & 1,18 & $-1,00$ & 3,11 & $-1,00$ & 6,61 & $-1,00$ \\
\hline Cryodraco antarcticus & 0,17 & & $-1,00$ & 0,00 & & 0,01 & $-1,00$ & 0,33 & $-1,00$ \\
\hline Neopagetopsis ionah & 0,06 & & $-1,00$ & 0,00 & & 0,03 & $-1,00$ & 0,10 & $-1,00$ \\
\hline Pagetopsis macropterus & 0,01 & & $-1,00$ & 0,00 & & 0,00 & & 0,02 & $-1,00$ \\
\hline Pseudochaenichthys georgianus & 1,72 & & $-1,00$ & 0,38 & $-1,00$ & 2,17 & $-1,00$ & 1,63 & $-1,00$ \\
\hline \multicolumn{10}{|l|}{ Gempylidae } \\
\hline Paradiplospinus antarcticus & 0,03 & & $-1,00$ & 0,02 & $-1,00$ & 0,02 & $-1,00$ & 0,04 & $-1,00$ \\
\hline \multicolumn{10}{|l|}{ Liparididae } \\
\hline Genioliparis sp. & 0,00 & & $-1,00$ & 0,00 & & 0,00 & $-1,00$ & 0,00 & $-1,00$ \\
\hline Liparididae sp. & 0,00 & & $-1,00$ & 0,00 & & 0,00 & $-1,00$ & 0,00 & \\
\hline \multicolumn{10}{|l|}{ Moridae } \\
\hline Moroteuthis sp. & 0,03 & & $-1,00$ & 0,00 & & 0,04 & $-1,00$ & 0,03 & $-1,00$ \\
\hline \multicolumn{10}{|l|}{ Muraenolepididae } \\
\hline Muraenolepis orangiensis & 0,08 & & $-1,00$ & 0,00 & & 0,03 & $-1,00$ & 0,14 & $-1,00$ \\
\hline \multicolumn{10}{|l|}{ Melampahidae } \\
\hline Melanphaes microps & 0,06 & & $-1,00$ & 0,00 & & 0,10 & $-1,00$ & 0,04 & $-1,00$ \\
\hline Melanphaes sp. & 0,01 & & $-1,00$ & 0,00 & & 0,00 & $-1,00$ & 0,02 & $-1,00$ \\
\hline Myctophidae & & & & & & & & & \\
\hline Gimnoscopelus nicholsi & 0,57 & 43,92 & 0,97 & 0,01 & 1,00 & 0,10 & 1,00 & 1,06 & 0,95 \\
\hline Electrona sp. & 0,11 & 3,86 & 0,94 & 0,05 & 0,98 & 0,03 & 0,98 & 0,19 & 0,91 \\
\hline Krefftichthys andersoni & & 0,10 & 1,00 & & 1,00 & & 1,00 & & 1,00 \\
\hline Lampanyctus achirus & & 0,30 & 1,00 & & 1,00 & & 1,00 & & 1,00 \\
\hline Protomyctophum normani & & 0,20 & 1,00 & & 1,00 & & 1,00 & & 1,00 \\
\hline Nototheniidae & & & & & & & & & \\
\hline Aethotaxis mitopteryx & 0,14 & & $-1,00$ & 0,01 & $-1,00$ & 0,06 & $-1,00$ & 0,23 & $-1,00$ \\
\hline Gobbionotothen gibberifrons & 36,73 & 12,09 & $-0,50$ & 43,69 & $-0,57$ & 42,97 & $-0,56$ & 30,45 & $-0,43$ \\
\hline Lepidonotothen nudifrons & 0,61 & 0,40 & $-0,21$ & 0,74 & $-0,30$ & 0,99 & $-0,43$ & 0,28 & 0,17 \\
\hline Notothenia rossii & 0,88 & & $-1,00$ & 0,61 & $-1,00$ & 0,69 & $-1,00$ & 1,08 & $-1,00$ \\
\hline Notothenia kempi & 15,08 & & $-1,00$ & 0,00 & & 0,20 & $-1,00$ & 29,74 & $-1,00$ \\
\hline Notothenia coriiceps & 5,49 & 2,17 & $-0,43$ & 20,49 & $-0,81$ & 7,89 & $-0,57$ & 0,68 & 0,52 \\
\hline Lepidonotothen macrophthalma & 0,00 & & $-1,00$ & 0,00 & & 0,00 & $-1,00$ & 0,01 & $-1,00$ \\
\hline Lepidonotothen larseni & 9,00 & 2,48 & $-0,57$ & 1,88 & 0,14 & 11,97 & $-0,66$ & 8,04 & $-0,53$ \\
\hline Trematomus newnesi & 1,85 & 1,58 & $-0,08$ & 2,45 & $-0,22$ & 2,90 & $-0,29$ & 0,90 & 0,27 \\
\hline Trematomus hansoni & 0,20 & & $-1,00$ & 0,00 & & 0,00 & & 0,39 & $-1,00$ \\
\hline Trematomus nicolai & 0,03 & & $-1,00$ & 0,00 & & 0,02 & $-1,00$ & 0,04 & $-1,00$ \\
\hline Trematomus pennelli & 0,03 & & $-1,00$ & 0,00 & & 0,00 & & 0,05 & $-1,00$ \\
\hline Trematomus vicarius & 0,08 & & $-1,00$ & 0,00 & & 0,13 & $-1,00$ & 0,07 & $-1,00$ \\
\hline Pleuragramma antarcticum & 3,44 & & $-1,00$ & 1,05 & $-1,00$ & 3,84 & $-1,00$ & 3,59 & $-1,00$ \\
\hline Notothenia sp. & 0,00 & & $-1,00$ & 0,00 & & 0,00 & & 0,00 & $-1,00$ \\
\hline Trematomus sp. & 1,32 & & $-1,00$ & 0,02 & $-1,00$ & 1,05 & $-1,00$ & 1,79 & $-1,00$ \\
\hline Paralepididae & & & & & & & & & \\
\hline Paratepididae sp. & 0,02 & & $-1,00$ & 0,00 & & 0,00 & & 0,03 & $-1,00$ \\
\hline Notolepis coatsi & & 3,40 & 1,00 & & 1,00 & & 1,00 & & 1,00 \\
\hline Zorctaae & & & & & & & & & \\
\hline Lycodapus sp. & 0,02 & & $-1,00$ & 0,00 & & 0,00 & $-1,00$ & 0,03 & $-1,00$ \\
\hline Peces Cartilaginosos & & & & & & & & & \\
\hline Rajidae & & & & & & & & & \\
\hline Bathyraja maccaini & 0,22 & & $-1,00$ & 0,00 & & 0,00 & & 0,43 & $-1,00$ \\
\hline Bathyraja sp. & 0,04 & & $-1,00$ & 0,00 & & 0,00 & & 0,08 & $-1,00$ \\
\hline
\end{tabular}


Tabla III.13: Análisis de la selectividad de presas para el lobo Fino Antártico en I. Laurie (IOS). M\%_IOS: es el porcentaje en masa de las especies de peces que fueron capturadas durante la campaña "US AMLR 99" (Tomado de Kock et al. 2000) expresadas para el total de la columna de agua y para cada estrato de profundidad (1, 2 y 3$)$;

M\%_dieta: es el porcentaje en masa de cada especie presa en la dieta del predador. Los valores de Ivlev $>0$ (enmarcados) indican selectividad positiva.

\begin{tabular}{|c|c|c|c|c|c|c|c|c|c|}
\hline \multirow{2}{*}{ LFA } & \multicolumn{3}{|c|}{ Total columna de agua } & \multicolumn{3}{|c|}{ Por estrato de profundidad } & \multirow[b]{2}{*}{ Ivlev_2 } & \multirow[b]{2}{*}{ M\%_3 } & \multirow[b]{2}{*}{ Ivlev_3 } \\
\hline & M\%_IOS & M\%_dieta & Ivlev & M\%_1 & Ivlev_1 & M\%_2 & & & \\
\hline \multicolumn{10}{|l|}{ Peces Oseos } \\
\hline \multicolumn{10}{|l|}{ Artedidraconidae } \\
\hline Pogonophryne sp. & 0,10 & & $-1,00$ & & & & & & \\
\hline \multicolumn{10}{|l|}{ Bathydraconidae } \\
\hline Batydraco marri & 0,00 & & $-1,00$ & & & & & & \\
\hline Gymnodraco acuticeps & 0,01 & & $-1,00$ & & & & & & \\
\hline Parachaenichthys charcotti & 0,00 & & $-1,00$ & & & & & & \\
\hline Racovitzia glacialis & 0,00 & & $-1,00$ & & & & & & \\
\hline \multicolumn{10}{|l|}{ Channichthyidae } \\
\hline Chaenocephalus acceratus & 8,99 & 3,00 & $-0,50$ & 22,3 & $-0,76$ & 14,3 & $-0,65$ & 2,5 & 0,08 \\
\hline Chaenodraco wilsoni & 0,00 & & & & & & & & \\
\hline Champsocephalus gunnari & 3,11 & & $-1,00$ & 4,8 & $-1,00$ & 5,5 & $-1,00$ & 1,0 & $-1,00$ \\
\hline Chinodraco rastrospinosus & 5,71 & 10,60 & 0,30 & 1,5 & 0,76 & 1,4 & 0,77 & 10,1 & 0,02 \\
\hline Cryodraco antareticus & 0,17 & & $-1,00$ & & & & & & \\
\hline Neopagetopsis ionah & 0,02 & & $-1,00$ & & & & & & \\
\hline Pseudochaenichthys georgianus & 13,78 & & & 1,7 & $-1,00$ & 38,2 & $-1,00$ & 2,0 & $-1,00$ \\
\hline \multicolumn{10}{|l|}{ Gempylidae } \\
\hline Paradiplospinus gracilis & 0,00 & & $-1,00$ & & & & & & \\
\hline \multicolumn{10}{|l|}{ Muraenolepididae } \\
\hline Muraenolepis microps & 0,02 & & $-1,00$ & & & & & & \\
\hline \multicolumn{10}{|l|}{ Myctophidae } \\
\hline Electrona antarctica & 0,08 & 4,00 & 0,96 & & & & & & \\
\hline Electrona sp & 0,0 & & $-1,00$ & & & & & & \\
\hline \multicolumn{10}{|l|}{ Gimosolus } \\
\hline Gimnoscopelus nicholsi & 0,18 & 66,50 & 0,99 & & & & & & \\
\hline Gimmoscopetus spp. & 0,00 & & $-1,00$ & & & & & & \\
\hline Krefftichthys andersoni & 0,00 & & $-1,00$ & & & & & & \\
\hline Protomyctophum normani & & 0,20 & 1,00 & & & & & & \\
\hline \multicolumn{10}{|l|}{ Nototheniidae } \\
\hline Dissostichus mawsoni & 0,01 & & $-1,00$ & & & & & & \\
\hline Gobionotothen gibberifrons & 31,31 & 13,30 & $-0,40$ & 68,33 & $-0,67$ & 38,92 & $-0,49$ & 19,17 & $-0,18$ \\
\hline Lepidonotothen larseni & 0,21 & & $-1,00$ & 0,42 & $-1,00$ & 0,25 & $-1,00$ & 0,14 & $-1,00$ \\
\hline Lepidonotothen nudifrons & 0,00 & & $-1,00$ & & & & & & \\
\hline Lepidonotothen squamifrons & 31,07 & & $-1,00$ & & & 1,04 & $-1,00$ & 61,72 & $-1,00$ \\
\hline Notothenia coriiceps & 0,27 & & $-1,00$ & & & & & & \\
\hline Notothenia rossii & 1,69 & & $-1,00$ & 0,51 & $-1,00$ & 0,22 & $-1,00$ & 3,13 & $-1,00$ \\
\hline Pagothenia borchgrevinki & 0,00 & & $-1,00$ & & & & & & \\
\hline Pleuragramma antarcticum & 0,01 & & $-1,00$ & & & & & & \\
\hline Trematomus bernachii & 0,04 & 2,40 & 1,00 & & & & & & \\
\hline Trematomus eulepidotus & 0,36 & & $-1,00$ & & & & & & \\
\hline Trematomus hansoni & 0,14 & & $-1,00$ & & & & & & \\
\hline Trematomus newnesi & 0,02 & & $-1,00$ & & & & & & \\
\hline Trematomus nicolai & 0,00 & & $-1,00$ & & & & & & \\
\hline Trematomus pennelli & 0,00 & & $-1,00$ & & & & & & \\
\hline Tramatomus tokarevi & 0,00 & & $-1,00$ & & & & & & \\
\hline \multicolumn{10}{|l|}{ Paralepididae } \\
\hline Magnisidus prionosa & 0,00 & & $-1,00$ & & & & & & \\
\hline Notosudidae & & & & & & & & & \\
\hline Scopelosaurus hamiltoni & 0,00 & & $-1,00$ & & & & & & \\
\hline Peces Cartilaginosos & & & & & & & & & \\
\hline Rajidae & & & & & & & & & \\
\hline Bathyraja eatonii & 0,04 & & $-1,00$ & & & & & & \\
\hline Bathyraja maccaini & 0,40 & & $-1,00$ & & & & & & \\
\hline Bathyraja sp. & 0,05 & & $-1,00$ & & & & & & \\
\hline
\end{tabular}


Tabla III.14: Análisis de la selectividad de presas para el Cormorán de Georgias en I. Laurie (IOS). M\% IOS: es el porcentaje en masa de las especies de peces que fueron capturadas durante la campaña "Antártida 8611" (Tomado de Balguerías 1989) expresadas para el total de la columna de agua y para cada estrato de profundidad $(1,2$ y 3 );

M\%_dieta: es el porcentaje en masa de cada especie presa en la dieta del predador. Los valores de Ivlev $>0$ (enmarcados) indican selectividad positiva.

\begin{tabular}{|c|c|c|c|c|c|c|c|c|c|}
\hline C. de Georgias & M\% & M\% & Ivlev & M\%_1 & Ivlev_1 & M\%_2 & Ivlev_2 & M\%_3 & Ivlev_3 \\
\hline \multicolumn{10}{|l|}{ Peces óseos } \\
\hline \multicolumn{10}{|l|}{ Artedidraconidae } \\
\hline Pogonophryne permitini & 0,08 & & $-1,00$ & 0,00 & & 0,00 & & 0,15 & $-1,00$ \\
\hline Pogonophryne sp. & 0,07 & & $-1,00$ & 0,00 & & 0,00 & $-1,00$ & 0,14 & $-1,00$ \\
\hline \multicolumn{10}{|l|}{ Bathydraconidae } \\
\hline Gelarchea australis & 0,00 & & $-1,00$ & 0,00 & & 0,00 & & 0,00 & $-1,00$ \\
\hline Gymnodraco acuticeps & 0,04 & & $-1,00$ & 0,04 & $-1,00$ & 0,01 & $-1,00$ & 0,05 & $-1,00$ \\
\hline Parachaenichthys charcotti & 0,14 & 1,00 & 0,73 & 0,61 & 0,24 & 0,18 & 0,69 & 0,02 & 0,97 \\
\hline Prionodraco evansii & 0,02 & & $-1,00$ & 0,01 & $-1,00$ & 0,01 & $-1,00$ & 0,03 & $-1,00$ \\
\hline Psilodraco breviceps & 0,00 & & $-1,00$ & 0,00 & & 0,00 & & 0,00 & $-1,00$ \\
\hline \multicolumn{10}{|l|}{ Channichthyidae } \\
\hline Chaenocephalus aceratus & 14,82 & & $-1,00$ & 26,14 & $-1,00$ & 20,19 & $-1,00$ & 8,39 & $-1,00$ \\
\hline Chaenodraco rastrospinosus & 2,10 & & $-1,00$ & 0,61 & $-1,00$ & 1,25 & $-1,00$ & 3,07 & $-1,00$ \\
\hline Chamsocephalus gunnari & 4,69 & & $-1,00$ & 1,18 & $-1,00$ & 3,11 & $-1,00$ & 6,61 & $-1,00$ \\
\hline Cryodraco antarcticus & 0,17 & & $-1,00$ & 0,00 & & 0,01 & $-1,00$ & 0,33 & $-1,00$ \\
\hline Neopagetopsis ionah & 0,06 & & $-1,00$ & 0,00 & & 0,03 & $-1,00$ & 0,10 & $-1,00$ \\
\hline Pagetopsis macropterus & 0,01 & & $-1,00$ & 0,00 & & 0,00 & & 0,02 & $-1,00$ \\
\hline Pseudochaenichthys georgianus & 1,72 & & $-1,00$ & 0,38 & $-1,00$ & 2,17 & $-1,00$ & 1,63 & $-1,00$ \\
\hline \multicolumn{10}{|l|}{ Gempylidae } \\
\hline \multicolumn{10}{|l|}{ Harpafigeridae } \\
\hline Harpafiger antarcticus & & 4,00 & 1,00 & & 1,00 & & 1,00 & & 1,00 \\
\hline \multicolumn{9}{|l|}{ Liparididae } & $-1,00$ \\
\hline Liparididae sp. & 0,00 & & $-1,00$ & 0,00 & $-1,00$ & 0,00 & $-1,00$ & 0,00 & \\
\hline \multicolumn{10}{|l|}{ Moridae } \\
\hline Moroteuthis sp. & 0,03 & & $-1,00$ & 0,00 & $-1,00$ & 0,04 & $-1,00$ & 0,03 & $-1,00$ \\
\hline \multicolumn{10}{|l|}{ Muraenolepididae } \\
\hline Muraenolepis orangiensis & 0,08 & & $-1,00$ & 0,00 & $-1,00$ & 0,03 & $-1,00$ & 0,14 & $-1,00$ \\
\hline \multicolumn{10}{|l|}{ Melampahidae } \\
\hline Melanphaes microps & 0,06 & & $-1,00$ & 0,00 & $-1,00$ & 0,10 & $-1,00$ & 0,04 & $-1,00$ \\
\hline Melanphaes sp. & 0,01 & & $-1,00$ & 0,00 & $-1,00$ & 0,00 & $-1,00$ & 0,02 & $-1,00$ \\
\hline \multicolumn{10}{|l|}{ Myctophidae } \\
\hline Electrona sp. & 0,11 & & $-1,00$ & 0,05 & $-1,00$ & 0,03 & $-1,00$ & 0,19 & $-1,00$ \\
\hline Gimnoscopelus nicholsi & 0,57 & & $-1,00$ & 0,01 & $-1,00$ & 0,10 & $-1,00$ & 1,06 & $-1,00$ \\
\hline \multicolumn{10}{|l|}{ Nototheniidae } \\
\hline Aethotaxis mitopteryx & 0,14 & & $-1,00$ & 0,01 & $-1,00$ & 0,06 & $-1,00$ & 0,23 & $-1,00$ \\
\hline Gobionotothen gibberifrons & 36,73 & 1,00 & $-0,95$ & 43,69 & $-0,95$ & 42,97 & $-0,95$ & 30,45 & $-0,93$ \\
\hline Lepidonotothen nudifrons & 0,61 & 11,00 & 0,87 & 0,74 & 0,69 & 0,99 & 0,97 & 0,28 & 0,75 \\
\hline Lepidonotothen macrophthalma & 0,00 & & $-1,00$ & 0,00 & & 0,00 & $-1,00$ & 0,01 & $-1,00$ \\
\hline Notothenia rossii & 0,88 & & $-1,00$ & 0,61 & $-1,00$ & 0,69 & $-1,00$ & 1,08 & $-1,00$ \\
\hline Notothenia kempi & 15,08 & & $-1,00$ & 0,00 & & 0,20 & $-1,00$ & 29,74 & $-1,00$ \\
\hline Notothenia coriiceps & 5,49 & 66,00 & 0,85 & 20,49 & 0,53 & 7,89 & 0,79 & 0,68 & 0,97 \\
\hline 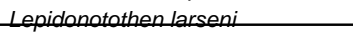 & ممب9 & & -1, & 1,88 & مחم-1, & 11,97 & - & (مبـ & $-1,00$ \\
\hline Notothenia sp. & 0,00 & & $-1,00$ & 0,00 & $-1,00$ & 0,00 & $-1,00$ & 0,00 & $-1,00$ \\
\hline Iromatomushani & 0,20 & & $-1,00$ & ــهـهـ & & ــ, هـ, & & ـ & $-1,00$ \\
\hline Trematomus newnesi & 1,85 & 17,00 & 0,80 & 2,45 & 0,75 & 2,90 & 0,71 & 0,90 & 0,90 \\
\hline 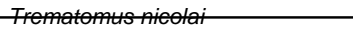 & 0,03 & & $-1,00$ & ـــ, & & 0,02 & $-1,00$ & - & $-1,00$ \\
\hline Trematomus pennelli & 0,03 & & $-1,00$ & 0,00 & & 0,00 & & 0,05 & $-1,00$ \\
\hline Trematomus vicarius & 0,08 & & $-1,00$ & 0,00 & & 0,13 & $-1,00$ & 0,07 & $-1,00$ \\
\hline Trematomus sp. & 1,32 & & $-1,00$ & 0,02 & $-1,00$ & 1,05 & $-1,00$ & 1,79 & $-1,00$ \\
\hline Pleuragramma antarcticum & 3,44 & & $-1,00$ & 1,05 & $-1,00$ & 3,84 & $-1,00$ & 3,59 & $-1,00$ \\
\hline \multicolumn{10}{|l|}{ Paralepididae } \\
\hline Paralepididae sp. & 0,02 & & $-1,00$ & 0,00 & & 0,00 & & 0,03 & $-1,00$ \\
\hline \multicolumn{10}{|l|}{ Zorcidae } \\
\hline Lycodapus sp. & 0,02 & & $-1,00$ & 0,00 & & 0,00 & $-1,00$ & 0,03 & $-1,00$ \\
\hline \multicolumn{10}{|l|}{ Peces Cartilaginosos } \\
\hline Rajidae & & & & & & & & & \\
\hline Bathyraja maccaini & 0,22 & & $-1,00$ & 0,00 & & 0,00 & & 0,43 & $-1,00$ \\
\hline Bathyraja sp. & 0,04 & & $-1,00$ & 0,00 & & 0,00 & & 0,08 & $-1,00$ \\
\hline
\end{tabular}


Tabla III.15: Análisis de la selectividad de presas para el Cormorán de Georgias en I. Laurie (IOS). M\%_IOS: es el porcentaje en masa de las especies de peces que fueron capturadas durante la campaña "US AMLR 99" (Tomado de

Kock et al. 2000) expresadas para el total de la columna de agua y para cada estrato de profundidad (1, 2 y 3$)$;

M\% dieta: es el porcentaje en masa de cada especie presa en la dieta del predador. Los valores de Ivlev $>0$

(enmarcados) indican selectividad positiva.

\begin{tabular}{|c|c|c|c|c|c|c|c|c|c|}
\hline \multirow[b]{2}{*}{ C. de Georgias } & \multicolumn{3}{|c|}{ Total columna de agua } & \multicolumn{3}{|c|}{ Por estrato de profundidad } & \multirow[b]{2}{*}{ Ivlev_2 } & \multirow[b]{2}{*}{ M\%_3 } & \multirow[b]{2}{*}{ Ivlev_ } \\
\hline & M\%_IOS & M\%_dieta & Ivlev & M\%_1 & Ivlev_1 & M\%_2 & & & \\
\hline \multicolumn{10}{|l|}{ Peces Oseos } \\
\hline \multicolumn{10}{|l|}{ Artedidraconidae } \\
\hline \multirow{2}{*}{\multicolumn{10}{|c|}{ Bathydraconidae }} \\
\hline & & & & & & & & & \\
\hline Batydraco marri & 0,00 & & $-1,00$ & & & & & & \\
\hline Gymnodraco acuticeps & 0.01 & & $-1,00$ & & & & & & \\
\hline Parachaenichthys charcotti & 0,00 & 2,20 & 1,00 & & & & & & \\
\hline Racovitzia glacialis & 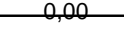 & & $-1,00$ & & & & & & \\
\hline \multicolumn{10}{|l|}{ Channichthyidae } \\
\hline Chaenocephalus aceratus & 8,99 & & $-1,00$ & 22,3 & $-1,00$ & 14,3 & $-1,00$ & 2,5 & $-1,00$ \\
\hline Chaenodraco wilsoni & 0,00 & & $-1,00$ & & & & & & \\
\hline Champsocephalus gunnari & 3,11 & & $-1,00$ & 4,8 & $-1,00$ & 5,5 & $-1,00$ & 1,0 & $-1,00$ \\
\hline Chinodraco rastrospinosus & 5,71 & & $-1,00$ & 1,5 & $-1,00$ & 1,4 & $-1,00$ & 10,1 & $-1,00$ \\
\hline Cryodraco antarcticus & 0,17 & & $-1,00$ & & & & & & \\
\hline Neopagetopsis ionah & 0,02 & & $-1,00$ & & & & & & \\
\hline Pseudochaenichthys georgianus & 13,78 & & $-1,00$ & 1,7 & $-1,00$ & 38,2 & $-1,00$ & 2,0 & $-1,00$ \\
\hline \multicolumn{10}{|l|}{ Gempylidae } \\
\hline \multicolumn{9}{|l|}{ Harpafigeridae } & \\
\hline \multirow{2}{*}{\multicolumn{10}{|c|}{ Muraenolepididae }} \\
\hline & & & & & & & & & \\
\hline Muraenolepis microps & 0,02 & & $-1,00$ & & & & & & \\
\hline \multicolumn{10}{|l|}{ Myctophidae } \\
\hline Electrona antarctica & 0,08 & & $-1,00$ & & & & & & \\
\hline Electrona sp. & 0,00 & & $-1,00$ & & & & & & \\
\hline Gimnoscopelus braueri & 0,01 & & $-1,00$ & & & & & & \\
\hline Gimnoscopelus nicholsi & 0,18 & & $-1,00$ & & & & & & \\
\hline Gimnoscopelus sp. & 0,00 & & $-1,00$ & & & & & & \\
\hline Krefftichthys andersoni & 0,00 & & $-1,00$ & & & & & & \\
\hline \multicolumn{10}{|l|}{ Nototheniidae } \\
\hline Dissostichus mawsoni & 0,01 & & $-1,00$ & & & & & & \\
\hline Gobionotothen gibberifrons & 31,31 & 13,60 & $-0,38$ & 68,33 & $-0,67$ & 38,92 & $-0,48$ & 19,17 & $-0,17$ \\
\hline $\begin{array}{l}\text { Lepidonotothen larseni } \\
\text { Lepidonotothen nudifrons }\end{array}$ & $\begin{array}{l}0,21 \\
0,00\end{array}$ & $\begin{array}{c}3,2 \\
15,10\end{array}$ & 0,88 & 0,42 & 0,77 & 0,25 & 0,86 & 0,14 & 0,92 \\
\hline Lepidonoton squamifrons & 0,00 & 15,10 & 1,00 & & & & & & \\
\hline Notothenia coriceps & (1) & & $-1,00$ & & & 1,04 & $-1,00$ & 61,72 & $-1,00$ \\
\hline $\begin{array}{l}\text { Notothenia coriiceps } \\
\text { Notothenia rossii }\end{array}$ & 0,27 & 32,40 & 0,98 & & & & & & \\
\hline Notothenia rossii & 1,69 & & $-1,00$ & 0,51 & $-1,00$ & 0,22 & $-1,00$ & 3,13 & $-1,00$ \\
\hline Pagothenia borchgrevinki & 0,00 & & $-1,00$ & & & & & & \\
\hline Pleuragramma antarcicum & 0,01 & & $-1,00$ & & & & & & \\
\hline Trematomus bernachii & 0,04 & 2,20 & 0,97 & & & & & & \\
\hline Trematomus eulepidotus & 0,36 & & $-1,00$ & & & & & & \\
\hline Trematomus hansoni & 0,14 & & $-1,00$ & & & & & & \\
\hline Trematomus newnesi & 0,02 & 5,80 & 0,99 & & & & & & \\
\hline Trematomus nicolai & 0,00 & & $-1,00$ & & & & & & \\
\hline Trematomus pennelli & 0,00 & & $-1,00$ & & & & & & \\
\hline Tramatomus tokarevi & 0,00 & & $-1,00$ & & & & & & \\
\hline \multicolumn{10}{|l|}{ Paralepididae } \\
\hline Magnisidus prionosa & 0,00 & & $-1,00$ & & & & & & \\
\hline Notosudidae & & & & & & & & & \\
\hline Scopelosaurus hamiltoni & 0,00 & & $-1,00$ & & & & & & \\
\hline Peces Cartilaginosos & & & & & & & & & \\
\hline Rajidae & & & & & & & & & \\
\hline Bathyraja eatonii & 0,04 & & $-1,00$ & & & & & & \\
\hline Bathyraja maccaini & 0,40 & & $-1,00$ & & & & & & \\
\hline Bathyraja sp. & 0,05 & & $-1,00$ & & & & & & \\
\hline
\end{tabular}


Tabla III.16: Análisis de la selectividad de presas para el petrel Damero en I. Laurie (IOS). M\%_IOS: es el porcentaje en masa de las especies de peces que fueron capturadas durante la campaña "Antártida 8611" (Tomado de Balguerías 1989) expresadas para el total de la columna de agua y para cada estrato de profundidad $(1,2$ y 3$)$; M\%_dieta: es el porcentaje en masa de cada especie presa en la dieta del predador. Los valores de Ivlev $>0$ (enmarcados) indican selectividad positiva.

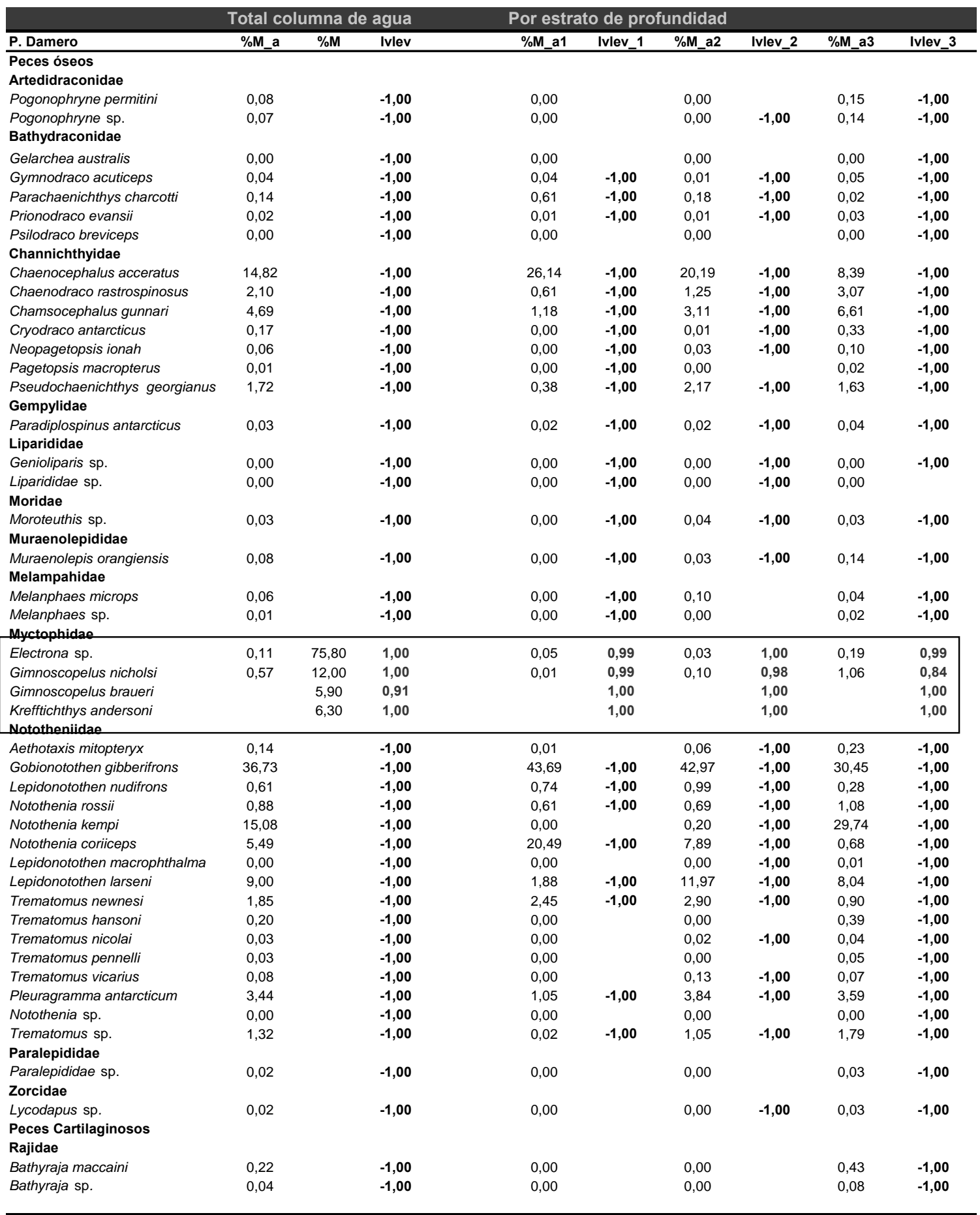


Tabla III.17: Análisis de la selectividad de presas para los petreles Damero y de las Nieves en I. Laurie (IOS). M\%_IOS: es el porcentaje en masa de las especies de peces que fueron capturadas durante la campaña "US AMLR 99"

(Tomado de Kock et al. 2000) expresadas para el total de la columna de agua y para cada estrato de profundidad (1, 2 y 3); M\%_dieta: es el porcentaje en masa de cada especie presa en la dieta del predador. Los valores de Ivlev >0 (enmarcados) indican selectividad positiva.

\begin{tabular}{|c|c|c|c|c|c|c|c|c|c|c|c|c|c|}
\hline \multirow[b]{2}{*}{ P. Damero } & \multicolumn{3}{|c|}{ Total columna de agua } & \multicolumn{4}{|c|}{ Total columna de agua } & \multicolumn{4}{|c|}{ Por estrato de profundidad } & \multirow[b]{2}{*}{ \%M_3 } & \multirow[b]{2}{*}{ Ivlev_3 } \\
\hline & \%M_IOS & \%M_dieta & Ivlev & P. de las Nieves & \%M_IOS & $\%$ M_dieta & Ivlev & \%M_1 & Ivlev_1 & \%M_2 & Ivlev_2 & & \\
\hline \multicolumn{14}{|l|}{ Peces Oseos } \\
\hline \multicolumn{14}{|l|}{ Artedidraconidae } \\
\hline \multicolumn{13}{|l|}{ Bathydraconidae } & \\
\hline Batydraco marri & 0,00 & & $-1,00$ & & 0,00 & & $-1,00$ & & & & & & \\
\hline Gymnodraco acuticeps & 0,01 & & $-1,00$ & & 0,01 & & $-1,00$ & & & & & & \\
\hline Parachaenichthys charcotti & 0,00 & & $-1,00$ & & 0,00 & & $-1,00$ & & & & & & \\
\hline Racovitzia glacialis & 0,00 & & $-1,00$ & & 0,00 & & $-1,00$ & & & & & & \\
\hline \multicolumn{14}{|l|}{ Channichthyidae } \\
\hline Chaenocephalus acceratus & 7,76 & & $-1,00$ & & 7,76 & & $-1,00$ & 22,3 & $-1,00$ & 14,3 & $-1,00$ & 2,5 & $-1,00$ \\
\hline Chaenodraco wilsoni & 0,00 & & $-1,00$ & & 0,00 & & $-1,00$ & & & & & & \\
\hline Champsocephalus gunnari & 2,68 & & $-1,00$ & & 2,68 & & $-1,00$ & 4,8 & $-1,00$ & 5,5 & $-1,00$ & 1,0 & $-1,00$ \\
\hline Chinodraco rastrospinosus & 4,93 & & $-1,00$ & & 4,93 & & $-1,00$ & 1,5 & $-1,00$ & 1,4 & $-1,00$ & 10,1 & $-1,00$ \\
\hline Cryodraco antarcticus & 0,15 & & $-1,00$ & & 0,15 & & $-1,00$ & & & & & & \\
\hline Neopagetopsis ionah & 0,01 & & $-1,00$ & & 0,01 & & $-1,00$ & & & & & & \\
\hline Pseudochaenichthys georgianus & 13,78 & & $-1,00$ & & 13,78 & & & 1,7 & $-1,00$ & 38,2 & $-1,00$ & 2,0 & $-1,00$ \\
\hline \multicolumn{14}{|l|}{ Gempylidae } \\
\hline Paradiplospinus gracilis & 0,00 & & $-1,00$ & & 0,00 & & $-1,00$ & & & & & & \\
\hline \multicolumn{14}{|l|}{ Muraenolepididae } \\
\hline Muraenolepis microps & 0,02 & & $-1,00$ & & 0,02 & & $-1,00$ & & & & & & \\
\hline \multicolumn{14}{|l|}{ Myctophidae } \\
\hline Electrona antarctica & 0,07 & 59,86 & 1,00 & & 0,07 & 86,6 & 1,00 & & & & & & \\
\hline Electrona sp. & 0,00 & & $-1,00$ & & 0,00 & & $-1,00$ & & & & & & \\
\hline Gimnoscopelus braueri & 0,01 & & $-1,00$ & & 0,01 & & $-1,00$ & & & & & & \\
\hline GImnoscopelus nicholsI & 0,15 & 10,68 & 0,97 & & 0,15 & & $-1,00$ & & & & & & \\
\hline Gimnoscopelus sp. & 0,00 & 24,48 & 1,00 & & 0,00 & 9,1 & 1,00 & & & & & & \\
\hline Kreffichthys andersoni & 0,00 & & $-1,00$ & & 0,00 & & $-1,00$ & & & & & & \\
\hline Protomyctophum normani & & 4,99 & 1,00 & & & & & & & & & & \\
\hline \multicolumn{14}{|l|}{ Nototheniidae } \\
\hline Dissostichus mawsoni & 0,01 & & $-1,00$ & & 0,01 & & $-1,00$ & & & & & & \\
\hline Gobionotothen gibberifrons & 26,99 & & $-1,00$ & & 26,99 & & $-1,00$ & & & & & & \\
\hline Lepidonotothen larseni & 0,18 & & $-1,00$ & & 0,18 & & $-1,00$ & 68,33 & $-1,00$ & 38,92 & $-1,00$ & 19,17 & $-1,00$ \\
\hline Lepidonotothen nudifrons & 0,00 & & $-1,00$ & & 0,00 & & $-1,00$ & 0,42 & $-1,00$ & 0,25 & $-1,00$ & 0,14 & $-1,00$ \\
\hline Lepidonotothen squamifrons & 26,79 & & $-1,00$ & & 26,79 & & $-1,00$ & & & & & & \\
\hline Notothenia coriiceps & 0,24 & & $-1,00$ & & 0,24 & & $-1,00$ & & & 1,04 & & 61,72 & \\
\hline Notothenia rossii & 1,46 & & $-1,00$ & & 1,46 & & $-1,00$ & & & & & & \\
\hline Pagothenia borchgrevinki & 0,00 & & $-1,00$ & & 0,00 & & $-1,00$ & 0,51 & $-1,00$ & 0,22 & $-1,00$ & 3,13 & $-1,00$ \\
\hline Pleuragramma antarcticum & 0,01 & & $-1,00$ & & 0,01 & & $-1,00$ & & & & & & \\
\hline Trematomus bernachii & 0,03 & & $-1,00$ & & 0,03 & & $-1,00$ & & & & & & \\
\hline Trematomus eulepidotus & 0,31 & & $-1,00$ & & 0,31 & & $-1,00$ & & & & & & \\
\hline Trematomus hansoni & 0,12 & & $-1,00$ & & 0,12 & & $-1,00$ & & & & & & \\
\hline Trematomus newnesi & 0,01 & & $-1,00$ & & 0,01 & & $-1,00$ & & & & & & \\
\hline Trematomus nicolai & 0,00 & & $-1,00$ & & 0,00 & & $-1,00$ & & & & & & \\
\hline Trematomus pennelli & 0,00 & & $-1,00$ & & 0,00 & & $-1,00$ & & & & & & \\
\hline Tramatomus tokarevi & 0,00 & & $-1,00$ & & 0,00 & & $-1,00$ & & & & & & \\
\hline Paralepididae & & & & & & & & & & & & & \\
\hline Magnisidus prionosa & 0,00 & & $-1,00$ & & 0,00 & & $-1,00$ & & & & & & \\
\hline Bathylagidae & & & & & & & & & & & & & \\
\hline Bathylagus glacialis & & & & & & 4,3 & 1,00 & & & & & & \\
\hline Notosudidae & & & & & & & & & & & & & \\
\hline Scopelosaurus hamiltoni & 0,00 & & $-1,00$ & & 0,00 & & $-1,00$ & & & & & & \\
\hline Peces Cartilaginosos & & & & & & & & & & & & & \\
\hline Rajidae & & & & & & & & & & & & & \\
\hline Bathyraja eatonii & 0,04 & & $-1,00$ & & 0,04 & & $-1,00$ & & & & & & \\
\hline Bathyraja maccaini & 0,35 & & $-1,00$ & & 0,35 & & $-1,00$ & & & & & & \\
\hline Bathyraja sp. & 0,04 & & $-1,00$ & & 0,04 & & $-1,00$ & & & & & & \\
\hline
\end{tabular}




\section{III.3.5. Distribución de la abundancia de tallas}

A continuación se muestran los resultados del solapamiento de las distribuciones de tallas de los peces representados en los muestreos de Balguerías (1989) y Kock et al. (2000) y en la dieta de los predadores tope correspondientes a los grupos tróficos (GT) considerados en este análisis.

\section{GT: Krill (1)}

Pingüinos de Adelia y de Barbijo

El solapamiento de las distribuciones de tallas de los ejemplares de E. antarctica presentes en las IOS y representados en la dieta de los pingüinos de Adelia y de Barbijo fueron bajos, con un valor de $\mathrm{S}_{\mathrm{k}}=8$ para ambas especies (ver tabla III.3, figuras III.7 y III.8). A diferencia de ello, el solapamiento que tuvieron las tallas de $G$. nicholsi consumidas por el pingüino de Barbijo y representadas en los muestreos de peces fue alto, $S_{k}=59,87$ (ver Tabla III.3).

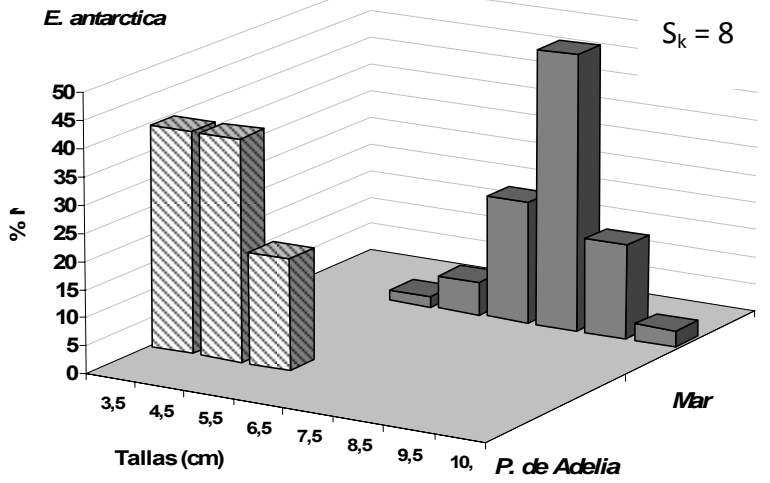

Figura III.6: Superposición de la talla de los peces consumidos por el Pingüino de Adelia (temporada 1998/99) y los representados en los arrastres realizados por Kock et al. (2000).
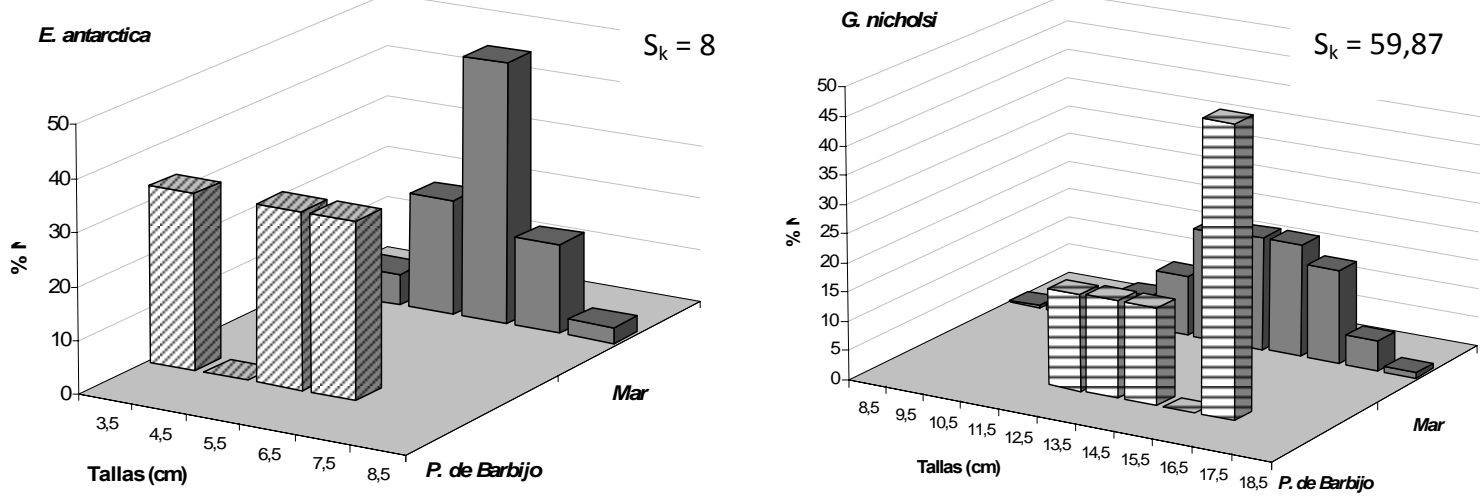

Figura III.7: Superposición de la talla de los peces consumidos por el Pingüino de Barbijo (temporada 1998/99) y los representados en los arrastres realizados por Kock et al. (2000). 


\section{GT: Krill (2)}

\section{a) Pingüino Papúa}

El pingüino Papúa consumió con mayor intensidad ejemplares de G. gibberifrons de 5,5 a $14,5 \mathrm{~cm}$. (con un valor medio de 12,00 $\pm 6,70 \mathrm{~cm}$. en 1996 y 14,76 $\pm 8,17 \mathrm{~cm}$. en 1999) y la distribución de talla de los ejemplares de esa especie representados en la dieta fue similar a la de los ejemplares representados en los arrastres (valor medio de $22,98 \pm 7,05 \mathrm{~cm}$. para la temporada 1987 y $28,40 \mathrm{~cm}$. para 1999), con un valor de $S_{1}=39,56$ para el solapamiento entre las tallas de la dieta y las representadas en el primer estrato de profundidad tomado por Balguerías (1989) y de $S_{2}=34,25$ para el segundo estrato. Con respecto a los muestreos de Kock et al. 2000, el valor de $S_{k}$ fue de 26,35. Las tallas medias de los ejemplares de $L$. larseni consumidos por el pingüino Papúa fueron $8,60 \pm 2,70 \mathrm{~cm}$. en 1996 y 10,57 $\pm 2,01 \mathrm{~cm}$. en 1999 y las representadas en los arrastres de 1987 y 1999 fueron $15,98 \pm 2,29 \mathrm{~cm}$. y $16,74 \mathrm{~cm}$. respectivamente. Los valores de $\mathrm{S}_{1}$ y $\mathrm{S}_{2}$ fueron 22,31 y 12,41 respectivamente, en tanto que el de $S_{k}$ fue 5,6. Las distribuciones de tallas de los ejemplares de $L$. nudifrons representados en la dieta del pingüino Papúa y en los arrastres presentaron mayor similitud que en los peces anteriores $\left(\mathrm{S}_{1}=32,9\right.$ y $\left.\mathrm{S}_{2}=25,83\right)$ (Figura III.8).
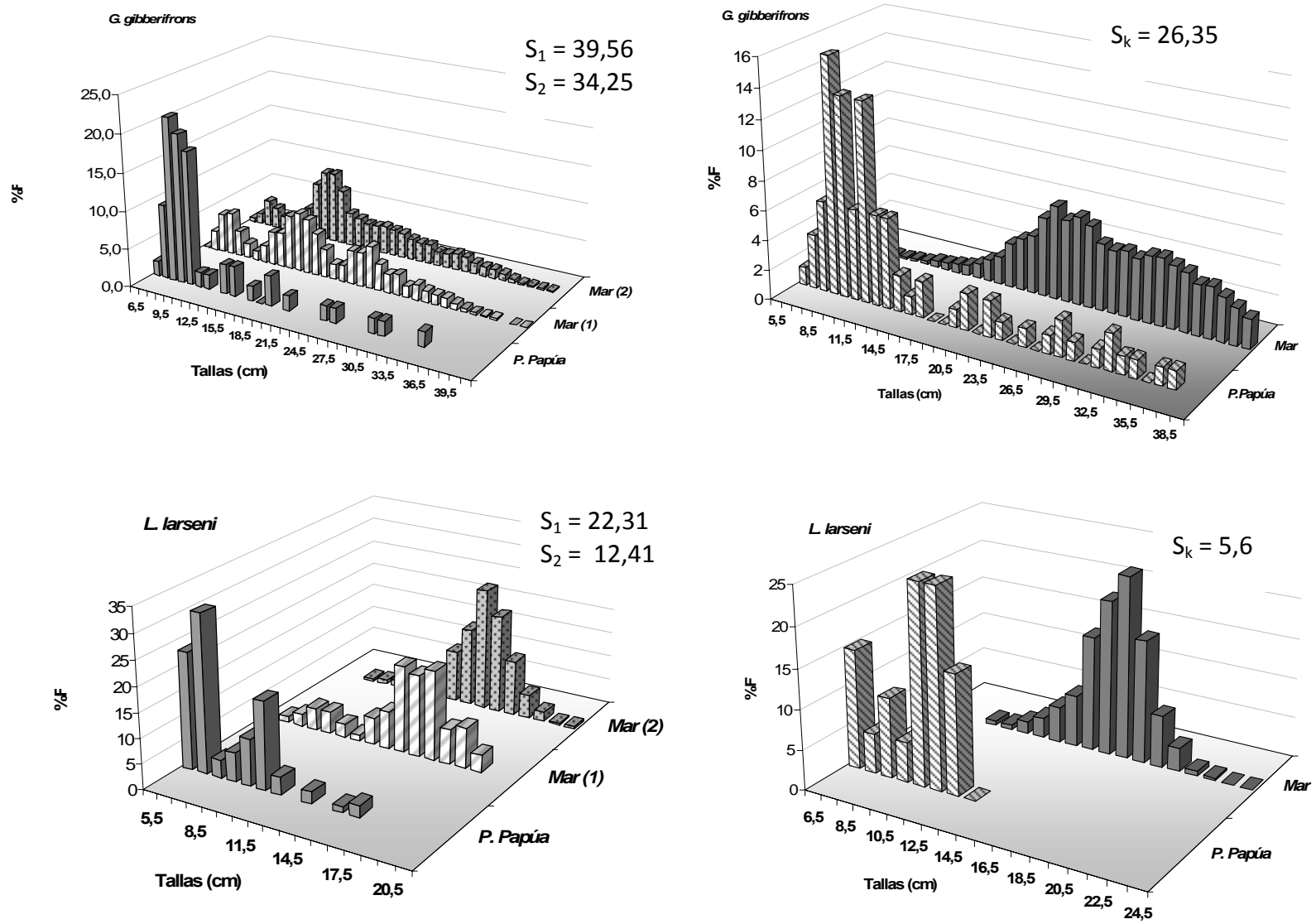

Figura III.8: Superposición de la talla de los peces consumidos por el Pingüino Papúa durante el Otoño 1996 y los representados en los arrastres realizados por Balguerías (1989) (izquierda) y los consumidos durante el Otoño 1999 y los representados en las capturas de Kock et al. (2000) (derecha). 


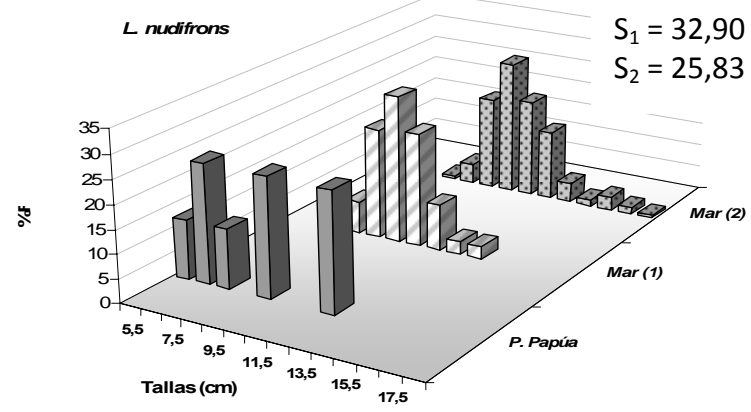

Figura III.8: Continuación.

\section{b) Foca de Weddell}

La talla media de los peces consumidos por la foca de Weddell durante la temporada 1999/00 $(18,1 \pm 9,2 \mathrm{~cm}$., rango 7,42-35,04 cm.) fue menor que la de los peces representados en los arrastres de 1987 y 1999 (ver tabla III.3). El solapamiento de las distribuciones de tallas de G. gibberifrons fue mayor cuando los peces representados en la dieta se compararon con los de los arrastres realizados en $1987\left(S_{1}=57,15 ; S_{2}=52,93\right)$ que con los de $1999\left(S_{k}=29,77\right)$. Si bien las tallas de este pez representadas en las capturas alcanzaron valores de 40,5 cm. en 1987 y $39,5 \mathrm{~cm}$. en 1999, la foca de Weddell sólo consumió individuos de hasta $30 \mathrm{~cm}$. (Figura III.9).
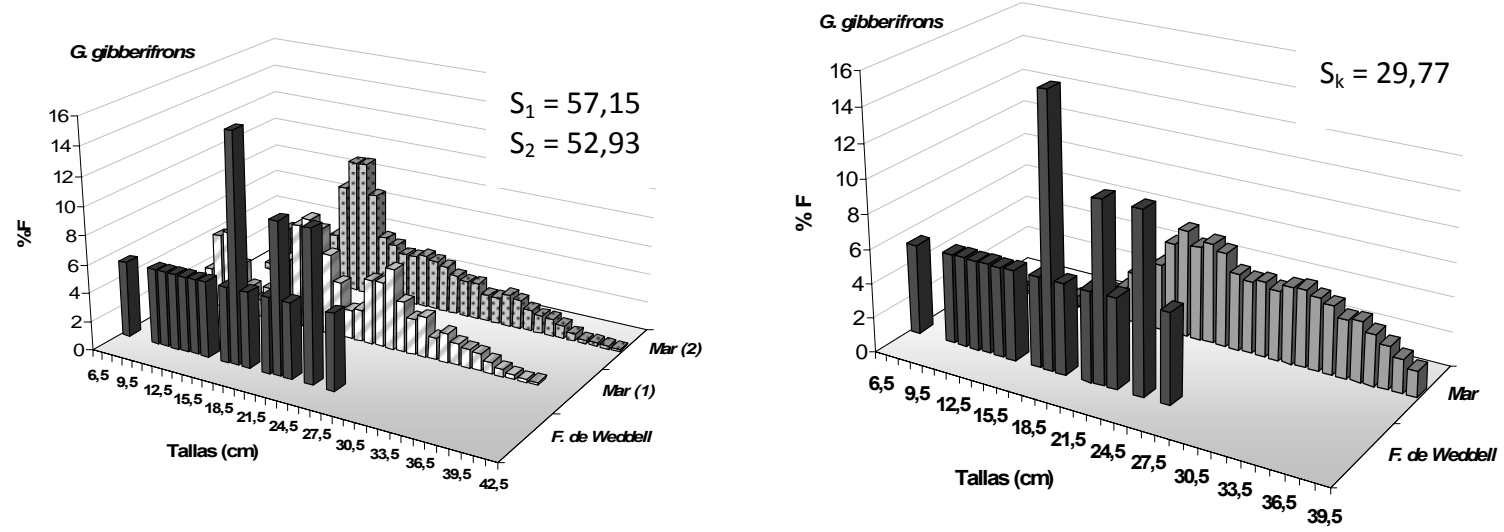

Figura III.9: Superposición de las tallas de los peces consumidos por la Foca de Weddell (1999/00) y los representados en los arrastres realizados por Balguerías (1989), izquierda, y por Kock et al. (2000), derecha.

\section{c) Lobo Fino Antártico}

La talla madia de los peces consumidos por el lobo Fino Antártico durante la temporada 1995/96 fue $15,46 \pm 10,4 \mathrm{~cm}$. y el rango resultó ser el más amplio entre todos los predadores considerados en este análisis (5,5 - 59,5 cm.). El valor de S para las distribuciones de tallas consumidas por el lobo Fino Antártico y las representadas en los arrastres varió marcadamente según la especie y fluctuó entre 0,0 para $C$. rastrospinosus y 73,37 para $L$. larseni (tabla III.18). Dependiendo de la especie presa, el valor medio de las tallas consumidas por el lobo Fino Antártico estuvo por debajo (C. ratrospinosus y 
E. antarctica) o por encima (G. gibberifrons, P. georgianus, C. aceratus y G. nicholsi) de la talla media de los peces representados en los arrastres. Las distribuciones de tallas se agrupan en las figuras III.10 y III.11.
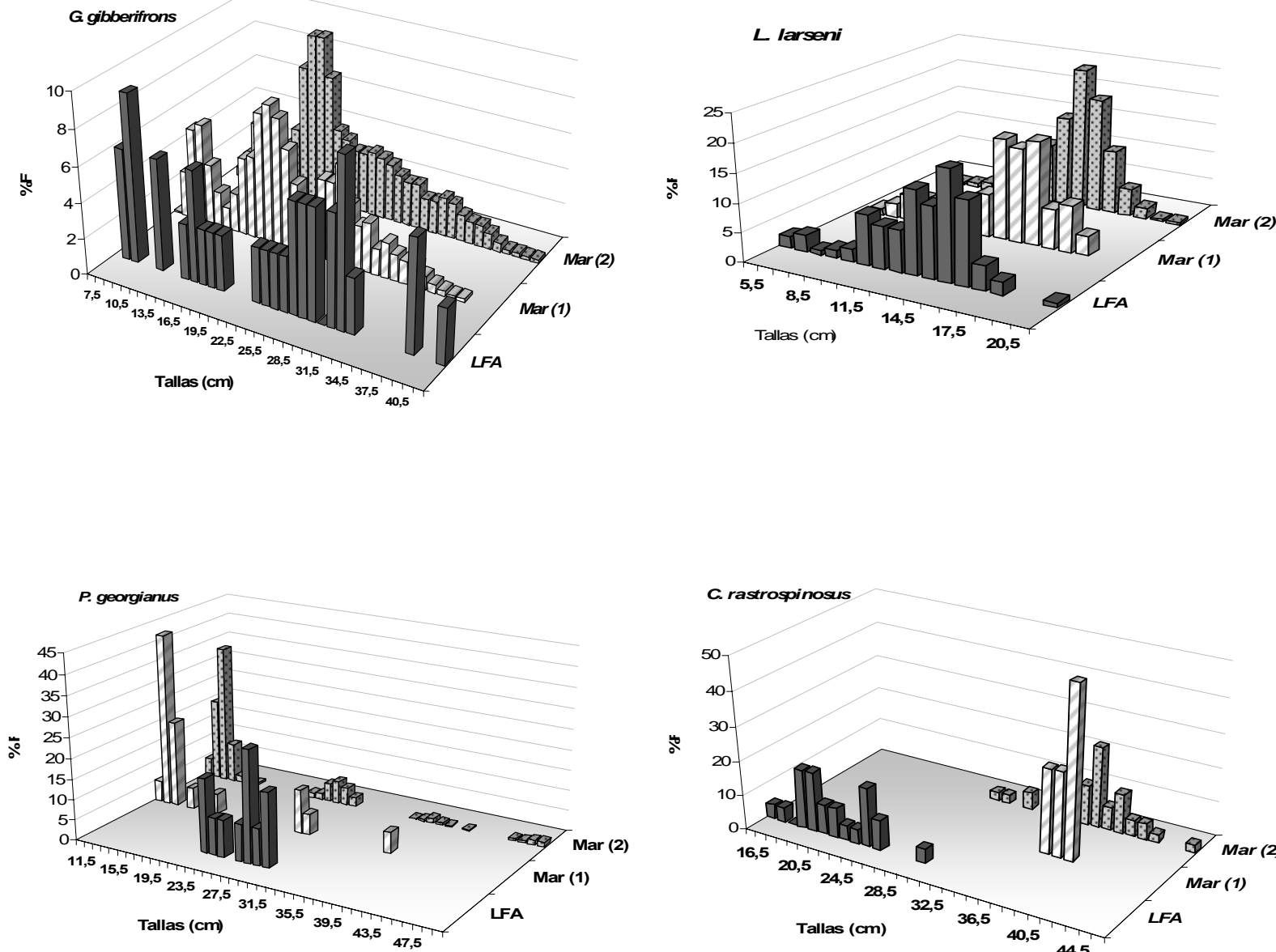

C. rastrospinosus
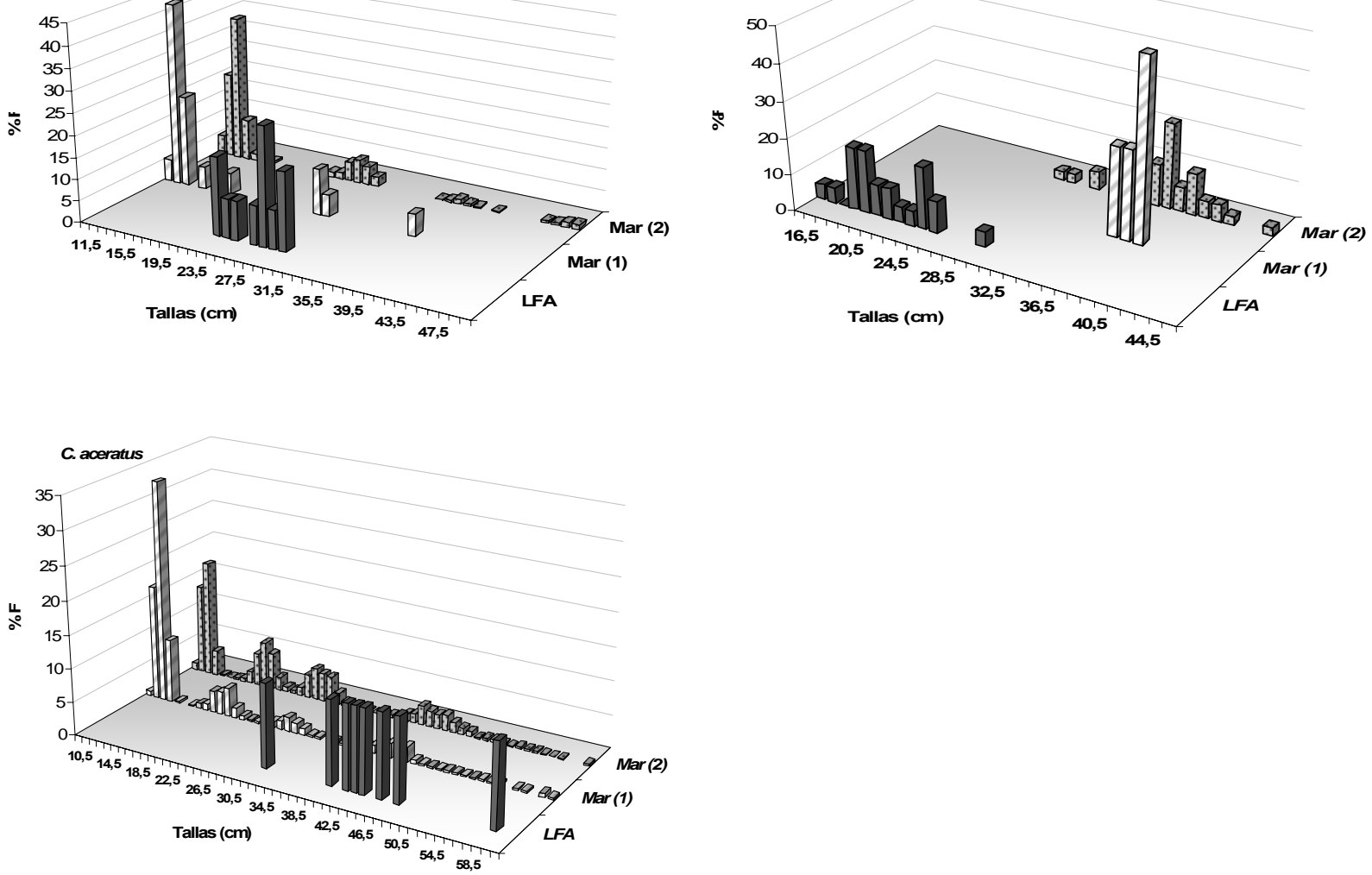

Figura III.10: Superposición de las tallas de los peces consumidos por el lobo Fino Antártico (1995/96) y los representados en los arrastres realizados por Balguerías (1989). 

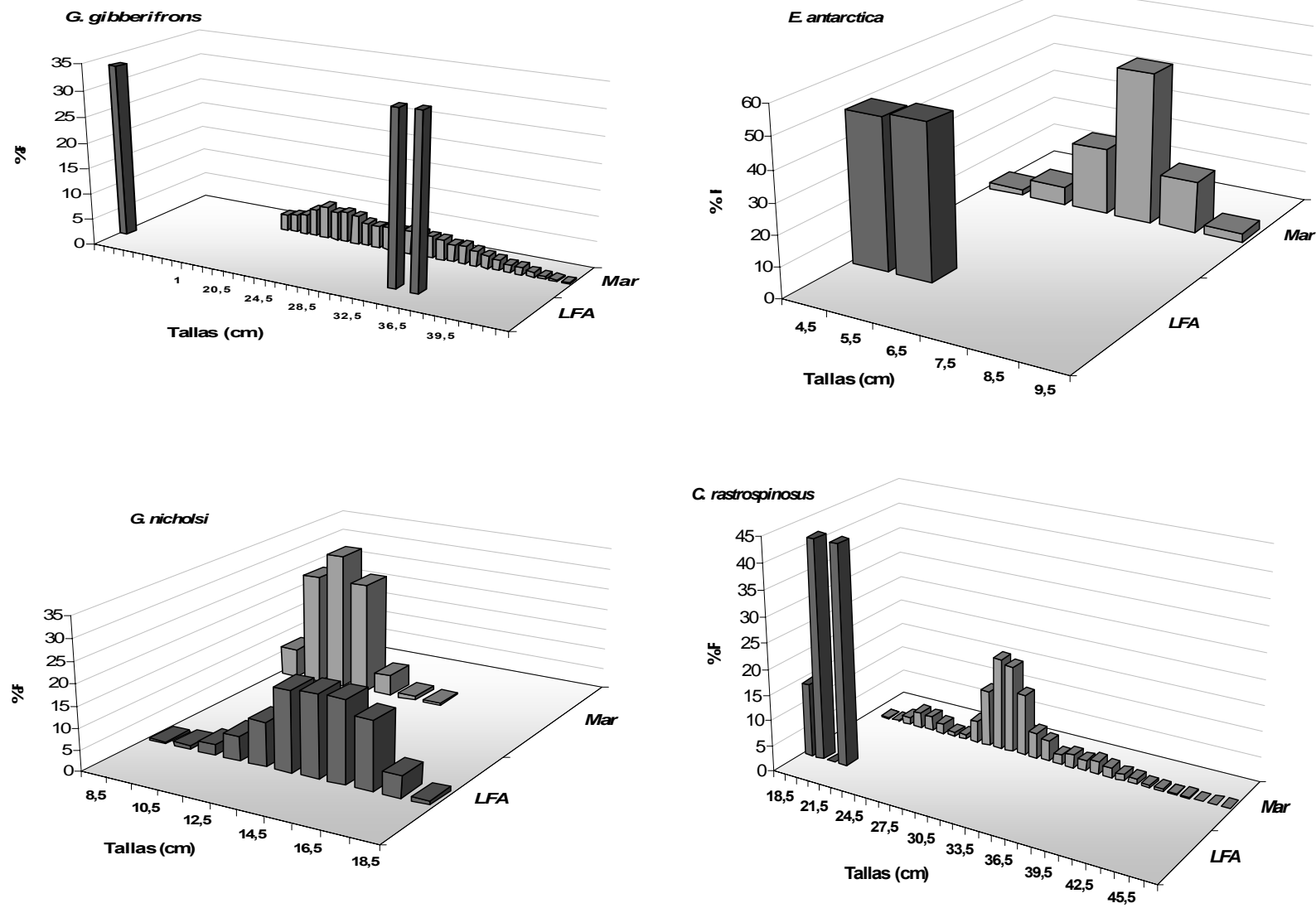

Figura III.11: Superposición de las tallas de los peces consumidos por el lobo Fino Antártico (1998/99) y los representados en los arrastres realizados por Kock et al. (2000).

Tabla III.18: Índice de solapamiento de las distribuciones de tallas de los peces consumidos por el lobo Fino Antártico (temporadas 1995/96 y 1998/99) y los representados en los arrastres realizados por Balguerías (1989), $S_{1}$ y $S_{2}$, y por Kock et al. (2000), $S_{k}$.

\begin{tabular}{|l|c|c|c|}
\hline & $\mathrm{S}_{1}$ & $\mathrm{~S}_{2}$ & $\mathrm{~S}_{\mathrm{k}}$ \\
\hline C. aceratus & 19,95 & 9,9 & -- \\
\hline C. rastrospinosus & 0,00 & 3,65 & 3,13 \\
\hline P. georgianus & 15,80 & 16,37 & -- \\
\hline E. antarctica & -- & -- & 8,00 \\
\hline G. nicholsi & -- & -- & 61,50 \\
\hline L. larseni & 72,08 & 73,37 & -- \\
\hline G. gibberifrons & 52,28 & 49,3 & 11,05 \\
\hline
\end{tabular}

\section{GT: Ictiófagos (1)}

\section{b) Cormorán de Georgias}

Las tallas medias de los peces consumidos por el cormorán de Georgias en las temporadas 1995/97 $(8,66 \pm 3,72 \mathrm{~cm}$., rango $3,5-23,5 \mathrm{~cm}$.) y 1998/99 $(9,37 \pm 2,87 \mathrm{~cm}$., rango $6,5-45,5 \mathrm{~cm}$.) fueron menores a 
las de los peces representados en los arrastres. Los valores de solapamiento resultaron bajos en todos los casos (tabla III.19). Las distribuciones de tallas se muestran en las figuras III.12 y III.13.
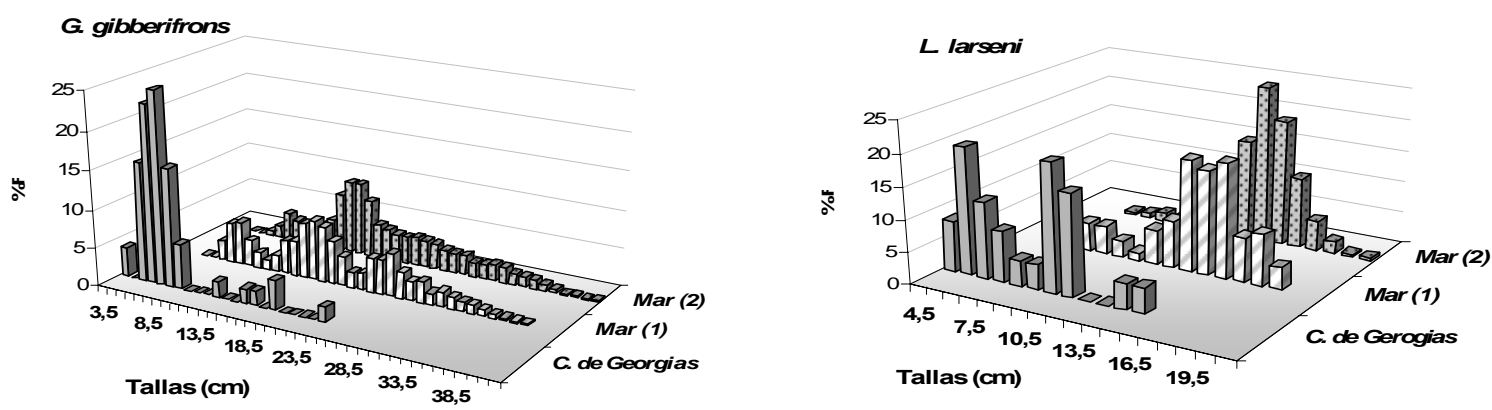

L nudifrons

Figura III.12: Superposición de las tallas de los peces consumidos por el Cormorán de Georgias durante la temporada 1995/96 y los representados en los arrastres realizados por Balguerías (1989)
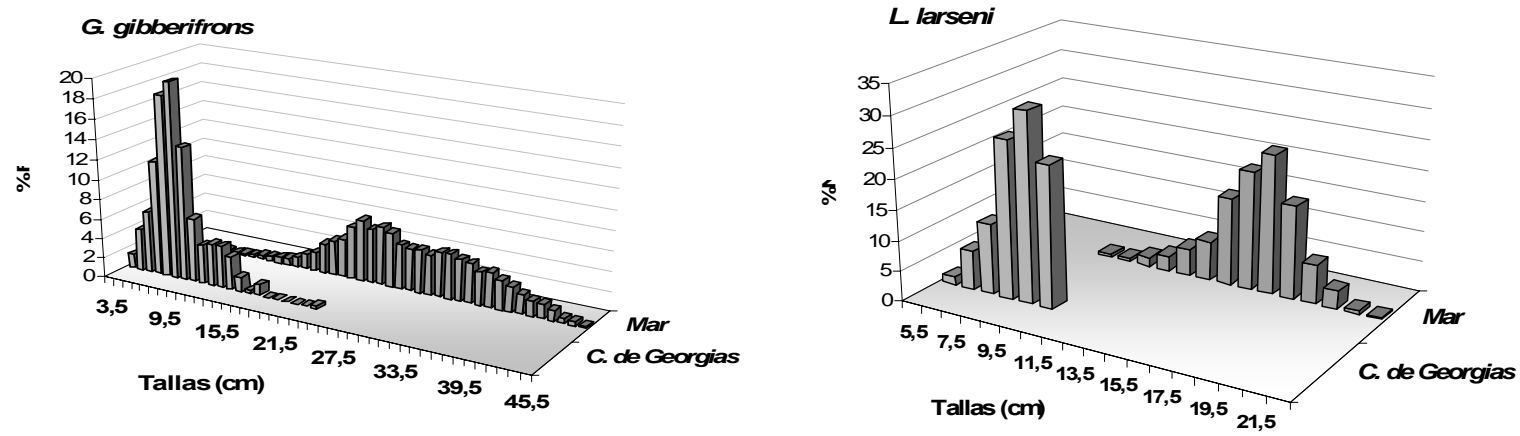

Figura III.13: Superposición de las tallas de los peces consumidos por el Cormorán de Georgias (1998/99).y los representados en los arrastres realizados por Kock et al. (2000). 
Tabla III.19: Índice de solapamiento de las distribuciones de tallas de los peces consumidos por el Cormorán de Georgias (temporadas 1995/96 y 1998/99) y los representados en los arrastres realizados por Balguerías (1989), $S_{1}$ y $S_{2}$, y por Kock et al. (2000), $S_{k}$.

\begin{tabular}{|l|c|c|c|}
\hline & $\mathrm{S}_{1}$ & $\mathrm{~S}_{2}$ & $\mathrm{~S}_{\mathrm{k}}$ \\
\hline G. gibberifrons & 24,31 & 13,41 & 4,5 \\
\hline L. larseni & 23,5 & 14,6 & 1,6 \\
\hline L. nudifrons & 52,85 & 28,35 & -- \\
\hline
\end{tabular}

\section{GT: Ictiófagos (2)}

\section{a) Petrel Damero}

Tal como se observara en el pingüino de Adelia, las tallas de $E$. antarctica consumidas por el petrel Damero fueron menores a las representadas en los arrastres (ver tabla III.3) siendo el valor de $S_{k}=$ 9,96 (Figura III.14).

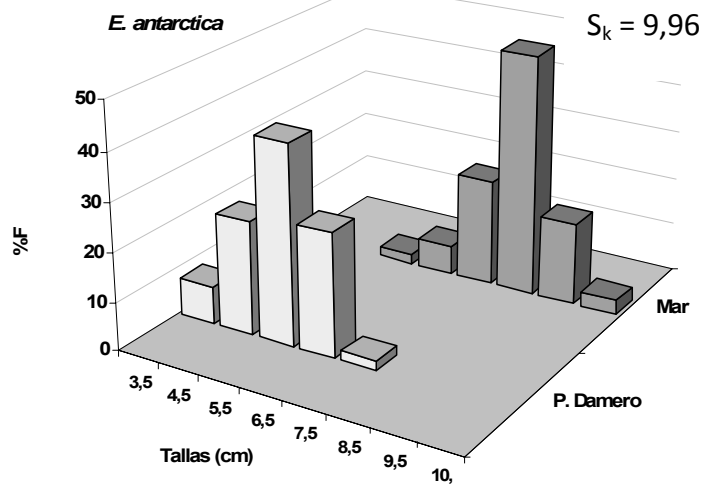

Figura III.14: Superposición de la talla de los peces consumidos por el Petrel Damero (1998/99) y los representados en los arrastres realizados por Kock et al. (2000).

\section{III.3.6. Diversidad en el consumo de peces}

Si bien los valores de diversidad $(H)$ y equitatividad $(E)$ fueron relativamente bajos en todos los predadores, el cormorán de Georgias y la foca de Weddell presentaron los valores más altos de $\mathrm{H}$ (2,00 y 1,38 respectivamente) y de $E(0,37$ y 0,25$)$, lo que refleja la diversidad de la dieta de estas especies (Tabla III.20). Teniendo en cuenta que ambos predadores consumen preferentemente peces con hábitos bento-demersales (Casaux 1998, Casaux et al. 1995, 1997, 1998, 2002, 2006, 2009, Casaux y Ramón 2002) y que la diversidad en términos de especie es mayor en los fondos marinos que en la columna de agua (Barrera-Oro 2002) se procedió a analizar la diversidad de la dieta para aquellos predadores que consumen peces bento-demersales, considerando a todos estos peces bento-demersales como un solo grupo con el objetivo de analizar la amplitud trófica. De acuerdo a este análisis H y E disminuyeron marcadamente en el cormorán de Georgias y en el pingüino Papúa (Tabla III.21). Curiosamente tanto en la foca de Weddell como en el lobo Fino Antártico el valor de $\mathrm{H}$ varió escasamente o no varió, lo que significa que en el pingüino Papúa y en el cormorán de Georgias el valor de $\mathrm{H}$ se explica únicamente por el consumo de peces bento- 
demersales, los que representan una fauna diversa (Barrera-Oro 2002). Es importante destacar que si bien la foca de Weddell y el lobo Fino Antártico mostraron valores de $\mathrm{H}$ menores que los del cormorán de Georgias y del pingüino Papúa, su dieta general es más diversificada (ver capítulo II).

Tabla III.20: Valores de Diversidad (H), Equitatividad (E) y Riqueza observados en los predadores ictiófagos de las IOS durante la temporada reproductiva 1999.

$\begin{array}{lccc} & \text { Diversidad (H) } & \text { Equitatividad } & \text { Riqueza } \\ \text { Pingüino Papúa } & 0,78 & 0,14 & \\ \text { Cormorán de Georgias } & 2,00 & 0,37 & \\ \text { Foca de Weddell } & 1,38 & 0,25 & \\ \text { LOBO FINO ANTÁRTICO } & 0,79 & 0,14 & \mathbf{4 4}\end{array}$

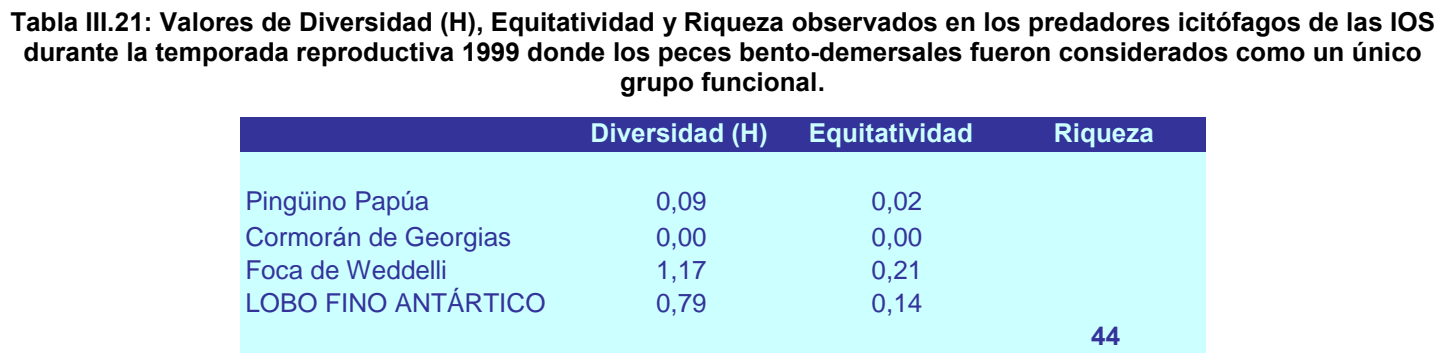

\section{III.4. Discusión}

\section{III.4.1. Composición y distribución de los peces en las IOS}

Se estima que a nivel global desde finales de 1980 la actividad de la pesca comercial ha disminuido y se considera que el $50 \%$ de los stocks de peces de todos los mares ya han sido pescados y que cerca del 30\% de ellos está sobreexplotado (Pauly et al. 2002, García y de Leiva Moreno 2003). Esto refleja que las políticas y estrategias de manejo pesquero son ineficaces en términos de una explotación ecológicamente sustentable (Botsford et al. 1997). Para lograr ese objetivo es de suma necesidad, entre otros factores, contar con datos actualizados y continuos de las abundancias y el estado poblacional de estos recursos. En las IOS la información sobre la composición y abundancia de la ictiofauna es escasa y está fragmentada en el tiempo. Hasta el momento, alrededor de este archipiélago se desarrollaron solo cuatro cruceros de investigación, a partir de los cuales entre los años 1985 y 1999 se determinó la composición de la ictiofauna de las IOS (Kock 1986, Balguerías 1989, 1991, Jones et al. 2000, Kock et al. 2000,). En base a los datos obtenidos durante las campañas "Antártida 8611" (Balguerías 1989) y "US AMLR 99" (Jones et al. 2000, Kock et al. 2000) se analizaron las tendencias de los stocks de peces de las IOS en términos de biomasa y de abundancia en las capturas y se consideraron también las distribuciones de talla de las diferentes especies. Estos dos cruceros reúnen los únicos datos sobre la comunidad de peces del archipiélago que pueden ser comparados entre sí; sin embargo, es importante aclarar que aunque los diseños experimentales y las áreas de muestreo de ambos fueron similares, existen diferencias entre las 
redes de arrastre utilizadas ${ }^{1}$. A pesar de ello, y asumiendo que los datos son comparables, el análisis de dicha información sugiere que la biomasa y la abundancia de casi todas las especies de peces, en particular G. gibberifrons, L. squamifrons, N. rossii,, P. georgianus, y varias especies de myctóphidos (tablas III.3 y III.4), aumentaron a lo largo del tiempo. También se puede observar que especies que parecían haber desaparecido del área luego de la intensa actividad pesquera llevada a cabo durante los 70' y los '80 (e.g. G. gibberifrons, N. rossii y L. squamifrons) presentaron una importante recuperación. Asimismo, comparando las biomasas estimadas por Jones et al. (2000) para las 8 especies más abundantes (98\% de las capturas) con lo reportado por Balguerías (1989) se observó un incremento de hasta el $200 \%$ en los stocks. En relación a G. gibberifrons, es probable que a través de la competencia el aumento de su población haya afectado negativamente a notothénidos costeros litorales como $N$. coriiceps, los que con el paso del tiempo disminuyeron sus abundancias (ver Tabla III.4). Pleuragramma antarcticum es otro notothénido que disminuyó su abundancia a lo largo del tiempo en las IOS. Este pez era considerado la especie dominante dentro de la comunidad pelágica en la mayoría de las costas antárticas, con una distribución que abarca desde la plataforma continental hasta los márgenes costeros de las áreas antárticas (DeWitt et al. 1990) por lo que esta disminución de sus stocks puede tener una implicancia ecosistémica importante dado que constituye una presa importante para varios predadores tope (Plötz 1986, Green y Burton 1987, Creet et al. 1994, Green et al. 1995, Casaux et al. 1997, Burns et al. 1998, La Mesa et al. 2004, Daneri et al. 2007, entre otros). Sin embargo el proceso observado en $P$. antarcticum en las IOS parece ser diferente al indicado para $N$. coriiceps dado que su disminución también fue observada en las ISS (Casaux et al. 2007). Moline et al. (2008) plantean la importancia que tiene la extensión del hielo marino sobre la dinámica poblacional de los peces antárticos y cómo los cambios en la extensión máxima de la cobertura invernal y la dinámica temporal de avance y retroceso del pack de hielo son variables ambientales con una fuerte influencia sobre la vida de los peces tanto en el océano abierto como en sistemas costeros. En este contexto, es de esperar que las especies más afectadas por estas variables sean aquellas que desarrollan algún período de su vida en dependencia directa del hielo marino, como parece suceder con $P$. antarcticum, especie que depende del pack de hielo para la apropiada eclosión de los huevos y la protección de los primeros estadíos larvales (Vacchi et al. 2004), o como C. rastrospinosus que utiliza la canopia de hielo como primer sitio de alimentación (Kellerman 1996). Llamativamente, la fuerte disminución de la abundancia de P. antarcticum observada en las IOS se vio acompañada de un aumento en la biomasa y abundancia de $C$. ratrospinosus, lo que evidencia que además de la extensión del hielo marino otros factores influyen fuertemente sobre las tendencias poblacionales de estas especies.

Si bien estos resultados sugieren que la recuperación de la abundancia de las poblaciones de peces observada a partir de 1991 (Balguerías 1991) se debió fundamentalmente al cierre de la pesca comercial en el área ocurrida en 1989/90 (Everson 1997, Everson et al. 1991, 1992, 1994, 2000 y 2002) el análisis de los índices ecológicos indicó que entre 1987 y 1999 la biodiversidad bajó y que la recuperación de la biomasa y abundancia se dio sólo en pocas especies tales como $P$. georgianus y $G$. gibberifrons. Algunas explicaciones de la estructura de las comunidades se han basado en las interacciones de las especies que las componen. La competencia fue considerada

\footnotetext{
${ }^{1}$ La red utilizada en 1999 consistía en un tamaño de poro 3 a 4 veces menor que la utilizada en 1987.
} 
durante mucho tiempo como un factor que incide fuertemente en la estructura de la comunidad (Schoener 1982). En relación con esa línea de pensamiento surge la hipótesis del disturbio intermedio que propone que la máxima diversidad de una comunidad se alcanza con intensidades medias de disturbio. Cuando los agentes causantes de mortalidad actúan con intensidades intermedias, evitan que las especies más competitivas excluyan a las demás de la comunidad. Si la intensidad del disturbio fuera baja las especies más competitivas no serían inhibidas, en tanto que si fuera alta ninguna de las especies podría compensar la gran mortalidad causada por el disturbio (Connell 1978, Lubchenco 1978). Desde este punto de vista, la pesca comercial desarrollada en las IOS parece haber tenido efectos de mediana intensidad sobre la diversidad de la fauna ictícola. Sin embargo, es probable debido el modo en que esta se desarrolló I (dirigida hacia las especies dominantes), la pesca haya generado un aumento temporal del índice de diversidad.

Con respecto al crucero de 1987, en el de 1999 para algunas de las especies se registró un aumento de las tallas medias y se observaron rangos de tallas más amplios (Tabla III.3). Este incremento podría estar evidenciando la eastabilización de las poblaciones de peces. Sin embargo, dado que el tamaño de la celda de la red fue menor en 1999 que en 1987, las tallas más pequeñas deberían haber estado mejor representadas en 1999 y en consecuencia las tallas medias de los peces capturados deberían haber sido menores. Es probable que estas diferencias en las tallas de los peces capturados en parte también se deban a diferencias entre cruceros en las localizaciones o profundidades de las estaciones de pesca.

\section{III.4.2. Análisis de selección de presas de los predadores tope en las IOS}

Para una correcta interpretación de los resultados de esta sección se debe tener en cuenta que los datos de las capturas y de los muestreos de las dieta de los predadores tope de las IOS no fueron llevados a cabo durante las mismas temporadas (incluso en algunos años la distancia temporal llegó a ser de 7 años) y que los modelos de capturas y sitios no fueron desarrollados en función de una evaluación de la disponibilidad de presas real para los predadores del archipiélago, por tanto los sitios muestreados no necesariamente coincidieron con las áreas de forrajeo de tales predadores. Por otro lado el tamaño de las redes deja de lado las capturas de ejemplares pequeños (entre 5 y $8 \mathrm{~cm}$. aproximadamente) las cuales son importantes dentro de la dieta de ciertas aves tales como las tres especies de pingüinos, el cormorán de Georgias, los procelláridos más pequeños como el petrel de las Nieves y el petrel Damero. Teniendo en cuenta que debido a los tipos de fondos y a la seguridad en las maniobras los cruceros, las capturas fueron realizadas en la zona de offshore (ver figuras III.1A y III.1.B), en tanto que ciertos predadores, como el cormorán de Georgias, se alimentan en la zona de inshore o litoral, con lo cual los resultados de selección de presas deben ser tomados con esta precaución y reflejar una tendencia hacia la selección.

Los pingüinos de Adelia y de Barbijo (GT: Krill 1) mostraron tendencias hacia la selección de peces de la familia Myctophidae y del notothénido T. newnesi (Tabla III.22). Durante primavera y verano estos peces ascienden a la zona epipelágica (50 a $200 \mathrm{~m}$.) en busca de alimento (principalmente krill) (Lubimova et al 1983, 1987), por lo que ambos pingüinos aprovecharían su presencia en los parches de krill. La superposición de tallas de los peces representados en la dieta y en los arrastres fue baja, lo que se debería a los tamaños de red ya que los pingüinos consumieron 
peces pequeños (menores a $5 \mathrm{~cm}$.), los que estuvieron escasamente representados en las capturas de los cruceros. Por otro lado, la similitud en las especies y tallas de peces seleccionados evidencia una alta competencia por el alimento entre ambos pingüinos.

Los predadores mixtos (GT: Krill 2) seleccionaron diferentes especies de peces pelágicos y bento-demersales. La disimilitud en las especies seleccionadas sugiere que la foca de Weddell, el lobo Fino Antártico y el pingüino Papúa, explotan los diferentes ambientes con distinta intensidad. La intensa predación sobre G. gibberifrons observada en la foca de Weddell y en el pingüino Papúa sugiere que estos predadores tienen una alta competencia por el alimento. Sin embargo, los peces consumidos por el pingüino Papúa fueron menores que los representados en la dieta de los otros predadores, lo que podría estar reflejando limitaciones para la captura y manipulación de peces más grandes. Entre estos predadores, el lobo Fino Antártico seleccionó la mayor variedad de presas, lo que confirma la plasticidad trófica reportada para esta especie (Casaux et al. 2003a y b) y consumió un amplio rango de tallas de peces (principalmente de las especies G. gibberifrons y L. larseni), lo que sugiere que explotó tanto aguas abiertas como fondos someros litorales.

El cormorán de Georgias (GT: Ictiófagos 1) seleccionó casi exclusivamente especies de notothéniidos. La única excepción es $H$. antarcticus, y ello se debe a que este pez bentónico y de talla pequeña no estuvo representado en los arrastres realizados por Balguerías (1989) y Kock et al. (2000). En este sentido, estos resultados acerca de selectividad de alimento deben ser considerados con precaución ya que la información acerca de la información de los peces proveniente de arrastres en aguas abiertas en tanto que este cormorán se alimenta en aguas litorales (Casaux 1998). De manera similar a lo ocurrido con los Krill 1, el rango de tallas consumido por este cormorán incluyó una importante fracción de ejemplares pequeños, las cuales no estuvieron representados en los arrastres por ser de menor tamaño que la trama de las redes empleadas. Si bien estos resultados pueden sugerir que el cormorán de Georgias tiene limitaciones para capturar peces de tallas grandes, estudios realizados en las ISS indican que el cormorán Antártico (una especie estrechamente emparentada con el cormorán de Georgias) es capaz de capturar peces de hasta 42 cm. (Casaux 1998, Casaux et al. 1998a y b). En base a ello se puede especular que las tallas de los peces consumidos por el cormorán responden a la disponibilidad de alimento local y no a limitaciones en la captura y manipulación de peces de gran talla.

Tanto el petrel Damero como el petrel de las Nieves (GT: Ictiófagos 2) seleccionaron mycthóphidos, lo que refleja un hábito alimentario pelágico, tal como fuera reportado por diferentes autores (Bierman y Voous 1950, Matthew 1953, Billings 1968, Beck 1969, Creet et al. 1994 y Soave et al. 1996). El rango de tallas consumidas por el petrel Damero tuvo escasa superposición con las de los ejemplares representados en los arrastres, lo que parece deberse al tamaño de malla de las redes utilizadas en los cruceros.

Con respecto a la selectividad de alimento, los valores más altos de selección de alimento en el pingüino Papúa y en el cormorán de Georgias se observaron en especies de notothénidos, en tanto que en los mamíferos eso también ocurrió con channíchthyidos y mycthóphidos. Sin embargo, y como se indicó previamente, dado que los arrastres fueron realizados en aguas abiertas, los valores de selección de alimento obtenidos para especies de hábitos litorales (principalmente el cormorán de Georgias y en menor medida el pingüino Papúa) deben ser interpretados con precaución. 
Tabla III.22: Peces seleccionados $(\mathrm{I}>0)$ por los predadores tope de las IOS. A: Calculado a partir de la biomasa de peces estimada por Jones et al (2000); B: Calculado a partir de la biomasa de peces estimada por Balguerías (1989); 1, 2, 3 representan los diferentes estratos de profundidad. Los nombres remarcados en gris refieren a las especies de peces no registradas en las capturas.

\begin{tabular}{|c|c|c|c|c|}
\hline & $\mathbf{A}$ & B1 & B2 & B3 \\
\hline $\begin{array}{l}\text { Pingüino de } \\
\text { Adelia }\end{array}$ & E. antarctica & $\begin{array}{l}\text { P. normani } \\
\text { T. newnesi }\end{array}$ & $\begin{array}{l}\text { P. normani } \\
\text { T. newnesi }\end{array}$ & $\begin{array}{l}\text { P. normani } \\
\text { T. newnesi }\end{array}$ \\
\hline $\begin{array}{l}\text { Pingüino de } \\
\text { Barbijo }\end{array}$ & $\begin{array}{l}\text { E. antarctica } \\
\text { G. nicholsi }\end{array}$ & $\begin{array}{l}\text { E. antarctica } \\
\text { G. nicholsi }\end{array}$ & $\begin{array}{l}\text { E. antarctica } \\
\text { G. nicholsi }\end{array}$ & $\begin{array}{l}\text { E. antarctica } \\
\text { G. nicholsi }\end{array}$ \\
\hline & T. newnesi & $\begin{array}{l}\text { T. newnesi } \\
\text { N. coatsi }\end{array}$ & $\begin{array}{l}\text { T. newnesi } \\
\text { N. coatsi }\end{array}$ & $\begin{array}{l}\text { T. newnesi } \\
\text { N. coatsi }\end{array}$ \\
\hline Pingüino Papúa & $\begin{array}{l}\text { G. gibberifrons } \\
\text { L. larseni } \\
\text { L. nudifrons } \\
\text { T. newnesi }\end{array}$ & $\begin{array}{l}\text { G. gibberifrons } \\
\text { G. nicholsi } \\
\text { L. larseni } \\
\text { T. newnesi } \\
\text { Electrona sp. }\end{array}$ & $\begin{array}{l}\text { G. gibberifrons } \\
\text { G. nicholsi } \\
\text { L. larseni } \\
\text { T. newnesi } \\
\text { Electrona sp. }\end{array}$ & $\begin{array}{l}\text { G. gibberifrons } \\
\text { G. nicholsi } \\
\text { L. larseni } \\
\text { T. newnesi }\end{array}$ \\
\hline $\begin{array}{l}\text { Petrel de las } \\
\text { Nieves }\end{array}$ & -- & $\begin{array}{l}\text { E. antarctica } \\
\text { G. opisthopterus } \\
\text { B. glacialis }\end{array}$ & $\begin{array}{l}\text { E. antarctica } \\
\text { G. opisthopterus } \\
\text { B. glacialis }\end{array}$ & $\begin{array}{l}\text { E. antarctica } \\
\text { G. opisthopterus } \\
\text { B. glacialis }\end{array}$ \\
\hline Petrel Damero & $\begin{array}{l}\text { E. antarctica } \\
\text { G. nicholsi } \\
\text { P. normani }\end{array}$ & $\begin{array}{l}\text { E. antarctica } \\
\text { G. nicholsi } \\
\text { G. braueri } \\
\text { K. anderssoni }\end{array}$ & $\begin{array}{l}\text { E. antarctica } \\
\text { G. nicholsi } \\
\text { G. braueri } \\
\text { K. anderssoni }\end{array}$ & $\begin{array}{l}\text { E. antarctica } \\
\text { G. nicholsi } \\
\text { G. braueri } \\
\text { K. anderssoni }\end{array}$ \\
\hline $\begin{array}{l}\text { Escúa Marrón } \\
\text { Cormorán de } \\
\text { Georgias }\end{array}$ & $\begin{array}{l}\text { L. nudifrons } \\
\text { H. antarcticus } \\
\text { N. coriiceps } \\
\text { T. bernacchii } \\
\text { T. newnesi } \\
\text { P. charcotti } \\
\text { L. larseni } \\
\text { L. nudifrons }\end{array}$ & $\begin{array}{l}-- \\
\text { H. antarcticus } \\
\text { L. nudifrons } \\
\text { P. charcotti } \\
\text { N. coriiceps } \\
\text { T. newnesi } \\
\text { P. georgianus }\end{array}$ & $\begin{array}{l}-- \\
\text { H. antarcticus } \\
\text { L. nudifrons } \\
\text { P. charcotti } \\
\text { N. coriiceps } \\
\text { T. newnesi } \\
\text { P. georgianus }\end{array}$ & $\begin{array}{l}-- \\
\text { H. antarcticus } \\
\text { L. nudifrons } \\
\text { P. charcotti } \\
\text { N. coriiceps } \\
\text { T. newnesi } \\
\text { P. georgianus }\end{array}$ \\
\hline Foca de Weddell & $\begin{array}{l}\text { C. aceratus } \\
\text { C. ratrospinosus } \\
\text { G. gibberifrons } \\
\text { L. larseni } \\
\text { L. nudifrons } \\
\text { T. newnesi }\end{array}$ & $\begin{array}{l}\text { C. rastrospinosus } \\
\text { C. aceratus } \\
\text { G. gibberifrons } \\
\text { L. nudifrons }\end{array}$ & $\begin{array}{l}\text { C. rastrospinosus } \\
\text { C. aceratus } \\
\text { G. gibberifrons } \\
\text { L. nudifrons }\end{array}$ & $\begin{array}{l}\text { C. rastrospinosus } \\
\text { C. aceratus } \\
\text { G. gibberifrons } \\
\text { L. nudifrons } \\
\text { T. newnesi }\end{array}$ \\
\hline
\end{tabular}


Tabla III.22: Continuación.

\begin{tabular}{|lllll|}
\hline Lobo Fino & & & \\
Antártico & E. antarctica & C. rastrospinosus & C. rastrospinosus & C. rastrospinosus \\
& C. ratrospinosus & G. nicholsi & G. nicholsi & C. aceratus \\
& G. nicholsi & Electrona sp. & L. larseni & G. nicholsi \\
& P. normani & k. andersoni & Electrona sp. & N. coriiceps \\
& P. bernacchii & L. achirus & k. andersoni & T. newnesi \\
& P. normani & L. achirus & Electrona sp. \\
& N. coatsi & P. normani & T. hansoni \\
& & N. coatsi & K. andersoni \\
& & & L. achirus \\
& & & P. normani \\
& & & N. coatsi \\
\hline
\end{tabular}

Al analizar la selectividad de alimento en relación a los estratos de profundidad se observó que las aves seleccionaron las mismas presas a diferentes profundidades, hecho que no ocurrió con los mamíferos. Estos resultados podrían estar evidenciando diferencias en las estrategias de forrajeo entre ambos grupos (ver capítulo IV), o en las consistencias en los patrones de selección de alimento.

\section{III.4.3. Diversidad en el consumo de 4 predadores tope de las IOS}

Tanto los valores de diversidad como de equitatividad observados en la dieta de los cuatro predadores considerados en este análisis (lobo Fino Antártico, foca de Weddell, pingüino Papúa y cormorán de Georgias) fueron bajos, lo que implica (i) alguna limitación en los predadores para consumir mayor diversidad de presas debido a restricciones en el balance energético entre la relación costo-beneficio o (ii) que las especies con mayor retorno energético fueron abundantes. La comparación de dichos resultados indica que durante el verano de 1999 el cormorán de Georgias y la foca de Weddell presentaron las dietas más diversas y más equitativas. Por el contrario, el lobo Fino Antártico y el pingüino Papúa presentaron valores de diversidad y equitatividad más bajos. Además de las consideraciones relacionadas con las capacidades de buceo y estrategias de forrajeo, estas diferencias podrían deberse a la disponibilidad diferencial de presas entre los ambientes demersales, explotados principalmente por la foca de Weddell y el cormorán de Georgias, y los ambientes pelágicos, explotados por el lobo Fino Antártico y el pingüino Papúa.

Tanto la dieta del pingüino Papúa como la del lobo Fino Antártico estuvieron dominadas por el notothéniido G. gibberifrons (87\% en masa) y por el myctóphido G. nicholsi (88\%) respectivamente. Como se comentó previamente, el pingüino Papúa consumió principalmente G. gibberifrons, un pez de hábitos demersales, y a diferencia del cormorán de Georgias, la diversidad en el consumo de presas no fue muy alta. Por otro lado, es importante destacar que si bien la composición de la dieta del cormorán de Georgias, fue más amplia y equitativa que en los demás predadores, casi la totalidad de los peces consumidos pertenecen a la familia Nototheniidae y presentan hábitos demersales litorales. Es por ello que en un segundo análisis de la diversidad de la dieta se agrupó a los peces demersales en un solo grupo de presas (Tabla III.21). Este análisis indicó que el cormorán de Georgias y el pingüino Papúa presentaron los valores más bajos de diversidad y equitatividad y sugiere que sus hábitos de forrajeo fueron menos flexibles que los del lobo Fino Antártico y de la foca de Weddell. Con respecto a los mamíferos, la foca de Weddell fue el predador menos selectivo. 
Trabajos previos ya han resaltado la flexibilidad alimentaria de este predador en relación a los cambios en la disponibilidad de alimento (Casaux et al. 1997a). A su vez, cuando la competencia con el lobo Fino Antártico empieza a ser importante, la foca de Weddell pasa a explotar con mayor frecuencia recursos bento-demersales diversificando así su dieta y disminuyendo el factor de competencia (Casaux et al. 2009).

\section{III.5. Conclusiones generales}

Este capítulo intentó hacer un resumen sobre la información disponible acerca de la fauna ictícola del archipiélago de las IOS y sobre cuáles son las especies de peces que están siendo activamente consumidas por los predadores tope que allí habitan.

En términos generales, la biomasa de peces reportada a partir de dos cruceros de investigación, antes y después del cierre de la pesca en el área, reflejó un importante incremento en las especies que fueron fuertemente explotadas, tal como G. gibberifrons. Aún así, es importante destacar que tal incremento estuvo sesgado, pues ciertos grupos de peces, como algunos notothénidos y en particular $P$. antarcticum, disminuyeron hasta casi un $99 \%$ su biomasa en comparación con los valores de biomasa de capturas anteriores.

El análisis de la selectividad de alimento indicó que el lobo Fino Antártico fue el predador que seleccionó mayor cantidad de especies de peces, en tanto que el pingüino de Adelia y el petrel de las Nieves lo hicieron en la menor medida, debido claramente a sus hábitos de alimentación basados preferentemente en el krill (ver capítulo II).

El estudio del solapamiento de las distribuciones de tallas mostró que las aves generalmente se alimentan de peces menores a los representados en las capturas, lo que se debe al tamaño de la malla de las redes utilizadas en los cruceros. En cambio, en el caso de los mamíferos se observó un mayor rango de tallas. El solapamiento en las distribuciones de tallas observado en el lobo Fino Antártico fue alto $(S>50)$ en $G$. gibberifrons y en $L$. larseni, lo que también ocurrió con $L$. nudifrons en el cormorán de Georgias y con G. gibberifrons en la foca de Weddell. Dada la posibilidad de manipulación sobre las presas (ver capítulo IV), estos predadores tienen la capacidad de capturar presas de tamaños grandes (en general mayores a $15 \mathrm{~cm}$ ).

El análisis de diversidad de la dieta mostró que aquellos predadores que se alimentan exclusiva o preferentemente de peces bento-demersales presentaron los valores más altos de diversidad. Este hecho se debería a que la comunidad de peces bento-demersales es más diversa que la pelágica, tal como se plantea en otros trabajos. 


\section{III.6. Referencias bibliográficas}

Anon (1990a) CCAMLR Statistical Bulletin Volume I (1970-1979). CCAMLR, Hobart, Australia.

Anon (1990b) CCAMLR Statistical Bulletin Volume 2 (1980-1989). CCAMLR, Hobart, Australia.

Balguerías E (1989) Informe de resultados Antártida 8611. Biología Pesquera. Publ. Inst. Esp. Oceanogr.

Barlow KE, Boyd IL, Croxall JP, Reid K, Staniland IJ y Brierley AS (2002) Are penguins and seals in competition for Antarctic krill at South Georgia? Marine Biology 140: 205-213.

Bax NJ (1998) The significance and prediction of predation in marine fisheries. ICES Journal of Marine Science, 55: 997-1030.

Begon M, Harper JH y Townsend CR (1999) Ecología: individuos, poblaciones y comunidades. 3era. Edición. Omega, Barcelona, España.

Berruti A y Colclough J (1987) Comparison of the abundance of pilchard in cape gannet diet and commercial catches off the Western Cape South Africa. South African Journal of Marine Science 51: 863-869.

Botsford LW, Castilla JC y Peterson CH (1997) The management of fisheries an marine ecosystems. Science 277(5325): 509515. doi: 10.1126/science.277.5325.509.

Burns JM, Trumble SJ, Castellini MA y Testa JW (1998) The diet of Weddell seals in McMurdo Sound, Antarctica as determined from scat collections and stable isotope analysis. Polar Biology 19: 272-282.

Casaux R (1998) Biología reproductiva y ecología alimentaria del cormorán antártico Phalacrocorax bransfieldensis (Aves, Phalacrocoracidae) en las Islas Shetlands del Sur, Antártida. Tesis doctoral, Universidad del La Plata, La Plata, Buenos Aires, $262 \mathrm{pp}$.

Casaux R. y Barrera-Oro E (2006) Shags in Antarctica: their feeding behaviour and ecological role in the marine food web. Antarctic Science 18: 3-14.

. Casaux R, Baroni A, Ramon A, Bertolin ML y DiPrinzio C (2009a) The diet of post-breeding Antarctic shags, Phalacrocorax bransfieldensis, at the Danco Coast, Antarctic Peninsula. Antarctic Science 32(3): 221-227.

Casaux R, Baroni A, Ramon A, Carlini A, Bertolin ML y DiPrinzio C (2009b) Diet of leopard seal Hidrurga leptonyx, at the Danco Coast, Antarctic Peninsula. Polar Biology 32: 307-310.

Casaux R, Carlini A, Corbalán A, Bertolin ML y DiPrinzio C (2009c) The diet of the Weddell Seal Leptonychotes weddellii at Laurie Island, South Orkney Islands. Polar Biology 32: 833-838.

Casaux R, Baroni A. Ramón, Favero y Silva MP (2007) Aspects of the foraging behaviour of the Antarctic Tern Sterna vittata gaini at Harmony Point, South Shetland Islands. Polar Biology 31: 327-331. doi:10.1007/s00300-007-0362-3.

Casaux R, Baroni A, Arrighetti F, Ramón A y Carlini A (2003a) Geographical variation in the diet of the Antarctic fur seal Arctocephalus gazella. Polar Biology 26: 753-758.

Casaux R, Baroni A y Ramón A (2003b) The diet of antarctic fur seals Arctocephalus gazella at the Danco coast, Antarctic Peninsula. Polar Biology 26: 49-54.

Casaux R, Baroni A y Carlini A (1998a) The diet of Antarctic fur seal Arctochepalus gazella at Harmony Point, Nelson Island, South Shetland Islands. Polar Biology 20: 424-428.

Casaux R, Soave G y Coria N (1998b) Laternfish (Myctophidae) in the diet of Cape Petrel Daption capense at the South Orkney Islands, Antarctica. Polar Biology 20: 364-366.

Casaux R, Baroni A y Carlini A (1997a) The diet of the Weddell seal Leptonychotes weddelli at Harmony Point, South Shetland Is-lands. Polar Biology 18: 371-375.

Casaux R, Coria N y Barrera-Oro E (1997b) Fish in the diet of the Antarctic shag Phalacrocorax bransfieldensis at Laurie Island, South Orkney Islands Polar Biology 18(3): 219-222. doi: 10.1007/s003000050179.

Coria N, Libertelli M, Casaux R y Darrieu C (2000) Inter-annual variation in the autumn diet of the Gentoo Penguin at Laurie Island, Antartctica. Waterbirds 23: 511-517.

de la Mare WK (1994) Estimating confidence intervals for fish stock abundance estimates from trawl surveys. CCAMLR Science 1: 203-207.

Creet S, van Franeker JA, van Spanje TM y Wolff WJ (1994) Diet of the pintado petrel Daption capense at King George Island, Antarctica, 1990/91. Mar Ornith 22: 221-229.

Croll DA y Tershy BR (1998) Penguins, fur seal and fishing: prey requirements and potential in the South Shetland Islands, Antarctica. Polar Biology 19: 365-374. 
Croxall JP, Prince PA, Rothery P y Wood AG (1998) Population changes in albatrosses at South Georgia. En: Albatross biology and conservation. Robertson G y Gales R (Eds). Chipping Norton, UK: Surrey Beatty \& Sons, pp. 69-83.

Daneri GA (1996) Fish diet of the Antarctic fur seal, Arctocephalus gazella, in summer, at Stranger Point, King George Island, South Shetland Islands. Polar Biology 16: 353-355.

Daneri GA y Coria NR (1992) The diet of Antarctic fur seals, Arctocephalus gazella, during the summer-autumn period at Mossman Peninsula, Laurie Island (South Orkneys). Polar Biology 11: 565-566.

Daneri GA, Negri A, Carlini AR y Corbalán A (2007) Estudio interanual del componente íctico de la dieta de Leptonychotes weddellii en Caleta choza, Península antártica. VI Simposio Argentino y III Latinoamericano sobre Investigaciones Antárticas CD-ROM. Contribución tipo Poster, Código CVCO307, 1 pp.

DeWitt HH, Heemstra PC y Gon O (1990) Nototheniidae. En: Fishes of the Southern Ocean. Gon O y Heemstra PC (Eds). Grahamstown, South Africa: J. L. B. Smith Institute of Ichthyology, pp. 279-331.

Everson I (1997) Preliminary report of UK fish survey in subarea 48.3. WG-FSA-97/39, 6pp. CCAMLR, Hobart, Australia.

Everson I, Marlow T, Belchier M, Forster R, Morley S, North AW, Szlakowski J y Wilhelms S (2002) fish stock assessment survey in subarea 48.3. WG-FSA 02/34, 6pp. CCAMLR, Hobart, Australia

Everson I, Kock KH y Ellison J (2000) Inter-annual variation in the gonad cycle of the mackerel icefish. Journal of fish biology 57(A): 103-111.

Everson I, Parkes G, Kock KH, Goss C, Cielniaszek Z, Szlakowski J, Daly H, Allcock L y Phillip G (1994) Result of the UK demersal fish in subarea 48.3. WG-FSA-94/18, 34pp. CCAMLR, Hobart, Australia.

Everson I, Parkes G, Campbell S, Kock KH, Szlakowski J, Cielniaszek D, Gos K y Wilhelms S (1992) Fish stock assessment survey in Subarea 48.3. Document WG-FSL4-9211 7. CCAMLR, Hobart, Australia.

Everson I, Kock KH, Campbell S, Parkes G, Cielniaszek D, Szlakowski J (1991) Reproduction in the mackerel icefish, Champsocephalus gunnari, at South Georgia Document WG-FSA 91/7. CCAMLR, Hobart, Australia

Everson I, Watkins JL, Bone DG y Foote KG (1990) Implications of a new acoustic strength for abundance estimates of Antarctic krill. Nature 345: 338-340.

Ferretti V, Soave GE, Casaux R y Coria NR (2001) Diet of the snow petrel Pagodroma nivea at Laurie Island, Antarctica, during the 1997/98 breeding season. Marine Ornithology 29: 71-73.

Green K y Burton HR (1987) Seasonal and geographical variation in the food of Weddell seals, Leptonychotes weddellii, in Antarctica. Australian Wildlife Researches 14: 475-489.

Green K, Slip DJ y Moore GJ (1998) The take of fish species by seabirds and marine mammals in the Australian Fisheries Zone around Heard Island: the potential for competition with commercial fishery. Polar Biology 20: $273-280$.

Green K, Burton H y Watts D (1995) Studies of the Weddell seals in the Vestfold Hills, East Antarctica. ANARE Research Notes 93: 1-64.

Greig-Smith P (1983) Quantative plant ecology, $3^{\text {rd }}$ edn. Blackwell Scientific Publications, Oxford.

Hill MO (1973) Diversity and evenness: a unifying notation and its consequence. Ecology 54: 427-432.

Ichii T, Takao T, Bengstson JL, Boveng P, Jansen JK, Hiruki LM, Meyer WR, Cameron MF, Naganobu M, Kawaguchi S y Ogishima T (1997) Importance of myctophid fish distribution for formation of foraging areas of chinstrap penguins and antarctic fur seals at seal Island. WG-EMM 97/28, 96/49 y 95/87 Agenda Item Nº y N². CCAMLR.

Ichii T, Naganobu M, Ogishima T (1996) Competition between the krill fishery and penguins in the South Shetland Islands. Polar Biology 16: 63-70.

Ichii T, Takao T, Bengtson J, Boveng P, Hansen J, Hiruki L, Meyer W, Cameron M, Naganobu M, Kawaguchi S y Ogishima T (1995) Importance of myctophids fish distributions for formation of foraging areas of Chinstrap penguins and Antarctic fur seals at Seal Island. CCAMLR. Ecosystem Monitoring and Management Working group, document 97/28, 24 pp.

Ivlev VS (1961) Experimental ecology of the feed-ing of fishes. Yale University Press, New Haven, Connecticut, USA.

Jones CD, Kock KH y Balguerías E (2000) Changes in biomass of eight species of finfish around the South Orkney Islands (Subarea 48.2) from three bottom trawl surveys. CCAMLR Science 7: 53-74

Kasatkina SM y Ivanova VF (2003) Fishing intensity of the Soviet fleet in krill fisheries in the southern Atlantic (Subareas 48.2 and 48.3). CCAMLR Science 10: 15-35.

Kellermann A (1996) Midwater fish ecology. En: Foundation for Antarctic Research west of the Antarctic Peninsula. Ross RM, Hofmann E, Quetin LB (Eds). Antarctic Research Series 70: 231-256. 
Kerfoot WC, y Sih A (1987) Predation: direct and indirect impacts on aquatic communities. University Press of New England, Hanover.

Kock KH (1986) The state of exploited Antarctic fish stocks in the Scotia Arc region during Sibex (1983-1985). Arch. FischWiss. 37 (Beih. 1): 129-186.

Kock KH, Jones CD y Wilhelms S (2000) Biological characteristics of Antarctic fish stocks in the Southern Scotia Arc region. CCAMLR Science 7: 1-41.

Kock KH, Duhamel G y Hureau JC (1985) Biology and status of exploited Antarctic fish stocks: a review. Biomass Scient Ser 6: 1-143.

Lande R (1996) Statistics and Partitioning of Species Diversity, and Similarity among Multiple Communities. Oikos 76(1): 5-13.

La Mesa M, Ashford J, Larson E, Vacchi M (2004) Age and growth of Scotia Sea icefish, Chaenocephalus aceratus, from the South Shetland Islands. Antarct Sci 16(3): 253-262.

Linton LR, Davies RW y Wrona FJ (1981) Resource utilization indices: an assessment. J Animal Ecol 50: $283-292$.

Lubimova TG, Shust KV y Popov VV (1987) Some features of the ecology of mesopelagic fish of family Myctophidae in the Southern Ocean. In: Biological Resources of the Arctic and Antarctic. Nauka, Moscow: 320-337.

Lubimova TG, Shust KV, Troyanovski FM y Semenov AB (1983) To the ecology of mass species of myctophids from the Antarctic Atlantic. In: Soviet Committee of Antarctic Research. The Antarctic. The Committee Report 22: 99-106.

Magurran AE (1988) Ecological diversity and its measurement. 179 pp Croom Helm Limited. London. University press. Cambridge.

Moline MA, Karnovsky NJ, Brown Z, Divoky GJ, Frazer TK, Jacoby CA, Torres JJ y Fraser WR (2008) High Latitude Changes in Ice Dynamics and Their Impact on Polar Marine Ecosystems. Ann NY Acad Sci 1134: 267.

Pauly D, Christensen V, Gue' nette S, Pitcher T, Sumaila UR, Walters C, Watson R y Zeller D (2002) Toward sustainability in world fisheries. Nature 418: 689-695.

Pennington M (1983) Efficient estimators of abundance, for fish and plankton surveys. Biometrics: $39281-39286$.

Pielou EC (1966) The measurement of diversity in different types of biological collections. Journal of Theorical Biology 13: 131144.

Plötz J (1986) Summer diet of Weddell seals (Leptonychotes weddelli) in the Eastern and Southern Weddell Sea, Antarctica. Polar Biology 6: 97-102.

Reid K (1995) The diet of Antarctic fur seals Arctocephalus gazella Peters 1875 during winter at South Georgia. Antarctic Science 7: 241-249.

Reid K, Sims M, White RW y Gillon KW (2004) Spatial distribution of predator/prey interactions in the Scotia Sea: implications for measuring predator/fisheries overlap. Deep-Sea Research II (51): 1383-1396

Shannon CE y Weaverw (1949) The mathematical theory of communiation. The Univ. of Illinois Press, Urbana, IL.

Simpson EH (1949) Measurement of Diversity. Nature 163: 688-688. doi:10.1038/163688a0.

Sinclair M, Valdimarsson G, Garcia S y de Leiva Moreno I (2003) Global overview of marine fisheries. En: Responsible Fisheries in the Marine Ecosystem. Sinclair M y Valdimarsson G (Eds). Wallingford, UK: FAO Rome, and CABI Publishing, pp. 1-24.

Trivelpiece WZ y Trivelpiece SG (1995) Changes in Adelia penguin recruitment: correlations to krill biomass estimates and imlications for the fisheries managment in the southern ocean. Wg-Emm 95/63, Methods Agenda item $\mathrm{N}^{\circ} 7$.

Vacchi M, La mesa M, Dalu M y McDonald J (2004) Early life stages in the life cycle of Antarctic silverfish, Pleuragramma antarcticum in Terra Nova Bay, Ross Sea. Antarctic Science 16 (3): 299-305. doi: 10.1017/S0954102004002135.

Zhao CS, DabuX y Li Y (2004) Relationship between Climatic factors and dust storm frequency in Inner Mongolia of China, Geophys. Res. Lett., 31, L01103. doi:10.1029/2003GL018351. 


\section{Estrategias de alimentación}

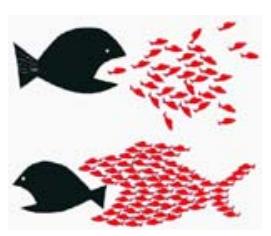

\section{IV.1. Introducción}

En su aspecto más amplio, la ecología trófica intenta explicar el modo en que los predadores responden a los cambios en la disponibilidad de sus presas, principalmente por medio del estudio de la composición de su dieta y del comportamiento de forrajeo que desplieguen (Montevecchi y Berutti 1991). Diversos los trabajos destacan la importancia del estudio de los hábitos alimentarios de aves y mamíferos ictiófagos para avanzar en el conocimiento del estatus de las poblaciones de peces y sobre la salud del ecosistema (Nettleship et al. 1984, Apollonio 1994, Green et al. 1998, Casaux y Barrera-Oro 2006, Einoder 2009). Cada predador explota los recursos alimentarios de manera diferente. Estas "estrategias" se relacionan con la disponibilidad de presas, y con la edad, experiencia y capacidades fisiológicas de los individuos (Lea et al. 2002). Las relaciones tróficas entre predadores y presas determinan fuertemente la estructura y la evolución del ecosistema que conforman. Es por ello que en la actualidad se siguen desarrollando modelos matemáticos y conceptuales que ilustran, estiman y ayudan a predecir los cambios que sufren los parámetros comunitarios tales como la estabilidad, la complejidad, la conectividad y los puntos de equilibrio (e.g. Fussmann y Heber 2002, Melián y Bascompte 2002). Dentro de las interacciones más importantes que rigen la dinámica de los ecosistemas, los procesos de competencia y cooperación son los principales factores que determinan el establecimiento y la intensidad entre las relaciones interespecíficas (Forero et al. 2004). Es por ello que poder medir estas interacciones es fundamental para poder estudiar las respuestas y la dinámica del ecosistema. Una forma de estudiar cuantitativamente dichos efectos es a través de la estimación de variables de interacción tales como el solapamiento de la dieta. Así entonces, los efectos del solapamiento entre predadores tope serán más fuertes en tanto compartan los mismos recursos, las mismas áreas de alimentación y los mismos períodos de forrajeo. Sumado a ello, es importante comprender en detalle el comportamiento de forrajeo, cuál o cuáles estrategias despliega cada especie y cómo las modifica en relación a las diferentes variables relacionadas. Los hábitos de forrajeo de un predador están mayormente condicionados por su morfología y su fisiología (Illius y Gordon 1993, Wainwright 1994). Aun así, dentro de estos límites, 
los animales suelen mostrar amplias variaciones en su comportamiento debido principalmente a la distribución y la disponibilidad de sus presas, cambios en las demandas energéticas de acuerdo a la etapa reproductiva o debido a fluctuaciones ambientales bien definidas (Cluton-Brock et al. 1982). Estas variaciones en la conducta se orientan en relación a la maximización de la eficiencia energética, la que se entiende como el balance neto entre energía consumida y energía demandada para la búsqueda y manipulación del alimento. En particular, las aves y mamíferos marinos (en su mayoría buceadores) deben gastar energía extra en relación a otros animales terrestres para lograr la localización de sus presas (Boyd et al. 1994). Uno de los supuestos de la teoría del aprovisionamiento óptimo (Mac Arthur y Pianka 1966) explica que el comportamiento de búsqueda del alimento será aquel favorecido por la Selección Natural en el pasado y que actualmente incremente en mayor grado la eficacia energética del predador (Begon et al. 1999). Así entonces, de acuerdo a esta teoría y a la clasificación ecológica del aprovechamiento del alimento, los predadores especialistas perseguirán sólo presas provechosas, en algunos casos destinando mucho tiempo y por ende invirtiendo mucha energía en su búsqueda, en tanto que un animal generalista dedicará un tiempo relativamente breve a la búsqueda pero capturará presas con variados retornos energéticos.

La información disponible sobre los hábitos de forrajeo de los predadores tope que habitan las Islas Orcadas del Sur (IOS) es poca y está fraccionada en el tiempo. Es por ello que la base bibliográfica con la que se cuenta será interpretada en la medida que exprese tendencias en el comportamiento y explique características fundamentales en la descripción de las relaciones espaciotemporales entre los predadores y entre ellos y sus presas. En los capítulos II y III se analizaron tres temas que son fundamentales para la interpretación de los resultados de este capítulo: 1) la composición de la dieta de cada predador, 2) la disponibilidad de las presas dentro de la zona que habitan y 3) la selectividad o preferencia de presas por parte de los predadores. A partir de esta información, y de reportes sobre la actividad y las estrategias de forrajeo de los predadores tope de las IOS, en este capítulo se analiza el comportamiento alimentario de los predadores.

\section{IV.2. Materiales y métodos}

\section{IV.2.1. Descripción y categorización de los hábitos de forrajeo}

A partir de la información disponible, los predadores fueron clasificados según:

a) Localización del área de forrajeo: Los predadores que mantienen sus actividades de alimentación en tierra, como por ej. los "Carroñeros" y los "Generalistas" (ver Capítulo II), fueron clasificados como "Terrestres". Los predadores cuya alimentación se desarrolló en el ámbito marino fueron clasificados como Marinos y a su vez subdivididos según la cercanía a la línea de costa en Litorales y de Aguas Abiertas (según la clasificación de Kock (1992), ver capítulo I). Los predadores marinos a su vez fueron divididos en consumidores bentónicos o pelágicos según la porción de la columna de agua que exploten. 
b) Tácticas de captura de presas: La descripción de las estrategias de forrajeo se realizó de acuerdo a la clasificación hecha por Ainley et al. (1984) para aves marinas:

1) Captura de presas superficiales en vuelo (Dipping): Captura de presas en la superficie del mar, o justo por debajo de ella, mientras se mantienen en vuelo y sólo contactan el agua con el pico.

2) Captura de presas superficiales en contacto con el mar (Contact Dipping): Estrategia similar a 1) salvo que el contacto con el agua se establece con el pico, patas (ayudan a mantener al individuo en la superficie del agua) y zona ventral del predador.

3) Recolección superficial (Surface Seizing): Captura activa de presas vivas en la superficie, o justo por debajo de ella, mientras el predador está posado en la superficie. El predador puede llegar a sumergir parte del cuerpo para capturar la presa.

4) Zambullida y persecución (Pursuit plunging): Captura de presas sub-superficiales mediante zambullida y persecución a poca profundidad.

5) Nado y buceo (Diving): reposo en superficie y captura de las presas mediante buceos con propulsión de alas o patas. Los buceos son clasificados en Superficiales (profundidad menor a 100 metros) y Profundos (profundidad mayor a 100 metros).

6) Carroñeo (Scavenging): Ingestión de restos de presas muertas que se encuentran disponibles en la superficie del mar o en bandejones de hielo. A pesar de la descripción de Ainley et al. (1984), en este trabajo también en esta categoría a aquellos predadores que carroñean sobre tierra.

7) Cleptoparasitismo (Kleptoparasitism): Robo de la presa a otra ave.

8) Caza (Hunting): Los predadores capturan y matan presas vivas en tierra. Dentro de esta categoría se incluyen también a aquellos predadores que consumen huevos de aves.

c) Según período de actividad: Los predadores cuya actividad de forrajeo fue más intensa durante las horas nocturnas y del atardecer fueron clasificados como "Nocturnos", en tanto que aquéllos cuyo pico de actividad fue observado durante las horas del luz fueron clasificados como "Diurnos".

\section{IV.2.1. Análisis del solapamiento de la dieta entre predadores y dentro de la} comunidad de las IOS

El solapamiento de presas entre pares de especies de predadores se estimó de acuerdo al índice de similitud de dietas "S" (Linton et al. 1981) según la ecuación:

$S=100\left(1-1 / 2 \sum\left|P_{x i}-P_{y i}\right|\right)$

(Ecuación 1)

donde $P_{x i}$ y $P_{y i}$ corresponden a las proporciones en la dieta de los predadores $x$ e $y$ de la presa $i$. Los valores de $\mathbf{S}$ varían entre 0 , en donde las presas no son compartidas por ambos predadores, y 100 , en el caso en que las dietas de los predadores son idénticas. El índice $\mathbf{S}$ se calculó en base a la contribución en masa porcentual $(\mathrm{M} \%)$ de las presas. Con el objeto que los valores sean 
comparables entre si, las biomasas $(\mathrm{M} \%)$ de las diferentes especies de peces presentes en la dieta de cada predador fueron relativizadas de acuerdo a la proporción de peces registrada en la composición general de la dieta. Es importante tener en cuenta que en este análisis los resultados de $S$ para los que se incluyen datos de predadores que consumen bajas cantidades de peces (tales como el pingüino de Adelia y el de Barbijo), pueden estar sobrestimados.

Para estudiar cuán estrechos son las relaciones tróficas entre los predadores de las IOS se calculó la re-ocurrencia de presas dentro de la comunidad, la cual fue estimada mediante el índice de Tyler (1972) según la siguiente ecuación:

$\% R=R / R_{\text {máx }} \cdot 100$

(Ecuación 2)

donde $\boldsymbol{R}$ representa la suma del número de re-ocurrencias dentro de la comunidad y $\boldsymbol{R}_{\text {máx }}$ es la cantidad máxima de re-ocurrencias posibles de acuerdo al número de presas y predadores que estén presentes en dicha comunidad, y se calcula como la suma de la cantidad de presas menos uno, dividido la cantidad de predadores presentes. Un valor alto de re-ocurrencia (> 50\%) indica que la comunidad presenta redes alimentarias muy dependientes entre sí, que comparten un gran numero de presas, y que la variación en la abundancia de algunas de ellas puede afectar a un gran número de predadores. Esto puede deberse a una oferta de alimento poco diversas, a la predominancia de una presa de alto retorno energético, y/o a la limitación de los predadores para diversificar las estrategias de alimentación. Por el contrario, un valor medio o bajo de re-ocurrencia de presas (< $50 \%$ ) indica que la trama trófica está menos inter-relacionada, ya sea porque la disponibilidad y abundancia de alimento es amplia o porque los predadores presentan características que les permiten diversificar sus estrategias de alimentación y sus dietas.

Con el objetivo de integrar la información aquí presentada sobre las relaciones tróficas dentro de la comunidad de predadores de las IOS, y teniendo en cuenta la información obtenida en este análisis, se procedió a diseñar un diagrama de interacciones: espacio-temporales que incluyan a los principales grupos de predadores de acuerdo a sus hábitos alimentarios (ver capítulo II), a las características espacio-temporales de las estrategias de alimentación, y al grado de solapamiento de la dieta entre especies.

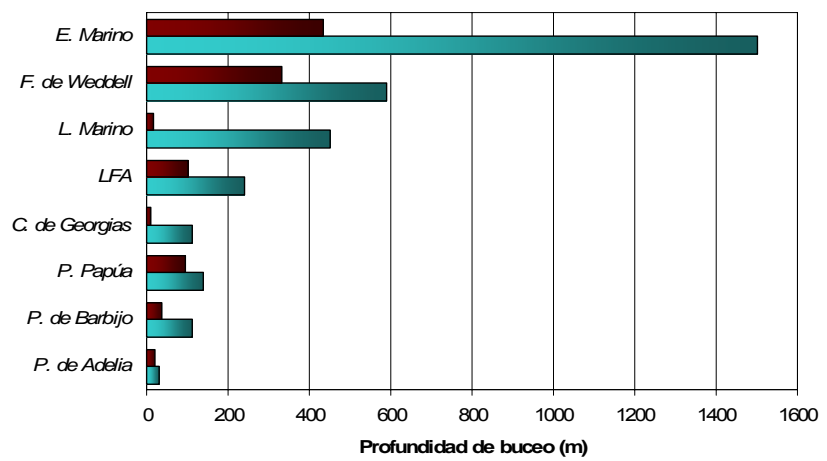

Figura IV.1: Profundidades de buceo (las barras celestes indican profundidad máxima y las rojas profundidad media) reportadas para predadores buceadores. Los datos del Pingüino de Adelia (Pingüino de Adelia) fueron tomados de Takahashi et al. (2004), los del Pingüino de Barbijo (Pingüino de Barbijo) de Mori (1997), los del Pingüino Papua (Pingüino Papúa) de Croxall et al. (1988), los del Cormorán de Georgias (Cormorán de Georgias) (Croxall et al. 1991), los del Lobo Fino Antártico (LOBO FINO ANTÁRTICO) de Boyd et al. (1994) y Staniland y Robinson (2008), los de la Foca de Weddell (Foca de Weddell) de Kooyman (1981) y Le Beouf et al. (1986), los del Leopardo Marino (Leopardo Marino) de Khun et al. (2006) y los del Elefante Marino del Sur (Elefante Marino) de Bailleul et al. (2007) y Slip et al. (1994). 
Tabla IV.1.: Detalle del área/s de forrajeo utilizada por cada predador tope de las IOS, principal estrategia desarrollada y la fuente de dicha información.

\begin{tabular}{|c|c|c|c|}
\hline Especie & Area & Estrategia & Bibliográfia \\
\hline \multicolumn{4}{|l|}{ Sphenicidae } \\
\hline Pingüino de Adelia & Marino - Pelágico - Litoral & Nado y buceo & $\begin{array}{l}\text { Volkman et al. (1980), Lishman (1985), Croxall y Lishman (1987), Clarke et al. (1995), Ropert-Coudert et al. (2001) } \\
\text { Lynnes et al. (2002), Romobolá et al. (2002), Takahashi et al. (2004) }\end{array}$ \\
\hline Pingüino de Barbijo & Marino - Pelágico - Litoral & Nado y buceo & $\begin{array}{l}\text { Volkman et al. (1980), Lishman (1985), Croxall y Lishman (1987), Ichii et al. (1997), Mori (1997), Lynnes et al. (2002) } \\
\text { Rombolá et al. (2002) }\end{array}$ \\
\hline Pingüino Papúa & Marino - Pelágico/Bentónico - Litoral & Nado y buceo & Conroy y Twelves (1972), Adams y Wilson (1987), Tanton et al. (2004) \\
\hline \multicolumn{4}{|l|}{ Procellaridae } \\
\hline Petrel Damero & abiertas & Captura en vuelo/ Carroñeo *1 & $\begin{array}{l}\text { Bierman y Voous (1950), Beck (1969), Jouventin et al. (1982), Harper et al. (1985), } \\
\text { Warham (1990), Creet et al. (1994), Ridoux (1994), Soave et al. (1996), Casaux et al. (1997), Coria et al. (1997), R. } \\
\text { Casaux (comunicación personal). }\end{array}$ \\
\hline $\begin{array}{l}\text { Petrel de las Nieves } \\
\text { Petrel Gigante Común }\end{array}$ & $\begin{array}{l}\text { Marino - Pelágico - Zona de pack de } \\
\text { hielo } \\
\text { Terrestre/Marino - Pelágico - Aguas }\end{array}$ & Captura en vuelo *2 & Shuntov's (1972), Watson (1975), Zink (1981), Griffiths (1983), Ainley et al. (1984), Steele (2005) \\
\hline & abiertas & Carroñeo/ Recolector sup./ Caza & Conroy (1972), Johnstone (1977), Hunter (1983), Prince y Morgan (1987), Gonzáles-Solís et al. (2000a y 2000b) \\
\hline \multicolumn{4}{|l|}{ Hydrobatidae } \\
\hline Petrel de Wilson & Marino - Pelágico - Aguas abiertas & Captura en vuelo/ Carroñeo *1 & $\begin{array}{l}\text { Murphy (1936), Falla (1937), Roberts (1940), Beck y Brown (1972), Croxall y Prince (1980), Ainley et al. (1984), , } \\
\text { Pennycuick et al. (1984), Prince y Morgan (1987), Büber et al. (2004), Reiss et al. (2008). Galbach et al. (2009) }\end{array}$ \\
\hline \multicolumn{4}{|l|}{ Phalacrocoracidae } \\
\hline Cormorán de Georgias & Marino - Bentónico - Litoral & Nado y buceo & $\begin{array}{l}\text { Ashmole (1971), Conroy y Twelves (1972), Schrieber y Clapp (1987), Croxall et al. (1991), Kato et al. (1992), } \\
\text { Williams et al. (1991), Wanless et al. (1992, 1999), Wanless y Harris (1993), Casaux et al. (1994, 2001, 2004), } \\
\text { Casaux (1998), Casaux y Barrera-Oro (2002), Casaux y Coria (2004) }\end{array}$ \\
\hline \multicolumn{4}{|r|}{ 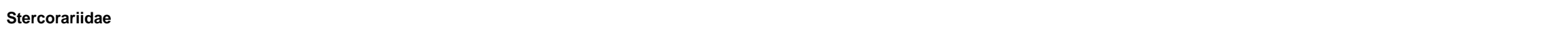 } \\
\hline Escúa Marrón & Terrestre/ Marino - Pelágico - Litoral & $\begin{array}{l}\text { Caza/ Carroñeo/ Captura en vuelo } \\
\text { con contacto }\end{array}$ & $\begin{array}{l}\text { Burton (1968), Davies (1978), Trivelpiece et al. (1980), Maxson y Berstein (1982), Furness (1987), Montalti et al. } \\
\text { (1996), Reinhardt et al. (1998), Hahn y Peter (2003), Hahn et al. (2008) }\end{array}$ \\
\hline \multicolumn{4}{|l|}{ Sternidae } \\
\hline Gaviotín Antártico & Marino - Pelágico - Litoral & Captura en vuelo con contacto & Ainley et al. (1984), Jablonsky (1995), Gochfeld y Burger (1996), Casaux et al. (2008) \\
\hline
\end{tabular}


Tabla IV.1: Continuación.

\begin{tabular}{|c|c|c|c|}
\hline \multicolumn{4}{|l|}{ Phocidae } \\
\hline Foca Cangrejera & Marino - Aguas abiertas & Nado y buceo & $\begin{array}{l}\text { Erickson et al. (1971), Condy (1976), Gilbert y Erickson (1977), Croxall et al. (1985), Costa et al. (1989), } \\
\text { Fraser et al. (1989), Erickson y Hanson (1990), Bengston y Steward (1992), Boyd et al. (1994), Nordoy et al. (1995), } \\
\text { Gales et al. (2004), Southwell et al. (2005), Burns et al. (2004, 2008) }\end{array}$ \\
\hline Foca de Weddell & Marino - Aguas abiertas - litoral & Nado y buceo & $\begin{array}{l}\text { Kooyman (1968), Kaufman et al. (1975), Siniff et al. (1977), Bartsch et al. (1992), Schreer y Testa (1995, 1996), } \\
\text { Plötz et al. (2001), R. Casaux (comunicación personal) }\end{array}$ \\
\hline $\begin{array}{l}\text { Leopardo Marino } \\
\text { Elefante Marino del Sur }\end{array}$ & $\begin{array}{l}\text { Marino - Aguas abiertas } \\
\text { Marino - Aguas abiertas }\end{array}$ & $\begin{array}{l}\text { Nado y buceo } \\
\text { Nado y buceo }\end{array}$ & $\begin{array}{l}\text { Khun et al. (2006), Nordoy y Blix (2009) } \\
\text { Callahan (1971), Boyd y Arnborn (1991), Hindell et al. (1991), McConell et al. (1992), Burton (1993), Slip y Burton } \\
\text { (1994), }\end{array}$ \\
\hline \multicolumn{4}{|l|}{ Otariidae } \\
\hline Lobo Fino Antártico & Marino - Aguas abiertas y Litoral & Nado y buceo & $\begin{array}{l}\text { Boyd y Croxall (1992), Daneri y Coria (1992, 1993), Boyd et al. (1994), Goldsworthy et al. (1997), } \\
\text { McCafferty et al. (1998), Bonadonna et al. (2000), Costa et al. (2000), Goebel et al. (2000), Guinet et al. (2001), } \\
\text { Lea et al. (2002), Casaux et al. (2003), Staniland y Robinson (2008) }\end{array}$ \\
\hline
\end{tabular}




\section{IV.3. Resultados}

\section{IV.3.1. Hábitos de forrajeo de los predadores tope de las IOS}

\section{IV.3.1.1. Aves}

\section{Spheniscidae}

Tanto el Pingüino de Adelia como el de Barbijo predan principalmente sobre krill, a diferencia del Pingüino Papúa que, si bien se alimenta mayormente de krill, incorpora a su dieta una importante cantidad de peces y ocasionalmente de cefalópodos (ver capítulo II). En base a estas diferencias es de esperar que el Pingüino Papúa desarrolle diferentes estrategias alimentarias con respecto a las otras dos especies.

Las estrategias de forrajeo y las profundidades y tiempos de buceo de los pingüinos han sido ampliamente estudiadas en numerosas localidades de Antártida (Sladen 1955, Lishman 1985, Trathan et al. 1996, Ropert-Coudert et al. 2001, Lynnes et al. 2002, Rombolá et al. 2003, Takahashi et al. 2004, entre otros). Los primeros estudios sobre actividad de forrajeo de pingüinos antárticos, en particular sobre las especies $P$. papua, Eudyptes chrysolophus y Aptenodytes forstefi, reportaron tiempos de buceo de hasta 18 minutos y profundidades cercanas a los 265 metros de profundidad (Scholander 1940, Kooyman et al. 1971 Conroy y Twelves 1972). Posteriormente, Jablonski (1985), Trivelpiece et al. (1987) y Volkman et al. (1980) reportaron diferencias sustanciales en las estrategias de alimentación de estas 3 especies de pingüinos e hicieron referencia a que el Pingüino Papúa se alimentaba más frecuentemente en áreas costeras, en tanto que las otras dos especies lo hacían con mayor asiduidad hacia aguas abiertas. Como se mencionó anteriormente, la dieta del Pingüino Papúa es diferente a la de las otras dos especies de pygoscélidos presentes en las IOS, lo que se debe fundamentalmente al frecuente consumo de peces y calamares, por lo cual es de esperar que se alimenten en zonas más cercanas a la costa donde abundan los peces bento-demersales. Es por ello que diversos estudios reflejan una diferencia en las estrategias de forrajeo entre el Pingüino Papúa (buceos más cercanos a la costa y más profundos) y las otras dos especies (Adams y Wilson 1987, Wilson et al. 1998). Para Trivelpiece et al. (1987) esta diferencia en el patrón de forrajeo entre el Pingüino Papúa y las otras dos especies, refleja una mayor capacidad de buceo del Pingüino Papúa (con máximos de 136 m., Croxall et al. 1998), en tanto que los buceos del Pingüino de Barbijo en pocas ocasiones exceden los $70 \mathrm{~m}$., (Lishman y Croxall 1983). Otra diferencia entre el Pingüino Papúa y las otras dos especies es que si bien, diferentes trabajos (Salden 1955, Lishman 1985, Croxall et al. 1988) indican que la actividad de forrajeo de los pingüinos es mayor durante las horas del atardecer y la noche, el Pingüino Papúa suele presentar picos de actividad durante las horas del día (Williams et al. 1992). Sumado a ello, tanto el Pingüino de Adelia como el de Barbijo si bien se alimentan en la zona litoral suelen hacer viajes de forrajeo extensos, varias decenas de millas hacia aguas abiertas, en tanto que el Pingüino Papúa se mantiene en la zona de aguas costeras (Croxall et al. 1988).

Los pingüinos de Adelia y de Barbijo presentan marcadas similitudes ecológicas, las que están fundamentalmente sustentadas por similitudes en la composición de la dieta y en los períodos y ciclos de reproducción (Lynnes et al. 2002). Takahashi et al. (2004) observaron que cuando viven en simpatría ambas especies sincronizan las salidas de alimentación y sugirieron que este fenómeno 
ayudaría a aumentar la eficiencia de forrajeo de ambas especies a través de la disminución del esfuerzo de búsqueda individual y del incremento de la tasa de captura de las presas. Si bien en áreas de simpatría la dieta de las dos especies suele ser similar (Trivelpiece et al. 1987), Sladen (1955), Volkman et al. (1980) y Lishman (1985) indicaron que durante la época reproductiva el Pingüino de Barbijo tiende a consumir más peces como una estrategia para disminuir la competencia interespecífica entre ambas especies. En un estudio posterior, Lynnes et al. (2002) estudiaron el comportamiento alimentario del Pingüino de Barbijo y del Pingüino de Adelia en la I. Signy (IOS) durante las temporadas reproductivas de 2000/01 y 2001/02 mediante la implantación de telémetros satelitales en 19 pingüinos de Adelia y en 24 pingüinos de Barbijo. Los resultados obtenidos indicaron que, concurrentemente con una baja disponibilidad de krill (Moline et al. 2004), durante la temporada de 2000/01 hubo una segregación espacial significativa entre ambas especies, en tanto que en la temporada siguiente, un año con mayor disponibilidad de presas (Lynnes et al. 2002), dicha segregación no fue observada. Además, estos autores observaron que el Pingüino de Adelia cambió la estrategia de uso del hábitat en ambas temporadas, hecho que no fue observado en el Pingüino de Barbijo. En relación a los viajes de forrajeo, Lynnes et al. (2002) también observaron que durante la temporada 2000/01 el Pingüino de Adelia forrajeó significativamente más lejos de la colonia (distancia media $100 \mathrm{~km}$.) que el Pingüino de Barbijo (58 km.). La conclusión que se desprende de este trabajo es que durante los años de baja disponibilidad de presas la segregación de áreas de forrajeo entre ambas especies es importante, lo que en años críticos no alcanza a evitar la disminución en el éxito reproductivo, especialmente en el Pingüino de Adelia. Estos resultados guardan relación con lo reportado por Rombolá et al. (2002), quienes indicaron que a medida que avanza el ciclo de cría del Pingüino de Barbijo, el Pingüino de Adelia suele alimentarse en zonas más alejadas de la costa. Dichos autores argumentan que esto podría deberse a una disminución local de presas. Sin embargo, este argumento no explica totalmente dicho comportamiento dado que el Pingüino de Barbijo en esos períodos permanecía forrajeando en las zonas costeras usualmente utilizadas por el Pingüino de Adelia. Dado que el incremento de las distancias de los viajes de alimentación del Pingüino de Adelia coincide con el inicio del período de cría del Pingüino de Barbijo, tal comportamiento estaría reflejando algún mecanismo a través del cual el Pingüino de Adelia sería excluido de zonas costeras por Pingüino de Barbijo. A su vez, se ha observado que la permanencia del pack de hielo en inmediaciones de las colonias a lo largo de la temporada de cría afecta negativamente el éxito reproductivo y el número de parejas reproductoras del Pingüino de Barbijo, hecho que no ocurre con el Pingüino de Adelia (Lishman 1985, Trievelpiece et al. 1987, Trathan et al. 1996, Rombolá et al. 2003). Dado que los años de gran extensión de hielo marino suelen resultar en buenos niveles de reclutamiento de krill, y teniendo en cuenta lo expresado previamente, dicho factor operaría de modo diferente sobre ambas especies (e.g. años de gran extensión de hielo favorecerían al Pingüino de Adelia debido a la menor competencia interespecífica, y años de poco hielo lo perjudicarían debido a que aumenta la competencia y el esfuerzo de forrajeo), por lo que la extensión del hielo marino jugaría un rol fundamental en la dinámica de ambas especies cuando reproducen en simpatría. En relación al pack de hielo, (Takahashi et al 2004) indicaron que durante el período de incubación los pingüinos de Barbijo y de Adelia utilizan los bloques de hielo como medio de 
transporte en la búsqueda de enjambres de krill, hecho que también fue observado por Ainley et al. (1986) lo que también los lleva a realizar viajes de forrajeo más extensos que

Con respecto a las diferencias sexuales, Cappell et al. (1993) observaron que machos y hembras del Pingüino de Adelia contribuyen de un modo diferente a la cría de los pichones. Sumado a ello, Clarke et al. (1995) encontraron diferencias significativas entre ambos sexos en las estrategias de forrajeo. Las hembras estudiadas realizaron salidas de alimentación más largas (entre 26 y 34 horas) y a mayor distancia (entre 40 y $120 \mathrm{~km}$.) y retornaron al nido con mayor cantidad de krill. Por el contrario, los machos realizaron viajes más cortos (entre 19 y 26 hs.) y más próximos a la zona costera (especialmente durante el período de guardería) y consumieron mayor cantidad de peces que las hembras. Estos autores concluyen que durante el período de cría temprano las hembras alimentan más activamente al pichón que los machos, lo que permitiría que los machos puedan recuperarse del mayor esfuerzo energético relacionado con el cortejo y la incubación de los huevos. Llegada la etapa de guardería los machos ya recuperados comienzan a desarrollar viajes más frecuentes y más extensos en tiempo y distancia.

\section{Procellariidae}

En términos generales, los miembros de esta familia viven la mayor parte de su vida en zonas de aguas abiertas dado que tienen adaptaciones morfológicas para volar extensas distancias y cubrir amplias áreas de alimentación. Estas aves sólo habitan zonas costeras durante la temporada reproductiva (Gladbach et al. 2007) y se alimentan fundamentalmente de presas pelágicas que por lo general son capturadas durante la noche (Prince y Morgan 1987). Las técnicas de forrajeo observadas en este grupo se corresponden con las estrategias 1, 2 y 3 definidas en la sección "Materiales y métodos", las que sólo les permiten explotar la superficie del agua y por ende son especies altamente dependientes de los recursos allí disponibles (Prince y Morgan 1987).

\section{Petrel Damero Daption capense}

Los estudios sobre el comportamiento alimentario del Petrel Damero lo describen como un predador de aguas abiertas y de presas pelágicas (Bierman y Voous 1950, Beck 1969, Creet et al. 1994, Soave et al. 1996 y Coria et al. 1997). Dadas estas características, los estudios sobre la actividad y las estrategias de forrajeo han sido focalizados en la determinación de las extensiones y duraciones de las salidas de alimentación. Beck (1969) identificó algunos patrones de comportamiento a partir de la observación de las dietas y rutas de forrajeo de 85 ejemplares adultos durante los meses de Enero y Febrero de 1966 en la I. Signy. Según estos resultados, los petreles consumen sus presas en zonas de aguas abiertas a distancias de hasta $640 \mathrm{~km}$. de la colonia. Trabajos previos desarrollados en otras localidades de Antártida reportaron distancias de forrajeo de entre 355 y $1860 \mathrm{~km}$. (Bierman y Voous 1950,). A partir del estudio desarrollado durante el verano de 1990/91 en la Isla 25 de Mayo, Islas Shetland del Sur (ISS), Creet et al. (1994) reportaron que el Petrel Damero presenta una estrategia de captura de presas en superficie y que como muchas otras aves presentes en la zona, es un predador oportunista y generalista. Numerosos trabajos analizaron la composición de la dieta de este petrel y la mayoría de ellos destacan que los peces fueron una presa frecuente a lo largo de todo el año (Ainley et al. 1984 y 1992, Ridoux 1994, Casaux et al. 1997 entre otros). Los trabajos 
desarrollados en las IOS indican que el krill y peces pelágicos (principalmente myctóphidos) son la presa principal de estas aves (Soave et al. 1996, Casaux et al. 1997, Coria et al. 1997). Beck (1969) observó que el consumo de carroña suele ser un recurso que complementa la dieta en períodos de escasa disponibilidad de presas pelágicas. En este sentido, este autor también indica que en ocasiones el consumo de restos de pingüinos recién matados por leopardos Marinos en el agua (proceso de facilitación), como así también de restos de peces muertos en la costa, suele ser muy importante, en tanto que el consumo de aves muertas sobre la tierra no representa un foco de atracción para esta especie. Jouventin et al. (1982) y Ridoux (1994) indicaron que durante la temporada reproductiva el Petrel Damero suele forrajear en zonas litorales, incluyendo la franja que comprende la zona intermareal. En cuanto a la estrategia de alimentación, Harper et al. (1985), Warham (1990), y Ridoux et al. (1994), indican que el Petrel Damero utiliza las técnicas de "Captura en vuelo" y de "Captura en vuelo con contacto" y que también suelen alimentarse por filtrado del agua. De acuerdo a lo observado en un estudio realizado en Isla Crozet, Ridoux (1994) indicó que la presencia en la dieta de presas de tamaño muy pequeño (e.g. nudibranquios e hidrozoos) sugiere que el método de filtrado es comúnmente utilizado por esta especie y coincide con Beck (1969) en que esta ave frecuentemente consume carroña.

\section{Petrel de las Nieves Pagodroma nivea}

El Petrel de las Nieves se distingue de los demás procelláridos por su marcada preferencia por los peces (Mounguin 1968, Ridoux y Offredo 1989, Ferretti et al. 2001, van Franeker 2001). Sin embargo, Griffiths (1983) observó que en el Mar de Ross este petrel suele carroñear sobre focas de Ross, Ommatophoca rossii, muertas en la costa. En coincidencia con Griffiths (1983), a partir de un estudio de dieta basado en el análisis de isótopos estables desarrollado en el sector Índico del continente antártico se observó que este petrel consumió peces y mamíferos marinos (Steele 2005). Griffiths (1983) también indica que el Petrel de las Nieves es un predador oportunista por lo que la composición de su dieta podría ser más diversa que lo indicado previamente.

En comparación con otros procelláridos, el Petrel de las Nieves posee una baja relación de carga alar, lo que lo hace menos adaptado para el forrajeo pelágico pero le proporciona mayor maniobrabilidad para el forrajeo entre bloques de hielo y zonas reducidas de aguas libres (Watson 1975, Zink 1981, Griffiths 1983, Ainley et al. 1984). El vuelo es poco especializado y con aleteos más frecuentes que en el resto de las especies que conforman la familia (Griffiths 1983) lo que resulta en un alto costo energético. Estas características limitan la extensión de los viajes de alimentación en comparación con otras especies de predadores pelágicos (Griffiths 1983), por lo que es de esperar que se alimenten en áreas con disponibilidad de alimento predecible y sobre presas con alto retorno energético. Según Ainley et al. (1984) la "Captura en vuelo con contacto" es una de las estrategias de forrajeo que el Petrel de las Nieves utiliza comúnmente (92\% de los ejemplares observados). Si bien las condiciones meteorológicas (intensidad y dirección del viento) y la temperatura y profundidad del agua determinan la disponibilidad de su alimento, Griffiths (1983) considera que éstas variables tienen poca influencia en la determinación de la distribución de las áreas de alimentación del Petrel de las Nieves, y que estas aves serían altamente dependientes de las zonas con cobertura de hielo marino (ver también Shuntov's 1972). Esta característica los diferencia del resto de los petreles, los 
que desarrollan estrategias de alimentación de tipo pelágicas en aguas abiertas generalmente ausentes de hielo marino.

\section{Petrel Gigante Común Macronectes giganteus}

El "carroñeo" sobre costas es el hábito de forrajeo predominante en el Petrel Gigante Común (Conroy 1972, Johnstone 1977, Hunter 1983). Sin embargo, este petrel puede desplegar una variada serie de estrategias de alimentación que incluyen el consumo de presas vivas (Hunter 1985). Entre sus presas principales se encuentran los pingüinos (obtenidos a través de la caza de individuos vivos o del carroñeo), el krill y peces. En relación a los cambios estacionales en la composición de la dieta, Hunter (1983) afirma que dado que en el invierno la disponibilidad de pingüinos disminuye, durante esta estación el krill y los peces serían las presas más importantes.

Con respecto a las capacidades de forrajeo, los petreles gigantes poseen una morfología que les permite caminar sobre el terreno cómodamente y así explotar mejor los recursos terrestres, especialmente la carroña. En el mar, las estrategias más observadas son el "Recolección superficial" y la "Captura en vuelo". En algunas ocasiones también se ha observado la captura de presas en superficie mediante nado y persecución (Prince y Morgan 1987) y el "cleptoparasitismo" sobre cormoranes (Casaux 1998). Un estudio sobre la actividad de forrajeo de los petreles Gigante del Norte y del Sur realizado en las IGS entre los meses de Octubre y Diciembre de 1998, divide los viajes de forrajeo en costeros y pelágicos (Gonzáles-Solís et al. 2000a). En resumen, los viajes costeros presentaron velocidades de vuelo menores que los pelágicos, cubrieron áreas más pequeñas y estuvieron asociados a tiempos de descanso sobre el mar más breves, particularmente durante la noche. Por el contrario, aquellos petreles que desarrollaron viajes pelágicos invirtieron más tiempo en la actividad de búsqueda.

En relación a las diferencias sexuales en la composición de la dieta, Hunter (1983) observó que en las IGS los machos consumían más carroña de pingüino y foca que las hembras, las que consumieron mayor cantidad de presas marinas vivas. Según este estudio, estas diferencias estarían relacionadas con el marcado dimorfismo sexual (el más marcado dentro de todos los géneros del orden Procellariformes), el que resulta en capacidades diferentes para acceder a presas de escaso tamaño o para defender recursos en tierra (Prince y Morgan 1987). En cuanto a las áreas de forrajeo utilizadas, Gonzáles-Solís et al. (2000a) observaron que las hembras suelen alimentarse con una alta proporción de calamares, peces y krill que son capturados a lo largo de viajes de forrajeo de tipo pelágico, en tanto que los machos suelen hacer viajes cortos en proximidades de las costas (Gonzáles-Solís et al. 2000b).

\section{Hydrobatidae}

\section{Petrel de Wilson Oceanites oceanicus}

Durante la etapa reproductiva el Petrel de Wilson consume principalmente krill, y cuando este recurso es limitado la dieta es suplementada con anfípodos (Quillfeldt 2002, ver capítulo II). Las áreas de forrajeo de esta especie se distribuyen en zonas de aguas abiertas sobre la plataforma continental siendo la zambullida en busca de alimentos sobre la superficie marina su principal estrategia de alimentación (Prince y Morgan 1987). Según un estudio realizado en el Mar de Ross (Ainley et al. 
1984), el Petrel de Wilson utilizó esta estrategia en el $97 \%$ de los casos observados. Estudios sobre estrategias de forrajeo basados en el análisis de isótopos estables y desarrollados en la Isla 25 de Mayo (ISS) durante las temporadas reproductivas 1995/96, 97/98, 99/00, 02/03, 03/04 у 04/05, evidenciaron que durante el periodo de puesta los adultos se alimentaron lejos de la costa en aguas abiertas y que durante el período de incubación lo hicieron en cercanías de la colonia sobre la plataforma (Galdbach et al. 2009). Esta estrategia puede estar relacionada con cambios en la abundancia y distribución del krill dado que el consumo de este crustáceo varía a lo largo de la etapa de cría y/o a que durante esa etapa, los requerimientos energéticos del pichón obligan a los padres a realizar viajes más cortos. En la mayoría de los casos las salidas de alimentación son nocturnas, lo que estaría determinado por los patrones de migración vertical del krill. Beck y Brown (1972) proponen que el carroñeo podría ser una estrategia alternativa de alimentación y Murphy (1936), Falla (1937) y Roberts (1940) reportan la observación de grupos de individuos alimentándose de carroña de pingüino. Este comportamiento, denominado por Hindle (1961) "local enhancement", está caracterizado por la asociación de un grupo de predadores consumiendo presas que fueron facilitadas de alguna manera por otros.

Con respecto a la extensión de las áreas de alimentación, Croxall y Prince (1980) y Pennycuick et al. (1984) reportan distancias de hasta 200 y $250 \mathrm{~km}$. de las colonias. A medida que los requerimientos del pichón aumentan, estas aves parecen aumentar la frecuencia de los viajes de forrajeo y por ende disminuyen la duración de los mismos (Archuby, comunicación personal).

En relación a diferencias sexuales en el esfuerzo de forrajeo y cría, Beck y Brown (1972) observaron que el macho invierte más tiempo en el cuidado del nido (por ejemplo, para mantener la entrada del mismo libre de nieve) y que la hembra alimenta más frecuentemente al pichón. Sin embargo, Galdbach et al. (2009) no corroboraron dicha observación por lo que ese patrón podría ocurrir sólo en respuesta a condiciones climáticas particulares. Sumado a ello, estos autores reportaron que durante las temporadas reproductivas 2002/03 y 2006/07, años que de acuerdo a Büber et al. (2004) y Reiss et al. (2008) presentaron escasa abundancia de krill, los machos visitaron con mayor frecuencia los nidos, en tanto que las hembras realizaron viajes de forrajeo más extensos. Por el contrario, en años en que la abundancia de krill fue alta las diferencias de forrajeo entre sexos fueron escasas y machos y hembras explotaron las mismas zonas y los mismos recursos.

\section{Phalacrocoracidae}

\section{Cormorán de Georgias Phalacrocorax georgianus}

Los cormoranes marinos son nadadores y buceadores que utilizan sus miembros inferiores para propulsarse (Ashmole 1971) y que se alimentan en zonas litorales durante viajes de forrajeo de corta duración (Schrieber y Clapp 1987). Tanto el cormorán Antártico (Phalacrocorax bransfieldensis) como el de Georgias realizan viajes de forrajeo diurnos (Williams et al. 1991, Casaux 1998, Wanless et al. 1999) y la duración promedio de cada viaje fluctúa entre 70 y 270 minutos de acuerdo a los requerimientos energéticos en el nido (Casaux 1998).

Con respecto a las profundidades de buceo del Cormorán de Georgias Conroy y Twelves (1972) reportaron la captura de un ejemplar en un trasmallo fondeado a 25 metros de profundidad en las IOS. Posteriormente, Croxall et al. (1991) describieron tres tipos de buceos para este cormorán 
en las IGS: buceos profundos, entre 35 y 116 metros de profundidad; buceos poco profundos, hasta 21 metros de profundidad; y buceos intermedios, entre 21 y 35 metros. Por otro lado, las observaciones de Casaux et al. $(1994,2001,2004)$ y Casaux y Coria $(2004)$ sobre el cormorán Antártico (especie estrechamente emparentada con el Cormorán de Georgias) en Isla Nelson (ISS) aportan una robusta base de datos, y reportan una profundidad máxima de buceo de 112,6 metros y tiempos máximos de inmersión de 5,35 minutos. Los valores medios de profundidad observados en el cormorán Antártico en las ISS fueron inferiores a los registrados para el Cormorán de Georgias en las IGS (Croxall et al. 1991, Kato et al. 1992, Wanless y Harris 1993). En relación a ello, Casaux y Barrera-Oro (2002) indicaron que estas diferencias no reflejan diferentes capacidades de buceo entre especies sino que responden a diferencias entre archipiélagos en la disponibilidad y distribución de las presas. En relación a esto, Casaux (1998) observó en el cormorán Antártico en las ISS que las secuencias de buceo (bouts) cortas se corresponden con buena disponibilidad de presas y que en años de escasa disponibilidad de recursos los bouts de buceo son más largos o son interrumpidos para explorar áreas más apropiadas, lo que a su vez se correlaciona positivamente con los éxitos reproductivos. Sin embargo, Kato et al. (1992) sugieren que durante la temporada 1989/90 en las IGS, donde el éxito reproductivo fue marcadamente menor que el observado en la temporada siguiente, los viajes de forrajeo fueron comparativamente más cortos, con un $30 \%$ de los buceos desarrollados en zonas poco profundas $(<21 \mathrm{~m}$.) y tiempos de búsqueda de menor duración. Wanless et al. (1992) analizaron las estrategias de forrajeo de 22 parejas de cormoranes de Georgias en las IGS y observaron que las características de los buceos dependían fuertemente de la zona en donde se alimentaban. Cuando los viajes de alimentación se desarrollaban en aguas litorales poco profundas (cercanas a los 5 metros de profundidad) los buceos fueron de corta duración ( $\leq 120$ segundos). Por el contrario, cuando los viajes de forrajeo se realizaron en aguas más profundas (entre 80 y $90 \mathrm{~m}$.) los buceos fueron más prolongados (> 120 segundos).

En relación a las tasas de captura, Casaux (1998 y 2004) y Casaux et al. (2001) indicaron que la cantidad y biomasa de presas capturadas por salida de alimentación y el número diario de salidas de alimentación aumentan con el crecimiento de los pichones, en tanto que la duración de las salidas disminuyó. Esto evidencia que estos cormoranes presentan mecanismos buffer, los que les permiten amortiguar cambios en la disponibilidad de presas o en los requerimientos energéticos de los pichones.

Casaux et al. (2001) analizaron simultáneamente las diferencias sexuales en las profundidades máximas de buceo y en la composición de la dieta del Cormorán Antártico en las ISS. Estos autores observaron que los buceos desarrollados por las hembras fueron significativamente más profundos (máximo 112,6 m.) que los realizados por machos, los que aportaron al nido una cantidad significativamente mayor de alimento, el que a su vez estuvo constituido por presas de mayor tamaño que las capturadas por las hembras. Estas observaciones contradicen las especulaciones hechas por Wanless et al. (1992) y Kato et al. (1996) para el Cormorán de Georgias en las IGS, acerca de que las hembras bucean más profundo dado que aportan mayor cantidad de alimento al nido. Según Casaux y Barrera-Oro (2006) los viajes de forrajeo realizados por los machos a áreas de poca profundidad están relacionados con que estos invierten mayor esfuerzo en el aprovisionamiento de alimento para los pichones. Dado que estas aves pueden agotar el stock de 
peces alrededor de la colonia (Leopold et al. 1998, Casaux y Barrera-Oro 2002), Casaux et al. (2001) sugieren que tales diferencias sexuales en las estrategias de cría y alimentación parecen tender a disminuir la competencia intra-específica, lo que a su vez contribuiría a preservar los stocks de peces y a optimizar el aporte de energía de los machos al nido.

\section{Stercorariidae}

\section{Escúa Marrón Catharacta lonnbergi}

Los recursos alimentarios de los escúas incluyen la mayoría de las aves y mamíferos que se reproducen dentro de la zona en donde habitan (Osborne 1988). Como fue descripto en el capítulo II, los pichones y huevos de pingüino representan un ítem alimentario importantísimo para esta especie, por lo que las áreas de nidificación de predadores y presas suelen estar asociadas (Emslie et al.1995). Una vez finalizada la temporada reproductiva, los escúas incrementan el consumo de recursos pelágicos (principalmente crustáceos marinos), aunque el carroñeo sigue siendo una estrategia ocasional (Burton 1968). Dado el amplio espectro alimentario de los escúas, es fácil deducir que las estrategias alimentarias también son muy variadas. En general, son considerados predadores muy activos que mantienen territorios de alimentación bien delimitados (Trivelpiece et al. 1980) y, en la mayoría de los casos, el éxito reproductivo está muy relacionado con la extensión y la capacidad de defensa de estos territorios (Hahn y Peter 2003). Además, la intensidad de los cuidados parentales parece estar fuerte y positivamente relacionada con buenas condiciones de alimentación y una óptima eficiencia de forrajeo (Furness 1987, Hahn y Peter 2003). A través de un estudio desarrollado en las islas Signy (IOS) y Bird (IGS), Burton (1968) y Osborne (1988) identificaron en esta especie cuatro comportamientos de alimentación: "Cleptoparasitismo", "Carroñeo", "Captura en vuelo" y "Caza”. El "Cleptoparasitismo" de escúas sobre el Petrel de Wilson, la Gaviota Cocinera, el C. Antártico y el Petrel Gigante fue documentado en numerosas ocasiones (Maxson y Berstein 1982, Reinhardt et al. 1998). El "Cleptoparasitismo" varía en intensidad según las poblaciones y es una estrategia de alimentación oportunista que responde a condiciones locales y temporales de disponibilidad de alimento (ver Maxson y Bernstein 1982). El "Carroñeo", descripto como el consumo de restos de vertebrados y de invertebrados marinos muertos en la línea de costa, parece ser la estrategia de alimentación más frecuente en esta especie (Burton 1968). Con respecto a la "Captura en vuelo", Burton (1968) indica que si bien la dieta de los pichones está básicamente conformada por peces, no existen registros para Isla Signy (IOS) de escúas predando directamente sobre recursos pelágicos marinos, y además agrega que estas aves no presentan adaptaciones morfológicas para realizar ese tipo de actividad. Sin embargo, esta estrategia de forrajeo fue documentada por Young (1963), por lo que es probable que sea una estrategia frecuente que es documentada solo ocasionalmente dado que se desarrolla en aguas abiertas poco observadas. La "Caza" (predación de huevos, pichones y adultos de aves, incluidos escúas) es una estrategia de particular importancia durante el período de crianza del pichón (Montalti et al. 1996). Los huevos suelen ser robados de nidos desprotegidos o incluso robados a los mismos padres y la predación de juveniles de pingüinos aumenta una vez finalizado el período de guardería de los mismos. Las presas más sensibles a este comportamiento son los pingüinos, petreles pequeños como los de las Tormentas, de las Nieves y Damero, la Paloma Antártica y el Gaviotín Antártico (ver Reinhardt et al. 
1998, Casaux et al. 2008). A diferencia de estas clasificaciones y según las adoptadas en este capítulo, Ainley et al. (1984) indican que el "Recolección superficial" (estrategia 3, ver más arriba) es una estrategia frecuente en los escúas y que fue utilizada por el $32 \%$ de los ejemplares observados en el Mar de Ross.

En un estudio llevado a cabo en la Isla 25 de Mayo (ISS), Hahn et al. (2008) observaron que el escúa Polar no desarrolló viajes de forrajeo a mar abierto, que la duración de los viajes fluctuó entre 14 y 208 minutos y que se alimentó en un área de 22,8 km. alrededor de los nidos. Estas observaciones resaltan la importancia de las áreas costeras como zonas de alimentación de esta especie y, aunque no se dispone de este tipo de datos para el escúa Marrón, se pueden tomar como referencia de los patrones de alimentación de esta especie.

En resumen, Burton (1968) propone que los escúas son predadores oportunistas con una dieta muy diversa que refleja la variedad de estrategias de alimentación que son capaces de desarrollar.

\section{Sternidae}

\section{Gaviotín Antártico Sterna vittata gaini}

La "Zambullida y persecución" es la estrategia de forrajeo comúnmente utilizada por el Gaviotín Antártico (Ainley et al. 1984, Gochfeld y Burger 1996). Pocos son los trabajos sobre la composición de la dieta de esta especie como así también sobre sus actividades de forrajeo. Los estudios sobre su alimentación son limitados y sólo 3 trabajos analizan la composición de la dieta de este gaviotín en la zona insular del sector Atlántico (Jablonsky 1995, Gochfeld y Burger 1996, Casaux et al. 2007b).

Casaux et al. (2007b) analizaron el comportamiento alimentario del Gaviotín Antártico en Isla Nelson (ISS) mediante la observación de 9 parejas reproductoras. Tal como se indicara en el Capítulo II, los peces predominaron en la dieta, y entre ellos Electrona antarctica y estadíos postlarvales de Notothenia coriiceps fueron las presas más importantes. Estos autores también observaron que la actividad de forrajeo se desarrolla al menos durante las horas de luz y que la composición de la dieta varía a lo largo del día, probablemente en relación a la disponibilidad de las presas. Los peces fueron la presa principal desde las primeras horas de la mañana hasta las $18 \mathrm{hs.}$ momento en que comienza a incrementarse el consumo de crustáceos, principalmente krill (Casaux et al. 2007b), lo que coincide con lo reportado por Gochfeld y Burger (1996). Casaux et al. (2007b) observaron que las salidas de alimentación, las que se desarrollaron a muy poca distancia de la colonia, duraron entre 1 y 16 minutos, y que el número de salidas por sesión de alimento fluctuó entre 1 (captura de peces) y 9 (captura de crustáceos). Como se observa, el número de salidas por sesión de alimento varió en función de la presa capturada. Estas aves soportan una fuerte presión de predación por parte de los escúas por lo que tienen que adaptar su estrategia de alimentación de modo de incrementar la capacidad de defensa social de los nidos. Es por ello que individuos de nidos vecinos alternan los turnos de alimentación de modo de mantener permanentemente protegidos todos los sectores de la colonia y seleccionan positivamente peces dado que, a través del menor número de salidas necesarias para satisfacer al pichón, de ese modo incrementan el tiempo en la colonia y la capacidad de defensa (Casaux et al. 2007b). Es por ello que en localidades donde la 
abundancia de escúas es alta, la capacidad de los gaviotines para emancipar pichones depende fuertemente de la disponibilidad de peces en inmediaciones de la colonia.

\section{IV.3.1.1. Mamíferos}

Los mamíferos marinos desarrollan variadas estrategias de alimentación, las que en la mayoría de los casos involucran buceos. Los mamíferos buceadores han adquirido adaptaciones fisiológicas que les permiten desarrollar buceos profundos y prolongados con bajos costos energéticos. Este comportamiento anaeróbico está controlado fundamentalmente por la gran cantidad de oxígeno que estos animales acumulan en sus tejidos y por la eficiencia metabólica en el uso del mismo (Kooyman et al. 1981). Hasta el momento, en los fócidos y pinnípedos se han descripto entre 6 y 7 tipos diferentes de buceo. Entre ellos, en casi todos las especies se destacan los buceos de forrajeo propiamente dicho, caracterizados por presentar un diagrama cuadrado con oscilaciones de profundidad o sin oscilaciones, y los de exploración, los cuales presentan diagramas de tipo cuña en U o en V (Thums et al. 2008).

\section{Phocidae}

\section{Foca Cangrejera Lobodon carcinophagus}

La foca Cangrejera es una especie sumamente abundante que se distribuye alrededor del continente antártico a lo largo de todo el año (Herickson y Hanson 1990, Burns et al. 2004). Su dieta está compuesta fundamentalmente por krill (Laws 1985, Green y Williams 1986, Lowry et al. 1988). Debido a los cambios temporales en las condiciones medio-ambientales, los enjambres de krill adoptan una distribución en parches que varía principalmente con la extensión del pack de hielo marino, los períodos de luz y las corrientes marinas (Siegel 1988, Trathan et al. 1993, Ichii et al. 1998, Lascara et al. 1999, Nicol 2006). Por ello, es de esperar que el comportamiento alimentario de la Foca Cangrejera varíe estacionalmente en respuesta a los factores de mayor influencia sobre la dispersión de las poblaciones de krill.

Si bien en las IOS no existen hasta el momento informes sobre el comportamiento de forrajeo de esta especie, reportes de estudios realizados en otras áreas de Antártida aportan datos sumamente interesantes al respecto. Diversas investigaciones realizadas durante los meses de verano indican que la profundidad media de forrajeo de la Foca Cangrejera se sitúa por encima de los 50 metros, y que los picos de actividad ocurren durante el atardecer (Erickson et al. 1971, Condy 1976, Gilbert y Erickson 1977, Croxall et al. 1985, Costa et al. 1989, Fraser et al. 1989, Erickson y Hanson 1990, Bengston y Steward 1992, Boyd et al. 1994, Nordoy et al. 1995, Gales et al. 2004). Por el contrario, los pocos estudios realizados durante los meses de invierno indican que en esta estación los buceos son más profundos, que los individuos permanecen en tierra en horas de oscuridad y que probablemente forrajeen sobre el fondo marino (Burns et al. 2004 y 2008). Estas observaciones sugieren que, a pesar del alto grado de especialización en el consumo de krill, la Foca Cangrejera presenta una plasticidad comportamental que parece estar determinada por una amplia variedad de factores ambientales. 
A partir de la observación de 6 focas en el Mar de Weddell durante el mes de Marzo de 1986, Bengston y Stewart (1986) describieron 4 tipos de buceos diferentes: viajes de buceo, buceos de forrajeo, buceos de forrajeo crepusculares y buceos exploratorios. Estos autores también observaron que los períodos de mayor actividad ocurrieron durante las horas del atardecer y la noche y que a pesar de ser considerado un predador de aguas poco profundas, esta foca ocasionalmente realiza buceos en profundidad. En un trabajo posterior Bengtson y Stewart (1992) sugieren que los buceos exploratorios responden al comienzo de una actividad de forrajeo en aguas poco profundas. Similarmente, pero sin clasificar a los diversos comportamientos de las focas, Nordoy et al. (1995) describieron la actividad de buceo a partir del seguimiento satelital de 3 hembras y 5 machos entre los meses de Febrero y Junio de 1993 en la Isla Queen Maud Land (sector Índico del OA). Las profundidades registradas raramente excedieron los 52 metros (70\% de los buceos en la temporada verano-otoño y $96 \%$ en el mes de Junio), en tanto que los valores máximos promediaron los 118 y 156 metros para esos períodos, registrándose un máximo absoluto de $528 \mathrm{~m}$. Con respecto a la duración de los buceos, Nordoy et al. (1995) informaron que la mayoría de los buceos fueron menores a los 2 minutos y que los buceos de corta duración se incrementaron a medida que se incrementaban las horas de oscuridad (56\% en Febrero y $86 \%$ en Junio). La información obtenida de los seguimientos satelitales indicó que las focas tuvieron un desplazamiento diario medio de $35 \mathrm{~km}$., lo que se correspondió con una velocidad media de $1,5 \mathrm{~km} . \mathrm{h}^{-1}$. La mayor distancia de forrajeo (medida entre el punto de forrajeo y el punto de instrumentación del individuo) fue de $3.875 \mathrm{~km}$. El promedio diario de inmersiones fue $143( \pm 26)$ buceos para el período de muda (fines de Febrero); este valor aumentó a $195( \pm 27)$ buceos diarios hacia finales de Marzo y en Junio disminuye a 125 buceos. Tal como ocurrió con la frecuencia de los buceos, el período diario de actividad de buceo varió estacionalmente. Durante los meses de verano la actividad fue mayor entre las 19 y las $7 \mathrm{hs}$. (69\% de los buceos), en tanto que en Abril sólo el $40 \%$ de los buceos fueron nocturnos. La áreas de forrajeo de esta foca están asociada a zonas de alta productividad biológica por lo que es muy poco frecuente encontrarlas alejadas de las zonas de hielo marginal (Gilbert y Erickson 1977, Nordoy et al. 1995, Southwell et al. 2005) dado que en esas áreas el krill, su principal presa, es abundante debido a las floraciones fito-planctónicas y epónticas (Nicol 2006). Es por ello también que, tal como ocurre con el Leopardo Marino (Rogers et al. 2005), a medida que avanza la temporada otoñal la Foca Cangrejera tiende a moverse hacia el norte conjuntamente con el desplazamiento del hielo marino (Laws 1984). Entre los meses de Abril y Noviembre de 2001 y 2002 Burns et al. (2004) estudiaron el comportamiento de buceo en 34 focas cangrejeras en la zona de Bahía Margarita, Península Antártica (PA). Las focas estudiadas pasaron el $29,7 \%$ del tiempo en la superficie, el $45,2 \%$ buceando y el restante $25,1 \%$ en tierra y el tiempo en superficie fue disminuyendo a medida que avanzaba la temporada invernal. A diferencia de lo reportado en trabajos desarrollados durante el verano, Burns et al. (2004) observaron que entre Abril y Junio la actividad de buceo fue mayormente diurna, en tanto que durante primavera las focas bucearon preferentemente durante la noche. El número de buceos diarios también varió a lo largo del año, siendo estos más frecuentes en los meses de Octubre y Noviembre y menos numerosos en Septiembre. Del mismo modo, se observó que el número de buceos diarios también varió ampliamente según los años; los valores obtenidos para 2001 promediaron los 119 buceos diarios, en tanto que en 2002 ese valor subió a 188 buceos. 
La profundidad media de buceo fue 75,8 metros y varió entre 6 - 664,5 m., en tanto que el tiempo promedio de inmersión fue de 4,6 minutos y varió entre 0,2 y 23,6 minutos. El $55 \%$ de los buceos registrados se desarrollaron a profundidades de entre 50 y 100 metros y el $34 \%$ de los mismos ocurrió a profundidades mayores a los $100 \mathrm{~m}$. De acuerdo a ello, Burns et al. (2004) dividieron los buceos en dos categorías: buceos poco profundos ( $<24 \mathrm{~m}$.) y profundos $(>24 \mathrm{~m}$.) y reportaron que el $65,9 \%$ de los buceos fueron profundos. El $76 \%$ de los individuos monitoreados no se desplazaron más allá de los $300 \mathrm{~km}$. de distancia de la zona de hielo marginal, siendo la distancia media $231 \mathrm{~km}$. y las máximas $1147 \mathrm{~km}$. en 2001 y $664 \mathrm{~km}$. en 2002. Con respecto a la cobertura de hielo, durante el invierno temprano las focas se agruparon en zonas donde la cubierta de hielo varió entre el 30 y $50 \%$ de la superficie y durante el invierno tardío utilizaron áreas con un $90 \%$ de cobertura. A su vez, estas áreas se correspondieron con zonas de agua poco profundas y de batimetría variada. Burns et al. (2004) concluyeron que durante los meses de invierno las focas realizan buceos substancialmente más largos (el $47 \%$ fue mayor a los 5 minutos) y más profundos que lo reportado para los meses de verano en trabajos previos, lo que permite especular que durante los meses de verano la Foca Cangrejera tiene la capacidad de explotar una fracción mayor de la columna de lo que se pensaba previamente.

La Foca Cangrejera parece desarrollar dos tipos de comportamiento alimentario a lo largo del año. Durante el verano se comporta principalmente como un predador nocturno que desarrolla buceos de corta duración en aguas poco profundas y en cercanías de la zona de hielo marginal, en tanto que en el invierno este comportamiento cambia considerablemente, registrándose un aumento de los buceos profundos y de los tiempos de inmersión. Según Burns et al. (2004 y 2008) estos cambios en el comportamiento de forrajeo estarían explicados por las variaciones estacionales en la distribución del krill, lo que a su vez está determinado por cambios en las variables ambientales. En relación a esto, diversos autores indican que durante los meses de invierno el zooplancton está ausente en la superficie siendo más abundante en las cercanías del fondo marino (Ashjian et al. 2004, Lawson et al. 2004, Zhou y Dorland 2004). Otro aspecto interesante relacionado con el comportamiento de forrajeo de la Foca Cangrejera es que, según se desprende de la observación de 150 a 200 individuos, estas focas podrían desarrollar buceos sincrónicos, los que estarían vinculados a un forrajeo cooperativo (Gales et al. 2004).

\section{Foca de Weddell Leptonychotes weddellii}

La Foca de Weddell es un mamífero marino que se alimenta fundamentalmente de peces y cefalópodos y que desarrolla estrategias de buceo que involucran inmersiones profundas y prolongadas. Esta foca está adaptada para explotar la zona costera y por lo general se la encuentra en zonas de amplias extensiones de hielo marino (Kaufman et al. 1975, Siniff et al. 1977, Bartsch et al. 1992, Plötz et al. 2001). Numerosos autores han clasificado diferentes tipos de buceo para esta especie (Kooyman et al. 1968, Kooyman 1981, Schreer y Testa 1995, 1996, Plötz et al. 2001, Davis et al. 2003). Inicialmente, los tipos de buceo fueron divididos en tres: (1) $<100 \mathrm{~m}$. de profundidad y 5 minutos de duración, (2) < $200 \mathrm{~m}$. y > 20 minutos, y (3) > $200 \mathrm{~m}$. y entre 8 y 15 minutos (Kooyman et al. 1968). Este autor también indicó que el buceo tipo (2) es un buceo exploratorio y que el tipo (3) es un buceo de forrajeo. Schreer y Testa $(1995,1996)$ sugirieron que los tipos de buceo descriptos en 
esta especie demostraban un comportamiento de forrajeo de tipo bentónico. Posteriormente, a partir de la observación de 10 adultos solitarios en las cercanías de Bahía McMurdo (sector Índico del OA), Davis et al. 2003 clasificaron los buceos en 4 tipos diferentes de acuerdo al análisis de los desplazamientos en tres dimensiones: (1) inmersiones de duración intermedia (15,0 \pm 4,2 minutos), profundidad media máxima de $378 \pm 93 \mathrm{~m}$. y descensos "empinados" con ascensos tipo "angulares". Las grabaciones de los videos muestran a las focas en actitud de captura, por ende este tipo de buceo fue clasificado como de alimentación. Los tipos (2), (3) y (4) conforman un continuo desde los muy cortos en distancia, lentos en velocidad y no lineales cercanos a la zona de hielo marginal (tipo 2 ) hacia los progresivamente largos, de alta velocidad y muy lineales (tipo 4) pero relativamente poco profundos (<142 m.) comparados con los tipo (1) y (2), indicando un comportamiento alternativo al de alimentación como la defensa del sitio de alimentación o la detección de otras focas cercanas al sitio. Se ha observado también que en función de los estados fisiológicos asociados a las diferentes etapas de crecimiento, la Foca de Weddell desarrolla diversas estrategias de buceo tendientes a maximizar las duraciones $y$ frecuencias de los buceos y las profundidades de los mismos (Burns et al. 1999). A partir del seguimiento de las rutas de forrajeo de 8 adultos en la ensenada Drescher (PA oriental) mediante la utilización de instrumental de telemetría, Plötz et al. (2001) obtuvieron 1356 horas de registros. El $31 \%$ de ese tiempo las focas permanecieron sobre el hielo y el $69 \%$ restante lo pasaron en el mar. Estos autores también indicaron que las salidas a tierra ocurren durante el día y que durante la noche y el amanecer las focas suelen permanecen en el mar. Por otro lado, en este estudio también se registró que los buceos más profundos fueron realizados entre las 8 y las 10 de la mañana y los valores máximos de profundidad llegaron a los 450 metros, en tanto que los buceos nocturnos fueron superficiales (<50 m.). En dicha localidad los buceos más frecuentes $(55 \%$ de los buceos) fueron registrados alrededor de los 70 metros. Sumado a ello, Plötz et al. (2001) sugieren que las focas inician su actividad de forrajeo con un primer buceo entre la superficie y los $160 \mathrm{~m}$. en un $64 \%$ de los casos y un segundo buceo entre los 160 y los $450 \mathrm{~m}$. en el $30 \%$ de los casos. En las áreas donde se desarrollaron todos estos estudios la Foca de Weddell es considerada un predador altamente dependiente del notothéniido Pleuragramma antarcticum y es por ello la mayoría de los trabajos en donde se describen sus hábitos de forrajeo consideran la distribución y abundancia de este pez como argumento explicativo. En el Sector Atlántico del Océano Antártico, incluidas las IOS; esta foca se alimenta fundamentalmente de peces mycthóphidos y demersales y de cefalópodos (Casaux et al. 1997a, 2006, 2009a) y además es capaz de variar su dieta y estrategia de forrajeo en relación a los cambios en la oferta alimentaria y a la intensidad de la competencia interespecífica (Casaux et al. 1997a, 2011) por lo que es probable que la Foca de Weddell sea capaz de desarrollar estrategias de buceo diferentes a las previamente descriptas.

\section{Leopardo Marino Hydrurga leptonyx}

El Leopardo Marino es considerado un animal solitario que se distribuye tanto en aguas antárticas como subantárticas (Walker et al. 1998, Rogers et al. 2005, Forcada y Robinson 2006). Condy (1977) y Bester et al. (2002) reportan que durante el verano el Leopardo Marino es observado frecuentemente alimentándose en zonas próximas al pack de hielo marino o en las cercanías a los sistemas de políneas (áreas de aguas abiertas rodeadas de hielo marino donde la fragmentación en 
generada por acción de vientos catabáticos o surgencia de agua cálida profunda). Sin embargo, Casaux et al. (2009b) reportaron focas leopardo alimentándose en zonas libre de hielo.

Sólo dos trabajos proveyeron información sobre el comportamiento de buceo del Leopardo Marino (Kuhn et al. 2006, Nordoy y Blix 2009). Kuhn et al. (2006) estudiaron el comportamiento de un individuo juvenil durante tres semanas y registraron tiempos medios de buceo inferiores a los 2 minutos y una profundidad media cercana a los 40 metros. Nordoy y Blix (2009) estudiaron el comportamiento de esta foca en la costa de Queen Maud mediante la técnica de telemetría. Los leopardos observados realizaron en promedio 160 buceos diarios durantes los meses de verano, en tanto que en invierno el número de buceos por día bajó a 30/40. Durante el período de mayor actividad (Febrero) la mayoría de los buceos (40-50\%) se desarrollaron entre las 21 y las 3 horas, en tanto que entre el 5 y $15 \%$ de los mismos fueron registrados entre las 9 y las 15 horas. De un modo diferente a lo observado en verano, la actividad de los leopardos en invierno fue mayor durante el día. A su vez, la duración de la mayoría de los buceos no excedió los 10 minutos $(80-90 \%$ de los buceos registraron tiempos menores a los 5 minutos) y, aunque la profundidad máxima alcanzada llegó a los 304 metros, la profundidad media no superó los 52 metros. Kuhn et al. (2006) obtuvieron valores similares a los reportados por Nordoy y Blix (2009) y en base a ello, estos autores concluyen que el Leopardo Marino es un típico buceador de aguas poco profundas y cuyas inmersiones son de corta duración.

\section{Elefante Marino del Sur Mirounga leonina}

El Elefante Marino del Sur es uno de los predadores más importantes de los ecosistemas marinos de la región sub-Antártica y Antártica (Laws 1977, Boyd y Arnborn 1991, McConnell et al. 1992). Aunque esta especie se distribuye en todo el Océano Antártico, las áreas de alimentación están espacialmente restringidas a zonas altamente productivas tales como los frentes oceánicos y las plataformas continentales (Slip y Burton 1993, Bornemann et al. 2000, Ballieul et al. 2007). Con respecto a los hábitos de forrajeo, esta especie es considerada un predador de aguas intermedias con eventuales incursiones hacia zonas más profundas (entre 200 y 1000 m) (Hindell et al. 1991, Campagna et al 1995, 1998). En comparación con las otras especies de mamíferos, el Elefante Marino se destaca por su gran capacidad de bucear hasta profundidades cercanas a los $1500 \mathrm{~m}$. y por períodos de tiempo muy extensos (cercanos a los 80 minutos) (Bailleul et al. 2007). En base a ello se puede especular que la capacidad de capturar presas no depende exclusivamente de la localización visual de las mismas, sino también de la capacidad de detectar cambios de temperatura en el agua en aquellas profundidades en las que la luz solar no penetra en la columna (Callahan 1971, McConell et al. 1992). La mayoría de los trabajos sobre buceo sobre el Elefante Marino indican que puede permanecer en el mar por largos períodos de tiempo. Aproximadamente entre el 80 y el $90 \%$ del tiempo monitoreado a través de técnicas de telemetría corresponde a períodos de actividad en el mar (Boyd y Arnborn 1991, Slip et al. 1994), llegándose a registrar en algunos casos una frecuencia de hasta 2,5 buceos por hora (Slip et al. 1994). En términos generales, las profundidades promedio de buceo rondan los $300 \mathrm{~m}$. y los tiempos de apnea medios los 20 minutos (Hindell et al. 1991, Slip y Burton 1993, Jonker y Bester 1994, Bornemann et al. 2000, Campagna et al. 2000, Ballieul et al. 2007). 
Varios autores elaboraron clasificaciones acerca de los tipos de buceo del Elefante Marino (Hindell et al. 1991, Jonker y Bester 1994, Slip et al. 1994). Según la clasificación de Slip et al. (1994) los buceos se dividen en dos grupos: los buceos de alimentación (aquellos en los que el individuo permanece uno o más minutos en la máxima profundidad, clasificados a su vez como tipo 1 y tipo 2), y los buceos de exploración (aquellos en los cuales los individuos pasan alrededor del $75 \%$ del período activo en el mar, y que a su vez son divididos en los tipos 3, 4, 5 y 6 ). Durante la actividad de buceo tipo 1 o buceo pelágico, la profundidad media varía entre 300 y $700 \mathrm{~m}$. y el tiempo de inmersión medio no supera los 12 minutos. Las hembras permanecen más tiempo en el mar que los machos $(77,6 \%$ y $35,9 \%$ respectivamente) marcando un patrón de buceo más profundo durante el día, y haciéndose menos profundo durante la noche. El buceo tipo 2 o buceo bentónico se caracteriza por desarrollarse a profundidades medias entre 450 y 550 m. y tiempos de inmersión cercanos a los 14 minutos. Con respecto a los buceos de exploración, el tipo 3 está caracterizado por un corto y rápido descenso a una profundidad usualmente mayor a los $200 \mathrm{~m}$., seguido de un descenso lento y prolongado, finalizando con un ascenso rápido hacia la superficie. Este tipo de buceo es comúnmente realizado por los elefantes durante las horas tempranas de la mañana. El buceo tipo 4 es catalogado como un buceo de desplazamiento, ya que se lo observa cuando los elefantes arriban a la zona reproductiva y cuando la dejan al final de la temporada. Está caracterizado por presentar una profundidad media de $343 \pm 133 \mathrm{~m}$. y tiempos de inmersión medios de 20,4 \pm 6,8 minutos. El buceo tipo 5 es una inmersión corta (menos de 1,5 minutos), de poca profundidad y en general son raros de observar, por lo que Slip et al. (2004) no pueden explicar el propósito de este comportamiento. Por último, el buceo tipo 6 es una combinación de los patrones anteriores, presentando una profundidad media de $485 \pm 249 \mathrm{~m}$. y un tiempo medio de inmersión de 19,5 \pm 6,7 minutos. La gran varianza de la profundidad se debe a los eventos poco usuales de inmersiones más profundas. Este tipo de buceo probablemente tiene varias funciones, incluyendo la exploración y el escape de los predadores.

El ciclo diario de actividad de los elefantes marinos presenta variaciones. Jonker y Bester (1994) encontraron diferencias significativas entre los tipos de actividad diurna y nocturna. Los buceos más profundos (500 - 600 m.) y más prolongados (23 - 40 minutos) fueron registrados durante las horas diurnas, en tanto que los buceos menos profundos $(300-400 \mathrm{~m}$.) y de menor duración (15 - 20 minutos) se registraron en horas nocturnas. Estos autores también indican que la actividad de forrajeo fue más intensa en las horas diurnas (10 - 14 hs.) que en las nocturnas (22 a 2 hs.). Sumado a ello, Slip et al. (1994) indicaron que las áreas exploradas por los elefantes durante las horas nocturnas son zonas más someras, lo cual coincide con la migración vertical de sus presas.

Con respecto a las diferencias sexuales, Slip et al (1994) registraron mayor actividad diurna por parte de las hembras. Tanto Slip et al. (1994) como McConnell y Fedak (1996) sugieren que los machos adultos suelen forrajear en aguas menos profundas o más cercanas a la costa que las hembras, lo que coincide con lo observado en el elefante Marino del Norte $M$. angustirostris mediante el análisis de isótopos estables de carbono (Burton y Kock 1999). A partir de datos de temperatura del agua, Slip et al. (1994) reportaron que las áreas de forrajeo de machos y hembras adultos monitoreados en la I. Macquarie durante 1988 y 1990 fueron diferentes. Los machos mostraron una mayor tendencia a la permanencia dentro del área de la plataforma continental, en tanto que las 
hembras presentaron mayor actividad en zonas de aguas más profundas o aguas abiertas (más allá de la plataforma). Aún así, ambos sexos mostraron el mismo patrón de comportamiento con respecto a la temperatura del agua, prolongando los buceos en masas de agua menos frías asociadas al frente polar. En base a ello, Bailleul et al. (2007) sugieren que la fuerte presencia de los elefantes en masas de agua con mayor temperatura estaría relacionada con la abundancia de peces en estos ambientes favorables (Magnuson et al. 1979, Kock 2005). Hindell et al. (1991) reportaron que las áreas de forrajeo del Elefante Marino en la I. Macquarie estaban asociadas a determinados patrones batimétricos, de salinidad y de temperatura. Sumado a ello McConell et al. (1992) relacionaron la dispersión geográfica de los elefantes en la IGS con aspectos físicos y biológicos particulares del océano. A su vez, en base al seguimiento de una hembra en su retorno al mar luego de terminado el período de muda, Boyd y Anrborn (1991) observaron una fuerte correlación entre el comportamiento de forrajeo y la temperatura del agua, sugiriendo que los elefantes utilizan las discontinuidades de temperaturas entre masas de agua como indicadores de la presencia o acumulación de presas. En coincidencia con estos autores, en un estudio desarrollado en Patagonia, Argentina, Campagna et al. (2000) observaron la importancia que tienen los cambios de temperatura para el Elefante Marino como guía de reconocimiento de frentes marinos. Esta capacidad puede ser entendida como una adaptación hacia el reconocimiento de los diversos ambientes marinos.

Con respecto a la extensión de los viajes de forrajeo, los estudios de seguimiento realizados en el Elefante Marino reflejaron distancias entre la colonia reproductiva y el sitio de alimentación de 1400 a 3000 km. y tiempos de duración que exceden los 60 días (Bester 1989, McConnell y Fedak 1996, Jonker y Bester 1998).

\section{Otariidae}

\section{Lobo Fino Antártico Arctocephalus gazella}

El Lobo Fino Antártico es uno de los predadores marinos que ha sido ampliamente estudiado en numerosas localidades de Antártida y del OA tales como las IGS (Boyd y Croxall 1992, Boyd et al. 1994, McCafferty et al. 1998, Staniland y Robinson 2008), I. Macquarie (Goldsworthy et al. 1997), el archipiélago Kerguelen (Bonadonna et al. 2000, Guinet et al. 2001, Lea et al. 2002), las ISS (Costa et al. 2000, Goebel et al. 2000, Casaux et al. 2003), la Península Antártica (Casaux et al. 2003a, 2003b, 2011) y las IOS (Daneri y Coria 1992, 1993). En conjunto, toda la información generada revela la marcada flexibilidad alimentaria y comportamental con la que el Lobo Fino Antártico se desenvuelve en relación a la variabilidad de los recursos en distintas localidades (McCafferty et al. 1998, Goebel et al. 2000, Guinet et al. 2001). Como fue descripto en el Capítulo II, el Lobo Fino Antártico es un activo consumidor de krill antártico. El krill varía su contenido energético según sus estadios de crecimiento (Clarke 1980) y su disponibilidad varía fuertemente de acuerdo a los cambios estacionales, oceanográficos regionales y globales (Loeb et al. 1997, Moline et al. 2004, Nicol 2006) por lo que, dependiendo de todos estos factores, en ocasiones peces con alto retorno energético pueden ser componentes importantes en su dieta (Staniland et al. 2007).

Numerosos estudios indican que el Lobo Fino Antártico presenta un comportamiento de forrajeo pelágico caracterizado por buceos nocturnos a poca profundidad, la que se incrementa durante las horas crepusculares (Boyd y Croxall 1992, Goldsworthy et al. 1997). A partir del estudio 
de 75 individuos durante 5 períodos de cría consecutivos (desde 1988 a 1993) en Isla Bird (IGS), Boyd et al. (1994) reportaron para esta especie 4 tipos de buceos diferentes. Estos 4 tipos de buceo son: tipo I o "corto", caracterizado por eventos de corta duración (aproximadamente 17 minutos) durante las horas de luz y/o crepusculares, sugiriendo un comportamiento exploratorio; tipo II o "largo", caracterizado por su larga duración (aproximadamente 80 minutos) y por ser nocturnos; tipo III o "poco profundo", reportado como actividad de forrajeo en áreas someras durante las horas nocturnas y con duraciones no mayores a 12 minutos, y probablemente realizados en asociación con otras especies consumidoras de krill; y tipo IV o "profundo", caracterizado por eventos de duración corta (aproximadamente 19 minutos) y profundidades relativamente profundas (entre 40-50 m.) en comparación con los demás tipos de buceo registrados. En otro estudio realizado a partir del seguimiento de 117 individuos en las Islas Kerguelen durante Enero de 2000, Lea et al. (2002) reportaron profundidades de buceo medias de $53 \pm 17 \mathrm{~m}$. y duraciones medias de 1,6 \pm 0,4 minutos. A su vez, el 87,5 \% de los buceos ocurrió durante la noche. Tal como observaran Boyd et al. (1994), Lea et al. (2002) registraron variaciones importantes entre individuos en los tiempos de cada buceo. Si bien la caracterización de los buceos no fue exactamente la misma que la desarrollada por Boyd et al. (1994), en términos comportamentales no presentó grandes diferencias.

Con respecto a las rutas de forrajeo, según Bonadonna et al. (2000) los lobos presentan dos tipos de rutas. En la primera los lobos tienden a quedarse largos períodos de tiempo alimentándose en áreas de forrajeo conocidas, y en la segunda realizan viajes "en bucle" buscando un parche de presas diferente al previamente explotado.

Staniland y Robinson (2008) analizaron las diferencias sexuales en los hábitos de forrajeo de 14 machos y 14 hembras lactantes durante Noviembre y Diciembre de 2004 en los alrededores de las IGS. Estos autores observaron diferencias sexuales significativas en los perfiles verticales y horizontales de los buceos. También observaron que las hembras suelen forrajear durante la noche en la zona del talud y en zonas más profundas, en tanto que los machos se alimentaron en zonas cercanas a los asentamientos reproductivos costeros concentrando su actividad sobre la plataforma continental y durante las horas del día, presentando a su vez buceos más prolongados que los de las hembras. En este sentido las hembras desarrollaron un comportamiento de forrajeo pelágico, en tanto que el de los machos fue de tipo bentónico. Es probable que estas diferencias en las estrategias de alimentación de algún modo estén asociadas al dimorfismo sexual reportado para esta especie (Doige et al. 1984, Boyd y McCamm 1989). En un estudio realizado por Boyd et al. (1991) se observaron diferencias en la actividad de forrajeo según la edad de los ejemplares monitoreados. En coincidencia con ello, Walker y Boveng (1995) reportaron que la duración de los viajes de forrajeo disminuye a medida que la edad de las hembras aumenta.

Dos estudios realizados en Isla Bird, IGS, (Boyd et al. 1994, McCafferty et al. 1998) reportaron respuestas similares a cambios en la disponibilidad de alimento en hembras de Lobo Fino Antártico para diferentes períodos de tiempo (entre 1988 y 1993 y entre 1994 y 1996 respectivamente). En ambos trabajos, las hembras estudiadas desarrollaron viajes de mayor extensión en años de menor abundancia de krill, lo cual resultó en un aumento de sus propios requerimientos energéticos $y$, en consecuencia, en una disminución en la capacidad de aprovisionamiento de leche a los cachorros. 


\section{IV.3.2.Solapamiento de la dieta en la comunidad de predadores tope de las}

Islas Orcadas del Sur

La tabla IV.2 muestra los valores de solapamiento de la dieta (S) para todos los pares de predadores aquí analizados.

La mayoría de los pares de especies que fueron consideradas en este análisis presentaron valores de $\mathrm{S}$ menores al $50 \%$ para la composición general de la dieta. Dada su similitud en la composición de la dieta y en las estrategias de forrajeo, los pingüinos de Barbijo y de Adelia presentaron el valor más alto de $S(99,95 \%)$ durante 1998/99, temporada en la que el krill fue abundante (ver capítulo II). El Pingüino Papuá presentó valores de solapamiento mayores al $50 \%$ con la Foca de Weddell, el Lobo Fino Antártico, el Petrel Damero y el Pingüino de Adelia. Por otro lado, tanto el Cormorán de Georgias como el Petrel de las Nieves predan casi exclusivamente sobre peces y en consecuencia mostraron altos valores de S. A diferencia de los demás predadores, el Petrel Gigante se alimenta principalmente de pingüinos por lo que los valores de $S$ con las demás especies fueron bajos, excepto con el Lobo Fino Antártico y la Foca de Weddell con los que compartió valores cercanos al $30 \%$. Por su parte, el Lobo Fino Antártico presentó valores de $\mathrm{S}$ por debajo del $50 \%$ con todas las especies estudiadas excepto con el Petrel Damero dado el alto consumo de peces pelágicos de ambas especies durante la temporada 1996/97, con los pingüinos Papúa y de Barbijo durante la temporada 1997/98 como resultado del intenso consumo de krill y con la Foca de Weddell durante la temporada 2001/02, también por compartir un alto consumo de krill (ver capítulo II).

En relación al solapamiento calculado a partir de los consumos sobre las diferentes especies de peces, casi todos los pares de predadores mostraron valores altos de $S$ (Tabla IV.3). Con la excepción de la Foca de Weddell y el Pingüino de Adelia, y dependiendo de la temporada, el Cormorán de Georgias fue la única especie que presentó bajos valores de solapamiento de peces con el resto de los predadores.

En general, y de acuerdo a los datos reunidos, los predadores considerados se pueden integrar en cuatro grandes grupos: aquellos que se solapan por el consumo de krill (I), de peces notothénidos (II), de peces myctóphidos (III) y de pingüinos (IV) (Tabla IV.4).

De acuerdo a la composición de la dieta, el porcentaje de re-ocurrencia de presas entre predadores para la composición general de la dieta varió entre 25,27 (1997/98) y 36,67 (1996/97), y las presas que más re-ocurrieron fueron los peces, el krill y los calamares. Asimismo, la re-ocurrencia de los peces varió entre 8,10 (1996/97) y 28,13 (1999/00). Los peces que más contribuyeron al porcentaje de re-ocurrencia fueron los notothéniidos G. gibberifrons, $N$. nudifrons y $N$. larseni, y el myctóphido E. antarctica (ver anexo de tablas, tablas IV.5 a IV.13). 


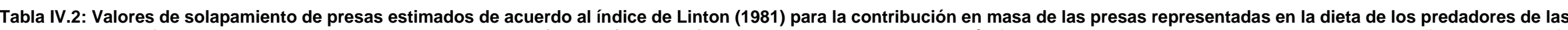

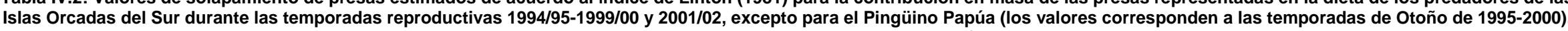
Los valores marcados en rojo representan un $\%$ de $S>50 \%$.

\begin{tabular}{|c|c|c|c|c|c|c|c|c|c|}
\hline Temporadas & & $1994 / 95$ & 1995/96 & $1996 / 97$ & $1997 / 98$ & 1998/ 99 & $1999 / 00$ & 2001/02 & General \\
\hline \multicolumn{10}{|l|}{ Pares de predadores } \\
\hline Pingüino Papúa & Cormorán de Georgias & 55,5 & 59,01 & 37,14 & 16,73 & 26,52 & 55,56 & & 38,99 \\
\hline Pingüino Papúa & Lobo Fino Antártico & 19,75 & 73,05 & 63,65 & 75,5 & 54,12 & 59,56 & & 65,18 \\
\hline Pingüino Papúa & Petrel Damero & & 40,2 & 71,05 & & & & & 55,63 \\
\hline Pingüino Papúa & Pingüino de Adelia & & & 62,56 & 84 & 69,04 & & & 71,87 \\
\hline Pingüino Papúa & Foca de Weddell & & & & & & 31,16 & & 31,16 \\
\hline Pingüino de Adelia & Petrel Damero & & & 33,61 & & & & & 33,61 \\
\hline Pingüino de Barbijo & Pingüino de Adelia & & & 96,99 & 99,24 & 99,85 & & & 98,69 \\
\hline Pingüino de Barbijo & Pingüino Papúa & & & 65,55 & 83,55 & 68,89 & & & 72,66 \\
\hline Pingüino de Barbijo & Petrel Damero & & & 63,6 & & & & & 63,60 \\
\hline Pingüino de Barbijo & Cormorán de Georgias & & & 3,69 & 0,36 & 0,05 & & & 1,37 \\
\hline Pingüino de Barbijo & Petrel de las Nieves & & & & 7,85 & & & & 7,85 \\
\hline Pingüino de Barbijo & Petrel Gigante & & & & & 1,43 & & & 1,43 \\
\hline Pingüino de Barbijo & Lobo Fino Antártico & & & 41,4 & 69,14 & 39,11 & & & 49,88 \\
\hline Cormorán de Georgias & Petrel Damero & & 1,91 & 61,09 & & & & & 31,50 \\
\hline Cormorán de Georgias & Petrel de las Nieves & & & & 82,83 & & & & 82,83 \\
\hline Cormorán de Georgias & Pingüino de Adelia & & & 0,68 & 0,73 & 0,01 & & & 0,47 \\
\hline Cormorán de Georgias & Foca de Weddell & & & & & & 38,07 & & 38,07 \\
\hline Lobo Fino Antártico & Foca de Weddell & & & & & & 38,31 & 67,3 & 52,81 \\
\hline Lobo Fino Antártico & Petrel Damero & & 32,35 & 59,3 & & & & & 45,83 \\
\hline Lobo Fino Antártico & Cormorán de Georgias & 19,75 & 40,96 & 26,53 & 18 & 11,57 & 15,31 & & 22,47 \\
\hline Lobo Fino Antártico & Pingüino de Adelia & & & 27,51 & 7,4 & 39,07 & & & 24,66 \\
\hline Lobo Fino Antártico & Petrel de las Nieves & & & & 15,21 & & & & 15,21 \\
\hline Petrel de las Nieves & Pingüino Papúa & & & & 24,2 & & & & 24,20 \\
\hline Petrel de las Nieves & Pingüino de Adelia & & & & 8,2 & & & & 8,20 \\
\hline Petrel Gigante & Lobo Fino Antártico & & & & & 22,54 & 26,17 & & 24,36 \\
\hline Petrel Gigante & Pingüino Papúa & & & & & 6,03 & 2,18 & & 4,11 \\
\hline Petrel Gigante & Pingüino de Adelia & & & & & 1,52 & & & 1,52 \\
\hline Petrel Gigante & Cormorán de Georgias & & & & & 1,06 & 0,39 & & 0,73 \\
\hline Petrel Gigante & Foca de Weddell & & & & & & 23,39 & & 23,39 \\
\hline
\end{tabular}




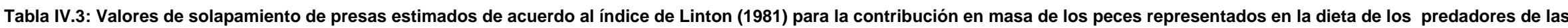

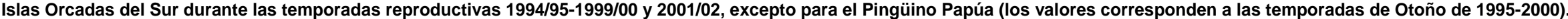
Los valores marcados en rojo representan un $\%$ de $S>50 \%$.

\begin{tabular}{|c|c|c|c|c|c|c|c|c|c|}
\hline Temporadas & & $1994 / 95$ & $1995 / 96$ & $1996 / 97$ & $1997 / 98$ & 1998/99 & $1999 / 00$ & 2001/ 02 & General \\
\hline \multicolumn{10}{|l|}{ Pares de predadores } \\
\hline Pingüino Papúa & Lobo Fino Antártico & 55,15 & 65,47 & & & 89,41 & 66,24 & & 69,07 \\
\hline Pingüino Papúa & Petrel Damero & & 69,31 & & & & & & 69,31 \\
\hline Pingüino Papúa & $\begin{array}{l}\text { Cormorán de } \\
\text { Georgias }\end{array}$ & 18,12 & 40,7 & & & 58,33 & 65,56 & & 45,68 \\
\hline Pingüino Papúa & Foca de Weddell & & & & & & 77,3 & & 77,30 \\
\hline Pingüino Papúa & Pingüino de Adelia & & & & & 89,72 & & & 89,72 \\
\hline Cormorán de Georgias & Petrel Damero & & 51,6 & 38,64 & & & & & 45,12 \\
\hline Cormorán de Georgias & Lobo Fino Antártico & 47,07 & 44,73 & 48,73 & 56,4 & 55,08 & 46,71 & & 49,79 \\
\hline Cormorán de Georgias & Foca de Weddell & & & & & & 58,69 & & 58,69 \\
\hline Cormorán de Georgias & Petrel de las Nieves & & & & 13,58 & & & & 13,58 \\
\hline Cormorán de Georgias & Pingüino de Adelia & & & & 58,59 & 55,37 & & & 56,98 \\
\hline Lobo Fino Antártico & Petrel Damero & & 80,16 & 59,33 & & & & & 69,75 \\
\hline Lobo Fino Antártico & Petrel de las Nieves & & & & 52,31 & & & & 52,31 \\
\hline Lobo Fino Antártico & Foca de Weddell & & & & & & 77,88 & 84,17 & 81,03 \\
\hline Lobo Fino Antártico & Pingüino de Adelia & & & & 96,68 & 99,38 & & & 98,03 \\
\hline Petrel de las Nieves & Pingüino de Adelia & & & & 54,95 & & & & 54,95 \\
\hline
\end{tabular}

Tabla IV.4. Predadores agrupados de acuerdo a la presa con la que solapan su dieta con otras especies: I: Krill, II: Peces notothénidos, III: Peces myctóphidos, IV: Pingüinos.

\begin{tabular}{|cccc|}
\hline I & II & III & IV \\
\hline Pingüino de Barbijo & $\begin{array}{c}\text { Cormorán de } \\
\text { Georgias }\end{array}$ & Petrel Damero & Lobo Fino Antártico \\
\hline Pingüino de Adelia & Pingüino Papúa & Petrel de las Nieves & Foca de Weddell \\
\hline Pingüino Papúa & Foca de Weddell & Lobo Fino Antártico & Petrel Gigante \\
\hline Petrel Damero & & & \\
\hline Lobo Fino Antártico & & & \\
\hline
\end{tabular}




\section{IV.4. Discusión}

\section{IV.4.1. Estrategias de forrajeo}

A partir de la bibliografía analizada en este capítulo se describieron las numerosas y diversas maneras en las que los predadores se alimentan de acuerdo a sus capacidades fisiológicas, morfológicas y a su flexibilidad comportamental y social. Las actividades de forrajeo de los predadores tope responden tanto a cambios en la disponibilidad del alimento (Cairns 1987, Burger y Piatt 1990, Montevecchi 1993) como a las variaciones de sus requerimientos energéticos de acuerdo a la etapa del ciclo reproductivo y/o la estación del año (Furness 1978). Asimismo, la diversidad de estrategias que presente cada predador está estrechamente vinculada con la variación en el uso temporal y espacial del ambiente, lo cual a su vez se relaciona con la intensidad de la competencia intra e interespecifica por el alimento y, en consecuencia, con el modo en que la comunidad aprovecha los recursos. La segregación espacial y temporal en el uso de las áreas de forrajeo, tanto entre individuos como entre especies, usualmente resulta en la diversificación de la dieta. Esta diversificación en la composición de la dieta favorece que varias especies exploten una misma área. En general, los predadores capaces de desarrollar diferentes estrategias de forrajeo, como es el caso del Lobo Fino Antártico, la Foca de Weddell y los escúas, suelen presentar una dieta más diversa que la del resto de las especies. Ahora bien, la competencia afectos diferentes parámetros poblacionales denso-dependientes tales como las tasas de fecundidad, supervivencia o crecimiento, entre otros (Begon et al. 1999). Como se sugirió previamente, la intensidad de esta competencia por el alimento está determinada por las capacidades de segregación espacial y temporal en el uso del ambiente entre las especies que componen dicha comunidad, y/o entre los individuos de una misma población.

De acuerdo a la información disponible, se identificaron dos estrategias diferentes en cuanto al uso de las áreas de alimentación. La primera diferenciación corresponde a predadores que se alimentan mayormente a partir de recursos terrestres (ya sea por medio de la caza activa o del carroñeo) tales como los escúas y el Petrel Gigante, y los que lo hacen a partir recursos marinos, como el resto de los predadores. Si bien el Petrel Gigante se alimenta tanto en el mar como en tierra, la intensidad con que carroñea en tierra sobre diferentes fuentes de alimento o con que caza pichones de pingüino hace que sea considerado un predador predominantemente terrestre. El ambiente marino puede a su vez ser subdividido en un ambiente de aguas abiertas y otro de aguas litorales (ver Kock 1992) (ver capítulo I). Dentro de los predadores que se alimentan en aguas abiertas se encuentran aquellas especies cuyas capacidades morfológicas les permiten desarrollar extensos viajes de forrajeo (tanto en tiempo como en distancia). Por el contrario, los predadores que se alimentan en aguas litorales, como es el caso del Cormorán de Georgias o el Pingüino Papúa, suelen desarrollar estrategias vinculadas con la búsqueda y persecución de presas en fondos marinos cercanos a la costa, por lo que presentan estrategias de buceo apropiada para aguas poco profundas.

La zona litoral presenta una columna de agua poco estratificada, lo que obliga al krill a realizar migraciones verticales entre los 40 y los 140 metros (Nicol 2006), aunque otros autores sugieren que este comportamiento se debe principalmente a la presión de predación (Gliwicz 1986, Frost y Bollens 1992). Debido a esta migración vertical del krill, sus predadores acomodarán los 
horarios de las salidas de alimentación de acuerdo a sus capacidades para explotar los diferentes estratos de la columna de agua. Por otro lado, las aguas litorales están caracterizadas por poseer abundantes recursos en proximidades de las colonias reproductivas, aunque pobres en términos de contenido energético tales como el krill maduro y los peces notothénidos, en comparación con los recursos que se encuentran en aguas abiertas tales como el krill grávido y peces mycthóphidos (Ichii et al. 2007). Las especies que suelen explotar la zona litoral pueden subdividirse entre aquellas que se alimentan en aguas superficiales y aquellas que lo hacen a mayor profundidad, fundamentalmente debido a que poseen mayores capacidades de buceo. En el primer grupo de encuentran los pingüinos de Adelia, de Barbijo y el Lobo Fino Antártico, dependientes casi exclusivamente del krill, y en el segundo grupo se encuentran el Cormorán de Georgias y el Pingüino Papúa, marcadamente más ictiófagos que las especies anteriores. Si bien el Lobo Fino Antártico explota una diversidad de ambientes, dada su flexibilidad trófica y sus adaptaciones fisiológicas y morfológicas, fue incluido dentro de este grupo ya que es la zona en donde permanece la mayor parte del tiempo invertido en alimentación (ver resultados).

A diferencia de lo que ocurre en aguas litorales, la presencia de una termoclina fuerte y poco profunda hace que en aguas abiertas el krill permanezca la mayor parte del tiempo en superficie. Es por ello que este ambiente es más predecible que la zona litoral en términos de localización y captura tanto del krill como de los cardúmenes de peces asociados, en particular para aquellos predadores cuya visión es muy buena y cuyas estrategias de forrajeo incluyen el Recolección superficial y la captura en superficie (ej. procelláridos). Debido a ello, los predadores que se alimentan casi exclusivamente de krill y de los peces myctóphidos asociados explotan preferentemente la zona de aguas abiertas. Tal como ocurre con la zona litoral, la zona de aguas abiertas también puede ser subdividida en un ambiente bentónico y otro superficial. Dentro de los predadores que explotan el ambiente bentónico se encuentran los buceadores por excelencia, tales como el Elefante Marino y la Foca de Weddell. Dentro de los predadores que explotan las aguas superficiales se encuentran las aves marinas que desarrollan estrategias de Recolección superficial y capturas en vuelo, tales como los procelláridos.

En relación a las estrategias de buceo, la eficiencia de los eventos de inmersión depende fuertemente de las capacidades fisiológicas de cada predador. La eficiencia de un buceador está basada tanto en las adaptaciones a la presión como a la hipoxia (Kooyman y Ponganis 1998). En el caso de los mamíferos marinos, la importante reserva energética que poseen les permite permanecer en zonas de aguas abiertas durante largo tiempo y así poder aprovechar todos estos sistemas oceánicos de alta productividad. En base a ello, los elefantes marinos despliegan buceos de larga duración y extensos viajes de alimentación tanto en distancia como en duración, lo que les permite alimentarse de presas con gran retorno energético disponibles en fondos profundos tales como los calamares de gran tamaño (ver capítulo II). Estas capacidades de forrajeo del Elefante Marino parecen estar fuertemente relacionadas con el tamaño corporal de los individuos (Ainley et al. 1984, Piatt y Nettleship 1985, Cooper 1986, Prince y Harris 1988, Burger 1991, Boyd y Croxall 1996, Schreer y Kovacs 1997). Estos autores indican que los animales de mayor tamaño, como el Elefante Marino, están mejor adaptados a eventos de buceo más prolongados y profundos dado que pueden acumular mayor cantidad de oxígeno (lo que se debe a la mayor cantidad de sangre) y que el 
metabolismo del oxígeno (tasa de consumo) se produce más lentamente. En comparación con los phócidos, los otáridos tienen una tasa metabólica básica alta y una menor eficiencia en la utilización del oxígeno (Kooyman y Ponganis 1998). Es por ello que, dadas estas limitaciones fisiológicas, los buceos del Lobo Fino Antártico son más someros y se desarrolla en la zona costera. En las aves buceadoras también se observan diversas estrategias también de acuerdo al ambiente que estas explotan. El Pingüino Papúa suele bucear en zonas litorales próximas a la costa en busca de presas bentónicas, en particular peces notothénidos (ver capítulo II), por lo que desarrolla buceos más profundos que los de los pingüinos de Adelia y de Barbijo, los que se alimentan en aguas abiertas. Por su parte, el Cormorán de Georgias se alimenta fundamentalmente de presas bentónico-litorales (ver capítulo II), por lo que su estrategia de forrajeo estará adaptada a realizar salidas de corta duración y búsqueda y captura de presas en el fondo marino.

Los cambios estacionales de la disponibilidad de las presas hacen que los predadores cambien sus estrategias de forrajeo a lo largo del tiempo, tal como se observó en el Pingüino Papúa y en la Foca Cangrejera en las temporadas de invierno y de verano, en relación a la variación espacial y estacional del krill. Diversos autores indican que durante los meses de invierno el zooplancton está ausente en la superficie y que desplaza a aguas próximas al fondo marino (Ashjian et al. 2004, Lawson et al. 2004, Zhou y Dorland 2004). Este cambio en la distribución del krill genera cambios directos en las estrategias de búsqueda del alimento de estos predadores. Burns et al. (2004, 2008) observaron que la Foca Cangrejera parece desarrollar dos tipos de comportamiento alimentario a lo largo del año. Durante el verano se comporta principalmente como un predador nocturno que desarrolla buceos de corta duración en aguas poco profundas y en cercanías de la zona de hielo marginal, en tanto que en el invierno este comportamiento cambia considerablemente, registrándose un aumento de los buceos profundos y de los tiempos de inmersión. Estos autores sugieren que tales cambios en el comportamiento de forrajeo responderían a variaciones estacionales en la distribución del krill, lo que a su vez está determinado por cambios en las variables ambientales. Con respecto al Pingüino Papúa, Williams et al. (1992) reportaron un comportamiento similar al de la Foca Cangrejera. Si bien estos argumentos explicarían las diferencias observadas en las profundidades medias de buceo de verano e invierno, no explican por qué razón durante el invierno aumentan los tiempos de búsqueda. Probablemente la escasez de luz durante el invierno condicione fuertemente la localización de los enjambres de krill o de los cardúmenes de peces. Sin embargo, como fue indicado previamente, la localización visual no parece ser el único método empleado en la búsqueda de presas (ver Elefante Marino en "Resultados").

Las estrategias de forrajeo de cada especie deberán ajustarse no sólo a la disponibilidad de las presas, si no también a los requerimiento energéticos de los individuos y al de sus crías durante la temporada de reproducción. Varios estudios han analizado las variaciones en las frecuencias de las salidas de alimentación en especies de aves y mamíferos de acuerdo al incremento en las necesidades energéticas de sus crías (Bengtson et al. 1994, Casaux 2004, Ichii et al. 2007). En general, durante el período de cría los predadores deben optimizar las salidas de alimentación, lo que consiguen reduciendo su duración y capturando presas con mayor retorno energético. En este sentido, Casaux et al. (2001) e Ichii et al. (2007) observaron que en predadores mixtos (ver capítulo II) se registra un aumento del consumo de peces myctóphidos a medida que los requerimientos de 
sus crías aumentan. Por otro lado, durante la etapa de cría algunas especies desarrollan estrategias más complejas que incluyen la cooperación entre individuos tendiente al cuidado de las crías, tal como ocurre con los pingüinos (Martínez 1992) o con el Gaviotín Antártico (Casaux et al. 2007b). Algunos predadores tales como el Petrel Gigante (Hunter 1983), el Petrel de Wilson (Büber et al. 2004, Reiss et al. 2008) y el Cormorán de Georgias (Casaux et al. 2001), entre otros, durante el período de cría suelen presentar diferencias sexuales en relación a los tiempos y distancias de forrajeo y a las presas consumidas. Si bien este comportamiento tiende a ser interpretado en términos de disminuir la competencia intraespecifica, estas diferencias sexuales también pueden interpretarse como un comportamiento de cooperación, a través del cual cada individuo optimiza sus capacidades fisiológicas y morfológicas en función de la búsqueda del alimento y aprovisionamiento de alimento a los pichones.

Las aves marinas durante el período reproductivo son un ejemplo típico de los predadores que se alimentan desde un punto fijo, los cuales para alimentarse se trasladan de sus colonias a sus áreas de alimentación. La teoría del forrajeo desde un punto central (Orians y Pearson 1979) predice que las presas cercanas a la colonia serán elegidas o preferidas sobre presas lejanas a la colonia y que por ende las aves marinas sólo se alimentarán de presas alejadas solo si la tasa de captura de presas se incrementa con la distancia. Tanto los pingüinos, como el gaviotín Antártico y el cormorán de Georgias son predadores que se alimentan en la zona litoral y que parecen desarrollar este tipo de estrategia. La teoría también predice que la preferencia de presas cercanas a la colonia, sin embargo, puede llevar al agotamiento local de las presas tal como fue documentado por Casaux (1998) para el cormorán de Antártico.

\section{IV.4.2. Solapamiento y re-ocurrencia de presas en la dieta}

El solapamiento de la composición general de la dieta fue más alto durante las temporadas reproductivas 1997/98, 1998/99 y 2001/02, lo que se debió principalmente al mayor consumo de krill por parte de la mayoría de los predadores. En un trabajo sobre la composición de la dieta de los pingüinos de Barbijo y de Adelia desarrollado en Isla Signy (IOS), Lynnes et al. (2004) observaron que las tallas de krill consumidas por los pingüinos se incrementaron desde 1997 hasta finales de 2000 y también registraron un aumento en la extensión de los viajes de forrajeo por parte del Pingüino de Barbijo durante 2000. Según estos autores ambas observaciones sugieren que durante esos años no hubo un ingreso de una cohorte de krill fuerte en la zona de las IOS y evidencian la ausencia de krill de tamaño pequeño en las zonas cercanas a las colonias. Pianka (1976) y Connell (1983) sugieren que cuando sólo el krill de gran tamaño está disponible, sus consumidores predan sobre la misma fracción de la población y así la competencia interespecífica se incrementa, tal como se observó durante las temporadas 1996/97 y 1997/98 en donde se registró un aumento del solapamiento de la dieta en los pares de predadores Pingüino de Adelia - Pingüino Papúa, Pingüino de Barbijo - Pingüino Papúa y Lobo Fino Antártico - Pingüino Papúa). Por el contrario, en la temporada 1998/99 los valores de solapamiento entre estas especies disminuyen (ver Tabla IV.2). En base a ello, y teniendo en cuenta lo reportado por Lynnes et al. (2004), tales valores de S podrían ser tomados como un indicador indirecto de la disminución de la competencia interespecífica durante esta temporada, lo que podría deberse a la diversificación de la dieta del Pingüino Papúa y del Lobo 
Fino Antártico. Es interesante destacar que si bien entre 1997/98 y 1998/99 el solapamiento entre estas dos especies disminuye principalmente porque ambos predadores consumen presas diferentes a las consumidas en temporadas anteriores (el Pingüino Papúa incorpora más peces a su dieta y el Lobo Fino Antártico más pingüinos), en 1999/00 el solapamiento vuelve a aumentar debido a que ambos incrementan el consumo de krill. Sin embargo, y teniendo en cuenta solamente el consumo de peces, en esta temporada el solapamiento entre ambos predadores diminuyó dado que el Lobo Fino Antártico consumió con mayor intensidad peces de la familia Myctophidae en tanto que el Pingüino Papúa consumió principalmente peces de otras familias.

Entre los predadores buceadores, los pingüinos de Adelia y de Barbijo fueron los que presentaron valores de solapamiento de la dieta más altos $(S=98,69 \%)$. Dado que en la dieta de ambos predadores predominaron las mismas especies (ver capítulo II) en conjunto estos resultados reafirman que sus estrategias de forrajeo son similares (Volkman et al. 1980, Lishman 1985, Croxall y Lishman 1987, Watanuki et al. 1993, Ainley et al. 1998, 2003, Jansen et al. 1998, Endo et al. 2002, Lynnes et al. 2002, Rombolá et al. 2002). El solapamiento medio de la dieta entre Lobo Fino Antártico - Pingüino Papúa fue del $57,61 \%$, presentó picos en las temporadas 1995/96 (S = 75,5\%) y 1997/98 $(S=73,05)$, y fue el tercer valor más alto entre todos lo predadores. La composición general de la dieta reflejó que durante 1995/96 ambos predadores predaron más intensamente sobre peces de la familia Nototheniidae. A diferencia de ello, durante 1997/98 el krill fue la presa más importante en ambas especies y el consumo de peces disminuyó marcadamente. El segundo valor más alto de solapamiento se dio entre dos especies que predaron principalmente sobre peces tales como el Cormorán de Georgias y el Petrel de las Nieves $(S=82,83)$. Estos resultados sugieren que estos tres pares de especies son los predadores que más compiten por el alimento.

Numerosos autores sugirieron que los pingüinos no son presa o, en caso de serlo, son solo una presa ocasional de los mamíferos marinos (Bonner y Hunter 1982, Fischer y Hureau 1988, Todd 1988). Sin embargo, Cobley y Bell (1998) observaron eventos de predación de la Foca de Weddell sobre el Pingüino Papúa. Si bien, Casaux et al. (1997a, 2006) no observaron a_esta presa en la dieta de la Foca de Weddell en la I. Nelson (ISS) ni en la Costa Danco (PA) respectivamente, Casaux et al. (2009) si la registraron en las IOS y sugirieron que ello podría reflejar una estrategia de forrajeo tendiente a disminuir la competencia interespecífica con otros predadores. Por otro lado, el consumo de pingüinos por parte del Lobo Fino Antártico parece estar relacionado de un modo indirecto con la disponibilidad de krill. La información disponible sobre composición de la dieta sugiere que en años de alta disponibilidad de krill esta presa desplaza a los peces notothéniidos en la dieta, y que a medida que aumenta el consumo de krill se observa también un aumento en el consumo de pingüinos (ver capítulo II). Esta asociación entre el consumo de krill y su consecuente consumo de pingüinos podría deberse a un aumento en la probabilidad de encuentro entre el Lobo Fino Antártico y los pingüinos cuando estos predadores forrajean con mayor intensidad sobre el krill.

Pares de especies que presentaron altos valores de solapamiento en relación a la composición general de la dieta tales como P. papua - Cormorán de Georgias y Cormorán de Georgias - Petrel de las Nieves, disminuyeron el nivel de solapamiento al considerarse solamente el consumo de peces. Esto se debe fundamentalmente a que estos predadores predaron con diferentes intensidades sobre especies de las diferentes familias. En el caso de la pareja Pingüino Papúa - 
Cormorán de Georgias, si bien en ambos predadores predominaron los peces notothéniidos, el Cormorán de Georgias predó principalmente sobre N. coriiceps, en tanto que el Pingüino Papúa lo hizo sobre L. larseni y G. gibberifrons. En relación a la pareja Cormorán de Georgias - Petrel de las Nieves, ambos predadores consumieron peces pertenecientes a familias diferentes y con distintas estrategias de vida. En tanto que el Cormorán de Georgias predó intensamente sobre notothéniidos bentónicos litorales, el Petrel de las Nieves consumió preferentemente peces myctóphidos de hábitos pelágicos.

A partir de los resultados sobre el solapamiento de la dieta (tablas IV.2 y IV.3), y en relación al ítem alimentario con el que se solapan sus dietas, se definieron 4 grupos de predadores (Tabla IV.4). Entre todos los predadores aquí analizados, el Lobo Fino Antártico es el predador que presentó mayor variedad de estrategias de alimentación (este capítulo) y una importante diversificación en la dieta (ver capítulo II), lo que se confirma al observar que esta especie estuvo representada en tres de los 4 grupos de solapamiento de dieta.

El cálculo de la re-ocurrencia de presas en una comunidad de predadores explica cuán estrechas son las relaciones tróficas y cuán flexibles pueden ser los predadores de esa comunidad para disminuir la competencia por el alimento a través de la diversificación de sus estrategias de alimentación. En relación a ello, la re-ocurrencia de presas en la comunidad de predadores de las IOS en todos los casos fue media-baja. De acuerdo a la información analizada, esto se debería a una oferta de alimento diversa y a la gran capacidad de los predadores diversificar sus estrategias de alimentación y así disminuir la competencia por el alimento.

Como se desprende de lo indicado previamente, la estimación del solapamiento y la reocurrencia de presas ayuda a comprender el funcionamiento de una comunidad y el grado con que los predadores dependen de las diferentes presas disponibles. Es por ello que frente a una posible reapertura de la pesca en la zona de las IOS, este tipo de acercamiento al conocimiento del sistema deberá ser tenido en cuenta al momento de fijar cupos de pesca y especies a pescar, en función de un manejo racional y ecológicamente sustentable de los recursos marinos.

\section{V.5. Conclusiones generales}

A partir de la bibliografía analizada en este capítulo se detallaron las numerosas y diversas maneras en las que los predadores se alimentan de acuerdo a sus capacidades fisiológicas, morfológicas y a su flexibilidad comportamental y social. Se analizaron las diversas estrategias que despliegan los predadores que se alimentan de recursos oceánicos, litorales o costeros disponibles en aguas superficiales y profundas o en tierra, Los predadores aquí considerados fueron clasificados de acuerdo a las presas principales, al ambiente que explotan (segregación espacial), al momento del día en que se alimentan (segregación temporal) y a las principales estrategias de alimentación. Esta información fue analizada en términos de la competencia por el alimento.

En cuanto a las presas principales, se observaron cuatro grupos de predadores. Esta diferenciación surgió de la existencia de estrategias de forrajeo similares entre las especies de cada grupo, del grado de solapamiento de presas entre pares de predadores y del grado de flexibilidad alimentaria de cada predador. Por otro lado, también se observó que cuando la disponibilidad de 
alimento disminuye, fundamentalmente cuando se trata de una presa clave como el krill, predadores como el Lobo Fino Antártico, la Foca de Weddell y el Pingüino Papúa son capaces de diversificar la composición de la dieta. De acuerdo a los índices analizados, esta plasticidad alimentaria resulta en una marcada disminución de la competencia del alimento por lo que, no solo opera favorablemente a nivel poblacional, sino que también lo hace a nivel comunidad. En relación a la segregación espacial, se observaron tres grupos de predadores en relación al modo en que utilizaron el ambiente: los que predan en aguas abiertas, los que lo hacen en aguas litorales o cercanas a la costa y los que se alimentan en tierra. La agrupación de estos predadores responde principalmente a las capacidades fisiológicas y morfológicas de cada uno. También se observaron diferencias sexuales en el uso de las áreas de alimentación en algunas especies tales como el Cormorán de Georgias, el Elefante Marino, el Petrel Gigante y el Petrel de Wilson. Este comportamiento es indicativo de la necesidad, no sólo de disminuir la competencia interespecífica, sino también la intraespecífica. Con respecto a los buceos, entre los predadores buceadores existen diferentes estrategias que favorecen la explotación de recursos en la columna de agua o en el fondo marino. Dependiendo de las capacidades fisiológicas de cada especie, los tiempos y las profundidades de los buceo varían, siendo el Elefante Marino y la Foca de Weddell los predadores más especializados para desarrollar buceos profundos y lejanos a la costa, en tanto que el Cormorán de Georgias lo fue para explotar la zona litoral. En relación al uso temporal del ambiente, se observó que las períodos de alimentación estuvieron determinados fundamentalmente por la disponibilidad temporal de las presas y por las capacidades de forrajeo de los predadores (fundamentalmente vinculadas a las capacidades de localización de las presas).

A modo de indicador indirecto de la competencia por el alimento, se analizó el solapamiento de las dietas entre pares de especies y la re-ocurrencia de presas para la comunidad de predadores en su conjunto. Estos indicadores, junto con la información sobre las diversas estrategias de forrajeo observadas en cada especie, permitió identificar a aquellos predadores con mayor capacidad de adaptación frente a los cambios en la disponibilidad de sus presas. En relación a ello, los predadores con mayores capacidades para amortiguar los cambios en la disponibilidad de presas fueron el Lobo Fino Antártico, el Pingüino Papúa y la Foca de Weddell.

La teoría ecológica predice que la coexistencia de potenciales competidores y la regulación de sus poblaciones pueden ser interpretadas, en parte, como una consecuencia de la superabundancia del alimento (Pianka 1976). En base a ello, Odum (1971) indica que el solapamiento de la dieta refleja la competencia por el alimento en condiciones de recursos limitados. La teoría ecológica también predice que aunque existiese una superabundancia de recursos, lo que permitiría la coexistencia de diferentes predadores, la selección natural igualmente operará en la diversificación de la morfología y de las estrategias de forrajeo (Pianka 1976). En este sentido, la variedad de estrategias de forrajeo desplegadas por los predadores antárticos, cómo así también su plasticidad alimentaria, parecen favorecer la coexistencia de los mismos dado que permitirían amortiguar, al menos hasta niveles medios de interferencia, la intensidad de los efectos derivados de períodos de escasa oferta de alimento. 


\section{IV.6. Referencias bibliográficas}

Adams NJ y Wilson MP (1987) Foraging parameters of gentoo penguins Pygoscelis papua at Marion Island. Polar Biology 7(1): 51-56. doi: 10.1007/BF00286824.

Adams NJ y Brown CR (1983) Dietary differentiation and trophic relationships in the sub-Antarctic penguin community at Marion Island. Mar Ecol Pro Ser 57: 249-258.

Ainley DG, Ballard G, Barton KJ, Karl BJ, Rau GH, Ribic CA y Wilson PR (2003) Spatial and temporal variation o diet within a presumed metapopulation of Adelie Penguins. The Condor 105: 95-106.

Ainley DG, Wilson PR, Barton KJ, Ballard G, Nur N y Karl B (1998) Diet and foraging effort of Adélie Penguins in relation to pack-ice conditions in the southern Ross Sea. Polar Biology 20: 311-319.

Ainley DG, Ribic CA y Fraser WR (1992) Does prey preference affect habitat choice in Antarctic seabirds? Mar Ecol Prog Ser 90: 207-221.

Ainley DG, Fraser WR, Sullivan CW, Torres JJ, Hopkins TL y Smith WO (1986) Antarctic mesopelagic micronekton: evidence from seabirds that pack ice affects community structure. Science 232: 847-849.

Ainley DG, O'Connor EF y Boekelhei-de RJ (1984) The marine ecology of birds in the Ross Sea, Antarctica. Ornithological Monographs 32.

Ardley RAB (1936) The birds of the South Orkney Islands. Discovery Rpts 12: 349-376, pls. X-XII.

Ashijan CJ, Rosenwaks GA, Wiebe PH, Davis CS, Gallager SM, Copley NJ, Lawson GL y Alatalo P (2004) Distribution of zooplankton on the continental shelf off Marguerite Bay, Antarctic Peninsula, during Austral Fall and Winter, 2001. Deep Sea Research Part II: Topical Studies in Oceanography 51(17-19): 2073-2098.

Ashmole NP (1971) Seabird ecology and the marine environment. En: Avian Biology, vol 1. Farner DS y King JR (Eds). Academic Press Inc., New York. pp 224-271.

Bailleul F, Charrassin JB, Monestiez P, Roquet F, Biuw M y Guinet C (2007) Successful foraging zones of southern elephant seals from the Kerguelen Islands in relation to oceanographic conditions. Philos Trans R Soc Lond B Biol Sci. 362(1487): 2169-2181. doi: 10.1098/rstb.2007.2109.

Barrera-Oro E (2003) Analysis of dietary overlap in Antarctic fish (Notothenioidei) from the South Shetland Islands: no evidence of food competition. Polar Biology 26(10): 631-637. doi: 10.1007/s00300-003-0520-1.

Barret RG (1974) Biology report, Base E. Br Antarct Surv Internal Report AD6/2E/1974/N.

Bartsch SS, Johnston SD y Siniff DB (1992) Territorial behaviour and breeding frequency of male Weddell seals (Leptonychotes weddellii) in relation to age, size, and concentrations of serum testosterone and cortisol. Canadian Journal of Zoology 70: 680-692.

Beck J (1969) Food, moult and age of first breeding in the cape pigeon, Daption capense Linnaeus. Br Antarct Surv Bull 21: $33-$ 44.

Beck JR y Brown DW (1972) The biology of Wilson's storm-petrel Oceanites oceanicus (Kuhl), at Signy Island, South Orkney Islands. BAS Sci Rep 69: 1-54

Bengtson JL y Stewart BS (1992) Diving and haulout behavior of crabeater seals in the Weddell Sea, Antarctica, during March 1986. Polar Biology 12(6-7): 635-644. doi: 10.1007/BF00236986.

Bengtson JL, Boveng PL, Hiruki LM, Jansen JK, Meyer WR, Schwartz MK y Walker BG (1994). Antarctic Marine Living Resources program: pinniped and seabird studies at Seal Island, South Shetland Islands, during the 1993-1994 austral summer. Antarctic Journal of the United States 29(5): 200-201.

Begon M, Harper JH y Townsend CR (1999) Ecología: individuos, poblaciones y comunidades. 3era. Edición. Omega, Barcelona, España.

Bester MN (1989) Movements of southern elephant seals and subantarctic fur seals in relation to Marion Island. Marine Mammal Science 5: 257-265. doi: 10.1111/j.1748-7692.1989.tb00339.x.

Bester MN, Ferguson JWH y Jonker FC (2002) Population densities of pack ice seals in the Lazarev Sea, Antarctica. Antarctic Science 14(2): 123-127.

Bevan RM, Woakes AJ, Butler PJ y Croxall JP (1995) Heart Rate and Oxygen Consumption of Exercising Gentoo Penguins. Physiological Zoology 68(5): 855-877.

Bierman WH y Voous KH (1950) Birds observed and collected during the whaling expeditions of the Willem Barendsz in the Antarctic, 1946-47 and 1947-48. Ardea 37, extra number, 1-132. 
Bonadonna F, Lea MA y Guinet C (2000) Foraging routes of Antarctic fur seals (Arctocephalus gazella) investigated by the concurrent use of satellite tracking and time-depth recorders. Polar Biology 23: 149-159.

Bonner W y Hunter S (1982) Predatory interactions between Antarctic fur seals, macaroni penguins and giant petrels. $\mathrm{Br}$ Antarct Surv Bull 56: 75-79.

Boyd IL y Croxall JP (1996) Dive durations in pinnipeds and seabirds. Canadian Journal of Zoology 74: 1696-1705.

Boyd IL y Croxall JP (1992) Diving behaviour of lactating Antarctic fur seals. Canadian Journal of Zoology 70: 919-928.

Boyd IL y Arnborn T (1991) Diving behaviour in relation to water temperature in the southern elephant seal Mirounga leonina: foraging implications. Polar Biology 11: 259-266.

Boyd IL y McCann TS (1989) Pre-natal investment in reproduction by female Antarctic fur seals. Behav. Ecol Sociobiol 24: $377-$ 385.

Boyd IL, Arnould JP, Barton T y Croxall JP (1994) Foraging Behaviour of Antarctic Fur Seals During Periods of Contrasting Prey Abundance. Journal of Animal Ecology 63(3): 703-713.

Boyd IL, Lunn NJ y Barton T (1991) Time budgets and foraging characteristics of lactating Antarctic fur seals. J Anim Eeal 60: 577-592.

Brierley AS y Watkins JL (1996) Acoustic targets at South Georgia and the South Orkney Islands during a season of krill scarcity. Mar Ecol Prog Ser 138: 51-61.

Brierley AS, Watkins JL y Murray AWA (1997) Interannual variability in krill abundance at South Georgia. Mar Ecol Prog Ser 150: 87-98.

Burger AE (1991) Maximum diving depths and un-derwater foraging in alcids and penguins. En: Studies of High-latitude Seabirds. 1. Behavioural, Energetic and Oceanographic Aspects of Seabird Feeding Ecology. Montevecchi WA y Gaston AJ (Eds). Canadian Wildlife Service Occasional Paper 68, pp 9-15.

Burger AE y Piatt JE (1990) Flexible time budgets in breeding Common Murres: buffers against variable prey abundance. Stud. Avian Biol. 14: 7183.

Burns AG, Zeng Z, Wang W, Lei J, Solomon SC, Richmond AD, Killen TL y Kuo YH (2008) The behavior of the F2 peak ionosphere over the South Pacific at dusk during quiet summer condition from COSMIC data. J. Geophys. Res. 113, A12305. doi: 10.1029/2008JA013308.

Burns JM, Costa DP, Fedak MA, Hindell MA, Bradshaw CJA, Gales NJ, McDonald B, Trumble SJ y Crocker DE (2004) Winter habitat use and foraging behavior of crabeater seals along the Western Antarctic Peninsula, Deep Sea Research Part II: Topical Studies in Oceanography 51(17-19): 2279-2303.

Burns JM, Castellini MA y Testa JW (1999) Movements and diving behaviour of weaned Weddell seal (Leptonychotes weddellii) pups. Polar Biology 21: 23-36.

Burton RW (1968) Breeding biology of the brown skua. Catharacta lonnbergii, at Signy Island, South Orkney Islands. Br Antarct Surv Bull 15: 9-28.

Burton RK y Koch PL (1999) Isotopic tracking of foraging and long-distance migration in northeastern Pacific pinnipeds. Oecologia 119: 578-585.

Butler PJ, Bevan RM, Woakes AJ, Croxall JP y Boyd IL (1995) The use of data loggers to determine the energetics and physiology of aquatic birds and mammals. Braz J med bioi Res 28: 1307-1317.

Cairns DK (1987) Seabirds as indicators of marine food supplies. Biol Oceanogr 5: 261-271.

Callahan JE (1971) Velocity Structure and Flux of the Antarctic Circumpolar Current South of Australia. Journal of Geophysical Research 76(24): 5859-5864. doi: 10.1029/JC076i024p05859.

Campagna C, Rivas AL y Marin MR (2000) Temperature and depth profiles recorded during dives of elephant seals reflect distinct ocean environments. Journal of Marine Systems 24(3-4): 299-312. doi: 10.1016/S0924-7963(99)00091-3.

Campagna C, Le Boeuf BJ, Blackwell SB, Crocker DE y Quintana F (1995) Diving behaviour and foraging location of female southern elephant seals from Patagonia. Journal of Zoology 236(1): 55-71.

Campagna C, Quintana F, LeBoeuf BJ, Blackwell S y Crocker DE (1998) Diving behaviour and foraging ecology of female southern elephant seals. Patagonia Aquat Mamm 24: 1-11.

Casaux R (2004) Diving patterns in the Antarctic shag. Waterbirds 27: 382-387.

Casaux R y Coria N (2004) Estrategia de buceo del Cormorán Antártico en Punta Armonía, Antártida. Vo Simposio Argentino y $I^{\circ}$ Latinoamericano sobre Investigaciones Antárticas, Buenos Aires, Argentina, Agosto-Septiembre de 2004.

Casaux R. y Barrera-Oro E (2002) Effects of a shore-based sampling programme on Notothenia coriiceps populations. Antarctic Science 14(3): 221-224. 
Casaux R, Bertolin ML y Carlini A (2011) Feeding habits of three seal species at the Danco Coast, Antarctica: a re-assessment. Polar Biology 34(10): 1615-1620. doi: 10.1007/s00300-011-0994-1.

Casaux R, Carlini A, Corbalán A, Bertolin ML y Di Prinzio C (2009a) The diet of the Weddell Seal Leptonychotes weddellii at Laurie Island, South Orkney Islands. Polar Biology 32: 833-838.

Casaux R, Baroni A, Ramon A, Carlini A, Bertolin ML y DiPrinzio C (2009b) Diet of leopard seal Hydrurga leptonyx, at the Danco Coast, Antarctic Peninsula. Polar Biology 32: 307-310.

Casaux R, Carlini A y Corbalán A (2007a) Composición de la dieta del Lobo Fino Antártico en las Islas Orcadas del Sur en 10 años consecutivos. $\mathrm{VI}^{\circ}$ Simposio Argentino y $\mathrm{III}^{\circ}$ Latinoamericano sobre Investigaciones Antárticas. Buenos Aires, Argentina, Septiembre de 2007.

Casaux R, Baroni A. Ramón, Favero y Silva MP (2007b) Aspects of the foraging behaviour of the Antarctic Tern Sterna vittata gaini at Harmony Point, South Shetland Islands. Polar Biology 31: 327-331. doi: 10.1007/s00300-007-0362-3.

Casaux R, Baroni A, y Ramón A (2006) The diet of the Weddell Seal Leptonychotes weddellii at the Danco Coast, Antarctic Peninsula. Polar Biology 29: 257-262.

Casaux R, Bellizia L y Baroni A (2004) The diet of the Antarctic fur seal Arctocephalus gazella at Harmony Point, South Shetland Islands: evidence of opportunistic foraging on penguins? Polar Biology 27(2): 59-65. doi: 10.1007/s00300-0030559-z.

Casaux R, Baroni A, Arrighetti F, Ramón A y Carlini A (2003a) Geographical variation in the diet of the Antarctic fur seal Arctocephalus gazella. Polar Biology 26: 753-758.

Casaux R, Favero M, Silva P y Baroni A (2001) Sex differences in diving depth and diet of Antarctic shags at the South Shetland Islands. Journal of Field Ornithology 72(1): 22-29. doi: 10.1648/0273-8570.

Casaux R. Baroni A y Carlini A (1998a) The diet of Antarctic fur seal Arctocephalus gazella at Harmony Point, Nelson Island, South Shetland Islands. Polar Biology 20: 424-428.

Casaux R, Soave G y Coria N (1998b) Laternfish (Myctophidae) in the diet of Cape Petrel Daption capense at the South Orkney Islands, Antarctica. Polar Biology 20: 364-366.

Casaux R, Baroni A, Carlini A (1997a) The diet of the Weddell seal Leptonychotes weddellii at Harmony Point, South Shetland Islands. Polar Biology 18:371-375.

Casaux R, Coria N y Barrera-Oro E (1997b) Fish in the diet of the Antarctic shag Phalacrocorax bransfieldensis at Laurie Island, South Orkney Islands Polar Biology 18(3): 219-222. doi: 10.1007/s003000050179.

Casaux RJ, Favero M, Barrera-Oro E y Silva P (1994) Preliminary results of a feeding trial on the blue-eyed shag Phalacrocorax atriceps. Documento WG-CEMP 94/29. CCAMLR, Cape Town, South Africa.

Chapell MA, Shoemaker, Janes DN, Bucher TL y Maloney SK (1993) Diving behavior during foraging in breeding Adelie Penguins. Ecology 74: 1204-1215.

Clarke A (1980) The biochemical composition of krill, Euphausia superba Dana, from South Georgia. J Exp Mar Biol Eco143: 221-236.

Clarke J, Manly B, Kerry K, Gardner H, Franchi E, Corsolini S y Focardi S (1998) Sex differences in Adélie penguin foraging strategies. Polar Biology 20(4): 248-258. doi: 10.1007/s003000050301.

Clutton-Brock TH, Guinness FE y Albon SD (1982) Red deer: behaviour and ecology of two sexes. University of Chicago Press, Chicago, Illinois, USA.

Cobley ND y Bell G (1998) Weddell seal (Leptonychotes weddellii) feeding on Gentoo penguins (Pygoscelis papua). Marine Mammal Science 14: 881-883. doi: 10.1111/j.1748-7692.1998.tb00773.x.

Condy PR (1977) Results of the fourth seal survey in the King Haakon VII Sea, Antarctica. S. Afr. Jour. of Antarctic Research 7: 10-13.

Condy PR (1976) Results of the third seal survey in the King Haakon VII Sea, Antarctica. S Afr Jour of Antarctic Research 6: 2-

Connell JH (1983) On the prevalence and relative importance of interspecific competition: evidence from field experiments. Am Nat 122: 661-696.

Conroy JWH (1972) Ecological aspects of the biology of the Giant Petrel, Macronectes giganteus (Gmelin) in the maritime Antarctic. Br Antarct Surv Scientific Reports 75, 74 pp. 
Conroy JWH y Twelves EL (1972) Diving depths of the gentoo penguin (Pygoscelis papua) and blue-eyed shag (Phalacrocorax atriceps) from the South Orkney Islands. Br Antarct Surv Bull 30: 106-108.

Cooper J (1986) Introduction, present status and control of alien species at the Prince Edward Islands, sub-Antarctic. South African Journal of Antarctic Research 16: 86-94.

Coria NR, Soave GE y Montalti D (1997) Diet of Cape Petrel Daption capense during the post-hatching period at Laurie Island, South Okney Islands, Antarctica. Polar Biol. 18: 236-239.

Costa DP, Goebel ME y Sterling JE (2000) Foraging energetics and diving behavior of the Antarctic fur seal, Arctocephalus gazella at Cape Shirreff, Livingston Island. En: Antarctic ecosystems: models for wider ecological understanding. Davisons W, Howard-Williams C y Broady P (Eds). New Zealand Natural Sciences Press, Christchurch, New Zealand, pp 77-84.

Costa DP, Croxall JP y Duck CD (1989) Foraging Energetics of Antartic Fur Seals in Relation to Changes in Prey Availability. Ecology 70(3): 596-606.

Creet S, van Franeker JA, van Spanje TM y Wolff WJ (1994) Diet of the pintado petrel Daption capense at King George Island, Antarctica, 1990/91. Marine Ornithology 22: 221-229.

Croxall JP y Lishman GS (1987) The food and feeding ecology of penguins. En: Seabirds, feeding ecology and role in marine ecosystems. Croxall JP (Ed) Cambridge Univ. Press, Cambridge, pp 101-134.

Croxall JP y Prince PA (1980) Food, feeding ecology and ecological segregation of seabirds at South Georgia. Biological Journal of the Linnean Society 14: 103-131.

Croxall J, Naito Y,Kato A, Rothery $P$ y Briggs D (1991) Diving patterns and performance in the Antarctic blue-eyed shag Phalacrocorax atriceps. Journal of the Zoological Society of London 225: 177-199.

Croxall JP, Davis RW, O'Connell MJ (1988) Diving patterns in relation to diet of gentoo and macaroni penguins South Georgia. Condor 90: 157-167.

Croxall JP, Prince PA, Ricketts C (1985) Relationships between prey life-cycles and the extent, nature and seal and seabird predation in the Scotia Sea. En: Antarctic nutrient and food webs. Condy PR y Laws RM (Eds) Springer-Verlag, Berlin, pp 516-533.

Daneri GA y Coria N (1993) Fish prey of the Antarctic fur seals, Arctocephalus gazella, during the summer-autumm period at Laurie Island, South Orkney Islands. Polar Biology 13: 287-289.

Daneri GA y Coria NR (1992) The diet of Antarctic fur seals, Arctocephalus gazella, during the summer-autumn period at Mossman Peninsula, Laurie Island (South Orkneys). Polar Biology 11: 565-566.

Davis RW, Fuiman LA, Williams TM, Horning M y Hagey W (2003) Classification of Weddell seal dives based on 3-dimensional movements and video-recorded observations. Mar Ecol Prog Ser 264: 109-122.

Doidge CW, Croxal JP y Baker JR (1984) Density-dependent pup mortality in the Antarctic fur seal Arctocephalus gazella at South Georgia. Journal of Zoology 202(3): 449-460.

Einoder LD (2009) A review of the use of seabirds as indicators in fisheries and ecosystem management. Fisheries Research 95(1): 6-13.

Emslie SE, Karnovsky N y Trivelpiece W (1995) Avian predation at penguin colonies on King George Island, Antarctica. Wilson Bull 107: 317-327.

Endo Y, Asari H, Watanuki Y, Kato A, Kuroki M y Nishikawa J (2002) Biological characteristics of euphausiids preyed upon by Adelie penguins in relation to sea-ice conditions in Lutzow-Holm Bay, Antarctica. Polar Biology 25: 730-738.

Erickson AW y Hanson MB (1990) Continental estimates and population trends in Antarctic seals. En: Ecological change and the conservation of Antarctic ecosystems. Kerry KR y Hempel G (Eds). Springer; Berlin, Germany; New York, pp 253-254.

Erickson AW, Siniff DB, Cline DR y Hoffman RJ (1971) Distributional ecology of Antarctic seals. En: Proceedings of a symposium of Antarctic ice and water masses. Sir George Deacon (Ed). Brussels: Scientific Community Antarctic Research. pp 55-76.

Falla RA (1937) Birds. Banzare Report Series B 2: 1-288.

Ferretti V, Soave G, Casaux R y Coria N (2001) Diet of the Snow petrel Pagodroma nivea at Laurie Island, Antarctica, during the 1997-98 breeding season. Marine Ornithology 29: 71-73.

Field I, Hindell MA, Slip DJ y Michael KJ (2001) Foraging strategies of southern elephant seals (Mirounga leonina) in relation to frontal zones and water masses. Antarctic Science 1(13): 371-379. doi: 10.1017/S0954102001000529.

Fischer W y Hureau J (1988) Fichas FAO de identificación de especies para los fines de pesca. Océano Austral (áreas de pesca 48,58 y 88 , área de la Convención CCAMLR). FAO, Roma. 
Forcada J y Robinson SL (2006) Population abundance, structure and turnover estimates for leopard seals during winter dispersal combining tagging and photo-identification data. Polar Biology 29 (12): 1052-1062. doi: 10.1007/s00300-006-0149y.

Forero MG, Bortolotti GR, Hobson KA, Donázar JA, Bertellotti M y Blanco G (2004) High trophic overlap within the seabird community of Argentinean Patagonia: a multiscale approach. J Anim Ecol 73: 789-801.

Fraser WR, Pitman RL y Ainley DG (1989) Seabird and fur seal responses to vertically migrating winter krill swarms in Antarctica. Polar Biology 10: 37-41.

Frost BW y Bollens SM (1992) Variability of die1 vertical migration in the marine planktonic copepod Pseudocalanlus newmani in relation to its predators. Can J Fish Aquat Sci 49: 1137-1141.

Furness RW (1978) Kleptoparasitism by Great Skuas (Catharacta skua, Brfinn) and arctic skuas (Stercorarius parasiticus, L.) at a Shetland seabird colony. Anim Behav 26: 1167-1177.

Furness GW (1987) The Skuas. T \& A D Poyser, Calton, United Kingdom.

Fussmann GF y Heber G (2002) Food web complexity and chaotic population dynamics. Ecology Letters 5: $394-401$.

Galdbach A, Braun C, Nordt A, Petre H y Quillfeltd P (2009) Chick provisioning and nest attendance of male and female Wilson's storm petrels Oceanites oceanicus. Polar Biology 32(9): 1315-1321. doi: 10.1007/s00300-009-0628-z.

Gladbach A, McGill RAR y Quillfeldt P (2007) Foraging areas of Wilson's storm-petrel Oceanites oceanicus in the breeding and inter-breeding period determined by stable isotope analysis. Polar Biology 30(8): 1005-1012. doi: 10.1007/s00300-0070258-2.

Gilbert JR y Erickson AW (1977) Distribution and abundance of seals in the pack ice of the Pacific sector of the Southern Ocean. En: Adaptations within Antarctic ecosystems. Llano GA (Ed). Washington, D.C.: Smithsonian Institution, 703-708.

Gliwicz M (1986) Predation and the evolution of vertical migration in zooplankton. Nature 320: 746-748

Gochfeld M y Burger J (1996) Family Sternidae (Terns). En: Handbook of the birds of the world, vol 3. del Hoyo J, Elliot A, Sargatal J (Eds). Lynx Editions, Barcelona, pp 624-667.

Goebel ME, Costa DP, Crocker DE, Sterling JT y Demer DA (2000) Foraging ranges and dive patterns in relation to bathymetry and time-of-day of Antarctic fur seals, Cape Shirreff, Livingston Island. En: Antarctic ecosystems: models for wider ecological understanding Davidson W, Howard-Williams C y Broady P (Eds). New Zealand Natural Sciences, Christchurch, pp 47-50.

Goldsworthy SD, Hindell MA y Crowley HM (1997) Diet and diving behaviour of sympatric fur seals Arctocephalus gazella and A. tropicalis at Macquarie Island. En: Marine mammal research in the Southern Hemisphere, vol 1. Hindell M, Kemper C (Eds). Surrey Beatty, Chipping Norton, pp 151-163.

González-Solís J, Croxall JP y Wood AG (2000a) Foraging partitioning between giant petrels Macronectes spp. and its relationship with breeding population changes at Bird Island,South Georgia. Mar Ecol Prog Ser 204: 279-288.

González-Solís J, Croxall JP y Wood AG (2000b) Sexual dimorphism and sexual segregation in foraging strategies of northern giant petrels Macronectes halli during the incubation period. Oikos 90: 390-398.

Green K y Williams R (1986) Observations on food remains in faeces of elephant, leopard and crabeater seals. Polar Biology 6: 43-45.

Griffiths AM (1983) Factors affecting the distribution of the Snow Petrel (Pagodroma nivea) and the Antarctic Petrel (Thalassoica antarctica). Ardea 71:145-150.

Guinet C, Dubroca L, Lea MA, Goldsworthy S, Cherel Y, Duhamel G, Bonadonna F y Donnay JP (2001) Spatial distribution of foraging in female Antarctic fur seals Arctocephalus gazella in relation to oceanographic variables: a scale-dependent approach using geographic information systems. Mar Ecol Pro Ser 219: 251-264.

Hahn S y Peter HU (2003) Feeding territoriality and the reproductive consequences in brown skuas Catharacta antarctica lonnbergi. Polar Biology 26(8): 552-559. doi: 10.1007/s00300-003-0522-z.

Hahn S, Ritz MS y Reinhardt K (2008) Marine foraging and annual fish consumption of a south polar skua population in the maritime. Polar Biology 31: 959-969. doi: 10.1007/s00300-008-0436-x.

Hakoyama H, Le Boeuf BJ, Naito Y y Sakamoto W (1994) Diving behavior in relation to ambient water temperature in northern elephant seals Canadian Journal of Zoology 72(4): 643-651.

Harper PC, Croxall JP y Cooper J (1985) A guide to foraging methods used by marine birds in Antarctic and Subantarctic seas. Biomass Handbook N 24. U S NOAA USA.

Hewitt RP, Watkins J, Naganobu M, Sushin V, Brierley AS, Demer D, Kasatkina S, Takao Y, Goss C, Malyshko A, Brandon M, Kawaguchi S, Siegel V, Trathan P, Emery J, Everson I y Miller D (2004) Biomass of Antarctic krill in the Scotia Sea in 
January/February 2000 and its use in revising an estimate of precautionary yield. Deep Sea Research Part II: Topical Studies in Oceanography 51(12-13): 1215-1236.

Hindell MA, Burton HR y Slip DJ (1991) Foraging grounds of southern elephant seals, Mirounga leonina, as inferred from water temperature data. Aust J Mar Freshwater Res. 42: 115-128.

Hunter S (1983) The food and feeding of the giant petrels Macronectes halli and M. giganteus at South Georgia. J Zool Lond 200: 521-538.

Hunter S (1985) The role of giant petrels in the Southern Ocean ecosystem. En: Antarctic nutrient cycles and food webs Siegfried WR, Laws RM, Condy PR (Eds). Springer, Berlin Heidelberg New York, pp 534-542.

Ichii T, Bengtson JL, Boveng PL, Takao Y, Jansen JK, Hiruki-Raring LM, Cameron MF, Okamura H, Hayashi T y Naganobu M (2007) Provisioning strategies of Antarctic fur seals and chinstrap penguins produce different responses to distribution of common prey and habitat. Mar Ecol Prog Ser 344: 277-297. doi: 10.3354/meps06873.

Ichii T, Katayama K, Obitsu N, Ishii H y Naganobu M (1998) Occurrence of Antarctic krill (Euphausia superba) concentrations in the vicinity of the South Shetland Islands: relationship to environmental parameters. Deep Sea Research Part I: Oceanographic Research Papers 45(8): 1235-1262. doi:10.1016/S0967-0637(98)00011-9.

Illius AW y Gordon IJ (1993) Diet selection in mammalian herbivores: constraints and tactics. En: Diet selection. An interdisciphnary approach to foraging behaviour. Hughes RN (Ed) Blackwell, Oxford, pp 157-181.

Jablonski B (1995) Distribution, abundance and biology of the Antarctic Tern Sterna vittata on King George Island (South Shetland Islands). Acta Zoológica Cracoviensia 29: 117-186.

Jablonski B (1985) The diet of penguins of King George Island, South Shetland Islands. Acta zool Cracov 29: 117-186.

Jansen JK, Boveng PL y Bengtson JL (1998) Foraging modes of chinstrap penguins: contrasts between day and night. Marine Ecology Progress Series 165: 161-172.

Johnstone GW (1977) Comparative feeding ecology of the giant petrels Macronectes giganteus (Gmelin) and M. halli (Mathews). En: Adaptations within Antarctic ecosystems. Llano G (Ed). Gulf Publishing, Houston, pp 647-668.

Jonker FC y Bester MN (1994) The diving behaviour of adult southern elephant seal, Mirounga leonina, cows from Marion Island. S. Afr. J. Antarct. Res. 24: 75-93.

Jouventin P, Stahl JC y Weimerskirch H (1982) La recolonisation des íles Crozet par les otaries (Arctocephalus tropicalis et $A$. gazella). Mammalia 46: 505-514.

Kato A, Croxall J, Watanuki Y y Naito Y (1992) Diving patterns and performance in male and female blue-eyed cormorants Phalacrocorax atriceps at South Georgia. Marine Ornithology 19: 117-129.

Kato A, Nishiumi I y Naito Y (1996) Sexual differences in the diet of king cormorants at Macquarie Island. Polar Biology, 16: 7577.

Kato A, Watanuki Y, Nishiumi I, Kuroki M, Shaughnessy P y Naito Y (2000) Variation in foraging and parental behavior of king cormorants. The Auk 117(3): 718-730. doi: 10.1642/0004-8038.

Kaufman GW, Siniff DB y Reichle R (1975) Colony behavior of Weddell seals, Leptonychotes weddellii, at Hutton Cliffs, Antarctica Rapports et Proces-Verbaux des Reunions 169.

Kawaguchl K, Ishikawa S y Matsuda 0 (1986) The overwintering strategy of Antarctic krill (Euphausia superba Dana) under the coastal fast ice off the Ongul Islands in Liitzow-Holm Bay. Mem Natl Inst Polar Res Spec Iss 44: 67-85.

Kock KH (1992) Antarctic fish and fisheries. Cambridge University Press, Cambridge.

Kock KH (2005) Antarctic icefishes (Channichthyidae): a unique family of fishes. A review, Part I .Polar Biol 28: 862-895. doi 10.1007/s00300-005-0019-z.

Kooyman GL (1968) An analysis of some behavioral and physiological characteristics related to diving in the Weddell seal. En: Biology of the Antarctic Seas. Antarctic Research Series, vol 3. Llano GA y Schmidt WL (Eds) American Geophysical Union, Washington,DC, pp 227-261.

Kooyman GL (1981) Weddell seal consummate diver. En: Weddell Seal: Consummate Diver. Kooyman GL (Ed), Cambridge University Press, New York, NY, USA/Cambridge, UK (Illustrated maps X+135p.).

Kooyman GL, Drabey CM, Elsner R y Campbell WB (1971) Diving behavior of the Emperor Penguin, Aptenodytes forsteri. Auk 88: 775-795.

Kooyman GL y Ponganis PJ (1998). The physiological basis of diving to depth: birds and mammals. Annu Rev Physiol 60: 19 32.

Kuhn CE, McDonald BI, Shaffer SA, Barnes J, Crocker DE, Burns JM y Costa DP (2006) Diving physiology and winter foraging behavior of a juvenile leopard seal (Hydrurga leptonyx). Polar Biology 29: 303-307. 
Lascara CM, Hoffman EE, Ross RM y Quentin LB (1999) Seasonal variability in the distribution of Antarctic Krill, Euphausia superba, west of the Antarctic Peninsula. Deep Sea Research Part I 46: 951-984.

Laws RM (1984) Seals. En: Antarctic ecology. Laws RM (Ed) Academic Press, London, pp 81-96.

Laws RM (1985) The ecology of the Southern Oceans. American Scientis 73: 26-40.

Laws RM (1977) Seals and Whales of the Southern Ocean. Phil. Trans. R. Soc. Lond B 26 279(963): 81-96. doi: 10.1098/rstb.1977.0073.

Lawson GL, Wiebe PH, Ashjian CJ, Gallager SM, Davis CS y Warren JD (2004) Acoustically-inferred zooplankton distribution in relation to hydrography west of the Antarctic Peninsula. Deep Sea Research Part II 51: 2041-2072.

Lea MA, Cherel Y, Guinet C y Nichols PD (2002) Antarctic fur seals foraging in the Polar Frontal Zone: inter-annual shifts in diet as shown from fecal and fatty acid analyses. Mar Ecol Prog Ser 245: 281-297.

Lescroël A, Ridoux V y Bost CA (2004) Spatial and temporal variation in the diet of the gentoo penguin (Pygoscelis papua) at Kerguelen Islands. Polar Biology 27: 206-216.

Leopold M, Van Damme C y Van Der Veer H (1998) Diet of cormorants and the impact of cormorant predation on juvenile flatfish in the Dutch Wadden Sea. Journal of Sea Research 40: 93-107.

Linton LR, Davies RW y Wrona FJ (1981) Resource utilization indices: an assessment. J Animal Ecol 50: $283-292$.

Lishman GS (1985) The food and feeding ecology of Adelie penguins (Pygoscelis adeliae) and chinstrap penguins (Pygoscelis antarctica) at Signy Island, South Orkney Islands. Journal of Zoology Lond 205: 245-263.

Lishman LR y Croxall JP (1983) Diving depths of the Chinstrap Penguin. Brit Antar Surv Bull 61: 21-25.

Loeb V, Siegel V, Holm-Hansen 0, Hewitt R, Fraser W, Trivelpiece W y Trivelpiece S (1997) Effects of sea ice extent and krill or salp dominance on the Antarctic food web. Nature 387: 897-900.

Lowry LF, Testa JW y Calvert W (1988) Winter feeding of Crabeater and Leopard seals near the Antarctic Peninsula. Polar Biology 8: 475-478.

Luna-Jorquera G y Culik BM (2000) Metabolic rates of swimming Humboldt penguins. Mar Ecol Pro Ser 203: 301-309.

Lynnes AS, Reid K y Croxall JP (2004) Diet and reproductive success of Adelie and Chinstrap penguins: linking response of predators to prey population dynamics. Polar Biology 27: 544-554. doi: 10.1007/s00300-004-0617-1.

Lynnes AS, Reid K, Croxall JP y Trathan PN (2002) Conflict or coexistence? Foraging distribution and competition for prey between Adelie and Chinstrap penguins. Marine Biology 141: 1165-1174.

Magnuson JJ, Crowder LB y Medrick PA (1979) Temperature as an ecological resource. American Zoology 19: 331-334.

MacArthur RH y Pianka ER (1966) On the optimal use of a patchy environment. Am Nat 102: 603-609.

Martinez I (1992) Family Spheniscidae (Penguins). En: Handbook of the birds of the world, vol 1. del Hoyo J, Elliott AR y Sargatal J (Eds). Barcelona: Lynx Edicions ICBP, pp 140-158.

Maxson S y Bernstein NP (1982) Kleptoparasitism bv South Polar Skuas on Blue-eyed Shags, Antarctica. Wilson Bull. 94: 269281.

McCafferty DJ, Boyd IL, Walker TR y Taylor RI (1998) Foraging responses of Antarctic fur seals to changes in the marine environment. Mar Ecol Prog Ser 166: 285-299.

McConnell BJ, Chambers C y Fedak MA (1992) Foraging ecology of southern elephant seals in relation to the bathymetry and productivity of the Southern Ocean. Antarctic Science 4 (4): 393-398.

McConnell BJ y Fedak MA (1996) Movements of southern elephant seals. Canadian Journal of Zoology 74: 1485-1496.

Moline MA, Claustre H, Frazer TK, Schofield O y Vernet M (2004) Alteration of the food web along the Antarctic Peninsula in response to a regional warming trend. Global Change Biology 10 (12): 1973-1980.

Montalti D, Casaux R, Coria N, Soave G (1996) The importance of fish in the diet of the south polar skua Catharacta maccormicki at the South Shetland Islands, Antarctica. Documento WG-EMM-96/32.CCAMLR, Hobart, 7 pp.

Montevecchi WA (1993) Birds as indicators of change in marine prey stocks. En: Birds as Monitors of Environmental Change. 217-266 pp. Furness RW y Greenwood JJD (Eds.) Chapman y Hall, Londres, 633 pp.

Montevecchi WA, Berruti A (1991) Avian indication of pelagic fisheries and trophic changes in the southwest and northwest Atlantic. Acta 20th Congr Int Ornithol. 4: 2246-2256.Melián CJ y Bascompte J (2002) Complex networks: two ways to be robust? Ecology Letters 5: 705-708.

Mougin JL (1968) Etude ecologique de quatre especes de petrels Antarctiques. Oiseau 38: 1-51. 
Murphy RC (1936) Oceanic birds of South America. New York: American Museum of Natural History.

Nicol S (2006) Krill, Currents, and Sea Ice: Euphausia superba and Its Changing Environment. BioScience 56(2):111-120. doi: 10.1641/0006-3568.

Nordøy ES y Blix AS (2009) Movements and dive behaviour of two leopard seals (Hydrurga leptonyx) off Queen Maud Land, Antarctica. Polar Biology 32(2): 263-270. doi: 10.1007/s00300-008-0527-8.

Nordøy ES, Folkow L y Blix AS (1995) Distribution and diving behaviour of crabeater seals (Lobodon carcinophagus) off Queen Maud Land. Polar Biology 15(4): 261-268. doi: 10.1007/BF00239846.

Osborne BC (1985) Aspects of breeding biology and feeding behaviour of Brown Skua Catharacta lombergi on Bird Island, South Georgia. Br Antarct Surv Bull 66: 57-71.

Odum EP (1971) Fundamentals of ecology. W. B. Saunders Co., Philadelphia, 544 pp.

Orians G y Pearson N (1979) On the Theory of Central Place Foraging. En: Analysis of ecological systems. Horn DJ, Mitchell RD y Stairs GR (Eds). Ohio State University Press, Columbus, Ohio. pp 155-177.

Pennycuick CJ, Croxall JP y Prince PA (1984) Scaling of foraging radius and growth rate in petrels and albatrosses (Procellariiformes). Ornis Scand 15: 145-154.

Pianka ER (1976) Competition and niche theory. En: Theoretical ecology: principles and applications. May RM (Ed) Blackwell, Oxford, pp 114-141.

Piatt JF, Nettleship DN (1985) Diving depths of four alcids. Auk 102: 293-297.

Prince PA y Harris MP (1988) Food and feeding ecology of alcids and penguins. Proc XIX Intl Ornithol Congr $1195-1204$.

Prince PA y Morgan RA (1987) Diet and feeding ecology of Procellariiformes. En: Seabirds: feeding ecology and role in marine ecosystems. Croxall JP (Ed), pp 135-171.

Quillfeldt P (2002) Seasonal and annual variation in the diet of breeding and non-breeding Wilson's storm-petrels on King George Island, South Shetland Islands. Polar Biology 25: 216-221.

Reinhardt K, Hahn S, Peter H-U (1998) The role of skuas in the food web of Potter Cove system-a review. Ber Polarforsch 299: $279-284$.

Reiss CR, Cossi AM, Loeb V y Demer DA (2008) Variations in the biomass of Antarctic krill (Euphausia superba) around the South Shetland Islands, 1996-2006. ICES J Mar Sci 65(4): 497-508. doi: 10.1093/icesjms/fsn033.

Ridoux V (1994) The diets and dietary segregation of seabirds at the subantarctic Crozét Islands. Marine Ornithology 22: 1192.

Ridoux V y Offredo C (1989) The diets of five summer breeding seabirds in Adélie Land, Antarctica. Polar Biology 9: 137-145.

Roberts B (1940) The life cycle of Wilson's petrel Oceanites oceanicus (Kuhl). Sci Rep British Graham Land Exped 1: 141-194.

Rogers TL, Hogg CJ y Irvine A (2005) Spatial movement of adult leopard seals (Hydrurga leptonyx) in Prydz Bay, Eastern Antarctica. Polar Biology 28(6): 456-463. doi: 10.1007/s00300-004-0703-4.

Rombolá E, Marschoff E and Coria N (2002) Interannual study of Chinstrap penguin's diet and reproductive success at Laurie Island, South Orkney Islands, Antarctica. Polar Biology 29(6): 502-509. doi: 10.1007/s00300-005-0081-6.

Ropert-Coudert Y, Kato A, Baudat J, Bost C-A, Le Maho Y y Naito Y (2001) Feeding strategies of free-ranging Adélie penguins Pygoscelis adeliae analysed by multiple data recording. Polar Biology 24(6): 460-466. doi: 10.1007/s003000100234.

Scholander PF (1940) Experimental investigations on the respiratory function in diving mammals and birds. Hvalradets Skrifter 22: $1-131$.

Schreer JF y Kovacs KM (1997) Allometry of diving capacity in air-breathing vertebrates. Canadian Journal of Zoology 75: 339358.

Schreer JF y Testa JW (1995) Statistical classification of diving behavior. Marine Mammal Science 11: 85-93.

Schreer JF y Testa JW (1996) Classification of Weddell seal diving behavior. Marine Mammal Science 12: 227-250.

Schrieber RW y Clapp RW (1987) Pelecaniform feeding ecology. En: Seabirds: feeding ecology and role in marine ecology systems. Croxall JP (Ed). Cambridge University Press. Cambridge, pp 173-188.

Shuntov VP (1972) Seabirds and biological structure of the ocean. Rep. by Nat. Tech. Info. Service, U.S. Dept. of Commerce, $566 \mathrm{pp}$. 
Siegel V (2005) Distribution and population dynamics of Euphausia superba: summary of recent findings. Polar Biology 29(1): 1-22. doi: 10.1007/s00300-005-0058-5.

Siegel V (1988) A concept of seasonal variation of krill (Euphausia superba) distribution and abundance west of the Antarctic Peninsula. En: Antarctic Ocean and resources variability.. Sahrhage D (Ed.). Berlin. Springer, pp 119-230.

Siniff DB, DeMaster DP, Hofman RJ y Eberhardt LL (1977). An analysis of the dynamics ot' a Weddell seal population. Ecological Monographs 47(3): 19-335.

Sladen WJL (1955) Some aspects of the behaviour of the Adelie and Chinstrap penguins. Acta 1 Ith Congr. Intern. Ornithol., Basel: 241-246.

Sladen WJL (1958) The pygoscelid penguins, I. Methods of study, II. The Adelie penguin. Falkland IsI Depend Surv Sci Rep 17: $1-97$.

Slip DJ y Burton HR (1993) Movements and diving behaviour of southern elephant seals from Heard Island. En: Abstracts of the Tenth Biennial Conference on the Biology of Marine Mammals Galveston, Texas, pp 11-15.

Slip JD, Hindell MA y Burton HR (1994) Diving behaviour of southern elephant seals from Macquarie Island: An overview. En: Elephant seals: population ecology, behaviour and Physiology, Le Boeuf BJ y Laws RM (Eds), pp 253-289.

Soave G, Coria N, Silva P, Montalti D y Favero M (1996) The diet of the Cape petrel Daption capense during the chick-rearing period at Fildes Peninsula and Harmony Point, South Shetland Islands, Antarctica. Commission for the conservation of Antarctic marine living resources, ecosystem monitoring and management working group, document 96/17, Bergen, Norway.

Southwell CJ, Kerry KR y Ensor PH (2005) Predicting the distribution of crabeater seals Lobodon carcinophagus off East Antarctica during the breeding season. Mar Ecol Prog Ser 299: 297-309.

Steele WK (2005) Stable isotope ratios of Antarctic petrel (Thalassoica antarctica) and snow petrel (Pagodroma nivea) bone collagen. Polar Biology 28(9): 672-679.

Staniland IJ, Boyd IL y Reid K (2007) An energy-distance trade-off in a central-place forager, the Antarctic fur seal (Arctocephalus gazella). Marine Biology 152(2): 233-241. doi: 10.1007/s00227-007-0698-9.

Staniland IJ, Robinson SL (2008) Segregation between the sexes: Antarctic fur seals, Arctocephalus gazella, foraging at South Georgia. Anim Behav 75: 1581-1590.

Takahashi A, Dunn MJ, Trathan PN, Croxall JP, Wilson RP, Sato K y Naito Y(2004) Krill-feeding behaviour in a Chinstrap penguin Pygoscelis antarctica compared with fish-eating in Magellanic penguins Spheniscus magellanicus: a pilot study. Marine Ornithology 32: 47-54.

Takahashi A, Dunn MJ, Trathan PN, Sato K, Naito Y y Croxall JP (2003) Foraging strategies of chinstrap penguins at Signy Island, Antarctica: importance of benthic feeding on Antarctic krill. Mar Ecol Prog Ser 250: 279-289.

Tanton JL, Reid K, Croxall JP y Trathan PN (2004) Winter distribution and behaviour of gentoo penguins Pygoscelis papua at South Georgia. Polar Biology 27: 299-303.

Thums M, Bradshaw CJA y Hindell MA (2008) A validated approach for supervised dive classification in diving vertebrates Journal of Experimental Marine Biology and Ecology 363(1-2): 75-83.

Todd F (1988) Weddell seal preys on Chinstrap penguin. Condor 90: 249-250.

Trathan PN, Croxal JO y Murphy EJ (1996) Dynamics of antarctic penguin populations in relation to inter-annual variability in sea ice distribution. Polar Biology 16(5): 321-330. doi: 10.1007/BF02342178.

Trathan PN, Priddle J, Watkins JL, Miller DGM y Murray AWA (1993) Spatial variability of Antarctic krill in relation to mesoscale hydrography. Mar Ecol Prog Ser 98(1-2): 61-71.

Trivelpiece WZ, Trivelpiece SG y Volkman NJ (1987) Ecological segregation of adelie, gentoo and chinstrap penguins at King George Island, Antarctica. Ecology 58(2): 351-361.

Trivelpiece WZ, Butler RG y Volkman J (1980) Feeding territories of Brown Skuas (Catharacta lonnbergi). The Auk 97: 669676.

Tyler AV (1972) Food resource division among northern, marine demersal fishes. J Fish Res Board Can 29: 997-1003.

Van Franeker JA (2001). Mirrors in ice. Fulmarine petrels and Antarctic ecosystems. Tesis doctoral. Universidad de Groningen, $274 \mathrm{pp}$.

Volkman NJ, Presler P y Trivelpiece W (1980) Diets of Pygoscelid Penguins at King George Island, Antarctica. The Condor 82(4): 373-378.

Wainwright PC (1994) Functional morphology as a tool in ecological research. En: Ecological morphology: integral organismal biology. Wainwright PC y Reilly SM (Eds). Chicago: University of Chicago Press, pp 42-59. 
Walker BG y Boveng P (1995) Effects of time-depth recorders on maternal foraging and attendance behavior of Antarctic fur seals Arctocephalus gazella. Canadian Journal of Zoology 73: 1538-1544.

Walker TR, Boyd IL, McCafferty DJ, Hun N, Taylor RI y Reid K (1998) Seasonal occurrence and diet of leopard seals (Hydrurga leptonyx) at Bird Island, South Georgia. Antarctic Science 10 (1): 75-81.

Wanless S, Finney S, Harris M y McCafferty D (1999) Effect of diel light cycle on the diving behaviour of two bottom feeding marine birds: the blue-eyed shag Phalacrocorax atriceps and the European shag P. aristotelis. Mar Ecol Prog Ser 188: 219224.

Wanless S y Harris M (1993) Use of mutually exclusive foraging areas by adjacent colonies of blue-eyed shags (Phalacrocorax atriceps) at South Georgia. Colon Waterbirds 16:176-182.

Wanless S, Harris MP y Greenstreet SPR (1998) Summer sandeel consumption by seabirds breeding in the Firth of Forth, south-east Scotland. ICES J Mar Sci 55: 1141-1151.

Wanless S, Harris M y Morris J (1992) Diving behaviour and diet of the blue-eyed shag at South Georgia. Polar Biology 12: 713-719.

Warham J (1990) The petrels: Their ecology and breeding systems. Academic Press (London and San Diego).

Watanuki Y, Kato A, Mori Y y Naito Y (1993) Diving performance of Adelie penguins in relation to food availability in fast sea-ice areas-comparison between years. Journal of Animal Ecology 62: 634-646.

Watson GE (1975) Birds of the Antarctic and Subantarctic. William Byrd Press, Richmond, Virginia.

Williams TD, Briggs DR, Croxall JP, Naito Y y Kato A (1992) Diving pattern and performance in relation to foraging ecology in the gentoo penguin, Pygoscelis papua. Journal of Zoology 227(2): 211-230.

Williams T, Croxall J, Naito Y y Kato A (1991) Diving patterns and processes in epipelagic and benthic foraging sub-Antarctic seabirds. International Ornithological Congress 20: 1393-1401.

Wilson GJ (1989) Marine palynology. En Antarctic Cenozoic history from the CIROS-1 drillhole, McMurdo Sound, Antarctica. Barrett PJ (Ed). Wellington, New Zealand,DSIR Publishing, Department of Scientific and Industrial Research Bulletin, v. 245 pp. 129-133.

Wilson PR, Ainley DG, Nur N, Jacobs SS, Barton KJ, Ballard G y Comiso JC (2001) Adélie penguin population change in the Pacific sector of Antarctica: relation to sea-ice extent and the Antarctic Circumpolar Current. Mar Ecol Prog Ser 213: 301309.

Wilson RP, Culik BM, Spairani HD, Coria NR y Adelung D (1991) Depth utilization by Penguins and Gentoo Penguin dive patterns. Rory P. Wilson, Boris Culik, Hugo J. Spairani, Nestor R. Coria and Dieter Adelung. Journal of Ornithology 132: 4760. doi: 10.1007/BF01640525.

Young EC (1963) Feeding habits of the south polar skua Catharacta maccormicki. Ibis 105: 301-318.

Zhou M y Dorland RD (2004) Aggregation and vertical migration behavior of Euphausia superba. Deep Sea Research Part II 51: $2119-2137$.

Zink RM (1981) Observation of seabirds during a cruise from Ross Island to Anvers Island, Antarctica. Wilson Bull. 93(I): 1-20. 


\section{V.7. Anexo de Tablas}

a) Re-ocurrencia composición general de la dieta

Tabla IV.5: Índice de re-ocurrencia de presas en la comunidad de predadores tope de las Islas Orcadas del Sur estimado de acuerdo al método de Tyler (1972). Las cruces indican las presas presentes en la dieta de cada predador. La re-ocurrencia es el número de presas que co-ocurren entre predadores tope.

\begin{tabular}{|c|c|c|c|c|c|c|c|c|c|c|c|c|c|}
\hline & $\begin{array}{c}\text { Pingüino de } \\
\text { Adelia }\end{array}$ & $\begin{array}{c}\text { Pingüino de } \\
\text { Barbijo }\end{array}$ & $\begin{array}{l}\text { Pingüino } \\
\text { Papúa }\end{array}$ & $\begin{array}{c}\text { Petrel } \\
\text { Damero }\end{array}$ & $\begin{array}{l}\text { Petrel de las } \\
\text { Nieves }\end{array}$ & $\begin{array}{c}\text { Petrel } \\
\text { Gigante }\end{array}$ & Escúa Marrón & $\begin{array}{l}\text { Gaviota } \\
\text { Cocinera }\end{array}$ & $\begin{array}{c}\text { Cormorán de } \\
\text { Georgias }\end{array}$ & $\begin{array}{l}\text { LOBO FINO } \\
\text { ANTÁRTICO }\end{array}$ & $\begin{array}{l}\text { Foca de } \\
\text { Weddell }\end{array}$ & $\begin{array}{c}\text { Foca } \\
\text { Cangrejera }\end{array}$ & $\begin{array}{c}\begin{array}{c}\mathbf{N}^{\circ} \text { Re- } \\
\text { ocurrencias }\end{array} \\
\end{array}$ \\
\hline \multicolumn{14}{|l|}{ Crustáceos } \\
\hline Krill & + & + & + & + & + & + & & + & & + & + & + & 9 \\
\hline Anfipodos & + & + & + & + & & + & & & + & + & + & & 7 \\
\hline Myscidos & & & & & & & & & & + & & & 0 \\
\hline Pygnogónido & & & & & & & & & & + & & & 0 \\
\hline \multicolumn{14}{|l|}{ Moluscos } \\
\hline Calamares & & + & + & & + & + & + & & + & + & + & & 7 \\
\hline Pulpos & & & & & & & & & + & + & + & & 2 \\
\hline Caracoles & & & & & & & & & + & + & + & & 2 \\
\hline Bivalvos & & & & & & & & & + & + & + & + & 3 \\
\hline Lapas & & & & & & & & & + & + & + & & 2 \\
\hline Poliquetos & & & & & & & & & + & + & + & & 2 \\
\hline Ascidias & & & & & & & & & & + & & & 0 \\
\hline Erizos & & & & & & & & & + & & & & 0 \\
\hline Peces & + & + & + & + & + & + & + & & + & + & + & + & 10 \\
\hline Pingüinos & & & & & & + & + & & & + & + & & 3 \\
\hline Aves voladoras & & & & & & + & + & & & & & & 1 \\
\hline Focas & & & & & & + & + & & & & & & 1 \\
\hline Algas & & & & & & & & & + & + & + & & 2 \\
\hline \multicolumn{14}{|l|}{$\begin{array}{l}\text { Total de Re- } \\
\text { ocurrencias }\end{array}$} \\
\hline $\begin{array}{l}\text { Máximo de Re- } \\
\text { ocurrencias }\end{array}$ & 187 & & & & & & & & & & & & \\
\hline \% de Re-ocurrencias & $27,30 \%$ & & & & & & & & & & & & \\
\hline
\end{tabular}


Tabla IV.6: Índice de re-ocurrencia de presas en la comunidad de predadores tope de las Islas Orcadas del Sur estimado de acuerdo al método de Tyler (1972) durante la temporada de verano austral 1997/98. Las cruces indican las presas presentes en la dieta de cada predador. La re-ocurrencia es el número de presas que co-ocurren entre predadores tope.

\begin{tabular}{|c|c|c|c|c|c|c|c|c|c|}
\hline & $\begin{array}{c}\text { Pingüino de } \\
\text { Adelia }\end{array}$ & $\begin{array}{c}\text { Pingüino de } \\
\text { Barbijo }\end{array}$ & $\begin{array}{l}\text { Pingüino } \\
\text { Papúa }\end{array}$ & $\begin{array}{c}\text { Petrel de } \\
\text { las Nieves }\end{array}$ & $\begin{array}{l}\text { Escúa } \\
\text { Marrón }\end{array}$ & $\begin{array}{c}\text { Gaviota } \\
\text { Cocinera }\end{array}$ & $\begin{array}{c}\text { Cormorán } \\
\text { de Georgias }\end{array}$ & $\begin{array}{l}\text { LOBO FINO } \\
\text { ANTÁRTICO }\end{array}$ & $\begin{array}{c}\mathrm{N}^{\circ} \mathrm{Re}- \\
\text { ocurrencias }\end{array}$ \\
\hline \multicolumn{10}{|l|}{ Crustáceos } \\
\hline Krill & + & + & + & + & & + & & + & 5 \\
\hline Anfípodos & + & + & + & & & + & & & 3 \\
\hline \multicolumn{10}{|l|}{ Moluscos } \\
\hline Calamares & & + & + & + & + & & & + & 4 \\
\hline Pulpos & & & & & & & + & & 0 \\
\hline Braquiópodos & & & & & & & + & & 0 \\
\hline Caracoles & & & & & & + & + & & 1 \\
\hline Bivalvos & & & & & & & + & & 0 \\
\hline Lapas & & & & & & + & + & & 1 \\
\hline Poliquetos & & & & & & & + & & 0 \\
\hline Peces & + & + & + & + & + & + & + & + & 7 \\
\hline Pingüinos & & & & & + & + & & + & 2 \\
\hline Aves voladoras & & & & & + & & & & 0 \\
\hline Focas & & & & & + & & & & 0 \\
\hline Algas & & & & & & & + & + & 1 \\
\hline Total de Re-ocurrencias & & & & & & & & & 24 \\
\hline $\begin{array}{l}\text { Máximo de Re- } \\
\text { ocurrencias }\end{array}$ & & & & & & & & & 98 \\
\hline \% de Re-ocurrencias & & & & & & & & & $24,50 \%$ \\
\hline
\end{tabular}


Tabla IV.7: Índice de re-ocurrencia de presas en la comunidad de predadores tope de las Islas Orcadas del Sur estimado de acuerdo al método de Tyler (1972) durante la temporada de verano austral 1998/99. Las cruces indican las presas presentes en la dieta de cada predador. La re-ocurrencia es el número de presas que co-ocurren entre predadores tope.

\begin{tabular}{|c|c|c|c|c|c|c|c|}
\hline & $\begin{array}{c}\text { Pingüino de } \\
\text { Adelia }\end{array}$ & $\begin{array}{c}\text { Pingüino de } \\
\text { Barbijo }\end{array}$ & $\begin{array}{l}\text { Pingüino } \\
\text { Papúa }\end{array}$ & $\begin{array}{c}\text { Petrel } \\
\text { Gigante }\end{array}$ & $\begin{array}{c}\text { Cormorán de } \\
\text { Georgias }\end{array}$ & $\begin{array}{l}\text { LOBO FINO } \\
\text { ANTÁRTICO }\end{array}$ & $\begin{array}{c}\mathrm{N}^{\circ} \mathrm{Re}- \\
\text { ocurrencias }\end{array}$ \\
\hline \multicolumn{8}{|l|}{ Crustáceos } \\
\hline Krill & + & + & + & + & & + & 4 \\
\hline Anfípodos & + & + & + & + & & + & 4 \\
\hline \multicolumn{8}{|l|}{ Moluscos } \\
\hline Calamares & & + & + & + & + & + & 4 \\
\hline Pulpos & & & & & + & & 0 \\
\hline Caracoles & & & & & + & & 0 \\
\hline braquiopodos & & & & & + & & 0 \\
\hline Bivalvos & & & & & + & & 0 \\
\hline Lapas & & & & & & + & 0 \\
\hline Poliquetos & & & & & + & & 0 \\
\hline Peces & + & + & + & + & + & + & 5 \\
\hline Pingüinos & & & & + & & + & 1 \\
\hline Aves voladoras & & & & + & & & 0 \\
\hline Algas & & & & & + & + & 1 \\
\hline Total de Re-ocurrencias & & & & & & & 19 \\
\hline Máximo de Re-ocurrencias & & & & & & & 72 \\
\hline$\%$ de Re-ocurrencias & & & & & & & $26,40 \%$ \\
\hline
\end{tabular}


Tabla IV.8: Índice de re-ocurrencia de presas en la comunidad de predadores tope de las Islas Orcadas del Sur estimado de acuerdo al método de Tyler (1972) durante la temporada de verano austral 1999/00. Las cruces indican las presas presentes en la dieta de cada predador. La re-ocurrencia es el número de presas que co-ocurren entre predadores tope.

\begin{tabular}{|c|c|c|c|c|c|c|c|}
\hline & $\begin{array}{l}\text { Pingüino de } \\
\text { Barbijo }\end{array}$ & $\begin{array}{l}\text { Pingüino } \\
\text { Papúa }\end{array}$ & $\begin{array}{c}\text { Petrel } \\
\text { Gigante }\end{array}$ & $\begin{array}{c}\text { Cormorán de } \\
\text { Georgias }\end{array}$ & $\begin{array}{l}\text { LOBO FINO } \\
\text { ANTÁRTICO }\end{array}$ & $\begin{array}{l}\text { Foca de } \\
\text { Weddell }\end{array}$ & $\begin{array}{c}\mathrm{N}^{\circ} \mathrm{Re}- \\
\text { ocurrencias }\end{array}$ \\
\hline \multicolumn{8}{|l|}{ Crustáceos } \\
\hline Krill & + & + & + & & + & + & 4 \\
\hline Anfípodos & + & + & + & & & & 2 \\
\hline Isopodos & & & & & & + & 0 \\
\hline Pygnogónido & & & & & + & & 0 \\
\hline \multicolumn{8}{|l|}{ Moluscos } \\
\hline Calamares & + & + & + & & + & & 3 \\
\hline Pulpos & & & & + & & + & 1 \\
\hline gastrópodos & & & & & + & + & 1 \\
\hline Bivalvos & & & & + & & & 0 \\
\hline Braquiópodos & & & & + & & & 0 \\
\hline Peces & + & + & + & + & + & + & 5 \\
\hline Pingüinos & & & + & & + & + & 2 \\
\hline Aves voladoras & & & + & & & & 0 \\
\hline Focas & & & + & & & & 0 \\
\hline Algas & & & & + & + & & 1 \\
\hline Total de Re-ocurrencias & & & & & & & 19 \\
\hline Máximo de Re-ocurrencias & & & & & & & 78 \\
\hline$\%$ de Re-ocurrencias & & & & & & & $24,36 \%$ \\
\hline
\end{tabular}


b) Re-ocurrencia composición de los peces en la dieta

Tabla IV.9: Índice de re-ocurrencia de presas en la comunidad de predadores tope de las Islas Orcadas del Sur estimado de acuerdo al método de Tyler (1972) durante la temporada de verano austral 1995/96. Las cruces indican las presas presentes en la dieta de cada predador. La re-ocurrencia es el número de presas que co-ocurren entre predadores tope.

\begin{tabular}{|c|c|c|c|c|}
\hline $1995 / 96$ & $\begin{array}{c}\text { Petrel } \\
\text { Damero }\end{array}$ & $\begin{array}{c}\text { Cormorán de } \\
\text { Georgias }\end{array}$ & $\begin{array}{l}\text { LOBO FINO } \\
\text { ANTÁRTICO }\end{array}$ & $\mathrm{N}^{\circ}$ Re-ocurrencias \\
\hline \multicolumn{5}{|l|}{ Bathydraconidae } \\
\hline P. charcoti & & & + & 0 \\
\hline \multicolumn{5}{|l|}{ Channichthyidae } \\
\hline C. aceratus & & & + & 0 \\
\hline C. rastrospinosus & & & + & 0 \\
\hline C. antarcticus & & & + & 0 \\
\hline P. georgianus & & & + & 0 \\
\hline \multicolumn{5}{|l|}{ Nototheniidae } \\
\hline G. gibberifrons & & + & + & 1 \\
\hline N. coriiceps & & + & + & 1 \\
\hline N. nybelini & & + & + & 1 \\
\hline N. nudifrons & & + & + & 1 \\
\hline P. bernacchii & & + & & 0 \\
\hline T. eulepidotus & & + & & 0 \\
\hline T. newnesi & & & + & 0 \\
\hline P. antarcticum & & & + & 0 \\
\hline \multicolumn{5}{|l|}{ Harpagiferidae } \\
\hline H. antarcticus & & & + & 0 \\
\hline \multicolumn{5}{|l|}{ Myctophidae } \\
\hline E. antarctica & + & & + & 1 \\
\hline G. braueri & + & & + & 1 \\
\hline G. nicholsi & + & & + & 1 \\
\hline G. opisthopterus & + & & + & 1 \\
\hline K. anderssoni & & & + & 0 \\
\hline P. choriodon & & & + & 0 \\
\hline P. normani & & & + & 0 \\
\hline \multicolumn{5}{|l|}{ Paralepididae } \\
\hline N. coatsi & & & + & 0 \\
\hline Total de Re-ocurrencias & & & & 8 \\
\hline Máximo de Re-ocurrencias & & & & 44 \\
\hline$\%$ de Re-ocurrencias & & & & 18,18 \\
\hline
\end{tabular}


Tabla IV.10: Índice de re-ocurrencia de presas en la comunidad de predadores tope de las Islas Orcadas del Sur estimado de acuerdo al método de Tyler (1972) durante la temporada de verano austral 1996/97. Las cruces indican las presas presentes en la dieta de cada predador. La re-ocurrencia es el número de presas que co-ocurren entre predadores tope.

\begin{tabular}{cccccc}
$1996 / 97$ & $\begin{array}{c}\text { Petrel de } \\
\text { las Nieves }\end{array}$ & $\begin{array}{c}\text { Petrel } \\
\text { Damero }\end{array}$ & $\begin{array}{c}\text { Cormorán de } \\
\text { Georgias }\end{array}$ & $\begin{array}{c}\text { LOBO FINO } \\
\text { ANTÁRTICO }\end{array}$ & $\begin{array}{c}\mathrm{N}^{\circ} \text { Re- } \\
\text { ocurrencias }\end{array}$ \\
\hline
\end{tabular}

Bathydraconidae
G. australis
G. acuticeps
P. charcoti

Channichthyidae
C. rhinoceratus
C. aceratus
C. wilsoni
C. rastrospinosus
C. antarcticus
P. georgianus

Nototheniidae

G. gibberifrons

N. coriiceps

$N$. nybelini

$N$. nudifrons

$P$. bernacchii

L. squamifrons

N. rossii

T. newnesi

$P$. antarcticum

Harpagiferidae

$H$. antarcticus

as Nieves

Damero Georgias

ANTÁRTICO ocurrencias

Myctophidae
E. carlsbergi
E. antarctica
G. braueri
G. nicholsi
G. opisthopterus
K. anderssoni
$P$. choriodon
P. normani
P. tenisoni

Paralepididae

N. coatsi

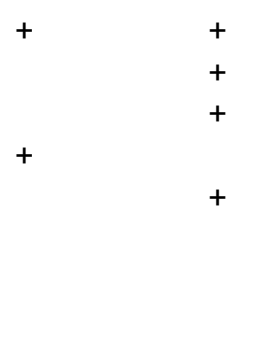

$+\quad 0$

$+\quad 0$

$+\quad 0$

$+\quad 0$

$+\quad 0$

$+\quad 0$

$+\quad 0$

$+\quad 0$

$+\quad 0$

Total de Re-ocurrencias

Máximo de Re-ocurrencias 
Tabla IV.11: Índice de re-ocurrencia de presas en la comunidad de predadores tope de las Islas Orcadas del Sur estimado de acuerdo al método de Tyler (1972) durante la temporada de verano austral 1997/98. Las cruces indican las presas presentes en la dieta de cada predador. La re-ocurrencia es el número de presas que co-ocurren entre predadores tope.

\begin{tabular}{ccccccc}
$1997 / 98$ & $\begin{array}{c}\text { Pingüino de } \\
\text { Adelia }\end{array}$ & $\begin{array}{c}\text { Petrel de las } \\
\text { Nieves }\end{array}$ & $\begin{array}{c}\text { Escúa } \\
\text { Marrón }\end{array}$ & $\begin{array}{c}\text { Cormorán de } \\
\text { Georgias }\end{array}$ & $\begin{array}{c}\text { LOBO FINO } \\
\text { ANTÁRTICO }\end{array}$ & $\begin{array}{c}N^{\circ} \text { Re- } \\
\text { ocurrencias }\end{array}$ \\
\hline
\end{tabular}

Bathydraconidae

P. charcoti Nieves Marrón Georgias ANTÁRTICO ocurrencias

Nototheniidae

G. gibberifrons

N. coriiceps

N. nybelini

$N$. nudifrons

N.rossii

P. bernachii

T. scotti

$T$. newnesi

Harpagiferidae

H. antarcticus

Myctophidae

E. antarctica

G. nicholsi

G. opisthopterus

\section{$+$}

$+$

$+$

$+$

$+$

$+$

$+$

$+$

$+$

P. choriodon

P. normani

Paralepididae

N. coatsi

$+$

Bathylagidae

B. glacialis

$+$

$+$

$+$

$+$
$+$

$+$

$+$

$+$

$+$

0

0

0

0

$+$

0

0 7

68

Máximo de Re-ocurrencias 
Tabla IV.12: Índice de re-ocurrencia de presas en la comunidad de predadores tope de las Islas Orcadas del Sur estimado de acuerdo al método de Tyler (1972) durante la temporada de verano austral 1998/99. Las cruces indican las presas presentes en la dieta de cada predador. La re-ocurrencia es el número de presas que co-ocurren entre predadores tope.

\begin{tabular}{|c|c|c|c|c|c|c|c|}
\hline $1998 / 99$ & $\begin{array}{l}\text { Pingüino de } \\
\text { Adelia }\end{array}$ & $\begin{array}{c}\text { Pingüino de } \\
\text { Barbijo }\end{array}$ & $\begin{array}{l}\text { Pingüino } \\
\text { Papúa }\end{array}$ & $\begin{array}{c}\text { Petrel } \\
\text { Damero }\end{array}$ & $\begin{array}{c}\text { Cormorán } \\
\text { de } \\
\text { Georgias }\end{array}$ & $\begin{array}{l}\text { LOBO FINO } \\
\text { ANTÁRTICO }\end{array}$ & $\begin{array}{c}\mathrm{N}^{\circ} \mathrm{Re}- \\
\text { ocurrencias }\end{array}$ \\
\hline \multicolumn{8}{|l|}{ Bathydraconidae } \\
\hline P. charcoti & & & & & + & & 0 \\
\hline \multicolumn{8}{|l|}{ Channichthyidae } \\
\hline C. aceratus & & & & & & + & 0 \\
\hline C. gunnari & & & & & & + & 0 \\
\hline C. antarcticus & & & + & & & & 0 \\
\hline \multicolumn{8}{|l|}{ Nototheniidae } \\
\hline G. gibberifrons & & + & + & & + & + & 2 \\
\hline N. coriiceps & & & & & + & & 0 \\
\hline N. nybelini & & & + & & + & & 1 \\
\hline N. nudifrons & & & + & & + & & 1 \\
\hline N. rossii & & & & & + & & 0 \\
\hline P. bernacchii & & & & & + & + & 1 \\
\hline T. newnesi & & + & + & & & & 1 \\
\hline \multicolumn{8}{|l|}{ Harpagiferidae } \\
\hline H. antarcticus & & & & & + & & 0 \\
\hline \multicolumn{8}{|l|}{ Myctophidae } \\
\hline E. antarctica & + & + & & + & & + & 3 \\
\hline G. nicholsi & & + & & + & & + & 2 \\
\hline G. opisthopterus & & & & + & & & 0 \\
\hline P. normani & & & & + & & + & 1 \\
\hline
\end{tabular}

Total de Re-ocurrencias

Máximo de Re-

ocurrencias 
Tabla IV.13: Índice de re-ocurrencia de presas en la comunidad de predadores tope de las Islas Orcadas del Sur estimado de acuerdo al método de Tyler (1972) durante la temporada de verano austral 1999/00. Las cruces indican las presas presentes en la dieta de cada predador. La re-ocurrencia es el número de presas que co-ocurren entre predadores tope.

\begin{tabular}{|c|c|c|c|c|c|c|}
\hline $1999 / 00$ & $\begin{array}{l}\text { Pingüino } \\
\text { Papúa }\end{array}$ & $\begin{array}{c}\text { Petrel } \\
\text { Damero }\end{array}$ & $\begin{array}{c}\text { Cormorán de } \\
\text { Georgias }\end{array}$ & $\begin{array}{l}\text { LOBO FINO } \\
\text { ANTÁRTICO }\end{array}$ & $\begin{array}{l}\text { Foca de } \\
\text { Weddell }\end{array}$ & $\begin{array}{c}\mathrm{N}^{\circ} \mathrm{Re}- \\
\text { ocurrencias }\end{array}$ \\
\hline \multicolumn{7}{|l|}{ Channichthyidae } \\
\hline C. rhinoceratus & + & & & & & \\
\hline C. aceratus & & & & + & + & 1 \\
\hline C. rastrospinosus & & & & & + & \\
\hline C. antarcticus & + & & & + & & 1 \\
\hline \multicolumn{7}{|l|}{ Nototheniidae } \\
\hline G. gibberifrons & + & & + & & + & 2 \\
\hline N. coriiceps & + & & + & & & 1 \\
\hline N. nybelini & + & & + & + & + & 3 \\
\hline N. nudifrons & + & & + & & + & 2 \\
\hline N. rossii & + & & + & & & 1 \\
\hline P. bernacchii & + & & + & & & 1 \\
\hline T. newnesi & + & & + & & + & 2 \\
\hline P. antarcticum & & & & + & & \\
\hline \multicolumn{7}{|l|}{ Harpagiferidae } \\
\hline H. antarcticus & + & & + & & & 1 \\
\hline \multicolumn{7}{|l|}{ Myctophidae } \\
\hline E. antarctica & + & + & & + & & 2 \\
\hline G. nicholsi & + & & & + & & 1 \\
\hline G. opisthopterus & & + & & & & \\
\hline
\end{tabular}

Total de Re-ocurrencias 


\section{Requerimientos energéticos}

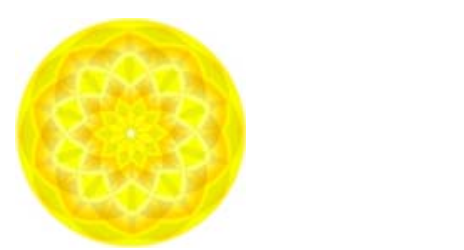

\section{V.1. Introducción}

En numerosas regiones antárticas y subantárticas, las aves y los mamíferos marinos superponen o superpusieron sus áreas de forrajeo con las de las actividades de las pesquerías comerciales. En Islas Orcadas del Sur (IOS) la pesca desarrollada entre 1970 y 1990 concentró sus esfuerzos en la captura de las Notothenia rossii y Chaenocephalus gunnari, de las cuales la primera llegó casi a desaparecer del área. Durante ese mismo período, algunas aves marinas han sufrido un intenso descenso poblacional, como es el caso del pingüino de Barbijo Pygoscelis antarctica (Trathan et al. 1996, N. Coria datos no publicados), el pingüino de Adelia Pygoscelis adeliae (Trathan et al. 1996) y el cormorán de Georgias Phalacrocorax georgianus (ver Cobley datos sin publicar en Rootes 1988, N. Coria datos no publicados). Sin embargo, otras especies parecen haber incrementado el tamaño de sus poblaciones como es el caso del pingüino Papúa Pygoscelis papua durante los años '90 (Croxall 1995), y del Lobo Fino Antártico Arctocephalus gazella (Waluda et al. 2010).

Las características o particularidades de una comunidad de predadores son comúnmente analizadas en términos de cantidad de especies, densidades de individuos o a través de diferentes índices como la diversidad, la equitatividad, la conectividad o la resiliencia. Si bien estos parámetros son los más utilizados, el análisis de los flujos de energía (bioenergética) de un ecosistema es un indicador que se basa en el estudio de las relaciones alimentarias de sus componentes y que tiene como objetivo cuantificar las relaciones tróficas y los consumos netos de los diferentes gremios que conforman esa comunidad (Odum 1959). La estimación de los recursos marinos necesarios para mantener estable una comunidad de predadores se genera a partir de información sobre la composición de la dieta, los requerimientos energéticos de cada población y del contenido calórico de las presas (Furness 1978, Croxall et al. 1984). A partir de ello se puede calcular la energía total necesaria o flujo energético total capaz de mantener las redes tróficas involucradas en una comunidad, la proporción del flujo energético que se pierde por procesos tales como la respiración, la producción de biomasa por parte de los 
productores primarios y secundarios, entre otras estimaciones. Tales estimaciones también brindan una vía alternativa para expresar los estimadores característicos que describen las estructuras comunitarias (Wiens 1989). Trabajar con los flujos de energía implica traducir los ritmos biológicos de cada población en términos de consumo. Para ello es necesario tener conocimiento sobre sus requerimientos energéticos, derivados de las tasas metabólicas y cómo éstos son suplidos a través de la alimentación diaria. La tasa metabólica se calcula en función de las demandas necesarias para mantener las funciones fisiológicas básicas, alimentarse, reproducirse y defenderse.

Existen numerosas expresiones para estimar las diferentes tasas metabólicas de las aves (Aschoff y Pohl 1970, Kendeigh 1970, Calder 1974, Pimm 1976, Kendeigh et al. 1977, Furness 1982, Walsberg 1983) y de los mamíferos marinos (Kleiberg 1947, 1975, Lavigne et al. 1986, McNab 1988, Boyd 2002). En general, las aves marinas presentan tasas metabólicas basales levemente más elevadas que las demás aves no passeriformes de peso equivalente (Ellis 1984), de la misma manera que las tasas metabólicas de los mamíferos marinos suelen ser más altas que las de los mamíferos terrestres de tamaños similares (Berta et al. 2005). En el caso de aves y mamíferos buceadores, al estimarse el gasto energético, además de la consideración de la tasa basal y el gasto energético vinculado a la búsqueda y manipulación del alimento, también se deberán tener en cuenta las particularidades de su fisiología relacionadas con las actividades de buceo tales como el gasto energético relacionado con la termorregulación, el control de la alta presión interna a grandes profundidades y la baja concentración de oxígeno en sangre, la locomoción en el agua fría y la osmorregulación (Berta et al. 2005).

Ahora bien, en el campo del manejo pesquero, la aplicación de los modelos bioenergéticos está fundamentalmente destinada a generar planes de manejo ecológicamente sustentables, lo cual implica tener en cuenta las necesidades de la industria como así también los requerimientos alimentarios necesarios para mantener las poblaciones de predadores estables. A través de ello se pretende desarrollar estrategias de pesca que puedan mantenerse en el tiempo evitando el agotamiento del stock de peces y el consecuente decrecimiento de las poblaciones de predadores dependientes de ellos.

Antártida siempre fue una zona de alto interés para la industria pesquera. Enmarcado dentro de los objetivos del Tratado Antártico (TA, ver capítulo I), las estimaciones sobre el consumo de presas de interés comercial por parte de los predadores distribuidos en las áreas de explotación comenzaron a ser de importancia para desarrollar modelos de manejo pesquero dentro del área de la Convención (ver más adelante). Los primeros estudios realizados en Antártida indicaron que las aves marinas son capaces de consumir entre el 22 y el $29 \%$ de la producción local de peces (Wiens y Scott 1975, Furness 1978). Dada la marcada declinación de las poblaciones de aves marinas en zonas de alta intensidad de pesca (Nettleship et al. 1984) algunos investigadores sugieren que estas aves y las pesquerías compiten fuertemente por los recursos (Furness 1978, Furness y Cooper 1982, Bourne 1983, Duffy 1983). Sin embargo, otros estudios sugieren que la competencia entre los predadores antárticos, especialmente los pingüinos, y la pesca comercial por los recursos marinos es aparente (Croxall et al. 1994). Teniendo en cuenta esta problemática, Duffy y Schneider (1994) sugieren estudiar en profundidad cómo varían los requerimientos energéticos de los predadores de una comunidad, cuantificando la biomasa (en términos 
de toneladas de presas consumidas anualmente) necesaria para cubrir esos requerimientos, considerando también sus variaciones estacionales. En base a ello, a través del conocimiento de la composición de la dieta de los predadores presentes en las IOS presentada en el capítulo II, de datos de censos poblacionales, y de la investigación sobre los requerimientos energéticos diarios de cada especie, se estimarán los requerimientos energéticos anuales de las poblaciones más importantes que conforman la comunidad de predadores ictiófagos de Isla Laurie y de las IOS. Es de esperar que esta información sea de utilidad para el mantenimiento de la estabilidad del ecosistema frente a una posible reapertura de la pesca comercial en la zona.

\section{V.2. Materiales y métodos}

\section{V.2.1. Recopilación de datos}

Los datos sobre la composición de la dieta y tallas de peces consumidos fueron obtenidos a partir de los análisis presentados en el Capítulo II.

Los requerimientos energéticos diarios para cada predador fueron obtenidos de publicaciones (Tabla V.1) o calculados a partir de las ecuaciones de Kendeigh (1970), Kleiberg (1975) y Nagy (1994) según cada caso (ver más adelante).

La estimación de las poblaciones de los predadores (aves y mamíferos) de las IOS se obtuvo de censos realizados por Coria (datos un publicados) durante las temporadas reproductivas 1993/94 y 1994/95, y de los reportes presentados por Burton (1968), Price (1985), Rootes (1988), Woehler (1993), Harris et al. (1998), Carilini et al. (2006), Annon. (2008), Patterson et al. (2008), Harris et al. (2011), Carlini (datos no publicados) y Casaux (datos no publicados).

El listado de las especies consideradas de interés comercial, sus límites de captura (krill para la subárea 48.2 y peces para la subárea 48.3) y las tallas de los peces capturados y de los peces comercializables se obtuvieron de los informes de captura correspondientes a los años 2009 y 2010 presentados a la Comsión para la Conservación de los Recursos Vivos Marinos Antárticos (CCRVMA) y de las medidas de conservación vigentes.

Tabla V.1: Bibliografía utilizada para obtener los valores de requerimientos energéticos diarios (RED) de los predadores tope de las IOS. *: Por falta de información bibliográfica los RED fueron calculados a partir de la fórmula de Kendeigh (1970) para las aves y de Nagy (1994) y Kleiberg (1975) para los mamíferos.

\begin{tabular}{|ll|}
\hline Aves & \\
\hline Spheniscidae & \\
Pingüino de Adelia & Croll y Tershy 1998 \\
Pingüino de Barbijo & Moreno y Sanz 1996, Croll y Tershy 1998 \\
Pingüino de Papúa & Croxall et al. 1988, Croll y Tershy 1998 \\
Procellariidae & \\
Petrel Damero & Hodum y Weathers 2003 \\
\hline
\end{tabular}


Tabla V.1: Continuación.

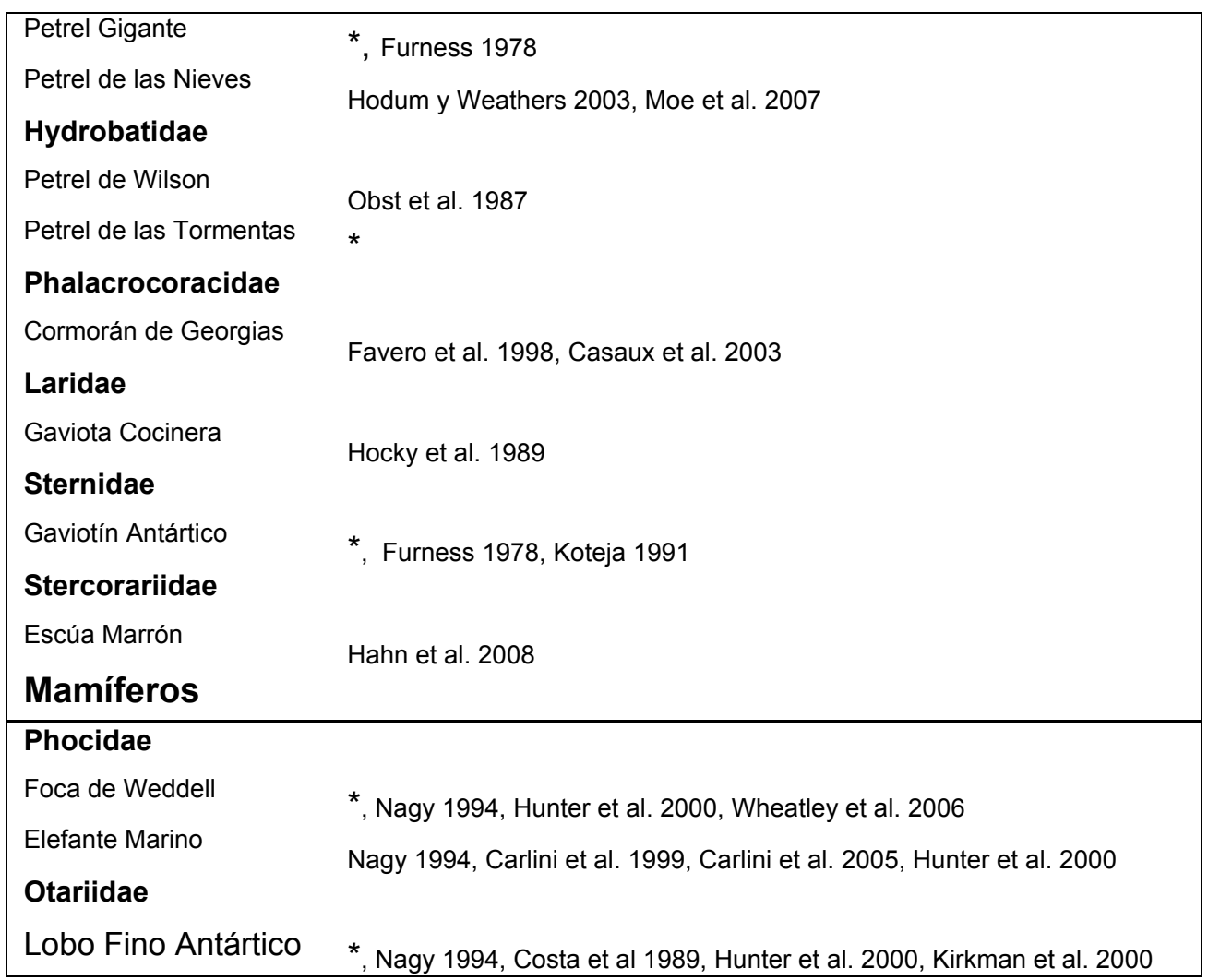

En función de la composición de la dieta de los predadores se calculó qué porcentaje de la misma estuvo compuesta por presas de interés comercial y qué porcentaje de las tallas de dichas presas se correspondieron con tallas explotables comercialmente.

\section{V.2.2. Análisis de datos}

\section{Requerimientos energéticos diarios (RED)}

En base al aporte de cada presa a la composición general de la dieta en términos de biomasa (M\%) (ver capítulo II) y al contenido energético de cada una de ellas (Tabla V.2) se calculó la contribución porcentual de cada presa a cada predador en términos de energía $(E \%)$.

El consumo anual de cada predador en términos energéticos se estimó multiplicando el número de individuos censados por el número de días de permanencia en las IOS y por los requerimientos energéticos diarios. Los requerimientos energéticos fueron extraídos de la bibliografía y en los casos de no haberse encontrado dicha información fueron estimados a partir de las ecuaciones: i) (Nagy 1994) y ii) (Kleiberg 1975) en el caso de los mamíferos, y iii) (Kendeigh 1970) en el caso de las aves: 
i) $\quad R E D(K j /$ día $)=5,27 \cdot W(g)^{0,723}$

ii) $\operatorname{TMB}(M j /$ día $)=0,293 \cdot W(K g)^{0,75}$; TMB: Tasa metabólica basal

iii) $\operatorname{TMB}(K j /$ día $)=4,33 \cdot W(g)^{0,53}$

Los RED comprenden la TMB más los requerimientos energéticos de las actividades relacionadas con el desplazamiento, la reproducción, y la alimentación, entre otros. En base a ello, Woehler y Green (1992) y Hunter et al. (2000) sugirieron que en el caso de los mamíferos los RED deben ser estimados a partir de un promedio entre la fórmula i) y 2,4 veces la fórmula ii), en tanto que para las aves marinas, Furness (1978) recomienda estimar los RED como 2 veces la fórmula iii). Los RED, conjuntamente con el aporte energético porcentual de cada presa a la dieta, fueron utilizados para estimar las toneladas de cada presa que cada predador consume a lo largo de la temporada reproductiva o del año, según su período de permanencia en la zona (Requerimientos Totales, RT). Dada la falta de información sobre la contribución en masa de los peces a la dieta del escúa Marrón y del elefante Marino para la zona de las IOS, las toneladas de pescado de consumo anual para la población del primero y su correspondiente energético fueron calculados a partir de las estimaciones propuestas por Hahn et al. (2008), en tanto que el consumo de alimento (en términos de tonelada) del Elefante Marino a lo largo del año en las IOS se calculó a partir de información sobre composición de la dieta generada en las ISS (Daneri y Carlini 2002). Dado que en las ISS el Elefante Marino consume importantes cantidades del pez Pleuragramma antarcticum, una especie muy poco representada en las IOS (ver capítulo III), los resultados obtenidos en esta sección deberán ser interpretados teniendo en cuenta un posible reemplazo de esta presa por otra en la zona de las IOS.

Tabla V.2: Contenido energético $(\mathrm{KJ} / \mathrm{g})$ de los principales ítems alimentarios de los predadores tope de las IOS. *1: Valor promedio de los datos para la familia; *2: Valor de C. aceratus.

\begin{tabular}{|lcl|}
\hline Presa & KJ/g & Referencia bibliográfica \\
\hline Krill & 4,35 & Croxall et al. (1985) \\
Anfípodos & 4,51 & Casaux (datos no publicados) \\
Lapas & 5,43 & Casaux (datos no publicados) \\
Calamar & 3,47 & Croxall et al. (1985) \\
Peces & 3,97 & Croxall et al. (1985) \\
Myctóphidos & 10,48 & *1 \\
E. antarctica & 10,05 & Van de Putte et al. (2006) \\
G. braueri & 10,91 & Tierney et al. (2002) extraído de Van de Putte et al. (2006) \\
Nototheniidos & 4,61 & \\
N. coriiceps & 3,35 & Márquez et al. (1996) \\
N. rossii & 3,45 & Márquez et al. (1996) \\
G. gibberifrons & 3,41 & Márquez et al. (1996) \\
P. antarcticum & 6,92 & Extraído de Hahn et al. (2008) \\
T. newnesi & 5,25 & Casaux (datos no publicados) \\
N. nudifrons & 5,33 & Casaux (datos no publicados) \\
P. bernacchii & 4,56 & Casaux (datos no publicados) \\
Channichtyidos & 4,73 & *2 \\
\hline
\end{tabular}


Tabla V.2: Continuación.

\begin{tabular}{|lrl|}
\hline $\begin{array}{l}\text { C. aceratus } \\
\text { Bathylagidae }\end{array}$ & 4,73 & Casaux (datos no publicados) \\
$\begin{array}{l}\text { B. antarcticus } \\
\text { Restos aves voladoras }\end{array}$ & 3,12 & Donnelly et al. (1990) extraído de Van de Putte et al. (2006) \\
Huevo pingüino & 5,72 & Casaux (datos no publicados) \\
$\begin{array}{l}\text { Pichón pingüino } \\
\text { Restos de mamíferos }\end{array}$ & 4,77 & Casaux (datos no publicados) \\
\hline
\end{tabular}

\section{Aves}

\section{Pingüinos}

Las poblaciones de pingüinos de Isla Laurie fueron estimadas en 85.000 parejas reproductivas para el pingüino de Adelia, 140.000 para el pingüino de Barbijo y en 460 para el pingüino Papúa (Coria datos no publicados), en tanto que para el total de las IOS las estimaciones fueron de 139.581, 347.318 y 8067 parejas reproductoras respectivamente (Woehler 1993). Para calcular los RET de estas aves se consideraron las variaciones de los RED a lo largo del ciclo reproductivo. Los RED de los pichones emancipados fueron considerados como los de los adultos no reproductores según lo calculado por Croll y Tershy (1998). Se consideró que el éxito reproductivo del Pingüino de Adelia es de 1,19 pichones por nido (Coria comunicación personal). Dado que no hay estimaciones disponibles sobre el éxito reproductivo en las IOS, para los pingüinos de Barbijo y Papúa, para estas especies también se utilizó dicho valor. El período de permanencia de los pingüinos en las IOS se estimó a partir de la información disponible en Rootes (1988).

\section{Cormorán de Georgias Phalacrocorax georgianus}

Las poblaciones de Isla Laurie e IOS en su conjunto fueron estimadas en 499 y 1.571 parejas reproductivas respectivamente (Coria datos no publicados; Harris et al 2011). Los RED variaron a lo largo del ciclo reproductivo y se estimaron en relación a las siguientes etapas: pre-puesta (30 días), incubación (30 días), cría temprana (30 días) y cría tardía (30 días). Los pichones fueron considerados como adultos no reproductores. El período de permanencia de los cormoranes en las IOS se estimó a partir de la información disponible en Rootes (1988).

\section{Petrel Gigante Común Macronectes giganteus}

La población estimada para este petrel en Isla Laurie y en las IOS en su conjunto fueron de 242 y 3400 parejas reproductivas respectivamente (Coria datos no publicados, Patterson et al. 2008). El éxito reproductivo estimado para el Petrel Gigante en las IOS es 0,72 pichones por nido (Coria 2006). Según lo sugerido por Evans (1973) y Furness (1978), se asumió que los RED de los petreles adultos fueron un 100\% más altos que la TMB estimada de acuerdo a Kendeigh (1970) (ecuación iii). Los RED de los pichones fueron calculados a partir de las curvas de crecimiento en peso (basadas en pesos tomados cada 10 días) estimadas por Coria (2006); los pichones emancipados se consideraron como adultos no 
reproductores. El período de permanencia del Petrel Gigante en las IOS se estimó a partir de la información disponible en Rootes (1988).

\section{Petrel Damero Daption capense}

La población de Petrel Damero estimada para las islas Laurie y Signy es de 84.000 y 12.000 parejas reproductivas respectivamente (Coria datos no publicados, Price 1985). Dado que no existen datos de éxito reproductivo de este petrel en las IOS se utilizó el valor estimado por Coria (2006) para el Petrel Gigante en I. Laurie. Los RED de los adultos se estimaron para las diferentes etapas del ciclo reproductivo de acuerdo a la cronología propuesta por Hodum y Weathers (2003) y a las siguientes consideraciones: la duración del período de puesta e incubación (fue de 45 días); el período de cría tuvo una duración de 47 días y en los RED de esta etapa se incluyeron los requerimientos de los pichones; durante el resto del ciclo los individuos fueron considerados como no-reproductores y sus RED se consideraron equivalentes a dos veces la TMB (ver arriba). Los pichones emancipados fueron considerados como adultos no reproductores. El período de permanencia del Petrel Damero en las IOS se estimó a partir de la información disponible en Rootes (1988).

\section{Petrel de las Nieves Pagodroma nivea}

La población de Petrel de las Nieves estimada para Isla Laurie es de 1250 parejas reproductivas (Coria datos no publicados). Dado que no hay estimaciones de éxito reproductivo para este petrel en las IOS se consideró el valor estimado por Coria (2006) para el Petrel Gigante en I. Laurie. Los RED de los adultos fueron estimados de acuerdo a la cronología propuesta por Hodum y Weathers (2003) y a las siguientes consideraciones: la duración del período de incubación es de 43 días y el período de cría es de 47 días. Los RED del período de cría incluyen los requerimientos de los adultos y de los pichones. Los adultos post-reproductores permanecen en las IOS 90 días. Los pichones emancipados fueron considerados como adultos post reproductores. El período de permanencia del Petrel de las Nieves en las IOS se estimó a partir de la información disponible en Rootes (1988).

\section{Petrel de Wilson Oceanites oceanicus}

La población de Petrel de Wilson estimada para las islas Laurie y Signy es de 2000 y 200.000 parejas reproductivas respectivamente (Coria datos no publicados, Harris et al. 2011). Tal como ocurrió con los petreles Damero y de Wilson, para el éxito reproductivo de esta especie se consideró la estimación hecha por Coria (2006) para el Petrel Gigante en I. Laurie. Los RED de los adultos se estimaron para las diferentes etapas del ciclo reproductivo de acuerdo a la cronología propuesta por Obst et al. (1987) y a las siguientes consideraciones: la duración del período de puesta e incubación fue de 40 días; el período de cría tuvo una duración también de 40 días y en los RED de esta etapa se incluyeron los requerimientos de los pichones; durante el resto del ciclo los individuos fueron considerados como noreproductores y sus RED se consideraron equivalentes a dos veces la TMB (ver arriba). El período de 
permanencia del Petrel de Wilson en las IOS se estimó a partir de la información disponible en Rootes (1988).

\section{Gaviotín Antártico Sterna vittata gaini}

La población de Gaviotín Antártico estimada para las islas Laurie y Signy es de 555 y 200 parejas reproductivas respectivamente (Coria datos no publicados, Rootes 1988). En relación al éxito reproductivo, se utiliza el valor promedio de las estimaciones hechas por Jablonski (1995) y Casaux et al. (2007) para el Gaviotín Antártico en las Islas Shetland del Sur (ISS). Los RED de los adultos fueron estimados de acuerdo a la cronología propuesta por Casaux (datos no publicados) y a las siguientes consideraciones: la duración del período de puesta e incubación es de 30 días; el período de cría es de 45 días y los RED de este período incluyen los requerimientos de los pichones; los adultos noreproductores permanecen en las IOS 195 días y sus RED equivalen a dos veces la TMB (ver arriba). Los pichones emancipados fueron considerados como adultos no reproductores. El período de permanencia del Gaviotín Antártico en las IOS se estimó a partir de la información disponible en Rootes (1988).

\section{Gaviota cocinera Larus dominicanus}

La población de Gaviota Cocinera estimada para las islas Laurie y Signy es de 339 y 50 parejas reproductivas respectivamente (Coria datos no publicados, Rootes 1988). Los RED de los adultos fueron extraídos a partir de los valores de demanda energética diaria estimados por Hocky et al. (1989) y considerando la demanda energética del período de cría según lo propuesto por Weathers (1992). Dado que no hay información disponible para las IOS, se asumió un éxito reproductivo de un pichón por nido. Los pichones emancipados fueron considerados como adultos no reproductores. El período de permanencia de la Gaviota Cocinera en las IOS se estimó a partir de la información disponible en Rootes (1988).

\section{Escúa Marrón Catharacta antarctica}

La población de Escúa Marrón estimada para Isla Laurie y las IOS en su conjunto es de 200 y 300 parejas reproductivas respectivamente (Coria datos no publicados, Harris et al. 2011). Los RED de los adultos fueron extraídos a partir de los valores de demanda energética diaria obtenidos por Harris et al. (2011) y considerando que los períodos de incubación y cría se extienden por 30 días cada uno (Burton 1968) y que los adultos no reproductores permanecen en las IOS por 150 días y sus RED fueron estimados a partir de la información aportada por Hahn et al. (2008). Los pichones emancipados fueron considerados como adultos no reproductores. El período de permanencia de los adultos reproductores en las IOS se estimó a partir de la información disponible en Rootes (1988). 
Los consumos totales de presas, tanto a nivel población como comunidad, fueron calculados a partir de reportes de dieta (ver capítulo II) y de estimaciones de los requerimientos energéticos de cada predador. Es importante aclarar que parte de la información utilizada no fue obtenida concurrentemente y que en el caso de algunos predadores, como por ejemplo el Elefante Marino, se utilizó información obtenida en otras localidades, lo que junto con la falta de estimaciones poblacionales de algunos predadores (Foca de Weddell, Petrel de las Nieves, Petrel Damero, entre otros; ver tabla V.10 y V.11) pueden haber afectado de algún modo los resultados. Sin embargo, y a pesar de ello, este estudio aporta información, no disponible hasta el momento, que permite incrementar el acercamiento a estrategias de manejo de los recursos holísticas e integrativas.

\section{Mamíferos}

\section{Foca de Weddell Leptonychotes weddellii}

La población estimada para la Foca de Weddell en I. Laurie es de 140 hembras reproductoras (Carlini datos no publicados), y de acuerdo a Siniff et al. (1977), Testa y Siniff (1987), y Husting y Testa (1998) se asumió que tuvieron un éxito reproductivo de 0,7 crías por hembra. La relación hembra-macho estimada para esta localidad es 1-3 (Carlini comunicación personal). Los RED de las hembras fueron calculados para 4 períodos diferentes a lo largo de todo el año: amamantamiento de la cría (45 días), primera fase acuática (15 días), período de muda (60 días) y segunda fase acuática (210 días) (Seal Conservation Society 2001). Los RED de los machos fueron divididos en la fase acuática y el período de muda. Los RED de los cachorros emancipados fueron calculados de acuerdo a su peso corporal para cada fase. El período de permanencia de la Foca de Weddell en las IOS se estimó a partir del censado de individuos (Carlini, datos no publicados).

\section{Elefante Marino del Sur Mirounga leonina}

Se consideró que el número de elefantes presentes en Isla Laurie es 72 , valor que deriva de censos realizados cada 5 días durante el año 2000 (Carlini datos no publicados), en tanto que el de las IOS es de 172 (Annon. 2008). El período de permanencia fue estimado en 255 días, los que se dividen en dos fases acuáticas (75 y 120 días respectivamente) y una de muda (60 días) (Le Beouf y Laws 1994). Los RED de cada fase acuática fueron calculados a partir de los datos reportados por Carlini et al. (2006) para hembras sub-adultas y por Boyd et al. (1993) para hembras mudando.

\section{Lobo Fino Antártico Arctocephalus gazella}

Se consideró que el número de lobos presentes en Isla Laurie y en las IOS en su conjunto es de 4.220 y de 4.769 individuos respectivamente, y que su tiempo de permanencia en el archipiélago es de 210 días (Carlini et al. 2006, Annon. 2008). Parte de esta información deriva de censos realizados cada 10-15 días entre los años 1996 y 2005 (Carlini et al. 2006). En dichos censos los individuos fueron clasificados como 
machos juveniles o machos adultos y la demanda energética poblacional se estimó de acuerdo a sus RED y a sus abundancias medias en cada mes.

\section{V.3. Resultados}

\section{V.3.1. Consumo de las poblaciones de predadores de las IOS}

\section{V.3.1.1. Consideraciones generales}

La estimación de los requerimientos energéticos diarios calculados para los predadores de las IOS se presentan en la Tabla V.3. Entre las aves, los RED variaron en función de la masa corporal. Los RED de las aves de mayor tamaño y de hábitos de forrajeo mixtos o exclusivamente ictiófagos tales como los pingüinos de Adelia y Papúa y el Cormorán de Georgias resultaron ser los más elevados para el grupo. Con respecto a los mamíferos, dada la importante diferencia en el tamaño corporal, el Elefante Marino fue la especie con mayor demanda energética. El Petrel de las Nieves, el Gaviotín Antártico, el Cormorán de Georgias y el Elefante Marino cubrieron sus RED principalmente a través del consumo de peces (Tabla V.4). Por el contrario, los pingüinos, el Petrel Damero, la Foca de Weddell y el Lobo Fino Antártico cubrieron sus necesidades energéticas con altos consumos de krill.

Tabla V.3: Requerimientos energéticos diarios (RED) para las aves (en KJ/día) y mamíferos (MJ/día) presentes en las IOS. $\hat{O}$ : RED machos, + : RED hembras, un adulto reproductor en época de cría.

\begin{tabular}{|c|c|c|c|}
\hline \multirow{2}{*}{ Aves } & \multicolumn{3}{|c|}{ KJ/día } \\
\hline & $q$ & $\hat{0}$ & 资 \\
\hline \multicolumn{4}{|l|}{ Spheniscidae } \\
\hline Pingüino de Adelia & 3526,42 & 3597,67 & 3386,58 \\
\hline Pingüino de Barbijo & 2749,17 & 3002,67 & 2393,33 \\
\hline Pingüino de Papúa & 3531,17 & 3523,58 & 2825,75 \\
\hline \multicolumn{4}{|l|}{ Procellariidae } \\
\hline \multicolumn{4}{|l|}{ Petrel de Wilson } \\
\hline Petrel Damero & 480 & 480 & 1196 \\
\hline Petrel de las Nieves & 417 & 417 & 793 \\
\hline \multicolumn{4}{|l|}{ Phalacrocoracidae } \\
\hline Cormorán de Georgias & 2280,3 & 2280,3 & 6741,64 \\
\hline \multicolumn{4}{|l|}{ Sternidae } \\
\hline Gaviotín Antártico & 340 & 340 & 224,94 \\
\hline \multicolumn{4}{|l|}{ Stercorariidae } \\
\hline Escúa Marrón & 1528 & 1528 & 1850 \\
\hline
\end{tabular}


Tabla V.3: Continuación.

\begin{tabular}{|l|ccc|}
\hline Mamíferos & \multicolumn{3}{c|}{ MJ/dia } \\
Phocidae & & & \\
Foca de Weddell & 48,77 & 69,53 & 23,81 \\
Elefante Marino & 61,71 & 233,55 & 62,90 \\
Otariidae & & & \\
Lobo Fino Antártico & 22,7 & 32,67 & -- \\
\hline
\end{tabular}

Tabla V.4: Contribución energética porcentual de las diferentes presas representadas en la composición general de la dieta de los predadores de las IOS.

\begin{tabular}{|c|c|c|c|c|c|c|c|c|}
\hline & $\begin{array}{l}\text { Pingüino } \\
\text { de Adelia }\end{array}$ & $\begin{array}{l}\text { Pingüino } \\
\text { de Barbijo }\end{array}$ & $\begin{array}{l}\text { Pingüino } \\
\text { de Papúa }\end{array}$ & $\begin{array}{c}\text { Petrel } \\
\text { Damero }\end{array}$ & $\begin{array}{c}\text { Petrel } \\
\text { Gigante }\end{array}$ & $\begin{array}{c}\text { Petrel de } \\
\text { Wilson }\end{array}$ & $\begin{array}{c}\text { Petrel de } \\
\text { las Nieves }\end{array}$ & $\begin{array}{l}\text { Gaviotín } \\
\text { Antártico }\end{array}$ \\
\hline Crustáceos & - & -- & -- & -- & -- & & -- & -- \\
\hline Krill & 99,11 & 99,50 & 57,27 & 45,43 & 0,72 & 0,27 & 3,88 & 2,19 \\
\hline Anfipodos & 0,41 & 0,45 & 0,12 & 0,42 & 0,05 & 0,23 & 0,68 & 2,78 \\
\hline Cefalópodos & -- & 0,02 & 0,90 & -- & 1,59 & & 0,37 & -- \\
\hline Lapas & -- & - & - & - & -- & & - & - \\
\hline Peces & -- & -- & -- & -- & 0,39 & & -- & - \\
\hline Otros & - & - & 0,22 & - & -- & & 1,30 & -- \\
\hline Aves & - & -- & - & - & - & & - & - \\
\hline Pingüinos & -- & - & - & -- & 90,00 & & -- & - \\
\hline Aves voladoras & -- & -- & - & - & 7,07 & & -- & - \\
\hline Mamíferos & - & - & - & - & 0,19 & & -- & -- \\
\hline
\end{tabular}

Tabla V.4: Continuación

\begin{tabular}{|l|ccccc|}
\hline & $\begin{array}{c}\text { Cormorán de } \\
\text { Georgias }\end{array}$ & $\begin{array}{c}\text { Gaviota } \\
\text { Cocinera }\end{array}$ & $\begin{array}{c}\text { Foca de } \\
\text { Weddell }\end{array}$ & $\begin{array}{c}\text { Elefante } \\
\text { Marino }\end{array}$ & $\begin{array}{c}\text { Lobo Fino } \\
\text { Antártico }\end{array}$ \\
\hline Crustáceos & 0,84 & 0,17 & 0,11 & -- & -- \\
Krill & -- & 14,56 & 33,66 & -- & 43,92 \\
Anfipodos & -- & 1,36 & -- & -- & -- \\
Moluscos & -- & 0,13 & 0,13 & -- & 2,96 \\
Cefalópodos & 2,1 & 0,13 & 26,18 & -- \\
Lapas & -- & 71,7 & -- & -- \\
Peces & -- & 7,95 & -- & -- & - \\
Notothéniidos & 74,32 & -- & 10,85 & 28,43 & 4,83 \\
Myctóphidos & -- & -- & - & 43,06 & 14,29 \\
\hline
\end{tabular}


Tabla V.4: Continuación.

\begin{tabular}{|l|ccccc|}
\hline Channícthyidos & 0,48 & -- & 6,4 & - & 5,52 \\
otros & 22,25 & -- & -- & -- & 0,17 \\
Aves & -- & -- & -- & -- & -- \\
Pingüinos & -- & 1,18 & 22,66 & -- & 28,32 \\
Aves voladoras & -- & 1,62 & -- & -- & - \\
Mamíferos & -- & 1,19 & -- & -- & - \\
\hline
\end{tabular}

En términos generales, las proporciones de aporte energético diario de las presas coincidieron con las proporciones de su contribución en biomasa. En este sentido, en la tabla V.5 los predadores fueron agrupados según la presa que contribuye mayoritariamente a cubrir sus requerimientos energéticos.

Tabla V.5: Predadores agrupados según las presas que cubren mayoritariamente sus RED.

\begin{tabular}{|c|c|c|c|c|}
\hline Krill & Notothénidos & Myctóphidos & Moluscos & Pingüinos \\
\hline 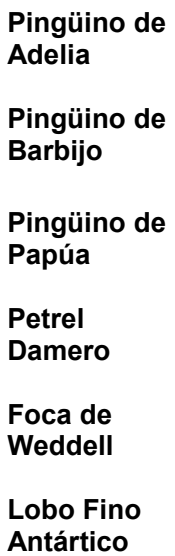 & $\begin{array}{l}\text { Gaviotín } \\
\text { Antártico } \\
\text { Cormorán de } \\
\text { Georgias }\end{array}$ & $\begin{array}{l}\text { Petrel de las } \\
\text { Nieves } \\
\text { Elefante Marino } \\
\text { * } \\
\text { Petrel de } \\
\text { Wilson }\end{array}$ & $\begin{array}{l}\text { Gaviota } \\
\text { Cocinera }\end{array}$ & $\begin{array}{l}\text { Petrel } \\
\text { Gigante }\end{array}$ \\
\hline
\end{tabular}

*Los resultados para el Elefante Marino se basaron en datos de dieta de las ISS, por tal razón, éstos pueden no estar reflejando correctamente lo que está sucediendo en la zona de estudio.

Es interesante destacar que aunque los peces myctóphidos no contribuyeron de un modo significativo a la dieta del Petrel Damero, del Petrel de las Nieves, del Gaviotín Antártico y del Elefante Marino en términos de biomasa (ver capítulo II), su contribución en términos energéticos fue importante. A modo de ejemplo se puede indicar que si bien el Petrel Damero consumió un $66 \%$ de krill en términos de biomasa, el $54 \%$ de sus necesidades energéticas fueron cubiertas a través del consumo de peces myctóphidos. Algo similar ocurrió con el Petrel de Wilson en el que el krill contribuyó con un $67 \%$ en términos de biomasa a la dieta y solo cubrió el $49,9 \%$ de los requerimientos energéticos, en tanto que los mycthóphidos aportaron un $28 \%$ en términos de biomasa y cubrieron el $50 \%$ de los requerimientos energéticos. 
V.3.1.2. Consumo anual de presas para la comunidad de predadores tope de la Isla Laurie

El consumo anual de alimento estimado para la comunidad de predadores tope de Isla Laurie fue $166.238,91$ toneladas de krill, $1.755,74$ toneladas de peces y 585,29 toneladas de cefalópodos, entre otros. En relación a estos valores, el 99\% del krill (164.589,83 Tn) y el 48,21 \% de los peces (846,38 Tn) fueron consumidos por la comunidad de aves marinas, en tanto que el $51,79 \%$ de los peces $(909,36 \mathrm{Tn})$ y el $98,62 \%$ de los cefalópodos $(577,23 \mathrm{Tn}$ ) fue consumido por los mamíferos marinos.

El Pingüino de Adelia fue el consumidor más importante de krill seguido por el Pingüino de Barbijo y el Lobo Fino Antártico (Tabla V.6). Con respecto a los peces, el Lobo Fino Antártico fue el predador más importante, seguido por la Foca de Weddell y el Petrel Damero. En el caso de los cefalópodos, la Foca de Weddell fue el predador más importante seguido por el Lobo Fino Antártico.

El flujo energético anual de la comunidad de predadores tope de Isla Laurie fue estimado en 7,46 x $10^{8} \mathrm{MJ}$, En concordancia con su densidad poblacional, dentro del grupo de las aves el Pingüino de Barbijo presentó la demanda energética más alta $\left(4,31 \times 10^{8} \mathrm{MJ}\right)$, seguido de el Pingüino de Adelia (2,86 $\times 10^{8} \mathrm{MJ}$ ). Tales demandas fueron cubiertas principalmente a través del consumo de krill, representado el $59,25 \%$ y el $39,25 \%$ respectivamente del consumo total anual de krill de toda la comunidad de predadores de Isla Laurie. Las aves con menores requerimientos energéticos fueron la Gaviota Cocinera $\left(7,25 \times 10^{4} \mathrm{MJ}\right.$, cubiertos en un $72 \%$ por lapas), seguida del Petrel de Wilson $\left(7,39 \times 10^{4} \mathrm{MJ}\right)$.

En el caso de los mamíferos, el Lobo Fino Antártico presentó la demanda energética más alta $\left(1,29 \times 10^{7} \mathrm{MJ}\right)$, la cual estuvo mayormente cubierta por el consumo de krill, el que representó alrededor del $0,74 \%$ del consumo anual de krill de la totalidad de la comunidad de predadores de Isla Laurie y el $74,82 \%$ del de los mamíferos considerados en este trabajo. El consumo anual de pingüinos por parte de la Foca de Weddell y del Lobo Fino Antártico fue importante $(980,56 \mathrm{Tn}$ ) y contribuyó a cubrir el $22 \%$ y el $28 \%$ de la demanda energética anual de estos predadores respectivamente (Tablas V.4 y V.6). Considerando que el peso promedio de un pingüino adulto ronda los $5 \mathrm{Kg}$. (Coria comunicación personal), tal consumo equivale a 196.112 individuos. Si se considera que la población de pingüinos ronda las 225.500 parejas y que el éxito reproductivo de estas aves se aproxima a 1,19 pichones por nido (Coria datos no publicados), ambos predadores consumen anualmente alrededor del $27,26 \%$ de la población total de pingüinos de Isla Laurie. Entre los mamíferos considerados, el Elefante Marino fue la especie con menor demanda energética (8,31 × 10 $\mathrm{MJ}$ ) (Tabla V.3).

Con respecto a la predación sobre las diferentes familias de peces, los predadores aquí analizados consumieron preferentemente myctóphidos (643,37 Tn. anuales), seguidos por los notothénidos (607,39 Tn. anuales). Es importante destacar la diferencia de rendimiento energético entre los individuos de ambas familias de peces. Si bien los consumos en término de biomasa fueron similares (ambas alrededor de las $600 \mathrm{Tn}$ ), los myctóphidos aportaron alrededor de 4 millones de MJ más de lo que aportaron los notothénidos (Tabla V.7). Con respecto a los predadores, y en términos de requerimientos energéticos, los notothénidos fueron consumidos mayormente por el Lobo Fino Antártico, por la F. del Weddell y por el Cormorán de Georgias; los myctóphidos fueron predados principalmente 
por el Petrel Damero y por el Lobo Fino Antártico, y los channíchthyidos fueron consumidos principalmente por el Lobo Fino Antártico seguido por la Foca de Weddell. (Tabla V.7).

En relación a las especies de peces, en términos de biomasa G. gibberifrons fue la especie más intensamente predada (391,60 Tn. anuales), seguida por G. nicholsi y C. aceratus (Tabla V.8 y V.9). En términos energéticos, las especies que más contribuyeron a cubrir las necesidades de los predadores

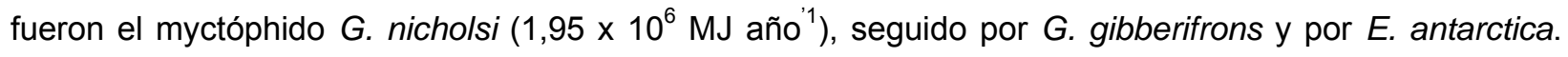
Con respecto a los predadores y a sus requerimientos energéticos, en todos los casos se observó que aquellos peces que fueron consumidos más intensamente en términos de biomasa, también fueron los que más contribuyeron a cubrir los requerimientos energéticos (Tabla V.8).

La calidad de las presas en términos energéticos queda expresada por su aporte calórico. En este sentido, los resultados presentados en la Tabla V.4 muestran claramente la importancia de los peces mycthóphidos en relación a su aporte de energía a los predadores. A modo de ejemplo se puede indicar que si bien el consumo en términos de biomasa de notothénidos y mycthóphidos por parte del Lobo Fino Antártico fue similar, en términos energéticos la energía aportada por los myctóphidos fue un orden de magnitud superior (ver Tabla V.7). 
Tabla V.6: Demanda energética poblacional anual (DEP) expresada en MJ/año de los predadores de las IOS, consumo de los principales ítems alimentarios en términos de biomasa (Tn) y de energía (MJ) y número de parejas reproductivas en Isla Laurie (tomado de Coria, datos no publicados). Los tamaños poblacionales de la Foca de Weddell representan el número de individuos adultos presentes en el área. Los tamaños poblacionales del Lobo Fino Antártico y del Elefante Marino corresponden al valor promedio de los picos máximos de abundancia observados a lo largo de las temporadas 1996 - 2005 y 2000 - 2001 respectivamente.

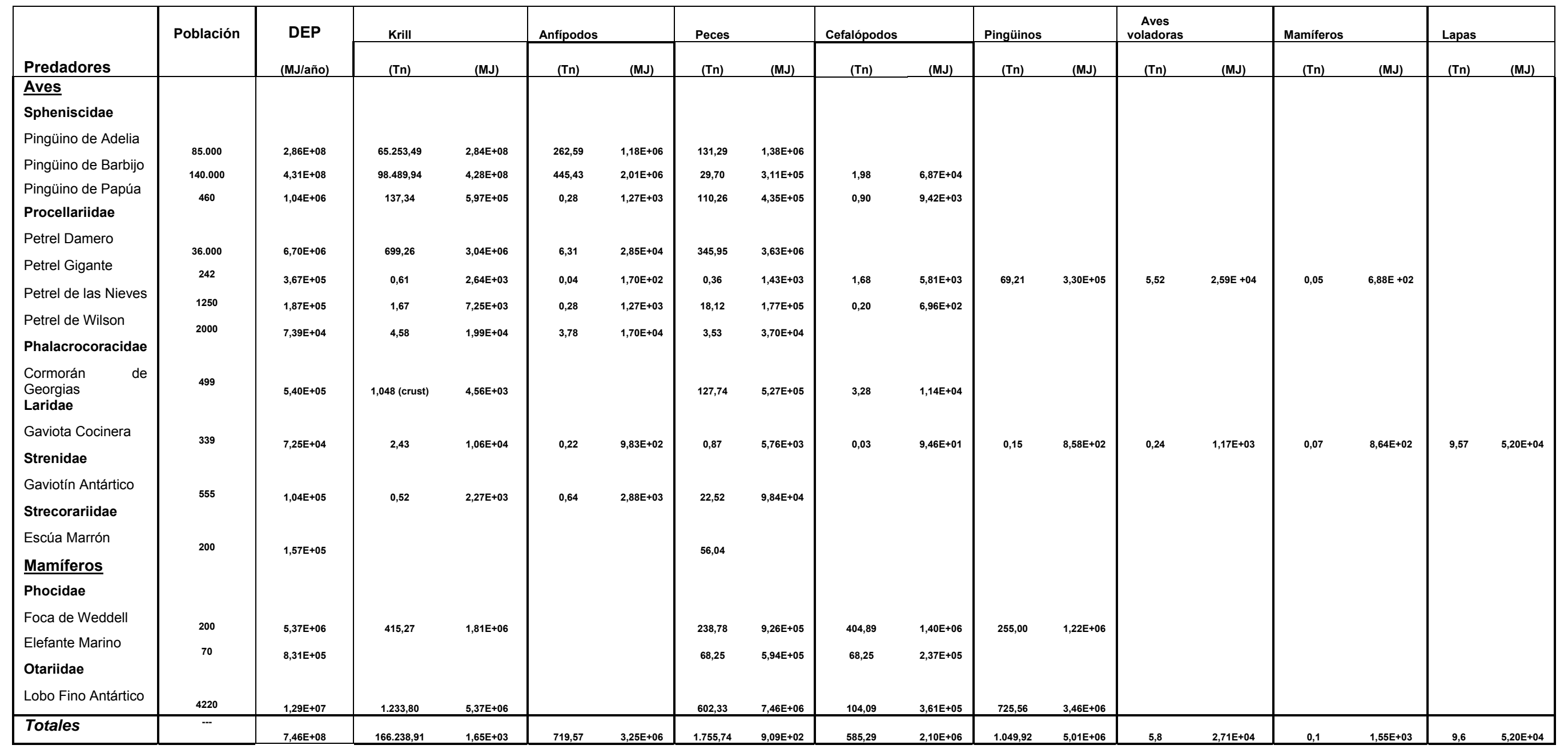


Tabla V.7: Consumo anual de peces (agrupados en familias) en términos de biomasa (Tn) y de energía (MJ) por parte de los predadores de Isla Laurie.

\begin{tabular}{|c|c|c|c|c|c|c|c|c|}
\hline & Nototheniidae (Tn) & (MJ) & Myctophidae (Tn) & (MJ) & Channichthyidae (Tn) & (MJ) & Otros (Tn) & (MJ) \\
\hline \multicolumn{9}{|l|}{ Aves } \\
\hline \multicolumn{9}{|l|}{$\begin{array}{l}\text { Spheniscidae } \\
\text { Pingüino de Adelia }\end{array}$} \\
\hline \multicolumn{9}{|l|}{ Pingüino de Barbijo } \\
\hline Pingüino de Papúa & 105,42 & $4,01 E+05$ & 1,78 & $1,94 E+04$ & 2,56 & $1,21 E+04$ & 0,50 & $2,31 E+03$ \\
\hline \multicolumn{9}{|l|}{ Procellariidae } \\
\hline Petrel Damero & & & 345,95 & $3,63 E+06$ & & & & \\
\hline Petrel de las Nieves & & & 17,34 & $1,75 E+05$ & & & 0,78 & $2,43 E+03$ \\
\hline Petrel de Wilson & & & 0,75 & $4,93 E+03$ & & & & \\
\hline \multicolumn{9}{|l|}{ Phalacrocoracidae } \\
\hline Cormorán de Georgias & 100,92 & $4,01 E+05$ & & & 0,55 & $2,60 \mathrm{E}+03$ & 26,27 & $1,20 \mathrm{E}+05$ \\
\hline \multicolumn{9}{|l|}{ Sternidae } \\
\hline Gaviotín Antártico & 19,08 & $6,39 E+04$ & 3,43 & $3,45 E+04$ & & & & \\
\hline Strecorariidae & & & & & & & & \\
\hline Escúa Marrón & 9,76 & & 46,28 & & & & & \\
\hline \multicolumn{9}{|l|}{ Mamíferos } \\
\hline \multicolumn{9}{|l|}{$\begin{array}{l}\text { Phocidae } \\
\text { Foca de Weddell }\end{array}$} \\
\hline & 166,11 & $5,83 E+05$ & & & 72,67 & $3,44 \mathrm{E}+05$ & & \\
\hline Elefante Marino & 34,13 & $2,36 \mathrm{E}+05$ & 34,13 & $3,58 \mathrm{E}+05$ & & & & \\
\hline \multicolumn{9}{|l|}{ Otariidae } \\
\hline Lobo Fino Antártico & 191,06 & $7,13 E+05$ & 193,71 & $2,03 E+06$ & 204,48 & $9,67 \mathrm{E}+05$ & 13,07 & $5,19 E+04$ \\
\hline TOTALES & 607,39 & $2,40 \mathrm{E}+06$ & 643,37 & $6,24 \mathrm{E}+06$ & 280,26 & $1,33 E+06$ & 40,62 & $1,77 \mathrm{E}+05$ \\
\hline
\end{tabular}


Tabla V.8: Consumo anual de peces (en términos de biomasa, $\mathrm{Tn}$ ) por parte de los predadores tope de Isla Laurie.

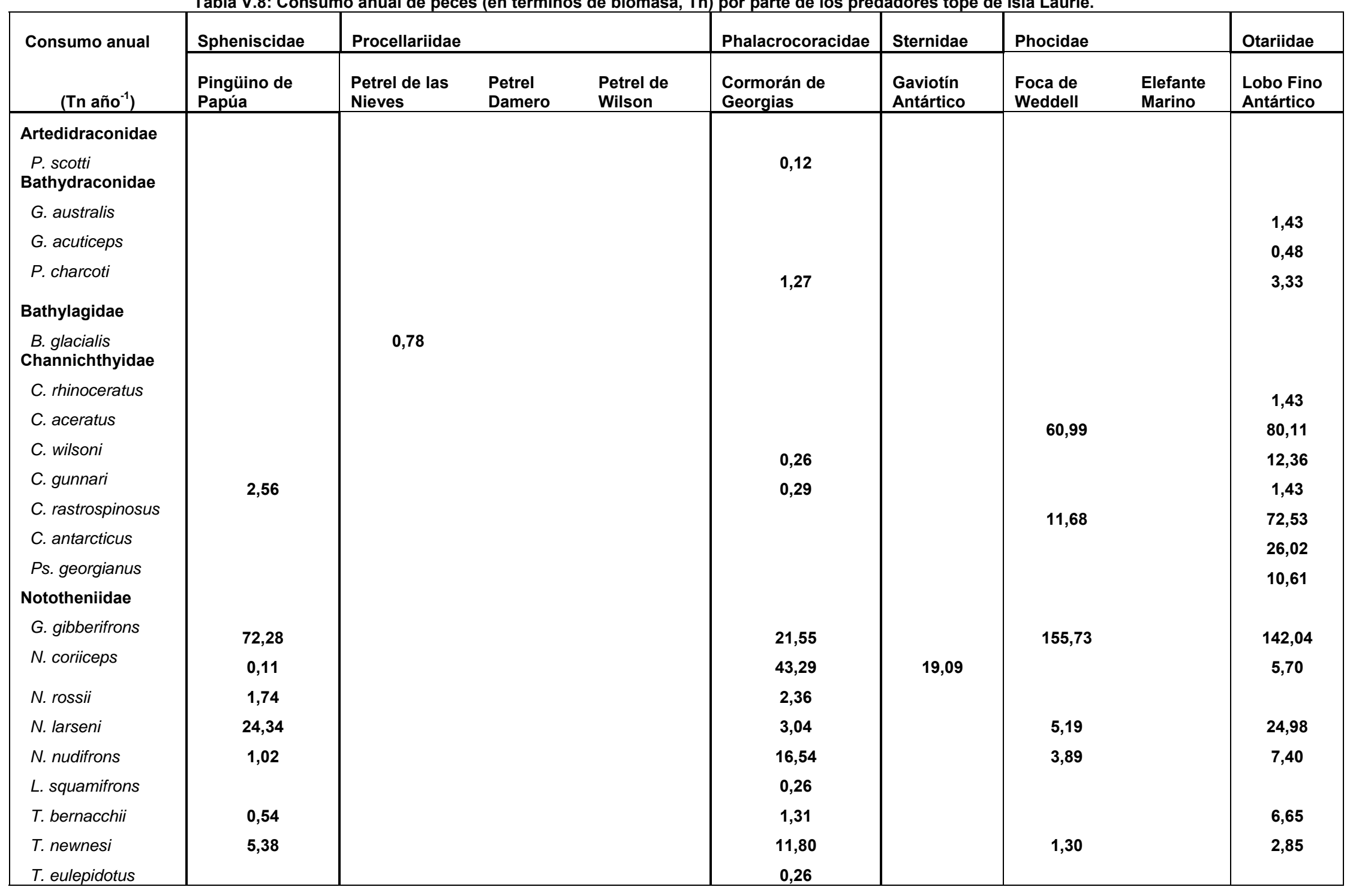


Tabla V.8: Continuación

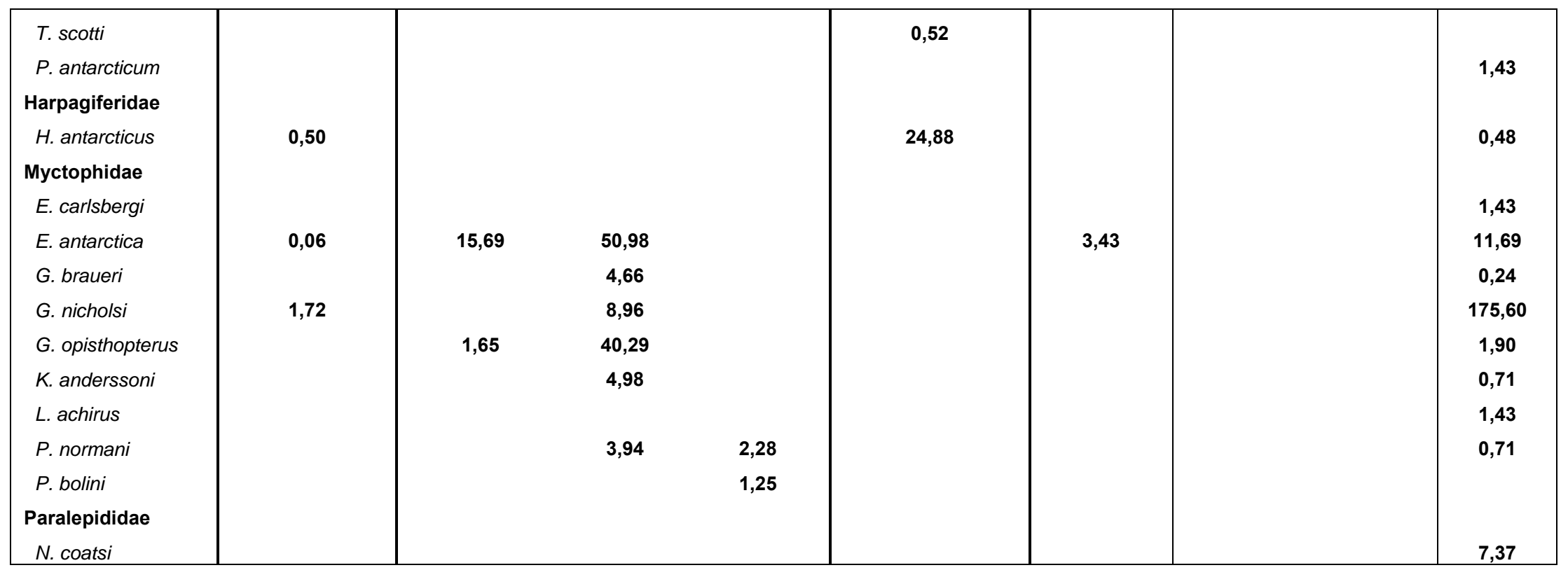


Tabla V.9: Consumo anual de peces en términos de energía (MJ) por parte de los predadores tope de Isla Laurie.

\begin{tabular}{|c|c|c|c|c|c|c|c|c|c|}
\hline \multirow[t]{2}{*}{ DEP (MJ año-1) } & \multirow{2}{*}{$\begin{array}{c}\text { Spheniscidae } \\
\begin{array}{c}\text { Pingüino de } \\
\text { Papúa }\end{array} \\
\end{array}$} & \multicolumn{3}{|l|}{ Procellariidae } & \multirow{2}{*}{$\begin{array}{c}\text { Phalacrocoracidae } \\
\begin{array}{c}\text { Cormorán de } \\
\text { Georgias }\end{array} \\
\end{array}$} & \multirow{2}{*}{$\begin{array}{c}\text { Sternidae } \\
\text { Gaviotín } \\
\text { Antártico } \\
\end{array}$} & \multicolumn{2}{|l|}{ Phocidae } & \multirow{2}{*}{$\begin{array}{l}\text { Otariidae } \\
\text { Lobo Finc } \\
\text { Antártico }\end{array}$} \\
\hline & & $\begin{array}{c}\begin{array}{c}\text { Petrel de las } \\
\text { Nieves }\end{array} \\
\end{array}$ & $\begin{array}{c}\text { Petrel } \\
\text { Damero }\end{array}$ & $\begin{array}{c}\text { Petrel de } \\
\text { Wilson }\end{array}$ & & & $\begin{array}{l}\text { Foca de } \\
\text { Weddell }\end{array}$ & $\begin{array}{c}\text { Elefante } \\
\text { Marino }\end{array}$ & \\
\hline $\begin{array}{l}\text { Artedidraconidae } \\
\text { P. scotti } \\
\text { Bathydraconidae } \\
\text { G. australis } \\
\text { G. acuticeps } \\
\text { P. charcoti } \\
\text { Bathylagidae } \\
\text { B. glacialis } \\
\text { Channichthyidae } \\
\text { C. rhinoceratus } \\
\text { C. aceratus } \\
\text { C. wilsoni } \\
\text { C. gunnari } \\
\text { C. rastrospinosus } \\
\text { C. antarcticus } \\
\text { Ps. georgianus } \\
\text { Nototheniidae } \\
\text { G. gibberifrons } \\
\text { N. coriiceps } \\
\text { N. rossii } \\
\text { N. larseni } \\
\text { N. nudifrons } \\
\text { L. squamifrons } \\
\text { T. bernacchii } \\
\text { T. newnesi } \\
\end{array}$ & $\begin{array}{l}1,21 E+04 \\
\\
2,46 E+05 \\
3,67 E+02 \\
6,01 E+03 \\
1,12 E+05 \\
5,46 E+03 \\
\\
2,45 E+03 \\
2,82 E+04\end{array}$ & $2,43 E+03$ & & & $\begin{array}{l}1,24 E+03 \\
1,36 E+03 \\
\\
7,35 E+04 \\
1,45 E+05 \\
8,14 E+03 \\
1,40 E+04 \\
8,82 E+04 \\
1,18 E+03 \\
5,98 E+03 \\
6,19 E+04 \\
\end{array}$ & $6,39 E+04$ & $\begin{array}{l}2,88 E+05 \\
5,52 E+04 \\
5,31 E+05 \\
2,39 E+04 \\
2,08 E+04 \\
6,81 E+03 \\
\end{array}$ & & $\begin{array}{l}5,66 E+03 \\
1,89 E+03 \\
1,32 E+04 \\
\\
6,74 E+03 \\
3,79 E+05 \\
5,84 E+04 \\
6,74 E+03 \\
3,43 E+05 \\
1,23 E+05 \\
5,02 E+04 \\
4,84 E+05 \\
1,91 E+04 \\
1,15 E+05 \\
3,94 E+04 \\
3,03 E+04 \\
1,50 E+04 \\
\end{array}$ \\
\hline
\end{tabular}


Tabla V.9: Continuación.

\begin{tabular}{|c|c|c|c|c|c|c|c|}
\hline $\begin{array}{l}\text { T. eulepidotus } \\
\text { T. scotti } \\
\text { P. antarcticum } \\
\text { Harpagiferidae } \\
\text { H. antarcticus } \\
\text { Myctophidae } \\
\text { E. carlsbergi } \\
\text { E. antarctica } \\
\text { G. braueri } \\
\text { G. nicholsi } \\
\text { G. opisthopterus } \\
\text { K. anderssoni } \\
\text { L. achirus } \\
\text { P. normani } \\
\text { P. bolini } \\
\text { Paralepididae } \\
\text { N. coatsi }\end{array}$ & $\begin{array}{l}2,31 \mathrm{E}+03 \\
6,06 \mathrm{E}+02 \\
1,88 \mathrm{E}+04\end{array}$ & $\begin{array}{l}1,58 E+05 \\
1,73 E+04\end{array}$ & $\begin{array}{l}5,34 \mathrm{E}+05 \\
4,89 \mathrm{E}+04 \\
9,39 \mathrm{E}+04 \\
4,22 \mathrm{E}+05 \\
5,22 \mathrm{E}+04 \\
4,13 \mathrm{E}+04\end{array}$ & $\begin{array}{l} \\
\\
2,39 E+04 \\
1,31 E+04\end{array}$ & $\begin{array}{l}1,21 \mathrm{E}+03 \\
2,42 \mathrm{E}+03 \\
1,15 \mathrm{E}+05\end{array}$ & $3,45 E+04$ & $\begin{array}{r}9,87 \mathrm{E}+03 \\
1,49 \mathrm{E}+04 \\
1,17 \mathrm{E}+05 \\
2,59 \mathrm{E}+03 \\
1,84 \mathrm{E}+06 \\
1,99 \mathrm{E}+04 \\
7,47 \mathrm{E}+03 \\
1,49 \mathrm{E}+04 \\
7,47 \mathrm{E}+03 \\
\\
2,92 \mathrm{E}+04\end{array}$ \\
\hline
\end{tabular}




\section{V.3.1.3. Consumo anual de presas para la comunidad de predadores tope de las Islas}

Orcadas del Sur

El consumo anual de alimento por parte de la comunidad de predadores de las IOS rondó las 367.929,21 toneladas, las que correspondieron a 357.612,59 toneladas de krill, 4.997,32 de peces y 875,38 de cefalópodos, entre otros (Tabla V.6). El Lobo Fino Antártico, el Petrel Gigante y la Foca de Weddell consumieron en total $2.424,65$ toneladas de pingüinos, de las cuáles 1.059,60 fueron consumidas exclusivamente por el Petrel Gigante y cubrieron alrededor del $90 \%$ de sus requerimientos energéticos. Dado que el peso promedio de un ejemplar adulto de pingüino ronda los $5 \mathrm{Kg}$. (Coria comunicación personal), estos tres predadores consumieron a lo largo de la temporada aproximadamente 484.930 pingüinos. Considerando que la población de pingüinos de las IOS ronda las 495000 parejas reproductivas y que el éxito reproductivo de estas aves se aproxima a 1,19 pichones por nido (Coria datos no publicados), este grupo consumió aproximadamente el $32 \%$ de la población total de pingüinos (Tabla V.10).

En términos de biomasa las aves consumieron el $99 \%$ del krill y el $72,3 \%$ de los peces, en tanto que el $88 \%$ de los cefalópodos fue consumido por los mamíferos marinos considerados. Dentro de las aves, el Pingüino de Barbijo fue el predador que más krill consumió, seguido por el Pingüino de Adelia y el Pingüino de Papúa. El Pingüino de Papúa fue el predador que más peces consumió, seguido por el Lobo Fino Antártico y el Cormorán de Georgias. El Elefante Marino fue el predador que más cefalópodos consumió, seguido por el Lobo Fino Antártico (Tabla V.10).

El flujo energético anual estimado para la comunidad de predadores tope del archipiélago de las

IOS fue 1,61 x $10^{9} \mathrm{MJ}$, El Pingüino de Barbijo fue el predador que más energía consumió, seguido por el Pingüino de Adelia y el Lobo Fino Antártico. En estos tres predadores el aporte energético del krill fue importante (Tabla V.10). Los predadores con menores requerimientos energéticos fueron la Gaviota Cocinera, el Gaviotín Antártico, el Escúa Marrón y el Petrel de las Nieves (Tabla V.10).

Con respecto al consumo de individuos de las diferentes familias de peces, los predadores aquí considerados consumieron preferentemente notothénidos (2.626,55 Tn y 1,05 x 10 $\mathrm{MJ}$ ), seguidos por myctóphidos (1.346,29 Tn. y 1,37 x 10 MJ). Los notothénidos fueron consumidos mayormente por el Pingüino de Papúa, el Cormorán de Georgias y el Lobo Fino Antártico, en tanto que los myctóphidos fueron consumidos principalmente por el Petrel Damero, el Petrel de Wilson y el Lobo Fino Antártico (Tabla V.11).

En términos de biomasa, los peces mayormente consumidos fueron G. gibberifrons (1.552,76 Tn. anuales), seguido por L. larseni y G. nicholsi (Tabla V.12). Las especies que más contribuyeron a cubrir los requerimientos energéticos de los predadores fueron $G$. gibberifrons, seguido por el myctóphido $P$. normani y el notothénido $L$. larseni. 
Tabla V.11: Consumo (Tn) y demanda energética poblacional anual de los predadores de las lOS sobre tres familias de peces presentes en el área.

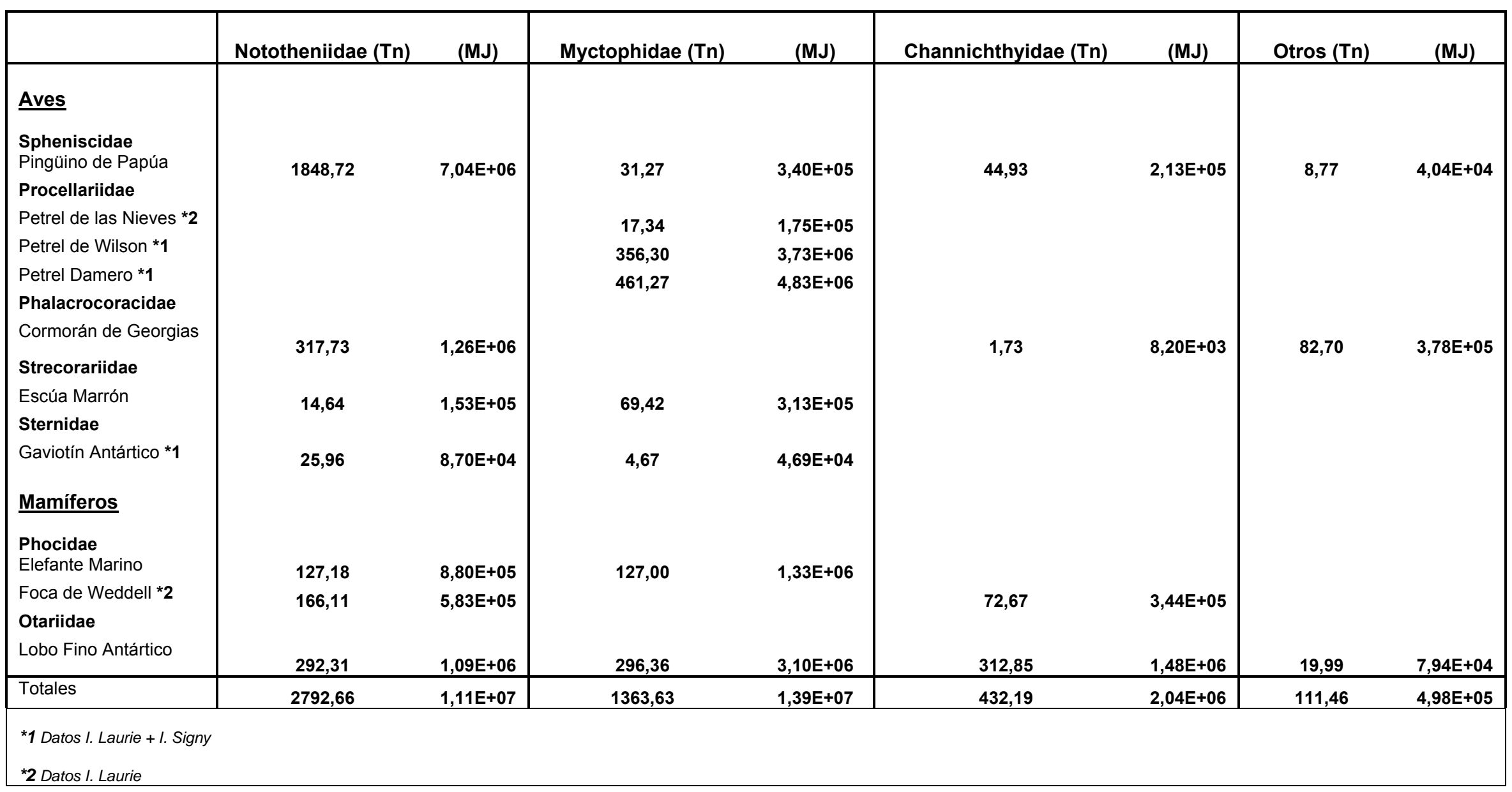


Tabla V.12: Consumo anual de los predadores tope de las IOS sobre las presas especies de peces (Tn año-1).

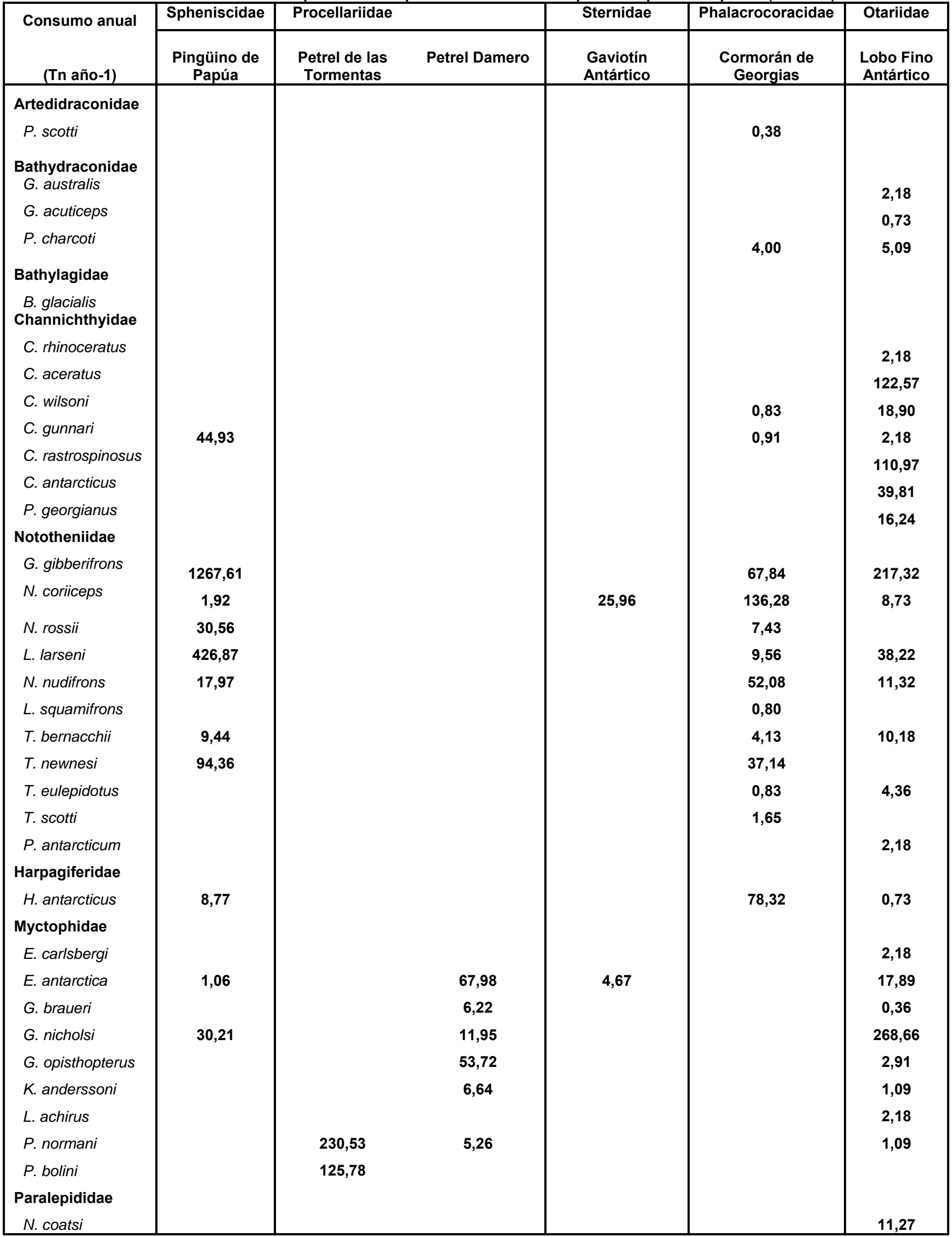


Tabla V.13: Requerimientos energéticos anuales de los predadores tope de las IOS sobre las presas especies de peces (MJ año-1).

\begin{tabular}{|c|c|c|c|c|c|c|}
\hline \multirow{2}{*}{ DEP (MJ año-1) } & Spheniscidae & Procellariidae & & Sternidae & Phalacrocoracidae & Otariidae \\
\hline & $\begin{array}{c}\text { Pingüino de } \\
\text { Papúa }\end{array}$ & $\begin{array}{c}\text { Petrel de las } \\
\text { Tormentas }\end{array}$ & Petrel Damero & $\begin{array}{c}\text { Gaviotín } \\
\text { Antártico }\end{array}$ & $\begin{array}{c}\text { Cormorán de } \\
\text { Georgias }\end{array}$ & $\begin{array}{l}\text { Lobo Fino } \\
\text { Antártico }\end{array}$ \\
\hline $\begin{array}{l}\text { Artedidraconidae } \\
\text { P. scotti } \\
\text { Bathydraconidae } \\
\text { G. australis } \\
\text { G. acuticeps } \\
\text { P. charcoti } \\
\text { Bathylagidae } \\
\text { B. glacialis } \\
\text { Channichthyidae } \\
\text { C. rhinoceratus } \\
\text { C. aceratus } \\
\text { C. wilsoni } \\
\text { C. gunnari } \\
\text { C. rastrospinosus } \\
\text { C. antarcticus } \\
\text { P. georgianus } \\
\text { Nototheniidae } \\
\text { G. gibberifrons } \\
\text { N. coriiceps } \\
\text { N. rossii } \\
\text { N. larseni } \\
\text { N. nudifrons } \\
\text { P. squamifrons } \\
\text { N. bolini } \\
\text { N. bernacchii } \\
\text { T. newnesi } \\
\text { T. eulepidotus } \\
\text { T. scotti } \\
\text { P. antarcticum } \\
\text { Harpagiferidae } \\
\text { H. antarcticus } \\
\text { Myctophidae } \\
\text { E. carlsbergi } \\
\text { E. antarctica } \\
\text { G. braueri } \\
\text { G. nicholsi } \\
\text { G. opisthopterus } \\
\text { K. anderssoni } \\
\text { L. achirus } \\
\text { P. normani } \\
\text { Paldae } \\
\text { P. }\end{array}$ & $\begin{array}{l} \\
2,13 E+05 \\
4,32 E+06 \\
6,44 E+03 \\
1,05 E+05 \\
1,97 E+06 \\
9,58 E+04 \\
4,30 E+04 \\
4,95 E+05 \\
4,04 E+04 \\
3,30 E+05\end{array}$ & (1) & 要 & $\begin{array}{l}8,70 \mathrm{E}+04 \\
, 69 \mathrm{E}+04\end{array}$ & $\begin{array}{l}1,49 E+03 \\
1,59 E+04 \\
\\
3,90 E+03 \\
4,29 E+03 \\
\\
2,31 E+05 \\
4,57 E+05 \\
2,56 E+04 \\
4,41 E+04 \\
2,78 E+05 \\
3,70 E+03 \\
1,88 E+04 \\
1,95 E+05 \\
3,80 E+03 \\
7,61 E+03 \\
3,61 E+05\end{array}$ & $\begin{array}{l}8,66 E+03 \\
2,89 E+03 \\
2,02 E+04 \\
\\
1,03 E+04 \\
5,80 E+05 \\
8,94 E+04 \\
1,03 E+04 \\
5,25 E+05 \\
1,88 E+05 \\
7,68 E+04 \\
7,41 E+05 \\
2,92 E+04 \\
1,76 E+05 \\
6,03 E+04 \\
4,64 E+04 \\
2,29 E+04 \\
1,51 E+04\end{array}$ \\
\hline
\end{tabular}




\section{V.3.2. Regulación de la pesca en el área de estudio}

La regulación de la pesca en Antártida ha pasado por varias etapas de evaluación desde la creación del TA hasta la actualidad. En la tabla V.14 se resumen las toneladas de pescado que fueron extraídas por las pesquerías comerciales en el área estadística 48 (Península Antártica, ISS, IOS e Islas Georgias del Sur (IGS), Figura V.1) entre los años 1970 y 1990, donde se destacan C. gunnari y G. gibberifrons como las especies mayormente capturadas.

Tabla V.14.: Toneladas (Tn) de pescado extraídas en el área estadística 48 entre los años 1970 y 1990 (1969/70 a 1989/90). Tomado de Kock (1989).

\begin{tabular}{|lc|}
\hline Nototheniidae & Tn \\
\hline N. rossii & 2.888 \\
G. gibberifrons & 38.821 \\
L. squamifrons & 239 \\
D. eleginoides & 258 \\
P. antarcticum & 110 \\
& \\
Channichthyidae & \\
\hline C. gunnari & 187.898 \\
C. aceratus & 2.605 \\
P. georgianus & 3.676 \\
C. rastrospinosus & 1.770 \\
\hline
\end{tabular}

A partir del análisis de las poblaciones de peces, actualmente se han fijado cupos de pesca para numerosas especies e incluso se ha vedado la pesca comercial de muchas de ellas para diferentes zonas, como es el caso de $N$. rossii en el área 48 en su conjunto luego de la década del '90. Si bien estas evaluaciones siguen realizándose, en términos de una explotación ecológicamente sustentable es fundamental que en la toma de decisiones se incorpore información sobre el consumo de los predadores tope $y$, en particular, sobre la posible competencia por las especies de interés comercial entre los predadores tope y las pesquerías.

Así entonces, con el objetivo de contrastar la información generada por este estudio y las gestiones de la CCRVMA se detalla a continuación un resumen de las actuales medidas de conservación (MC) relevantes en lo relacionado a este trabajo.

La siguiente lista muestra las especies que han sido tenidas en cuenta en la aplicación de límites de captura estipulados por la CCRVMA para la zona de la Convención Antártica. 


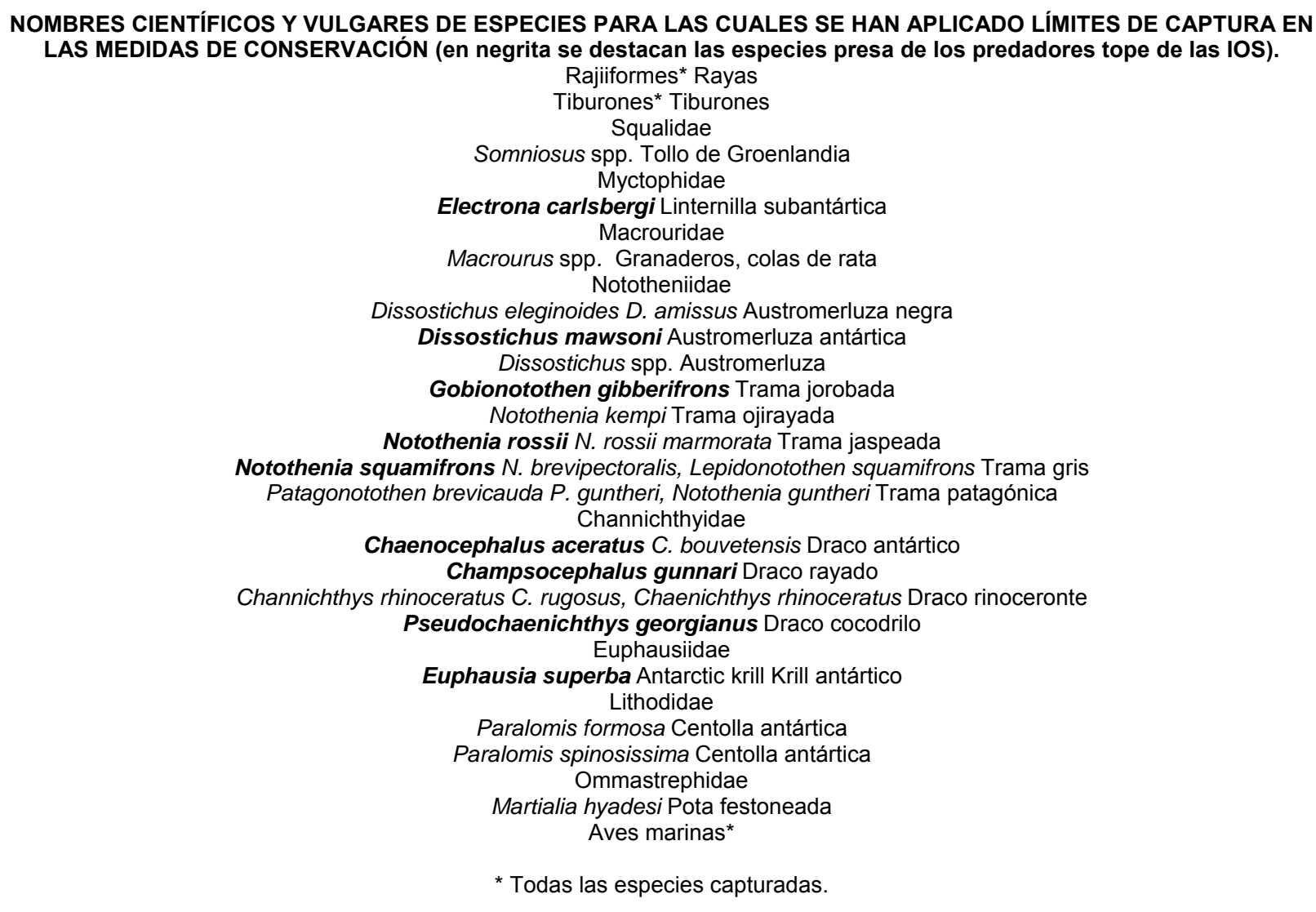

De acuerdo a la MC 32-01, las especies habilitadas para la pesca comercial durante la temporada 2010/11 en el Área de la Convención Figura V.1) son:

- $\quad$ Draco rayado (Champsocephalus gunnari)

- $\quad$ Austromerluzas (Dissostichus spp.)

- Krill (Euphausia superba)

- Centollas (Paralomis spp.)

Cabe aclarar que la temporada de pesca para todas las especies en el Área de la Convención comienza el 1 de diciembre y finaliza el 30 de noviembre del año siguiente. Por otro lado es importante aclarar que en durante la última reunión (SC-CAMLR-XXIX) la CCRVMA apoyó la prohibición en la pesca de peces en las subáreas 48.1 (Península Antártica (PA) e ISS) y 48.2 (IOS) (Figura V.1). 


\section{Área 48}

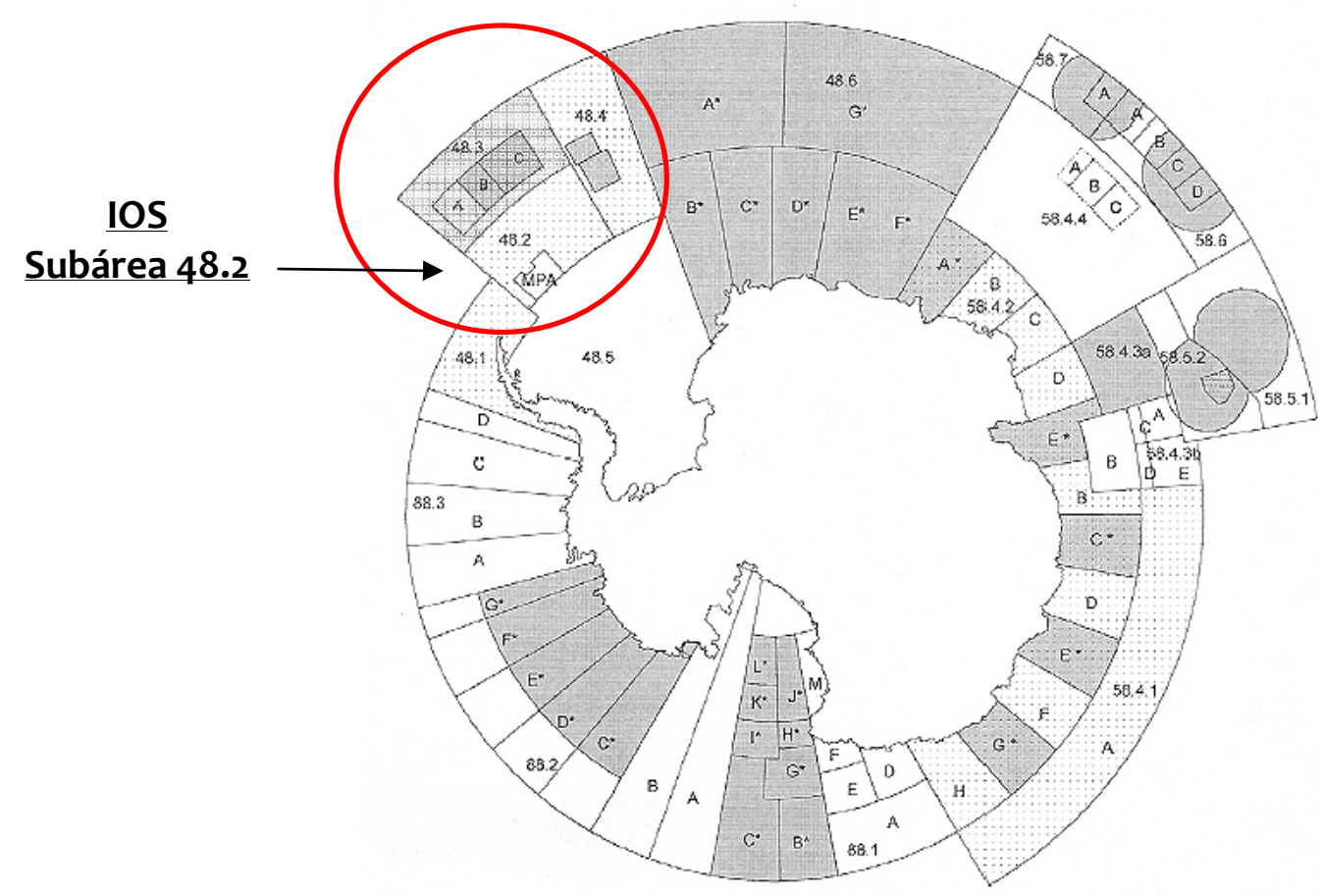

Figura V.1: Divisiones de las subáreas estadísticas de pesca designadas por la CCRVMA. El círculo rojo indica el sector del Área 48 en el que se encuentran las IOS (48.2). Todas las secciones identificadas con letras conforman el Área de la Convención del Tratado Antártico.

Con el fin de contribuir a la conservación de la biodiversidad de la subárea 48.2 (IOS), la CCRVMA aprobó durante la sesión de 2008/09 la designación de un área marina protegida (AMP) en la plataforma sur de las IOS (SC-CAMLR-XXVIII). Por lo tanto se decidió adoptar la siguiente medida de conservación.

\section{91-03 (2009)}

Se prohíbe todo tipo de actividad de pesca dentro del área definida, con la excepción de actividades de investigación científica acordadas por la Comisión.

Límites del AMP: El área marina protegida en la plataforma sur de las IOS está limitada por una línea que comienza en los $61^{\circ} 30^{\prime} \mathrm{S}, 41^{\circ} \mathrm{O}$; continúa hacia el oeste hasta los $44^{\circ} \mathrm{O}$ de longitud; luego hacia el sur hasta los $62^{\circ} \mathrm{S}$ de latitud; luego hacia el oeste hasta los $46^{\circ} \mathrm{O}$; luego hacia el norte hasta los $61^{\circ} 30^{\prime} \mathrm{S}$; continúa hacia el oeste hasta los $48^{\circ} \mathrm{O}$ de longitud; luego hacia el sur hasta los $64^{\circ} \mathrm{S}$ de latitud; luego hacia el este hasta los $41^{\circ} \mathrm{O}$ de longitud; y luego hacia el norte hasta el punto de inicio (Figura V.2). 


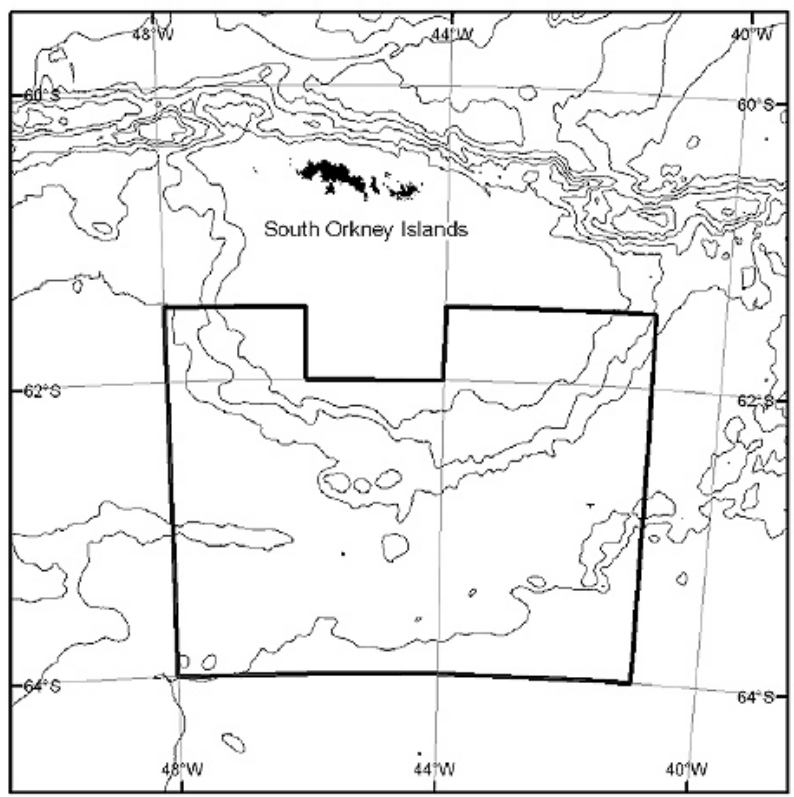

Figura V.2: La línea gruesa negra muestra los límites del área marina protegida de la plataforma sur en las IOS. Los contornos batimétricos se presentan en intervalos de 1000 metros.

Las siguientes MC hacen referencia a las prohibiciones de la pesca en las distintas subáreas:

\section{Subárea 48.2 (IOS)}

MC 32-05 (1986)

Prohibición de la pesca dirigida a N. rossii en los alrededores de las IOS.

\section{32-03 (1998)}

Queda prohibida la captura de peces (todas las temporadas, todas las especies y para todas las artes de pesca) en la subárea estadística 48.2 excepto con fines de investigación científica desde el 7 de noviembre de 1998 hasta que se haya llevado a cabo una prospección de biomasa del stock, sus resultados hayan sido notificados al Grupo de Trabajo para la Evaluación de las Poblaciones de Peces y evaluados por dicho grupo, y la Comisión haya decidido reanudar la pesquería sobre la base del asesoramiento brindado por el Comité Científico de la CCRVMA.

Las siguientes MC hacen referencia a los límites de captura y las prohibiciones de la pesca el las subáreas 48.1 y 48.3 :

\section{Subárea 48.1 (PA e ISS)}

\section{32-04 (1986)}

Prohibición de la pesca dirigida a $N$. rossii (todas las temporadas y todas los artes de pesca) en la zona de la PA e ISS 


\section{32-02 (1998)}

Prohibición de la pesca de peces (todas las temporadas, todas las especies y todas los artes de pesca) en la subárea estadística 48.1 .

\section{Subárea 48.3 (IGS)}

La prohibición de la pesca dirigida a $N$. rossii en los alrededores de las IGS queda establecida desde 1985 (MC 32-06). Hacia 1995, se establecen restricciones de captura para la pesca secundaria de esta especie y de otras cuatro especies más (MC 33-01): G. gibberifrons, C. aceratus, Pseudochaenichthys georgianus, y Lepidonotothen squamifrons. Los límites de captura por temporada fijados fueron las siguientes:

\begin{tabular}{|l|c|}
\hline Especies & Límite de captura $(\mathrm{Tn})^{*}$ \\
\hline G. gibberifrons & 1.470 \\
C. aceratus & 2.200 \\
P. georgianus & 300 \\
L. squamifrons & 300 \\
N. rossii & 300 \\
\hline
\end{tabular}

*Límites de captura establecidos para la temporada 1995 y aplicados para la temporada 2009/2010.

Luego, hacia 1999 queda expresamente prohibida la pesca dirigida a estas especies a lo_que se suma la prohibición de pesca de la especie Patagonotothen guntheri (MC 32-07). En 2003 se prohibió la pesca dirigida a otra especie clave en la dieta de los predadores tope, Electrona carlsbergi (MC 32-17). Hacia el 2009 se suman restricciones a la pesca sobre Dissostichus eleginoides expresamente designadas para las temporadas 2009/10 y 2010/11, y se fija un límite de captura para esta especie durante esa temporada de 3000 toneladas (MC 41-02). Luego se establecen límites de captura para $C$. gunnari de 2305 toneladas para la temporada 2010-11 (MC 42-01) y de 1535 toneladas para 2011/12. Finalmente, durante el mismo año también se establecen restricciones a la pesca de centollas (MC 5201).

\section{Recurso Krill (Euphausia superba)}

La pesca de krill en el archipiélago de las IOS y zonas aledañas como la PA, ISS y las IGS se reabrió a partir de la temporada 2008/09 por decisión de la CCMRVA. Para ello se estableció un nivel crítico de captura por encima del cual la pesca se cierra. Dicho valor fue establecido en 620.000 toneladas (MC51-01) distribuidas de la siguiente manera (MC 51-07):

Subárea 48.1............... 25\% (155.000 Tn)

Subárea 48.2................ 45\% (279.000 Tn)

Subárea $48.3 \ldots \ldots \ldots \ldots \ldots . . . . .45 \%$ (279.000 Tn)

Subárea $48.4 \ldots \ldots \ldots \ldots \ldots . . . .15 \%$ (93.000 Tn) 
En relación a todo lo presentado se confeccionó una tabla (Tabla V.15) en donde se resumen los consumos por parte de los predadores sobre las distintas especies comerciales permitidas en la zona de las IOS. Dado que en las IOS actualmente está prohibida la pesca comercial de peces, la proximidad entre este archipiélago y las IGS, y porque la comunidad de predadores es similar en ambos archipiélagos, a modo de simulación de lo que podría ocurrir luego de una potencial reapertura de la pesca de peces en las IOS, en este análisis también se consideró información proveniente de las IGS.

Tabla V.15.: Tamaños poblacionales de los predadores de las IOS y la estimación del consumo anual de especies comerciales en términos de biomasa (Tn.), porcentaje de especies comerciales incluidas en la dieta de cada predador (\% Esp.).

\begin{tabular}{|c|c|c|c|c|}
\hline & $\begin{array}{l}\text { Población } \\
\text { estimada }\end{array}$ & Esp. comerciales & Predación anual (Tn) & $\%$ Esp. \\
\hline \multicolumn{5}{|l|}{ Aves (parejas) } \\
\hline \multicolumn{5}{|l|}{ Spheniscidae } \\
\hline Pingüino de Adelia & 139.581 & E. superba (krill) & $107.154,68$ & 99,4 \\
\hline Pingüino de Barbijo & 347.318 & E. superba (krill) & $244.338,06$ & 99,5 \\
\hline \multirow[t]{4}{*}{ Pingüino de Papúa } & 8.067 & E. superba (krill) & $2.408,455$ & 55,2 \\
\hline & & C. gunnari & 44,93 & 1,1 \\
\hline & & G. gibberifrons & $1.267,61$ & 29,1 \\
\hline & & N. rossii & 30,56 & 0,7 \\
\hline \multicolumn{5}{|l|}{ Procellariidae } \\
\hline Petrel Gigante & 3.400 & E. superba (krill) & 9,28 & 0,8 \\
\hline $\begin{array}{l}\text { Petrel de las } \\
\text { Tormentas }\end{array}$ & 202.000 & E. superba (krill) & 462,31 & 38,5 \\
\hline \multicolumn{5}{|l|}{ Laridae } \\
\hline $\begin{array}{l}\text { Gaviota Cocinera *1 } \\
\text { Strenidae }\end{array}$ & 389 & E. superba (krill) & 2,38 & 17,8 \\
\hline Gaviotín Antártico *1 & 755 & E. superba (krill) & 0,71 & 2,2 \\
\hline Phalacrocoracidae & & C. gunnari & & \\
\hline Georgias & 1.571 & & 0,91 & 0,2 \\
\hline & & G. gibberifrons & 67,84 & 16,3 \\
\hline & & L. squamifrons & 0,80 & 0,2 \\
\hline & & N. rossii & 7,43 & 1,8 \\
\hline
\end{tabular}


Tabla V.15: Continuación.

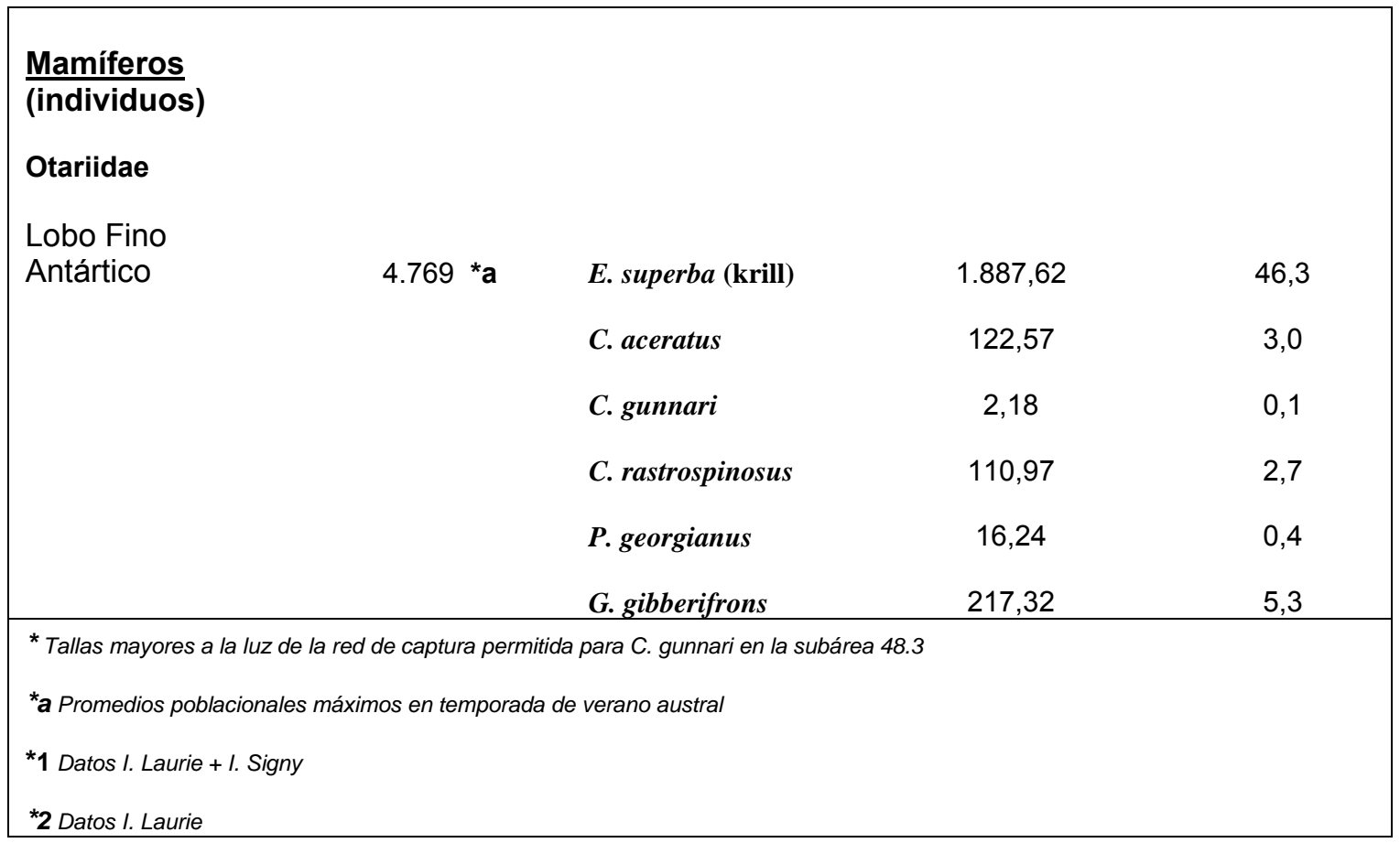

\section{V.4. Discusión}

En el año 1993, la pesquería comercial proveía empleo a más de 200 millones de personas y aportaba el $19 \%$ de las proteínas animales consumidas a nivel mundial (FAO 1993). Sin embargo, la pesca comercial genera efectos directos e indirectos en el medio marino. Dentro de los efectos directos las pesquerías remueven aproximadamente el $8 \%$ de la producción primaria del mar, reducen el stock de las especies seleccionadas o "blanco", lo que afecta negativamente principalmente a las poblaciones de especies longevas y de bajas tasas reproductivas (Pauly y Christensen 1995). Los efectos indirectos de la pesca son aquéllos que repercuten sobre el ecosistema marino alterándolo substancialmente por medio de la destrucción de los ambientes bentónicos (Ludwig et al. 1993, Dayton et al. 1995). Sumado a ello, la pesca comercial genera una disminución en la abundancia de los predadores tope, especialmente en comunidades dominadas por los modelos de control "top-down" (Mann y Breen 1972, Simenstad 1978) como es el caso de Antártida. A pesar de ello, la industria pesquera raramente toma en cuenta las aproximaciones ecosistémicas en sus modelos de captura.

La pesquería comercial en Antártida ha pasado por períodos de diferente intensidad. En relación al sector occidental del Océano Antártico, luego de un gran desarrollo durante las décadas del 70 y del 80 , y concurrentemente con la baja rentabilidad de la industria pesquera, hacia fines de la década del 80 CCRVMA cierra precautoriamente la pesca de peces en la PA y las ISS (Subárea 48.1) y en las IOS 
(Subárea 48.2). CCRVMA también indicó que la pesca podrá reabrirse sólo cuando resultados de estudios científicos demuestren que los stocks de peces se han recuperado. En relación a ello, las últimas dos prospecciones de peces realizadas en 1999 (IOS) y 2003 (PA/ISS) no evidenciaron la recuperación de los stocks. Sin embargo, dado el lapso de tiempo entre la prospección de 1999 y el presente, y que la información considerada en este estudio sugiere que los stocks de peces se estarían recuperando, es probable que en un corto plazo la pesca de peces en las IOS se reabra.

En general, las investigaciones que relacionan las interacciones entre predadores y pesquerías solo han considerado una o muy pocas especies tanto para los predadores como para las presas (Furness 1982, Beddington et al. 1985, Ichii et al. 1996, 1997, Wienecke y Robertson 2002, Barlow et al. 2002, Reid et al. 2004, entre otros). Los trabajos que tratan a la comunidad de predadores tope como una entidad en sí misma, incorporando las poblaciones en una red compleja de interacciones tróficas dependientes entre si son escasos (Woehler y Green 1992, Green et al. 1998). Aunque en los modelos de captura actualmente se está incorporando el nivel de análisis multiespecífico (Botsford et al. 1997), éstos siguen considerando sólo a las especies presa. En relación a ello, los resultados expuestos en este capítulo son de suma utilidad en términos de la conservación del ecosistema antártico pretendida por los países miembro del TA (ver capítulo I). Por tal razón, el objetivo de este capítulo fue estimar los consumos, a nivel población y de comunidad, de los predadores de las IOS para proveer información de utilidad para el desarrollo de políticas de conservación en dicha área.

En términos energéticos, la comunidad de predadores de las IOS presenta una demanda anual de $1,61 \times 10^{9}$ MJ. Las especies con mayor demanda energética son el Pingüino de Barbijo $\left(1,07 \times 10^{9}\right.$ $\left.\mathrm{MJ} a n ̃ 0^{-1}\right)$, el Pingüino de Adelia $\left(4,7 \times 10^{8} \mathrm{MJ}\right.$ año $\left.{ }^{-1}\right)$ y el Lobo Fino Antártico $\left(1,98 \times 10^{7} \mathrm{MJ}\right.$ año $\left.{ }^{-1}\right)$, en tanto que la de menor demanda fue la Gaviota Cocinera $\left(7,11 \times 10^{4} \mathrm{MJ}\right.$ año $\left.{ }^{-1}\right)$. Del total estimado para el consumo de biomasa anual, el $98 \%$ fue obtenido por parte de la comunidad de aves marinas. Por otro lado es probable que el consumo de cefalópodos haya sido subestimado dado que no existe un apropiado relevamiento de la Foca de Weddell, uno de los principales consumidores de este molusco, en la totalidad de las IOS. La tabla V.16 muestra los predadores de las IOS que consumieron con mayor y menor intensidad los diferentes tipos de presas. Tanto el Petrel Gigante (carroña) como el P. Barbijo (krill) presentaron una dieta compuesta principalmente por un solo tipo de presa. El Pingüino de Papúa fue el predador más importante de peces, lo que en gran parte se debe a la abundancia de este predador en el archipiélago. Aunque las estimaciones de densidad poblacional de Foca de Weddell hayan estado subestimadas, este predador resultó ser el consumidor más importante de cefalópodos del archipiélago.

En un estudio similar al presentado en este capítulo desarrollado en la zona de las islas Heard y Mc Donald, en donde la comunidad de mamíferos es más grande que en las IOS (ver Woehler y Green 1992) y está permitida la pesca comercial de krill y peces, se reportó que la totalidad de los predadores consumen anualmente 521.365 toneladas, lo que equivale a $2,17 \times 10^{9} \mathrm{MJ}$. Del total de la biomasa consumida, 165.000 toneladas fueron aportadas por los peces, 312.000 por los crustáceos y 41.600 por los cefalópodos. A diferencia de lo observado en estas islas donde los peces aportan el 31,65\% de lo consumido por la comunidad de predadores, en las IOS son los crustáceos, principalmente el krill, los 
que juegan un papel fundamental en el aporte de energía a los predadores. Es probable que estas diferencias se deban principalmente a la gran abundancia en las islas Heard y Mc Donald de mamíferos marinos y del pingüino Eudyptes chyisolophus, todos ellos grandes consumidores de peces. Aún así, de un modo similar a lo observado en las IOS, el $80 \%$ de la biomasa total estimada para las islas Heard y Mc Donald fue consumida exclusivamente por las aves marinas.

Tabla V.16: Consumo de presas (máximo y mínimo en Tn.) por parte de los predadores de las IOS. *: Valor calculado únicamente para la I. Laurie. No hay datos de censo de la Foca de Weddell para las IOS.

\begin{tabular}{|l|lll|}
\hline Presa & Krill (Tn) & Peces (Tn) & Cefalópodos (Tn) \\
\hline Máximo consumidor & Pingüino de Barbijo & Pingüino de Papúa & Foca de Weddell \\
& 244338,06 & 1933,7 & 404,89 * \\
\hline Mínimo consumidor & Petrel Gigante & Petrel Gigante & P. Barbijo \\
& 9,28 & 5,52 & 4,91 \\
\hline
\end{tabular}

En relación a los peces, los diferentes predadores consumieron con distintas intensidades peces de las diferentes familias. Los myctóphidos fueron consumidos mayormente por el Petrel de Wilson (356,3 Tn.), en tanto que los notothénidos lo fueron por el Pingüino de Papúa (1848,72 Tn.) y los channíchthyidos por el Lobo Fino Antártico (312,85 Tn.). Las especies de peces más consumidas fueron G. gibberifrons y E. antarctica (Tabla V.8), en tanto que los predadores que más peces consumieron fueron el Pingüino de Papúa (alrededor de 2.000 Tn. anuales) y el Lobo Fino Antártico (1.930 Tn año ${ }^{-1}$ ). Comparado con lo observado en otros trabajos, el consumo de peces en las IOS no parece ser muy importante. A modo de ejemplo se puede indicar que los consumos anuales de peces por parte del Lobo Fino Antártico y del Pingüino de Papúa en Isla Heard fueron de 20.065 y 8.692 toneladas respectivamente (Green et al. 1998). Esto se debería principalmente a la mayor abundancia de Lobo Fino Antártico (21.536 individuos) y de Pingüino de Papúa (26.900) en Isla Heard que en las IOS (ver tabla V.10). En relación a las cantidades de peces extraídos durante el período de explotación comercial y los requerimientos de los predadores, entre 1970 y 1990 se extrajeron en el área de las IOS 38.821 toneladas de G. gibberifrons, lo que equivale aproximadamente a 2.100 toneladas anuales, un valor cercano a lo que consume anualmente la población de Pingüino de Papúa (ver Tabla V.13). En el caso de C. gunnari, durante el período de pesca comercial se extrajeron de las IOS 187.898 toneladas, lo que equivale a aproximadamente 9.400 toneladas anuales y excede marcadamente la biomasa de este pez requerida por toda la comunidad de predadores. En el caso de la pesca de krill, el nivel crítico establecido en 2009 por CCRVMA para la temporada de pesca 2010/2011 en las IOS fue de 279.000 toneladas, un valor cercano a lo requerido anualmente por la comunidad de predadores de ese archipiélago (aproximadamente $360.000 \mathrm{Tn}$.). Tales niveles de captura revelan la importancia de la integración de las variables poblaciones de los predadores tope en los modelos de explotación pesquera 
Los límites de captura establecidos para la pesca directa en la subárea 48.3 (IGS) (ver página 208) fueron tenidos en cuenta en este trabajo en función de hipotetizar sobre lo que ocurriría ante una posible reapertura de la actividad pesquera en las IOS. En algunos casos los niveles de extracción autorizados para las IGS están próximos a los requerimientos de algunos predadores de las IOS, como es el caso de Pingüino de Papúa con respecto a G. gibberifrons (consumo anual Pingüino de Papúa: 1.267 Tn.; límite de captura: 1.470 Tn.). Además, si se considera no sólo la pesca directa, sino también la secundaria, los niveles de extracción de G. gibberifrons autorizados en las IGS representan el 98\% de lo requerido anualmente por todos los predadores de las IOS. Teniendo en cuenta los consumos de los predadores tope y considerando que ello en cierto modo refleja la abundancia de las presas dentro de las áreas de forrajeo (Casaux y Barrera-Oro 1993), es probable que C. gunnari, C aceratus y $N$ rossii no sean tan abundantes como para justificar su explotación en las IOS, hecho que no ocurriría con $G$. gibberifrons Actualmente, la única explotación permitida en las IOS es la del krill y lo extraído anualmente representa el $78 \%$ del consumo total de la comunidad de predadores tope que allí habitan. Considerando que G. gibberifrons representa aproximadamente el $30 \%$ de la dieta del Pingüino de Papúa, este predador deberá ser particularmente tenido en cuenta en el caso de planificar un modelo pesquero para la zona. Lo mismo ocurre con el Cormorán de Georgias y el Lobo Fino Antártico (ver tabla V.15)

Además de los cupos de extracción, también es preciso considerar las medidas precautorias que regulan la actividad pesquera. La MC 42-01 de 2010 indica que si en cualquier lance se obtiene más de $100 \mathrm{~kg}$. de $C$. gunnari y más del $10 \%$ de los individuos son menores a $240 \mathrm{~mm}$. de longitud total, el barco de pesca deberá trasladarse a otra zona situada a una distancia mínima de 5 millas náuticas del sitio. La MC 33-01 indica que de obtenerse capturas secundarias, ésta deberá ser menor a 2 toneladas para que el barco pueda permanecer en la zona de captura; de lo contrario también deberá situarse a una distancia de 5 millas náuticas. Estas medidas, si bien parecen tener algún sentido precautorio con respecto a no agotar los stocks de peces en una determinada zona, no tienen en cuenta ningún criterio ecológico multiespecífico, fundamentalmente que las distancias de desplazamiento de los barcos estén en sintonía con la extensión de las áreas de forrajeo de los predadores.

El análisis desarrollado parece indicar que la competencia por los recursos entre predadores y la industria pesquera llevada a cabo en las IOS tuvo lugar. Por tales razones, según los resultados obtenidos, se sugiere la aplicación de modelos de explotación que consideren los consumos de los predadores tope más importantes. También es importante considerar el rol que desempeña el Lobo Fino Antártico dentro de la comunidad de las IOS. Entre todos los predadores, el Lobo Fino Antártico es uno de los consumidores más importantes y, según los datos poblacionales que se manejaron en este trabajo, su actividad se centra de manera muy intensa en la zona de la I. Laurie (Tablas V.10 a V.13). Por otro lado los censos poblacionales de Lobo Fino Antártico han mostrado una variación muy importante en cuanto a la cantidad de arribos por temporada y a los picos poblacionales (Carlini et al. 2006) reflejando una importante recuperación de la población en esta zona de las IOS y de las IGS (Barlow et al. 2002). Por ello, las tendencias poblacionales y sus implicancias en los niveles de consumo 
también deberán ser tenidas en cuenta al momento de generar modelos de explotación pesquera en esa zona.

El sistema de manejo habitualmente adoptado por las pesquerías lleva al colapso de los recursos (Nicol y de la Mare 1992). La CCRVMA ha tomado una aproximación ecosistémica al manejo de las áreas del sur del frente polar antártico usando la teoría del sistema de control para examinar la cosecha de especies individuales, como por ejemplo krill antártico. Para que dicha estrategia sea ecológicamente sustentable, el modelo debe incorporar el consumo de los predadores de las especies a extraer. Sin embargo no existen aún programas de monitoreo de consumo de los predadores a largo plazo en muchas de las zonas actualmente explotadas (Green et al. 1998).

Durante la reunión de 2008 (SC-CAMLR-XXVIII) se comenzaron a tener en cuenta políticas relacionadas con los predadores consumidores de krill con colonias terrestres en las zonas de pesca. Aún así se declaró que las medidas acordadas hasta el momento no son lo suficientemente precautorias como para proporcionar protección a esas especies. Es claro que existe un grado de preocupación en relación a los niveles críticos de pesca, a las áreas a explotar y a las consecuencias que su implementación tenga sobre la conservación de la fauna antártica. Sin embargo, estos factores de preocupación aun no se reflejan en los modelos de explotación. Sin tener en cuenta las relaciones de cada celda, gremio ecológico o grupo, dentro de la compleja red de los ecosistemas antárticos, no se podrán estimar límites de captura que aseguren la conservación de las poblaciones de peces y de las comunidades de predadores dependientes. 


\section{V.5. Conclusiones generales}

En este capitulo se han analizado los requerimientos energéticos diarios y anuales de los predadores tope de las IOS y por qué tipo presa son cubiertos. Los pingüinos resultaron ser los predadores más importantes en términos de demanda energética anual, seguidos por el Lobo Fino Antártico. Estos resultados junto con información acerca de los límites de captura y especies autorizadas para la pesca en la zona de las IOS, sugieren que el P. Barbijo, el Pingüino de Papúa y el Lobo Fino Antártico son los predadores más involucrados en la problemática relacionada con la pesca comercial. A su vez, la información generada en este capítulo pone de manifiesto la importancia del desarrollo de modelos multiespecíficos que incluyan tanto a las presas como a sus predadores, en vistas del manejo pesquero sustentable y acorde a un plan de conservación del ecosistema antártico tal como los países miembro del TA pretenden. Durante la última reunión de la CCRMVA se decidió seguir con el cierre de la pesca de peces en la zona de las IOS como así también en la de la PA e ISS. La posible reapertura de la pesca plantea escenarios poco favorables para la comunidad de predadores por lo que, en términos de generar herramientas que sean de utilidad para elaborar políticas de manejo sustentable, es necesario desarrollar programas de monitoreo a largo plazo sobre sus tendencias poblacionales y sobre sus requerimientos y consumos anuales. 


\section{V.6. Referencias bibliográficas}

Annon (2008) Scar expert Group on seals: Status of Stocks.

Aschoff J y Pohl H (1970) Der Ruheumsatz von Vogeln als Funktion der Tageszeit und der Kiirpergrosse. J Omithol 111: 38-47.

Apollonio, S (1994) The use of ecosystem characteristics in fisheries management. Rev Fish Sci 2(2): 157-180.

Barber RT y Chavez FP (1986) Ocean variability in relation to living resources during the 1982-83 El Niño. Nature 319: $279-285$.

Barlow KE, Boyd IL, Croxall JP, Reid K, Staniland IJ y Brierley AS (2002) Are penguins and seals in competition for Antarctic krill at South Georgia? Marine Biology 140: 205-213.

Beddington JR, Beverton RJH y Lavigne DM (1985) Marine mammals and fisheries. Allen \& Unwin, London.

Berta A, Sumich JL y Kovacs KM (2005) Marine mammals: Evolutionary biology, 2da. Ed. Academic Press. Elsevier Inc. London.

Botsford LW, Castilla JC y Peterson CH (1997) The management of fisheries and marine ecosystems. Science 277(5325): 509515. doi: 10.1126/science.277.5325.509.

Bourne WRP (1983) Birds, fish and offal in the North Sea. Marine Pollution Bulletin 14(8): 294-296.

Boyd IL (2002) Estimating food consumption of marine predators: Antarctic fur seals and macaroni penguins. Journal of Applied Ecology 39(1): 103-119.

Boyd I, Arnbom T y Fedak M (1993) Water flux, body composition and metabolic rate during molt in female southern elephant seals (Mirounga leonina). Physiol Zool 66(1): 43-60.

Burger J, Gochfeld M (Eds). Birdlife Conservation Series 1. Birdlife International, Cambridge, pp 26-38.

Burton RW (1968) Breeding biology of the brown skua. Catharacta lonnbergi (Mathews) at Signy Island, South Orkney Islands. Br Antarct Surv Bull 15: 9-28.

Caddy JF y Mahon R (1995) Reference points for fisheries management. FAO Fish Tech Pap 347, 83 pp.

Calder WA (1974) Consequences of body size for avian energetics. En: Avian energetics. Paynter RA Jr (Ed). Publication Nuttall Ornith. Club, pp 86-151.

Carlini A, Daneri GA, Casaux R y Márquez MEI (2006) Haul-out pattern of itinerant male Antarctic fur seals (Arctocephalus gazella) at Laurie Island, South Orkney Islands. Polar Research 25 (2): 139-144.

Carlini AR, Coria RN, Santos MM, Buján SM (2005) The effect of Chinstrap penguins on the breeding performance of Adélie penguins. Folia Zool (Brno) 54: 147-158.

Carlini AR, Márquez MEI, Daneri GA y Poljak S (1999) Mass changes during their annual cycle in females of southern elephant seals at King George Island. Polar Biology 21: 234-239.

Casaux R y Barrera-Oro (1993) The diet of the blue-eyed shag, Phalacrocorax atriceps bransfieldensis feeding in the Bransfield Strait. Antarctic Science 5: 335-338.

Casaux R, Baroni A. Ramón, Favero y Silva MP (2007) Aspects of the foraging behaviour of the Antarctic Tern Sterna vittata gaini at Harmony Point, South Shetland Islands. Polar Biology 31: 327-331. doi: 10.1007/s00300-007-0362-3.

Casaux R, Baroni A y Ramón A (2003) The diet of Antarctic fur seals Arctocephalus gazella at the Danco coast, Antarctic Peninsula. Polar Biology 26: 49-54.

Clark CW (1984) Strategies for multispecies management: objectives and constrains. En: Exploitation of Marine Communities. May RM (Ed). Springer, Berlin, pp 303-312.

Coria NR (2006) Biología reproductiva y ecología alimentaria del Petrel gigante del sur Macronectes giganteus (AVES, Procellariidae) en las Islas Shetland del Sur y Orcadas del Sur, Antártida. Tesis Doctoral. Facultad de Ciencias Naturales y Museo, Universidad Nacional de La Plata, La Plata, Buenos Aires, Argentina.

Costa DP, Croxall JP y Duck CD (1989) Foraging Energetics of Antartic Fur Seals in Relation to Changes in Prey Availability. Ecology 70(3): 596-606.

Croll DA y Tershy BR (1998) Penguins, fur seal and fishing: prey requirements and potential in the South Shetland Islands, Antarctica. Polar Biology 19: 365-374. 
Croxall JP (1995) Sexual size dimorphism in seabirds. Oikos 73: 399-402.

Croxall JP, Davis RW y O'Connell MJ (1988) Diving patterns in relation to diet of gentoo and macaroni penguins South Georgia. Condor 90: 157-167.

Croxall JP, Prince PA y Ricketts C (1985) Relationships between prey life-cycles and the extent, nature and seal and seabird predation in the Scotia Sea. En: Antarctic nutrient and food webs. Condy PR y Laws RM (Eds) Springer-Verlag, Berlin, pp 516533.

Croxall JP, Prince PA, Hunter I, McInnes SJ y Copestake PG (1984) The seabirds of the Antarctic Peninsula, islands of the Scotia Sea, and Antarctic continent between $80^{\circ} \mathrm{W}$ and $20^{\circ} \mathrm{W}$ : their status and conservation. ICBP Tech Publication 2: 637-666.

Daneri GA y Carlini A (2002) Fish prey of the southern elephant seal, Mirounga leonina, at King George Island, South Shetland Islands, as reflected by stomach lavage. Polar Biology 25: 739-743.

Dayton PK, Thrush SF, Agardy TM y Hofman RJ (1995) Environmental effects of marine fishing. Aquatic Conservation: Marine and Freshwater Ecosystems 5(3): 205-232.

Donelly J, Torres JJ Hopkins TL y Lancarft TM (1990) Proximate composition of Antarctic mesopelagic fishes. Marine Biology 106(1): 13-23. doi: 10.1007/BF02114670.

Duffy DC (1983) The foraging ecology of Peruvian seabirds. The Auk 100(4): 800-810.

Duffy DC y Schneider DC (1994) Seabird-fishery interactions: a manager's guide. En: Seabirds on islands. Nettleship DN, Buger J y Gochfeld M (Eds) Birdlife Conservation Series 1. Birdlife International, Cambridge, pp 26-38.

Ellis HI y Gabrielsen GW (2001) Energetics of free-ranging seabirds. En: Biology of marine birds. Schreiber EA et al. (Eds). CRC Marine Biology Series 1: 359-407.

Evans PR (1973) Avian resources of the North Sea. En: North Sea Science. Goldberg ED (Ed). Cambridge, Mass, pp 400-412.

FAO (1993) Fisheries Series 40. Fisheries Statistics Series 111, 72 pp.

Favero M, Casaux R, Silva MP, Barrera-Oro E y Coria N (1998) The diet of the Antarctic Shag during summer at Nelson Island, Antarctica. Condor 100: 112-18.

Furness RW (1982) Competition between fisheries and seabird communities. Adv Mar Biol 20: 225-307.

Furness RW (1978) Energy requirements of seabirds communities: A bionenergetics model. Journal of Animal Ecology 47: $39-53$.

Furness RW y Cooper J (1982) interactions between fisheries and seabirds communities. Adv Mar Biol 20: 225-307.

Green K, Slip DJ y Moore GJ (1998) The take of fish species by seabirds and marine mammals in the Australian Fisheries Zone around Heard Island: the potential for competition with a commercial fishery. Polar Biology 20 (4): 273-280. doi: $10.1007 / \mathrm{s} 003000050303$.

Hahn S, Ritz MS y Reinhardt K (2008) Marine foraging and annual fish consumption of a south polar skua population in the maritime. Polar Biology 31: 959-969. doi: 10.1007/s00300-008-0436-x.

Harris CM, Carr R, Lorenz K y Jones S (2011) Important Bird Areas in Antarctica: Antarctic Peninsula, South Shetland Islands, South Orkney Islands - Final Report. Prepared for BirdLife International and the Polar Regions Unit of the UK Foreign \& Commonwealth Office. Environmental Research \& Assessment Ltd., Cambridge.

Hasting KK y Testa JW (1998) Maternal and birth colony effects on survival of Weddell seal offspring from McMurdo Sound, Antarctica. Journal of Animal Ecology 67(5): 722-740.

Hilborn R (1992) Current and future trends in fisheries stock assessment and management. South African Journal of Marine Science 12(1): 975-988. doi: 10.2989/02577619209504756.

Hilborn R y Walters CJ (1992) Quantitative Fisheries Stock Assessment: Choice, Dynamics and Uncertainty. New York, NY: Chapman and Hall. 570 pp.

Hocky PAR, Ryan PG y Bosman AL (1989) Age related intraspecific kleptoparasitism and foraging success of Kelp Gulls Larus dominicanus. Ardea 77 (2): 205-210.

Hodum PJ y Weathers WW (2003) Energetics of nestling growth and parental effort in Antarctic fulmarine petrels. Journal of Experimental Biology 206: 2125-2133. 
Hunter AMJ, Trites AW y Pauly D (2000) Estimates of basal metabolic and feeding rates for marine mammals from measurements of maximum body length. Proceeding of the comparative nutrition society 2000: 103-106.

Ichii T, Takao T, Bengstson JL, Boveng P, Jansen JK, Hiruki LM, Meyer WR, Cameron MF, Naganobu M, Kawaguchi S y Ogishima $\mathrm{T}$ (1997) Importance of myctophid fish distribution for formation of foraging areas of chinstrap penguins and antarctic fur seals at seal Island. WG-EMM 97/28, 96/49 y 95/87 Agenda Item N6 y N7. CCAMLR.

Ichii T, Naganobu M y Ogishima T (1996) Competition between the krill fishery and penguins in the South Shetland Islands. Polar Biology 16: 63-70.

Jablonski B (1995) Distribution, abundance and biology of the Antarctic Tern Sterna vittata on King George Island (South Shetland Islands). Acta Zoológica Cracoviensia 29: 117-186.

Kendeigh SC (1970) Energy Requirements for Existence in Relation to Size of Bird. The Condor 72(1): 60-65.

Kendeigh SC, Dolnik VR y Gavrilov M (1977) Avian energetics. En: Granivorous birds in ecosystems. Pinowski J y Kendeigh SC (Eds). Cambridge Univ. Press, New York, pp 127-204.

Kirkman S, Wilson W, Klages N, Bester M y Isaksen K (2000) Diet and estimated food consumption of Antarctic fur seals at Bouvetøya during summer. Polar Biology 23: 745-752.

Kleiber M (1975) Metabolic turnover rate: A physiological meaning of the metabolic rate per unit body weight. Journal of Theoretical Biology 53(1): 199-204.

Koteja P (1991) On the relation between basal and cell metabolic rates in birds and mammals. Functional Ecology 5: 56-64.

Lavigne DM, Innes S, Worthy AJ, Kovacs KM, Schmitz OJ y Hickie JP (1986) Metabolic rates of seals and whales. Canadian Journal of Zoology 64: 279-284.

Le Boeuf BJ y Laws RM (1994) Elephant seals: population ecology, behavior and physiology. University of California Press, Berkeley, California, USA, 414 pp.

Ludwig D, Hilborn R y Walters C (1993) Uncertainty, resource exploitation and conservation: lessons from history. Science 60(5104): 17-36.

Mann KH y Breen PA (1972) The Relation Between Lobster Abundance, Sea Urchins, and Kelp Beds. Journal of the Fisheries Research Board of Canada 29(5): 603-605.

Márquez MEI, Casaux RJ y Mazzotta AS (1996) Bacalaos antárticos: peces magros de alto contenido proteico. La Industria Carnica Latinoamericana 105: 34-39.

McNab BK (1988) Complications inherent in scaling the basal metabolism. Fed Proc 291: 1541-1552.

Metherell AK, Cambardella CA, Parton WJ, Peterson GA, Harding LA y Cole CV (1995) Simulation of soil organic matter dynamics in dryland wheat-fallow cropping systems. En: Soil management and greenhouse effect. Advances in soil science. R. Lal et al. (Eds). CRC Press, Boca Raton, FL, pp 259-270.

Moe B, Angelier F, Bech C y Chastel O (2007) Is basal metabolic rate influenced by age in a long-lived seabird, the snow petrel? Journal of Experimental Biology 210: 3407-3414.

Moreno JM y Sanz JJ (1996) Field Metabolic Rates of Breeding Chinstrap Penguins (Pygoscelis antarctica) in the South Shetlands. Physiological Zoology 69(3): 586-598.

Nagy KA (1994). Field bioenergetics of mammals: what determines field metabolic rate? Austr J Zool 42: 43 -53.

Nettleship DN, Sanger GA y Springer PF (1984) Marine Birds: their feeding ecology and commercial fisheries relationships. Proc. Pacific Seabirds Group Symposium, Seatle, Washintong. Special publication Candadian Wildlife Services, Otawa, Ont. 220 pp.

Odum EP (1959). Fundaments of Ecology. 2da. Edición. Odum EP (Ed) Philadelphia, Saunders Co.

Obst BS, Nagy KA y Ricklefs RE (1987) Energy utilization by Wilson's Stomr-Petrel (Oceanites oceanicus). Physiological Zoology 60: $200-210$.

Patterson DL, Woehler EJ, Croxall JP, Cooper J, Poncet S, Peter HU, Hunter S y Fraser WR (2008) Breeding distribution and population status of the Northern Giant Petrel Macronectes halli and Southern Giant Petrel M. giganteus. Marine Ornithology 36: 115-124.

Pauly D y Christensen V (1995) Primary production required to sustain global fisheries. Nature 374: 225-257. 
Pearcy WG (1992) Ocean ecology of North Pacific salmonids. Washington Sea Grant Program/Univ. Washington Press, Seatle.

Pielou EC (1966) Species diversity and pattern diversity in the study of ecological succession. Journal of Theorical Biology 10: $370-$ 383.

Pimm S (1976) Estimation of the duration of molt. Condor 78: 550.

Polovina JJ, Mitchum GT y Evans GT (1995) Decadal and basin-scale variation in mixed layer depth and the impact on biological production in the Central and North Pacific, 1960-88. Deep Sea Research Part I: Oceanographic Research Papers 42(10): $1701-1716$

Price RA (1985) Ornithological report 1985-86 season. British Antarctic Survey (Unpublished report AD6/2H/1985/Q1).

Reid K, Sims M, White RW y Gillon KW (2004) Spatial distribution of predator/prey interactions in the Scotia Sea: implications for measuring predator/fisheries overlap. Deep-Sea Research II (51): 1383-1396

Rootes DM (1988) The status of birds at SIGNY island, South Orkney Island. Br Ant Surv Bull 80: 87-119.

Sainsbury KJ (1988) The ecological basis of multispecies fisheries, and management of a demersal fishery in tropical Australia. En: Fish Population Dynamics: The Implications for Management. Gulland JA (Ed). Chichester and New York: John Wiley \& Sons Ltd, pp 349-382.

SC-CAMLR-XXVIII (2009) Informe de la vigésimo octava reunión de la comisión. 26 de Octubre- 6 de Noviembre de 2009. Hobart, Australia.

SC-CAMLR-XXIX (2010) Informe de la vigésimo novena reunión de la comisión. 25 de Octubre- 5 de Noviembre de 2010. Hobart, Australia.

Shelton PA (1992) Detecting and incorporating multispecies effects into fisheries management in the North-West and South-East Atlantic. S Afr J Mar Sci 12: 723-737.

Sherman K, Alexander LM y Gold BD (1990) Food chains, yields, models, and management of large marine ecosystems. AAAS National Meeting, (USA). Westview Press, Boulder (USA).

Simenstad CA, Estes JA y Kenyon KW (1978) Aleuts, Sea Otters, and Alternate Stable-State Communities Science 200(4340): 403411. doi: $10.1126 /$ science. 200.4340 .403

Siniff DB, DeMaster DP, Hofman RJ y Eberhardt LL (1977). An analysis of the dynamics ot' a Weddell seal population. Ecological Monographs 47(3): 19-335.

Sissenwine MP y Daan N (1991) An overview of multispecies models relevant to management of living resources. ICES Mar Sci Symp 193: 6-11.

Sugihara G, García S, Gulland JA, Lawton JH, Maske H, Paine RT, Platt T, Rachor E, Rothschild BJ, Ursin EA y Zeitschel BFK (1984) Ecosystem dynamics. Group Report. En Exploitation of Marine Communities. May RM (Ed) Dahlem Konference Springer-Verlag, Berlin, Germany, pp 131-153.

Testa JW y Siniff DB (1987) Population Dynamics of Weddell Seals (Leptonychotes weddellii) in McMurdo Sound, Antarctica. Ecological Monographs 57(2): 149-165.

Tierney M, Hindell MA y Goldsworth S (2002) Energy content of mesopelagic fish from Macquarie Island. Antarctic Science 14: 225230. doi: $10.1017 / S 0954102002000020$.

Trathan PN, Croxal JO y Murphy EJ (1996) Dynamics of Antarctic penguin populations in relation to inter-annual variability in sea ice distribution. Polar Biology 16(5): 321-330. doi: 10.1007/BF02342178.

Van de Putte A, Flores H, Volckaert F y van Franeker JA (2006) Energy Content of Antarctic Mesopelagic Fishes: Implications for the Marine Food Web. Polar Biology 29(12): 1045-1051. doi: 10.1007/s00300-006-0148-z.

Venrick EL, McGowan JA, Cayan DR y Hayward TL (1987) Climate and Chlorophyll a: Long-Term Trends in the Central North Pacific Ocean. Science 238(4823): 70-72. doi: 10.1126/science.238.4823.70.

Walsberg GE (1983) Avian ecological energetics. En: Avian biology, vol. 7. Farnet DS, King JR y Parkes KC (Eds). Academic Press, New York, pp 161-220. 
Waluda CM, Gregory S y Dunn MJ (2010) Long-term variability in the abundance of Antarctic fur seals Arctocephalus gazella at Signy Island, South Orkneys. Polar Biology 33(3): 305-312. doi: 10.1007/s00300-009-0706-2.

Weathers WW (1992) Scaling nestling energy requirements. Ibis 134: 142-153.

Wheatley KE, Bradshaw CJA, Harcourt RG, Davis LS y Hindell MA (2006) Chemical immobilization of adult female Weddell seals with tiletamine and zolazepam: effects of age, condition and stage of lactation. BMC Veterinary Research 2: 8. doi: $10.1186 / 1746-6148-2-8$.

Wienecke B y Robertson G (2002) Seabird and seal-fisheries inter actions in the Australian Patagonian toothfish Dissostichus eleginoides trawl fishery. Fish Res 54: 253-265.

Wiens, J (1989) The ecology of bird communities. Cambridge Univ. Press, Cambridge Nuttall Ornithol Club 15, Cambridge, Massachusetts, pp 86-151.

Wiens JA y Scott JM (1975) Model estimation of energy now in Oregon coastal seabird populations. Condor 77: $439-452$.

Woehler EJ (1993) The distribution and abundance of Antarctic and Subantarctic penguins. Sci Comm Antarc Res, Scott Polar Res Inst, Cambridge.

Woehler EJ y Green K (1992) Consumption of marine resources by seabirds and seals at Heard Island and the McDonald Islands. Polar Biology 12(6-7): 659-665. doi: 10.1007/BF00236989. 


\section{Modelización ecotrófica}

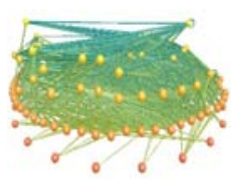

\section{VI.1. Introducción}

La generación de modelos matemáticos surge como una aproximación formal hacia la descripción de las dinámicas de sistemas complejos. En ecología, los modelos matemáticos son usados fundamentalmente como generadores de hipótesis con la intención de simular situaciones posibles dentro de un ecosistema. Formular un concepto teórico en forma de modelo permite poner a prueba predicciones que derivan directamente de tal concepto, observar posibles consecuencias, explicar discrepancias entre los datos experimentales y las predicciones e identificar indicadores críticos que expliquen el comportamiento del sistema (Momo y Capurro 2006). A partir de los primeros trabajos sobre crecimiento poblacional (Mathus 1798, Verhulst 1838, 1845) y sobre dinámicas de competencia y predación (Lotka 1925, Volterra 1926, entre otros) los modelos matemáticos fueron insertándose dentro del ámbito de la ecología y tomando fuerza por su capacidad de explicación y predicción.

La trama alimentaria del Océano Antártico $(\mathrm{OA})$ es ampliamente dependiente del krill (Euphausia superba). La mayoría de los predadores tope, tanto aves como mamíferos marinos, consumen esta presa en mayor o menor medida (excepto especies como el cormorán Phalacrocorax sp. que es predominantemente piscívoro). Ello hace que la abundancia del krill regule de manera significativa las relaciones de competencia, y también su intensidad, entre los diversos predadores y que estos desplieguen diferentes estrategias de alimentación para adaptarse a sus variaciones. Consecuentemente, la variabilidad en la disponibilidad local de krill también afecta de manera importante al éxito reproductivo de numerosos predadores tope (Croxall et al. 1999). Se han formulado diversas propuestas tendientes a identificar las causas de la variación regional y temporal en la abundancia de krill, las que involucran tanto las dinámicas de las zonas de hielo marginal como así también las variaciones en los sistemas de frentes marinos de la Corriente Circumpolar Antártica. Condiciones favorables de cobertura de hielo marino y una dinámica oceanográfica apropiada generan una importante producción primaria en las zonas de barrera de hielo y de hielo marginal (ZHM) (Atkinson 2004, Bertolin y Schloss 2009), donde la distribución del krill alcanza su máxima abundancia. En relación a ello, años con abundante hielo son seguidos por años con abundancia de krill (Loeb et al. 1997). A partir de datos integrados en el tiempo desde 1926 a 2003 Atkinson et al. 
(2004) demostraron una relación directa entre la densidad de krill y la cobertura de hielo marino para el OA. Varios mecanismos fueron propuestos para explicar esta relación. Las algas diatomeas que viven debajo del pack de hielo marino son un recurso alimentario importantísimo para el krill, en especial para la supervivencia de las larvas entre temporadas de invierno (Nicol 2006). Además, el hielo marino puede servir al krill de protección contra sus predadores (McGrath Grossi y Sullivan 1987, Marschall 1988). Ahora bien, la cantidad de alimento que las larvas puedan consumir durante el verano estará influido en parte por el derretimiento del pack de hielo; en tales períodos de deshielo, la comunidad fitoplanctónica presenta una alta capacidad de crecimiento. El derretimiento del hielo costero aumenta la estabilidad de la columna de agua (estratificación) favoreciendo así a los eventos de floraciones algales (Garrison et al. 1989, Fryxell, 1989). Por ende, otra de las variables importantes y condicionantes de la abundancia del krill será la temperatura del agua.

Enmarcado en este contexto y a modo exploratorio se realizó un modelo matemático de predación y competencia entre tres predadores tope de las Islas Orcadas del Sur (IOS) el lobo Fino Antártico Arctocephalus gazella, el pingüino Papúa Pygoscelis papua y el cormorán de Georgias Phalacrocorax georgianus. Es de esperar que el desarrollo de este modelo sirva de punto de partida para la comprensión de la dinámica entre predadores y presas y entre predadores entre si, y pueda ser utilizado como punto de partida para el desarrollo de modelos más abarcativos que contemplen las variaciones en la disponibilidad de presas.

\section{VI.2. Materiales y Métodos}

El sistema de estudio se sitúa en la zona costera de las IOS (Figura II.1), se extiende desde la línea de costa hasta el límite de la zona de Inshore y está constituido biológicamente por dos niveles tróficos. El nivel de base (presas) lo conforman el krill y los peces pelágicos y bento-demersales. El segundo nivel trófico (predadores) está conformado por el Lobo Fino Antártico, el Pingüino Papúa y el Cormorán de Georgias. Los supuestos del modelo consideran que (i) el crecimiento de las poblaciones de predadores (cada una en ausencia de las otras) es de tipo logístico, y ante adecuada disponibilidad de alimento estas crecen hasta alcanzar su capacidad de carga $\mathrm{K}$, (ii) las poblaciones de los predadores nunca toman valores iguales a 0 , (iii) en ausencia de predadores, las poblaciones de peces tienen un crecimiento exponencial, en tanto que el krill queda regulado exclusivamente por las variables ambientales relacionadas con la cobertura de hielo marino y la temperatura del agua, (iv) como no es de interés para este trabajo incorporar al modelado las ecuaciones que regulen la disponibilidad de presas, tanto el krill como los peces serán considerados como recursos del sistema y no como variables, lo que matemáticamente implica que sus densidades son implícitas al sistema y no explícitas y $(v)$ el efecto de la variación de los recursos se observa dentro de los parámetros y se considera solo la retroalimentación positiva entre competidores. Ello implica que la presencia de una de las poblaciones de predadores influye sobre las otras como si se agregaran más individuos de la misma población al sistema, con lo cual las otras poblaciones tendrán menos posibilidades de acceder al recurso.

Así entonces, el comportamiento del sistema queda planteado de la siguiente manera: 
Variable independiente: disponibilidad de krill

a) Alta disponibilidad de krill: Tanto el Lobo Fino Antártico como el Pingüino Papúa incrementan el consumo de krill y disminuyen el de peces demersales. Sumado a ello el Lobo Fino Antártico aumenta también el consumo de peces myctóphidos asociados a los enjambres de krill y disminuye la predación sobre los pingüinos, con lo cual el Pingüino Papúa tendrá menor presión de predación y el Cormorán de Georgias tendrá menor competencia sobre sus recursos.

b) Baja disponibilidad de krill: Lobo Fino Antártico y el Pingüino Papúa predarán más intensamente sobre peces demersales, aumentará la predación de pingüinos al final de la etapa de guardería por parte del Lobo Fino Antártico y la competencia por los recursos en la zona de inshore (ver capítulo I) será mayor para todos los predadores

De acuerdo a este sistema, y en relación a la disponibilidad de krill (alta y baja), se generó un modelo matemático continuo basado en las ecuaciones del modelo de Lotka (1925) y Volterra (1926) para competencia entre diferentes poblaciones de predadores, de donde surgen las siguientes ecuaciones que describen el comportamiento del sistema:

$$
\frac{d N_{1}}{d t}=r_{1} N_{1}\left(1-\frac{N_{1}+\alpha N_{2}}{K_{1}}\right)
$$

Matemáticamente se agrega un término cuadrático a la ecuación básica del modelo de Volterra (1926) en donde $\mathrm{N}$ es la abundancia de los predadores, $r$ (tasa de crecimiento intrínseco de ese predador) es la pendiente de la curva de crecimiento poblacional en temporada reproductiva, $\mathrm{N}_{1}$ representa la abundancia en número del predador 1 y $\mathrm{N}_{2}$ la del predador 2 , $\mathrm{K}$ es la capacidad de carga de esa población o el máximo de individuos alcanzado durante una temporada reproductiva y $\alpha$ es la interacción entre predadores expresado como el factor de competencia a lo largo de una temporada reproductiva, calculado a partir del índice de solapamiento de la dieta descrito por Linton et al. (1981). Este índice expresa la intensidad (en porcentaje) con que dos especies de predadores comparten el mismo recurso alimenticio en la misma área y a lo largo del mismo período de tiempo (Hurlbert 1978).

Índice de solapamiento de Linton et al. (1981):

$$
S=100\left(1-1 / 2 \sum\left|P_{x i}-P_{y i}\right|\right)
$$

donde $P_{x i}$ y $P_{y i}$ corresponden a la contribución porcentual a la dieta de las especies de predadores $X$ e $y$ de la presa $i$. Los valores de $\mathbf{S}$ varían entre 0 , en donde las presas no son compartidas por ambos predadores, y 100, en el caso de que las dietas de los predadores son idénticas.

El modelo propuesto no fue ejecutado dado que no se pudo acceder a bases de datos precisas y obtenidas concurrentemente y dado también a la falta de datos de cobertura de hielo y temperatura del agua superficial de mar. 


\section{VI.3. Resultados}

Los siguientes modelos conceptuales ilustran e interpretan las relaciones establecidas entre las diferentes especies de predadores y sus recursos. La figura VI.1 representa una temporada de alta abundancia y disponibilidad de krill, en tanto que la figura VI.2 refleja el caso contrario.

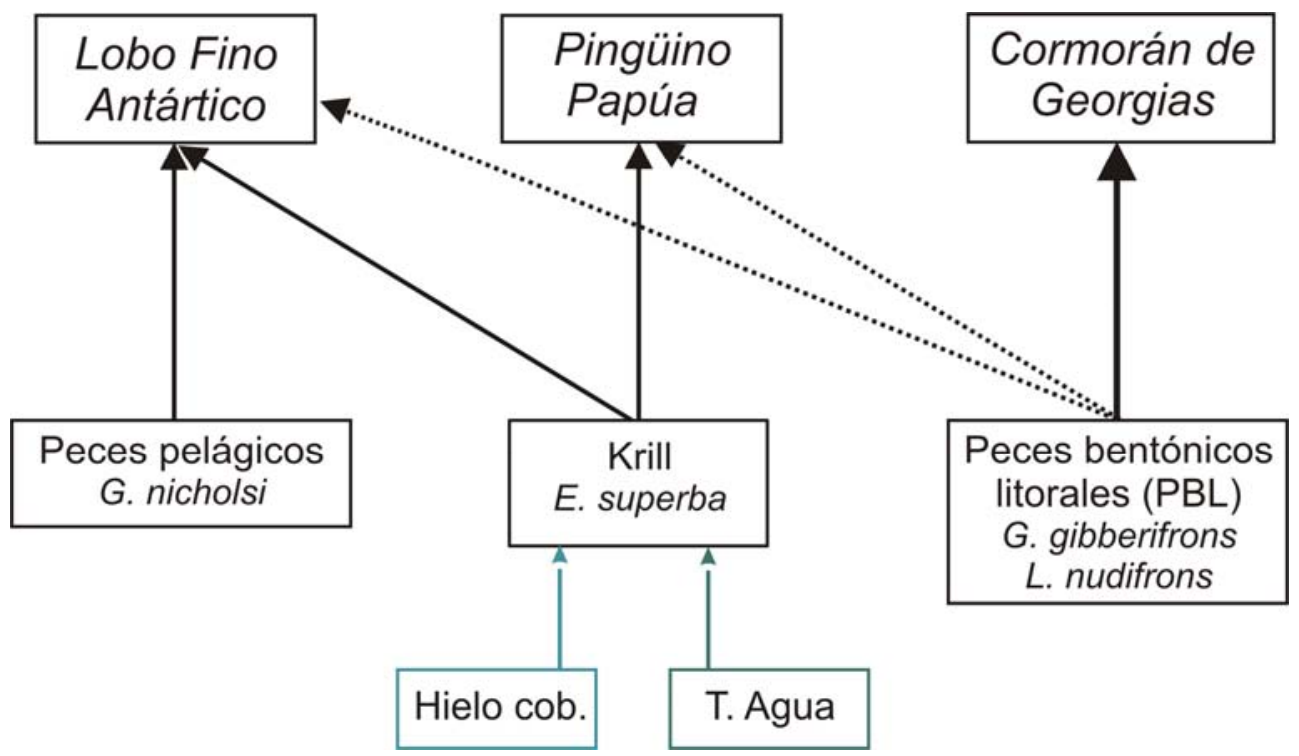

Figura VI. 1: Modelo conceptual sobre las relaciones tróficas de tres predadores tope en las IOS para una temporada de alta disponibilidad de krill. Hielo cob.: cobertura de hielo marino invernal; T. Agua: temperatura superficial del agua de mar.

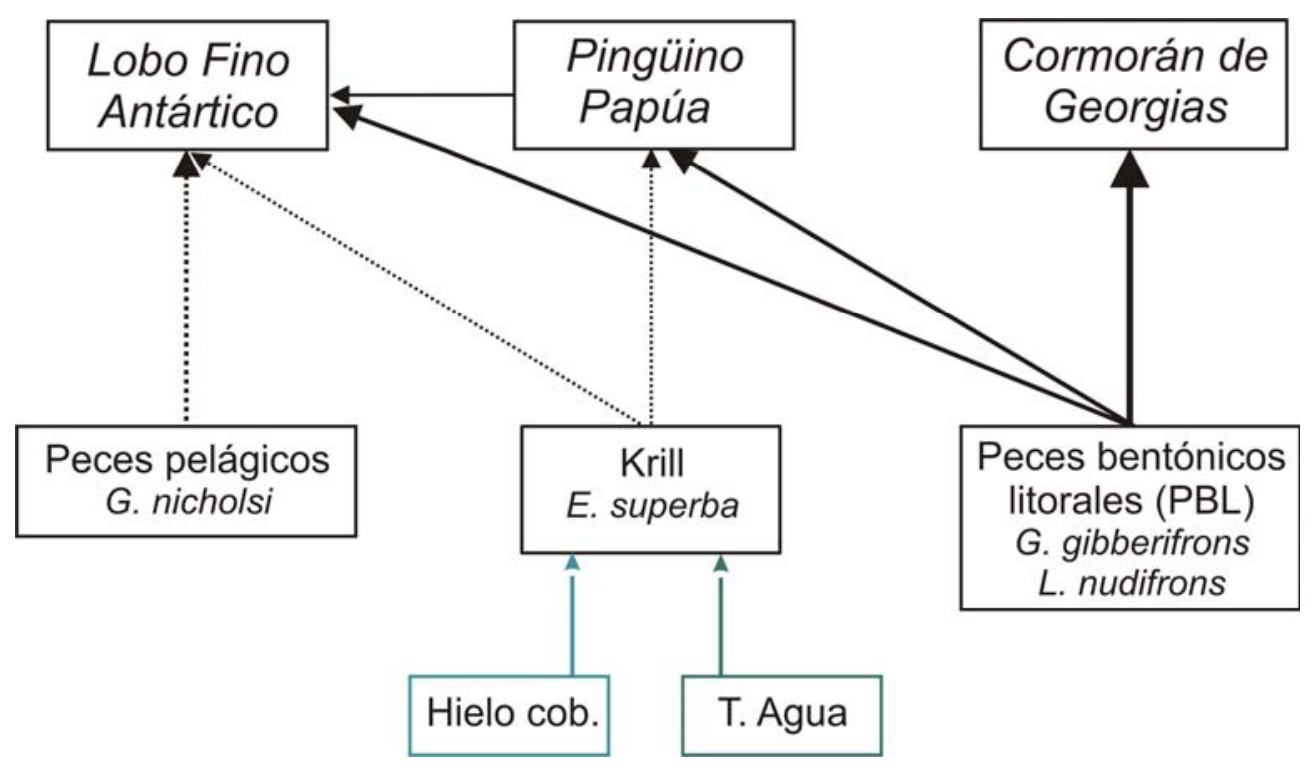

Figura VI. 2: Modelo conceptual sobre las relaciones tróficas de tres predadores tope en las IOS para una temporada de baja disponibilidad de krill. Hielo cob.: cobertura de hielo marino invernal; T. Agua: temperatura superficial del agua de mar. 
Las siguientes ecuaciones representan la velocidad de crecimiento de la población de cada predador según el modelo matemático elegido y según el marco biológico conceptual definido anteriormente:

a) Velocidad de crecimiento de la población del Cormorán de Georgias

$$
\begin{aligned}
& \frac{d C}{d t}=r_{C} C\left(1-\frac{C+\alpha_{C L} L+\alpha_{C P} P}{K_{C}}\right) \\
& \alpha_{C L}=f_{1}(P B L) \\
& \alpha_{C P}=f_{1}(P B L)
\end{aligned}
$$

donde $r_{c}$ es la tasa intrínseca de crecimiento de la población del Cormorán de Georgias, $\alpha_{C L}$ y $\alpha_{C P}$ son los coeficientes de competencia del Lobo Fino Antártico y del Pingüino Papúa con el Cormorán de Georgias respectivamente, calculados en función del índice de solapamiento de dietas sobre los peces bentónico-litorales ( $P B L)$ (ecuación 1), L y $C$ son las abundancias en número del Lobo Fino Antártico y del Cormorán de Georgias respectivamente y $\mathrm{K}_{\mathrm{C}}$ es la capacidad de carga para la abundancia del Cormorán de Georgias

El consumo de peces demersales por parte del Lobo Fino Antártico y del Pingüino Papúa será menor en años de alta disponibilidad de krill. En estas condiciones los coeficientes de solapamiento de dieta $\left(\alpha_{C L}\right.$ y $\left.\alpha_{C P}\right)$ serán menores y la competencia por el alimento disminuirá, la función 1 será decreciente, y a medida que aumentan los PBL el coeficiente de competencia disminuye. Se puede esperar que durante esas condiciones la población de cormoranes (C) alcance valores de abundancia cercanos al $\mathrm{K}_{\mathrm{c}}$, teniendo un crecimiento de tipo logístico.

b) Velocidad de crecimiento de la población del Lobo Fino Antártico

$$
\begin{aligned}
& \frac{d L}{d t}=r_{L} L\left(1-\frac{L+\alpha_{L C} C}{K_{L}}+\beta_{L P} P\right) \\
& \alpha_{L C}=f_{1}(P B L) ; \\
& \beta_{L P}=f_{2}(\text { Krill })
\end{aligned}
$$

donde $r_{L}$ es la tasa intrínseca de crecimiento de la población del Lobo Fino Antártico, $\alpha_{L C}$ y $\beta_{L P}$ son los coeficientes de competencia del Cormorán de Georgias y del Pingüino Papúa con el Lobo Fino Antártico respectivamente en donde $\alpha_{\mathrm{LC}}$ es el índice de solapamiento calculado sobre el consumo de PBL (función 1, decreciente) y $\beta_{\mathrm{LP}}$ es una función (2) dependiente de la cantidad de krill, L, C y P son las abundancias en número del Lobo Fino Antártico, el Cormorán de Georgias y el Pingüino Papúa respectivamente y $\mathrm{K}_{\mathrm{L}}$ es la capacidad de carga para la abundancia del Lobo Fino Antártico. Según el modelo conceptual, el factor de competencia $\beta_{L P}$ varía (crece o decrece) en relación a la abundancia de krill. A baja abundancia de krill el Lobo Fino Antártico tiende a incrementar el consumo de 
pingüinos por lo que $\beta_{\mathrm{LP}}$ será mayor a 0 (creciente) hasta que la abundancia de krill sea tal que el Lobo Fino Antártico reduzca el consumo de pingüino. A grandes concentraciones de krill, $\beta_{\mathrm{LP}}$ será menor a 0 ya que el Lobo Fino Antártico no preda sobre los pingüinos. Dado este comportamiento la función 2 deberá ser:

$$
\beta_{L P}=\frac{b(\text { Krill })-(\text { Krill })^{2}}{1+a(\text { Krill })^{2}}
$$

b) Velocidad de crecimiento de la población del Pingüino Papúa

$$
\begin{aligned}
& \frac{d P}{d t}=r_{P} P\left(1-\frac{P+\alpha_{P C} C}{K_{P}}+\beta_{P L} L\right) \\
& \alpha_{P C}=f_{1}(P B L) \\
& \beta_{P L}=f_{3}(\text { Krill })
\end{aligned}
$$

donde $r_{P}$ es la tasa intrínseca de crecimiento de la población del Pingüino Papúa, $\alpha_{P C}$ y $\beta_{P L}$ son los coeficientes de competencia del Cormorán de Georgias y del Lobo Fino Antártico con el Pingüino Papúa respectivamente en donde $\alpha_{P C}$ es el índice de solapamiento calculado sobre el consumo de PBL (función 1, decreciente) y $\beta_{\mathrm{PL}}$ es una función (3) dependiente de la cantidad de krill, L, C y P son las abundancias en número del Lobo Fino Antártico, el Cormorán de Georgias y el Pingüino Papúa respectivamente y $\mathrm{K}_{\mathrm{p}}$ es la capacidad de carga para la abundancia del Pingüino Papúa. Según el modelo conceptual, la función que defina al factor de competencia $\beta_{\mathrm{PL}}$ deberá ser estrictamente negativa asintótica al valor 0 cuando las concentraciones de krill sean muy altas. La ecuación de la función 3 deberá ser:

$$
\beta_{P L}=-e^{-b(k r i l l)}
$$

(Ecuación 7)

\section{VI.4. Discusión}

Los modelos matemáticos son herramientas que permiten recortar los escenarios observados y sustraer de ellos la mayor cantidad de elementos posible de un modo simple con el fin de explicar el comportamiento del sistema observado. Estos presentan numerosos supuestos biológicos y restricciones dadas por la misma matemática empleada que, en muchos casos, no tienen resultados biológicos fácilmente interpretables. Aún así, teniendo en claro la problemática a resolver, la modelización ayuda a simplificar, identificar y analizar las variaciones de las poblaciones y de sus interacciones dentro de un ecosistema y puede ser bien empleada como un punto de partida para generar hipótesis. En este trabajo en particular, el modelo postulado es una simple guía de comportamiento que puede ser aplicada para estudiar la dinámica de las poblaciones de los 
predadores seleccionados a lo largo del tiempo y en un futuro puede ser ampliado para facilitar una mejor comprensión del funcionamiento del ecosistema de las IOS. Sumado a ello, si bien el modelo planteado en este trabajo es extremadamente simple, puede utilizarse como base para desarrollar modelados más complejos que incluyan otros compartimentos y comportamientos del ecosistema, de acuerdo a modificaciones dentro del marco del modelo de competencia diseñado por Lotka (1925).

El circuito de competencia por el alimento planteado responde a observaciones sobre la dieta y el comportamiento de las tres especies de predadores considerados recopiladas a lo largo de aproximadamente 10 años de muestreo tanto en las IOS como en zonas aledañas (ver capítulos II y IV). La intensidad de las interacciones propuestas se basa en la abundancia del krill, ya que la dinámica del modelo depende de funciones que están fuertemente vinculadas a esta variable. Tanto la cobertura de hielo marino como la temperatura media del agua juegan un papel fundamental en la determinación de la disponibilidad de esta presa en cada temporada. El cambio en la extensión del hielo es por lo tanto un factor muy importante para la interpretación del sistema sobre escenarios futuros. Así entonces los inviernos que presenten menores extensiones de hielo marino y por tiempos menos prolongados resultarán en veranos con menores abundancias de krill y, según este modelo, la competencia entre predadores aumentará. En relación a los cambios en la extensión de hielo marino, Nicol et al. (2000) hacen una interpretación de los posibles cambios en la hidrodinámica de las aguas a partir de su reducción y los efectos que ello podría tener sobre el funcionamiento del ecosistema antártico. La distribución de la producción primaria se refleja a gran escala en la distribución del krill y de sus predadores. El principal alimento del krill son las algas diatomeas epónticas (algas fitoplanctónicas que desarrollan una fase de su vida sobre la superficie sumergida del hielo). Estudios recientes muestran que a medida que la extensión del hielo marino disminuye, otros organismos del zooplancton tales como las salpas (Salpa thompsonii) comienzan a ser más abundantes en los lugares antes dominados por krill (ver también Walsh et al. 2000, Pakhomov et al. 2002, Atkinson et al. 2004). Entonces, la disminución en la extensión del hielo causada principalmente por un aumento de la temperatura media del agua superficial puede alterar la composición específica del fitoplancton marino disminuyendo la disponibilidad de alimento para el krill, y puede también ocasionar la reducción de los ambientes necesarios para el crecimiento de las larvas de krill (Nicol 2006). Este escenario es negativo para las redes tróficas costeras ya que el carbono transferido dentro de la cadena alimentaria decrece. Asimismo, el krill constituye el alimento preferido de numerosas aves y mamíferos, en tanto que las salpas no parecen ser componentes importantes en la dieta de dichos predadores. Sin embargo, esto podría estar enmascarado por el hecho que los restos de dichos organismos son difíciles de identificar en las muestras de dieta. Así entonces, los factores que regulan la abundancia del krill son fundamentales para entender el comportamiento de este sistema en el que en años donde la abundancia de este crustáceo es alta la competencia interespecífica, fundamentalmente para el Cormorán de Georgias, es baja. Por el contrario, cuando la disponibilidad de krill es baja, no sólo se incrementa la competencia, ya sea por el escaso krill y fundamentalmente por los peces demersales, si no que el Lobo Fino Antártico preda con mayor intensidad sobre los pingüinos.

Hasta hace relativamente pocos años, el consumo de pingüinos por parte del LOBO FINO ANTÁRTICO era un evento poco documentado y cuando se lo registraba se hipotetizaba acerca de 
que la captura de estas aves era parte de un juego y que los ejemplares muertos no eran ingeridos (Bonner y Hunter 1982, Fischer y Hureau 1988). A partir de la década del 90 numerosos trabajos desarrollados tanto en las IOS como en las Islas Shetland del Sur y en la Península Antártica (Daneri y Coria 1992, Casaux et al. 1998, 2004) reportaron la presencia de pingüinos en muestras de dieta del Lobo Fino Antártico. Posteriormente, Casaux et al. (2004) determinaron que los pingüinos eran capturados para ser consumidos, llegando en algunas temporadas a ser la presa principal, y que en cierta medida la abundancia de pingüinos determinaba la distribución de los lobos a lo largo de la costa. Es probable que en la década del 80 se subestimara el aporte de los pingüinos a la dieta del Lobo Fino Antártico. Sin embargo, también es probable que los cambios en la extensión de la cobertura de hielo marino (Nicol 2006) con la consecuente disminución del krill y aumento de salpas (Nicol et al. 2000, Walsh et al. 2000, Pakhomov et al. 2002, Atkinson et al. 2004) haya ocasionado que el Lobo Fino Antártico incrementara el consumo de esa presa alternativa.

Si bien el Lobo Fino Antártico y el Pingüino Papúa consumen PBL (Berón et al. 2000, Coria et al. 2000, Casaux et al. 2003a, b), es el Cormorán de Georgias quien predominantemente se alimenta de estas presas (Casaux y Ramón 2002). Es importante destacar que la marcada ictiofagia observada en el Cormorán de Georgias en las IOS es similar a la reportada para otros cormoranes distribuidos en regiones antárticas y sub-antárticas (Shaw 1984, Brothers 1985, Espitalier-Noel et al. 1988, Green et al. 1990, Wanless y Harris 1993, Ridoux 1994, Coria et al. 1995, Kato et al. 1996, Favero et al. 1998, Casaux y Barrera-Oro 2006, entre otros). Esta marcada dependencia de los PBL observada en los cormoranes sugiere que ante un escenario donde disminuya la abundancia de estos peces, ya sea por implicancias relacionadas con el manejo pesquero o por aumento de la competencia con otros predadores debido a la disminución del krill, las tendencias poblacionales de estas aves se verían negativamente afectadas, hecho que ya fue reportado para las Islas Shetland del Sur (Casaux y Barrera-Oro 2006).

La abundancia del Lobo Fino Antártico en las IOS durante la temporada de verano es sumamente variable (Carlini et al. 2006). No existen hasta el momento estudios que permitan identificar las variables que determinan la abundancia de esta población. Sin embargo, según los resultados analizados en esta tesis, los ciclos de abundancia del krill y los del Lobo Fino Antártico en el archipiélago de las IOS no están correlacionados. Según el modelo propuesto, el Lobo Fino Antártico influye fuertemente sobre el cambio en las relaciones interespecíficas de competencia, por lo que es importante conocer los factores que regulan su tendencia poblacional. A modo de ejemplo se puede indicar que aquellos años en que co-ocurran una alta abundancia de Lobo Fino Antártico y una baja oferta de krill debería esperarse un grado alto de competencia entre el Lobo Fino Antártico y el resto de los predadores ictiófagos. Sumado a ello, de los predadores aquí seleccionados el Lobo Fino Antártico es el que presenta menor grado de selectividad de presas (ver capítulo III), y puede adaptarse a los cambios en la disponibilidad de alimento ya sea variando la composición de la dieta o desarrollando diferentes estrategias de forrajeo. Por ello, de comprenderse qué factores determinan la variabilidad en la abundancia de esta población se podría interpretar cuales son las implicancias a nivel ecosistémico del grado de competencia entre predadores. 


\section{VI.5. Referencias bibliográficas}

Atkinson A, Siegel V, Pakhomov E y Rothery P (2004) Long-term decline in krill stock and increase in salps within the Southern Ocean. Nature 432: 100-103.

Berón MP, Coria NR y Favero M (2002) Monitorio de la dieta post-reproductiva del Pingüino Papúa (Pygoscelis papua) en Isla Laurie (Orcadas del Sur, Antártida): Período 1997-1999. Ornitología Neotropical 13: 413-422.

Bertolin ML y Schloss IR (2009) Phytoplankton production after the collapse of the Larsen A Ice Shelf, Antarctica. Polar Biology 32(10): 1435-1446.

Bonner W, Hunter S (1982) Predatory interactions between Antarctic fur seals, macaroni penguins and giant petrels. Br Antarct Surv Bull 56:75-79.

Brothers N (1985) Breeding biology, diet and morphometrics of the King Shag, Phalacrocorax albiventer purpurascens, at Macquarie Island. Australian Wildlife Research 12: 81-94.

Carlini A, Daneri G, Casaux R y Márquez M (2006) Haul-out pattern of itinerant male Antarctic fur seals (Arctocephalus gazella) at Laurie Island, South Orkney Islands. Polish Polar Research 25(2): 139-144.

Casaux R. y Barrera-Oro E (2006) Shags in Antarctica: their feeding behaviour and ecological role in the marine food web. Antarctic Science 18: 3-14.

Casaux R y Ramón A (2002) The diet of the South Georgia Shag Phalacrocorax georgianus at South Orkney Island in five consecutive years. Polar Biology 25: 557-561.

Casaux R, Baroni A y Carlini A (1998) The diet of Antarctic fur seal Arctochepalus gazella at Harmony Point, Nelson Island, South Shetland Islands. Polar Biology 20: 424-428.

Casaux R, Baroni A, Arrighetti F, Ramón A, Carlini A (2003a) Geographical variation in the diet of the Antarctic fur seal Arctocephalus gazella. Polar Biology 26: 753-758.

Casaux R, Baroni A y Ramón A (2003b) The diet of antarctic fur seals Arctocephalus gazella at the Danco coast, Antarctic Peninsula. Polar Biology 26: 49-54.

Casaux R, Bellizia L y Baroni A (2004) The diet of the Antarctic fur seal Arctocephalus gazella at Harmony Point, South Shetland Islands: evidence of opportunistic foraging on penguins? Polar Biology 27(2): 59-65.

Coria N, Libertelli M, Casaux R y Darrieu C (2000) Inter-annual variation in the autumn diet of the Gentoo Penguin at Laurie Island, Antartctica. Waterbirds 23: 511-517.

Coria NR, Spairani H, Vivequin S y Fontana R (1995) Diet of Adelie penguins Pygoscelis adeliae during the post-hatching period at Esperanza Bay, Antarctica, 1987/88. Polar Biology 15: 415-418.

Croxall JP, Reid K y Prince PA (1999) Diet, provisioning and productivity responses of marine predators to differences in availability of Antarctic krill. Mar Ecol Prog Ser 177: 115-131.

Daneri GA y Coria NR (1992) The diet of Antarctic fur seals, Arctocephalus gazella, during the summer-autumn period at Mossman Peninsula, Laurie Island (South Orkneys). Polar Biology 11: 565-566.

Espitalier-Noel G, Adams NJ y Klages NT (1988) Diet of the Imperial Cormorant Phalacrocorax atriceps at subantarctic Marion Island. Emu 88: 43-46.

Fischer W y Hureau J (1988) Fichas FAO de identificación de especies para los fines de pesca. Océano Austral (áreas de pesca 48, 58 y 88, área de la Convención CCAMLR). Roma, FAO 1(1): 232 pp.

Favero M, Casaux R, Silva P, Barrera-Oro E y Coria N (1998) The diet of the Antarctic Shag during summer at Nelson Island, Antarctica. Condor 100: 112-118.

Fryxell GA (1989) Marine phytoplankton at the Weddell Sea ice-edge: Seasonal changes at the specific level. Polar Biology 10: $1-18$.

Garrison DL y Buck KR (1989) The biota of Antarctic Pack Ice in the Weddell Sea and Antarctic Peninsula regions. Polar Biology 10: 211-219.

Green K, Williams R y Slip D (1990) Diet of Macquarie Island Cormorant Phalacrocorax atriceps purpurascens. Corella 14(2): 53-55.

Hurlbert SH (1978) The measurement of niche overlap and some relatives. Ecology 59: 57-67.

Kato A, Nishiumi I y Naito Y (1996) Sexual differences in the diet of King Cormorants at Macquarie Island. Polar Biology 16: 7577. 
Kock KH (1992) Antarctic fish and fisheries. Cambridge University Press, Cambridge

Linton LR, Davies RW y Wrona FJ (1981) Resource utilization indices: as assessment. Journal of animal ecology 50: $283-292$.

Loeb V, Siegel V, Holm-Hansen O, Hewitt R, Fraser W, Trivelpiece W y Trivelpiece S (1997) Evidence of sea-ice extent and krill or salp dominance on the Antarctic food web. Nature 387: 897-900.

Lotka AJ (1925) Elements of Physical Biology. Williams \& Wilkins, Baltimore.

Malthus TR (1798) An Essay on the Principle of Population as it Affects the Future Impror ement of Society, with remarks on the Speculations of Mr. Godwin,M. Colzdorcet, and Other Writers. J. Johnson (Ed). St. Paul's Churchyard, London.

Marschall HP (1988) The overwintering strategy of Antarctic Krill under the pack-ice of the Weddell Sea. Polar Biology V9: 129135.

McGrath Grossi S y Sullivan CW (1985) Sea ice microbial communities. V. The vertical zonation of diatoms in an Antarctic fast ice community. Journal of Phycology 21: 401-409.

Momo F y Capurro A (2006) Ecología matemática, aplicaciones y principios. Ediciones Cooperativas. Buenos Aires, 114 pp.

Nicol S (2006) Frill, Currents, and Sea Ice: Euphasia superba and its changing environment. BioScience 56(2): 111-120.

Nicol S, Pauly T, Bindoff NL, Wright S, Thiele D, Hoise GW, Strutton PJ y Woehler E (2000) Ocean circulation off Antarctica affects ecosystem structure and sea-ice extent. Nature 406: 504-507.

Nöthig EM, Bathmann U, Jennings Jr. JC, Fahrbach E, Gradinger R, Gordon LI y Makarov R (1985) Regional relationships between biological and hydrographical properties in the Weddell Gyre in late austral winter 1989. Marine Chemistry 35: 325-336.

Pakhomov E, Froneman PW y Perissinotto R (2002) Salp/Krill interactions in the southern Ocean: especial segregation and implications for the carbon flux. Deep Sea Research Part II 49: 1881-1907.

Ridoux V (1994) The diets and dietary segregation of seabirds at the subantarctic Crozét Islands. Marine Ornithology 22: 1192.

Shaw P (1984) Factors affecting the breeding performance of the Antarctic blue-eyed shag (Phalacrocorax atriceps bransfieldensis). Tesis doctoral. Universidad de Durham.

Verhulst PF (1838) Notice sur la loi que la population suit dans son accroisissement. Corresp. math. phys., A. Quetelet, 10: 113-121.

Verhulst PF (1845) Recherches mathimatiques sur la loid'accroissement de la population. Mbm. Acad. R. Belg., 18: 1-38.

Volterra V (1926) Variazioni e fluttuazioni del numero de individui in specie animali conviventi. Memori della Reale Accademia Nazionale di Lincei 2: 31-113.

Walsh JJ, Dieterle DA y Lenes J (2001) A numerical analysis of carbon dynamics of the Southern Ocean phytoplankton community: the roles of light and grazing in effecting both sequestration of atmospheric CO2 and food availability to larval krill. Deep-Sea Research Part I 41: 1-48.

Wanless S y Harris M (1993) Use of mutually exclusive foraging areas by adjacent colonies of blue-eyed shags (Phalacrocorax atriceps) at South Georgia. Colon Waterbirds 16:176-182. 


\section{Conclusiones finales}

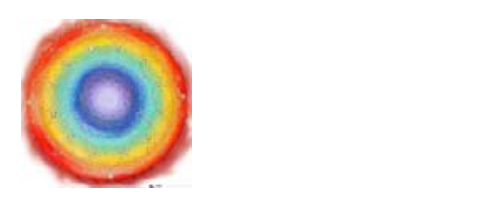

Los estudios ecosistémicos brindan la posibilidad de observar e interpretar los ambientes naturales junto a los seres vivos que los habitan de un modo holístico o integrado. Esta aproximación al conocimiento del ecosistema permite entender cómo las interrelaciones entre especies y procesos son fuertemente interdependientes y forman una red de nodos interconectados. Así una pequeña alteración en uno de sus nodos puede influir de un modo significativo contundente en los demás. Es por ello que este tipo de análisis debería ser considerados más frecuentemente en el planteo y resolución de nuevos interrogantes, ya sea en la biología como en las demás ciencias, pues enriquece nuestra visión y nuestro contacto con el mundo que habitamos de manera significativa. Aún así, hoy en día, los enfoques más integradores de este tipo de estudios se encuentran aún limitados técnico-tecnológicamente como así también por los alcances propios del lenguaje matemático con el que contabilizamos, probamos y explicamos lo que queremos poner a prueba.

Antártida, como cualquier otro nodo de la red de interdependencias, conforma un continente sensible a los cambios globales y regionales. Como se mencionó en varias ocasiones, si el interés de las autoridades que hoy gestionan y deciden cualquier intervención en el territorio antártico, conservar a sus seres vivos y a sus recursos, se hace indispensable estudiar y comprender en un nuevo nivel de entendimiento. Este nuevo acercamiento debería plantear nuevas formas de trabajo para predecir a más corto plazo las consecuencias que los cambios naturales y antrópicos tienen sobre las poblaciones de seres vivos. Así entonces, uno de los objetivos de este trabajo fue poner de manifiesto la falta de una visión ecosistémica en los estudios llevados a cabo en el pasado y actualmente en la Antártida, en especial los que refieren a la explotación de los recursos vivos marinos. Los resultados presentados mostraron la relevancia que tienen los cambios en la disponibilidad de presas sobre el comportamiento de los predadores tope y sus relaciones inter-específicas, a la vez que pusieron de manifiesto que la utilización de diferentes parámetros alimentarios y poblacionales de los predadores tope como indicadores de procesos de cambio en las presas puede resultar en una fuente de información alternativa frente a la desventaja de la falta de cruceros de investigación o bien como su complemento. 
El principal objetivo de este trabajo fue ampliar el conocimiento de la biología de los predadores tope de las Islas Orcadas del Sur (IOS) e identificar parámetros confiables que permitan detectar cambios tempranos en el ecosistema y ayuden a administrar racionalmente la pesca o la actividad humana. Para ello se analizó conjuntamente la información sobre los aspectos alimentarios de los diferentes predadores como así también se investigó sobre los aspectos relacionados con la competencia por el alimento en pos de profundizar el conocimiento de la estructura trófica del ecosistema de las IOS.

La pesquería en Antártida ha pasado por períodos de diferente intensidad. El archipiélago de las IOS fue sometido a varios años de explotación pesqueraza que finalizó hacia fines de la década del ' 80 y tuvo un alto impacto sobre las poblaciones de peces, en particular sobre las especies Notothenia rossii, Gobionotothen gibberifrons, $y$ Champsocephalus gunnari. La información presentada en este trabajo se vuelve necesaria al momento de considerar una posible reapertura de esta actividad en función de la conservación de sus recursos y de sus habitantes.

Por medio del análisis de la composición general de la dieta se pudieron identificar tendencias en las poblaciones de peces como así también agrupar a los distintos predadores en grupos tróficos (GT) de acuerdo a los ítems alimentarios principales y secundarios. De acuerdo a estos análisis se puede inferir que G. gibberifrons y $N$. rossii estarían en una fase de recuperación de sus stocks, en tanto que la abundancia de Pleuragramma antarcticum parece haber disminuido marcadamente. A su vez, esta información se complementa y se sustenta con la aportada en el Capítulo III, en donde se compara la abundancia de peces aportada por dos cruceros de investigación desarrollados en los años 1987 y 1999.

Mediante la clasificación de los predadores en diversos grupos tróficos de acuerdo a los ítems alimentarios principales y secundarios, se identificaron grupos potenciales de competencia inter-específica por el alimento. Entre ellos cabe destacar al GT "Krill (1)" compuesto por el pingüino de Barbijo, el pingüino de Adelia y el petrel de Wilson y al GT "Krill (2)" compuesto por el pingüino Papúa, el lobo Fino Antártico, la foca de Weddell y la foca Cangrejera. Si bien los miembros de los demás GT también son competidores potenciales, el análisis de los hábitos de forrajeo resaltó a estos dos grupos y dentro de ellos destacó a los pares de especies pingüino de Adelia y de Barbijo y pingüino Papúa y lobo Fino Antártico como los más importantes en términos de competencia dado que comparten zonas y horarios de alimentación. Es importante destacar también que, dada la similitud de especies de peces presa compartidas con el GT "Ictiófagos (1)", el cormorán de Georgias se vuelve un competidor para el pingüino Papúa y el lobo Fino Antártico durante años de baja disponibilidad de krill.

La información sobre la composición de la dieta y la selectividad de alimento sugiere que el lobo Fino Antártico, seguido por la foca de Weddell y el pingüino Papúa, es el predador con mayor diversidad de presas consumidas y por lo tanto pareciera ser el más flexible frente a los posibles cambios en la disponibilidad de presas.

Las estimaciones de consumo anual de presas de las poblaciones de predadores en algunos casos arrojaron valores cercanos, a los límites de captura establecidos por la Comisión para la Conservación de los Recursos Vivos Marinos Antárticos para las IOS y 
zonas aledañas. Esto resalta la importancia de implementar políticas de manejo que consideren los requerimientos de los predadores, principalmente de aquellos potencialmente más vulnerables a la explotación pesquera tales como los pingüinos de Barbijo y Papúa y el lobo Fino Antártico. Como ejemplo, y a modo exploratorio, se planteó un pequeño modelo matemático en donde se consideraron las relaciones tróficas entre tres predadores y sus presas. A través de este planteo se pudo evidenciar lo importancia potencial que puede tener el modelo de explotación de un recurso cuando se incorporan las diversas piezas que interactúan con él.

Con respecto a las metodologías desarrolladas para el análisis de la composición de la dieta, Numerosos autores indicaron que el análisis de contenidos estomacales es la técnica que mejor refleja la composición real de la dieta. Sin embargo, esta técnica suele producir un alto grado de stress en los individuos muestreados y por lo tanto, también en las colonias. Es por ello que en la mayoría de los trabajos sobre composición de la dieta desarrollados en la zona de estudio y zonas aledañas, se aplicó la técnica de análisis de pellets o feces, los que suelen subestimar el aporte de los peces a la dieta. Por otro lado, el análisis del solapamiento de las tallas de los peces representados en las capturas de los cruceros de investigación y de los representados en la dieta de los predadores aquí considerados, también tuvo sus limitaciones. Por un lado los datos no fueron concurrentes en el tiempo ni en el espacio, tanto porque las capturas fueron realizadas sólo en la zona offshore y en intervalos de profundidad que algunos casos estuvieron más allá de las capacidades físicas de buceo de varios de los predadores, como porque la información sobre la dieta no siempre coincidió con la fecha de las capturas. Por otro lado, el tamaño de celda de las redes utilizadas en los cruceros no fue el apropiado para la comparación de la información con la composición de la dieta de los predadores, ya que las tallas más pequeñas (entre 5 y $10 \mathrm{~cm}$.), que en algunos casos tuvieron una alta representación dentro de las dietas, no estuvieron representadas en las capturas. Aún así, dado que la información proveniente de ambos cruceros es la única disponible sobre las comunidades de peces de las IOS, los resultados de esta sección fueron de utilidad para vislumbrar tendencias sobre la recuperación de ciertas poblaciones de peces, aunque es necesario que estas se interpreten prudentemente.

La posible reapertura de la pesca en la zona de las IOS, en el caso de que esta no sea apropiadamente panificada, puede presentar escenarios poco favorables para las poblaciones de predadores tope. Es por ello que este trabajo representa una base de datos fundamental a la hora de planificar programas de monitoreo a largo plazo sobre las tendencias poblacionales ofreciendo un terreno firme donde desarrollar políticas de manejo racionales y sustentables. 